\title{
The development of the multilateral trade regime
}

Citation for published version (APA):

Giernalczyk, W. (2018). The development of the multilateral trade regime: exploring institutional change. [Doctoral Thesis, Maastricht University]. ProefschriftMaken Maastricht. https://doi.org/10.26481/dis.20181218wg

Document status and date:

Published: 01/01/2018

DOI:

10.26481/dis.20181218wg

Document Version:

Publisher's PDF, also known as Version of record

\section{Please check the document version of this publication:}

- A submitted manuscript is the version of the article upon submission and before peer-review. There can be important differences between the submitted version and the official published version of record.

People interested in the research are advised to contact the author for the final version of the publication, or visit the DOI to the publisher's website.

- The final author version and the galley proof are versions of the publication after peer review.

- The final published version features the final layout of the paper including the volume, issue and page numbers.

Link to publication

\footnotetext{
General rights rights.

- You may freely distribute the URL identifying the publication in the public portal. please follow below link for the End User Agreement:

www.umlib.nl/taverne-license

Take down policy

If you believe that this document breaches copyright please contact us at:

repository@maastrichtuniversity.nl

providing details and we will investigate your claim.
}

Copyright and moral rights for the publications made accessible in the public portal are retained by the authors and/or other copyright owners and it is a condition of accessing publications that users recognise and abide by the legal requirements associated with these

- Users may download and print one copy of any publication from the public portal for the purpose of private study or research.

- You may not further distribute the material or use it for any profit-making activity or commercial gain

If the publication is distributed under the terms of Article $25 \mathrm{fa}$ of the Dutch Copyright Act, indicated by the "Taverne" license above, 


\section{The Development of the Multilateral Trade Regime \\ Exploring Institutional Change}

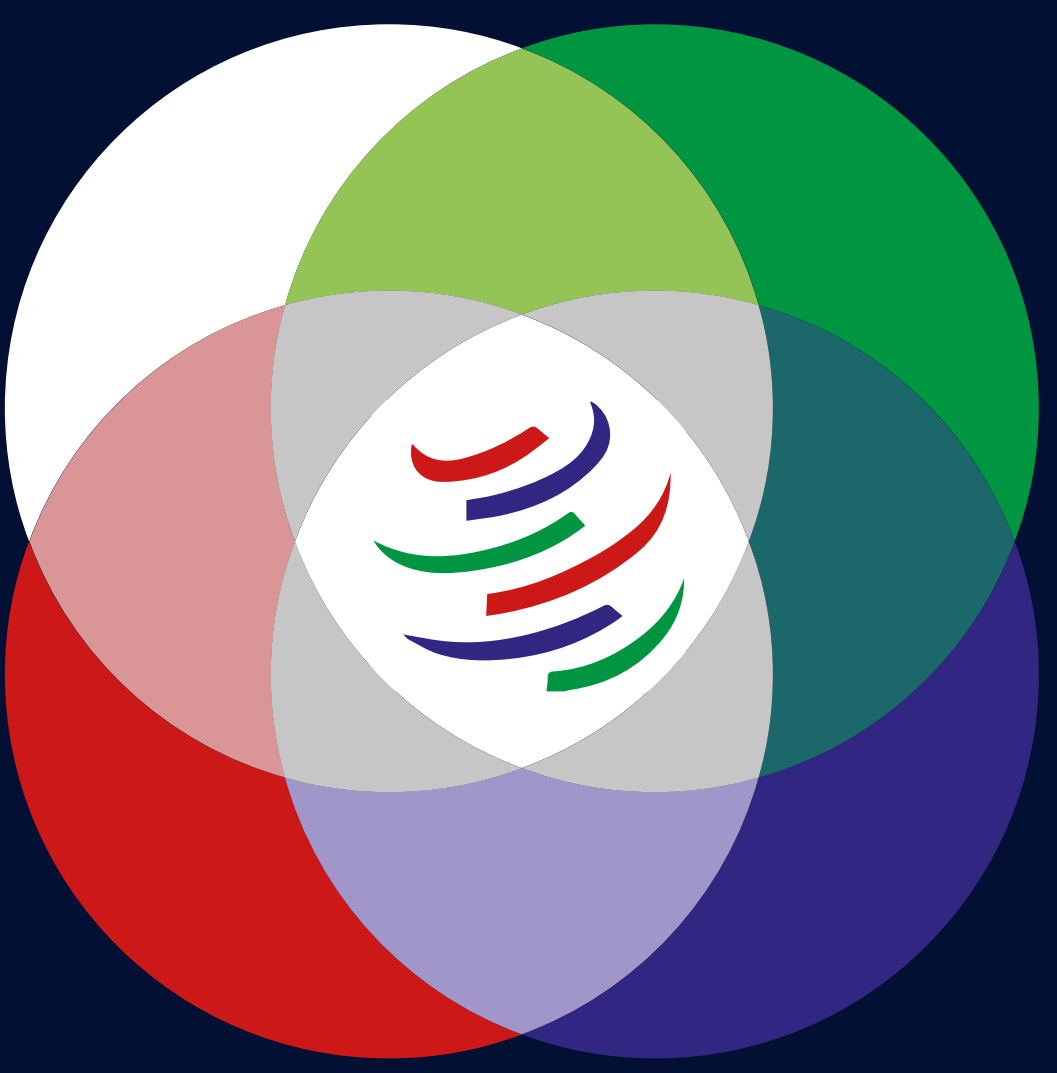

Wolfgang Giernalczyk 



\title{
The Development of the Multilateral Trade Regime - Exploring Institutional Change
}

\author{
Wolfgang Giernalczyk
}


ISBN: 978-94-6380-149-2

Printed by: ProefschriftMaken || www.proefschriftmaken.nl 
The Development of the Multilateral Trade Regime Exploring Institutional Change

\author{
Dissertation
}

to obtain the degree of Doctor at Maastricht University, on the authority of the Rector Magnificus Prof. Dr. Rianne M. Letschert in accordance with the decision of the Board of Deans, to be defended in public on Tuesday $18^{\text {th }}$ of December 2018, at 9.30 hours

by

Wolfgang Giernalczyk 


\section{Supervisors}

Prof. Dr. Peter van den Bossche

Prof. Dr. Manfred Elsig, University of Bern

\section{Assessment Committee}

Prof. Dr. Mathieu Segers (Chair)

Prof. Dr. Thomas Conzelmann

Prof. Dr. Dirk de Bièvre, University of Antwerp

Dr. Maarten Smeets 


\section{Acknowledgements}

The support of several people was helpful in the process of researching and writing this dissertation. At this point I would like to use the opportunity to express my gratitude to them.

First of all, I would like to thank the 19 negotiators and Secretariat members who actively participated in the Uruguay Round and who were willing to share their experiences with me during personal interviews. Your accounts provided valuable insights and enriched the narrative of the trade regime's institutional history immensely. Without you, proper process tracing would have hardly been possible. My thanks also go to the staff of the WTO library, whose guidance was very helpful in discovering sources and finding my way through the GATT archive.

Furthermore, I would like to express my gratitude to the members of the assessment committee: Prof. Dr. Thomas Conzelmann, Prof. Dr. Dirk de Bièvre, Prof. Dr. Mathieu Segers and Dr. Maarten Smeets. Thank you for taking the time to read and assess this dissertation. Your comments will be very helpful for improving my research in the future.

I would also like to express my sincere gratitude to my supervisors, Prof. Dr. Peter van den Bossche and Prof. Dr. Manfred Elsig. Your input and support was extremely helpful in the course of this research. Peter, thank you for all the advice during the fruitful and inspiring conversations in your office at the law faculty, which you regularly allowed to go over time despite your busy schedule. Thank you also for opening so many doors, connecting me to people in the trading system that I otherwise would not have had the opportunity to get in touch with. Manfred, thank you for being willing to step in at a time when I was looking for direction and for providing this direction during my stays at the WTI. Your input and advice on the theoretical sections was invaluable for this dissertation.

Several colleagues also supported this research, both directly and indirectly. I would like to begin by thanking the colleagues from the Faculty of Law at Maastricht University for welcoming me at IGIR, and allowing me to present my ideas during seminars and conferences. Your input was very helpful and inspiring.

My thanks go also to the colleagues at the WTI for hosting me, and especially to Jappe Eckhardt for showing me around and providing company during my stays in Bern.

Of course I am immensely grateful for my colleagues at UCM. It is a great privilege to work in such a nice, inspiring and supportive environment. Although all of you would deserve being mentioned, please forgive me that for the sake of brevity I only mention those that had the most direct impact on my research and career as an academic. Thank you Harm, for giving me the opportunity to embark on this research project in the first place. Who knows where I would be now, if you would not have offered me a position at the College. I am extremely grateful for this. Teun, thank you for your guidance whenever I got the opportunity to take up new responsibilities during my professional development - I learned a lot. Wilfred and Nicolai, thanks 
for the good office atmosphere and all the conversations - some of them funny others serious, but none of them a waste of time. Jenny, thanks not only for having supported me in the final stages of this research project as one of my paranymphs, but also for sharing PhD and other work experiences during joint car rides. Anouk, the final steps of this research project would have been far more difficult without your organizational support. I am extremely grateful for this. In this vein I would also like to thank Sharon, Eefje and Kelly for their support in preparation of my defence.

To stay productive in the long run it is also necessary to switch off at times and not to think of work. I would like to thank my close friends - Sander, Bram, Hugo, Joel, Willem, Jonathan, Tom, Thomas and David - for being very helpful in this respect. I would also like to thank Thomas Schuster for offering company and a bed to sleep when I was on my research trips in Geneva.

Finally, I am skeptical whether it would have been possible to complete this research successfully without the support of my family. My deepest gratitude goes to my parents. Being aware of your unconditional support is invaluable. This provides comfort and security - no matter what happens, there is always a safety-net.

I would also like to thank my grandmother, Maria, although you could not accompany me anymore in the process of researching and writing this dissertation, the mindset that you conveyed to me provided me with the optimism, motivation and stamina to succeed.

Astrid, not only are you a big sister to look up to, but you have also been of great practical help in times of need. Whenever necessary, you jumped in on short notice and spent many hours on formatting and cover design. Without you this dissertation would look far less professional. In this respect, I would also like to thank Michael and Julius for not bothering when Astrid had to support me once again and could not spend the time with you.

Most importantly, my deepest thanks of all go to Lydia. What would I be without you? Thank you for your company, your love, your patience, for taking care of things and your relentless support. Finally, Sophia, thank you for the simple fact of your existence, for your smiles and the joy you spread - and, for the final push. 


\section{Contents}

$\begin{array}{lll}\text { Abbreviations } & \text { VI }\end{array}$

1 Introduction 1

2 Theoretical Framework: Conceptualizing Change 19

2.1 Introduction 20

2.2 Functional Design of International Institutions: Promises and Problems of Rational Design $\quad 22$

2.2.1 Rational Institutionalism 22

2.2.2 Rational Design 24

2.2.3 Shortcomings of Rational Design 26

2.3 Centralization and Control: Specification, Interaction and Design Sets 29

2.3.1 Conceptualizing Centralization 30

2.3.2 Conceptualizing Control 34

2.3.3 The Interaction of Centralization and Control: Design Sets 37

2.3.4 Conclusion 46

$2.4 \quad$ The Notion of Change 49

2.4.1 Rational Design and Change 50

2.4.2 Limiting Costs and Risk Aversion: The Benchmark Problem of Rationality 52

2.4.3 Institutional Change as a Coordination Problem 54

2.4.4 Change in Historical Context $\quad 57$

2.4.5 Conclusion: Bounded Rational Design 60

2.5 Conclusion 63

3 Administration and Decision-Making Structures: The Establishment of the $\begin{array}{ll}\text { WTO } & 65\end{array}$

3.1 Introduction 67

3.2 The Establishment of the WTO as a Focal Entity 71

3.2.1 The Case as a Matter of Centralization and Control 71

3.2.2 Rational Design Explanations 83

3.2.3 Design in Context: Historical Legacy 94

3.2.4 Negotiating Design 120

3.3 Design Sets: Centralization and Control - Decision-Making in the WTO 137

3.3.1 The Puzzle of Rational Design 137

3.3.2 Process Tracing of Decision-Making Arrangements in the Trade Regime 141 
$\begin{array}{lll}\text { 3.3.3 Conclusion } & 167\end{array}$

$\begin{array}{lll}3.4 & \text { Conclusion } & 168\end{array}$

$4 \quad$ Adjudication in the Trade Regime: Reforming Dispute Settlement 171

$4.1 \quad$ Introduction 173

4.2 The Case as a Matter of Centralization and Control 176

4.2.1 General 177

$\begin{array}{lll}4.2 .2 & \text { Specific } & 178\end{array}$

4.3 Explanations of Rational Design 183

4.3.1 Positive Contributions of Rational Design 183

4.3.2 Problems of Rational Design 190

4.3.3 Conclusion 192

4.4 Design in Context: Historical Legacy 193

4.4.1 Dispute Settlement in the ITO 194

4.4.2 Dispute Settlement in the GATT (Initial Setup) 198

4.4.3 Development of Dispute Settlement in the GATT 201

4.4.4 The Impact of History on the Uruguay Round Negotiations 213

4.4.5 Conclusion 219

4.5 Negotiating Design: Process and Dynamics 221

4.5.1 Strengthening Procedures: Homogenous Preferences and Early Decisions 222

4.5.2 Blocking Decisions: Heterogeneous Preferences, Power and the Grand Bargain 226

4.5.3 Spin-off Design Changes 244

4.5.4 Conclusion 256

4.6 Design Interaction: Centralization and Control 258

4.6.1 Control of the DSB as an Instance of Pooling 259

4.6.2 Control of Delegation in Dispute Settlement: Panels and the Appellate Body 261

4.6.3 The Impacts of Dispute Settlement: Control over Domestic Implementation $\quad 266$

4.6.4 Conclusion 268

4.7 Conclusion 269

5 Transparency in the Trade Regime: The Emergence of the Trade Policy

Review Mechanism 273

5.1 Introduction 274

5.2 The Case as a Matter of Centralization and Control 277

5.2.1 General 277

$\begin{array}{lll}\text { 5.2.2 Pooling } & 278\end{array}$

$\begin{array}{ll}5.2 .3 & 279\end{array}$

5.3 Explanations of Rational Design 282

5.3.1 The Underlying Rationale (Theoretical Plausibility) 282 
5.3.2 The Emergence of the Idea and its Rationale (Empirical Plausibility) 284

5.4 Design in Context: Historical Legacy 291

5.4.1 Providing Information and Facilitating Transparency in the ITO 291

5.4.2 Providing Information and Facilitating Transparency in the GATT 293

5.4.3 The Impact of History on the Uruguay Round Negotiations 299

5.5 Negotiating Design: Process and Dynamics 301

5.5.1 Reviewing General Developments, Notifications and Domestic Transparency 301

5.5.2 Individual Member Review 303

5.5.3 Conclusion: Balancing Design and Reaching Agreement 312

$\begin{array}{lll}5.6 & \text { Conclusion } & 314\end{array}$

6 Conclusion $\quad 317$

$\begin{array}{ll}\text { References } & 337\end{array}$

$\begin{array}{ll}\text { Interviews } & 353\end{array}$

$\begin{array}{ll}\text { Summary } & 355\end{array}$

$\begin{array}{ll}\text { Valorization Addendum } & 363\end{array}$

$\begin{array}{ll}\text { About the Author } & 369\end{array}$ 


\section{Abbreviations}

ATC

BoP

CTG

CTS

DDA

DDG

DG

DSB

DSU

EC

ECOSOC

EEC

EPU

EU

FOGS

G7

GATS

GATT

IATA

IBRD

ICJ

IMF

ITC

ITO
Agreement on Textiles and Clothing

Balance of Payments

Council for Trade in Goods

Council for Trade in Services

Doha Development Agenda

Deputy Director General

Director General

Dispute Settlement Body

Dispute Settlement Understanding

European Communities

Economic and Social Council

European Economic Community

European Payments Union

European Union

Functioning of the GATT System

Group of Seven

General Agreement on Trade in Service

General Agreement on Tariffs and Trade

International Air Transport Association

International Bank for Reconstruction and Development

International Court of Justice

International Monetary Fund

International Trade Center

International Trade Organization 


$\begin{array}{ll}\text { MFN } & \text { Most Favored Nation } \\ \text { MTO } & \text { Multilateral Trade Organization } \\ \text { NATO } & \text { North Atlantic Treaty Organization } \\ \text { OECD } & \text { Organization for Economic Co-operation and Development } \\ \text { OTC } & \text { Organization for Trade Cooperation } \\ \text { RTAA } & \text { Reciprocal Trade Agreements Act } \\ \text { SCM } & \text { Subsidies and Countervailing Measures } \\ \text { SPS } & \text { Sanitary and Phytosanitary Measures } \\ \text { TBM } & \text { Textile Monitoring Body } \\ \text { TBT } & \text { Technical Barriers to Trade } \\ \text { TNC } & \text { Trade Negotiations Committee } \\ \text { TPRB } & \text { Trade Policy Review Body } \\ \text { TPRM } & \text { Trade Policy Review Mechanism } \\ \text { TRIPS } & \text { Trade-Related Aspects of Intellectual Property Rights } \\ \text { UK } & \text { United Kingdom } \\ \text { UN } & \text { United Nations } \\ \text { UNCTAD } & \text { United Nations Conference on Trade and Development } \\ \text { US } & \text { United States Trade Representative } \\ \text { USSR } & \text { USTR }\end{array}$





\section{Introduction}

"In the long run, it may well be the machinery that is most important (i.e. the procedures), rather than the existence of any one or another specific rule of trade conduct." (Jackson, 1969, p. 788)

This quote is almost 50 years old but it is probably as relevant today as it was at the time of its publication. It stems from John H. Jackson's seminal analysis of the multilateral trading system, which was governed by the General Agreement on Tariffs and Trade (GATT) at the time. The quote reflects Jackson's concern with the largely improvised and relatively weak institutional structure that the GATT provided for the maintenance of the trading system and was meant to underline his calls for the reform of this structure. ${ }^{1}$ With the advent of the World Trade Organization (WTO) in 1995 this reform had taken place and since then the trading system is governed by a proper international organization. However, 23 years after the WTO's creation closer attention to the machinery is warranted once again, since the WTO currently faces a severe crisis triggered by the growing dissatisfaction of its membership with shortcomings in its institutional setup.

This setup has been subject to severe criticism. Amongst several critics the US is presently the most vocal and influential one. In its 2018 Trade Policy Agenda the US government expresses its dissatisfaction with the WTO, stating that "[i]nstead of serving as a negotiation forum where countries can develop new and better rules, it has sometimes been dominated by a dispute settlement system where activist "judges" try to impose their own policy preference on Member States" (p.2). This statement serves as a condense overview to exemplify the main problems that beset the institutional setup of the WTO. First, it highlights the shortcomings of the WTO's decision-making structures and its inability to legislate. The reoccurring failures of the Doha Round to live up to its ambitions and to produce significant new multilateral trade agreements are exemplary for this problem and already led to various proposals for WTO reform in the past. Related to this is the observation that the WTO as an actor in itself is not very well setup to help overcome problems regarding its legislative and administrative functions.

\footnotetext{
${ }^{1}$ This is not to suggest that Jackson regarded substantive rules as unimportant, nor that such rules should be neglected at the costs of a greater attention to institutions. Clearly, both, rules and institutions are crucial for a well-functioning multilateral trading system. However, an explicit call for attention to institutions is at times necessary, given that the long term benefits of institutions often seem less present on the day-to-day political agenda than the immediate consequences of changes in substantive rules.
} 
Generally seen as a 'member driven organization', the WTO possesses limited actorness, and the role of its Secretariat in influencing and facilitating the production of the WTO's policy output is severely confined. ${ }^{2}$ Second, the statement shows that even the dispute settlement system, which used to be the organization's most complimented feature, is increasingly getting under pressure. The US is just the most relentless amongst several critics that are suspicious of an increasingly legalized system and who accuse the WTO's main adjudicative organ - the Appellate Body - of judicial activism, regularly overstepping the boundaries of its mandate. ${ }^{3}$ These first two problems give rise to a third one, which is also implied in the US statement: The organization's weak legislative branch in contrast to its strong judicial branch lead to an institutional imbalance. Judicial decisions that displease the WTO's membership cannot be offset by legislative action due to the cumbersome decision-making practices of the organization and its limited actorness. This puts the entire multilateral system at risk, since influential members feel increasingly alienated by judicial decisions, while the legislative system is stalled. The US is very vocal about this, claiming in the 2018 trade policy agenda that it is subject to "outdated and underperforming trade deals" and international bureaucracies that undermine its interests (p.1). While the US position is certainly an extreme one, the listed problems indicate that the trading system is beset with fundamental flaws regarding those institutional structures that are supposed to govern international cooperation.

These flaws are not new, and calls for reform have been frequent throughout the history of the WTO. ${ }^{4}$ However, in the current political climate such flaws become increasingly relevant and more dangerous to the multilateral trading system than ever before. As a result of the WTO's institutional shortcomings, more and more countries focus on regional and bilateral agreements to manage their trade relations, reducing the relevance of the multilateral system. More than that, as one of its most important members the US is responding to the institutional shortcomings and is currently acting in a way that is likely to significantly harm the system. Its current administration already showed in other contexts that it is less concerned about long standing patterns of international cooperation than its predecessors, and that it does not hesitate damaging multilateral structures to achieve short term national interests. It already made clear that the multilateral trading system poses no exception to this, stating that the US "will not allow the WTO - or any other multilateral organization - to prevent us from taking actions that are essential to the economic well-being of the American people" and that "our trade policy will aggressively defend U.S. national sovereignty" (USTR, 2018, pp.2-3). The

\footnotetext{
${ }^{2}$ When reference to the actorness of the WTO is made, this is meant to refer the organization as whole and its ability to reach decisions. This should be distinguished from the ability of the Secretariat to act autonomously and influence decision-making. This distinction will be made clear by explicitly referring to 'the Secretariat' whenever the analysis is meant to relate to the Secretariat's role as a specific entity within the organization at large. In all other cases it should be understood that reference is made to the organization in its entirety.

${ }^{3}$ For an overview of US accusations against the Appellate Body, see the government's 2018 trade policy agenda, pp. 24-28.

${ }^{4}$ For an overview of reform proposals of the WTO's institutional structures up to 2009, see Deere-Birkbeck and Monagle (2009).
} 
administration already put these words into practice by focusing increasingly on protectionist policies, bilateral deal making, and by blocking the appointment of new members to fill vacant positions in the Appellate Body - risking to leave the Appellate body hamstrung by 2019. These actions are undermining the multilateral system and put the WTO in a serious institutional crisis. Thus, the need to address the longstanding governance problems of the WTO seems more pressing than ever before and the debate about institutional reform of the organization is currently on top of the political agenda.

However, despite the pressing need it is uncertain whether institutional reform can be achieved in the near future and whether it would be satisfactory. After all, debates about the shortcomings and reform of institutional structures are not new to the trading system. As indicated by Jackson's quote above, throughout the system's history many discussions about the adequacy of the institutions in charge of multilateral trade have taken place, pointing out that the functioning of these institutions has regularly been sub-optimal. Such debates have often been accompanied by sensitive proposals for institutional reform. However, it seems that more often than not institutional change does not result from such proposals, despite apparent functional advantages of such change. Even in those cases were change occurs it is often delayed or it does not adequately address all institutional weaknesses identified in a preceding debate, and new shortcomings become apparent quickly after the change has taken place. This leads to the result that the institutional structures of the trade regime have been regularly out of sync with the demands of their environment. Given that a well-functioning institutional structure would be beneficial to all actors involved in the trading system, this is a puzzling observation, which inspired the questions this research seeks to answer.

\section{The Questions}

Considering that properly functioning international institutions are desirable and that mainstream institutional theories in international relations explain the existence of such institutions by their functional advantages, the question arises why it seems so difficult to change the institutional structures of the multilateral trading system when they function suboptimally. Which factors drive institutional change and under which conditions are institutional arrangements reformed? What are the political dynamics of institutional change and can certain patterns of change (or the absence thereof) be identified? These are the questions that inspire this research. In light of the abovementioned institutional crisis of the WTO these questions are particularly relevant. Answering them can help to understand the current shortcomings of the system and to assess the likelihood of successful future institutional change.

Due to the variety of institutional arrangements that can be examined when answering these questions it is necessary to narrow down the kind of institutional changes this research is concerned with. The research focuses on those instances of institutional change that are related to the institutional structures that govern cooperation in the multilateral trading system. To capture this reference is made to the 'institutional structures of the multilateral trade regime'. This terminology has been chosen to highlight that the focus of this study is not on institutional change broadly conceived, but that it examines the dynamics of change of tangible 
constitutional features that determine the policy output and governance of international cooperation and organization. The term 'regime' used in this context does not refer to any specific definition of this concept as used in international relations theory or international law, but is simply meant to capture the different organizational forms that existed to facilitate the functioning of the multilateral trading system throughout its history. It should therefore be understood as a means to enhance clarity of expression, by providing a generic term that should be read to encompass the International Trade Organization (ITO), the Organization for Trade Cooperation (OTC), the GATT and the WTO. 'Institutional structures' in in turn refers to those institutional features of the regime that determine how policy outputs are derived and who respectively which institutional entities - are empowered to do so. This can include different kinds of policy outputs, related to different functions of the trade regime, including legislative decision-making, regime administration, dispute resolution, as well as information gathering and transparency facilitation. To put it differently, the research focuses on changes in the institutional architecture of the trading system's international organizations that determine policy output, including instances of granting authorities from the state to the international level and institutional developments related to decision-making mechanisms.

As it is shown in chapter 2 these kinds of institutional features are captured by two analytical variables that have been developed by Koremenos, Lipson, and Snidal (2001a) in the context of the rational design framework. These variables are labeled 'centralization' and 'control'. Using this terminology it is possible to specify the formulation of the guiding question for this research. Accordingly the research seeks to explore under which circumstances the international trade regime's institutional arrangements regarding centralization and control change.

\section{The Method}

To address this question the research relies on theory guided process tracing. From a literature review of different strands of institutionalist theory - rational institutionalism and historical institutionalism in particular - a framework is developed to guide empirical investigation of institutional changes in the trade regime. The framework does so by conceptualizing centralization and control as analytical variables that are used to identify relevant institutional structures, and by pointing to possible dynamics that should be paid attention to when investigating the process of institutional change. Thus the framework does not deductively derive testable hypotheses, but is merely meant to guide empirical investigations that take an inductive approach. The findings of such investigations are used to draw conclusions, which can contribute to further theory development.

Equipped with this framework three cases are analyzed to gain a better understanding of institutional change in the trade regime. The cases focus on different functional domains covered by the institutions of the regime, since it can be assumed that the dynamics of change differ per function - a change in legislative decision-making structures is likely to be different from one in dispute settlement or surveillance mechanisms (Deere-Birkbeck, 2010). All cases relate to institutional changes in centralization and control that resulted from the Uruguay Round. The Uruguay Round can be regarded as the most important negotiation round in the 
history of the trade regime. The negotiations took place between the beginning of 1987 and the end of 1993 and led to a significant transformation of the institutional structures of the regime, including the establishment of the WTO. The first case examines exactly this establishment, and the design of the WTO's general administrative architecture and legislative decision-making procedures. The second looks into the changes in dispute settlement that resulted from the Uruguay Round, with a main focus on the choice to take decisions by reverse consensus and the creation of the Appellate Body. The third analyzes the design of the Trade Policy Review Mechanism (TPRM) as an enhancement of the regime's information gathering and transparency facilitation function.

These cases have been selected for several reasons. First of all, the cases are highly relevant due to their historical importance. Secondly, the cases fit well to the kind of phenomena this research is interested in, as they all constitute instances of changes in institutional structures that govern multilateral trade cooperation. Thirdly, it is advantageous to pick three cases from the same historical episode, as this keeps the time frame of investigations constant. This allows to control for confounding factors and a comparison between the dynamics of change in different functional domains becomes possible. Although one might argue that this comes at the expense of neglecting the longitudinal dynamics of change, the research circumvents this weakness by embedding each case in a thorough examination of the institutional history from which it emerged. Finally, the Uruguay Round has been selected as a pool for case studies for pragmatic reasons: data and interview partners are available to allow for process tracing. This would have been more difficult when earlier historical episodes of institutional change would have been chosen.

Said process tracing is of crucial importance to the case analyses. It allows to reveal the actual motives that led actors to engage in the process of institutional change and to fully understand the dynamics that unfolded in this process. By employing a process tracing approach the research seeks to avoid post-hoc functionalist explanations that explain existing institutional structures solely by the functions that they fulfill and are thereby prone to overlook important explanatory factors that are not functional in nature.

In conducting the case analyses information from various kinds of sources is used. These include secondary literature from scholars of the multilateral trading system, as well as written accounts of former negotiators and Secretariat members that participated in the Uruguay Round. As primary sources the research relies on official negotiation documents and interviews with former negotiators and Secretariat members. Official negotiation documents have been retrieved online from the archive available on the WTO's website ${ }^{5}$ and from the online GATT Digital Library provided by Stanford University. ${ }^{6}$ References to official documents are made in footnotes by naming the document symbol. ${ }^{7}$ Regarding interviews, 19 interviews with former

\footnotetext{
${ }^{5} \mathrm{https}: / /$ www.wto.org/gatt_docs/

${ }^{6}$ https://gatt.stanford.edu/page/home

${ }^{7}$ To keep the size of footnotes limited title and date have not been mentioned, but can easily be traced back by searching for the symbol on one of the abovementioned websites.
} 
Uruguay Round negotiators and Secretariat members have been conducted between February 2015 and June 2018. These interviews have been conducted in person in Geneva and Brussels, and by telephone. ${ }^{8}$ Furthermore, interviews that have been recorded for the WTO Creation Project have been consulted as well. Recordings of these interviews can be retrieved online. ${ }^{9}$

\section{The Relevance}

The historical investigation of institutional change in the trade regime as it is conducted in this research is relevant from an empirical as well as a theoretical perspective. From an empirical perspective, the research is particularly relevant in light of the present institutional crisis the WTO is facing, since it assists explaining the current shortcomings of the organization. Tracing the historical roots of the institutional structures that characterize the present setup of the trade regime contributes to a better understanding why these structures look the way they do and thereby helps to identify the underlying causes of the institutional problems that are currently witnessed. Furthermore, investigating the dynamics of institutional change contributes to assessing the likelihood of success of different proposals aimed at rectifying such problems. If patterns or factors can be identified in the course of the research that facilitated or hampered institutional change in the past, it might be possible to apply these insights by analogy to tell/estimate whether the present conditions for endeavors of institutional change are favorable or not. Embedding the empirical research in a theoretical framework facilitates the identification of general patterns. This sets the research apart from existing historical accounts of the trade regime's development, which constitute valuable and factually rich narratives but hardly ingrain their findings in a wider theoretical context.

Also from a theoretical perspective the research provides relevant insights. The notion of change of institutional structures of international organizations does not seem satisfactorily covered by existing theoretical frameworks. Rational institutionalism provides powerful theoretical assumptions about the emergence and design of international organizations, but neglects contextual factors that influence institutional change in a given historical trajectory. Historical institutionalism in turn focuses on such contextual factors, but fares less strong on providing causal mechanisms that induce change. This research draws on the strengths of both schools of thought and seeks to contribute to a better theoretical understanding of the dynamics of institutional change by developing a theoretical framework to guide empirical investigations of change, and using the gathered empirical insights to inform further theory

\footnotetext{
${ }^{8}$ Interviewees have been selected on the basis of their knowledge of and involvement in the relevant negotiation processes during the Uruguay Round. When doing so the aim to make a balanced selection of different perspectives was kept in mind and interviews were conducted with representatives of the most important developed countries, influential developing countries and Secretariat members. Interviews were conducted in semi-structured fashion, with the same set of questions used as a guideline in every interview. It was the purpose of the interviews to enrich the historical narrative, close gaps that remained from literature and archival research, and to identify the actual motives that drove institutional change. Interviewees have been anonymized. Interview transcripts are on file with the author. For a detailed overview of interviews see the table on page 353.

${ }^{9} \mathrm{http} / / /$ www.wtocreation.org
} 
development. Investigating the trade regime for this purpose is particularly suitable due to its rich and diverse history of institutional change. This history can be roughly divided into three different clusters: Formal, grand, but unsuccessful attempts to design organizational structures (i.e. the failed ITO and OTC); the less formal, incremental and pragmatic development of the GATT in different functional domains, ranging from administration and decision-making to dispute settlement and information gathering; and the successful creation of the WTO as a proper international organization, providing a comprehensive organizational structure for the management of multilateral trade relations. ${ }^{10}$ This diverse history with its successes and failures, and different dynamics of change promises to be a rich pool of information that can be fed back into theory. The resulting contribution towards a theory of institutional change is not only relevant for the trade regime, but to facilitate understanding the development and change of international organizations in general. In this respect this research is supposed to provide an impetus for developing a widely applicable theory of change in the governance structures of international cooperation and organization. Reoccurring debates about the reform of the UN, the IMF, the World Bank and other international organizations indicate the relevance of such a theory. Furthermore a better theoretical understanding of institutional change is important, because "it has been repeatedly demonstrated that if institutions do not adapt to change, they will wither, becoming increasingly regarded as vestiges of an older world driven by different interests than those that shape the present" (World Trade Organization, 2007, p. 361). It is thus highly interesting to grasp the dynamics of such adaptation and when institutional change is likely to be successful.

\section{The Structure}

To achieve abovementioned ambitions and explore which factors drive institutional change four substantial chapters follow this introduction, before the main findings of the research are recapitulated in a concluding section.

Chapter 2 develops the theoretical framework that is used to guide empirical investigations. It takes the rational design framework developed by Koremenos et al. (2001a) as underlying basis for this. Rational design is regarded as particularly suitable because with centralization and control it provides two variables that capture the institutional structures that are relevant to this research. Centralization indicates whether a focal entity conducts a particular institutional task. It thereby indicates who, i.e. which institutional bodies or actors, are in charge of a certain kind of policy output. Control in turn indicates how such output is derived. Together they can indicate the institutional architecture that governs an international organization. Furthermore, the rational design framework provides conjectures that specify under which conditions centralization and control are assumed to vary. It thereby offers a starting point to conceptualize

\footnotetext{
${ }^{10}$ One could identify the development of the WTO since 1995 as a fourth cluster. While this is highly plausible, it goes beyond the scope of the research project.
} 
institutional change, since a change in these conditions can be associated with a change in institutional design features.

However, the chapter argues that the rational design framework only constitutes a starting point to guide the empirical investigations conducted in this research, because it depicts four weaknesses that need to be addressed. First, its variables are only very broadly defined and need to be specified further before they can be applied to the empirical analyses of international organizations. Second, the framework does not elaborate on the possible interaction of its different variables. Yet, such interaction can be important to fully understand real-world instances of institutional design. Third, rational design has not been developed to explicitly capture the notion of change. It approaches institutional design as a static-equilibrium and takes a 'snapshot' of an organization's institutional structure at a particular point in time. Thereby the framework is prone to neglect long-term dynamics of institutional change. Fourth, the rational design framework takes a functional approach to the emergence of institutional structures. This can induce post-hoc research designs that explain the existence of such structures by the functions they fulfill. Such approaches are at risk to overlook alternative explanatory factors of institutional design.

To address these shortcomings the rational design framework is adapted for the purpose of this research. In a first step centralization and control, as relevant variables are specified and their interaction is explored. Considering the specification of variables, it becomes clear that both, centralization and control, can be conceptualized in several different ways. As such centralization can be thought of as generally describing all kinds of international cooperation that take place via some form of international organization. Beyond that centralization can be conceptualized in further detail to capture two kinds of specific institutional setups that are devised for this purpose. The first describes institutional bodies that consist of the membership of an organization (centralization as pooling). The second describes the delegation of tasks to an external, third party (centralization as delegation). Turning to control, a distinction can be made between a conceptualization of the variable that captures the control that the membership of an organization has over the processes by which the organization's policy outputs are derived, and one that describes the ability of members to control the implementation of such output. Furthermore another distinction can be made between control capturing how autonomous an organization is in relation to its membership and control indicating the relative influence that an organization's members have in relation to each other. These finer conceptual distinctions of the variables are important because the different forms of centralization and control can be more or less suitable depending on the function an organizational entity is supposed to fulfill, and because they pose different strategic challenges of institutional design. As such, the different forms that the variables can take presumably follow different logics of institutional design. Furthermore such fine distinctions are necessary to analyze the institutional architecture of an international organization in detail.

Such analyses need to take interaction effects into account, since centralization and control necessarily occur together in the actual institutional design of an international organization. An 
institutional entity that counts as an instance of centralization needs to be governed somehow, which necessarily raises questions of control. The different conceptual distinctions of each variable can be combined to derive how centralization and control interact. Due to the difference in underlying strategic challenges of institutional design the different forms of centralization require different kinds of control mechanisms for example. When an institutional body that consists of an organization's membership (pooling) is supposed to fulfill a certain function control is about managing the horizontal relationship of an organization's members amongst each other, for example by devising adequate decision-making mechanisms. In cases of delegation control is concerned with managing a vertical relationship between an organization's membership and a third party to ensure that the third party acts in the desired manner, for example by devising means to monitor the third party or by limiting its mandate. Thus, the empirical manifestation of control can be contingent on the type of centralization. In turn, control can also have an impact on centralization. Depending on the design and strength of control mechanisms institutional bodies or third parties can be more or less autonomous in fulfilling their tasks. As such, control determines the degree of centralization. When interacting the two variables form design sets that describe the institutional setup of an international organization and that follow different logics of institutional design. This implies that a meaningful empirical analysis requires awareness of the various different forms the chosen variables of the rational design framework can take, while paying attention to their interaction in design sets that constitute the building blocks of an international organization.

In a second step the chapter addresses the two remaining problems of the rational design framework by elaborating on the notion of change and arguing that process tracing is necessary in empirical investigation to minimize the risk of omitting non-functional explanatory factors that influence institutional change. Four sets of factors that need to be taken into account to understand the underlying dynamics of institutional change are derived in this part of the chapter. The first set of factors is provided by the rational design framework itself. The framework's basic idea that institutional design is a functional response to a collective action problem faced by states in the international arena, and the corresponding implication that a variation in the characteristics of such a problem leads to a variation in institutional design, is a powerful theoretical starting point to build upon. Accordingly attention should be directed to changing characteristics of a collective action problem and the corresponding institutional response.

However, usually institutional change is more complex than the suggested functional link between the characteristics of a collective action problem and institutional design. This is highlighted by the three remaining sets of factors. The factors in these sets are likely to compromise functional responses to collective action problems. In this light the second set rests on the assumption that designers are risk averse and seek to limit uncertainty and costs of institutional design. This implies that they proceed cautiously when changing institutional structures and that they are willing discard functionally optimal opportunities for change, that are perceived as too risky or too costly. The third set of factors points out that the design and 
change of institutional structures is often contested, because actors have heterogeneous interests. Thus, institutional change regularly constitutes a coordination problem to find mutually acceptable agreements on design. Such problems are particularly severe when distributional issues are at stake and resolving them is often only possible when the actors in favor of change are sufficiently powerful to overcome the opposition of those who resist change. Even when this is possible, the result might nonetheless be a functionally suboptimal compromise. The fourth and last set of factors points to the importance of the institutional and historical context in which change takes place. This highlights the importance of long-term historical investigation, and of institutional and cognitive path dependencies that limit the options for change and that make change contingent on previous developments. The review of factors shows that several different elements need to be taken into account when investigating institutional change and that the assumptions of rational design constitute only one of these elements.

Based on this the chapter concludes that careful empirical process tracing of institutional change is a necessity to understand how designers balance benefits, costs and risks of different design options; how they solve coordination problems when negotiating change; and how a particular episode of change is influenced by earlier institutional developments, i.e. how it is embedded in a wider institutional history. Furthermore, given that risk aversion, coordination problems, and path dependent trajectories can compromise the functionality of institutional design; change should not be conceived as a fully rational, but rather as a bounded rational process. Finally, based on the specification of variables and the factors that influence institutional change, the chapter recommends a generic structure that is applied to guide the case studies conducted for this dissertation and that informs the structure of subsequent chapters. Accordingly each case study chapter will first reflect on the case at hand as a design set consisting of combinations of different variants of centralization and control. Thereafter the chapters examine the suitability of rational design explanations to account for the emergence of institutional change and the specific design this change takes. Then the case is embedded in its wider historical context, to account for potentially long-term dynamics of change and the impact of path dependency. Afterwards, the negotiation process of institutional change is traced to examine which factors influenced a particular episode of change and how potential coordination problems were overcome. Lastly, attention is paid to the considerations of design interactions in the process of negotiating change and how risk aversion and the desire to limit the costs of institutional change influenced this process. The first case this structure is applied to is the emergence of the WTO.

Chapter 3 explores why it was possible during the Uruguay Round to create the WTO as a proper international organization and why its general, administrative institutional structures and legislative decision-making procedures look the way they do. In addressing these questions establishing the case of the WTO's creation as an instance of a change in centralization and control is done first. This shows that the advent of the WTO clearly constitutes an increase in 
centralization in comparison to the GAT, due to its more formal status as a proper international organization, its stronger enforcement capacity, wider scope and larger membership. However, when examining the WTO's institutional architecture in greater detail differences to the GATT are less pronounced and it becomes clear that the degree of centralization is significantly limited by the tight control that the membership maintains over the organization's legislative and administrative functioning. This is exemplified by the fact that every single member has in principle the opportunity to block decision-making and the membership's unwillingness to provide the Secretariat with a strong, independent role in influencing the organization's policy output. Clearly, being 'member driven' is one of the main characteristics of the WTO's institutional culture. As such, despite the fact that the organization enjoys a stronger standing as a focal entity within the multilateral trading system than its predecessor, it is limited in its ability to form policies independently of its membership.

To explain the emergence of the WTO and its institutional structures the rational design framework is consulted first. In doing so it is shown that on a high level of abstraction rational design can account reasonably well for the creation of the WTO. Generally speaking, the idea to create the WTO was motivated by the desire for having a proper organizational structure to support the implementation of the substantive agreements that resulted from the Uruguay Round, which was in turn initiated as a response to address the collective action problems that beset the multilateral trading system during the 1980s. However, rational design faces shortcomings in accounting for the WTO's specific institutional architecture and why the organization emerged despite initially strong opposition by the US as the most powerful actor during negotiations.

To address these shortcomings the chapter proceeds by examining the wider history of the trade regime's institutional development. This shows that the WTO's administrative and decision-making structure can largely be considered as a formalized continuation of (informal) practices that had developed incrementally in the GATT. In this respect the creation of the WTO is to be interpreted as a significant last step, a tipping point, of a long-term process of institutional development that shows strong traces of path dependency. Throughout this development irreversible trajectories were created, which ensured that being 'member driven' would become such a strong feature of the trade regime that some functionally beneficial design options, such as the creation of a small scale institutional body or the strengthening of the Secretariat, had to be forgone when the WTO was created. Overall, embedding the creation of the WTO in its wider historical context contributes to understand the organization's specific institutional setup. However, it does not address how opposition to the WTO's creation was overcome.

Tracing the negotiation process that led to the creation of the WTO sheds light on this matter. Such process tracing points to power as an important factor influencing institutional change and shows that institutional questions can often not be separated from questions on substance. This section of the chapter argues that the US as an initially powerful veto player, eventually dropped its opposition to the establishment of the WTO after it had realized that the 
creation of an organization could be used as a means to ensure substantively beneficial negotiation outcomes. Given the asymmetric distribution of power at the time, the US and other developed countries were able to use the creation of the WTO to overcome the opposition of many developing countries to a uniform application of the Uruguay Round's substantive agreements. This ensured that all regime members would have to sign up to all major substantive agreements that resulted from round. Hence, the creation of the organization was used to resolve contested distributive questions on substance to the advantage of the trade regime's most influential members, which in turn provided sufficient incentive for the US to drop its opposition. The argument in this part of the chapter does not necessarily contradict the functional assumption that the creation of an international organization is a means to facilitate the implementation of substantive agreements, but highlights that it does so on the terms of the most powerful.

Finally, chapter 3 examines how concerns over costs and risks of institutional change influenced the WTO negotiations and how they are reflected in design interactions of centralization and control. Adding to the historical section it is shown that the long-standing emphasis on individual control and sovereign equality that characterized the trade regime's history also shaped the Uruguay Round negotiations. Concerns over control, playing out in a path dependent institutional context limited the opportunities for formal institutional change and reinforced existing trajectories. Functional gains from further centralization were of secondary importance to considerations of individual control during the negotiations and had to be forgone. Thus, the WTO remained very similar to the GATT In terms of decision-making and regime administration. Its institutional autonomy in this respect is limited, decision-making is highly inclusive and power asymmetries amongst members are not reflected in formal legislative and administrative procedures. To compensate for this lack of formal centralization the WTO continues the trade regime's practice to rely on informal procedures that are less inclusive and that account for power asymmetries. Given the distributive nature of designing control mechanisms and the trade regime's emphasis of being member driven, the combination of formal decision-making procedures that provide even the smallest regime member with high individual control and informal procedures that de facto limit decision-making to the most relevant members, is a convenient way of maintaining the illusion of sovereign equality while taking political realities into account and ensuring that the organization can derive decisions in a reasonably efficient manner. However, when informal decision-making fails, formal procedures cannot be fallen back upon and the large amount of individual control implies that decisionmaking can easily get paralyzed.

Overall the chapter shows that functional approaches like the one of rational design are a useful starting point to understand the emergence of the WTO, its institutional architecture and decision-making principles. They provide reasonably adequate accounts of the underlying motives for change. However they face weaknesses in explaining how these motives are translated into actual design. Some ideas get lost in translation, since historical context, negotiation dynamics, and concerns over individual control moderate and at times distort 
functional design. In the case of the WTO this moderation implied that institutional change was more conservative with respect to its administration and legislative function than the news of the creation of a new international organization would on the surface suggest.

Regarding centralization as pooling, not only does the WTO, in contrast to the GATT, contain an institutional body that is solely dedicated to the administration of the regime's dispute settlement function, but - more importantly - the introduction of reverse consensus changed decision-making structures in such a way that dispute settlement is a quasi-automatic process. This directly relates to further centralization as delegation, since the adjudication process that is conducted by panels and the Appellate Body can hardly be controlled anymore once it has been set in motion. Also the introduction of the Appellate Body itself constitutes an increase in the degree of centralization as delegation - for the first time in the trade regime's history an independent standing body of experts is involved in the dispute settlement process. Finally, the streamlining of the panel procedures that was decided upon during the Uruguay Round also contributed to further centralization as delegation. Together these developments let to a highly institutionalized and much more legalistic approach to the resolution of disputes in the international trade regime than it used to be the case before the Uruguay Round.

To understand this institutional change the rational design framework is consulted first, showing that in theory the framework is highly suitable to account for the reform of the trade regime's dispute settlement mechanism. Also empirical investigations reveal that the underlying motives that motivated the reform correspond well to the assumptions of the framework. In essence the trade regime's membership wanted to address functional deficiencies of the dispute settlement system that were thought to endanger the implementation of substantive agreements and the credibility of the GATT. Thus the rational design framework initially seems to provide a suitable explanatory account. However, once again, this only holds at a high level of abstraction. Specific design features of the dispute settlement system and the negotiation dynamics that brought them about are neglected by the functional approach of rational design. Thereby the impact of coordination problems, of power as an important factor to overcome these problems, and of historical legacies on institutional change is overlooked.

To address this the chapter proceeds by delineating the development of dispute settlement mechanisms throughout the trade regime's history. In doing so it becomes clear that path dependencies partially explain the dynamics of change and the resulting design of the WTO's dispute settlement system. They provide a seemingly paradoxical explanation of both, conservative but also revolutionary aspects of the institutional reforms that the Uruguay Round brought about. On the one side, institutional path dependencies show that large parts of the WTO's approach to dispute settlement, are a continuation of practices that had incrementally developed throughout the history of the GATT. In this regard the reform of dispute settlement can be interpreted as a significant tipping point in a long-term process of institutional development, rather than the result of a revolutionary moment of rational design. On the other side, some elements of the reform - like the introduction of reverse consensus and the 
Appellate Body - constitute a significant break with the past and changed the trade regime's culture of dispute settlement from a political, conciliatory one to a highly legalistic one. It is argued that cognitive path dependencies contribute to understand this revolutionary change: Designers underestimated the implications of the reform and did not expect a significant shift in legal culture, because their expectations of the results of change were biased by their experiences with the longstanding GATT system. Thus the break with the past was not fully intended and the degree of centralization that resulted from the reforms was higher than initially foreseen. It seems plausible that this facilitated the reforms, as it downplayed potential costs of the large increase in centralization. Overall, the historical review illuminates how past practices have informed the design of the WTO's dispute settlement system in a bounded (instead of fully) rational process. Yet it does not help to understand how coordination problems during the negotiations were overcome.

Such problems certainly existed. Despite the fact the trade regime's members shared the general view that the dispute settlement system needed to be reformed, they differed in opinion on how this reform should look like. To show how such problems were overcome the chapter continues by tracing the negotiation process that led to the reforms. When doing so it becomes apparent that the institutional changes that emerged from the Uruguay Round can be grouped in three clusters according the underlying dynamics that unfolded during the negotiation process. The first cluster is characterized by interest homogeneity and the absence of major coordination problems. Low cost reforms with limited risks, like the procedural improvements of the panel process belong to this cluster. The second cluster in contrast is characterized by significant preference heterogeneity and a major coordination problem. At the heart of this problem were different negotiation interests of the US and the EC regarding decision-making procedures in dispute settlement. Initially the EC was firmly opposed to US demands for a more automatic approach to dispute settlement, including calls to reform the existing approach of decision-making by consensus. Only when the US made use of its powerful position in the international trading system and resorted to aggressive unilateral policies to open foreign markets the EC (and others) were induced to change their negotiating position. Power thus played a crucial role in the reform of the system. The third cluster captures the remaining elements of the reform, which can all be regarded as spin-off effects of two larger considerations in the Uruguay Round negotiations. First, the decision to establish the Appellate Body and the introduction of exclusive jurisdiction can largely be considered as domino effects of changes in decision-making. Second, the unification of the dispute settlement system and the establishment of an institutional body solely dedicated to the administration of the dispute settlement system emerged in the slipstream of the wider negotiations that led to the introduction of the WTO and the decision that all members of the trade regime would have to sing up to all of the substantive agreements resulting from the Uruguay Round. Overall, tracing the negotiation process of the dispute settlement reforms shows that the most important changes were not only due to a common, rational motivation to address functional problems, 
but also strongly influenced by the distribution of power at the time and the ensuing negotiation dynamics.

The last section of the chapter takes a closer look at the design interaction of centralization and control, and highlights how the trade regime's membership sought to find an adequate balance between the benefits, the costs and the risks of creating a more independent dispute settlement system by devising adequate control elements. Since impartiality and independence are important features of the dispute settlement system, and since the enforcement of existing obligations is politically less sensitive than the negotiation of new obligations, it is not surprising that control is less stringent for dispute settlement than for the WTO's legislative procedures. This is best exemplified by the introduction of reverse consensus for major decisions in the dispute settlement process. However, other design features were supposed to counterbalance this revolutionary reduction of control, such as: high decision-making thresholds regarding legislative procedures; limited mandates of the DSB, panels and the Appellate Body; restricting the access to dispute settlement to governments; requirements to review the dispute settlement reforms; the review of panel reports by disputants and the Appellate Body; the members' possibility to influence the selection of panel and Appellate Body members; and the flexibility that the membership has regarding the implementation of a dispute's outcomes. These design features indicate that the membership intended to create a more efficient system that was nonetheless possible to keep in check. As such controlling the WTO's autonomy in dispute settlement was a relevant factor that influenced the design of the system. The same holds true for control mechanisms that determine the relative influence of different members on the system - albeit to a lesser extent. Despite the fact that impartiality and independence are crucial in dispute settlement the initial demand by Europeans and Americans to have a larger influence on determining the composition of the Appellate Body, the disregard of developing countries' demands to strengthen special and differential treatment in dispute settlement, and the fact that the system ultimately leaves the capability to enforce the outcomes of a dispute contingent on market size indicate that considerations about the symmetry of control played a role in the design of the system. Thus, although dispute settlement in the WTO is outstanding regarding its strength and independence - i.e. its degree of centralization -, to fully understand its institutional setup and the circumstances of its emergence it is necessary to also pay attention to the means of control that designers integrated in the system during the process of institutional change.

In sum, the chapter finds that the explanations of rational design account well for the core motivation of the change in the dispute settlement system, but historical process tracing and attention to the interaction of centralization and control is necessary to get a better understanding of its particular design features. Furthermore power is highly significant to account for the large degree of centralization that the Uruguay Round brought about in the trade regime's dispute settlement domain. 
Chapter 5 introduces the last case study and examines the emergence of the Trade Policy Review Mechanism (TPRM) - a design feature that can be easily overlooked in comparison to the establishment of the WTO and the reforms in dispute settlement, but which is nonetheless important. The TPRM clearly constitutes a change in the degree of centralization regarding the trade regime's information gathering and transparency facilitation function. For the first time in its history the regime's institutions were explicitly mandated to systematically and comprehensively review the policies of individual regime members. This included a significant increase in centralization as delegation, since the Secretariat was entrusted with an unprecedented role in the production of comprehensive review reports of individual members.

The chapter shows that the functional explanations of rational design are highly adequate to understand how this increase in the degree of centralization came about. Theoretical assumptions of rational design fit extremely well to the centralization of information gathering and transparency facilitation in the trade regime and are confirmed when tracing the actual motivations that led to the introduction of the TPRM. In contrast to the other case studies it is shown that the impact of the regime's previous historical development and of coordination problems during the negotiation process was relatively limited.

This is not to say that the historical context in which the emergence of the TPRM was embedded is completely irrelevant. Of course the TPRM was not created in isolation of this context. After all, the long-term incremental development of the GATT provided a suitable basis of institutional structures to build upon. However the impact of path dependence on the TPRM was moderate. While the TPRM might have been facilitated and inspired by existing GATT practices, external influences - such as a policy proposal by an independent expert group that informed the Uruguay Round negotiations and existing surveillance mechanisms in other international organizations - were at least as, if not more influential in its creation and design. In this light the TPRM can be described as a tipping point that builds upon existing structures, but that was at most moderately influenced by these structures.

Turning to the negotiation process of the TPRM it is evident that its design process was relatively uncontroversial. The TPRM did not touch upon major distributional questions. Interests were mainly homogenous and coordination problems not very severe. Tracing the TPRM's negotiation process does therefore not disclose significant explanatory factors that cannot be accounted for by the rational design framework. However, it points to the importance of interaction effects between centralization and control. The trade regime's membership aimed to keep the degree of centralization moderate by devising a design set that balances centralization and control carefully. This was already apparent throughout the negotiation process when several regime members were skeptical of providing the Secretariat with too much autonomy in the production of its review reports, leading to an agreement that ultimately left the precise role of the Secretariat unspecified. Additionally, in the eventual agreement the concern over control is primarily expressed by the TPRM's limited mandate, which explicitly sets it apart from dispute settlement and which stresses that the TPRM is not a means to enforce substantive obligations. This limits the impact of the TPRM and makes it a relatively soft tool to 
facilitate compliance with the substantive rules of the multilateral trade regime, keeping sovereignty costs low.

Overall, these low costs in combination with the fact that the TPRM did not touch upon major distributional questions probably explains why the rational design approach is so suitable to explain its emergence. These conditions seem to provide fertile soil for functional design to flourish in a given institutional context without major disturbances.

The last chapter summarizes the main findings of this research in a concluding section, which reflects on the findings of the case studies in relation to the theoretical framework provided in chapter 2 . The section ultimately argues that institutional change should be thought of as a bounded rational process that is motivated by the desire to find functional solutions to collective action problems, but that devising such solutions is compromised by intervening factors such as risk aversion, coordination problems, and historically developed path dependencies. This general insight is further specified and several conclusions are provided that posit which dynamics are likely to influence institutional change in centralization and control. These conclusions are meant to provide an impetus for the investigation of change in other international organizations and are supposed to facilitate the development of a theory of change in the institutional structures that govern international cooperation. Finally, the insights gathered throughout this research are used to reflect on the origins of the trade regime's current institutional crisis and the prospect to overcome it. 



\section{Theoretical Framework: Conceptualizing Change}

2.1 Introduction

2.2 Functional Design of International Institutions: Promises and Problems of Rational Design

Rational Institutionalism

Rational Design $\quad 24$

2.2.3 Shortcomings of Rational Design 26

2.3 Centralization and Control: Specification, Interaction and Design Sets 29 


\subsection{Introduction}

The origin and change of institutional structures of international organizations is a complex process that can be influenced by various different factors. Empirical investigation of change of an organization's institutional structures is turned into a formidable challenge by the sheer amount of potentially relevant information and factors that could be taken into account. Without guiding principles and some basic assumptions that outline which factors are to be considered relevant and how these factors relate to each other, such investigation would be impossible. A theoretical framework helps in making guiding principles and assumptions explicit. To be useful such a framework needs to fulfil at least two conditions. First, it should capture the phenomenon of interest in abstract analytical concepts. Second, it should identify general mechanisms and causal logics that seek to describe the dynamics that lead to the emergence and change of institutional structures of international organizations. It is the purpose of this chapter to derive such a framework to guide the approach that is taken to the case studies analyzed in the subsequent empirical chapters.

To do so rational institutionalism is regarded as a good starting point to understand the basic logic that underlies the existence of international organizations. More specifically, rational design as a specific framework within the rational institutionalist tradition is chosen as the main reference point for the theoretical framework developed in this chapter. Rational design provides useful analytical concepts to capture the phenomenon this research is most interested in - the institutional structures that govern the multilateral trade regime. Furthermore, the rational design framework provides an overview of potentially relevant factors that lead to the emergence of such structures. However, the rational design framework in itself does not suffice to guide empirical investigation for the purpose of this research, since it suffers from four important shortcomings: its analytical concepts are only broadly defined; it is not specified how these concepts interact; it is has not been developed to account for dynamic processes of change; and the framework induces the employment of research designs that are prone to overlook potentially important explanatory factors.

To overcome these weaknesses the framework is specified and supplemented. The first two shortcomings are addressed by reviewing how the relevant concepts of the rational design framework have been applied in other studies of institutional design and by drawing on theoretical advancements in literature on international delegation. By doing so the concepts of interest are specified and it is shown how they interact. The latter two shortcomings are addressed by putting the rational design framework in relation to literature that engages with the notion of institutional change. Especially insights from the literature on historical institutionalism will be used for this purpose. Based on this an overview of factors that need to be taken into account to fully understand the origins and change of the institutional structures of the multilateral trade regime is presented. 
Overall, the elaboration in this chapter provides the necessary guidance for the following empirical chapters by taking the basic assumptions of rational design and specified versions of its analytical concepts as a solid basis that is supplemented by an overview of possible factors that influence the dynamic of institutional change. This leads to the insight that a full understanding of the emergence of the trade regime's institutional structures can only be achieved by historical process tracing. To get to this conclusion rational approaches are elaborated upon in the first section of the chapter. This is followed by a section that is dedicated to the specification of the relevant analytical concepts provided by the rational design framework. Thereafter different factors that can influence institutional change are elaborated upon. Finally, the main findings of the chapter are summarized in a concluding section, which makes use of the theoretical elaborations in this chapter to derive a generic structure that is followed to order the analyses conducted in the empirical chapters. 


\subsection{Functional Design of International Institutions: Promises and Problems of Rational Design}

A theoretical framework to guide empirical investigations needs to be capable of capturing the phenomenon of interest. For the current research this requires that such a framework provides a conceptualization of the relevant institutional structures of international organizations and an overview of the dynamics of their design and change. Functional theories on international institutions constitute a good starting point for both. In the following a brief overview of rational institutionalism as a general school of thought that rests on a functionalist logic is provided. This introduces some basic assumptions of functionalism and gives a powerful explanatory account of the core rationale for the existence of international institutions and organizations. To understand differences and changes in institutional design this is indispensable. Then rational design is introduced as a specific variant of rational institutionalism. It adds to the general school of thought by specifying design features that can vary across international institutions and organizations. This is crucial for the development of the theoretical framework as it points to the dependent and independent variables that guide empirical investigation. However, as it will be shown in the last part of this section, the rational design framework does not suffice to guide empirical investigation as it suffers from four significant shortcomings.

\subsubsection{Rational Institutionalism}

To understand institutional development of international organizations it is necessary to understand the factors that lead to the emergence of such organizations in the first place. Rational institutionalism offers a promising starting point in this respect. According to basic functionalist logic rational institutionalism posits that international institutions arise as a response to collective action problems. It starts out with the basic assumption - common in international relations - that two main characteristics of the international realm are anarchy and interdependence. The first one refers to the absence of an authority that possesses the legitimate means and the capacity to govern the relations among sovereign states. The second one stipulates that transactions among states usually entail reciprocal costly effects (Keohane \& Nye, 1977). In such an unregulated environment, behavior under the condition of interdependence is likely to lead to collective action problems, such as the undersupply of public goods, insufficient regulation of negative externalities, coordination problems, and collaboration problems. Drawing on concepts from game theory and microeconomics, rational institutionalists argue that states cooperate to overcome these collective action problems (Krasner, 1983). For such cooperation to happen it is not necessary that states have altruistic motives. Instead rational institutionalists argue that cooperation arises when states have a well-ordered set of 
fixed preferences and behave in a self-interested, strategic manner (Frieden, 1999; Keohane, 1984).

In theory such cooperation can be successful without institutional support from an international organization (K. W. Abbott \& Snidal, 2002; Axelrod, 2003). However, institutionalization via the establishment of formal international organizations, is supposed to facilitate cooperation due to the functions such organizations fulfill (K. W. Abbott \& Snidal, 1998). Such functions can include gathering and facilitating the exchange of information, providing a forum for states to enter into a dialogue and discuss policies, supporting the negotiation of international agreements, facilitating enforcement of such agreements by reducing incentives for defection, and in general reducing the transaction costs of international cooperation (K. W. Abbott \& Snidal, 1998; Keohane, 1984; Martin, 1992; Martin \& Simmons, 1998; Stein, 1983).

The case for institutionalized cooperation can be easily exemplified when considering a situation that resembles the characteristics of a prisoner's dilemma as it is modeled in game theory. In such a situation, actors would have individual incentives to defect and not stick to an agreement, despite the fact that cooperation would be beneficial for all parties involved. Because of these individual incentives to defect cooperation is unlikely to occur without institutional support and establishing an organization can help overcoming such a collaboration problem. By facilitating the exchange of information an organization increases the likelihood that actors embark on a pareto efficient cooperation strategy in the first place. Once such a cooperation strategy is achieved the likelihood that actors stick to this strategy is increased when cooperation takes place under the tutelage of an international organization, because cooperation in an organization tends to take place in the long run. Under this condition it can be assumed that the incentives to defect in the short run decrease due to the potential long run disadvantages when other actors would start retaliating in kind. Incentives to defect are further reduced when an organization has the task to collect and disseminate information about behavior of its members, since it becomes less likely that defection will go unnoticed. The likelihood of defection on an agreement is further reduced if the organization has enforcement capacities at its disposal. For these reasons cooperation amongst states is stabilized when taking place under the guidance of international organizations.

The rational institutionalist approach is a powerful explanatory starting point, demonstrating why self-interested states cooperate under the conditions of anarchy and interdependence in the international environment and the collective action problems these conditions can lead to. It furthermore explains why it is beneficial for states to institutionalize this cooperation in international organizations. However, the general rationalist approach does not account for variations in the design of international organizations' institutional structures. Why is it that some organizations are setup significantly differently than others with respect to their institutional features? This question is addressed by the rational design framework as stipulated by Koremenos, Lipson \& Snidal (2001a). 


\subsubsection{Rational Design}

The rational design framework belongs to the wider school of rational institutionalism and as such is also functionalist in nature. Like the more general approach it also assumes that states (or other actors) use international institutions in order to reach their collective goals and that the design of organizations is dependent on this. The framework adds to the general approach by providing a systematic explanation how variation in collective action problems leads to variation in institutional features across different forms of international cooperation (Koremenos et al., 2001a).

The framework does so by identifying several dependent and independent variables and deductively deriving the assumed relationships between these variables. Regarding dependent variables, it is assumed that international institutions vary on five key dimensions: membership, scope, flexibility, centralization, and control. Membership refers to variations in institutional rules that define the criteria and costs that actors have to meet to become part of an institution. Membership can be exclusive or inclusive, regional or universal, restricted to states or also open to non-state actors. Scope refers to the range of issues an international institution is concerned with. This range can be broad or narrow. The EU for example covers a wider range of issues than NATO. Similarly, the inclusion of trade in services could be regarded as an extension in scope of the international trade regime. Flexibility concerns an institution's ability to react to changing circumstances. Escape clauses, as well as provisions for renegotiation and ratification of an institutional agreement after a certain period of time are examples for institutional flexibility (Koremenos et al., 2001a). Centralization is related to the question whether a single focal entity conducts certain institutional tasks. Such tasks could be the collection and dissemination of information, the adjudication of disputes, reduction of transaction costs, coordination of operational activities, setting standards, etcetera (Duffield, 2003). Control essentially refers to decision-making rules and the governance of an international institution, including voting arrangements, such as required majorities and the question whether all members are equally influential to determine institutional decisions or not. Control can also include considerations about the financing of an institution and the election of key officials (Koremenos et al., 2001a).

As independent variables the rational design framework identifies four basic parameters of the international environment that influence the design of international institutions: the presence and severity of distribution problems; the presence and severity of enforcement problems; the number of actors and asymmetries among them; and uncertainty about behavior, the state of the world, and other's preferences (Koremenos et al., 2001a). Distribution problems arise when more than one possible cooperative agreement as solution to a collective action problem exists and when these different solutions have different distributional implications for the actors involved. ${ }^{1}$ An enforcement problem exists when actors have large incentives to defect on a particular agreement. ${ }^{2}$ The number of actors and their asymmetry refers to the amount of

\footnotetext{
${ }^{1}$ Other authors use coordination problems as a label to describe similar situations (Martin, 1992; Stein, 1983).

${ }^{2}$ Similar ideas are labeled as collaboration problem by other authors (Martin, 1992; Stein, 1983).
} 
actors that are relevant to arrange an institutional solution to a collective action problem, and their respective capabilities to influence this solution according to their interests. Uncertainty is split up into three kinds of uncertainty: uncertainty about other's behavior, i.e. incomplete information about other's behavior in a strategic situation characterized by interdependence; uncertainty about the state of the world, i.e. incomplete information about possible solutions to problems, consequences of a particular arrangement, or future technological, political, or economic developments for example; and uncertainty about preferences, i.e. other actors' preferred outcomes in a strategic situation.

Based on the list of dependent and independent variables and four underlying assumptions ${ }^{3}$ the rational design framework deductively derives several conjectures of bivariate relationships between dependent and independent variables. These relationships indicate how specific design features of an institution vary in response to a variation in the parameters that states face when approaching a particular problem. Just to mention one of the conjectures as an example, flexibility is supposed to increase with uncertainty about the state of the world, because rational actors would build in flexibility in institutional arrangements to be able to adapt to unforeseen future developments.

The specification that the rational design framework adds to more general variants of rational institutionalism is highly useful for the development of a theoretical framework to investigate the dynamics of institutional change in the trade regime. It provides specific variables that capture the phenomenon of interest and its conjectures indicate potential factors that influence variation of these variables. Centralization and control are the dependent variables this research focuses on. In light of the empirical phenomena described in the introductory chapter they are considered to capture the kind of institutional structures this research is interested in best, because centralization in essence captures who determines policy outputs of an international organization and control captures how such outputs are determined. Furthermore they are empirically and theoretically highly relevant as they touch upon key constitutional features of international organizations (K. W. Abbott \& Snidal, 1998; Koremenos et al., 2001a; Koremenos, Lipson, \& Snidal, 2001b).

The conjectures of the rational design framework already provide an indication of factors that can influence variation of centralization and control, and can be used as a basis to examine institutional change. Regarding centralization it is suggested that:

- Centralization increases when uncertainty about behavior increases.

- Centralization increases when uncertainty about the state of the world increases.

- Centralization increases when number increases.

- Centralization increases with the severity of the enforcement problem.

\footnotetext{
${ }^{3}$ The four assumptions are that: " 1 .... States and other international actors, acting for self-interested reasons, design institutions purposefully to advance their joint interests. ... 2.... The value of future gains is strong enough to support a cooperative agreement. ... 3. ... Establishing and participating in international institutions is costly. ... 4. ... States are risk-averse and worry about possible adverse effects when creating or modifying international institutions." (Koremenos et al., 2001a, pp. 781-782).
} 
With respect to control Koremenos, Lipson and Snidal (2001a) suggest the following conjectures:

- Individual control decreases when number increases.

- Asymmetry of control increases with asymmetry of actors (number).

- Individual control (to block undesirable outcomes) increases with uncertainty about the state of the world.

Yet, as useful as the rational design framework is by providing dependent variables and an indication of factors that explain a variation in these variables, it merely constitutes a starting point for the development of a theoretical framework to investigate the change of institutional structures in international organizations. This is due to a number of shortcomings of the framework that become particularly apparent when institutional change over time is the issue under consideration. An overview of these shortcomings is provided in the next section.

\subsubsection{Shortcomings of Rational Design}

The rational design framework has not been left un-criticized. Four main considerations stand out when reviewing the literature engaging with the framework: First, it is claimed that the variables are defined at a very high level of abstraction and that a more specific definition of variables is necessary for the application to and meaningful analysis of specific empirical cases. Second, and related to the first, it is criticized that the framework neglects potential interaction effects of its variables. Third, the rational design framework as it originated focuses on analyses of institutional variation at a particular point in time. Consequently it neglects variation within a particular institutional context across time and needs to be adapted to capture the notion of change. Fourth, it has been noted that many empirical studies that apply rational design do so in a way that is prone to overlook potential alternatives to rational explanations of institutional design.

The first criticism of the rational design framework concerns the high level of abstraction at which its variables are defined (Duffield, 2003; Thompson, 2010). Even the authors of the rational design literature themselves acknowledge that finer conceptual distinctions of the variables need to be developed (Koremenos et al., 2001a, 2001b; Koremenos \& Snidal, 2003). Without such finer conceptual distinction the application of the framework leads to analytical problems. The core of such problems is that rational design can capture very different empirical phenomena that rest on very different dynamics of institutional design under the same theoretical variable. To exemplify the point with one of the chosen dependent variables, the establishment of an international organization as a forum of states to facilitate discussion and political dialogue, and setting up an independent judicial organ that makes a binding assessment of states' compliance to an international agreement could both the captured as instances of centralization. However, such institutional structures are obviously very different in purpose and follow different design logics. The former is political and provides an opportunity to exchange subjective views, while the latter is supposed to make objective judgments in an independent 
and neutral manner. As such it would be problematic to treat them under the same variable. It should also be pointed out that different kind of collective action problems might lead to different forms of centralization. When an organization is supposed to deal with enforcement problems for example, this is likely to influence centralization related to the collection of information and to adjudication, but does not necessarily lead to a higher likelihood of increased centralization with regards to rule making; especially not when interests of designing actors diverge (Hawkins, Lake, Nielson, \& Tierney, 2006; Martin, 1992).

A second shortcoming of the rational design framework is that the framework only stipulates bivariate relationships between dependent and independent variables; thereby it is unable to account for more complex causal mechanisms arising from potential interaction effects amongst variables. Although the authors themselves acknowledge that the dependent variables could be substitutes for each other, complement each other, or conflict with each other, they do not specify the implications of this for institutional design (Duffield, 2003; Koremenos et al., 2001a). Empirically, interaction effects are very likely to occur in the complex institutional design of international organizations. In the context of this research, the most important interaction effect that has to be taken into account is the one that can occur between control and centralization. These two variables are likely to supplement each other. As pointed out by Duffield (2003), it does not only matter which tasks are centralized, but also how they are centralized and who is in charge of the them. This indicates that it is questionable whether centralization can even be treated independently of control within the context of an international organization: If a centralized body has a particular task to fulfill, this body must be governed somehow, which automatically raises the question of control. This insight is supported by principal-agent theory, which plausibly assumes that the occurrence of centralization ${ }^{4}$ is contingent on the availability of appropriate control features (Hawkins et al., 2006).

The third shortcoming of the rational design framework in the context of the current research is that it does not adequately cover long-term developments and the notion of change. The framework was developed to analyze institutional design as a static equilibrium (Koremenos et al., 2001a, 2001b). This implies that it takes a 'snapshot' of institutional design and explains such design by the immediate triggers that led to it. Such an approach is problematic in so far as it neglects possible causal mechanisms that only unfold in the long-term (Pierson, 2004). Longterm historical investigation of institutional change adds causal depth to an analysis and highlights the importance of context in which an exercise of institutional design takes place. The history of institutional structures can leave an impact on the design of new structures in several ways: It can determine the procedures and rules of institutional decision-making that need to be followed when designing a new institutional arrangement; it specifies which actors are involved in the design process and what their influence is; and it can influence these actors' identities, interests, preferences and perceptions. This implies that a longitudinal investigation of institutional change over time adds to a full understanding of institutional design, even when

${ }^{4}$ Principal-agent theory refers to delegation and not centralization. However, as it is explained on p. 30 , in footnote 6 , these concepts can overlap. 
only a design feature that emerged at a particular point in time is the main issue under investigation (Pierson, 2004; Wendt, 2001).

The fourth and final criticism of rational design is a methodological one that is not inherent in the framework itself, but which is nonetheless important to keep in mind. The rational design literature does not prescribe a particular research approach, nor does it suggest any guidelines to design empirical research (on the contrary it welcomes scholars to specify their research design as they see fit). Yet, the suggested functional conjectures of the framework often induce a tendency to rely on post hoc explanations. In such cases institutional choices are solely explained by the institutional outcomes under investigation, i.e. the function of a design feature is regarded as the reason for its existence. However, such explanations neglect the examination of more detailed causal mechanisms underlying a design process and are thereby prone to overlook alternative explanations for a design feature to come about (Thompson, 2010). Empirically such alternative explanations are very likely to exist (Duffield, 2003). Furthermore functional rationality is an implausible theoretical assumption (Pierson, 2000). Looking at outcomes and explaining them in a post hoc manner is useful to establish a correlation between cooperation problems and institutional design, but is not sufficient to prove causation (Frieden, 1999). To get insights into the real causes of a certain design feature it is necessary to look at the process of design, at strategic decisions and the alternatives to these decisions to check whether the choices of designers were indeed motivated by the search for a functional response to a collective action problem or not (Thompson, 2010).

The preceding four problems need to be addressed when developing a framework that guides theoretical investigation of institutional change in international organizations. The following two sections will do so. The first one specifies centralization and control as relevant dependent variables and elaborates on their interactions. Thereby it addresses the first two problems. The second one elaborates on the notion of change of institutional structures, points out the importance of historical context, and calls for process tracing as the approach that should be taken to empirical investigations. It thereby addresses the last two problems. 


\subsection{Centralization and Control: Specification, Interaction and Design Sets}

The dependent variables chosen for this research are of high theoretical and empirical importance. Empirically the variables do not only capture the relevant phenomena this research is interested in, but also describe politically sensitive design features that can entail sovereignty costs and that are considered to be core constitutional features of international organizations (Abbott \& Snidal, 2000; Hathaway, 2008; Koremenos, Lipson, \& Snidal, 2001a). From a theoretical perspective the variables are interesting because of their potential to be further explored. The necessity to do so has been pointed towards in several comments on the rational design project. First and foremost, critics have made the previously mentioned general point, that rational design's variables are defined at a too high level of abstraction and that further specification is necessary. Secondly, the rational design framework has been criticized for neglecting potentially important analytical concepts that can influence institutional design, such as delegation and power (Duffield, 2003; Thompson, 2010). Engaging with centralization and control more deeply can address this criticism, as the former is related to delegation while the latter can contribute to clarify the impact of power in institutional design. Third, a theoretical elaboration on centralization and control sheds light on interaction effects of these variables, addressing another one of the previously mentioned general criticisms. Thus conceptualizing centralization and control is necessary and valuable for further theory development (Koremenos, Lipson, \& Snidal, 2001b; Koremenos \& Snidal, 2003). In the context of this research this is especially relevant as such a finer conceptualization is a methodological necessity to develop a theoretical framework that is readily applicable to empirical investigation.

The following section sets out to provide such a conceptualization. It is shown that centralization and control describe analytically different institutional design features, but that they interact in such a way that they need to be examined in tandem to fully understand complex empirical manifestations of institutional arrangements. It is argued that institutional design of centralization is invariably related to considerations of control and vice versa. On the one hand different types of centralization determine the mechanisms that states employ to exert control over an international organization. On the other hand the amount of control that is exerted determines the degree of centralization. This implies that in the process of actual institutional design, designers often consider questions of centralization and control simultaneously. The following elaboration clarifies why that is, but for the sake of clarity it does so sequentially. First centralization is addressed and afterwards control. Such a sequential approach enhances clarity of theoretical elaboration as well as empirical application, while still allows to understand the variables' interaction.

In line with this the following will first elaborate on centralization, showing that it can be conceptualized as taking three different forms. Thereafter control will be examined and its different conceptualizations highlighted. After the two variables have been individually 
addressed a taxonomy of design sets is developed that shows how centralization and control interact by supplementing each other. This interaction allows for analyzing complex arrangements of nested and interdependent institutional structures. Conceptualizing centralization is the necessary starting point to develop these arguments further.

\subsubsection{Conceptualizing Centralization}

To conceptualize centralization in further detail the definition of the variable as provided by the rational design framework should be recalled. According to the authors of the framework centralization is present when a single focal entity conducts a particular institutional task (Koremenos et al., 2001a). This broad definition leaves a lot of room for interpretation.

In the following section it is argued that centralization can be thought of in three different ways. ${ }^{5}$ First of all centralization captures the general idea that describes the establishment and transfer of authorities to an international organization. Within this general notion of centralization two more specific variations of centralization can be captured. The first one can be labeled 'centralization as pooling' and describes the establishment and transfer of authorities to an international body that is composed of representatives of the members of an organization. The second one can be labeled 'centralization as delegation' and describes the establishment and transfer of authorities to a third party to act on behalf of the members of an organization. Thus, the crucial difference between these two variants lies in the characteristics of the entity that is supposed to fulfill a certain task - is it a collective body of members of an organization acting or a third party acting on behalf of the membership. This distinction is also made by studies elaborating on the conceptualization of international delegation, which can be depending on the definition used in a particular study - regarded as synonymous to centralization (Brown, 2010; Hooghe \& Marks, 2014; Koremenos, 2008; Lake, 2007). ${ }^{6}$ In the following a brief literature review on the use of centralization in empirical applications of the rational design framework supports the classification of centralization into the three types

\footnotetext{
${ }^{5}$ The line of reasoning in this section is similar Elsig's conceptualization of international organizations as complex agents (2010).

${ }^{6}$ For the sake of clarity the term 'centralization' is used even when reference is made to studies that use the term 'delegation'. This is of course only done when the definition of delegation used by the original author can be considered as generally synonymous with the definition of centralization. To provide an example, Bradley and Kelley (2008) define delegation broadly in a way that significantly overlaps with rational design's definition of centralization "as a grant of authority by two or more states to an international body to make decisions or take actions" (p.3). Thus, depending on the definition the concepts can be used interchangeably.

It needs to be pointed out though that this assumption only holds under the condition that a focal entity is charge of conducting a task. Although centralization usually entails an act of delegation, the opposite is not necessarily true. In theory a task can be delegated to several different actors, leading to the opposite of centralization. Thus the congruence of centralization and delegations rests of the logic that delegation occurs if centralization occurs. But it would not be possible to reverse this statement (if delegation occurs, then centralization occurs) unless one would add the necessary condition of a focal entity (if delegation to a focal entity occurs, then centralization occurs). The broad definition of delegation quoted earlier seems to implicitly take this into account since it mentions an "international body" as an entity to which authorities can be delegated and does not explicitly mention the option to delegate authorities to several bodies.
} 
suggested. ${ }^{7}$ It reveals that all three variations of the concept are used interchangeably under the label centralization. This is analytically misleading since the different variants rest on different design logics.

The definition of centralization provided by rational design merely refers to a focal entity conducting an institutional task. This permits for a broad conceptualization of centralization that treats an international organization as the focal entity in question. This has been done in existing literature to describe a particular form of international cooperation (Bradley \& Kelley, 2008; Koremenos, 2007, 2008; Martin, 1992). In an application of the rational design framework Richards (2001) for example regards policy output generated and regulated under auspice of the International Air Transport Association (IATA) as an example of centralization, in contrast to bilateral agreements on the regulation of international aviation markets. Oatley's (2001) interpretation of the concept is similar to that of Richards. He also adopts a broad perspective in classifying the establishment of the European Payments Union (EPU) as a highly centralized form international cooperation (Oatley, 2001). ${ }^{8}$ Generally, the centralization of cooperation is one of the main characteristics of international organizations and contains several functional benefits (Abbott \& Snidal, 1998). In this respect even organizations that only serve as forums for an exchange of views and for negotiations can already be regarded as functionally beneficial forms of centralization (Abbott, Keohane, Moravcsik, Slaughter, \& Snidal, 2000; Goldstein, Kahler, Keohane, \& Slaughter, 2000). Public discourse often reflects this general understanding of centralization by labeling decisions taken within the framework of an international organization as a decision of the organization itself. This treats an international organization as a singular focal entity that provides policy outputs. Such a general conceptualization of centralization can be useful to get an overview of the relationship between an organization and its members, but it does not allow for a more nuanced analysis of how such policy outputs are derived by the interplay of different kinds of focal entities within an organization. For this the differentiation between centralization as pooling and centralization as delegation is required. The way that centralization is treated in many empirical applications of the rational design framework corresponds to this differentiation.

Mattli (2001) for example seems to regard centralization as equivalent to delegation to third parties. He examines whether the rational design framework is applicable to private international arrangements for the settlement of trade and investment disputes. ${ }^{9}$ For his

\footnotetext{
${ }^{7}$ The literature that explicitly mentions centralization as an independent variable in empirical applications of the rational design framework does not reflect much on the theoretical meaning of the concept. Instead the literature circumvents the weaknesses of centralization's broad definition by using it in a way that is specifically tailored to the empirical phenomenon under investigation in a particular study.

${ }^{8}$ The authors of the rational design framework interpret Oatley's study differently, arguing that the US functions as a focal actor in Oatley's case study and that therefore centralization is given without formal delegation (Koremenos et al., 2001b). Here a different interpretation is chosen since Oatley mainly focuses on the crucial role of the US in the process of setting up the EPU according to its interest. Once the EPU was created though Oatley points out that centralization was present in the form of delegation of decision-making authorities to the EPU's managing board (2001).

${ }^{9}$ Notably Mattli applies the rational design framework to agreements amongst firms and not amongst states.
} 
investigation Mattli (2001) considers centralization to be present if parties to a dispute refer to an institutionalized arbitration center for resolving a dispute, while he regards it as absent when parties rely on ad hoc arbitration. The difference between the two ways of arbitration lies in the fact that institutionalized arbitration centers have the authority to set procedures, collect information and monitor, while "the arbitrator in an ad hoc case depends entirely on the good will of the parties for a smooth process of dispute resolution" (Mattli, 2001, p. 927). Accordingly, Mattli's understanding centralization seems to entail that authorities need to be explicitly delegated by the parties involved to an external focal entity for centralization to be considered present.

Other studies contrast to Mattli's in the interpretation of centralization by employing it exclusively according to the definition of pooling. While he acknowledges that centralization can take the form of delegation to third parties, Pahre's study for example focuses on clustered negotiations. He treats such negotiations as a form of centralized bargaining (Pahre, 2001). Clustered negotiations take place when many countries bargain simultaneously within a regime, or when one state bilaterally negotiates with several other states on the same issue and each bilateral negotiation is linked to the other negotiations (Pahre, 2001). Kim (2010) picks up on Pahre's idea of clustered negotiations as a form of centralization and applies this to the negotiation rounds in the GATT. Similarly, in his study on treaties regulating the treatment of prisoners of war, Morrow (2001) seems to regard multilateral treaty negotiation during international conferences as an instance of centralization. Mitchell and Keilbach's research corresponds to the interpretation of centralization as pooling as well. Their study focuses on testing the conjectures of the rational design framework in the field of intergovernmental environmental cooperation. In this study they consider institutionalized exchange of side payments, agreed upon and managed by the members to an environmental agreement, as a form of centralization (Mitchell \& Keilbach, 2001). Thus the study regards the pooling of resources and the collective management of their distribution as an instance of centralization. ${ }^{10}$ In all of these cases no actors except for the parties to the agreement are involved in the process of centralization, which is in line with the definition of pooling.

It should be pointed out that the different forms of centralization are not mutually exclusive. Several studies use centralization in a way that corresponds to all of its three variants. In his study on international aviation markets Richards (2001) does not only interpret centralization broadly as mentioned above but also uses the concept more specifically, referring to international conferences of the IATA as instances of centralization, as well as the collection of information by the IATA and its authority to sanction. ${ }^{11}$ While the first activity corresponds to

\footnotetext{
${ }^{10}$ Mitchell and Keilbach's study also indicates that centralization should only be regarded as present when authorities are transferred explicitly to an international body. The performance of institutional tasks by a selfappointed actor, is not considered to indicate centralization. In this respect their study does not regard unilateral US actions aiming to coerce compliance of states with the International Convention for the Regulation of Whaling to be an instance of centralization (Mitchell \& Keilbach, 2001).

${ }^{11}$ Richards is more explicit in labeling the latter aspect as centralization. However, his article implies that the former can be regarded as an example of centralization as well.
} 
pooling, the second corresponds to delegation. ${ }^{12}$ Koremenos (2008) also uses all three different conceptions of centralization in her empirical application of the rational design framework. Similar to the argument presented at the beginning of this section, her study starts out by conceptualizing centralization broadly, as a transfer of authorities to administer an international agreement to some form of international organization. Consecutively she differentiates this broad understanding of centralization into two more specific conceptions that she calls internal delegation and external delegation. Internal delegation seems to be similar to pooling as it refers to "delegation to a collective formed by the members of the agreement themselves" (Koremenos, 2008, p. 152). External delegation in turn is similar to centralization as delegation, referring to "delegation to a third party outside of the agreement" (Koremenos, 2008, p. 152).

Despite the fact that the different variants of centralization are regularly used simultaneously in empirical studies it is important to stress that they indicate empirically different phenomena. Delegation describes a hierarchical relationship "in which an agent receives a conditional grant of authority to act for a principal under some specified conditions" (Lake, 2007, p. 231). Pooling in turn is resembles "joint decision making among the principals themselves" (Hooghe \& Marks, 2014, p. 5) and occurs when individual states transfer authority to an international body that is composed of several states and that acts on their behalf. ${ }^{13}$ Despite the fact that no third party is involved in pooling, actions by the collective body are still likely to differ from actions preferred by individual members of the body. As such the collective can be assumed to be an entity that behaves differently from the aggregation of its individual, constituent parts. ${ }^{14}$

It is important that the differences of delegation and pooling are kept in mind in empirical investigations of institutional design since the underlying causal mechanisms that inform the design process of these institutional features follow different logics (Hooghe \& Marks, 2014; Koremenos, 2008). Depending on the collective action problems actors are facing, either delegation or pooling might be an adequate functional response. Delegation for example might be particularly suitable when preferences of an international organization's membership are homogenous or when a task requires expertise and neutrality (Hawkins, Lake, Nielson, \& Tierney, 2006). In contrast, when interests of an organization's membership are heterogeneous and institutional tasks are politically highly sensitive, then centralization as pooling might be a more appropriate design feature.

\footnotetext{
${ }^{12}$ It should be noted that the membership of the IATA consists of airlines, not of states. For the purpose of this exemplification this special feature of Richards' study is not relevant tough. The point can still be made that the principals take some decisions and actions in the IATA themselves, while others are delegated to third parties.

${ }^{13}$ Some scholars only regard pooling to be present when states give up their individual capacity to block collective decisions (e.g. Hooghe \& Marks, 2014). However, for this research giving up veto options is not regarded as a necessary condition for the presence of pooling, as it can be assumed that collective decisions that could in theory be vetoed, but are not, can potentially still differ from decisions that individual states would have preferred if they would have decided unilaterally.

${ }^{14}$ Simply the fact that usually compromises need to be found when different actors with different preferences are supposed to come to a collective decision makes this assumption plausible.
} 
Furthermore delegation and pooling in themselves pose different strategic problems for states that need to be taken into account in institutional design (Lake, 2007). When delegation to an external agent occurs the main strategic issue a (collective) principal faces is agency slack, defined as "independent action by an agent that is undesired by the principal" (Hawkins et al., 2006, p. 8). One of the key challenges of institutional design when considering centralization as delegation is thus to devise institutional mechanisms that minimize the likelihood of slack (Hawkins et al., 2006). The issue in question is the management of the vertical relationship between members of an organization and a third party.

The strategic problem that arises in instances of pooling in contrast is concerned with defining the horizontal relationship of an organization's members amongst each other. This is a fundamentally different issue. The collective decision-making nature of pooling requires that states with diverging preferences on policy outcomes need to decide on a collective policy reasonably acceptable to all. "In pooling sovereign states are trading off between a unilateral policy closer to their preferences and a collective policy that is more efficacious in addressing some common problem" (Lake, 2007, p. 232). While pooling can theoretically lead to paretooptimal policies, it

"...will always leave some states aggrieved. Institutions will affect how the preferences of member states are aggregated into a collective decision, but unless national preferences are identical or the status quo is extreme, a policy that is more preferred by one state will typically be less preferred by at least one other. Institutions can minimize the bias in collective decision making, and thereby minimize the aggregate dissatisfaction of states, but they cannot ultimately solve the problem of disparate preferences and collective choice inherent in pooling sovereignty" (Lake, 2007, p. 233).

The difference between agency slack and collective decision-making as underlying strategic problems of delegation and pooling highlights the importance to take the distinction between these two design features into account when analyzing institutional structures. "Delegation and pooling of authority involve dissimilar trade-offs for states and this produces different combinations in the institutional structure of international organizations" (Hooghe \& Marks, 2014 , p. 8). Consequentially, it is important to be aware of the difference between delegation and pooling.

The difference in strategic problems associated with delegation and pooling is closely related to control as an institutional design feature. The next section provides a finer conceptualization of control to be able to explore this relationship further.

\subsubsection{Conceptualizing Control}

According to the rational design framework, control can manifest itself in various ways in institutional design, but the framework does not provide a clear-cut definition of control. It mainly refers to the concept as capturing design features that determine how collective 
decisions are made ${ }^{15}$, but also points out that it can be expressed in different ways, like institutional arrangements governing the selection of key officials or those that determine how an organization is financed (Koremenos et al., 2001a). Clearly, further specification is required. Just like centralization, control can be conceptualized in various different ways. A systematic overview of the different conceptualizations of control needs to be provided to avoid conflating different expressions of control in institutional design.

First of all a distinction can be made between a conceptualization that understands control as indicating the ability of an international organization to act more or less independently of its membership and a conceptualization that understands control as indicating the relative influence different members have within an organization vis-à-vis each other. The former describes the relationship between the organization and its membership. It indicates the autonomy of an organization. An organization in which decisions are taken by simple majority voting would for example have to overcome less veto points to derive policy outputs and would therefore be more autonomous than one which requires decision-making by special majorities or unanimity. The latter describes the relationship between members amongst each other and indicates the symmetry of influence within an organization. An organization that takes decisions by weighted voting is for example less symmetrical than one in which each member has the same amount of votes. ${ }^{16}$

The rational design framework seems to use control in both ways without being explicit about the distinction. This is indicated by the fact that the framework explicitly identifies required majorities in decision-making as an indicator of control, as well as distribution of votes and veto rights of a minority of states (Koremenos et al., 2001a). Also the conjectures the framework establishes with respect to control suggest that the framework allows distinguishing control according to the two variants established above. To recall, the conjectures on control state that:

${ }^{15}$ This formulation suggest a synonymous meaning of control and pooling of sovereignty (Hooghe \& Marks, 2014). Both in essence refer to the strategic problem of pooling sovereignty - collective decision-making according to this formulation. Indeed the two concepts are closely related. Nevertheless it is argued that they indicate analytically different phenomena. While centralization in the form of pooled sovereignty refers to the question whether a task or policy is subject to collective decisions in the first place, control refers to the institutional mechanisms that guide how the collective decision is derived. Furthermore, as it is argued below control can be exerted in other spheres than collective decision-making. It could for example also refer to the means a principal has available to control an agent or relate to dynamics that influence the policy output of an international organization outside pooled decision-making structures. A member of an international organization that is particularly powerful in the international arena in general might formally have the same amount of votes as less powerful members in the organization, but can still influence organizational policies more due to informal leverage.

${ }^{16}$ Of course this distinction is a theoretical ideal and in real-world institutional design the difference between control as autonomy and as symmetry might be more blurred. The two could for example find expression in the same institutional design feature. The veto rights of the permanent members of the UN Security Council (UNSC) for example do not only indicate asymmetrical control by giving those members with a permanent seat in the UNSC a possibility to block decisions that other UN members do not have, but also make the UNSC's policy output highly dependent - and thus less autonomous - on the approval these members. 
- Individual control decreases when number increases.

- Asymmetry of control increases with asymmetry of actors (number).

- Individual control (to block undesirable outcomes) increases with uncertainty about the state of the world.

Independent of the causal mechanisms that are supposed to operate in the relationships expressed by the conjectures, the first and the third conjecture clearly refer to the ability of a state to hinder an organization from generating undesired policies. ${ }^{17}$ The second conjecture in turn explicitly refers to the relative influence of an organization's members to determine policy output in relation to other members.

Making the distinction between control indicating institutional autonomy and control indicating relative influence is useful since it draws attention to the different strategic considerations states are confronted with when designing control mechanisms. In each case institutional design can be a delicate issue. Regarding institutional autonomy, it is necessary to find a balance between granting an organization with sufficient autonomy to allow it to function efficiently on the one hand, and the demand of members to minimize sovereignty costs and maintain a maximum of individual control on the other hand. Considering relative influence, on the one side control structures should accurately reflect geopolitical realities and the relative standing of members in the international arena; as such they should give more weight to the powerful. On the other side they also need to be perceived as at least minimally legitimate by less powerful members. Therefore there are boundaries to formally manifest high asymmetries of influence in institutional design (Stone, 2011). Striking such balances can be difficult. If an organization is too tightly controlled by its membership or control is excessively symmetrical, decision-making can get cumbersome and the organization might ultimately be deadlocked. Yet, if an organization is allowed to act too autonomously or is too dominated by its most powerful members it can be regarded as exclusive and illegitimate. ${ }^{18}$ Designers have a repertoire of several different design features - both formal and informal - at their disposal when facing the

\footnotetext{
${ }^{17}$ The first conjecture also seems to be related to relative influence of a state in relation to other states, as the amount of control is a function of the number of members of an institution and thus individual control is dependent on other states. However, the conjecture does not refer in any way to the relative weight of influence. Individual control is supposed to decrease due to increasing numbers simply by virtue of logic. Whether the amount by which it decreases is equal amongst all members of an institution or not is irrelevant for the assumed logic that underlies the conjecture. Thus the conjecture does not specifically address symmetry.

18 This also highlights an inherent dilemma of rational design: Finding purely rational design solutions is not always possible. Institutional design of control is inherently political and as such the perception which design is most rational differs across actors. A case can be made for institutional design that only allows for collective decisions to be taken when all states agree to the decision (e.g. unanimity requirements). This can ensure that the decision is adhered to by all states and that states do not perceive it as illegitimate (Schermers \& Blokker, 2003). However it can also paralyze the decision-making body and hinder the production of policy output (Scharpf, 1988; Schermers \& Blokker, 2003). Alternatively a case can also be made for authoritative decision-making by a limited set of states. This has the advantage that decisions can be reached efficiently but risks that excluded states feel alienated, regard the decision to be illegitimate, and would not implement it (Schermers \& Blokker, 2003). It is not possible to tell which design feature would be the more rational one in such a situation and a judgment on this is likely to depend on the political position of the beholder.
} 
challenge of devising control mechanisms of international organizations. However, before this will be addressed in further detail another basic distinction that should be taken into account when conceptualizing control should be pointed out first.

This second basic distinction differentiates between control over the process by which policy outputs within an international organization are derived and control over the domestic implementation of such policy output. Interpreting control as determining how the membership of an organization as a whole, or a particular member therein can influence the process of an organization to develop a certain policy output is probably the most common understanding of the variable. As it will be shown further below this can be expressed by several different design features, ranging from voting arrangements, over the selection of international public officials and the determination of their mandates, to agreements how an organizations should be financed. Yet, in addition to this interpretation it should also be taken into account that states can also retain control by determining how the policy output of an organization is domestically implemented (Sarooshi, 2005). Whether control over implementation of policy output is high or low depends on the kind of obligation such output entails, on its precision, and on the means that an organization has at its disposal to enforce this output (Abbott et al., 2000; Bradley \& Kelley, 2008; Hooghe \& Marks, 2014). Regarding obligation, non-binding output of an organization such as recommendations or guidelines leave more control over domestic implementation than a decision or a ruling which is meant to be legally binding. Considering precision, a vaguely phrased decision leaves more control over domestic implementation than one that precisely prescribes behavior and that leaves little room for interpretation. Finally, regarding means of enforcement, when an international organization has strong means available to induce compliance with a decision, enforceability is high and control over implementation is low. The opposite is the case if an organization has only weak means to induce compliance with its decisions. While an analysis of the institutional structures of international organizations might tend to focus on design features that are related to control over policy making processes within an organization, the ability to influence domestic implementation of policy output should nonetheless be kept in mind as a potentially important facet of control. After all, it is plausible that the two influence each other. If control over domestic implementation of policy output is high then states might care less about control of the processes by which such output is derived and vice versa. This can impact the dynamics of institutional design.

Such dynamics are also influenced by the interaction of centralization and control. Having provided a basic overview of the different conceptualizations of both variables the stage is set to examine this interaction and to provide a more detailed overview of the specific design features that can be employed to express centralization and control.

\subsubsection{The Interaction of Centralization and Control: Design Sets}

In the following it is argued that a full understanding of the institutional architecture of international organizations can only be achieved by examining how different conceptualizations 
of centralization and control are combined in actual institutional design. In such real world manifestations of institutional design the variables form design sets that consist of combinations of both of them. Treating the variables as analytically separate as it has been done so far is useful to understand the different building blocks of such design sets, but centralization and control need to be thought of in tandem to fully understand the dynamics of institutional design and its manifestation in the institutional architecture of an international organization.

In design sets centralization and control interact in a supplementary manner in two ways. First, the rigor by which control is exerted determines the degree of centralization. If a focal entity is controlled very stringently and if states have high control over the implementation of that entity's policy output, then its autonomy and authority to act decrease, which implies a reduction in the degree of centralization and vice versa (Bradley \& Kelley, 2008). ${ }^{19}$ Secondly, the different strategic problems that are associated with the different forms of centralization determine the type of control mechanisms that are employed in institutional design. Avoiding agency slack in centralization as delegation requires different types of control mechanisms than the strategic challenge of devising collective decision-making mechanisms which occurs in instances of centralization as pooling. These general interactions of centralization and control can be further specified by elaborating on different combinations of the various conceptualizations of the variables.

Starting with the general view on centralization it is possible to make statements about the strength of an international organization - and thus its degree of centralization - by examining the amount of control that the organization's membership has over the domestic implementation of the organization's policy output. From this general perspective the degree of centralization is higher if such policy outputs are obligatory (i.e. legally binding), precisely formulated and backed up by strong enforcement mechanisms. With the weakening of these factors the degree of centralization decreases.

While this perspective provides a starting point, it is incomplete as it neglects control over the processes by which policy outputs within an organization are derived. The general perspective on centralization treats international organizations as black box and does not permit to analyze processes within this black box. However, such analysis is necessary to make a comprehensive assessment of an international organization's degree of centralization and to understand different control mechanisms in further detail.

A more specific approach needs to be devised to provide an analytical toolkit that allows to examine the institutional architecture by which policy outputs are produced. This toolkit is derived by combining the remaining four conceptualizations of centralization and control: centralization as delegation, centralization as pooling, control indicating autonomy of an

\footnotetext{
${ }^{19}$ Interpreting the degree of centralization in this way is in accordance with the treatment of the degree of delegation as a related concept in academic literature. Abbott, Keohane, Moravcsik, Slaughter and Snidal (2000) seem to implicitly employ the same understanding when deriving indicators for delegation in their elaboration on legalization. Brown is more explicit in this respect. His metric for measuring delegation indicates the degree of delegation by referring to the authorities an agent has with respect to the services it can provide and the autonomy of the agent to provide such services (Brown, 2010).
} 
organization and control indicating symmetry of influence. When doing so a taxonomy of four possible design sets is derived as presented in table 1.

\begin{tabular}{|c|c|c|c|}
\hline & & \multicolumn{2}{|c|}{ Centralization } \\
\hline & & Delegation & Pooling \\
\hline \multirow{2}{*}{$\begin{array}{l}\overline{0} \\
\text { ํํㄴ } \\
\text { Oे }\end{array}$} & छे & $\begin{array}{l}\text { Design set indicating } \\
\text { autonomy of third } \\
\text { parties }\end{array}$ & $\begin{array}{l}\text { Design set indicating } \\
\text { autonomy of institutional } \\
\text { decision-making }\end{array}$ \\
\hline & है & $\begin{array}{l}\text { Design set indicating } \\
\text { relative influence of an } \\
\text { organization's members } \\
\text { on third parties }\end{array}$ & $\begin{array}{l}\text { Design set indicating } \\
\text { relative influence of an } \\
\text { organization's members } \\
\text { in institutional decision- } \\
\text { making }\end{array}$ \\
\hline
\end{tabular}

Table 1: Taxonomy of design sets of centralization and control

The table provides an overview of the possible interaction of centralization and control within an international organization. Thereby it provides a guideline to systematically examine an organization's institutional anatomy. Reading it horizontally, the table displays the impact of control on design sets, with the top row indicating the degree of centralization and the lower row indicating the relative influence that states have on focal entities. This allows distinguishing between the different strategic considerations that are at play when control mechanisms are designed. When investigating such design sets it is important to keep in mind that control can be expressed formally - e.g. in form of written rules and procedures - as well as informally. Often the informal ways to control an organization can be at least as important as formal mechanisms, especially when control is concerned with relative influence of states on institutional policies (McIntyre, 1954; Stone, 2011; Zamora, 1980). Vertically the table displays the impact of the different variations of centralization on design sets. The distinction made in the columns of the table directs attention to the fact that the difference in strategic problems that are associated with centralization as delegation and centralization as pooling as it was pointed out in section 2.3.1, determines the type of control that is employed in institutional design. Accordingly, control mechanisms per design set vary significantly, depending on the type of centralization. Keeping these points in mind the taxonomy can be used to provide a systematic overview of the different ways in which centralization and control can be expressed in the institutional design of 
an international organization. This overview is provided according to each design set as indicated in the different cells of the table. ${ }^{20}$

\subsubsection{Design Set 1: Centralization as Delegation and Control Indicating Autonomy}

In the first design set centralization and control describe the institutional design features that influence the autonomy of an organization with respect to the tasks that are delegated to third parties. In this respect control refers to the mechanisms that specify the means of a (collective) principal (i.e. an organization's membership) to control an agent (i.e. a third party, like an organization's secretariat). Control mechanisms determine how autonomously this agent can act and thereby determine the degree of centralization, but their specific design is in turn influenced by the strategic problem that is associated with centralization as delegation. It is to be recalled that this strategic problem consists of principals' concerns of to avoid agency slack. As such, control in delegation is mainly about designing a contractual relationship between a principal and an agent in such a way that opportunistic behavior by the agent is reduced.

This can be done in several different ways. Hawkins, Lake, Nielson and Tierney (2006) list five formal control mechanisms principals can use when delegating authorities to an agent. ${ }^{21}$ First, they mention that contracts that regulate a principal-agent relationship can vary in specificity. If rules in the contract are very precise an agent has less autonomy to act. If a contract leaves a lot of discretion to an agent due to a lack of specific rules, the agent obviously possesses more autonomy. Secondly, principals can design ex post control mechanisms by requiring the agent to report on its activities or by monitoring the agent. The tougher such monitoring and reporting requirements are, the lower is the degree of centralization. Thirdly, exerting control ex ante is possible as well. Principals can screen and select agents with preferences that are closely aligned to their own. This is assumed to reduce the likelihood of slack. If ex ante selection procedures are uncritical the degree of centralization can be assumed to increase. Fourthly, institutional checks and balances can be created to control agents. Hiring several agents that compete with each other or creating other entities in an organization with partially opposing mandates to the ones of the agent are examples of this form of control. Also, an agent's actions and decisions might be subject to approval by another institutional body. If such checks and balances are present the autonomy of the agent is reduced. Fifthly, principals can create incentives for agents

\footnotetext{
${ }^{20}$ Of course it is important to keep in mind that the derived design sets are theoretical constructs. As such they are simplified categories of more complex empirical phenomena. The sharp boundaries drawn in the taxonomy are likely to be more blurred in reality. The selection of a key public official serves as an example for this. Such a selection would usually be associated with centralization as delegation. This interpretation can be defended on the grounds that selection procedures can be an appropriate way to reduce the risk of agency slack. If an agent is selected that is known to have similar preferences to a principal, the likelihood of opportunistic behavior by the agent is reduced ex ante (Hawkins et al., 2006). Thus the procedures are concerned with the regulation of the relationship between a (collective) principal (i.e. the members of the organization) and an agent (the public official). Yet, alternatively one could also link the same example to pooling, because the selection process of a high public official is usually subject to collective decision-making. Which perspective is adopted depends on the purpose of the empirical investigation.

${ }^{21}$ Bradley and Kelley (2008) provide a similar list. However, their list conflates the notion of delegation and pooling.
} 
by rewarding desirable behavior and sanctioning undesirable behavior. Strong sanctioning mechanisms decrease the degree of centralization.

The exact design of these mechanisms can vary, but it should be mentioned that it is seldom perfect (Hawkins \& Jacoby, 2006). ${ }^{22}$ Even sophisticatedly designed control mechanisms can leave space for agents to increase their autonomy. This is often dependent on the characteristics of the authorities delegated, the characteristics of the agent, and the behavior of the agent (Barnett \& Finnemore, 1999; Hawkins \& Jacoby, 2006). Due to this a principal-agent relationship often develops dynamically and changes over time (Tallberg, 2002). Such change points to informal components of control in delegation. Especially when an agent has a lot of discretion the agent can employ informal strategies to increase its autonomy. Hawkins and Jacoby (2006) list four such strategies: "agent interpretation of potential mandates prior to delegation, agent reinterpretation of their mandates once delegation has occurred, agent efforts to increase their permeability to third-parties, and agent efforts to buffer principal monitoring" (p. 205).

Providing an exhaustive list of informal mechanisms that influence control in a principalagent relationship and agent autonomy is difficult though. Kenneth Dam puts this aptly when writing about secretariats of international organizations. He states that international "secretariats do not operate by rules that can be summarized and analyzed. They are administrative bodies that contribute interstitially to policy decision as they respond to individual challenges and opportunities" (Dam, 1970, p. 339). Even (or especially) the personality and management style of high public officials can have a significant impact on principal-agent relationships and institutional performance (Dam, 1970). ${ }^{23}$ In light of this difficulty, close attention in case specific analysis is required to spot informal developments that influence agent autonomy and control. ${ }^{24}$

\subsubsection{Design Set 2: Centralization as Pooling and Control Indicating Autonomy}

In the second design set the focus is put on those design features of centralization and control that express the autonomy of an organization in instances of centralization as pooling. The strategic problem of pooling determines the type of control mechanisms used, whose strength in turn indicates the degree of centralization. When centralization is expressed as pooling the strategic problem lies with the difficulties of collective decision-making to derive mutually acceptable policy output despite potentially heterogeneous preferences.

\footnotetext{
22 Hawkins and Jacoby list fives reasons that inhibit control of agents (2006). Firstly, agents can fool principals when being monitored or when they report. Secondly, costs of designing optimal control mechanisms might be too high. Thirdly, the preferences of principals can change, which might lead the principals to provide more autonomy to the agent. Fourthly, principals could disagree about the design of control mechanisms. And fifthly, the benefits of having an agent that is not perfectly controlled are still higher than the benefits of not delegating authorities to an agent.

${ }^{23}$ For the specific case of the GATT this was confirmed in conversations with former GATT secretariat members and is exemplified in written form by De Souza Farias (2013).

${ }^{24}$ Van Den Bossche's analysis of the development of the WTO's Appellate Body serves as an example of this strategy (2006).
} 
In this respect control is mainly - but not only - related to decision-making procedures and voting requirements in collective decision-making by an organization's membership. The amount of control and thereby the degree of centralization tends to be a function of the number of veto players in the decision-making process. Majority requirements are important indicators in this respect and simple majorities indicate a higher degree of centralization than super majorities or unanimity requirements. If decisions need to be taken by unanimity or consensus for example, each state has the capacity to block collective decisions that it regards as undesirable and thus maintains high individual control. Consequently the autonomy of an organization is limited, as the collective will of the majority of the membership cannot supersede the opposition of particular members. The opposite is the case when decision-making requirements face lower thresholds. In this case an organization as a collective is more autonomous in relation to individual members since the ability of any individual member to influence organizational decisions is limited (Hooghe \& Marks, 2014). With low thresholds a member or group of members could simply be outvoted.

From an arithmetic perspective the design options in this set are thus rather straightforward. However, decision-making mechanisms are highly sensitive and difficult to devise as they touch on sovereignty concerns of states. A delicate balance needs to be struck between taking such concerns into account while still allowing an organization to derive decisions efficiently. The degree of centralization should thus be neither too high, nor too low. Furthermore, formal decision-making requirements are often accompanied by informal negotiation and bargaining practices to prepare a decision. Such informal facets of decision-making also tend to touch on the distributive question of who is empowered in an international organization. Thus, as it is elaborated below, the question of symmetry is always present when control in the context of pooling is considered (McIntyre, 1954; Stone, 2011). This complicates institutional design in this set further.

In addition to decision-making structures, autonomy of a focal entity in instances of pooling can also depend on financing agreements of an international body and exit options from that body. When the funding of an international body is independent of its membership and withdrawal from a body is very difficult or politically costly then the degree of centralization is relatively high. In contrast, if the body is highly dependent on members' financial contributions and withdrawal is easy then the members can exert more control and the degree of centralization decreases (Bradley \& Kelley, 2008).

\subsubsection{Design Set 3: Centralization as Delegation and Control Indicating Symmetry}

In the third design set centralization and control are conceived as capturing whether the influence of certain states on third parties in principal-agent relationships is higher than the influence of other states. Thus, it captures whether influence in the process of delegation is symmetric or asymmetric. This is largely dependent on the control mechanisms employed. Although control in instances of delegation is predominantly related to a focal entity's autonomy, it can also affect symmetry. 
Asymmetric influence on agents is seldom a formalized feature of international delegation. Nonetheless it exists; for example when some members of an organization have a larger influence on the selection of key officials than others. This would imply ex ante asymmetrical control, since a sub-group of states that compose the collective principal has the ability to choose an agent that is assumed to be closer to its preferences. In the International Monetary Fund (IMF) attempts to appoint a non-European Managing Director have always been blocked by European lobbying for example (Boughton, 2004). ${ }^{25}$ Asymmetrical control can also be manifested in other ways. Stone argues that powerful states within an institution are usually able to influence agents by preempting an "agent's decision even after delegation has occurred" (2011, p. 27). Accordingly he posits that although

"it is possible to delegate significant powers to international institutions, [...] they cannot really be made autonomous vis-à-vis great power intervention. [...] The danger embodied in delegation is not that the agency will run out of control, but that it will be captured by the most powerful state in the system." (Stone, 2011, p. 27)

Providing a specific list of informal means to exert asymmetric control is difficult and those means can differ depending on the case under consideration (Stone, 2011). However, generally it can be stipulated that the ability to exert informal influence is contingent on the degree of transparency in an organization. If transparency is high the ability of powerful actors to influence third parties is lower; if transparency is low the likelihood of informal asymmetric control increases (Stone, 2011).

\subsubsection{Design Set 4: Centralization as Pooling and Control Indicating Symmetry}

In the fourth and final design set centralization and control indicate the relative influence of states in collective decision-making. The strategic problem of devising appropriate decisionmaking mechanisms that occurs in this instance of centralization as pooling poses a formidable challenge to design proper control mechanisms. On the one hand the standing of an organization's members and their relative influence in the international arena needs to be adequately represented and larger influence must be given to the powerful. On the other hand control mechanisms must be reasonably inclusive to ensure that weaker members do not feel disadvantaged and alienated from the organization. This challenge can be approached by employing formal as well as informal design features.

Formally, a focal entity is symmetrically controlled when decision-making processes are inclusive and voting rules are egalitarian. Under these conditions membership in an institutional body is open to all members of an organization and each member is assigned the same amount of votes. Control is formally asymmetric, when membership in an institutional body is limited to a sub-set of the membership of an organization, when votes are weighted and when certain states have the option to veto decisions while others have not (Koremenos et al., 2001a). The

\footnotetext{
${ }^{25}$ By custom, the post of Managing Director of the IMF has always been held by a European. Similarly, an American has always held the post of President of the World Bank.
} 
UN Security Council is probably the most prominent example of this design set, but also other institutions like the IMF and the World Bank contain institutional bodies in which seats are permanently reserved for the most important members of the organization and where votes are weighted.

However, even in institutions whose formal design indicates equal influence of states, asymmetric control is not uncommon (Mclntyre, 1954; Stone, 2011). Decision-making procedures can formally provide a level playing field while they de facto provide an advantage to the powerful. ${ }^{26}$ Especially when decision-making is not transparent and bargaining is a common form of taking decisions, powerful states with more capacities than others have a higher ability to influence decisions according to their desired outcomes (McIntyre, 1954; Stone, 2011). This ability stems from various sources. Powerful states can have more leverage in international institutions because they usually have more attractive outside options they can fall back on when a collective decision cannot be reached; because they have superior financial or negotiating capacities and superior information; because other states might hesitate to antagonize them; and because they can shift negotiations to a different forum, first negotiating with a sub-set of states to then present the outcome of such a negotiation to a wider set of states as a fait accompli (Stone, 2011). Very powerful states might even have the ability to alter the status quo, so that their preferred outcome is advantageous to others states in the light of new circumstances while it would not have been if the status quo would have remained the same (Moe, 2005; Scharpf, 1997). ${ }^{27}$ Again it should be noted though that the exact mechanisms that indicate asymmetric control are case dependent and vary across institutions (Stone, 2011). In this respect a possible interaction of formal and informal control mechanisms should be kept in mind since the dynamic of reaching a decision informally can differ depending on the formal procedures that could be fallen back upon (Zamora, 1980).

\subsubsection{Combining Design Sets in Complex, Multilayered Institutiona/Structures}

Having provided an overview of the different combinations of centralization and control that occur in the four design sets, it is possible to take these sets as an analytical guideline for empirical investigation. The sets point to different manifestations of centralization and control in institutional design and highlight the different strategic considerations that underlie such design. Thus, the sets pave the way for a systematic analysis of the institutional architecture of an international organization.

When conducting such an analysis one more important point needs to be taken into account though: Design sets do not only determine the setup of a single focal entity, they are also embedded in a wider institutional hierarchy. As such, different design sets can form complex, nested and interrelated institutional structures that - taken together - form an international organization's multilayered institutional architecture. One way this can occur is by a mix of

\footnotetext{
${ }^{26}$ Several authors have specified this argument for the global trade regime (e.g. Kim, 2010; Wilkinson, 2011). See also section 3.3 .

${ }^{27}$ For an application of this argument to the trade regime see section 3.2.4.2.
} 
pooling and delegation. External agents can for example prepare a policy that is decided upon by a collective body of states. Vice versa it is not unusual that states take a collective decision that is to be executed by an external agent (Lake, 2007). As Lake and McCubbins (2006) point out, the design of centralization as delegation can be strongly influenced by that of centralization as pooling and related control mechanisms. It is thus useful to take the interaction of centralization and control on several layers of nested institutional entities in a complex organizational structure into account. ${ }^{28}$ Keeping this, and the classification of design sets in mind it is possible to systematically examine the institutional structure of an international organization.

This can be exemplified by a reference to WTO dispute settlement. ${ }^{29}$ From a general perspective the WTO is the focal entity in charge of settling disputes in the multilateral trade regime. The outcomes of dispute settlement are legally binding and their enforcement is ultimately contingent on the retaliatory power of the disputants as indicated by their market size. This makes control over domestic implementation of the outcomes of a dispute settlement procedure asymmetrical, as it is high for large economies and moderate for small ones. On a more specific level pooling is present in form of the Dispute Settlement Body (DSB) as the supreme organ in charge of dispute settlement procedures and delegation is present in form of panels and the Appellate Body as the entities in charge to actually adjudicate a particular dispute. Control over the adjudication procedure in the DSB is low, since all countries would have to agree by consensus to block the outcome of a particular dispute as expressed in panel and Appellate Body reports. This in turn implies a high degree of centralization as delegation. The members of the WTO try to balance this by carefully selecting candidates for the Appellate Body in a rigorous screening procedure. Furthermore, within delegation the Appellate Body serves as an institutional check to control the quality of panel reports. Overall, the degree of centralization in dispute settlement considering policy outputs of the WTO from a general perspective is rather high, with powerful countries being more able to control the domestic implementation of such policy output than less powerful ones. Reaching such a general conclusion requires analyzing the different entities that constitute dispute settlement in the WTO, but also to take into account how they relate to each other.

\footnotetext{
${ }^{28}$ Such an approach has also been taken by Oatley's application of the rational design framework (2001). He points out that control over centralized bodies was carefully balanced on different institutional levels of the European Payments Union (EPU). The EPU's managing board had the authority to demand changes in macroeconomic policies by the EPU's members in exchange for economic assistance and could take such decisions by majority rule. However, this institutional autonomy was counterbalanced by the fact that the managing board's decisions had to be approved by the Joint Trade and Payments Committee and Executive Committee of the Organization for European Economic Co-operation (OEEC). Decisions in these committees required unanimity approval. Thus, control rules operated on two different levels and counterbalanced each other.

${ }^{29}$ For a detail elaboration on this see section 4.2.
} 


\subsubsection{Conclusion}

To conclude, the preceding elaboration on the conceptualization of centralization and control has led to several insights. First, examining each variable on its own is useful as it directs attention to important variations between the different conceptualizations of the variables. This shows that different strategic considerations can be at play in the design of institutional structures related to centralization and control. Centralization as pooling follows a different design logic and might be appropriate in different situations than centralization as delegation for example. Similarly different strategic considerations influence the design of control mechanisms that indicate an organization's autonomy in comparison to those that indicate symmetry of control. Such insights allow for a proper understanding of the building blocks of design sets. Second, to understand the institutional architecture of an international organization it is indispensable to think in terms of such sets, because centralization and control interact in a supplementary manner. While the difference in strategic problems between designing centralization as pooling and centralization as delegation determines which kinds of control mechanisms are employed, the rigidity of control determines the degree of centralization. It is thus a logical necessity to think of centralization and control in tandem to get a thorough understanding of institutional structures. ${ }^{30}$ Centralization captures whether and which authorities are transferred to a focal entity, and which actors compose this entity; control specifies how such an entity is governed. Third, several design sets can be interrelated and form more complex institutional structures on various layers within an organization's wider institutional architecture. In a blend of delegation and pooling for example, an agent that acts on behalf of an organization's membership is usually controlled by a collective body of members, whose control mechanisms are in turn determined by collective decision-making rules. Also, it can be assumed that a focal entity which produces policy outputs that states have limited control over with respect domestic implementation, is likely to be subject to strict control mechanisms regarding the process by which such output is produced. Overall, taking these insights into account allows for a systematic and comprehensive analysis of an international organization's institutional architecture. This is a necessary prerequisite for the empirical investigation of institutional change in the trade regime, as it will be conducted in the following chapters.

In addition to these insights, the preceding elaboration also contributes to theory development by addressing important criticisms of the rational design framework. One of the most important of these criticisms has been the high level of abstraction of the framework's variables. This does not only hinder the framework from being readily applicable to empirical analysis, but also risks that different empirical phenomena, which follow different design logics

\footnotetext{
${ }^{30}$ This being said, the analysis of the institutional changes in the multilateral trade regime conducted in the following chapters accounts for this interaction, but for the sake of clarity does so sequentially. Institutional changes will be addressed in terms of centralization first, before control is added as a dimension that potentially influenced a change in centralization. After all, without a focal entity there would be no necessity to consider control.
} 
are captured under the same variable. This can be analytically misleading. The different strategic considerations that are at play when designing centralization as pooling and centralization as delegation, as well as the differences between control indicating autonomy and control indicating symmetry highlight the plausibility of this concern. One would compare apples with pears when treating pooling and delegation in the same manner for example. The conceptualizations provided so far specify the variables of the rational design framework and are an attempt to make the framework readily applicable to empirical investigation while avoiding analytical confusion. ${ }^{31}$ Furthermore, the conceptualizations address another criticism of the rational design framework by suggesting how the framework's variables relate to delegation and power as important concepts used in the discourse on international organizations. In the case of centralization this has been done very thoroughly by showing its relation to delegation. In the case of control the notion of symmetry and explicitly distinguishing it from control indicating autonomy provides an avenue to incorporate the concept of power in the rational design framework. Finally, it was criticized that the framework neglects interaction effects and for the case of centralization it was pointed out that it is not only important to investigate what kind of tasks are centralized, but also to take into account how they are centralized and by whom they are conducted. The design sets that were introduced address exactly these shortcomings and specify the interaction of centralization and control. Thereby they provide a systematic overview of the different combinations in which the variables can occur and the different underlying design considerations that can be at play in these combinations. This allows to make statements that go beyond the simple assertion whether centralization and control are present, but to indicate how and to what extent they are present. Thus, the design sets provide a toolkit to analyze the anatomy of an international organization.

Beyond this, the notion of degree of centralization that results from the interaction of the variables provides interesting opportunities for longitudinal investigations of institutional change. Examining the degree of centralization allows to not only regard the introduction or termination of focal entities in charge of a certain task as changes in centralization, but also a strengthening or weakening of their control mechanisms. This sharpens the focus of empirical investigation by pointing to the institutional attributes - i.e. the control mechanism - that need to be taken into account when investigating changes in centralization. Furthermore, in a longitudinal investigation it is not necessary to specify an objective baseline to determine the degree of centralization. ${ }^{32}$ By taking a historical approach it is possible to compare given institutional structures at a particular point in time to a historical reference point. This allows to identify trends in the development of centralization. For the historical investigation of

\footnotetext{
${ }^{31}$ This is not to say that other studies do not distinguish between different forms of centralization and control, or that they apply the variables in an analytically confusing manner. However, often analytical distinctions are not made explicitly and are not systematically linked back to the rational design framework. Doing so is regarded to be the theoretical contribution that the preceding section provides to the rational design framework.

32 This would constitute a formidable theoretical challenge. For first steps in this direction see Brown (2010), who provides an additive index of the degree of delegation.
} 
institutional change in the trade regime, which will be conducted in the following chapters this is particularly interesting.

However before this investigation can be conducted the remaining criticisms of the rational design framework - its disregard for the notion of institutional change and the risk of omitting important explanatory factors - still need to be addressed. The following section will do so. 


\subsection{The Notion of Change}

Having clarified the analytical concepts used to guide this research, it still needs to be explored what the underlying dynamics of institutional change in an international organization are. The rational design framework is once again a useful starting point to investigate these dynamics. The basic idea that variation in institutional design is a response to variation in collective action problems is highly valuable. By linking institutional design features to the characteristics of a collective action problem that an organization is supposed to address the framework provides guidance for investigating change. Accordingly, attention should be paid to changes in these problem characteristics and the corresponding response in institutional design. However, institutional change is more complex than what is suggested by the direct link between dependent and independent variables expressed in the conjectures of the rational design framework. The following section seeks to shed light on this complexity and thereby develops the analytical framework to guide empirical investigations further.

Historical institutionalism is consulted to achieve this. Although historical institutionalism and rational institutionalism are often portrayed as rivalry schools of thought, they should rather be thought of as complementary and the combination of the two is not only feasible but promising (Hall, 2009; Katznelson \& Weingast, 2005). Rational approaches can provide theoretical guidelines to historical accounts with respect to general patterns of behavior, while historical approaches specify what these patterns can exactly look like by providing particular contextual information (Katznelson \& Weingast, 2005)

From this combination four clusters of factors are derived that potentially influence the dynamics of institutional change and should be taken into account in analyses thereof. First of all, the explanatory factors of rational design should be considered as they can shed light on the core motivations that drive institutional change. Secondly, actors are assumed to be risk averse and aim to design institutions cautiously in a way that limits sovereignty costs. This requires taking the interaction between centralization and control into account. Third, it should be taken into account that the design and change of institutional arrangements is often contested. Interest heterogeneity amongst actors lead to coordination problems and make institutional change a highly political process. In investigating this process it is crucial to take power as an explanatory factor into account. Fourth, institutional design depends on the organizational context in which it is embedded. This is to say that history is important. Design responses to a collective action problem in the context of an existing organization might differ significantly from responses to the same problem outside of such context.

The factors mentioned in these clusters can influence institutional change to varying degrees. The assumptions of rational design are likely to be compromised by the factors highlighted in the three other clusters. In this respect institutional change can still be regarded as an attempt to address collective action problems in a functional manner, but that the political nature of this task, its complexity, as well as a given organizational context that developed over 
time obscure the direct link between collective action problems and functional response as posited by rational design. Accordingly, the logic that is regarded to realistically capture institutional change is one of "history-dependent rationality", not of "functional-rationality" (March \& Olsen, 1998). The basic idea behind this distinction is visualized in the figure below. How history-dependent rationality plays out and what the relative influence of the factors in the four different clusters is in real-world exercises of institutional change can only be understood by carefully tracing the process leading to such change and embedding this process in the wider historical development of an organization. By doing so the risk of overlooking explanatory factors not mentioned in the rational design framework is minimized and the causal depth of an analysis is increased (Pierson, 2004; Thompson, 2010; Wendt, 2001). Such process tracing can be guided by an awareness of the factors that can influence the dynamics of change as they will be presented in the following.

a) Functional rationality

\begin{tabular}{|l|l|}
\hline $\begin{array}{l}\text { Independent variables } \\
\text { of rational design / } \\
\text { collective action } \\
\text { problem }\end{array}$ & $\longrightarrow \begin{array}{l}\text { Dependent variables / } \\
\text { institutional design as } \\
\text { fully rational response }\end{array}$ \\
\hline
\end{tabular}

b) History-dependent rationality

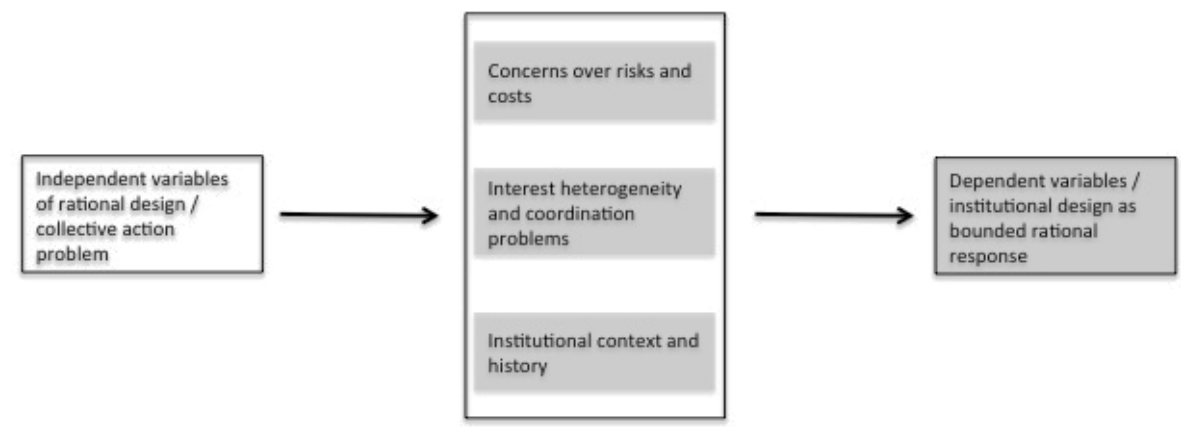

Figure 1: Different assumptions regarding the logic of institutional design

\subsubsection{Rational Design and Change}

The rational design framework was developed to analyze institutional design as a static equilibrium (Koremenos, Lipson, \& Snidal, 2001a, 2001b). Thereby it does not explicitly account for the notion of institutional change and the special dynamics thereof. Nonetheless the conjectures of rational design are a useful starting point to develop a framework that guides the investigation of change since they provide an overview of relevant characteristics of collective action problems that can motivate institutional change. As it is put by the authors of the rational design framework: "Understanding how the components of an equilibrium fit together helps 
identify the circumstances under which an equilibrium becomes unstable and when a new equilibrium will emerge" (Koremenos et al., 2001b, p. 1075). Design change is regarded as a response to inadequate functioning of an organization, because the organization does not match the characteristics of the collective action problem anymore. A plausible cause for such a mismatch would be a change in said characteristics (Koremenos et al., 2001b). In this regard it is useful to have a closer look at the relevant conjectures of the rational design framework. ${ }^{33}$

Regarding the conjectures about centralization, the first conjecture states that an increase in centralization is positively related to an increase in uncertainty about behavior. This relation is supposed to hold because information about the behavior of other parties is supposed to support cooperation by facilitating the establishment of a reputational bond. Centralizing the provision of information is useful due to the credibility associated with a neutral and independent actor providing the information, and can be relatively cost efficient. Furthermore, centralized information provision is supposed to aid an adequate interpretation of others' behavior. A third party can for example clarify whether a certain act is to be regarded as a breach of a cooperative agreement or not. Thus one would expect centralization of information gathering and interpretation to increase when uncertainty about behavior increases over time. Similarly, one would expect an increase in centralization when uncertainty about the state of the world increases. Again, the rationale underlying this conjecture is that actors have a desire to reduce this uncertainty and that centralized information gathering is likely to be reliable and cost efficient. Another conjecture on centralization states that the larger the number of parties addressing a collective action problem, the more centralization should be observable. This is due to the fact that centralization is supposed to reduce transaction costs associated with large numbers. Centralized bargaining procedures facilitated by organizational structures, centralized information gathering and centralizing operational activities are listed by the authors of the rational design framework as institutional responses to an increase in number. Finally, it is assumed that an increase in the incentives to defect on an agreement, i.e. an increase in the enforcement problem, leads to more centralization. This is because it is assumed that centralized adjudication or enforcement mechanisms, as well as centralized information gathering induce actors to comply with an agreement. In sum, theoretically one should be able to observe institutional change relating to centralization whenever an organization is not functioning satisfactorily in addressing various forms of uncertainty, handling large numbers, or ensuring rule abidance to an agreement.

Turning to the conjectures of control, the first one states that individual control decreases with an increase in the number of actors involved in a collective action problem. The conjecture assumes that due to larger numbers each individual actor has to accept a decrease in control in order to achieve collective benefits. The second conjecture on control posits that control reflects the asymmetry of actors. This is to say that an organization consisting of members with asymmetrical capabilities also contains asymmetrical control features. The underlying reasoning

${ }^{33}$ All of the information about the underlying rationale of the conjectures is based on the rational design framework as described in Koremenos et al. (2001a). 
of this conjecture assumes that the control mechanisms in an international organization have to reasonably reflect geopolitical realities and importance of different members to an organization. It is assumed that actors who are more important to the organization demand more control of the organization and that other actors accept this to ensure the participation of the important ones. The third and final conjecture about control states that individual control to block undesirable organizational policy output increases when uncertainty of the world increases. This can for example be expressed by the ability to veto certain organizational decisions and is ultimately due to the fact that actors are assumed to be risk averse. Thus, according to these conjectures institutional change of control mechanism should be related to an increase in number, changing symmetry, and an increase in uncertainty.

In theory rational design assumes a direct relation between a change in the independent variables that describe a collective action problem and a change in institutional design. For a framework to guide empirical investigation this is useful to take into account as it points to the factors that need to be considered as possible triggers of institutional change. However, the dynamics of change are more complex. Problems and their changing characteristics can be considered a necessary, but not a sufficient condition for change (Campbell, 2004). Actors are risk averse and might avoid change as they might not be aware of the full implications of design changes; they might have heterogeneous preferences leading to intense political struggles over change that obscure the link between rational design's dependent and independent variables; and finally existing institutional structures established in the past can influence the direction change takes. The authors of the framework admit that these factors can interfere with the framework's conjectures, but do not specify how this can happen (Koremenos et al., 2001b). The factors can turn institutional design into an incremental process only fully understandable by taking a long-term perspective. The snapshot a static equilibrium analysis provides would consequently not be sufficient to fully understand institutional change (Pierson, 2004). Furthermore, these factors can inhibit a functional response to a collective action problem. Therefore the theoretical assumption of functionality is an implausible one and post hoc functionalist explanations should be avoided (Pierson, 2000). Empirical investigation of processes to identify the motives for design choices and of the dynamics that underlie these choices is necessary to check whether institutional change is really brought about by the logic of rational design or whether it follows other dynamics. To guide such investigation an overview of the factors that compete with functionality is given in the following.

\subsubsection{Limiting Costs and Risk Aversion: The Benchmark Problem of Rationality}

An important - and plausible - assumption of the rational design framework is that actors are risk averse and try to limit the potential costs of institutional design (Koremenos et al., 2001a). This implies that the possibility of institutional change is contingent on the possibility to balance the expected benefits of change with potential risks and costs. When estimating whether the benefits of changing institutional structures of an international organization are 
likely to outweigh potential costs and risks, designers are particularly concerned about unintended consequences of change, up to the point that change becomes impossible because the uncertainty about future effects of change is too high (Hall, 2009; Jupille, Mattli, \& Snidal, 2013). This is particularly relevant for changes in centralization and control since changes in institutional structures specifying the procedures to generate policy outcomes - i.e. those that delineate the rules of rulemaking - are the most likely to entail unexpected consequences (Jupille et al., 2013; Martin \& Simmons, 1998). This implies that the overall baseline for the degree of centralization can be rather low (Koremenos et al., 2001a).

Furthermore, the concern over risks and costs underlines the importance of design interaction as pointed out in section 2.3. Risk averse actors try to create safety nets and seek to find an adequate balance between centralization and control. On the one hand efficiency gains from high degrees of centralization are desired. On the other hand concerns over sovereignty costs and unintended consequences of centralization are expressed by careful design of control mechanisms. The occurrence of centralization is thus dependent on the availability of mutually acceptable control mechanisms (Lake \& McCubbins, 2006; Stone, 2011). How the balance between centralization and control is struck depends on the particular organizational function in question. The focal entities in charge of legislative functions are usually tightly controlled, while executive and judicial functions such as information gathering and dispute resolution tend to be subject to less stringent control (Stone, 2011). As it has been pointed out in section 2.3.3 the mechanisms of control depend on centralization occurring as delegation or as pooling.

The observation that institutional design is a balancing act of cost and benefits conducted by risk averse actors does in itself not contradict the rational design approach. Nonetheless, when developing a framework to guide empirical investigation it is important to explicitly point out for two reasons. First of all, it points to a dynamic of change that is cautious and incremental. A satisfactory solution to a collective action problem that minimizes the risks of change by reducing the degree of change to a minimum can be preferable to a potentially perfect one where change is significant but entails high risks and uncertainty (Jupille et al., 2013). In contrast to extreme assumptions of full rationality such a perspective allows to explain institutional imperfections. Secondly, the fact that design is a balancing act that leads to design interactions of centralization and control points to a benchmark problem of rational, functional approaches. Often it is simply not possible to make theoretical predictions about exact design features that constitute design sets of centralization and control, or only to make them at a very high level of abstraction. Without knowledge about the context in which an exercise of institutional design took place it is not possible to tell which consideration was more important to designers effectively achieving collective benefits via centralization or protecting oneself from the costs and uncertainty of design by devising rigorous control mechanisms. Both considerations are expressed in the conjectures of rational design and can be deemed rational. The only way to explain the exact institutional design of an organization is by carefully tracing the design process to analyze how competing demands in the process of creating a functional entity played out. 


\subsubsection{Institutional Change as a Coordination Problem}

Rational approaches to institutional design often entail the shortcoming that they do not explicitly account for the political struggle that accompanies the process of institutional change. Such a struggle can disturb the link between a collective action problem and institutional design as a functional response to such a problem (Pierson, 2004). In this sense the process of institutional change in itself constitutes a coordination problem that entails bargaining and transaction costs. Although the rational design framework acknowledges that change can be the result of a hard political bargaining process, especially when multiple different design outcomes with different distributional implication exists, it does not further elaborate on the possible dynamics of such bargaining processes (Koremenos et al., 2001b). Once more, empirical process tracing is necessary to explore how such dynamics unfold in particular instances of institutional change. Yet, theoretical guidelines can be established to assist such process tracing. This is done in the following paragraphs. Accordingly, it is assumed that the complexity of a coordination problem depends on the number of actors that are involved in institutional change and their preference heterogeneity, and that the distribution of power is a crucial factor that determines whether a coordination problem that results from heterogeneous preferences can be overcome.

The larger the number of actors and the more diverse their preferences, the higher the transaction costs to overcome the coordination problem of change and the lower the degree and likelihood of change as a functional response to a collective action problem (Pierson, 2004). Large numbers can be problematic in themselves as they imply more complex and costlier bargaining procedures. When preferences of actors are homogenous it is likely that such problems can be overcome. However, heterogeneous preferences can lead to formidable problems - even when numbers are small. The functional assumption of institutional design being a rational response to a collective action problem tends to overlook diverging positions of different actors regarding the necessity and kind of change. While some actors perceive change as necessary and desirable to address changing parameters of a collective action problem, others might disagree to such an assessment and do not support change in the first place. Furthermore, even if there is consensus on the necessity for change amongst all actors involved, there might still be disagreements on the type and degree of change that is desired to address the problem at hand.

Whether actors prefer or oppose change usually depends on the expected distribution of the benefits of such change. Institutional design is seldom free of distributive consequences and it should therefore not be surprising when actors' preferences are heterogeneous. Those who feel disadvantaged by existing institutional structures tend to exert pressure for change to improve their situation, while beneficiaries of the status quo tend to resist change (Jupille et al., 2013; Pierson, 2004). Especially when disadvantaged actors perceive the distribution of material benefits to be unfair it is likely that they demand change (Colgan, Keohane, \& Van de Graaf, 2012; Jupille et al., 2013). Such demands can also affect institutional design sets of centralization and control as they have direct, as well as indirect distributive implications. The resulting coordination problems can be particularly difficult to overcome as design sets of centralization 
and control determine power relationships and influence over policy output in an organization considerably into the future. To understand the dynamics of coordination problems it is helpful to identify direct and indirect sources of distributive issues affecting the design of centralization and control.

A direct reflection of distributional issues can be found in design sets that express symmetry of control in an international organization. Designing control mechanisms that reflect symmetry is a zero-sum game - if one actor gains in influence, another one loses. As it has been pointed out in section 2.3.2 this can make the design of control mechanisms a highly complex endeavor. Institutional structures need to reflect power asymmetries in the international arena sufficiently to induce the powerful to participate in an international organization, while they cannot be too asymmetrical to avoid alienating less powerful actors (Stone, 2011). This problem can be overcome by combining formal institutional rules with informal ones, where formal rules are usually to the advantage of less powerful actors while powerful actors can still exert larger influence informally (Stone, 2011). Nonetheless, design sets that relate to the symmetry of control can leave those who are less influential in an organization dissatisfied - especially when asymmetry of control leads to policy outputs that are perceived as disadvantageous for them. Such actors are likely to demand changes in these design sets to become more influential. As Pierson (2004) puts it, “...actors who are aggrieved but not co-opted are an important source of pressure for institutional change" (p.138).

Also, when the distribution of power in the international arena shifts, pressures to change the control mechanisms of an international organization can arise to ensure that these shifts are reflected in institutional arrangements. Under these circumstances rising powers usually tend to challenge the status quo while declining powers seek to preserve it (Jupille et al., 2013). The rational design conjecture that links asymmetry in number to asymmetry of control indicates that power in the international arena has an impact on institutional design. Accordingly a change in the distribution of power in the international arena should be reflected in a change of institutional control mechanisms. However, the conjecture does not explicitly take the political struggles associated with changing control features into account. As pointed out, such a change implies a zero-sum game and is therefore prone to be contested. As it will be further elaborated below, especially in an already existent institutional context challengers to the status quo face significant obstacles to change when the actors benefiting from existent design features of control can veto such change.

It can be expected that struggles over design sets that determine symmetry of control are most severe when legislative decision-making in an international organization is concerned - i.e. when centralization and control features form design sets that govern how new substantive agreements are reached. After all, the negotiation of substantive agreements is often distributive in character and leaves some actors benefiting from an agreement more than others. Such legislative functions are most likely to be carried out in institutional bodies that take the form of centralization as pooling. Delegation is only likely if preferences on the substantive agreements to be reached are very homogenous (Hawkins, Lake, Nielson, \& Tierney, 2006). It 
can be expected that high individual control over the process to reach substantive agreements is especially important to states when sovereignty costs of such agreements are likely to be high. If states have low control over the domestic implementation of agreements for example, the distributive question about the symmetry of control becomes increasingly important, preference heterogeneity is likely to increase, and the severity of the coordination problem that needs to be solved to reach mutually satisfactory design sets increases.

Next to design features that directly imply distributional consequences in themselves, distributional issues can also have an indirect influence on the design process of centralization and control. In this case resulting coordination problems are less likely to affect design sets related to symmetry of control and centralization as pooling, but rather those that represent control indicating autonomy and centralization as delegation. These design features are suitable to facilitate the implementation of already existing substantive agreements - e.g. in the form of monitoring or dispute settlement arrangements (Hawkins et al., 2006). In such cases one could expect coordination problems of institutional design to be lower. After all, once a substantive agreement has been reached and accepted, it can be expected that all actors have an interest in the implementation of this agreement. Therefore, it would be plausible that preferences regarding institutional structures that are related to implementation are relatively homogenous. While this can be the case - especially when expected sovereignty costs are low - it is important to point out that institutional design features aimed at facilitating the implementation of substantive agreements can also be contested. This is due to an link between these features and substantive agreements (Fearon, 1998). To understand why this is the distributive character of substantive agreements should be recalled. This implies that the costs to comply with substantive agreements might vary across actors. If this is the case then even the organizational questions about facilitating implementation of an agreement contain a distributive dimension. Those who expect to benefit from substantive agreements will favor that implementation is facilitated and consequentially prefer a high degree of centralization, while those who expect to lose out of such agreements will prefer more flexibility in implementation and demand a lower degree of centralization. This can lead to hard bargaining over organizational questions on centralization and control, influencing the likelihood of change (Fearon, 1998; Thompson, 2010). Thus the investigation of changes in centralization and control cannot only focus on the processes of change and distributional questions that are directly related to the design features in question, but also needs to take into account how these institutional features relate to the distributive implications of the substance they are supposed to govern. ${ }^{34}$

The coordination problems of institutional change can be a significant obstacle, compromising the functional value of an organization's institutional setup or even preventing the possibility for change altogether. The relative capabilities of the actors involved, i.e. the distribution of power, is a crucial factor in institutional change, influencing whether coordination problems resulting from preference heterogeneity can be overcome (Colgan et al., 2012; Hall,

\footnotetext{
${ }^{34} \mathrm{On}$ a related note it should be pointed out that the degree of centralization is likely to be low if all relevant actors are concerned about compliance costs of substantial agreements (Thompson, 2010).
} 
2009; Jupille et al., 2013; Stone, 2011; Thompson, 2010). When interests are not homogenous, those actors in favor of change need to be powerful enough to overcome the opposition of those who resist change. Thus demands for change by relatively weak actors are unlikely to be successful. Powerful actors or sufficiently powerful coalitions of actors are more likely to be successful when pursuing change. This is due to a negotiation advantage that may result from attractive alternatives to fall back upon in the absence of solving a coordination problem, superior negotiation capabilities, the ability to shift negotiations to a different forum, or the ability alter the status quo unilaterally in such a way that the powerfuls' preferred negotiation outcome becomes attractive to those who were initially opposed in light of the changed status quo (Moe, 2005; Scharpf, 1997; Stone, 2011). The power distribution in the process of institutional change is determined by the structural power actors possess in the international arena, but also by existing formal and informal institutional provisions such as collective decision-making rules (Stone, 2011). As it will be pointed out in the next section, the latter can even increase the severity of a coordination problem and thereby reduce the likelihood of change.

In sum, paying attention to coordination problems and power is important to understand the dynamics of change. Change might not be possible when coordination problems are severe and proponents of change are not powerful enough to overcome opposition, or be sub-optimal when resolving a coordination problem requires making compromises of limited functional value. At the same time, the presence of coordination problems implies that there might not be one single rational design, but that rationality lies in the eye of the beholder. For an actor that expects low compliance costs of a substantive agreements a high degree of centralization is a rational response to a potential enforcement problem, while this is not the case for an actor who expects high compliance costs for example. Thus, empirical investigation of institutional change needs to take the dynamics of possible coordination problems and related considerations of power into account.

\subsubsection{Change in Historical Context}

A static equilibrium approach to institutional design as promoted by the rational design framework examines an organization and its design at a particular point in time. By taking such a snapshot it is prone to overlook important dynamics that can only be depicted when taking a longitudinal approach. What might appear as a sudden episode of institutional change might for example simply be a tipping point in a more long-term evolutionary process (Campbell, 2004; Pierson, 2004). Similarly, institutions can also change significantly without any tipping point, in the sense that change might simply be the product of continuous and incremental adjustment. While each instance of change in such a process might seem negligible, the ultimate result of the process can be considerable (Campbell, 2004; Pierson, 2004). A snapshot of institutional design would miss such dynamics.

Even more importantly, it can be argued that examination of institutional change over time adds greater causal depth to the analysis of institutional design, even when a certain design 
feature at a particular point in time is the main issue under investigation (Wendt, 2001). The basic assumption underlying this idea is that an institution and its design "play a causal feedback role" (Wendt, 2001, p. 1033). Accordingly, past designs are assumed to influence new design decisions: an institution is not only shaped by the constitutive actors, but - once in place - these actors and their behavior are also shaped by the institution (Katznelson \& Weingast, 2005; Martin \& Simmons, 1998; Wendt, 2001). To understand how this takes place requires taking the historical context of institutional development into account, including long-term processes of institutional change. By doing so it is possible to specify how exactly causal feedback mechanisms operate. Thus, to thoroughly understand how a particular design feature of an institution came about it does not seem sufficient to analyze them as a simple technical procedure - i.e. as a purely functional response to exogenous occurrence or changes of collective action problems - but endogenous feedback effects - i.e. the previously established institutional setup in which these arrangements occur - need to be considered as well (Campbell, 2004; Katznelson \& Weingast, 2005; Martin \& Simmons, 1998; Pierson, 2004; Thelen, 1999; Wendt, 2001).

The general idea that institutional designs are contingent on already established institutional structures and that these structures tend to be self-reinforcing is labeled as path dependency. Even the authors of the rational design framework themselves remark that:

"...institutional arrangements are determined not simply by existing conditions (the focus of comparative static analysis) but also by the historical development of the institution ("path dependence"). Because existing institutions reflect their development they might differ significantly from what might be created de novo" (Koremenos et al., 2001b, p. 1076)

Thus, timing and sequence of design is important, since past designs determine the framework for new designs in a path dependent process. This framework tends to restrict design options at a particular point in time by limiting them to an institutionally pre-defined sub-set (Scharpf, 1997). In the following, two ways in which path dependence can influence change in institutional design are described. One relates to previously established institutional structures of decision-making, the other relates to the cognitive impact institutional history can leave on designers.

Regarding previously established decision-making structures, organizations can create 'structure-induced' equilibria, also known as lock in effects. This implies that certain early choices of institutional design can become irreversible (Pierson, 2004). Initial design choices on centralization and control can be particularly important in this respect and create feedback loops in themselves as they determine the institutional rules that need to be followed in the process of change (Koremenos et al., 2001b). In such a process centralization specifies which actors are involved, while control specifies their relative influence. Changing the rules of the game is only possible by playing according to the existing rules of the game. Such existing rules influence the resources, incentives structures and behavior of states, which makes the likelihood of change 
contingent on the given organizational setting (Hall, 2009; Pierson, 2004). This can reinforce the above mentioned coordination problem as existing decision-making structures might insert veto points that need to be overcome for change to be feasible. Whether change is possible depends on the amount as well as on the structure of veto points. Especially self-referencing veto points i.e. actors benefiting from existing structures control the process of changing these structures can be difficult, if not impossible, to overcome (Pierson, 2004). ${ }^{35}$ Thus institutional history and the development of decision-making structures can be important determinants and limitations for change. As it is aptly put by Wendt (2001): "Every time states and other actors make choices about international institutions, they are simultaneously making choices about who is empowered, and not empowered, to make such decisions" (p. 1035). This determines the strategic setting of change and requires attention to history.

A second way in which institutional change can be contingent upon earlier developments is less related to power, but more to the effect existing institutional structures can have on actors' identities, interests, perceptions and expectations (Wendt, 2001). One variant of this more cognitive form of path dependency assumes that an existing institution provides normative guidelines for appropriate behavior. When actors internalize these norms and make them part of their identity, they might start to behave in a way that is not only regarded as most beneficial from a purely rational cost benefit analysis, but they also take into account which behavior would be seen as appropriate within a particular institutional context (March \& Olsen, 1996; Wendt, 2001). In this sense the set of possible design alternatives is constrained further by the norms that developed within the institutional context. ${ }^{36}$ On a related, but analytically different note institutional history can also shape preferences of actors (Katznelson \& Weingast, 2005). The different kinds of feedback mechanisms serve as example how preferences might arise as a combination of a rational cost-benefit analysis in the strategic setting of a given institutional context and of the judgment which behavior is appropriate. In this perspective rationality is context depended and strategic interaction cannot be understood separate from this context. ${ }^{37}$

Another variant of cognitive path dependency assumes that institutional history affects actors' perceptions and expectations (Wendt, 2001). According to this variant it is assumed that past experiences gathered in an institutional setting create cognitive scripts that are used to filter information and place it in existing mental maps (Pierson, 2004). The understanding of the political world is therefore path dependent in itself. Past experiences are assumed to influence which kinds of institutional changes are perceived to be feasible, as well as the expectations actors have regarding effects of change. This in turn reinforces path dependency since designers think and act in the ways they are used to. Consequently actors are induced to closely stick to familiar design features that they use as a cognitive repertoire for institutional innovation

\footnotetext{
${ }^{35}$ Unsuccessful attempts to change the structure of the UN Security Council that would be to the disadvantage of the veto powers are an obvious example that comes to mind in this respect.

${ }^{36}$ For an impact of norms in the history of the multilateral trade regime see Finlayson and Zacher (1983).

${ }^{37}$ See Copelovitch and Putnam (2014) for empirical support of this point and further elaboration of the importance of institutional context in relation to the rational design framework.
} 
(Campbell, 2004). According to Campbell (2004) "[i]nstitutional innovations usually consist of a creative recombination - a bricolage - of institutional principles and practices that entrepreneurs have inherited from the past and that are available as part of their repertoire" (p.178).

Thus, investigating the history of an organization's development is recommended to gain a comprehensive understanding of institutional change, even when this change is concerned with a single incidence at a particular point in time. A historical approach can help to identify dynamics of change that a static equilibrium analysis would neglect and points to the importance of timing and sequence in institutional design due to the different effects of path dependency that are likely to unfold in a given institutional setting. This does not imply that such a historical approach is contradictory to the strategic, functional approach promoted by rational design. It should rather be considered as complementary. A given institutional context as it evolved throughout history sets the frame in which actors can still take strategic and supposedly functional decisions. "Change is seen as the consequence (whether intended or unintended) of strategic action (whether intuitive or instrumental), filtered through perceptions (however informed or misinformed) of an institutional context that favors certain strategies, actions and perceptions over others" (Hay \& Wincott, 1998, p. 955).

\subsubsection{Conclusion: Bounded Rational Design}

Having reviewed different factors that can influence institutional change, it can be concluded that the rational design framework is a good starting point to explain the general logic of institutional design on an abstract level. Its value lies in highlighting the link between different characteristics of collective action problems and institutional variation as an intentional response to such problems. However, this on its own is not suitable as a blueprint for empirical investigations. The rational design framework has not been developed for the analysis of intuitional change over time. It therefore neglects the importance of institutional context that has to be taken into account for a thorough analysis. Furthermore, functionalism as a theoretical assumption can lead to inappropriate research designs, prone to omitted variable bias. The complexities of designing institutional change, its inherent political nature, and the impact of historical and institutional context make it likely that intervening variables obscure the direct causal link between collective action problems and institutional design. This makes post hoc functionalistic accounts unlikely to accurately represent causal mechanisms.

Thus, a framework to guide empirical investigation of change should start out with the powerful assumption of rational design that a variation of design is an intentional response to a variation of the characteristics of a collective action problem, but needs to supplement this assumption by pointing to the factors that compromise this link. According to the elaboration above such factors include: risk aversion and concern over the potential costs of design, inducing actors to be cautious - potentially at the expense of efficiency; interest heterogeneity and the process of solving coordination problems of change, including the role of power in this process; and the importance of feedback loops emerging throughout institutional history that induce 
path dependencies by shaping the strategic context of the coordination problem of change and influencing actors' mindsets. These factors can hinder institutional change and increase the likelihood that change is incremental and path dependent. Two main insights can be drawn from this.

First of all, it is appropriate to think of institutional designers as bounded rational actors. ${ }^{38}$ If one would conceptualize actors as fully rational optimizers, possessing full information about the payoff structures of different designs one could indeed assume that they would choose what is regarded to be the most efficient institutional design to address a particular problem. In this respect a functional account that explains the origins of a design feature by its effects would be plausible. However, the complexities of the process of institutional change as pointed out above can lead to institutional structures that do not constitute such a perfectly functional response to a collective action problem. Thus conceptualizing actors as bounded rational seems more realistic. The assumption of bounded rationality assigns limited cognitive capabilities to actors, as well as limited amounts of information, especially when decisions have to be taken under time pressure. It is thereby able to bridge the approach of the rational design framework with the other factors that might inhibit designing institutional change. In line with the elaboration on the importance of institutional context provided above, the assumption of bounded rationality indirectly acknowledges the influence of institutional context on design choices. When designers are conceptualized as bounded rational it is plausible that they will rather search for a satisfactory solution to a collective action problem than for an optimal one. Such actors will only move towards a more, but not necessarily fully, optimal solution and thereby rely on the repertoire available to them in the given institutional context as much as possible. This is also in line with the assumption of risk aversion and the need to balance the costs and benefits of change. Yet, actors are still expected to design institutions as a response to collective action problems and it is assumed that they intend to do so rationally, but they simply cannot always do so given the context they find themselves in. The logic that is regarded to realistically capture institutional design is one of "history-dependent rationality", not of "functional-rationality" (March \& Olsen, 1998).

Secondly, empirical process tracing embedded in the wider context of an institution's historical development is a methodological necessity to fully understand the causes and dynamics of change. The limitations to fully rational design disqualify post hoc explanations of design choices that use functionalism as a theoretical assumption. Instead the process of institutional choice, the motivations of different actors and their relation to each other in a strategic setting that leads to certain choices should be empirically examined (Thompson, 2010). While it might be the case that the desire to find functional solutions to collective action problems is the underlying motivation for the design of international institutions, the explanatory power of this assumption can only be accurate on a high level of abstraction. Exploring which exact design choices will be taken in the light of several possible alternatives

\footnotetext{
${ }^{38}$ The argument in this paragraph is based on Jupille et al. (2013).
} 
requires empirical investigation of how these choices are made and for which reasons they are made. In this respect the importance of path dependence highlights that one should not only examine the immediate process that leads to the particular episode of institutional change a research is interested in, but one also has to embed this episode in the wider historical context of institutional development. 


\subsection{Conclusion}

The aim of this chapter was to provide a framework that is able to guide the empirical investigations of institutional change in the multilateral trade regime as it is conducted in the following chapters. To do so the framework needs to fulfill two basic requirements. It needs to capture the phenomenon of interest in analytical concepts and it has to provide guidance on underlining dynamics that affect institutional design and change. The rational design framework as developed by Koremenos et al. (2001a) constitutes a good starting point on both requirements. With centralization and control it provides suitable variables to describe the institutional structures that govern the multilateral trade regime, and its conjectures provide first insights on the conditions under which these variables vary. However, rational design faces shortcomings regarding the specification of its variables and their interactions effects; was not developed to analyze dynamic processes of institutional change; and can lead to inappropriate research approaches that rely on post hoc functionalist explanations.

To address these shortcomings further specification of the chosen variables was required and a general overview of the factors that can influence the dynamic of institutional change was added to supplement the framework. Regarding the specification of centralization and control as relevant dependent variables it is to be concluded that the variables can take various different forms, which follow different design logics. Centralization can be conceived broadly, as pooling, and as delegation. Control needs to be differentiated into control over the implementation of policy outputs of an international organization and control over the process to derive these policy outputs. The latter can be further split up. Accordingly control can indicate the autonomy an organization has in relation to its membership, or it can indicate the relative influence members have over an organization in relation to each other. Awareness of these distinctions is important for empirical analysis, since the different conceptualizations of the variables follow different design logics. Centralization as pooling and centralization as delegation might be more or less appropriate design features depending on the function an organizational entity fulfills. Furthermore, the design of control mechanisms depends on the different kinds of centralization, since pooling and delegation pose different strategic challenges to designers. This points to the observation that centralizations and control interact by supplementing each other.

Although it is valuable to be aware of their analytical distinction, to fully understand design sets as they occur in multilayered and complex empirical manifestations of institutional design it is necessary to think of the two variables in tandem. While centralization describes what kind of institutional body is in charge of a particular function, control outlines how much authority this body has and how it is governed. In this respect the amount of control exerted over an institutional entity determines the degree of centralization. Thus, for a meaningful analysis it is necessary to be aware of the various different forms the variables can take, while paying attention to how these different forms are assembled and affect each other in complex structures of institutional design sets. 
Considering the notion of change, empirical investigation needs to show awareness of the different factors that can influence the dynamic of change. One set of relevant factors is provided by the rational design framework, describing how changes in the different characteristics of a collective action problem lead to institutional variation in centralization and control. However, other factors can interfere with the assumed relationship between collective action problems and institutional design. These include risk aversion and the desire to minimize the costs of institutional design; coordination problems of design resulting from interest heterogeneity - and power as a significant factor that determines whether and how such cooperation problems are overcome; and past trajectories that determine the institutional context in which a particular episode of change takes place and that influence the degree and direction of change. Under these conditions institutional change is best conceived as a bounded rational process, in which actors might still intend to design institutional structures as a response to functional problems, but are inhibited in this process by the factors that interfere with the link of collective action problems and institutional response. Under such conditions it is impossible to predict how the different factors play out within a given context, therefore empirical investigation needs to carefully trace the process and motivations of design, and embed this in the wider history of past institutional development.

What do these insights imply for the approach to the empirical investigations conducted in the following chapters? First of all, it has been pointed out in different parts of the chapter that the design of centralization and control, and the change thereof differs depending on the function a particular institutional entity is supposed to fulfill. This confirms the decision to approach the different institutional changes in the multilateral trade regime that emerged from the Uruguay Round in different chapters according to different functions. Secondly, within each chapter the outcomes of institutional change are reflected upon as a design set consisting of combinations of different variants of centralization and control. In doing so centralization is examined first, before elaborating on mechanisms of control. This enhances clarity and is intuitively plausible since considerations of control would be irrelevant in the absence of a centralized focal entity. Thirdly, in each chapter the process of change needs to be analyzed in various steps to take the different factors mentioned above into account. In doing so it is examined first how plausible the assumptions of rational design are in accounting for the change in question. Then the process of change is embedded in its wider historical context, to account for potentially long-term dynamics and the impact of path dependency. Afterwards, the negotiation process of the design features that constitute the change needs to be traced to examine the coordination problems of institutional change, the impact of interest heterogeneity, power and potentially other factors that influenced the negotiation of institutional change. Lastly, attention is paid to the considerations of design interactions in the negotiation of change and how risk aversion and the desire to limit the costs of institutional change influenced the exact kind of institutional structures as they eventually emerged from the Uruguay Round. All of the following chapters roughly proceed in their analysis according to this generic structure. 


\section{Administration and Decision- Making Structures: The Establishment of the WTO}

$\begin{array}{lll}3.1 & \text { Introduction } & 67\end{array}$

3.2 The Establishment of the WTO as a Focal Entity 71

3.2.1 The Case as a Matter of Centralization and Control 71

3.2.1.1 General 71

$\begin{array}{lll}\text { 3.2.1.2 Specific } & 73\end{array}$

Pooling $\quad 73$

$\begin{array}{ll}\text { Delegation } & 77\end{array}$

3.2.1.3 Conclusion 81

3.2.2 Rational Design Explanations 83

3.2.2.1 Positive Contributions of Rational Design 83

The Underlying Rationale 83

The Emergence of the Idea $\quad 86$

The Rationale Behind the Idea $\quad 87$

3.2.2.2 Problems of Rational Design 91

3.2.2.3 Conclusion 93

3.2.3 Design in Context: Historical Legacy 94

3.2.3.1 The ITO and its Failure 95

3.2.3.2 The Emergence of the GATT 99

3.2.3.3 The GATT's Institutional Development 102

Pooling in the GATT 103

Delegation in the GATT 113

$\begin{array}{lll}\text { 3.2.3.4 Conclusion } & 118\end{array}$

3.2.4 Negotiating Design 120

3.2.4.1 The Negotiation process: a chronological overview 122

3.2.4.2 Negotiation dynamics: substance, institutions and power 127 The Organization as Bargaining Chip 128

The Organization as Tool of the Powerful 130

3.2.4.3 Conclusion 134

3.3 Design Sets: Centralization and Control - Decision-Making in the WTO 137

$\begin{array}{lll}\text { 3.3.1 The Puzzle of Rational Design } & 137\end{array}$ 
3.3.2 Process Tracing of Decision-Making Arrangements in the Trade Regime 141

3.3.2.1 Design Sets in Historical Perspective: The Development of Decision-Making 142

Design Sets in the ITO 142

Design Sets in the GATT 146

Tariff Negotiations 152

Conclusion 155

3.3.2.2 Negotiating Design Sets during the Uruguay Round 157

No Institutional Body with Limited Membership $\quad 157$

$\begin{array}{ll}\text { Decision-Making Provisions } & 161\end{array}$

The Secretariat 165

$\begin{array}{lll}\text { 3.3.3 Conclusion } & 167\end{array}$

$\begin{array}{lll}3.4 & \text { Conclusion } & 168\end{array}$ 


\subsection{Introduction}

Third time's the charm: the creation of a formal international organization in charge of the regulation of multilateral trade had failed twice before it finally succeeded. In the 1940s and 1950s neither the International Trade Organization (ITO), nor the Organization for Trade Cooperation (OTC) could be established and consequently the multilateral trade regime had to cope with the provisional and limited institutional structure of the GATT for almost 40 years. ${ }^{1}$ As such, it can be rightfully stated that the creation of the WTO constitutes a milestone in the history of the trade regime. And indeed, the establishment of the WTO has been described as "the most dramatic advance in multilateralism since the inspired period of institution building of the late 1940s" (Sutherland et al., 2004, p. 9). It is this outstanding historical relevance that calls for an exploration of the institutional change from the GATT to the WTO.

On first sight and looking at the trade regime in its entirety, the WTO differs significantly from the GATT in several ways. First of all, they differ with respect to their legal status. While the GATT was strictly speaking only a provisionally applied multilateral trade agreement, with hardly any explicitly mentioned institutional provisions, the WTO is a permanent, fully-fledged international organization with legal personality and clearly defined functions and institutional structures. Second, the WTO covers a wider scope of substantive agreements than the GATT. While the GATT focused on trade in goods, the WTO also covers trade in services, intellectual property regulation, trade related investment measures, and increasingly incorporates the previously neglected subjects of agriculture and textiles in the trade regime. Furthermore, in contrast to the GATT, almost all of the agreements covered under the WTO apply to all of the regime's members. ${ }^{2}$ Third, the WTO is better equipped to monitor and enforce the covered agreements than the GATT, due to the introduction of the Trade Policy Review Mechanism (TPRM) and its reformed dispute settlement system. Finally, the regime's membership of the WTO is significantly larger than that of the GATT and by now the WTO can be labeled as a universal international organization that includes all of the major trading powers. ${ }^{3}$

\footnotetext{
${ }^{1}$ In 1963 a group of experts suggested to the Economic and Social Council (ECOSOC) to create a UN agency in charge of international trade, which work under the instructions of United Nations Conference on Trade and Development (UNCTAD). The GATT was supposed to be in integrated into this agency as a Committee on Tariffs. This can be listed as a third attempt to create an international organization in charge of multilateral trade, but took place outside the GATT regime and was not seriously considered by the most important states. Calls upon UNCTAD at the time of its establishment, to conduct work related on the creation of a formal trade organization did also not lead to any specific results (Hoekman \& Kostecki, 2009).

${ }^{2}$ The GATT covered several so called plurilateral agreements. These agreements where only applicable to those contracting parties that signed on to them. When the WTO was established most plurilateral agreements became applicable to the entire membership of the WTO. Only four plurilateral agreements were left in place: The Agreement on Trade in Civil Aircraft, the Agreement on Government Procurement, the International Dairy Agreement and the International Bovine Meat Agreement. The last two expired by the end of 1997.

${ }^{3}$ The most recent accession to the WTO was the one of Afghanistan in July 2016. Since then WTO consists of 164 members.
} 
However, when looking more closely at the way that business is done in the WTO on a daily basis and at its core institutional architecture, differences between the GATT and the WTO decrease. Except for the introduction of the TPRM and reforms in dispute settlement - which will be specifically addressed in consecutive chapters - those institutional aspects that relate to centralization and control - such as setup and structure of institutional bodies, the role of the Secretariat, and the way decisions are taken - are similar to those of the GATT. As Footer mentions, the "most striking aspect of the new World Trade Organization [...] is the extent to which it preserves and consolidates the body of law and practice which has evolved out of the development of the GATT" (1997, p. 653). Furthermore, the WTO is characterized by an interesting dichotomy. Depending on one's perspective one can either interpret the emergence of the WTO and its institutional framework as a significant or limited change in centralization. "On the one hand, there is the strong underlying objective to integrate all administrative, decision-making and dispute settlement functions of the Uruguay Round agreements into one central authority" (Steger, 2000, p. 137). On the other hand the autonomy of this central authority is significantly limited by high levels of individual control, due to the presence of consensus as the main decision-making rule and a small-scale secretariat with limited influence. In other words, the WTO clearly is a focal entity, but it is one with relatively little autonomy to determine policy independently of its membership.

To explain this dichotomy this chapter analyzes the establishment of the WTO as an international organization and the emergence of its institutional architecture. This includes the structures related to legislative decision-making and those related to facilitate the administration of substantive agreements. Thereby the chapter seeks to answer three related questions: Why did the institutional change that resulted in the creation of the WTO come about? How did this change come about; which processes led to it? And why did the institutional architecture take shape in its eventual form and not in a possible alternative one?

The theoretical framework as developed in chapter 2 is used to guide the answers to these questions. Overall it is argued that a functional motivation can be regarded as the underlying cause of the WTO's emergence, but that the GATT's history, the negotiation process, and concerns over control shaped the outcome significantly. As such, rational design can only provide a partial account of the WTO's emergence and institutional architecture. A rationalist account might be adequate to acquire an abstract understanding of the WTO's emergence, but misses out on details and causal depth. The separate sections of the chapter provide a more nuanced version of this general argument.

The chapter is distributed in two main parts. The first is concerned with the establishment of the WTO and its general administrative, institutional structure. The second part focuses on its decision-making procedures, highlighting the interaction of centralization and control in institutional design. Each of these main parts consists of separate sub-sections. Section 3.2.1 of the first part sets the stage by providing an overview of the WTO's institutional architecture and clarifying how the emergence of the WTO can be seen as an instance of centralization according to the conceptualization of the variable that has been derived in chapter 2. Section 3.2.2 of the 
first part examines how well the rational design framework accounts for the establishment of the WTO, by looking at the main motivations that led to the emergence of the organization. It becomes clear that functional explanations like those of rational design are suitable to explain the underlying motivations that induced actors to suggest the establishment of an international organization in charge of multilateral trade, but that it does not explain why such suggestions eventually succeeded and why the organization took the shape it did. Section 3.2.3 examines the influence of the GATT's historical legacy on the design of the WTO. This highlights the incremental nature of institutional change that eventually culminated in the establishment of the WTO. Thereby the static, 'snapshot' explanation of rational approaches is put into perspective and doubt is cast on the conceptualization of actors as fully rational designers. With respect to its administrative institutional form the WTO does not seem to be much more than another incremental step along the GATT's trajectory, taken by risk adverse actors that draw heavily on past experience. This is crucial to explain why the WTO took the shape it did. Section 3.2.4 of the first part traces the negotiation process of the WTO, explaining why the establishment of an international organization travelled successfully from being a proposal to becoming reality. This section highlights the link between negotiations on substance and those on institutional structure: without substantive agreements that were perceived to be beneficial for the main players of the regime - especially the United States of America (US) - the creation of the WTO would have been unlikely. Asymmetries in power amongst actors were crucial to bring this constellation of substantive and institutional negotiation results about.

At least as important as the link to substantive negotiations to successfully establish the organization was striking an adequate balance of centralization and control and most of the negotiations were related to this issue. Because of this, the entire second part of this chapter is devoted to design sets related to exactly this balance. In this regard the focus of the second part lies on the decision-making procedures of the WTO, their history and their negotiation in the Uruguay Round. Section 3.3.1 of the second part introduces the different features of decisionmaking in the trade regime and how they relate to centralization and control. In this respect a relative absence of formal institutional change in the transition from the GATT to the WTO becomes evident and possibilities to explain this by applying the rational design framework are reflected upon. It is posited that the theoretical toolkit of rational design is inadequate to do so and that process tracing is necessary to account for the balance that is struck between centralization and control in decision-making. Section 3.3.2 of the second part provides said process tracing by looking at the history and the negotiation of decision-making in the trade regime. This clearly shows that concerns over the reduction of transaction costs and improving the efficiency of legislative decision-making are of secondary importance in comparison to concerns over individual control.

In sum it can be stated that the creation of the WTO as a focal entity was relatively uncontroversial once the substantive agreements of the trade regime were perceived to be favorable to the main players, but that the form of its design needs to be understood in 
historical context and by acknowledging the primacy of individual control as influential factor in the composition of design sets. 


\subsection{The Establishment of the WTO as a Focal Entity}

\subsubsection{The Case as a Matter of Centralization and Control}

As it has been pointed out in the introduction, taking a general perspective the establishment of the WTO as a proper international organization constitutes a clear increase in centralization in comparison to the GATT. The WTO rest on a solid legal footing, covers more members and a wider scope than the GATT, and with the TPRM and the Dispute Settlement Understanding (DSU) it has strong means to induce rule abidance at its disposal. However, on a more specific level, the exact institutional architecture forms design sets that entail control features which significantly limit the degree of centralization as pooling and as delegation. As such the WTO has limited possibilities to autonomously form policies that are independent of its members' preferences. The following elaborates on the WTO's institutional structure in further detail.

\subsubsection{General}

According to the conceptualization provided in chapter 2 the establishment of the WTO can be conceived as an instance of centralization when the variable is interpreted in its broadest possible form. In chapter 2 it was pointed out that without further specification centralization can be understood as states granting authority over a policy domain to an international organization. This is in line with Martin's understanding of centralized multilateral cooperation (1992), and K. W. Abbott's and Snidal's definition of centralization as "a concrete and stable organizational structure and an administrative apparatus managing collective activities" (1998, p. 9). In this respect the WTO can be seen as the focal entity, providing the administrative structure in charge of managing the policy domain of multilateral trade. As Article II:1 of the WTO Agreement stipulates, the WTO is supposed to "provide the common institutional framework for the conduct of trade relations among its Members in matters related to the agreements and associated legal instruments in the Annexes to this Agreement."

According to this general perspective the creation of the WTO can be considered a step towards more centralization in comparison to the GATT in several ways. It should be pointed out first that the WTO is formally a 'stronger' institution than the GATT, as it rests on a strong legal footing. Contrary to the GATT, the WTO is a proper international organization with legal personality that is permanently established. The substantive provisions under the WTO agreement are no longer provisionally applied, as it was the case in the GATT. Furthermore, the WTO has exclusive jurisdiction to interpret these provisions, can take legally binding decisions and possesses stronger means of enforcement than the GATT. The WTO also covers a larger scope than the GATT, provides a single dispute settlement system for all of the covered agreements and has an institutionalized procedure for the review of countries' trade policies the Trade Policy Review Mechanism (TPRM). Clearly, the WTOs large scope and legal standing as 
an international organization increased its status as the focal entity for multilateral trade cooperation in comparison to the GATT.

Secondly, and perhaps most significantly, the WTO serves as an institutional umbrella for the different substantive agreements that constitute the multilateral trade regime. The GATT was unable to play this role. As Winham (2006) points out, there were concerns over the fragmentation of the GATT by the time of the Uruguay Round since the GATT could not be considered a single treaty instrument by that time, "but rather a cluster of more than 180 agreements that had differing memberships and differing purposes" (p. 12). This was mainly a result of the introduction of plurilateral agreements that emerged from the Kennedy and the Tokyo rounds. These agreements only applied to those parties of the trade regime that decide to sign on to them. Before the conclusion of the Uruguay Round most plurilateral agreements while being associated with the GATT - had their own institutional and dispute settlement procedures. This created the risk that without "a formal mechanism of coordination, it was highly likely that the agreements flowing from the Uruguay Round would produce further decentralization and even legal chaos in the trade regime" (Winham, 2006, p. 12). The creation of the WTO put an end to this fragmentation, since most plurilateral agreements were multilateralized as a part of the Uruguay Round's single undertaking and became subject to a unified dispute settlement system. Those plurilaterals that remained in place at the end of the Uruguay Round were embedded within the WTO's institutional structure. In this respect the WTO can be understood as an institutional umbrella, covering a variety of different substantive trade agreements.

Finally, it should be noted that contrary to the GATT, in the case of the WTO it is clearly identifiable which tasks the organization as a focal entity is supposed to fulfill. The WTO's functions are explicitly mentioned in in the WTO Agreement. While essentially the GATT also carried out these functions, the GATT's original status as an agreement (instead of an organization) meant that they were not explicitly mentioned. According to Article III of the WTO Agreement the WTO has five functions: The first function asks the WTO to facilitate the implementation, administration and operation of the substantive agreements covered under the WTO agreement. Secondly, the WTO is supposed to facilitate the negotiations of new trade agreements and is supposed to act as a forum for this purpose. The third and the fourth function call upon the WTO to administer the dispute settlement system and the TPRM respectively. According to the last explicitly mentioned function the WTO is supposed to cooperate with other international organizations, and with the IMF and the World Bank in particular to achieve "greater coherence in global economic policy making" (Art. III.5). ${ }^{4}$ To fulfill these functions the WTO rests on a particular institutional architecture. In the following the specific institutional mechanisms in charge of the first two mentioned functions are examined.

\footnotetext{
${ }^{4}$ Van den Bossche \& Zdouc identify the provision of technical assistance to developing countries as another function of the WTO. While this is not listed explicitly in the agreement as one of its functions, they argue that this function is implied in the WTO agreement and expressed by the several activities the WTO and its members conduct in this area (Van den Bossche \& Zdouc, 2017).
} 


\subsubsection{Specific}

Having defined the WTO as a focal entity broadly, further elaboration is possible by making use of the specified conceptualization of centralization provided in chapter 2 , and examine the anatomy of the institution according to pooling and delegation as different variants of centralizations and their relation to control. When doing so it becomes clear that the WTO's autonomy vis à vis its membership is limited concerning its administrative and legislative functions. This is due to the fact that pooling is the dominant variant of centralization and organized in such a way that formally allows for a high degree of individual control, at the same time delegation is very limited.

\section{Pooling}

Pooling is present in several institutional bodies, which are hierarchically structured on four different levels.

At the head of the WTO stands the Ministerial Conference, being the highest political organ of the WTO. It is responsible for ensuring that the WTO fulfills its functions and has "the authority to take decisions on all matters under any of the Multilateral Trade Agreements" according to the WTO's decision-making rules (Art. IV:1). This authority entails the ability to establish institutional bodies like committees and working parties (Kaiser, 2006). The Ministerial Conference is a plenary body, consisting of all WTO members represented at ministerial level. As such it clearly constitutes an instance of pooling with a formally high degree of individual control. The WTO Agreement stipulates that the Ministerial Conference should meet at least every two years (a demand that has not been met, since the Ministerial Conference that was planned for 2007 has been cancelled). In practice the sessions of the Ministerial Conference are major events that provide political leadership to the WTO (Van den Bossche \& Zdouc, 2017). As such the Ministerial Conference does not exercise its powers to facilitate the day-to-day administration of the organization.

This task is conducted by the General Council. The General Council is located on the second level within the WTO's hierarchy. It is supposed to ensure a smooth, continuous management of the WTO on a day-to-day basis. To do so it exercises all the powers and tasks of the Ministerial Conference, adopts the organization's budget and manages the WTO's relations with other governmental- and nongovernmental organizations. Like the Ministerial Conference, the General Council is not restricted in membership. WTO members are represented by ambassadors, first secretaries or heads of mission in the Council (Kaiser, 2006). The General Council is chaired by a member's representative, who is elected annually. Council meetings convene at least once every two months (Van den Bossche \& Zdouc, 2017).

Next to the Council on the second level within the WTO's institutional hierarchy are the Dispute Settlement Body (DSB) and the Trade Policy Review Body (TPRB). Despite the fact that their name indicates institutional bodies genuinely different from the General Council, the DSB and the TPRB are equivalent to the Council, except for their name and function. Thus the General Council meets as DSB when its concerned with issues arising under the Dispute 
Settlement Understanding (DSU), such as the adoption of panel or Appellate Body reports ${ }^{5}$ and it meets as TPRB when it is concerned with issues related to the TPRM. While the membership regulations of the Council, the DSB and the TPRB are obviously the same, chairmanship and rules of procedure can differ (Kaiser, 2006).

On the third institutional level are several bodies working under the aegis of the General Council. Three of these bodies are specialized councils designated to oversee the three main agreements on substance that are covered in Annex 1 of the WTO agreement: the Multilateral Agreement on Trade in Goods (GATT 1994), the General Agreement on Trade in Services (GATS) and the agreement on Trade-Related Aspects of Intellectual Property Rights (TRIPS). These agreements and their governing bodies emerged as a result of the trade regime's increase in scope that was negotiated during the Uruguay Round. The bodies overseeing the agreements are the Council for Trade in Goods (CTG), the Council for Trade in Services (CTS) and the Council for Trade-Related Aspects of Intellectual Property Rights. These three specialized councils conduct those tasks that are explicitly ascribed to them by the WTO Agreement and those that are delegated to them by the General Council. However, the powers the specific councils wield are limited and do not explicitly entail the authority to take legal or political decisions - due to pragmatic necessities occasional disregard for this limitation has been tolerated though (Van den Bossche \& Zdouc, 2017). To facilitate their work the specialized councils are allowed to establish advisory subsidiary bodies (Kaiser, 2006; Van den Bossche \& Zdouc, 2017). Like the Ministerial Conference and the General Council, the specialized councils are open to all members and chaired by an elected representative of a member. The specialized councils meet as often as necessary to fulfill their functions.

Next to the specialized councils in the WTO's institutional hierarchy are several committees and working parties/groups. Such committees and working parties/groups also work under the auspices of the General Council. Some of them are provided for by the WTO Agreement, others can be established by the Ministerial Conference or the General Council. Committees differ from working parties/groups in three ways: they are permanent, while Working parties/groups are temporary; they can have the authority to establish subsidiary institutional bodies, which working parties/groups do not have; and they are usually in charge of a designated area of responsibility, while working parties are concerned with particular issues (Kaiser, 2006). Examples of committees accountable to the General Council include the Committee on Trade and Development, The Committee on Regional Trade Agreements, the one on Balance of Payments Restrictions, and one committee dealing with the WTO's budget, financial and administrative matters. Working parties exist to deal with accessions for membership and currently working groups exist on 'Trade, debt and Finance', as well as on 'Trade and Technology Transfer'. Committees and working parties have limited powers, since they usually act as forums for discussions with mainly an advisory function (Kaiser, 2006). Like almost all institutional

\footnotetext{
${ }^{5}$ Panels and the Appellate Body are two very important institutional organs, which can be interpreted as instances of delegation in the WTO's judicial function. The following chapter elaborates on these bodies in further detail.
} 
bodies related to pooling committees and working parties have in common that they are open to the entire membership of the WTO.

Further committees and working parties exist on the fourth level of the WTO's institutional hierarchy. These committees and working parties share similar characteristics to the ones that are accountable to the General Council, but are located as subsidiary bodies of the specialized councils in the institutional structure. Their work is related to the respective council under which they are established. Committees under the aegis of the CTG include the Committee on Market Access, one on agriculture, one on subsidies and countervailing measures, and one on antidumping practices for example. The TRIPS Council does not act as a patron of any committees or working parties, but the CTS is responsible for the committees on 'Trade in Financial Services' and on 'Specific Commitments', and for working parties on 'Domestic Regulation' and 'GATS Rules'. Again, participation in these committees and working parties is open to all WTO members.

Next to this fixed institutional structure, the WTO has also established institutional arrangements to conduct the negotiations of the Doha Development Agenda (DDA). The supreme body in charge of the negotiations is the Trade Negotiations Committee (TNC), overseeing and steering the Doha Round negotiations generally. The TNC in turn works under the auspices of the General Council and reports to it on a regular basis (Van den Bossche \& Zdouc, 2017). Special negotiation groups on 'Market Access', 'Rules' and 'Trade Facilitation' were established to deal with more specific issues, but the majority of the negotiations is conducted during special sessions of the WTO's standing bodies described above (Van den Bossche \& Zdouc, 2017). It is not uncommon in the history of the trade regime that institutional structures are established for the purposes of a trade negotiation round (Winham, 2006), but it should be noted that this form of centralization is usually created ad hoc in the context of the demands of a specific negotiation round and temporary in nature. In line with the standing bodies of the WTO, the structures established for the Doha Round resemble a very inclusive form of pooling, since all formal DDA bodies are open to all members. However, as a notable difference it should be pointed out that it is the WTO's Director General (DG) who chairs the TNC and not a member's representative as it is the case in all other institutional bodies.

Seemingly the only exception to the general pattern of open membership in the WTO's institutional bodies are the three committee's that govern the WTO's remaining plurilateral agreements: The Trade in Civil Aircraft Committee, the Government Procurement Committee and the Information Technology Agreement Committee. ${ }^{6}$ Unsurprisingly, their governing bodies are only open to those members that signed the corresponding agreements. Thus, while membership seems restricted in relation to the WTO's membership, it is inclusive with respect to the parties that are legally bound by the agreements. The three committees have the task to administer the plurilateral agreements on Trade in Civil Aircraft, on Government Procurement,

\footnotetext{
${ }^{6}$ In the past the 'International Dairy Council' and the 'International Meat Council' constituted two other bodies with limited membership in charge of plurilateral agreements. However with the termination of the 'International Dairy Agreement' and the 'International Bovine Meat Agreement' in 1997 these bodies ceased to exist.
} 
and on Information Technology. The first two of these agreements are part of the WTO Agreement that resulted from the Uruguay Round, but did not belong to the Single Undertaking. The third agreement resulted from the Singapore Ministerial Conference in December 1996. The plurilateral committees are embedded in the WTO's institutional structure, but are not under the guidance of any of the councils. They merely inform the General Council (in case of the Trade in Civil Aircraft Committee and the Government Procurement Committee) and the CTG (in case of the Information Technology Agreement Committee) about their work (B. M. Hoekman \& Kostecki, 2009; Van den Bossche \& Zdouc, 2017).

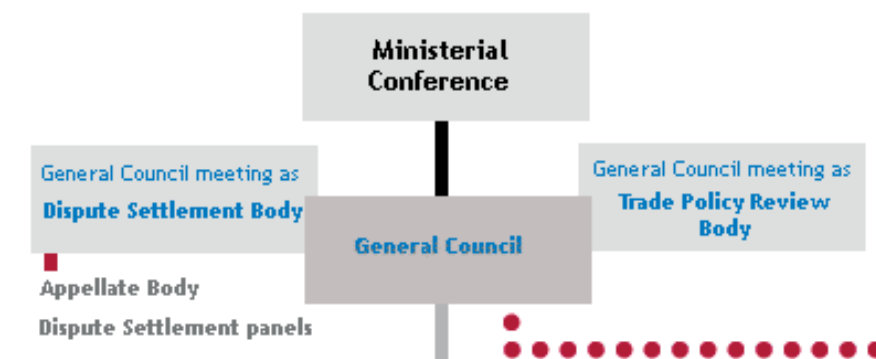

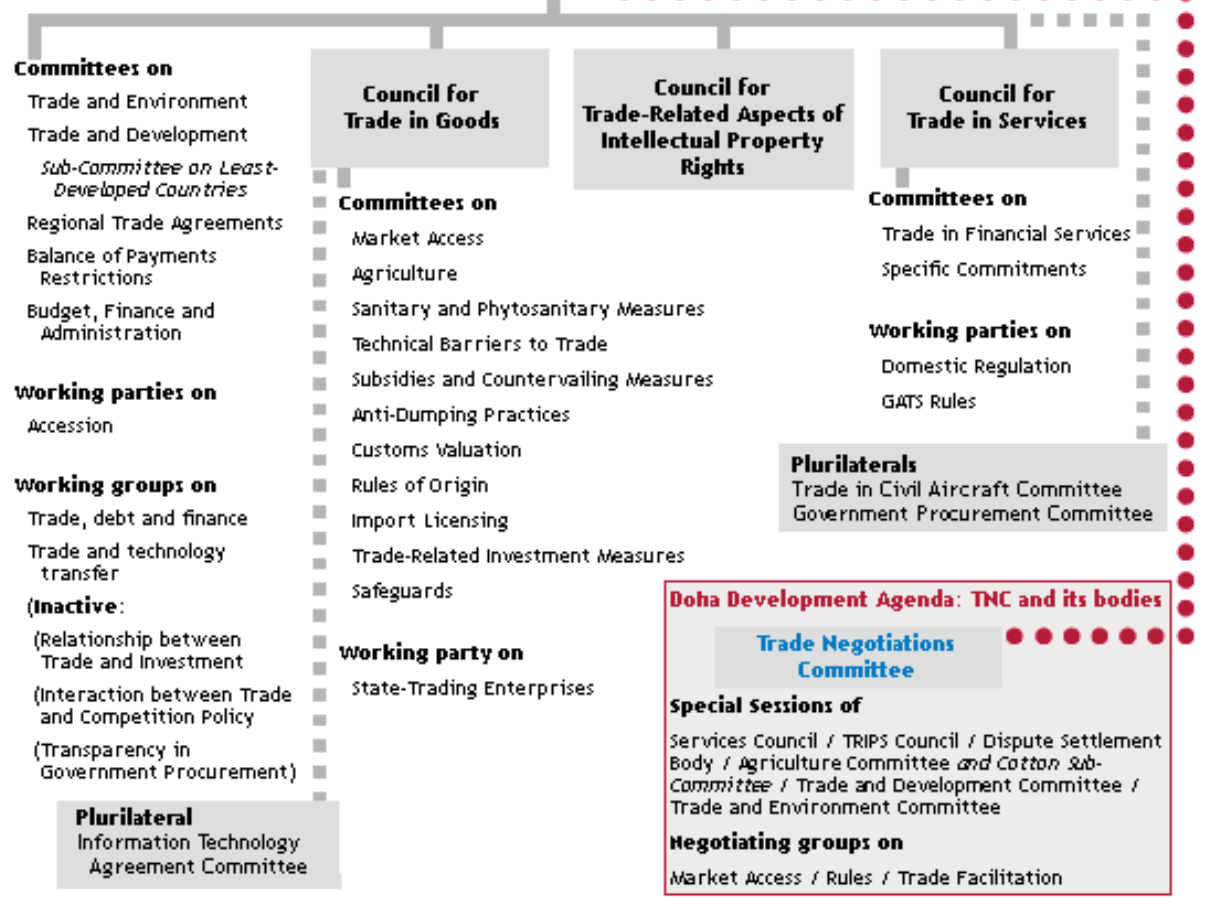

Figure 2: Organigram of the WTO7

\footnotetext{
${ }^{7}$ Source: https://www.wto.org/english/thewto_e/whatis_e/tif_e/org2_e.htm, retrieved 27.01.2018
} 
Having examined the institutional bodies that relate to pooling the question arises what these oberservations imply regarding the the autonomy of the organiztion. In this respect it is outstanding that all institutional bodies are open to all WTO members. There is no body with limited membership like an executive board or an advisory council to provide leadership or direct the organization. The circumstance that theoretically all members can participate in all of the organization's organs decreases the WTO's autonomy vis à vis its collective membership with respect to the WTO's administrative and legislative function. ${ }^{8}$ As one former negotiator put it during and iterview: "We wanted to make sure that the WTO remained a member driven organization, and this would have been harder to do if you would have some sort of formalized executive council“ (Int09). Autonomy is reduced further by the organization's decision-making practices. Although decisions could theoretically be taken by vote, the practice of taking decisions by consensus that emerged as a custom throughout the development of the GATT has become such a strong norm that taking decisions differently is essentially a taboo. ${ }^{9}$ The same Uruguay Round negotiator quoted above continued his work as a delegate in the WTO and based on this experience pointed out that "even though you have about five pages how you vote on things. You can forget all about that because we don't use any of these voting rules." In essence, this provides each member with a veto to block organizational decisions. Furthermore, when decision-making is deadlocked in an institutional body, the decision can be referred to a superordinate institutional body (Van den Bossche \& Zdouc, 2017), providing another institutional check inhibiting undesired behavior of subordinate bodies. Turning to delegation as the second specified variant of centralization does not significantly change the assessment of the organization's autonomy considering its administrative and legislative functions as being limited.

\section{Delegation}

The WTO entails several institutional bodies related to centralization as delegation. With respect to the administrative and legislative functions of the organization the most important of those is the WTO's Secretariat. ${ }^{10}$ The Secretariat is established by Article VI of the WTO

8 The WTO's judicial organs are an important exception to this. Considering dispute settlement, the organization is very independent. This will be addressed in detail in the next chapter.

${ }^{9} \mathrm{~A}$ detailed analysis of the WTO's decision-making procedures is provided in section 3.3.

${ }^{10}$ The International Trade Center (ITC) is another institutional body related to delegation. The ICT is a joint institution established in 1964 under the aegis of GATT (now WTO) and the United Nations Conference on Trade and Development (UNCTAD) providing trade related technical assistance to developing countries. As such it is not related to the legislative functions of the WTO.

Further important instances of institutional bodies related to delegation include dispute settlement panels and the Appellate Body. However these bodies do also not relate to the WTO's its administrative and legislative functions, but to its judicial function. They will be addressed in further detail in the following chapter. Another body related to the WTO's judicial function used to be the Textile Monitoring Body (TBM), consisting of 11 independent and impartial members. The TBM was supposed to monitor the implementation of Agreement on Textiles and Clothing (ATC), but ceased to exist with the termination of the ATC agreement in 2005 (Van den Bossche \& Zdouc, 2017). Other bodies that would count as instances of delegation only play a minor role in the WTO. Most of them are provided for by the WTO Agreement on an ad hoc basis and have not been a called upon, such as the technical experts that can be consulted in case of disputes arising under the Agreement on Technical Barriers to Trade (TBT Agreement) and the Agreement on the Application of Sanitary and Phytosanitary Measures 
agreement, but its exact setup, power and functions are left unspecified (Bohne, 2010; Footer, 2006). Specific tasks of the Secretariat can be found in different sections of the WTO agreement and in practice the Secretariat is involved in all of the organization's five explicitly mentioned functions - administration, implementation and operation of the substantive agreements; negotiation; trade policy review; dispute settlement; and cooperation with other organizations. Furthermore, the Secretariat also provides technical assistance to developing countries, advises countries desiring to accede to the WTO, and manages public relations (Van den Bossche \& Zdouc, 2017).

The Secretariat is headed by the DG, who is appointed by the General Conference, for a term of four years that can be renewed once. ${ }^{11}$ The DG has four Deputy Director Generals (DDGs) that are also temporarily appointed. ${ }^{12}$ The DG and the DDGs are responsible for various divisions working in different functional domains. Some divisions conduct work related to a range of the WTOs activities, while other divisions are concerned with specific tasks in service of a particular WTO body (Bohne, 2010). Examples of divisions include divisions on: 'Legal Affairs', 'Rules', 'Economic Research and Statistics', 'Development', 'Agriculture and Commodities', 'Trade Policy Reviews', 'Language Services and Documentation' etcetera. Each division is headed by a director, who is a career civil servant.

Overall the influence of the Secretariat is low. The WTO is often characterized as a 'member driven' organization, indicating the primacy of the membership in determining the direction of the WTO's policies. The Secretariat's formal room to shape policy output is extremely limited. It is only supposed to facilitate the process. In doing its work is supposed to be technical and professional and it is not supposed to take initiative (Footer, 2006). Also, in comparison to other international organizations the Secretariat is very small and deals with a limited budget, which inhibits its work. ${ }^{13}$ Clearly the membership tries to keep the Secretariat on a short leash: members are reluctant to increase the Secretariat's budget and powers, emphasize that the Secretariat is supposed to stay neutral (and the Secretariat is careful to avoid formal value judgments of member's policies and behavior), and they monitor the Secretariat carefully (Bohne, 2010; Elsig, 2010a; Xu \& Weller, 2004). When members have the feeling that the Secretariat is exceeding its boundaries, they seek to address this. This happened for example in 2002 when a group of developing countries issued a joint communication, which stressed that

(SPS Agreement) (Kazeki, 2009). Even the Permanent Group of Experts established under the Agreement on Subsidies and Countervailing Measures (SCM Agreement) as an institutional body that is not ad hoc has not been made use of in the WTO so far (Kazeki, 2009; Van den Bossche \& Zdouc, 2017).

${ }^{11}$ This appointment process has not always been easy and was at times subject to fierce negotiations amongst members (Van den Bossche \& Zdouc, 2017; Xu \& Weller, 2004)

12 The number of DDGs has been debated. While functionally it might not be necessary to have four DDGs, politically this large number leaves enough room to staff the positions with persons who come from diverse geographical backgrounds, ensuring that the different major trading regions feel represented in the Secretariat (Van den Bossche \& Zdouc, 2017; Xu \& Weller, 2004).

${ }^{13}$ According to an interview with a leading Secretariat member, the limited size and budget is problematic, but also enables the Secretariat to present itself as lean and efficient in comparison to other international organizations (Int05). 
the DG and Secretariat is supposed to stay impartial and should not make value judgments on issues discussed amongst members (Footer, 2006; Van den Bossche \& Zdouc, 2017). VanGrasstek (2013) describes the relationship between the WTO's members and its Secretariat in the following way:

"No member is prepared to delegate sovereignty to an international organization, and certainly not to its staff. In the same way that the membership views with caution any proposals that might enhance the power of the director-general, so too do they scrutinize any proposals to expand the budget, staffing or mandates of the Secretariat as a whole. If the Secretariat is lean, that is because the members want to keep it that way." (p. 533)

Although the Secretariat's autonomy is formally limited, it needs to be acknowledged that this autonomy differs across the WTO's different functional domains. Certainly, the Secretariat is relatively autonomous when it comes to the production of reviews in the context of TPRM. Also, in the field of technical assistance and dispute settlement it is able to work reasonably independently. However, with respect to administering and implementing the trade agreements and in the context of the WTO's negotiation function the membership maintains tight control over the organization (Bohne, 2010; Elsig, 2010b). In this domain interviews have confirmed that the Secretariat cannot be considered as an entity that independently contributes to political discussions (e.g. Int14). Also the fact that 'Facilitating Negotiations' made only 3\% of the WTO cost allocation for the Secretariats' budget in 2012, despite the fact that members spend most of their time and activities devoted to this function, is indicative of the Secretariat's limited influence in this area (VanGrasstek, 2013)

Most of the WTO's administrative and legislative tasks formally take place in the institutional bodies that have been described above as instances of pooling. It is thus the members' delegates that are in charge of these functions, with the Secretariat playing a similar role in each of them. While a member of the Secretariat is present during meetings of the different institutional bodies, its role is merely supportive. In this context the Secretariat's staff is to take minutes, circulate documents, prepare background information, and to assist the chair (Bohne, 2010; Elsig, 2010a; Van den Bossche \& Zdouc, 2017). During meetings the Secretariat is passive and only takes the floor when being asked (Bohne, 2010). Neither the DG, nor the Secretariat has any formal power to initiate or suggest decisions, let alone having a say in taking them (Footer, 2006; Xu \& Weller, 2004). It is the elected chairman of institutional bodies who plays a central role and who has some means to influence policy output (Odell, 2005). Of course, the chairman is assisted by the Secretariat, but clearly stays in charge as exemplified by the statement of a former negotiator describing the role of the chairman and the Secretariat during the Uruguay Round:

"In the Uruguay Round, the chairs used the secretariat extensively. The chairs were very active. And it was not that the chairs were pushed by the Secretariat. It was the 
chairs that called the secretariat to assist them to develop drafts... it was not that the Secretariat pushed for certain things. It was because the chairs asked them." (Int04)

In this context it is the DG's role as the chair of the Trade Negotiations Committee (TNC) that constitutes an exception to the limited authority of the Secretariat. In its role as chair of the TNC the DG can make use of several means to facilitate negotiations. ${ }^{14}$ The DG can also influence policies by calling for informal sessions with a selected group of members to facilitate negotiations (Bohne, 2010; Xu \& Weller, 2004). Besides this the formal authority of the DG is limited.

His ${ }^{15}$ influence depends heavily on his personality and leadership style. Certainly, the DG can leave a significant impact on the trade regime such as the GATT's first head of the Secretariat Sir Eric Wyndham White (Curzon \& Curzon, 1973; Dam, 1970; De Souza Farias, 2013; Jackson, 2006; McKenzie, 2008; Xu \& Weller, 2004), or Arthur Dunkel and Peter Sutherland with their generally acknowledged, significant impact on the conclusion of the Uruguay Round (Paemen, 2005; VanGrasstek, 2013). ${ }^{16}$ However, not every DG has managed to leave this kind of impact on the trade regime. After all, the DG

"has no power to command, no sanctions to apply. He can use moral persuasion or logic. No state is likely to sell out its economic interests just because the DirectorGeneral asks them to. They act in their own interest and the Director-General's greatest opportunity is to show them where their interests lie." (Xu \& Weller, 2004, p. 260)

Personalities and context can also play a role in the influence of the Secretariat apart from the DG. In the WTO's administrative and legislative work it is in the relation with the chairs of different institutional bodies that the Secretariat can exert influence informally. It has been noted above that part of the Secretariat's task consists of assisting the chair. The Secretariat's informal influence depends on how far this assistance goes. Important tasks of the chair consist of directing decision-making by drafting texts for agreements for example. If the chair relies heavily on secretarial support and advice the Secretariat can indirectly and informally influence the WTO's policies (Bohne, 2010; Xu \& Weller, 2004). Of course the amount of influence of the Secretariat depends on the personality and skills of the chairperson, and the chair's relationship with the Secretariat member. A chair with a lot of expertise might rely less on secretarial support than an inexperienced one for example. Also, the influence of the Secretariat on the work of WTO's institutional bodies tends to be higher when it comes to the administration and implementation of existing agreements in comparison to the negotiation of new agreements in

\footnotetext{
${ }^{14}$ These means include agenda setting powers, mediation amongst conflicting positions, steering of debates and framing of issues, as well interacting with other chairs to explore the possibilities of package deals (Elsig, 2010a).

${ }^{15}$ So far there has not been a female Director-General in the history of the trade regime.

${ }^{16}$ The importance of the impact that Dunkel and Sutherland left on the conclusion of the Uruguay Round was also confirmed in several of the interviews conducted with former negotiators and secretariat members.
} 
(Bohne, 2010). Especially in the area of negotiation the informal influence of the Secretariat should not be overestimated, since members closely monitor it. A delegate's quote in Bohne (2010) exemplifies this point:

"I am not saying that there have not been instances where a particular nuance is given [by the Secretariat] to certain things, which would try and influence discussion. But I think, by and large, nowadays members are more aware, they are more involved in the negotiating process, this kind of thing is on the decline." (p. 77)

Another indirect way to influence the WTO's policy output is by providing informal advice to delegations that approach the Secretariat and thereby influencing their positions (Bohne, 2010; Xu \& Weller, 2004). This opportunity to influence depends on context again, as it is mainly members with limited resources that only have small or no permanent delegations in Geneva who approach the Secretariat for advice (Xu \& Weller, 2004). Similar to the other means of the Secretariat to shape policies, the degree of the Secretariat's influence is a function of its expertise in a certain area, in relation to the expertise of the member. But again, the Secretariat acts carefully to avoid being accused of not being neutral and it behaves only reactively, not proactively (Bohne, 2010; Xu \& Weller, 2004).

To summarize, the DG's and the Secretariat's work is crucial to ensure a smooth functioning of the WTO, but their impact on the organization's policy output should not be overestimated. It needs to be acknowledged that their informal influence can be higher than their formal powers would suggest, but is dependent on context and personalities, and even in this respect the DG and the Secretariat need to act cautiously. They are mainly reactive and need to stay neutral especially regarding the administrative and negotiation function of the WTO. It has been argued that the Secretariat's influence in these fields is even on the decline (Elsig, 2010a). ${ }^{17}$ Members are carefully monitoring the Secretariat and put a high emphasis on keeping the WTO to stay a member driven organization. The problem in this context, as a former delegate and later leading Secretariat figure mentioned half-jokingly, is that the members don't always know how to drive (Int09).

\subsubsection{Conclusion}

Having assessed the WTO as an instance of centralization a mixed picture emerges. Clearly the WTO, being a proper international organization in charge of multilateral trade fulfills the criterion of being a focal entity. Generally speaking its creation can be considered as an increase in centralization in comparison to the GATT: the WTO has explicitly mentioned functions, a stronger legal standing, stronger dispute settlement and monitoring capacities, and ends the fragmentation of the multilateral trade regime that emerged under the GATT by providing an institutional umbrella for various substantive agreements. However, while this development and especially the increased scope of the WTO and its strengthened dispute settlement capacity

\footnotetext{
17 This view has also been confirmed in an interview conducted with a former long-standing secretariat member (Int15).
} 
should not be underestimated, looking at its institutional setup with respect to the two functions that ask it to ensure the implementation, administration and operation of existing agreements and that demand to facilitate the negotiating of new agreements, it becomes clear that centralization is limited when associating the degree of centralization with the autonomy of the focal entity under examination. In this respect the autonomy of the organization to actively shape political outputs independent of its members seems severely restricted: All organs with decision-making capacity are pooled, open to all members and (except for the adoption of panel and Appellate Body reports in the DSB) work by consensus. All of this contributes to high individual control of members. The Secretariat as an instance of delegation does not function as a counterweight to the dominance of members in the organization: it has limited freedom to play a pro-active role when the administration of existing- and negotiation of new agreements is concerned, and it is tightly controlled by the members.

The contrast that emerges from a more nuanced analysis of the WTO's institutional architecture in comparison to the publicly perceived image arising from its creation and title as a proper international organization shows that it is not only important to examine whether centralization occurred, but also how it occurred. Leaving out the latter can lead to confusion and the expectation that the organization can deliver a policy output that its institutional structure does not allow for. A former Uruguay Round negotiator pointed out that at the time of its creation many people thought that a new major international organization had been established, but that the WTO is more an organization in name than in fact, and that it is characterized by a difficulty to initiate constructive policy discussions short of negotiation. ${ }^{18}$ Indeed, on the one hand the creation of the WTO is widely acclaimed to be the "greatest institution building moment since the foundation of the IMF and the World Bank" ${ }^{19}$ On the other hand its institutional structure does not seem to make it as independent a focal entity as such grandiose accounts of its creation would suggest. Footer (2006) does even posit that the WTO cannot be regarded as a proper international organization, because it does not live up to one of the defining features of an organization "with a will of its own and identity separate from that of its Members" (pp. 334-335). ${ }^{20}$

After the assessment of the organization's general characteristics and its institutional architecture in relation to centralization, the question arises how and why the WTO emerged in this way on January $1^{\text {st }}, 1995$. The starting point to address this question is conducted in the next section by assessing the explanation that rational design can offer.

\footnotetext{
18 Interview with John Weekes in the context of the WTO Creation Project. A video recording of the interview was retrieved from: http://www.wtocreation.org/en/videos?video=31171021.

19 Interview with Peter Sutherland in the context of the WTO Creation Project. A video recording of the interview was retrieved from http://www.wtocreation.org/videos?video=31135707.

${ }^{20}$ This strict assessment is contested by Bohne (2010).
} 


\subsubsection{Rational Design Explanations}

An assessment of the adequacy of rational design explanations to account for the emergence of the WTO and its institutional architecture leads to the conclusion that rational design can provide a reasonably adequate account on a high level of abstraction, but that this account leaves significant gaps that need to be filled by supplementary explanations.

\subsubsection{Positive Contributions of Rational Design}

According to rational institutionalism as described in chapter 2 the creation of a multilateral organization for the regulation of international trade can be generally understood as a functional response to the collective action problem of mercantilist individual trade policies. According to such an account international trade cooperation is interpreted as a prisoner's dilemma. In this scenario mutual cooperation entails the highest possible gains for all parties involved, but incentives of individual actors to defect leave cooperation instable. If a party gives in to such incentives this can trigger a downward spiral of mutual defection where everyone loses out. Although it is possible to maintain cooperation without centralized organizations (Axelrod, 2003), an organization can stabilize cooperation by fulfilling several functions (K. W. Abbott \& Snidal, 1998). According to functional arguments international trade cooperation is more likely to persist when an international organization serves as a forum for negotiations, assembles and disseminates information, monitors the behavior of its members, facilitates the resolution of disputes by acting as an honest broker and conciliator amongst conflicting parties, and ensures compliance by adjudication and authorization of sanctions. ${ }^{21}$ This functional logic is also reflected by the conjectures of the rational design framework. To recall, the conjectures of rational design assume that cooperation will be increasingly centralized when uncertainty (about behavior or the state of the world) is high, when cooperation is supposed to take place amongst a large amount of actors, and when incentives to defect from cooperation are high (Koremenos, Lipson, \& Snidal, 2001a).

\section{The Underlying Rationale}

The general rationale for the centralization of cooperation via the establishment of an international organization to prevent defection from multilateral trade agreements is clearly reflected in the history of the trade regime in form of the attempted creation of the ITO. This attempt needs to be understood against the backdrop of more general US efforts to design a system for the governance of international economic affairs, aiming to ensure long run cooperation amongst states after the Second World War (WWII). The ITO was regarded as a necessary supplement to the International Monetary Fund (IMF) and the World Bank. The three organizations were supposed cover the full spectrum of international economic cooperation (Lacarte Muró, 2011; Wilcox, 1972). The perceived necessity to ensure economic cooperation by

\footnotetext{
${ }^{21}$ Several scholars have written on the functional benefits of (institutionalized) cooperation on trade matters facilitated by an international organization. The WTO's trade report of 2007 provides an overview of the different arguments (World Trade Organization, 2007).
} 
setting up international organizations was derived from the experiences of the great depression, resulting mercantilist economic policies, and WWII. Both, historical analyses and individuals that were involved in the endeavor ascribe the willingness to setup international organizational structures for economic cooperation to a common understanding that the severity of the economic crisis of the 1930s increased by selfish - "beggar they neighbor" - national economic policies and that this was one of the permissive causes for the outbreak of the WWII (Goldstein, 2002; Jackson, 1969; Wilcox, 1972). ${ }^{22}$ In this respect multilateral institution building in the 1940s, including the effort to establish the ITO, can be interpreted as a response to the breakdown of international cooperation before WWII and its negative consequences. The creation of international organizations was heavily motivated by the desire to avoid such a breakdown in the future.

Also the creation of the WTO as an outcome of the Uruguay Round coincides with the erosion of multilateral trade cooperation and a desire to counter this. After a period that was generally prosperous during the 1950s and 60s, the world economic situation started to deteriorate in the 1970s. In the wake of the collapse of the Bretton Woods system in 1971, and the oil crises in 73 and 79, growth in exports, production and productivity decreased, while inflation increased. Policy attempts to counter inflation slowed down domestic growth and increased unemployment, interest rates rose and many developing countries struggled with an increasing burden of foreign debt (Winham, 2005). This economic environment provided fertile ground for protectionist policies and compliance to the norms of the trade regime was decreasing. Countries turned towards regionalism, started to act unilaterally and introduced grey area measures, i.e. policies that were not explicitly violating but circumventing GATT provisions. The GATT as an institution and its rules were regarded as insufficient at the time to provide a comprehensive answer to the protectionist threat, and the outcome of the Tokyo Round negotiations was unable to reverse this trend (Croome, 1999; Paemen \& Bensch, 1995; Preeg, 1995; Winham, 2005). To address the situation and to defend the multilateral trading system the first calls for a new trade negotiation round arose already soon after the completion of the Tokyo Round in 1979.

Looking at the motivation for initiating what would later be known as the Uruguay Round it is easy to find evidence that corresponds to the functional logic suggested by rational design arguments. The GATT Secretariat for example assessed the situation in the early 80s in a way that is strikingly similar to the prisoner dilemma that is used as a model to justify the institutionalization of trade relations. This is exemplified in a speech given by DG Arthur Dunkel in 1981 in which he

"concluded that governments were being restrained from a substantial slippage towards protectionism only by 'a kind of balance of terror': a fear that if they resorted

\footnotetext{
${ }^{22}$ This was also expressed in an interview with Julio Lacarte, a veteran of the multilateral trade regime who already participated in the negotiations for the ITO. A video recording of the interview was retrieved from: https://www.youtube.com/watch?v=3A6z9INFxEQ.
} 
to trade restrictions these would evoke retaliation, as well as undermining the trading system as a whole" (Croome, 1999, p. 6).

To avoid this, the GATT's Consultative Group of 18 expressed that international cooperation would have to be improved to overcome protectionist pressures and the trading system was supposed to be strengthened (Croome, 1999). The strengthening of the system also belonged to the goals of the main protagonists of the Uruguay Round: The European Communities (EC) considered "strengthening of the multilateral structures and disciplines of the GAT" to address protectionism as a main objective of the Uruguay Round (Paemen, 2005). Similarly, "Japan's most important overall objective was the strengthening of the rules-based multilateral open trading system in a way designed to restrict protectionism of any kind..." (Endo, 2005, p. 173). Also the Punta del Este Declaration that launched the Uruguay Round leaves no doubt that the negotiations were motivated by a logic that fits the general rational account. The declaration refers to the desire to stop protectionism and to "develop a more open, viable and durable multilateral trading system." ${ }^{23}$ To achieve this, the declaration lists the strengthening of the GATT and the multilateral trading system and the ambition to "bring about a wider coverage of world trade under agreed, effective and enforceable multilateral disciplines" 24 as objectives of the negotiation. The discussions that took place in the preparatory committee of the round exemplify that this functional reasoning continued also after the decision was taken to launch a new round. ${ }^{25}$

Recapitulating the argument so far there seems to be a straightforward correspondence of the rational design account with the occurrence of centralization in form the WTO's creation: One of the rational design conjectures suggests that the likelihood of centralization increases when the incentives to defect on an agreement increase. ${ }^{26}$ As a result of the economic situation in the 1970s and 80s such incentives indeed increased and the Uruguay Round was launched as a response to combat this. Since the Uruguay Round led to the creation of the WTO, the emergence of the WTO can be ultimately traced back to an enforcement problem represented by the threat of protectionism.

While this argument seems plausible the full account of the WTO's creation is not that straightforward. Although the Uruguay Round can generally be seen as a rational response to the prisoner's dilemma of multilateral trade, and more specifically including the strengthening of dispute settlement procedures and improving the GATT's monitoring capacities can be interpreted as steps to address enforcement problems and uncertainty, the functional account provided so far is problematic. Before a thorough overview of the different shortcomings of such an account is provided below, the first and most obvious problem to the functionalist account

\footnotetext{
${ }^{23}$ MIN.DEC, p.1

${ }^{24}$ MIN.DEC, p.2

${ }^{25}$ E.g. PREP.COM(86) SR/4

${ }^{26}$ C4: Centralization increases with the severity of the enforcement problem." (Koremenos, Lipson, \& Snidal, 2001, p. 789).
} 
provided so far needs to be addressed: the Punta del Este Declaration did not include the creation of an international organization in the negotiation mandate and negotiators did not expect at the beginning of the round that this could be one of the round's outcomes. It was only in the beginning of 1990 that the first serious considerations of creating an international organization emerged in the context of the negotiations. So while the motivations that led to the Uruguay Round provide important contextual information and confirm a functional account at a high level of abstraction ${ }^{27}$, the first test of the plausibility of such an account requires to examine whether the more specific rational that accompanied the call for the creation of an organization in 1990 also corresponds to functional considerations. When doing so it becomes clear that the basic underlying logic is indeed inspired by functionalism. But before examining the rationale, it is useful to provide a chronological overview of the emergence of the idea first.

\section{The Emergence of the Idea}

The intellectual blueprint for the WTO was provided by Professor John H. Jackson, an influential legal scholar and commentator on GATT. In several of his publications Jackson examined the GATT's institutional weaknesses and called for reform (Jackson, 1969, 1978). In a paper, presented on a conference in Bielefeld, Germany in 1987 his call included the establishment of a new organization in charge of multilateral trade (Jackson, 1991). Jackson repeated this call in January 1990 when presenting a paper at a Chatham House sponsored conference in London (Steger, 2000; VanGrasstek, 2013). He elaborated on the ideas presented in these papers in greater detail in a book published in 1990 titled "Restructuring the GATT System". Next to an analysis of the GATT's shortcomings, the book includes specific suggestions of the institutional features that a new "World Trade Organization" 28 should entail.

It is highly likely that Jackson's ideas were not left unnoticed in the trade regime. GATT Secretariat and government officials were present during both of the above-mentioned conferences (Petersmann \& Hilf, 1991; VanGrasstek, 2013). Jackson also went to Geneva in early 1990 and presented his ideas at the GATT headquarters (Steger, 2000; VanGrasstek, 2013). Furthermore, his connection to Debra Steger, at the time a Canadian official and negotiator in the Uruguay Round, support the thesis that Jackson's ideas inspired the establishment of an international trade organization. Steger had been one of Jackson's students in the early 80s at the University of Michigan, read a draft of Jackson's book, worked with him informally on the issue and pushed the idea for an international organization in the Canadian government (VanGrasstek, 2013). Thus, a search for the rationale underlying the establishment of a trade organization needs to take Jackson's work into account.

Next to the academic origins of the idea, its development within the GATT during the Uruguay Round negotiations also needs to be traced. Canada and the EC were mainly responsible for bringing the issue into the round. Already in 1987 a communication from Canada

\footnotetext{
${ }^{27}$ Even launching the round itself was already problematic and entailed less common interest than a purely rational account would suggest (Croome, 1999; Paemen \& Bensch, 1995; Preeg, 1995; Winham, 2008).

${ }^{28}$ This was the name Jackson provisionally suggested to describe his idea.
} 
was submitted to the FOGS (Functioning of the GATT System) negotiation group ${ }^{29}$ which mentioned that "it might be useful also to examine the proposals considered during the discussions to establish an international trade organization." ${ }^{30}$ However, at the time this idea was not seriously picked up and even Canada did not fully believe in its feasibility (Croome, 1999). Only towards the end of 1989 the idea was considered more seriously when the establishment of an organization was discussed during informal meetings of the Quad - a highly influential informal group in the negotiations, consisting of representatives from the US, the EC, Canada and Japan (Preeg, 1995). Subsequently the EC's legal service prepared a draft paper about an organizational framework and provided this informally to other GATT delegations in the beginning of 1990 (VanGrasstek, 2013). In Renato Ruggiero, the Italian Trade Minister at the time, the idea to establish an international organization found a high level political supporter, who expressed enthusiasm for it in February 1990 (Stewart, 1993; VanGrasstek, 2013).

Political support was also found in Canada. Inspired by Jackson's ideas Debra Steger wrote a paper on the establishment of an international organization and submitted it to the Canadian government. Although many received the idea expressed in the paper skeptically, John Crosbie, the Canadian Trade Minister at the time, picked it up and lobbied for it on a high political level (VanGrasstek, 2013). In early April 1990 Crosbie sent letters to the other trade ministers of the Quad and to the GATT's DG. More significantly, at the Quad meeting in Puerto Callarta, Mexico from the $18^{\text {th }}$ until the $20^{\text {th }}$ of April Crosbie formally presented the idea to his peers in a paper that suggested the establishment of a "Multilateral Trade Organization" (MTO) (Stewart, 1993; VanGrasstek, 2013). ${ }^{31}$ In early July the idea even received support on the highest political level. At the Group of Seven (G7) Houston Summit the leaders of the seven major industrial democracies ${ }^{32}$ suggested to address "the concept of an international organization... at the conclusion of the Uruguay Round" (G7, 1990). Back in Geneva this happened a lot earlier when the EC submitted the first formal proposal for the creation of an organization in the context of the Uruguay Round negotiations. The proposal is dated July $9^{\text {th }}, 1990$ and was already discussed in the FOGS group during its meeting on June $25-26 .{ }^{33}$

\section{The Rationale Behind the Idea}

When tracing the rationale of the idea to create an international organization in charge of multilateral trade it becomes clear that it corresponds reasonably well to the underlying logic of the rational design framework. The general assumption was that a stronger focal entity than the GATT would be required to ensure stable cooperation in the context of a changing economic

${ }^{29}$ This negotiation group was in charge of the intuitional negotiations at the time.

${ }^{30}$ MTN.GNG/NG14/W/10, p.4

${ }^{31}$ Canada also lobbied for the organization in other forums, for example in May during another Quad meeting on ministerial level and also in September 1990 during a meeting attended by members of the Asia-Pacific Economic Cooperation (APEC) (Steger, 2000; VanGrasstek, 2013).

32 The G7 summit was attended by the Heads of State and Heads of Government of Canada, France, Germany, Italy, Japan, the United Kingdom and the United states, as well as the President of the Commission of the European Communities.

${ }^{33}$ MTN.GNG/NG14/W/42 
environment, and to deal with the increased scope and complexity of the trade regime that would result from the Uruguay Round. Jackson for example makes an explicit reference to the prisoner's dilemma of multilateral trade and was concerned that mutual defection could ensue under the existing GATT structure (Jackson, 1990). According to Jackson the GATT entailed several weaknesses that left trade cooperation unstable. These weaknesses could be traced back to the GATT's origin as a trade agreement that needed to replace an international organization when the ITO failed. They included: the fact that the GATT was only provisionally applied and allowed for GATT inconsistent domestic legislation; the difficulty to amend the GATT; the GATT's fragmentation that resulted from the Tokyo Agreement - including differences in dispute resolution and membership of the various plurilateral agreements; the fact that the powers of the CONTRACTING PARTIES as the GATT's main decision-making organ were unspecific and that decision-making procedures were not fully clear; the lacking effectiveness of dispute settlement procedures; and the GATT's ambiguous relationship with the IMF and the World Bank (Jackson, 1990). Jackson posited that the establishment of a stronger international organization would help to overcome these problems. In essence he called for more centralization to address a situation that could theoretically be described as enforcement problem - a high likelihood to defect on an agreement and increasing instability of multilateral cooperation.

It is hardly surprising that those who picked up on Jackson's idea to carry it into the realm of the Uruguay Round negotiations argued in a similar vein. Debra Steger mentions for example that the increasing scope and complexity of agreements negotiated during the Uruguay Round demanded for a stronger administrative structure. She points out that a "strong institutional structure, with a high degree of integration of its institutional mechanisms, particularly with respect to dispute settlement, was necessary to ensure that the rights and obligations of WTO Members were effectively administered and enforced" (Steger, 2000, p. 39). Also the paper presented by John Crosbie at the ministerial Quad meeting in April 1990 refers to protectionism, unilateralism and an increasing membership as challenges that require the establishment of an international organization (VanGrasstek, 2013). While the reference to protectionism and unilateralism corresponds to the rational design conjecture that links enforcement problems with centralization, the notion of an increasing membership suggests that considerations reflecting the conjecture that links an increase in number to higher centralization also played a role in the rationale to create an international organization. ${ }^{34}$

Also the EC's proposal that was submitted to the FOGS group corresponds to a functional account. According to the proposal the EC aimed to strengthen the GATT as an institution "to ensure that the future multilateral trading system will organizationally be able to administer the outcome of the Round in all areas effectively." ${ }^{35}$ More specifically the EC regarded the GATT's weak institutional basis as a problem that should be addressed. Furthermore the fragmentation

\footnotetext{
34 Jackson also made a reference to an increasing membership in his call for a "World Trade Organization" (1990).

${ }^{35}$ MTN.GNG/NG14/W/42, p.2
} 
of the trade regime was regarded as problematic and the EC wanted to embed the different plurilateral agreements in a common institutional structure to improve administrative effectiveness. It was also suggested to replace the different dispute settlement procedures of the plurilateral agreements with one unified dispute settlement system as a part of the organization. Furthermore, the EC argued that the GATT had obtained the status of a de facto international organization due to the creation of the TPRM in 1989, which extended the character of the GATT beyond being a contractual agreement. The EC also regarded the establishment of an organization as useful to clarify the relationship between agreements on trade in goods and trade in services: At the beginning of the Uruguay Round it had been agreed to negotiate goods and services in two parallel, but separate tracks. How these tracks could be implemented and what their relationship would be at the closure of the round was left open to be decided on a later date. According to the EC's argument an organization could house the goods and services tracks of the negotiations under a single roof, as much as it could serve as an umbrella for the plurilateral agreements. Finally, the EC argued that a new organization would be in a better position to intensify cooperation with the IMF and the World Bank. ${ }^{36}$

The link to TPRM and dispute settlement that is mentioned in the different suggestions for the establishment of an organization increase the plausibility of a rational account to explain the creation of the WTO further. As it will be shown in chapter 5 , the emergence of the TRPM can largely be understood as an attempt to increase transparency in the trade regime. This motivation can in turn be interpreted as corresponding to the rational design conjecture positing that centralization increases with uncertainty about behavior and as such the TPRM can be accounted for by a functional explanation. So the EC's argument that the creation of an organization should be considered because the establishment of the TPRM changed the nature of the GATT from being a contractual agreement into becoming an international body, indirectly supports the thesis that the WTO's creation is functionally motivated since the functionally motivated creation of the TPRM contributed to the rationale for the creation of the WTO.

Similarly, dispute settlement reform - as it will be shown in chapter 4 - was to a certain degree motivated by the desire to increase the effectiveness of the GATT's dispute resolution procedures and to strengthen its capability to enforce substantive agreements. While this is not the full account of dispute settlement reform, at least partially it can be considered as a functional response to an enforcement problem. As already suggested in the different proposals for the creation of an organization, the reform of dispute settlement was closely associated with the creation of an organization. According to an interview with a negotiator in charge of the institutional provisions (Int11) this link was strengthened to such a degree during the negotiations that Julio Lacarte, the chairman of the group in charge of institutional negotiations, at one point presented the creation of a unified dispute settlement system as conditional upon the creation of an organization. Thus, the link of dispute settlement reform and the creation of the WTO also indirectly strengthens a functional interpretation of the WTO's creation: if dispute

${ }^{36}$ MTN.GNG/NG14/W/42 
settlement reform can at least be partially understood as a response to an enforcement problem, and if this reform of dispute settlement contributed positively to the creation of an organization, the creation of the WTO can in this way also be indirectly understood as a response to an enforcement problem.

As it becomes clear from the account provided so far, the establishment of the WTO can be interpreted as being motivated by the desire to build a common house for all the different outcomes of the Uruguay Round ${ }^{37}$ : Most of the plurilateral agreements were multilateralized and integrated into the institutional structure of the WTO; this integration included the establishment of a unified dispute settlement system, applicable to all of the substantive agreements under the WTO's roof; the TPRM was permanently institutionalized in the organization; and the creation of the organization was an elegant solution to the problem of housing the different substantive areas of the Uruguay Round negotiations - goods, services, and intellectual property - whose relationship was not clarified at the beginning of the round ( $B$. Hoekman, 2009; Lacarte Muró, 2011; Steger, 2000). Having such a common house - i.e. a focal entity - was assumed to provide functional benefits in form of a stronger capacity to implement and administer the agreements under its roof.

Interpreting the WTO as a common house for the different outcomes of the Uruguay Round negotiations also explains the institutional architecture presented in the previous section: next to the General Council there is the TPRB and the DSB to provide for institutionalized reviews and the unified dispute settlement system. Covered by this, on the next lower level of the institutional hierarchy are the different councils for the different kinds of substantive agreements - the CTG, the CTS and the Council for TRIPS. While it is difficult to apply the conjectures of the rational design framework directly to this institutional architecture due to their abstract nature, the logical, apparently rational appeal of this architecture cannot be denied: A council, an information gathering body and a body for dispute settlement are at the top to ensure coherent administration, gathering of information, and enforcement of all the different agreements on substance. These different substantive agreements are in turn governed by separate subordinate bodies, which ensures adequate specialization. The claim that the WTO's institutional setup is functionally motivated is also supported by former EC negotiator Hugo Paemen, positing that the substantive "nature of the institution has also determined its administrative structure" (Paemen \& Bensch, 1995, p. 260). Paemen argues that having a general council at the top of the institutional structure is a logical institutional representation of the fact that all the different agreements of the trade regime rest on the same basic principles and that these agreements are in practice equivalent in terms of the obligations they put on the WTO's members. With the General Council at the top questions can be addressed that the individual councils in charge of the detailed administration of the separate agreements cannot address.

Other former negotiators have confirmed this position in interviews. One stated that

\footnotetext{
${ }^{37}$ This was also confirmed in interviews with former negotiators and secretariat numbers (e.g. Int07; Int08).
} 
"the nature of the mandate and the subjects that were covered are ultimately responsible for the creation of the WTO and the dispute settlement system as it exists now. [...] It almost lay in the logic of things that an organization should be there, which administers everything." (Int16)

Also John Weekes, former Canadian ambassador to the GATT, has pointed out that the suggestion to house the results of the different substantive negotiations under separate councils, which in turn would be grouped under the general umbrella of the WTO "was such a good practical suggestion that that's really when it began to become obvious that that was the way we are going to move." ${ }^{38}$

\subsubsection{Problems of Rational Design}

As appealing as the rational account seems to be, it is exactly when looking at the institutional architecture in further detail that the shortcomings of functional explanations become evident. The first section of this chapter has shown that the WTO is largely controlled by its members - all institutional bodies are open to the entire membership; decisions are taken by consensus, which implies that every member has the opportunity to veto a decision, and the Secretariat plays a relatively passive role. It is no secret that the WTO's performance, especially concerning its negotiation function, is inhibited by the strong emphasis that members put on keeping the organization 'member driven' and further delegation to the Secretariat would be functionally beneficial (Elsig, 2010a). Especially in the light of a trend towards a continously increasing memberhship, which was already forseable at the time of the Uruguay Round, the rational design framework suggests that centralization should increase to reduce transaction costs of decision-making and to facilitate implementation of agreements (Koremenos et al., 2001a).

Suggestions, based on functional reasoning to this effect were made at the time. In his proposal for the creation of an organization Jackson pointed out that the organization should include "a smaller body to act as more efficient guiding group for the organization, since the size of the GATT membership has now become such as to make such guidance difficult except through informal means which are sometimes resented" (Jackson, 1990, p. 95). Furthermore Jackson also criticized the decision-making processes of the GATT and called upon members to find a more adequate balance between consensus on all issues and the one-nation-one-vote principle (Jackson, 1990). These issues were considered during the Uruguay Round. The establishment of an institutional body with limited membership was discussed several times in the FOGS group, but failed to muster sufficient support (Croome, 1999). Also on the issue of decision-making, the first drafts of an organizational charter implied decision-making by consensus, but did not explicitly spell it out. The explicit provision to take decisions by consensus was only added in later versions (VanGrasstek, 2013). Furthmore, proposals in the FOGS group to increase the role of the Secretariat in the trade regime did not receive sufficient support (Xu \&

\footnotetext{
${ }^{38}$ Interview with John Weekes in the context of the WTO Creation Project. A video recording of the interview was retrieved from: http://www.wtocreation.org/en/videos?video=31171021
} 
Weller, 2004). So while rational design can reasonably account for the existing institutional design features that are of functional value, it faces its boundaries when asked for an explanation of those features that would have potentially provided further functional benefits, but failed to get approval despite having been considered.

As much as rational design is challenged by explaining why centralization did not go further, it is equally challenged by explaining why centralization did go as far as it did. The creation of the WTO was not a forgone conclusion and alternative proposals were made during the negotiations. At the time these proposals were assumed to reach the same goals as the creation of an organization and an organization as a common house to implement all the different Uruguay Round agreements was not regarded necessary by some parties. At the FOGS meeting where the EC presented the first proposal to establish an organization in June 1990 the US tackled the different arguments given in the EC's proposal to show that a formal organization would not be needed (Croome, 1999). The US argued that it would be possible to implement the different agreements that would result from the Uruguay Round without the creation of an organization. Furthermore, the US delegate pointed out that the GATT does not lack a proper institutional basis as the EC claimed. After all the GATT had a functioning secretariat and it had proven its ability to adopt, implement and interpret trade rules for more than 40 years already. Its institutional basis would also suffice to improve the cooperation with the IMF and the World Bank without creating an organization as long as there would be sufficient political will to do so. The US also regarded more political will as the key to end the fragmentation of the trade regime. It argued that the creation of an organization would not increase such political will and that it would not make countries accept agreements they would not want to accept. Similarly, including services agreements in the GATT was also a question of political will and contrary to the EC'S argument the US claimed that the GATT already had the legal means to integrate services into its framework. ${ }^{39}$ Finally, the US argued that a unified dispute settlement structure that would cover all of the separate substantive agreements could be established without the creation of an organization and that the negotiating group on dispute settlement was already discussing this. ${ }^{40}$ Later on the US delegation followed up on this reasoning in a non-paper in September 1990 which suggested to bundle all the different agreements under the aegis of the multilateral trade regime by use of a protocol (VanGrasstek, 2013). ${ }^{41}$ Assuming the validity of these arguments for now raises the question why the WTO was created, while apparently functionally equivalent alternatives existed.

The arguments against the creation of an organization indicate another weakness of rational accounts: They tend to suggest more homogeneity of interest than actually exists. Judith Goldstein (2002) has already pointed this out when examining the emergence of the GAT, and

\footnotetext{
${ }^{39}$ The US referred to the broad powers given to the CONTRACTING PARTIES under Article XXV of the GATT Agreement, to take decisions that "further the objectives of the Agreement."

${ }^{40}$ MTN.GNG/NG14/18

${ }^{41}$ The preferred use of a protocol approach was also confirmed by an interview with a US delegate, who participated in the institutional negotiations (Int09).
} 
the same seems to hold for the creation of the WTO. The US maintained its initially hostile reaction to the creation of an organization all the way towards the end of the Uruguay Round and only changed its position in the very last minute, right before the end of the negotiations (Croome, 1999). While being the most important the US was not the only party that reacted skeptically to the suggestion to create an organization. Many delegations had doubts when the EC introduced its proposal. They were concerned that discussions about an international organization would distract attention from important substantive negotiations. ${ }^{42}$ Facing such opposition, why did the idea to create an organization eventually succeed? And can this success be explained by factors that correspond to the rational design framework?

\subsubsection{Conclusion}

To recapitulate: It can be stated that rational design explanations seem adequate on a high level of abstraction. A connection can be made between the economic problems that led to the launch of the Uruguay Round and the creation of the WTO as an outcome of the round. However, this would overlook that the GATT's members did not intend to create an organization at the outset of the round. Tracing the emergence of the idea to create an organization is a first step to overcome this problem and shows that initial motives for the creation of the organization correspond reasonably well to the assumptions of rational design: Broadly speaking, the creation of an organization was regarded as a useful means to implement and enforce the various substantive agreements of the trade regime. The functional arguments for the initiation of the Uruguay Round and for the creation of an organization even supplement each other, since the notion of an organization as umbrella for different agreements on substance allows to connect the functional argument for the launching of the Uruguay Round to the one about the creation of the organization: The round was initially inspired by the desire to address the collective action problem of multilateral trade. This in turn required the negotiation of new and more complex substantive agreements and to increase the scope of the trade regime, which eventually introduced the necessity for a new organizational structure.

Nonetheless, while a functional account can capture the underlying, abstract idea to create an organization well, several problems remain. Rational design does not explain why the organization took the shape it eventually did in light of several (potentially more functional) alternatives; why the idea survived in light of serious opposition; and whether other factors than those suggested by rational design also influenced the organization's creation. Of course, one could counter this criticism by claiming that rational design is judged too harshly and that the criticism rests on a naïve interpretation of rational design. After all, rational design acknowledges the presence of factors that inhibit purely functional solutions to collective action problems, such as risk aversion, the necessity for policy compromises and obstacles to change resulting from existing path dependent institutional structures. However, it does not provide analytical tools that suggest how the balance between functionality and these competing factors is struck

\footnotetext{
${ }^{42}$ MTN.GNG/NG14/18; MTN.GN/NG14/W/44
} 
in institutional design. For this the process of institutional creation needs to be traced. A good starting point for this is examining the GATT's history. This also clarifies in how far the WTO's emergence can be interpreted as a single moment of institutional design.

\subsubsection{Design in Context: Historical Legacy}

Tracing the historical development of the trade regime from the emergence of the GATT in 1947 until the creation of the WTO in 1995 leads to the conclusion that one has to resist the temptation to interpret the creation of the WTO as a single moment of institutional creation or even revolutionary change. Of course, the increase in scope that came along with the Uruguay Round and the reform of dispute settlement can be described as revolutionary, but the WTO's administrative and decision-making structure can be interpreted as a formalized continuation of (informal) practices that developed incrementally throughout the GATT's history. The trade regime's institutional development towards greater centralization should be seen as a long-term process, with the creation of the WTO as a significant last step, a tipping point so to say. In line with the assumptions of historical institutionalism described in chapter 2 this process is characterized by path dependence and careful, incremental decisions of actors, who were content with satisfactory and not necessarily optimal institutional design. This sheds doubt on the assumptions of rational design, up to the point that institutional development of the trade regime is labeled at times as "institution building by accident" (Winham, 2008, p. 145).

While the emergence of the WTO was not an instance of accidental institution building, the claim that the WTO is strongly shaped by the GATT's incremental development is not a very controversial one. Hoeckman and Kostecki (2009) note for example that the "WTO builds on the organizational structure of the GATT and its Secretariat-to a significant extent it formalizes and extends the structures that had gradually evolved over a period of some 50 years" (p. 49). The WTO agreement itself provides the GATT's legacy even with legal relevance when noting in Article XVI.1 that:

"Except as otherwise provided under this Agreement or the Multilateral Trade Agreements, the WTO shall be guided by the decisions, procedures and customary practices followed by the CONTRACTING PARTIES to GATT 1947 and the bodies established in the framework of GATT 1947."

Negotiators of the WTO Agreement during the Uruguay Round also pointed out that the GATT's practices had a major influence on the WTO's institutional provisions. Negotiation committees requested the Secretariat to provide background papers about past GATT practices as input for negotiations. ${ }^{43}$ Furthermore negotiators stated that the creation of the organization

${ }^{43}$ For the negotiations on institutions examples of such papers include a background note on existing surveillance functions in the GATT (MTN.GNG/NG14/W/3); one on ministerial involvement in the GATT (MTN.GNG/NG14/W/4); one on the history of the Consultative Group of 18 (MTN.GNG/NG14/W/5); one about the review session that took place in 1954/55 (MTN.GNG/NG14/W/12); and one about notification procedures in the GATT (MTN.GNG/NG14/W/18). 
was mainly an exercise in codifying existing customs and traditions (Int01, Int09). One of them pointed out that at "the end of the day we were following extremely closely the existing practice. We didn't reinvent the wheel. The effort was to a very large extend to codify what had been existing practices under the GAT" (Int01). The main challenge in this exercise was to codify sufficiently and accurately without 'over-codifying' (Int01). As other negotiators and Secretariat members pointed out, in this process tradition played a strong role and negotiators tried to preserve those institutional structures that where perceived to function well (Int02, Int06, Int18), including intangible features such as "the spirit, the attitudes, and the philosophy" (Int07). Apparently negotiators "were very much in a GATT frame of mind. In those days we knew nothing else. So it was kind of a feeling that the GATT would continue" as a formally established organization (Int17).

Clearly, it can be posited that cognitive scripts resulting from experience with existing practices have influenced the administrative institutional structure of the WTO in a process that corresponds to cognitive forms of path dependency as described in chapter 2. A former negotiator summarized this nicely, pointing out that the WTO was "created by the people at the time who were immersed in the GATT culture" (Int17). From a different perspective, but also highlighting the impact of cognitive path dependence, another former negotiator pointed out that even those design features of the WTO that were intended to differ from the GATT were used by the membership according to behavioral patterns, norms and traditions that had evolved throughout the GATT (Int19).

Given this undisputable link between the GATT and the WTO, the interesting avenue to follow is the one that traces the GATT's development from its beginning up to the point when it reached the transition to the WTO. This provides an understanding of the institutional practices negotiators relied on and how they developed. In conducting such an investigation it becomes clear that the institutional structures of the trade regime are highly influenced by path dependency and incrementalism. Institutional designers had a large repertoire of existing GATT principles and practices at their disposal that they could build on to find new solutions to the institutional challenges at the time of the WTO's creation.

\subsubsection{The /TO and its Failure}

Any account of the GATT's institutional development needs to start with the event that necessitated such development: the failure of the ITO. Had the ITO come into existence as planned, the trade regime would have had a full-blown institutional structure to rely on right from the start. As it has been pointed out above, the attempted creation of the ITO can be understood as a response to the breakdown of economic cooperation in the 1930s and the desire to build up an institutional architecture for the regulation of international economic affairs after World War II. Initial ideas to create an institution responsible for the regulation of

At least one former negotiator explicitly pointed out in an interview that he heavily relied on such background notes (Int04). 
international trade date as far back as $1942 .{ }^{44}$ Several years of preparation and pre-negotiations followed ${ }^{45}$, before efforts to establish an international organization in charge of trade regulation culminated in the Havana Conference. At this conference delegations from fifty-six countries met between November 1947 and March 1948 to negotiate the Havana Charter for an International Trade Organization - the constituting document of the ITO (Wilcox, 1972).

Similar to the WTO, it would have been the main purpose of the ITO to ensure that the substantive provisions of the Havana Charter would become effective and be adhered to by the ITO's members. The ITO would have been a fully-fledged international organization covering a wide scope of substantive agreements. ${ }^{46}$ In doing so the ITO was supposed to fulfill several functions. It was supposed to administer the substantive provisions of the Havana Charter; foster consultations amongst its members; collect, analyze and distribute information about international trade; undertake studies on trade and related issues; propose trade policies and advise members on such policies; facilitate the negotiation of trade agreements and the resolution of disputes; and cooperate with other international organizations (Bronz, 1949; Wilcox, 1972). As stated earlier, the overall motivation underlying the Charter's purposes was to ensure long run, stable economic cooperation and trade patterns (Bronz, 1949; Wilcox, 1972). In line with this it is not surprising that the Charter displays a strong dedication towards economic liberalism, promoting free and non-discriminatory trade. However, it needs to be pointed out that the Charter's call for liberalism was not an absolute one. The Charter could rather be seen as an example of "embedded liberalism" (Ruggie, 1983), allowing for exceptions to liberal trade policies when certain conditions would be met (Wilcox, 1972).

The Havana charter clearly specifies the ITO's intended institutional structure. It provided for a Conference, an Executive Board, Commissions established as regarded necessary by the Conference, other organs if required, and a Director General and Staff (Art. 73). ${ }^{47}$ The Conference would have been the principal body of the organization, consisting of all members (Art. 74.1), meeting annually or for special sessions (Art.76.1). The Conference was empowered to ultimately determine the organization's policies (Art.77.1). It would also have acted as an appeals body for disputes (Art.95), which would be decided upon in first instance by the

\footnotetext{
${ }^{44}$ The roots of the idea can be found in a memorandum written by James Meade who worked for the UK's Economic Section of the War Cabinet Secretariat at the time. Meade wrote the memorandum in the context of US-UK negotiations of the Atlantic Charter. For a detailed Account see Irwin, Mavroidis and Sykes (2008)

45 Between 1943 and 1945 the US and the UK negotiated bilaterally about ways to govern international trade. This was followed in 1946 and 1947 by preparatory negotiations amongst 18 countries, which produced a draft charter suggesting the establishment of the International Trade Organization (Irwin et al., 2008).

${ }^{46}$ The substantive provisions of the Havana Charter were outlined in five chapters, dealing with employment, development, commercial policy, restrictive business practices and inter-governmental commodity agreements. Linking these issues in an international organization can be regarded as a significant intellectual innovation (Drache, 2000).

${ }^{47}$ The Charter also reserved a role for the International Court of Justice (IIC). After controversial discussions it was eventually decided during the ITO negotiations that the International Court of Justice (ICJ) could be asked for an advisory opinion on legal questions considering decisions by the Conference (Rubin, 1949). Although the ICJ would have been prohibited to provide advice regarding the economic issues of a dispute, its ruling on the legal issues under consideration would have been binding (Art.96).
} 
Executive Board (Art.94). Next to dispute settlement, the Executive Board would have been in charge for the execution of the ITO's policies and would have had further powers as delegated by the Conference (Art. 77.2 \& Art. 81.1). In contrast to the Conference membership in the Executive Board would have been restricted to eighteen members (Art. 78.1). Of the eighteen seats on the Executive Board, eight would have been reserved to the ITO members of chief economic importance as determined by the conference every three years by a two-thirds majority vote (Art.78.2 (c) \& Art.78.3 (a)). The other ten members of the Executive Board would also have been elected every three years by the Conference by a two-thirds majority (Art.78, 3 (b)). Overall broad geographical representation of membership would have been required for the composition of the Executive Board (Art. 78.2(a)). Next to the Conference and the Executive Board as fixed institutional bodies, the ITO was authorized to establish other institutional bodies, such as Commissions as it deemed appropriate (Art. 82). ${ }^{48}$ These Commissions would usually have had the purpose to deal with specific problems related to international trade. The Executive Board would have appointed members to such Commissions on the basis of expertise (Art. 83.1) and not as representatives of member states (Art. 88.2). For the day-to-day administration of the organization's policies the Charter provided for the position of a DirectorGeneral as chief administrative officer (Art. 84.1) and Staff working under the Director-General's supervision (Art. $85.1 \&$ Art. 85.2). The Director-General would have been appointed by the Conference upon recommendation of the Executive Board (Art. 84.1). Director-General and Staff would have worked in the capacity of international public servants and therefore would not have been allowed to receive instructions from governments (Art. 88.1).

In contrast to the two other economic organizations, the IMF and the World Bank, there would have been no weighted voting in the ITO. Both, in the Conference as well as in the Executive Board each member would have had one vote (Art. 75.1 \& Art. 79.1). If not specified differently in specific provisions of the Havana Charter, usually decisions in both bodies would have been taken by the majority of votes cast (Art.75.2 \& Art.79.2). Notable special majorities were the two-thirds majorities required for amendments (Art.100.1-2), for the election of members of the Executive Board (Art.78.2 (c) \& Art.78.3 (a)), and for decisions on waiving certain obligations the Charter imposes on a particular member (Art.77.3). Furthermore, whether one of the most important exceptions to the agreement - the balance-of-payments exception, allowing quantitative restrictions on imports - was granted would have depended on a decision taken by the IMF (Bronz, 1949; Wilcox, 1972). So, although the ITO would not have directly accounted for economic power in its voting structure, at least with respect to this exception weighted voting in the IMF would have influenced ITO policies (Wilcox, 1972).

\footnotetext{
${ }^{48}$ Regarding such commissions, negotiators considered to specify institutional provisions further, but decided against this. Bronz mentions for example that:
}

"During the negotiations, provision was made in various drafts of the Charter for specific commissions with responsibilities with respect to particular chapters of the Charter. However, it was finally decided to leave the particular decisions to the ITO, and not to tie its hands by too detailed administrative provisions." (1949, p. 1122) 
However, as it is well known the Havana Charter was never ratified, and the ITO consequently never came into existence. The factual account of the ITO's failure is relatively straightforward: After the US administration under President Harry S. Truman failed to muster Congressional support for the Charter in 1949 and 1950, Truman announced in December 1950 that the Charter would not be submitted again for Congressional approval. This marked the quiet, but definite end of the ITO, as without the US - being the economically most powerful and potential most important member of the organization - other countries also had no incentives to join the organization (Van den Bossche \& Zdouc, 2017).

Regarding the reasons for Congressional coolness towards the Havana Charter the account is more complex and it is difficult to single out one single explanation. Probably a mix of substantive and institutional features of the Charter, coupled with unfortunate historical circumstances led to the demise of the ITO. Regarding substance it was argued that the balance between liberal rules and exceptions to these rules in the Charter alienated both, business groups in favor of free trade and business groups in favor of protectionism, leaving relatively few groups outspokenly supporting the Charter and lobbying in Congress ${ }^{49}$ (Curzon \& Curzon, 1973; Diebold, 1993-1994, 2002). Furthermore, it is likely that the Havana Charter's large substantive scope deterred risk averse actors, due to the high likelihood of unintended consequences following from the establishment of the ITO (Jupille, Mattli, \& Snidal, 2013). This concern was reinforced by the ITO's institutional features. Due to the ITO's high degree of centralization and lack of formal recognition of US' supremacy in the organization it was expected that the ITO's establishment would entail high sovereignty costs for the US (Jupille et al., 2013). In an environment that was decreasingly supportive of international institution building at the beginning of the 1950s the lack of weighted voting amplified the negative sentiment towards a strong international organization (Hudec, 1990a; Jupille et al., 2013; Zamora, 1980). Arguments were made that the US would be left in a constant minority position, being unable to limit the abuse of exceptions to substantive provisions (Diebold, 1993-1994, 2002). Finally, the broader historical context needs to be considered as well to understand the demise of the ITO. While the immediate aftermath of WWII was regarded as an opportune moment to set up an organization for the regulation of international trade, notably three years had passed between the negotiation of the Havana Charter and the attempted ratification. In the meantime the Cold War had intensified, the outbreak of the Korean War demanded the attention of the US administration, the US faced a small economic recession in 1949, and Truman's Democratic Party had lost seats to the Republicans in the 1950 Congressional midterm elections. In this context the Marshal Plan and the North Atlantic Treaty Organization (NATO) promised

\footnotetext{
${ }^{49}$ While liberal groups where afraid that exceptions and escape clauses in the Charter were so numerous that the ITO would not be able to lead to more open foreign markets, protectionists in turn felt threatened by the foreign competition that the liberal principles anchored in the charter would have allowed for (Diebold, 19931994, 2002).

It is also considered that negotiators of the Charter did not sufficiently communicate and cooperate with domestic stakeholders during the negotiations, leaving the negotiators ill-informed on preferred substantive provisions and decreasing these stakeholders' committed to the charter (Odell \& Eichengreen, 1998).
} 
immediate political benefits in the international arena, while the ITO would only have provided such benefits in the long run (Diebold, 1993-1994, 2002). This led to the absence of policy entrepreneurs fighting for the establishment of ITO within the Truman administration and a lack of presidential leadership (Diebold, 1993-1994; Odell \& Eichengreen, 1998).

No matter which of these explanations is most important, the failure of the ITO had significant repercussions on the further development of the trade regime and thereby influenced the dynamics of institutional design and change considerably into the future. Along with the demise of the ITO, its clearly defined institutional provisions disappeared as well. Thus, the failure of the ITO necessitated the incremental institutional development of its replacement, the GATT. The following section examines this development.

\subsubsection{The Emergence of the GATT}

The failure of the ITO did not mark the end of the regulation of trade affairs on the international level, since the GATT was able to fill the gap left by the ITO. The GATT was negotiated parallel to the ITO negotiations and it was planned to eventually incorporate the GATT into the ITO. ${ }^{50}$ When the US administration published the "Proposals for the Expansion of World Trade and Employment" to set the foundation for the negotiation of the ITO, it also invited a group of fifteen countries ${ }^{51}$ to conduct negotiations on the reductions of tariffs. The rationale to negotiate tariffs ahead to the completion of the ITO negotiation lay in the assumption that the momentum for liberalization was highest right after WWII. It was feared that waiting with tariff negotiations for the establishment of an international organization would risk this momentum and that that protectionist pressures would then inhibit the negotiation of tariff concessions (Jackson, 1969). The decision to limit such negotiations to a small set of countries most relevant to international trade was taken because it was believed that negotiations would otherwise be hampered by the presence of "less important, and for the most part protectionist-minded states" (quoted in Irwin et al., 2008, p. 63). ${ }^{52}$ To ensure that the negotiated tariff concessions would not be breached, these negotiations were accompanied by

\footnotetext{
${ }^{50}$ The GATT's substantive provisions were largely overlapping with the provisions in the commercial policy chapter of the Havana Charter. Further provisions for automatic changes in the GATT were made so that it could be easily incorporated in the ITO upon the Havana Charter's entry into force (Dam, 1970; Jackson, 1969). The tariff concessions negotiated under the GATT would have been attached in a protocol to the ITO to provide more substance to those aspects of the Havana Charter that would have dealt with commercial policy (Irwin et al., 2008).

${ }^{51}$ The countries originally invited were: Australia, Belgium, Brazil, Canada, China, Cuba, Czechoslovakia, France, India, Luxembourg, the Netherlands, New Zealand, South Africa, the Soviet Union, and the United Kingdom. The Soviet Union never replied to the invitation.

${ }^{52}$ Quoted here is a suggestion by Canadian officials to US state department officials. The US state department endorsed this reasoning (Irwin et al., 2008). Thus, interestingly, one of the reasons for the GAT's emergence in its original form was the desire to avoid one of the major problems that besets the WTO today: the difficulty to negotiate agreements with a large number of actors. And indeed, decision-making in the early years of the GATT is generally characterized as relatively unproblematic. This is partially ascribed to the GATT membership being dominated by a small, exclusive group (Toye, 2003) of likeminded trade diplomats (Hudec, 1999a; Jackson, 1969).
} 
negotiations on a set of rules to safeguard the tariff concessions (Irwin et al., 2008). These rules constitute the nucleus of the GATT. ${ }^{53}$

The GATT was negotiated at the Geneva Conference of the Preparatory Committee for the ITO. ${ }^{54}$ The negotiations were already completed in October 1947, half a year before the end of the ITO negotiations. Despite the fact that the GATT was supposed to be incorporated into the ITO once the Havana Charter was ratified, it was decided to implement the results of the negotiations immediately. This was done for two reasons. First, in October 1947 it was expected that it would still take time until the ITO would enter into force. Waiting until then to give effect to the negotiated tariff concessions was considered disadvantageous due to potential disruptions of trade patterns that could emerge from a long time span between the agreement on tariff concessions and their entry into force. As Jackson (2006) puts it:

"Although these concessions were still secret, the negotiators knew that it was inevitable that their contents would begin to creep into public knowledge and, as they did so, traders would be influenced by them. Sellers might anticipate a forthcoming tariff reduction by holding back their product until the new tariff came into force. World trade patterns could thus be seriously disrupted if a prolonged delay occurred before the tariff concessions came into force." (p.94)

The second reason to immediately apply the GATT is to be found in the US administration's aim to circumvent Congress in the application of the GATT by joining the GATT under the provisions of the Reciprocal Trade Agreements Act (RTTA). The RTAA was introduced in 1934 to reverse the protectionist trend in US trade policies at the time and marked a significant shift in power from the legislative to the executive branch in trade policymaking, allowing increasing influence of export-oriented interest on US trade policy (Haggard, 1988; Irwin, 1998; Irwin et al., 2008; Winham, 2008). Under the RTAA the executive branch was essentially authorized to enter international trade agreements without congressional approval. Although the RTAA was renewed in 1945, it would have expired in 1948. So the US administration had to act before the expiry of the RTAA if it wanted to become a contracting party to the GATT without Congress' explicit permission.

While bypassing domestic legislative procedures in the GATT's implementation removed the US Congress as a significant veto point from many decisions on multilateral trade, it entailed serious repercussions for the GATT and its institutional development. First of all, it implied a

\footnotetext{
53 These rules aim to ensure adherence to tariff concession and the application of these concessions in a nondiscriminatory manner via the most favorite nation (MFN) principle (Jackson, 1969). Similar to the ITO the GATT entails a strong, but not absolute commitment to liberalism, leaving policy space to tailor free trade commitments according to domestic demands (Gorter, 1954). Being only concerned with trade barriers the GATT's rules had a much more limited scope than the ITO's, lacking provisions on employment, development, restrictive business practices and commodity agreements - whether that was a strength or a weakness was subject to debate at the time (Diebold, 2002; Gorter, 1954).

${ }^{54}$ Eventually the membership of the preparatory committee and of the negotiating parties during the GATT negotiations turned out to be identical.
} 
legally weak status. Some states that intended to become party to the GATT maintained laws that were not fully compatible with some of the substantive provisions of the GATT. Obviously, bringing such laws in accordance with the agreement would have required legislative action. This in return would have cost time and risked that domestic legislative processes would block the GATT. To avoid the necessity for changing domestic law it was decided to attach a protocol to the GATT, which specified that the agreement would only be applied provisionally - the Protocol of Provisional Application. This allowed for existing domestic laws to be inconsistent with most of GATT's substantive provisions, without a violation of these provisions (Dam, 1970; Irwin et al., 2008; Jackson, 1969). The GATT remained provisional throughout its entire existence.

Secondly, implementing the GATT under RTAA left it with hardly any institutional provisions. While the RTAA allowed the US' executive branch to enter trade agreements without congressional approval, it did not allow the President to create or to enter an international organization related to trade issues (Irwin et al., 2008; Jackson, 1967). "Congress made it very clear, in hearings with the US negotiators [...] that the president could not accept a GATT if it had attributes of an organization" (Jackson, 2006, p. 93). Consequently US negotiators felt the necessity to strip the GATT of all provisions that would have made it legally identifiable as an international organization (Jackson, 1969, 2006). And indeed, legally speaking, the GATT cannot be classified as an organization; it was merely an agreement, as its name suggests (Dam, 1970; Irwin et al., 2008). How careful the negotiators were to avoid the impression of the GATT being an organization is exemplified by the wording used in the agreement: signatories of the GATT are not called "members", but "contracting parties"(Irwin et al., 2008)..$^{55}$ Also the term "Interim Trade Committee" that is found in early drafts of the GATT and that denoted an institutional body to administer the GATT was changed during the negotiations to "CONTRACTING PARTIES acting jointly". The use of upper case when referring to "CONTRACTING PARTIES" indicated common action by the signatories without explicit reference to an institutional organ or membership (Dam, 1970; Jackson, 1969). When the reference was made to the "contracting parties" in lower cases it indicated that signatories to GATT act in their individual capacity (Jackson, 1969). This was done to maintain the possibility for the entire membership to act collectively while avoiding the impression that the GATT could be regarded as an organization.

Initially it was planned that the CONTRAACTING PARTIES would conduct basic administrative functions for the GATT until the ITO would be established. To do so the CONTRACTING PARTIES met annually or for special sessions. The CONTRACTING PARTIES consisted of representatives from all GATT members and where headed by a chairman selected from the membership. Analogous to the ITO provisions, each contracting party had one vote in the GATT (Art. XXV.3) and most decisions would have to be taken by majority of votes cast, unless specified differently in the agreement (Art. XXV.4). Notable special majorities are the two-thirds majorities for waivers freeing members from certain obligations imposed by GATT (Art. XXV.5), and the

\footnotetext{
${ }^{55}$ For reasons of convenience no such distinctions will be made in the following text. Signatories of the GATT will be referred to as contracting parties, parties, or members.
} 
provisions for amendments, which required - depending on the sort of obligations the amendment would relate to - either a two-thirds majority or unanimity (Art. XXX.1). However, in practice voting occurred rarely. The norm developed that decisions should be taken by consensus, which in theory provided each contracting party a veto right (Footer, 1997, 2006; Jackson, 1967).

The consequences of implementing the GATT under the RTAA had more serious implications than linguistic improvisation, since not all potentially useful organizational provisions could be covered up by the creative use of terminology and spelling. Consequently, such provisions had to be left out, leaving the GATT with almost no institutional architecture. Institutional bodies like a secretariat or an executive board were not mentioned at all in the GATT's text and only the "CONTRACTING PARTIES" resembled some form of institutional organ with decision-making capacity (Dam, 1970; Irwin et al., 2008; Jackson, 1969). This, and the fact that the CONTRACTING PARTIES were not in continuous session, inhibited functioning of the GATT significantly and necessitated the careful and incremental development of institutional procedures, whose trajectory would still be followed by the WTO.

\subsubsection{The GATT's Institutional Development}

Developing more institutional procedures than mentioned in the original GATT text was necessary because various substantive provisions implied that the GATT would carry out certain functions ${ }^{56}$ that required more sophisticated institutional structures than initially existed. The GATT text implies that the CONTRACTING PARTIES would carry out various tasks, such as taking decisions on waivers, amendments and accession. Furthermore, the CONTRACTING PARTIES were in charge of dispute resolution; they had the right to release members from substantive obligations when a member requested to make use of the exceptions listed in the GATT text; they were supposed to review member's behavior under the various reporting requirements listed in the GATT text; and the text refers to cooperation of the CONTRACTING PARTIES with the IMF. Finally, the CONTRACTING PARTIES also picked up the function to facilitate the negotiation of further trade liberalization early on in its history. Eventually the GATT proved itself and became the focal entity for multilateral trade cooperation for almost 50 years, acting as a forum for negotiations and trade policy consultations, a tool to facilitate the settlement of trade disputes, and a collector and distributer of information on trade related matters. However, the CONTRACTING PARTIES could hardly have achieved this without developing further institutional structures.

\footnotetext{
${ }^{56}$ The GATT text does not mention any functions explicitly, but Jackson identified three original functions implied in the agreement.
}

(1) The protection of the value of the tariff concession against "nullification" by various nontariff import barriers; (2) Establishing a "code of trade conduct" to channel protectionist devices away from certain types of barriers; and (3) The institution of consultation procedures and joint action to carry out the basic purposes of the agreement, i.e. the "organizational" functions." (1969, p. 29) 
The seed of this institutional development is to be found in the considerable ambiguity of the CONTRACTING PARTIES' mandate. Article XXV of the GATT elaborates on the possibility for joint action by the contracting parties and is the only article in the text that implies the existence of something like an institutional body (Jackson, 1969). This article can be regarded as one of the prerequisites enabling the GATT to develop further institutional structures (Davey, 2005; Jackson, 1969). Article XXV.1 is very broadly formulated. It states that:

\begin{abstract}
"Representatives of the contracting parties shall meet from time to time for the purpose of giving effect to those provisions of this Agreement which involve joint action and, generally, with a view of facilitating the operation and furthering the objective of this Agreement."
\end{abstract}

So, the article allowed the CONTRACTING PARTIES to take measures related to those provisions in the agreement that specifically define tasks of the CONTRACTING PARTIES, but even allowed for taking other measures as long as they facilitated the operation and further the objectives of the GATT. Thus, the authority Article XXV vested in the CONTRACTING PARTIES was very broadly defined, which left room for a wide ranging interpretation of the CONTRACTING PARTIES' powers (Jackson, 1969). Although the CONTRACTING PARTIES had to use this article carefully, to avoid sending the signal of being an international organization and triggering domestic opposition, Article XXV permitted the development of those institutional structures that enabled the GATT to fulfill the functions implied in its substantive agreements. ${ }^{57}$ In doing so the GATT acted pragmatically; those structures that were regarded necessary were established, while avoiding formal obstacles. This implied that the GATT continuously increased its degree of centralization to eventually turn into a quasi-international organization, whose structures heavily influenced those of the WTO. Corresponding to the first section, the following account of the GATT's institutional history is split up according to those developments that relate to pooling and those relating to delegation.

\title{
Pooling in the GATT
}

Considering pooling, the CONTRACTING PARTIES are at the core of the development of an institutional architecture that would eventually also characterize the WTO. Already during the negotiations for the GATT it was expected that the occasional meetings of the CONTRACTING PARTIES would not suffice to administer the general agreement satisfactorily. In anticipation of the necessity for taking decisions in between sessions the CONTRACTING PARTIES were allowed to make use of postal and telegraphic voting. ${ }^{58}$ This solution was not sufficient though to deal with important issues arising between sessions. For example, if a party felt the need to make use of certain exceptions permitted in the agreement, this could have required consultations according to the rule permitting the exception. If the reason for making use of the exception

\footnotetext{
${ }^{57}$ The establishment of the Council of Representatives was explicitly justified by reference to Art. XXV.1, for example.

${ }^{58} \mathrm{E} / \mathrm{PC} / \mathrm{T} / \mathrm{TA} / \mathrm{PV} 25$
} 
required urgent action, waiting for the next meeting of the CONTRACTING PARTIES to conduct these consultations would not have been a feasible option (Dam, 1970). Consequently, the CONTRACTING PARTIES started to develop institutional provisions to deal with matters arising in between sessions. This would eventually lead to a proper organizational structure.

That such a structure would emerge could have hardly been foreseen when the CONTRACING PARTIES took the first cautious step towards greater institutionalization. At the time many problematic issues that required consultations in between sessions were related to balance-of-payments matters. To address such matters the CONTRACTING PARTIES agreed in July 1949 to provide the Chairman of the CONTRACTING PARTIES with certain authorities to deal with balance-of-payments issues (Dam, 1970). ${ }^{59}$

\begin{abstract}
"The chairman was given the power to convene special sessions of the CONTRACTING PARTIES, to entrust consultations to an ad hoc committee and to canvass the contracting parties to obtain a consensus that consultations should be commenced in those circumstances where the General Agreement gave the initiative to the CONTRACTING PARTIES. In addition, a 'selected committee' was established for certain types of intersessional balance-of-payments consultations" (Dam, 1970, pp. 336-337)
\end{abstract}

One year later, in expectation of the failure of the ITO a working party established by the CONTRACTING PARTIES recommended that the GATT should establish a standing committee for intersessional business that would not only have been restricted to balance-of-payments issues. $^{60}$ However, the CONTRACTING PARTIES were too cautions to act upon this recommendation straightaway (Dam, 1970; Jackson, 1969). ${ }^{61}$ It took another year - when the ITO's failure had become evident - for the CONTRACTING PARTIES to agree to the establishment of an Intersessional Committee at their $6^{\text {th }}$ session (Dam, 1970; Jackson, 1969). ${ }^{62}$ Yet again, the CONTRACTING PARTIES acted cautiously and did not establish it as a standing committee, but limited its existence to the time-period between the sixth and the seventh session (Dam, 1970; Jackson, 1969). The Committee was supposed to prepare the agenda for the next session of the CONTRACTING PARTIES and to deal with "urgent intersessional business". ${ }^{63}$ Its membership was limited to seven GATT members, determined by the Chairman of the CONTRACTING PARTIES. This procedure was repeated for the time period between the CONTRACTING PARTIES' and $8^{\text {th }}$ session ${ }^{64}$, and between the $8^{\text {th }}$ and $9^{\text {th }}$ session. ${ }^{65}$ At the $9^{\text {th }}$ session of the CONTRACTING PARTIES in 1954/55 it was decided to make the Committee a permanent one (Jackson, 1969). The Committee's membership was increased to seventeen members that were elected at the last

\footnotetext{
${ }^{59} \mathrm{GATT/CP.3/50/Rev.1}$

${ }^{60} \mathrm{GATT} / \mathrm{CP} .5 / 49$; The report suggested that the standing committee should have a limited membership of 15 , but explicitly pointed out that it should not be regarded as having an executive function.

${ }^{61}$ GATT/CP.5/SR.25; It was decided to submit the report of the working party to governments.

${ }^{62}$ GATT/CP.6/SR.22; The intersessional committee was established despite the opposition of Czechoslovakia.

${ }^{63} \mathrm{GATT} / \mathrm{CP} .6 / 41$

${ }^{64}$ SR.7/13; Membership and functions are outlined in L/67/Rev.1. Procedures are described in L/74.

${ }^{65} \mathrm{SR} .8 / 21$
} 
CONTRACTING PARTY session of each calendar year. ${ }^{66}$ However, contracting parties that were not members of the Intersessional Committee or of its subsidiary bodies had the right to attend meetings as observers. Additionally, it was possible for non-members of the committee to still participate when they indicated a substantial interest in an issue and desired to be represented (Dam, 1970). The Intersessional Committee was chaired by the Chairman of the CONTRACTING PARTIES and met when called for by the Executive Secretary of the GATT. The Intersessional Committee was supposed to conduct business between the sessions of the CONTRACTING PARTIES and had the authority to deal with issues that the CONTRACTING PARTIES referred to it and with other matters requiring urgent action. For these purposes the Intersessional Committee also possessed the authority to establish working parties and it was allowed to provide the CONTRACTING PARTIES with recommendations on disputes that were referred to it (World Trade Organization, 1995).

The establishment of the Intersessional Committee was not the only institutional development that occurred during the $9^{\text {th }}$ session since the entire session was dedicated to reviewing the functioning of GATT, including institutional arrangements. In this respect the CONTRACTING PARTIES also undertook a second attempt to establish a proper international organization, the Organization for Trade Cooperation (OTC). To do so a working party was dedicated to work on institutional matters. This working party produced an "Agreement on the Organization for Trade Cooperation" to fill the institutional gap that was created by the ITO's failure and to overcome the shortcomings entailed by this failure (Bronz, 1956; Dam, 1970; Jackson, 1969). It was initially hoped for that the Intersessional Committee would simply facilitate the administration of the GATT until the OTC with a more solid, proper institutional structure could take over.

While the endeavor to create a proper organization sounds like a watershed development, the institutional provisions of the OTC closely resembled existing GATT practices. As such they exemplify the path-dependent, incremental character of the trade-regime's institutional development. The OTC would have consisted of an Assembly, an Executive Committee and a Secretariat (Art.4). ${ }^{67}$ The Assembly would mirror the CONTRACTING PARTIES. It would have been the supreme body of the organization, consisted of all members, who would have been the same ones as the contracting parties to the GATT. Like the CONTRACTING PARTIES, the Assembly would have gathered for annual meetings or special sessions (Art.5). The Executive Committee was planned to be very similar to the newly established Intersessional Committee, which in turn - as already mentioned - is an offspring of the incremental development of intersessional procedures. The Executive Committee would have been elected by the Assembly and would have consisted of seventeen members. ${ }^{68}$ Five of the seventeen seats on the Executive Board would have been reserved for those OTC members that had the highest shares

\footnotetext{
${ }^{66}$ SR.9/44

${ }^{67}$ Reference to Articles in this paragraph is according to GATT document L/327, Annex I.

${ }^{68}$ The original proposal of the draft OTC charter mentions 16 members of the Executive Council. This was changed to 17 , according to L/327/Add.1.
} 
in international trade. The other members would have been chosen periodically in such a way that the composition of the Committee reflected diversity in geographical location, degrees in economic development, types of economies and economic interests (Art.6a). The Committee would have exercised the powers and duties delegated to it by the Assembly. Decisions on which powers to delegate would have to be taken by a two-thirds majority in the Assembly (Art.6b). Debates about the powers of the Executive Committee also reflect the path dependent, incremental approach to institutional development in the trade regime, since the working party that drafted the OTC agreement suggested that the Assembly might initially take those powers and duties assigned by the CONTRACTING PARTIES to the Intersessional Committee as a guideline when deciding which powers and duties to delegate to the OTC's Executive Committee. ${ }^{69}$ The relation of the Executive Committee and the Assembly would also have been similar to the GATT's arrangements regarding appeals to the Assembly. Any OTC member would have had the right to appeal to the Assembly if it would not have agreed with a decision by the Executive Board (Art.6.c). Also with respect to decision-making there would have been large similarities since each member would have had one vote in the OTC's bodies (Art.8). Finally, the OTC agreement provided for a Director General, who would have been appointed by the Assembly (Art7.a). The Assembly would also have determined the powers and duties of the Director General (Art.7.a). The Director General would have been in charge of a secretariat (Art.7.c). ${ }^{70}$ As it will be shown below, in the section on delegation, this was also similar to the GATT's practices that had developed by then.

Since the creation of the OTC denoted a formal approach to create an international organization domestic legislative approval would have been necessary to establish the OTC. To increase the chances of ratification of the OTC agreement it entailed an explicit provision to shield sovereignty (Bronz, 1956). According to Article 3.d of the agreement the organization would have been prohibited to impose any new obligations on one of its members without agreement of that member or to amend the provisions of the GATT agreement. This provision turned out to be of no avail, since the OTC suffered the same fate as the ITO and did not get approval from the US Congress. The exact reasons for the OTC's failure do not seem to be very well documented, but John Jackson (1969) assumes that the reasons for it are to be found in a mix of protectionist tendencies and struggle for influence between the legislative and executive branch in the US.

${ }^{69}$ Report on the draft Organizational Agreement, L/327.

${ }^{70}$ Also regarding its functions the OTC would have been similar to those provided for the ITO in the Havana Charter and those that GATT would eventually take up. The OTC was supposed to administer the GATT; facilitate consultations and sponsor trade negotiations; conduct studies on issues related to international trade and make recommendations based on these studies; and to collect, analyze and publish information and data on international trade (Art.3). While the last two aspects on conducting studies and collection of information were provided for in the ITO, it should be pointed out that the systematic conduct of similar tasks occurred very late in the GATT's history as it is shown in chapter 5. In this respect the creation of the OTC would have denoted a significant development regarding such functions. 
When it became clear that the creation of the OTC would fail, attention was given to the improvement of the intersessional procedures once again (Dam, 1970) and in 1959 a special committee was setup to review the organizational structure of the CONTRACTING PARTIES (Jackson, 1969). ${ }^{71}$ Based on the recommendations of this committee, the CONTRACTING PARTIES decided in 1960 to terminate the existence of the Intersessional Committee and replaced it with the Council of Representatives. ${ }^{72}$ The Council differs from the Intersessional Committee in two significant ways, whose correlation is to be noted. First of all, its membership was not restricted. Every contracting party was allowed to be a member of the Council as long as it was willing to bear the responsibilities of membership. ${ }^{73}$ Even contracting parties that were not permanent members of the Council could be co-opted as a full member for certain sessions if they had a primary interest in the issues discussed at this session. The Council was presided over by a chairman, who was elected at the annual session of the CONTRACTING PARTIES. Debates about the Council's composition were controversial, since it needed to be decided whether the Council should be kept small for reasons related to efficiency or whether its membership should be universal to increase the likelihood that the CONTRACTING PARTIES would equip it with sufficient authorities. ${ }^{74}$ The fact that the debate eventually led to unrestricted membership, potentially at the costs of efficiency exemplifies the difficulty of establishing an institutional body that grants some countries the privilege of membership while denying it to others in a well-established institutional context were all players are used to the right of participating in all institutional bodies.

As just pointed out, the negotiation history of the Council indicates that the increase in membership was a prerequisite for the second feature that distinguished it from the Intersessional Committee: ${ }^{75}$ It was significantly more powerful (Dam, 1970). Authorities of the Council entailed the ability to setup its own subsidiary bodies and to elect its own officers. The Council was supposed to deal with issues that required urgent attention, report to the CONTRACTING PARTIES and recommend how they should act - including recommendations on dispute resolution and waivers, supervise the work of subsidiary bodies established by the CONTRACTING PARTIES, and prepare the sessions of the CONTRACTING PARTIES. Furthermore, the Council had the right to

"... deal with such other matters with which the CONTRACTING PARTIES may deal at their sessions, and to exercise such additional functions with regard to matters [...] as may be expressly delegated to it by the CONTRACTING PARTIES, including action on behalf of the CONTRACTING PARTIES, in performing functions under the provisions of the General Agreement, other than action under paragraph 5 of Article XXV, and under

\footnotetext{
${ }^{71}$ L/1200; L/1216; W.16/15; W.16/15/Corr.1

${ }^{72}$ SR.16/11

${ }^{73}$ Originally contracting parties that desired to be members of the Council had to be willing and able. The words 'and able' were removed from the decision to establish the Council; W.16/15/Corr.2

${ }^{74} \mathrm{~L} / 1200 ; \mathrm{L} / 1216 ; \mathrm{SR} .16 / 11$

${ }^{75} \mathrm{~L} / 1200 ; \mathrm{L} / 1216$
} 
decision and other formal actions taken by the CONTRACTING PARTIES." (World Trade Organization, 1995, p. 1100-1001)

Thus, the possibility to delegate authorities to the Council was only limited by the exemption on the decisions on waivers, which were explicitly reserved to the CONTRACTING PARTIES. In 1968 the Chairman of the CONTRACTING PARTIES reminded the GATT membership of this and suggested that the CONTRACTING PARTIES would only focus on issues of major importance to shorten the agenda for the sessions of CONTRACTING PARTIES in light of an increasing GATT workload. The CONTRACTING PARTIES agreed to this suggestion and since "that time, the Council has handled all business other than final decisions on waivers." (World Trade Organization, 1995, p. 1101). Kenneth Dam (1970) notes that the Council became "the central organ of the GATT" and that sessions of the CONTRACTING PARTIES turned "into appellate bodies for issues that are too delicate or too important to be definitively resolved by operationlevel civil servants" (p.339). Clearly the creation of the Council with its wide ranging authorities significantly facilitated the operation of the GATT (Jackson, 1969).

Decisions to be taken in the Council required the same amount of majorities as those that would be required in the CONTRACTING PARTIES. But analogous to the CONTRACTING PARTIES decisions in the Council were taken by consensus. Decisions taken by the Council could be appealed to and referred to the CONTRACTING PARTIES, in case a member felt adversely affected by them.

With the creation of the Council the core organizational structure of the GATT had been established and only one mentionable change to this structure occurred at the Uruguay Round's midterm review in 1988, when it was decided that every second year the CONTRACTING PARTIES would meet at ministerial level. Kenneth Dam goes so far to say that "the creation of the Council has permitted the GATT to complete its transformation from a collegial body meeting at widely spaced intervals to a fulltime international 'organization'”' (Dam, 1970, p. 339).

This transformation exemplifies the dynamics of change in the trade regime. The GATT changed carefully and incrementally until it eventually turned into a quasi-international organization. The process of change corresponds to rational design in so far as every step taken can be regarded as a functional response to a perceived problem. However, at the same time these responses were constrained by the circumstances of the institutional context, which facilitated an incremental and path-dependent development. Functionally speaking each step in the development of political bodies was motivated by the desire to give effect to the substantive agreement of the GATT and to address challenges like the failure of the ITO, the OTC and an increasing workload of the GATT that came with an increase in membership. At the same time this process took place without explicit treaty authority ${ }^{76}$ and each step of this institutional development had to be taken carefully to avert hostile reactions by members' domestic legislative bodies, especially the US Congress. This form of path dependent development was

\footnotetext{
${ }^{76}$ Jackson considers the development of institutions to give effect to a treaty that does not provide for the development of such institutions a precedent in international law (1969).
} 
facilitated by lock in effects: When the ITO was negotiated the creation of a powerful Executive Board would have been possible. After this, the institutional development indicates how difficult it is to centralize in form of creating strong institutional bodies with limited membership in an institutional context where actors are used to participate in all bodies. Early bodies with limited membership like the Intersessional Committee had limited powers and with an increase in authority came an increase in membership. While the OTC provided for an Executive Committee it would have been considerably less powerful than the Executive Board of the ITO (Bronz, 1956). By the time the Council was created increasing powers came at the price of efficiency in form of unconditional membership as indicated by its negotiation history. Clearly the institutional structures described so far did not emerge from a single moment of rational design and are characterized by a mix of functional intentions compromised by path dependence and political struggles. This dynamic would continue even after Kenneth Dam's assessment of the GATT's transformation into an international organization.

When the global economic situation was tense in the beginning of the 1970s due to the breakdown of the Bretton Woods system and the first oil crisis, the Director General at the time, Olivier Long, initiated the establishment of the Consultative Group of 18 (CG.18). After intense consultations with GATT members in 1973 and 74, Long submitted a note to the Council in July 74 that suggested creating a small body of high level officials to facilitate the management of the GATT. ${ }^{77}$ After difficult negotiations about the composition of such a body (Blackhurst \& Hartridge, 2004) ${ }^{78}$, the Council established the CG.18 in July $1975 .{ }^{79}$ While Long hoped that the CG.18 would eventually develop a stronger role in the management of the GATT, it was initially supposed to "discuss trade problems from a political viewpoint, anticipate development and facilitate the 'concentration of policies in the trade field"' (Blackhurst \& Hartridge, 2004, p. 714). In doing so the CG.18 was supposed to have a purely advisory function that was explicitly prohibited to infringe on any authorities of the CONTRACTING PARTIES or the Council, and it had no power to take decisions. ${ }^{80}$ Many members of the group were represented by officials at Deputy Minister level (Blackhurst \& Hartridge, 2004). ${ }^{81}$ Considering the group's composition, its name is slightly misleading. The group consisted of 18 full members that were allowed to be represented by two people and nine alternate members that were allowed to be represented by one person. Additionally the EC and its members counted for one of the 18 full members although the EC's members accompanied the EC's delegate to the meetings and each of them had two seats as well (Blackhurst \& Hartridge, 2004). So in essence the membership was significantly larger than 18 . The membership was approved annually by the CONTRACTING

${ }^{77} \mathrm{~L} / 4048$

${ }^{78}$ Also: MTN.GNG/NG14/W/5

${ }^{79} \mathrm{C} / \mathrm{M} / 107$

${ }^{80} \mathrm{~L} / 4204$

${ }^{81}$ According to the GATT Secretariat (MTN.GNG/NG14/W/5) not all members followed the original intention of sending high level officials from capitals to the meetings of the group. In such cases delegates from Geneva attended the group's meetings. 
PARTIES and was supposed to rotate 'as appropriate'.$^{82}$ The group was allowed to select its own chairman and decided for the GATT's Director General as Chair. ${ }^{83}$

The CG.18's creation and history resembles a similar mix of functional intentions constrained by institutional context that had characterized the GATT's institutional development previously. Clearly the original intentions of the DG when suggesting to create the group seem to correspond well to the conjectures of rational design. The underlying motivation was to increase the efficiency of the GATT's operation in the fragile economic context of the 1970s and Long anticipated that the group would become increasingly influential after its establishment (Blackhurst \& Hartridge, 2004). ${ }^{84}$ One of the DG's arguments in favor of the establishment of the CG.18 resembles the rational design conjecture that centralization increases with number. As Long pointed out in his proposal for the establishment of the CG.18:

"Since the GATT came into effect, the number of contracting parties has increased from 23 to 83, while the Council now numbers some 60 members. These two organs continue to retain their full competence and authority, but it can reasonably be argued that the nature of their functions and their continually growing membership preclude the possibility of their operating with the required flexibility and the speed as compact, dynamic bodies specifically geared to anticipating, and if possible forestalling, emergencies in the trade field, or confronting such emergencies if they arise." ${ }^{85}$

However at the same time the establishment of the CG.18 was compromised by existing institutional structures. First of all, its establishment was similarly cautious and incremental as the emergence of intersessional procedures. Initially the CG.18 was established provisionally for one year. In 1976 it was decided to renew its mandate for another year and in 1977 it was decided that the CG.18 should stay in place until the end of the Tokyo Round. Only in 1979 the Council decided to establish the group as a standing GATT body. ${ }^{86}$ Secondly, the group's composition and mandate resemble the interrelation of power and size that already characterized the earlier developments of the GATT's institutional bodies. Establishing the CG.18 with its limited membership was only possible in such a way that its existence would not question the authorities of previously established institutional bodies, as mentioned above. The importance of this is not only exemplified by that fact that it is explicitly mentioned in the group's mandate, but also by the development of its name. The name originally suggested in Long's proposal was "Management Group"; which was changed to "Consultative Group" to underline that the group would not have any decision-making powers (Blackhurst \& Hartridge, 2004). Also debates about its composition resemble the previously described difficulties to create institutional bodies with limited membership in an existing institutional context that

\footnotetext{
${ }^{82}$ MTN.GNG/NG14/W/5

${ }^{83}$ MTN.GNG/NG14/W/5

${ }^{84}$ According to former Secretariat members, the initiation of the CG.18 was inspired by the example of the executive boards of the IMF and the World Bank (Int06, Int08).

${ }^{85} \mathrm{~L} / 4048, \mathrm{p} .8$

${ }^{86}$ MTN.GNG/NG14/W/5
} 
grants all parties access to all institutional bodies. As pointed out earlier, membership of the CG.18 was a lot larger than its name suggests. If one adds up the number of full members, the EC's members and alternate members, the group consisted of 36 members at the time of its establishment - twice as many members as foreseen for the ITO's executive board. The comparison to the Council where approximately 60 countries regularly participated at the time puts the exclusivity of the CG.18 into perspective. Despite this and despite the group's limited powers, membership stayed a controversial issue throughout the group's history. In 1985 the group got under high pressure to increase its membership ${ }^{87}$ and it was agreed to increase the amount of full members from 18 to 22 (Blackhurst \& Hartridge, 2004). After this decision the group ceased to exist. It was not terminated, but simply did not meet again. Its disappearance can largely be ascribed to the membership issue. For some it had always been too large to be effective and too small to be representative (Blackhurst \& Hartridge, 2004; Croome, 1999; Zutshi, 2001). ${ }^{88}$ This was certainly reinforced by the decision to increase its membership.

The bodies described so far were at the upper levels of the institutional hierarchy and covered all matters that arose under the GATT. Except for the CG.18 they would become important building blogs that the Uruguay Round's institutional negotiators relied on when creating the WTO, reinforcing the thesis that the WTO's emergence had a path dependent character. This is strengthened further by other institutional developments on a lower level in the GATT's hierarchy. Throughout its history the GATT established ad hoc working parties and committees. Some of them became standing bodies that were directly incorporated in the WTO's structure.

Working parties or committees were usually established at sessions of the CONTRACTING PARTIES, by the Intersessional Committee, or by the Council to study a particular issue of interest to the contracting parties and to report on that issue (Jackson, 1969). They count as instances of pooling, because contrary to the provisions in the ITO, the members in a committee or working party usually were participating in their function as representatives of a particular contracting party and not as neutral experts (Jackson, 1969). Most of these bodies were only temporary and their establishment can be regarded as a response to a particular interest of the contracting parties (Jackson, 1969). During negotiation rounds for example a trade negotiations committee is established to administer the negotiations. This ceases to exist after the completion of a round. However, some of the committees turned out to become permanent bodies. The GATT's Analytical Index lists four principal standing bodies established in the GATT: The Committee on Balance-of-Payments restrictions; the Committee on Budget, Finance and Administration; the Committee on Tariff Concessions; and the Committee on Trade and Development (World Trade Organization, 1995).

From the very first negotiations of the multilateral trade regime's institutional structures balance of payments (BoP) exceptions belonged to the most important features the regime's members paid attention to (Dam, 1970; Irwin et al., 2008; Wilcox, 1972). To provide the

\footnotetext{
${ }^{87}$ Discussions in the Council exemplify the controversy about membership, see C/M/194.

${ }^{88}$ This was also confirmed in interviews (Int06, Int17).
} 
opportunity for the necessary consultations that were required to make use of BoP exceptions specified in the general agreement, ad hoc working parties were setup from 1949 onwards already and also the Intersessional Committee was at times in charge of BoP consultations (Jackson, 1969). In 1956 a Consultations Committee was setup for the purpose of dealing with BoP issues, before in 1958 - after initial hesitation due to sovereignty concerns - the decision was taken to establish the Committee on Balance-of-Payments as a standing body (Jackson, 1969). The BoP Committee was in charge of consultations on BoP related matters and reported back to the Intersessional Committee, the Council and the CONTRACTING PARTIES. The Committee on Budget, Finance and Administration also has its roots in ad hoc working parties, which were annually established by the CONTRACTING PARTIES to review the budget and examine administrative issues. In 1962 the Budget Committee was established as a standing body. It reported its findings to the Council and sometimes made recommendations. There were no specific regulations on the membership of this committee, but it was usually kept small and its composition was open for changes (World Trade Organization, 1995). The Tariff Concessions Committee was established in 1980 upon recommendation of the Director General. ${ }^{89}$ It was supposed to facilitate the implementation of results of the Tokyo Round by keeping tariff schedules up to date, supervising the staging of tariff reductions, and providing a forum for discussion on tariff related questions. Composition of the Committee was determined by the Council (Stewart, 1993). The Committee on Trade and Development was established in 1965, in anticipation of the amendment that added Part IV to the GATT to incorporate development issues more explicitly into the GATT. ${ }^{90}$ The Committee on Trade and Development took over from "Committee III" which was established as result of a report from 1958 that investigated how the interests of developing countries could be promoted in GATT. ${ }^{91}$ It had the task to facilitate the implementation of part IV, which was aimed at strengthening the position of developing countries in the GATT. ${ }^{92}$

All of these bodies and some of the bodies established under the Tokyo Round's multilateral agreements have their counterparts in the WTO. Also some of the tasks of working parties that were established under the GATT were continued by corresponding working parties established

\footnotetext{
${ }^{89}$ L/4884/Add.1; SR.35/5

${ }^{90}$ Part IV entails an article that calls on the CONTRACTING PARTIES to "establish institutional arrangements as may be necessary to further the objectives set forth in Article XXXVI and to give effect to the provision of this part" (Art. XXXVIII.2 (f)). Considering that by that time the CONTRACTING PARTIES had already developed a habit of establishing institutional arrangements to fulfill the demands of substantive provisions, the implications of the article does not seem groundbreaking. However it should be pointed out that this is the only article in the agreement that explicitly and directly refers to the authority of the CONTRACTING PARTIES to develop institutional structures for the GATT (Jackson, 1969). Part IV became effective in 1966. In anticipation of this the CONTRACTING PARTIES replaced Committee III with the Committee on Trade and Development already in 1965.

${ }^{91}$ In light of an increasing membership of developing countries, a panel of experts was asked to investigate how the standing of developing countries could be improved in the GATT. The resulting report that the panel produced is known as Haberler Report, named after the chairman of the panel.

${ }^{92}$ The amendment of the GATT needs to be understood in light of the political circumstances at the time, when Developing Countries got increasingly dissatisfied with their standing in international economic affairs and initiated the creation of UNCTAD.
} 
under the WTO. Transitional arrangements to avoid procedural and institutional duplications were agreed on in the transition period between the GATT's termination and the WTO's entry into force. ${ }^{93}$ This indicates the institutional continuity between the GATT and the WTO. The same continuity for bodies that are instances of pooling can also found in the main institutional arrangements counting as delegation - the GATT Secretariat.

\section{Delegation in the GATT}

The GATT agreement mentions no provisions for a secretariat or related institutional provisions. This was another consequence of the GATT's emergence without domestic legislative approval, as explained above. Surely, reference to a secretariat would have implied characteristics of an international organization. The only hint towards secretarial services provided in the original GATT text are references to the Secretary-General of the United Nations, which were included to regulate depositing multilateral agreements and to call the first meeting of the CONTRACTING PARTIES (Jackson, 1969). To ensure that the necessary, basic secretarial services would be provided despite the lack of institutional provisions the CONTRACTING PARTIES acted pragmatically and requested the Interim Commission for the International Trade Organization (ICITO) to provide such services. What started as a tentative arrangement would continue throughout the GATT's entire lifespan. An entity legally external to the GATT became its permanent secretariat and while its structure was extremely rudimentary at the beginning, it would incrementally develop and become integrated in the WTO. In the course of this development the tasks, size and budget of the Secretariat continuously increased, while remaining limited in comparison to other international organizations. The Secretariat's history exemplifies the same tension between rational, functional design and the obstacles posed to this design by the given historical and institutional context that already characterized the development of the institutional structures related to pooling.

The roots of the Secretariat's development are to be found in the negotiation history of the ITO when the ICITO was created. In March 1948 at the Havana Conference, those states that negotiated and singed the ITO Charter decided to establish the ICITO (World Trade Organization, 1995). Its original purpose was to prepare the Havana Charter's entry into force. Upon the formal establishment of the ITO the ICITO was supposed to be dissolved. ${ }^{94}$ To perform its functions the ICITO established a secretariat, headed by an Executive Secretary. The first Executive Secretary of the ICITO was Eric Wyndham White, who was appointed at the ICITO's first meeting and who in turn appointed the necessary staff to fulfill the ICITO's functions.

\footnotetext{
${ }_{93} \mathrm{PC} / 11, \mathrm{~L} / 7582$

${ }^{94}$ The ICITO's structure mirrored that of the ITO. Formally it consisted of the Havana Charter's Signatories, but provisions were made for and Executive Committee of 18 members. The Executive Committee in turn would select and Executive Secretary who would be in charge of the composition of his staff. This staff would consist of neutral, international public servants, selected based on expertise. The ICITO only met once to establish the Executive Committee. During this meeting the ICITO delegated all its powers to the Executive Committee. The Executive Committee only met rarely and its main function was to select its Executive Secretary (World Trade Organization, 1995).
} 
However, the ICITO's Secretariat went beyond its main function and also lent its service to the GATT. The preparatory work for the Havana Charter indicates that the ICITO Secretariat was permitted to provide services to the CONTRACTING PARTIES, who quickly decided to make use of this opportunity (World Trade Organization, 1995). Already at their second session in 1948, the CONTRACTING PARTIES requested the provision of the ICITO's Secretariat services and the provision of such services is noted in the rules of procedure of the CONTRACTING PARTIES (World Trade Organization, 1995). This is how a formally external institution became the GAT's Secretariat. Once more the GATT ensured the provision of basic, but essential institutional structures without legal connotations of being an international organization. Since the establishment of the ITO was still expected at the time, this arrangement was only thought to be of temporary nature, but eventually became permanent.

A legal argument can be made that in theory the CONTRACTING PARTIES would have been permitted to establish its own secretariat based on the broad authorities of article XXV (Jackson, 1969) However, the GATT was cautious and eager to maintain the facade that it is not an international organization. And since the arrangements for the provision of secretariat services that had been made proved to function, the CONTRACTING PARTIES did not make use of this option by the time it turned out that the ITO was doomed to fail. In fact, in 1951 a GATT working party recommended in its report for the Continuing Administration of the General Agreement that the GATT should continue to utilize the services of the ICITO and wait for the establishment of more permanent arrangements "until such time as the Contracting Parties are in a position to accept permanent arrangements." ${ }^{\prime 95}$ In this context it was also decided in 1951 to finance the ICITO by contributions from the contracting parties. Previously this had been done by loans from the UN Working Capital Fund (Curzon \& Curzon, 1973; Xu \& Weller, 2004). ${ }^{96}$ Ever since then ICITO Secretariat has fulfilled no other functions anymore than working for the GATT (Jackson, 1969). Since an attempt to establish secretarial structures more formally within the GATT failed with the failure of the OTC, this arrangement continued throughout the GATT's entire lifetime.

Some changes took place that contributed to the formalization of the Secretariat's position within the GATT - especially that of its chief officer - but that did not alter the situation that legally it was the ICITO providing for the Secretariat. In 1957 an amendment to the GATT took effect $^{97}$ that replaced some of the references in the GATT text to the Secretary-General of the United Nations with references the Executive Secretary of the Contracting Parties. From that time onwards the role of the Executive Secretary was formally anchored in the GATT text (Jackson, 1969). In March 1965 the CONTRACTING PARTIES decided to change the name of the Secretariat's chief officer from Executive Secretary to Director General. ${ }^{98}$ This was probably done to increase the rank and prestige of the GATT's chief officer (Jackson, 1969). To avoid legal

\footnotetext{
${ }^{95} \mathrm{GATT} / \mathrm{CP} .6 / 41$, p.3

${ }^{96}$ In 1953 the CONTRACTING PARTIES decided to pay the UN for the secretariat services provided prior to

${ }^{97}$ The amendment was agreed to in 1955 (Jackson, 1969).

${ }^{98}$ W.22/12
} 1951. 
complications and the necessity to amend the GATT the CONTRACTING PARTIES acted pragmatically. They simply decided that it would be the same person, who would hold the three legally different positions that existed by March 1965 - the one of the Executive Secretary to the ICITO, the one of Executive Secretary to the Contracting Parties, and the one of Director General (Jackson, 1969). This implied that the CONTRACTING PARTIES appointed the Director General, but that formally the Executive Committee of the ICITO had to confirm this appointment (World Trade Organization, 1995). In practice the legal distinctions between the different positions has basically been ignored and the ICITO Secretariat has been essentially regarded as the GATT'S Secretariat.

Other changes were more pragmatic in nature and relevant for the Secretariat's operation. Remarkable in this respect is the Secretariat's growth in terms of size, budget and organizational structure that occurred throughout the years. Xu and Weller (2004) provide an overview of this growth. In terms of size they show that the amount of permanent employees increased from initially 10 , to 58 by the end of the 1950s, to 214 by late 1960 's and 300 by 1985 . Also the budget of the Secretariat increased throughout the years. In 1949 it operated on a budget of $70000 \$$. This increased to $686898 \$$ by 1960 and 3.4 million dollars by 1970 . This trend continued and throughout the last decade of the GATT the Secretariat's budget grew by $7 \%$ annually (Xu \& Weller, 2004). The Secretariat also became more elaborately structured throughout the years. By early 1960 it consisted of three units - in charge of information and library services, language services, and administrative and financial services respectively - and two divisions - the trade policy and the trade intelligence division, which were coordinated by the Office of the Executive Secretary. The amount of divisions increased to 6 by 1970 and 16 by 1987 . Five more division level units were added until 1994 (Xu \& Weller, 2004).

An argument can be made that these developments were to some extent functionally motivated, corresponding to the needs that arose from an increasing membership and the regime's expansion in terms of functions and scope (Curzon \& Curzon, 1973; Xu \& Weller, 2004). A few examples exemplify this point, showing that the Secretariat's evolution can be interpreted as the operational supplement to developments in the regime at large. It was the GATT's response to the OTC's failure for example that let the same special committee, which led to the establishment of the Council to also suggest an enlargement and strengthening of the Secretariat to ensure the GATT's functioning. ${ }^{99}$ Considering the increase in organizational structures and tasks, the increased attention that was paid to the needs of developing countries in the late 1950s and early 1960s led the Secretariat to take up tasks that could be labeled as technical assistance, to the creation of a development division, and to the establishment of the International Trade Center (ITC) for example (Xu \& Weller, 2004). Another example is the decision that the Secretariat would support the administration of the plurilateral agreements resulting from the Tokyo Round by providing services to the institutional bodies established by these agreements (World Trade Organization, 1995). The Tokyo Round led also to an increase in

${ }^{99} \mathrm{~L} / 1216$ 
the Secretariat's role regarding the monitoring of the trade regime, which was increased much further during the Uruguay Round as it is shown in chapter 5 . Also the creation of the legal affairs division in 1981 serves as an example of the Secretariat's development as functional response to necessities arising from a changing trade regime. As pointed out by Marceau, Porges and Baker (2015) the establishment of this division was regarded as necessary to support panels that struggled with the increasing complexity of disputes (Porges, 2015). Finally, regarding the GATT's negotiation function the Secretariat's role increased as well, due to an increasing complexity of negotiations (Winham, 2006). ${ }^{100}$

However as much as this development can be interpreted as the response to functional demands of the trade regime, this should not be equated with an ideal correspondence to predictions of rational design. After all, the Secretariat's development was significantly hampered by obstacles emerging from the institutional and historical context it was embedded in. First of all, despite its growth the Secretariat remained small in comparison to the secretariats of other international organizations and struggled with the relatively limited amount of resources at its disposal. Part of its growth in budget needs to be accounted for by inflation and the contracting parties increased the Secretariat's resources only reluctantly (Curzon \& Curzon, 1973; Dam, 1970; Xu \& Weller, 2004). The call to strengthen the Secretariat made by the special committee in 1960 for example was only agreed to in principle, and it was explicitly pointed out that this would not imply the implementation of specific plans for the recruitment of new staff by the DG. Such recruitment "would proceed over a period and in accordance with authority agreed by the CONTRACTING PARTIES from time to time." ${ }^{101}$ The Secretariat's budget remained small despite its growth, probably due to its uncertain legal basis and improvised origin. This fostered an institutional culture that cherished a small Secretariat, which was reinforced by a general unwillingness of contracting parties to provide more resources (Jackson, 1969; Xu \& Weller, 2004). Furthermore Xu and Weller point out that the Secretariat "seldom asked for an increase in its budget mainly to avoid confrontations with the contracting parties" (Xu \& Weller, 2004, p. 88).

100 In the early rounds the role of the Secretariat was minimal as it was just supposed to provide "appropriate assistance" to the parties negotiating. Even "tariff and trade statistics as well as the request and offer lists were prepared by the participating governments themselves and the Secretariat merely helped to circulate them" (Hoda, 2001, p. 69). Yet with the increasing complexity of trade negotiations the importance of the Secretariat as a facilitating organ also increased (Winham, 2006). While the Secretariat was still mainly in charge of keeping records during the Kennedy Round and had no influence on the substance of the negotiations, by the time of the Tokyo round the Secretariat increasingly analyzed and prepared issues under consideration (Winham, 2006). This included the preparation of reports on the tariff structures and trade statistics of the most important countries of the regime, and maintaining a detailed file with duty rates and statistics on imports of these countries (Hoda, 2001). During the Uruguay round the Secretariat's role increased further. Next to the provision of trade statistics it also evaluated tariff offers, analyzed tariff schedules before they were approved and verified, calculated the average reduction of tariff rates, and reported whether members commitments and actions were in line with the targets set during the Round (Hoda, 2001). At times the Secretariat staff also supported the chairs of negotiation groups in drafting of negotiation text. The draft agreement of the Uruguay Round created by Director-General Arthur Dunkel is the most important and well known example of this type of secretarial support (Winham, 2006).

${ }^{101}$ SR.16/11, p.163 
Secondly, while being very important for the smooth functioning of the regime, the Secretariat's formal powers are limited. Much of the Secretariat's influence is informal, and depended on individual character traits and expertise of staff. Especially the head of the Secretariat can strongly influence its working style and effectiveness and certainly some individuals significantly shaped the fate of the GATT, such as the former DGs Arthur Dunkel and Peter Sutherland who are widely regarded as having played a significant role in ensuring the success of the Uruguay Round (Paemen \& Bensch, 1995; VanGrasstek, 2013). Also the GATT's first Executive Secretary and Director General Eric Wyndham White stands out as an important individual, who shaped the GATT in its early years. Due to his expertise and leadership style he is said to have influenced most of the major decisions in the GATT's early history (Curzon \& Curzon, 1973; Dam, 1970; De Souza Farias, 2013; Jackson, 1969; McKenzie, 2008; Xu \& Weller, 2004). Nonetheless even under a person as influential as Wyndham White it was the Chairman of the CONTRACTING PARTIES and not the Secretariat who held most administrative power (Xu \& Weller, 2004). Furthermore, ultimate control remained with the membership. The contracting parties did not hesitate to block Wyndham White's initiatives in case they disagreed (Curzon \& Curzon, 1973).

Aside from individuals, turning to the Secretariat at large, of course it needs to be admitted that it fulfilled a crucial function in the GATT. It is unlikely that the GATT would have functioned properly if it would not have been for an organ that took care of routine tasks such as the maintenance of liaison with members and other international organizations, the distribution and archiving of documents, the administration of telegraphic ballots, the preparation of sessions of the CONTRACTING PARTIES and the Council, and supporting the budget committee by contributing to the preparation of the budget (Xu \& Weller, 2004). Furthermore the Secretariat became increasingly important in the facilitation of negotiations by providing information and analyses, by assisting the chairmen of negotiating groups, and by its head acting as moderator and honest broker to break deadlocks (Curzon \& Curzon, 1973; Winham, 2006; Xu \& Weller, 2004). However, once again it was always the membership that was ultimately in control of decisions and that enjoyed the formal right of initiative. Despite the increasing role of the Secretariat and its importance in facilitating negotiations, the degree of delegation should not be overestimated as its role hardly went beyond that of a negotiation facilitating and moderating agency. Even in its most developed form - the current WTO Secretariat - its impact on policy output remains relatively limited in an environment dominated by an institutional culture characterized as member driven, as pointed out earlier in this chapter.

By the time the WTO was established the Secretariat's structures had developed sufficiently to be taken over by the new organization. This highlights that the WTO followed the GATT's trajectory and that its creation can hardly be considered as a single moment of rational design. The direct connection between the GATT's and WTO's Secretariat can easily be proven by referring to the "Agreement on the Transfer of Assets, Liabilities, Records, Staff and Functions from the Interim Commission of the International trade Organization and the GATT to the World Trade Organization", adopted by the WTO's General Council at its first meeting in January 1995. 
The agreement states that, "to the extent practicable the Secretariat of the GATT 1947 shall become the Secretariat of the WTO" and that "all assets and liabilities of the GATT 1947 and the ICITO shall be assets and liabilities of the WTO". ${ }^{102}$ The Secretariat structures that incrementally developed throughout the GATT's history were simply taken over and incorporated in the WTO. This is fully in line with one of the main conclusions that can be generally derived from this section.

\subsubsection{Conclusion}

In summary it can be stated that the review of the GATT's institutional development provides important insights about the process and dynamics of change in the trade regime, and about the shape of the WTO's organizational structure. First of all institutional change in the trade regime was incremental and path dependent. The most important institutional structures emerged in consecutive steps. New features built upon existing ones, slowly increasing the authority of institutional bodies. This is exemplified by the development of intersessional procedures, which eventually culminated in the establishment of the Council. Bolder attempts of institutional design either failed or were of limited success, as indicated by the failure of the OTC or the limited success and eventual demise of the Consultative Group of 18. Secondly, this incremental process sheds light on the dynamics of institutional change. The development of the trade regime seems to be determined by an interplay of two competing forces: the functional requirements that trigger institutional change and ask for a rational solution to existing challenges on the one hand, and contextual factors inhibiting such change on the other hand. Two main contextual factors stand out that have influenced the GATT's development and contributed to path dependence - one external, the other internal to the GATT. Externally, domestic veto points - especially the US Congress - blocked attempts of bold institutional change. Circumventing such veto points demanded incrementalism and careful institutional design that would not risk domestic political backlash. At the same time, the cautious, incremental development necessitated by the avoidance of external veto points has internally led to trajectories that led to lock in effects. It has led to a membership that got used to being formally in full collective control of the GATT - the GATT's early history required that pooled bodies were either fully inclusive or had limited influence, and led to a Secretariat that formally had little administrative power. During times when the membership was limited this was not problematic, but as the GATT grew, further centralization in form of organizational bodies with limited membership or a more influential Secretariat would have facilitated administration and decision-making according to the assumptions of rational design. However, such steps would have required (parts of) the membership to voluntarily give up influence. This is hardly rational from the perspective of individual members and consequently such steps towards greater centralization were of limited success. In essence the GATT's early history had let it on a hardly reversible path that ultimately resulted in an institutional culture characterized as member driven and that put an emphasis on formal sovereign equality.

${ }^{102} \mathrm{WT} / \mathrm{L} / 36$, p.1 
Thirdly, this path sheds light on the WTO's organizational shape. The design process of the WTO's organizational structures can be interpreted as bricolage - a process were institutional designers build on a repertoire of existing principles and practices to find new solutions to institutional challenges. In this process some parts of the GATT's institutional structure could simply be taken over and incorporated in the WTO. Existing committees and working parties, as well as the Secretariat belonged to those aspects of the designer's repertoire that could be easily included in the WTO without much adaptation. Furthermore, the Ministerial Conference at the peak of the WTO can be interpreted as the institutional equivalent of the CONTRACTING PARTIES. While the two differ in the political level of representation, this difference is in essence merely a firm institutionalization of the 1988 decision to have bi-annual meetings of the CONTRACTING PARTIES on ministerial level. ${ }^{103}$ The membership also took over the member driven character of the GATT, an aspect of institutional culture, which they explicitly did not want to see changed (e.g. Int01, Int09).

Other structures needed to be adapted, such as the council structure for example. Instead of only one council, the WTO entails four councils - the General Council and the three councils in charge of the specific agreements covered by the WTO: goods, services and intellectual property. While this is a significant difference it stands out that the GATT practice to administer substantive agreements by the use of councils was maintained. In essence the GATT model has been taken over for the agreements on services and intellectual property, kept for the agreement on trade in goods, and another council has been added on top as a coordinating organ. As the former Canadian Ambassador to the GATT, John Weekes, has pointed out, this arrangement seemed like a good and practical way to combine the different substantive agreements emerging from the Uruguay Round under a single institutional roof. ${ }^{104}$ Clearly the creation of the council structure exemplifies a mixture of functional motivation and historical experience and seems to fit the definition of bricolage well: a new structure to fulfill the demands of the day was created by relying on experience with existing structures and using them as inspiration. The same holds for the Dispute Settlement Body and the Trade Policy Review Body. Although their names suggest that they are genuinely new bodies, knowing that these bodies are synonymous to the General Council, with merely different names puts the apparent novelty of the bodies into perspective. Thus it is clear that existing institutional structures strongly influenced the shape of the WTO and considering the incremental development of the these structures, the creation of WTO's architecture can hardly be interpreted as a single moment of rational design.

\footnotetext{
${ }^{103}$ According to a former Canadian negotiator the Ministerial Conference was intended to add a new facet to the institutional structures of the trade regime by providing policy direction on a higher, more prestigious political level. However, confirming the idea of cognitive path dependency this negotiator pointed out that it never worked this way because the membership of the regime continued to make use of this design feature in the same way that it used the meetings of the CONTRACTING PARTIES (Int19).

${ }^{104}$ Interview with John Weekes in the context of the WTO Creation Project. A video recording of the interview was retrieved from: http://www.wtocreation.org/en/videos?video=31171021.
} 
Reviewing the GATT's history has provided supplementary information to the accounts of rational design and is able to fill some gaps in the rational account of the WTO's creation. It sheds light on the dynamics of institutional change in the trade regime and indicates why the WTO emerged in its particular institutional shape. However, the two main questions that capture the limitation of rational design's account are not comprehensively answered yet. It still needs to be clarified why centralization went as far as it did - why was the creation of the WTO eventually successful in light of initially serious opposition? Furthermore, it is also not fully clear why centralization did not go further - why was consensus decision-making institutionalized and why did the Consultative Group of 18 for example not manage to create a trajectory that was followed in the WTO, despite its apparent appeal from a rational design perspective? To answer these questions it is necessary to examine the negotiation process of the WTO and to look at the interaction between centralization and control.

\subsubsection{Negotiating Design}

Earlier in this chapter the emergence of the idea to establish an international organization has been traced to examine how well it corresponds to the trajectories of the rational design framework. It has been shown that rational design corresponds reasonably well to the underlying motives of those actors that initiated the creation of an organization. While John Jackson provided the intellectual blueprint for an organization, on formal, governmental level it was Canada and the European Communities (EC) who carried the idea into the negotiations. These parties, as well as Mexico, were the strongest proponents for the creation of an organization. However, the idea was not warmly welcomed by all of the other parties to the Uruguay Round. The strongest and most significant opposition came from one of the most important and powerful players in the round - the United States. As it has been pointed out above, the United States argued that most of the reasons the EC brought forward in its initial proposal to establish an organization were not valid. The US delegation argued in the FOGS group in June 1990 that the GATT relied on a solid institutional structure already and that implementing the substantive agreements resulting from the Uruguay Round, reversing the fragmentation of the GATT that resulted from the Tokyo codes, and providing for a unified dispute settlement system were mainly questions of political will and not of creating an international organization.

The disagreement amongst the parties is a classic example of a coordination problem as described in chapter 2. To recall, such coordination problems need to be overcome for change to occur and rational accounts are prone to overlook the impact of coordination problems on preventing or moderating institutional change. The severity of coordination problems depend on the heterogeneity of interests of the parties negotiating the change in question and the amount and the structure of veto points that need to be overcome to achieve change. In light of heterogeneous preferences and veto points achieving change is often only possible when the actors in favor of change are sufficiently powerful to overcome opposition and veto points. 
Applying these theoretical assumptions to the situation in the summer of 1990 the prospects for the creation of an organization did not appear very rosy. As pointed out, interests were heterogeneous and the opposition to the creation of an organization led by the United States was particularly powerful. Furthermore veto points were formidable. Not only would the most important parties to the GATT have to agree to the establishment of an organization, such agreement would also have to be ratified by parliaments. Especially the US Congress had a wellknown and well-deserved reputation for preventing the creation of international organizations, as it was experienced within the trade regime when the Congress blocked both attempts to create an organizational structure for the regime - the ITO and the OTC (VanGrasstek, 2013). Also within the GATT many actors were skeptical about the feasibility to create an organization and concerned that negotiations on such a matter would divert attention from important negotiations on substance (Croome, 1999; VanGrasstek, 2013). Initially even Director General Arthur Dunkel, while privately probably appreciating the suggestion to put the GATT on more solid institutional footing, in public remained reserved concerning the creation of an organization (Croome, 1999; VanGrasstek, 2013). Naturally the question emerges how the coordination problem was eventually overcome and why the creation of the WTO succeeded despite the initially grim prospects.

By tracing the negotiation process this section addresses this question. It is mainly argued that the coordination problem on institutional matters was overcome because it was a useful means for the powerful players in the GATT to overcome other coordination problems related to substantive negotiations. This highlights the point made in section 2.4 .3 that the link between institutional and substantive negotiations needs to be taken into account to understand the process of institutional change. In this process it was crucial that the United States changed its initial assessment that the creation of an organization would not increase the political will of negotiating parties to accept substantive agreements that the US regarded as favorable. Once the US realized that it could use the creation of an organization as a tool to overcome the coordination problem that arose from heterogeneous interests on substantive issues in its favor, its outlook on the creation of an organization became more positive (Ehlermann \& Ehring, 2005). US negotiators used the proposal to create an international organization in two ways during the negotiation. First of all, the US used its opposition to the creation of an organization as a bargaining chip in the negotiation process to achieve substantively beneficial negotiation results. Secondly, together with other developed states it used the creation of the organization to ensure that all substantive agreements resulting from the Uruguay Round would be applicable to all parties of the trade regime and enforceable via a unified dispute settlement system. By doing so the fragmentation of the regime and alleged free riding that resulted from the Tokyo codes could be reversed. The substantive results that emerged by using the creation of the WTO as a strategic means in the negotiation process were even for the US Congress convincing enough to agree the establishment of the organization. Power played an important role in this respect, as this move was only feasible due to the stark asymmetry of influence 
between developed and developing countries at the time. Before this argument is fleshed out in further detail it is useful to present a chronological overview of the organizational negotiations.

\subsubsection{The Negotiation process: a chronological overview ${ }^{105}$}

In section 3.2.2.1 the emergence of the idea to create an international organization was traced. It was shown that John $\mathrm{H}$. Jackson as an influential academic developed the idea outside of the GATT. This idea was favorably received by Italian trade minister Renato Ruggiero and Canadian trade minister John Crosbie. Crosbie lobbied for the establishment of an international organization throughout spring 1990. Eventually a formal proposal was brought into the negotiations by the EC in a FOGS group meeting in June 1990. However, the reaction in the FOGS group was reserved. Many delegations were concerned that negotiations on the establishment of an international organization would demand too much time and attention to be conducted during the Uruguay Round, and that they would unnecessarily distract from important negotiations on substance (Croome, 1999; VanGrasstek, 2013). As already mentioned, especially the US delegation was opposed to the creation of an international organization, arguing that the most important issues that the creation of an organization would address - particularly ending the fragmentation of the GATT system and clarifying how the separate substantive agreements negotiated during the round should be implemented - could be reached without the creation of an organization, as long as sufficient political will would be mustered. In light of such opposition the discussion was essentially left out of formal FOGS negotiations for the rest of the year (Croome, 1999). ${ }^{106}$

Informally the discussion continued though. During a Quad meeting in July Canada presented a paper about the establishment of an organization and another one about the legal difficulties of implementing the separate substantive agreements negotiated during the round (Steger, 2000). It is interesting to note that both issues were presented in the same context, since the former eventually became the solution for the latter. This was in essence what the EC had argued in its original proposal presented to the FOGS group in June. In informal papers exchanged in fall 1990 the EC continued arguing that the establishment of an organization is the only logical way to implement the results of the round, while the US defended the position that this would not be necessary (Steger, 2000). The US delegation suggested addressing the question about implementation by bundling the results of the round via the introduction of a protocol (VanGrasstek, 2013). Instead of establishing an organization the main focus during the negotiations should lie on establishing an effective, small management group in the GATT; on eliminating free riding that resulted from unequal obligations between members and non-

${ }^{105}$ Unlike previous episodes of institutional change in the trade regime, the negotiations of WTO are not well documented in official GATT documents. Consequently this section mainly relies on accounts of contemporary witnesses gathered via interviews and via their publications. Also secondary literature that derived its account from interviews has been consulted.

${ }^{106}$ In the September FOGS group meeting the Chairman of the group decided to postpone discussions about the establishment of an organization until further progress in the negotiations at large had been made. See MTN.GNG/NG14/20. This is also reflected in the draft agreement for the Brussels Ministerial Meeting where it was mentioned that the issue could be picked up again (Croome, 1999). 
members of plurilateral agreements; and on ensuring that the results of the round would be accepted as a single undertaking (Steger, 2000).

In December 1990 contracting parties gathered for the Brussels Ministerial Meeting. Originally this meeting was supposed to close the Uruguay Round. By the time of the meeting it had not been clarified whether an organization should be established, what the relationship between the separate substantive agreements would be, and whether the agreements' implementation would require acceptance by all parties (single undertaking) or whether they could be implemented selectively, as plurilateral agreements (Croome, 1999). However, unresolved issues on substance were far more important than the unresolved institutional issues. Negotiations about agriculture were most controversial in this respect. These eventually led to the failure of the Brussels Ministerial and engulfed the Uruguay Round in a severe crisis. Paradoxically, this crisis turned out to be a blessing for institutional negotiations. With substantial negotiations being deadlocked more time and attention could be spend on the establishment of an organization, eliminating a major concern many delegations expressed during the June FOGS meeting (VanGrasstek, 2013). In this respect the unexpected availability of more time can be ascribed as a factor leading to the establishment of the WTO. An EC negotiator pointed out for example that the organizational negotiations became more relevant for him when the head of his delegation approached him, pointing out that more time was available since the negotiations would not end very soon, so more attention should be paid to an institutional agreement (Int01). Nonetheless, time cannot be the only important variable, as the US delegation remained firm in its opposition to the creation of an organization.

After the failure of the Brussels Ministerial the setup of the negotiations was changed. Negotiating groups were reorganized and the number of groups concerned with negotiations on goods was reduced from fourteen to six. One of these six groups was concerned with institutions. This group was supposed to work on the Final Act concluding the round and to continue the work that had so far been conducted in the negotiation groups on dispute settlement and the work that had been conducted in the FOGS group. ${ }^{107}$ Since most of the institutional decisions would be political in nature and had to be taken towards the end of the Uruguay Round, it was only in fall 1991 that the negotiating group on institutions would resume formal meetings (Croome, 1999). By then Canada and the EC - with Mexico as co-sponsor - had prepared a draft charter for an international organization, which they tabled in the institutions group in November (Croome, 1999; Steger, 2000). The name of the organization suggested in the draft was Multilateral Trade Organization (MTO) - a working title that survived until the very end of the round and which was only changed to WTO last minute upon request of the US. Despite objections of several parties, Julio Lacarte as Chairman of the institutions group requested the group to review the draft MTO agreement and prepare it to the extent that it could be finalized after the completion of substantive negotiations. Parallel to this the group also worked on an integrated dispute settlement system that would cover all of the different

${ }^{107}$ Only one of the group's meetings is officially documented in the GATT's archives; see MTN.GNG/IN/1 
substantive agreements resulting from the round (Steger, 2000). Integrated dispute settlement would later on contribute to the establishment of the WTO.

The work of the institutions group culminated in intense meetings in December 1991. During these meetings the group produced a draft MTO agreement that was largely based on the draft submitted by Canada, the EC and Mexico (Steger, 2000; VanGrasstek, 2013). Although the US delegation still opposed the establishment of an international organization due to concerns over of congressional opposition, it participated in the organizational negotiations nonetheless (Croome, 1999). The draft that resulted from these negotiations was forwarded to the Trade Negotiations Committee, to be included in the Draft Final Act that was produced upon the request of DG Arthur Dunkel at the end of 1991 to create a focal point that would serve as basis to complete the Uruguay Round (Croome, 1999). ${ }^{108}$ This so called 'Dunkel Draft' bundled the draft agreements produced in the Uruguay Round's separate negotiation groups in a single text. The MTO agreement was added to the Dunkel Draft at the end of the document in an annex (Steger, 2000). ${ }^{109}$ Although the Dunkel Draft became an important focal point to complete the Uruguay Round indeed, it did not lead to the immediate success its initiator had hoped for since disagreements over agriculture once again prohibited a swift completion of the round. While the US upheld its opposition to the establishment of an organization, negotiations on the MTO agreement continued in the remaining two years of the round. ${ }^{110}$

In the beginning of 1992 the setup of the negotiations changed once again and the negotiations were conducted in four separate groups. One of these groups, the Legal Drafting Group, was tasked with checking the agreements in the Dunkel Draft for legal conformity and internal consistence, but also took up the negotiations on institutional issues (Croome, 1999; Steger, 2000). ${ }^{111}$ The work in this group took place in formal as well as informal meetings between January and May 1992. Most of this work was concerned with the clarification of institutional provisions that could not have been fully worked out in the limited amount of time left in late 1991. This included the specification of the relationships of different institutional bodies towards each other, and clarifying the question how the different rules and institutions resulting from the Uruguay Round would be integrated in a single organizational structure (Croome, 1999). Once again despite its formal opposition to the establishment of an organization the US actively participated in these negotiations (Croome, 1999; Steger, 2000).

Those who interpreted this participation as a softening of the US' opposition must have been taken by surprise when the US delegation explicitly reaffirmed in December of 1992 that it could not accept the establishment of an organization. During a private dinner amongst chief

\footnotetext{
108 It is interesting to note that despite their opposition to the establishment of the MTO, the US negotiators did not block that the draft MTO agreement would be annexed to the Draft Final Act (Croome, 1999).

${ }^{109}$ MTN.TNC/W/FA

110 Most changes between the MTO agreement annexed to the Dunkel Draft and the eventual WTO agreement relate to decision-making procedures. These procedures were subject to intense negotiations as is discussed in section 3.3 .

111 The other three newly established negotiation groups worked on market access for goods and services respectively, and on substantive changes to the Draft Final Act.
} 
negotiators US negotiators were firm and explicit in their view that the idea to establish an international organization had to be abandoned. This affirmation of the US' opposition was probably triggered by domestic concerns of the freshly elected Clinton administration. As Debra Steger (2000) put it:

"As a result of the increasing interest of environmental groups in trade matters, especially in response to the circulation of the panel report in United States Restrictions on Imports of Tuna, and the negotiation of the North American Free Trade Agreement (the "NAFTA"), the United States' negotiators viewed the MTO charter as a lightning rod for domestic opposition of the Uruguay Round in the United States." (p. 145)

As an alternative the US delegation once more promoted the idea that the round could be concluded and agreements be implemented by use of a protocol that would have addressed legal and administrative matters, making the creation of a formal organizational structure unnecessary (Croome, 1999; Steger, 2000). Amongst other things the protocol was supposed to have provided for a unified dispute settlement system and to end the fragmentation of the GATT by requiring that all of the substantive results of the round would have to be accepted by all parties as a single undertaking (Croome, 1999; Stewart, 1993).

Indeed, many of the other delegations were taken by surprise by the fundamental nature of the US' rejection. By late 1992 it was assumed that the US opposition to the MTO stemmed mainly from dissatisfaction with decision-making procedures that were still under negotiations and from the concerns over congressional approval, but not from fundamental opposition to the idea itself anymore (Croome, 1999). At this stage of the negotiations most parties expected "that an MTO was part of the overall balance of the Uruguay Round package" (Steger, 2000, p. 145). Unsurprisingly the US' position met unanimous opposition from other negotiating parties who accused the US of institutional cherry picking. While the US desired those institutional reforms it regarded as beneficial, such as the unified dispute settlement system and the implementation of substantive results via a single undertaking, it refused to renounce using retaliatory measures unilaterally and rejected the establishment of the MTO (Croome, 1999). ${ }^{112}$ At the time several other controversial issues accompanied the institutional disagreements. Particularly agriculture turned out to be a stumbling block again, resulting in the failure to conclude the round in late 1992. In early 1993, once more, the negotiations were put to a halt.

Some of the delegates that had been previously concerned with institutional negotiation made use of this opportunity to informally consult about outstanding issues of the MTO agreement that were regarded to be problematic. The ideas developed in this context particularly those related to decision-making in the MTO - were expected to accommodate the US, which did not participate in these consultations. Consequently it is hardly surprising that in August 1993 the US "sparked strongly hostile reactions, particularly from the European

\footnotetext{
112 Part of this discussion is reflected in the notes of the Trade Negotiations Committee meeting on December 18th, 1992; see MTN.TNC/28
} 
Community and India, when it expressed continuing doubts that a new multilateral trade organization was needed, and argued that it would be 'unwise to burden the negotiations' with the proposal" (Croome, 1999, p. 306). The US maintained its opposition in September when the negotiation group on institutions under the chairmanship of Julio Lacarte was re-established and started negotiations at the end of the month. The US argued that the inclusion of the draft MTO agreement in the Dunkel Draft did not imply that the creation of an organization would be a desired outcome of the Uruguay Round that has to remain on the negotiation agenda. It pointed out that the MTO agreement had a different status than the other agreements included in the Dunkel Draft, due to the fact that the negotiations were not completed before the agreement was added to the draft. The other parties in the negotiation group opposed this view and responded that the purpose of the group was to solve outstanding institutional issues instead of debating the question whether an organization should be established in principle (Croome, 1999).

Nonetheless, in November the US renewed its proposal to implement and integrate the Uruguay Round agreements with a protocol, named General Agreements on Trade (GAT) (Preeg, 1995; VanGrasstek, 2013). The Chairman of the negotiating group rejected this alternative, arguing that he had received the mandate by the DG to negotiate the creation of an organization, while having no mandate to lead negotiations on alternatives to this. Faced with this situation the US delegation agreed to participate in negotiations, but pointed out that this would not signal agreement to the establishment of an organization in principle (Steger, 2000). In the following the negotiations group focused on resolving outstanding issues of the MTO agreement, with voting arrangements being the most difficult subject to address (Croome, 1999). On November $14^{\text {th }}$, after intense, often late night negotiations the institutions group managed to produce an agreement on the MTO and another one on an integrated dispute settlement system (Croome, 1999; Steger, 2000).

Despite this breakthrough, the US did not lift its reservations towards the establishment of the MTO (Steger, 2000). This only happened after a series of high-level bilateral negotiations in late November and early December between the US and the EC. During these negotiations the US Trade Representative (USTR), Mickey Kantor, and the EC's Commissioner for Trade, Sir Leon Brittan, addressed the most important outstanding issues of the Uruguay Round. Amongst those was the MTO agreement to which the US agreed on the penultimate day of the round, under the condition that the name of the organization would be changed to World Trade Organization (WTO) (Croome, 1999; Steger, 2000). The Uruguay Round closed on the $15^{\text {th }}$ of December 1993 and the WTO agreement was signed in April 1994 during the Marrakesh Ministerial Conference. After the closing of the round the most formidable hurdle the WTO had to take was being approved by the US Congress (Preeg, 1995). Eventually this turned out to be less problematic than feared throughout the round. Although concerns over ceding sovereignty were raised in the US domestic political debate, the WTO agreement passed both chambers of the Congress with surprisingly comfortable margins in late November and early December 1994 (Porges \& 
Price, 2005; Preeg, 1995; VanGrasstek, 2013). ${ }^{113}$ The WTO was ready to be set up on the $1^{\text {st }}$ of January 1995.

\subsubsection{Negotiation dynamics: substance, institutions and power}

Having reviewed the chronological process that led to the establishment of the WTO the question remains which factors allowed to resolve the coordination problem that was apparent during the negotiations. As pointed out above overcoming coordination problems is a function of preference heterogeneity of the involved actors and the veto points that need to be overcome to reach change. In terms of preference heterogeneity it becomes clear from the chronological overview that the analytical focus needs to be on the United States position to explain how the coordination problem was solved. Canada and the EC as influential industrialized players and originators of the idea were obviously in favor of the organization right from the beginning. Developing countries - due to their weaker position in the international trade arena - also had a natural tendency to support a stronger multilateral system and saw the establishment of an organization mainly in their favor (Preeg, 1995; Shell, 1995). ${ }^{114}$ Furthermore, latest after the failure of the Brussels Ministerial Meeting, the main concern of most actors that were initially skeptical of the establishment of an organization disappeared since more time was available for institutional negotiations. The US remained as the most significant actor opposed to the idea of establishing an organization and due to its power its opposition constituted a formidable veto point. Thus the analytical focus needs to lie on the United States' position. Why did the US delegation drop its opposition to the creation of an organization at the very end of the round, and why did the US Congress, which had blocked the establishment of an organization in charge of the multilateral trading system twice did not do so a third time?

The simple answer to this question is that the substantive results of the Uruguay Round where sufficiently attractive for the US to make the creation of an organization acceptable even to Congress. In this sense the following argument does not contradict the rational account that the emergence of the WTO is regarded as an instance of centralization in response to facilitate the implementation and administration of an increasingly complex trade regime, characterized by a larger scope and more members. However it supplements this account by highlighting that this occurred mainly on terms advantageous the most influential members of the regime. The negotiation of the WTO agreement reflects James Fearon's (1998) two step argument, that establishing international institutions should not solely be regarded as a coordination problem to enforce international agreements, but also as a coordination problem with respect to agreeing on the substance of the agreements to be enforced. In case of the WTO

113 The House of Representatives voted on the $29^{\text {th }}$ of November, with 288 votes in favor and 146 votes against the legislation enacting the results of the Uruguay Round. The Senate voted on December 1st, with a marking of 76 to 24 in favor of the legislation (Preeg, 1995).

114 This view was also validated by interviews with negotiators from influential developing countries (Int05, Int11, Int16; also Int13). 
the two steps were interwoven, since the negotiations on the establishment of an organization were used to solve the coordination problem on substance. This occurred in two ways.

\section{The Organization as Bargaining Chip}

First of all, the US delegation's opposition to the establishment of an organization was less fundamental than it seemed, but at least partially tactically motivated. As one US negotiator pointed out when talking about the hesitation to agree to an organizational agreement:

"We later went along with it, in fact we kind of wanted it to happen. But we only wanted it to happen if it met all kind of very, very strict conditions of which we were afraid we would never get through the negotiation process." (Int02)

According to the same negotiator the US wanted to decide on organizational questions about administration and implementation only after it had been assured that substantive agreements were satisfactory from the US' perspective. ${ }^{115}$ In the meantime the opposition to the establishment of an organization was used as a "bargaining chip both within the institutional negotiating group and more broadly in the Round" (Preeg, 1995, p. 125). ${ }^{116}$ As it is quoted in Paemen and Bensch (Paemen \& Bensch, 1995, p. 220):

"At an especially tedious informal Trade Negotiations Committee meeting in December 1992, Rufus Yerxa, the head of the U.S. representation to GATT, passed a note to the Community negotiator. It said: 'For 2 years you've played the heavy in these negotiations. Now it's our turn! We've decided it's the only way to get concessions."'

Paemen and Bensch point out that this note was only meant half-jokingly in the sense that it contained the essence of the US negotiation strategy to obtain the negotiation objectives it pursued in the broader context of the round. In this broader context the US aimed mainly for better access to foreign markets by reducing tariff and non-tariff barriers, to strengthen the GATT's dispute settlement system, to strengthen the rules on trade-distorting subsidies and other unfair trade practices, to incorporate stronger rules on agricultural trade, to include trade in services in the regime, as well as the protection of intellectual property rights, and to create a less fragmented system were all actors would commit to all of the most important substantial agreements (GAO, 1994; Porges \& Price, 2005). These negotiating objectives were formally laid out by Congress in the 1988 Omnibus Trade and Competitiveness Act (19 U.S.C. 2901). Overall the US was highly successful in achieving its negotiating objectives (GAO, 1994; Porges \& Price, 2005). As Porges and Price (2005) put it, "one cannot help but comment on the extent to which the final Uruguay Round agreement reflected U.S. aspirations and negotiating objectives" (p.404).

Reluctance to agree to the establishment of the WTO was partially responsible for this, since this "institutional change [...] made it possible to achieve almost all of the Uruguay Round

\footnotetext{
115 This is also confirmed by Steger (2000).

${ }^{116}$ This was also suggested in an interview with a former EC negotiator (Int18).
} 
objectives by Congress in the 1988 Act" (Porges \& Price, 2005, p. 403). Especially the last attempt to actively oppose the creation of an organization, when the US in November 1993 reinvigorated its proposal to implement the results of the Uruguay Round with a protocol is described as "holding position" to gain an advantage on substantive negotiations (VanGrasstek, 2013). During these final stages of the round negotiation stakes were still high. In intense bilateral discussions between the US and the EC politically sensitive negotiations over agriculture, textiles and apparel, anti-dumping, subsidies, steel, electronics, as well as audiovisual and financial services still had to be finalized (Croome, 1999). Even right before the end holding back agreement to the establishment of an organization still turned out useful to the US. Upon domestic pressure from computer chip producer Intel the US demanded a last minute change in the TRIPS agreement. In return the US delegation offered to agree to changes demanded by others in the subsidies agreement and to accept the creation of an organization (Preeg, 1995). This was one of the last bargains of the Uruguay Round and the way for the creation of the organization was cleared.

The logic behind the US opposition to the creation of an organization in order to gain an advantage in other areas of negotiations is reasonably straightforward. However, it needs to be pointed out that this tactic would have faced limited chances of success if it had not been for the credibility of the United States' opposition. According to VanGrasstek (2013) the United States was particularly well placed to follow this strategy due the reputation of its Congress. After all, the US Congress had prevented attempts to establish an international trade organization in the history of the trade regime twice already and also had impeded international cooperation in other fields when rejecting US membership in the League of Nations for example. Thus,

"... negotiators in the executive branch can sometimes point to an apparently uncontrollable Congress in order to avoid making commitments that they say would be unacceptable on Capitol Hill, or to obtain commitments from other countries that they claim are the sine qua non to securing congressional approval of the final deal. While there are no doubt occasions when this posturing involves a degree of manufactured brinkmanship, the fact that Congress did indeed reject several important agreements in the past ensures that not all threats can be dismissed as bluffs." (VanGrasstek, 2013, p. 63$)^{117}$

Consequently the US was able to use the other negotiating parties' concern over Congressional approval of an organization to press for the desired substantive results in a "two level game" (Putnam, 1988).

\footnotetext{
117 While the US strategy generally seemed to have worked, not all of its negotiating partners were fully convinced of the credibility of the US opposition. The EC's trade commissioner Sir Leon Brittan stated that by the final phase of negotiations in late 1993 it was assumed that consensus on institutional reforms existed (VanGrasstek, 2013). The US also did not always follow this strategy as consistently as it could have. Deputy United States Trade Representative (USTR), Julius Katz, mentioned in a public discussion in April 1992 for example that despite some outstanding issues he had "no doubt [...] that in the end the MTO will be accepted; the idea will not be jettisoned" (quoted in Preeg, 1995, p. 125).
} 
Interpreting the US opposition as partially tactically motivated also helps to explain why the United States participated in negotiations about the WTO agreement despite remaining opposed to the idea in principle. While the US' opposition was probably genuine at times, if it would have been as fundamental as the US claimed throughout the negotiations it would not have made sense to participate in the negotiations about detailed organizational provisions. By taking a two-pronged approach of being actively involved in shaping the WTO agreement while formally opposing the idea the US was able to shape the organizational structures according to its demands without giving up its "bargaining-chip".

\section{The Organization as Tool of the Powerful}

The second way in which institutional negotiations were intertwined with discussions on substance is probably even more important to explain the emergence of the WTO. The decisive factor to ensure US agreement to the WTO was the realization that the establishment of an organization could be used to ensure that all of the Uruguay Round's negotiation parties would be bound by all important substantive obligations resulting from the round. In the beginning of the chapter this unification of the system has been pointed out as one of the main achievements of the Uruguay Round, which strongly contributes to classifying the creation of the WTO as an instance of centralization. After all, it ended the fragmentation that characterized the multilateral trading system since the Tokyo Round. Except for four remaining plurilateral agreements the Uruguay Round's agreements were adopted as a single undertaking.

However, this was not a foregone conclusion. From its very origins the round was characterized by a fundamental coordination problem stemming from disagreements about the scope and the implementation of the substance covered. Already in preparation of the round there had been disputes about the scope of the round. Ahead of the Punta del Este meeting that launched the round, the committee in charge of preparing the meeting had prepared two draft ministerial declarations. While a large group of countries supported the first declaration, which called for the inclusion of services, intellectual property and investment in the negotiations, a group of 10 developing countries led by India and Brazil opposed this expansion in scope. This group argued that agriculture and textiles - two areas in which they had a comparative advantage - should be integrated more firmly in the regime before an expansion in scope can take place. Eventually supporters of expanding the scope of the regime won the day under the condition that goods and service negotiations would take place on two separate tracks (Croome, 1999; Preeg, 1995). ${ }^{118}$ However, in Punta del Este it was not decided how the results of the negotiations should eventually be implemented and whether the tracks should be integrated. The ministerial declaration mentions that once results of the negotiations have been established "Ministers meeting also on the occasion of a Special Session of CONTRACTING PARTIES shall

118 This issue was so sensitive that it even determined the number of gavel strokes with which the Punta del Este meeting would be concluded. While Brazil and the EC wanted the Chairman of the meeting to close with two strikes, symbolizing the two negotiation tracks, the US insisted that the meeting would be closed with one strike, symbolizing the unity of the ministerial declaration. Eventually the meeting was closed with three gavel strikes (Preeg, 1995). 
decide regarding the international implementation of the respective results." ${ }^{119}$ This implied that at the launch of the negotiations it was still conceivable that the Uruguay round would be closed in the same way as the Kennedy and the Tokyo Round, allowing negotiation parties to select by which substantive agreements they would be bound. Although the Punta del Este declaration mentions that the negotiations should be treated as a single undertaking, this did not imply that all GATT members would have to sign on to all agreements. The meaning of single undertaking was not elaborated in the declaration and it was taken to merely specify the procedure of the negotiations instead of a rule about the implementation of results. It simply meant that negotiations on different subjects would take place simultaneously and that the round would only be concluded once agreement on all the different negotiation subjects was reached. It was only in the course of the round that the single undertaking was reinterpreted to ensure that all agreements would apply to all parties (VanGrasstek, 2013).

This reinterpretation was particularly in the interest of developed countries and allowed the United States to achieve two of its most important negotiation objectives: the elimination of perceived free riding and the possibility of cross retaliation in dispute settlement (GAO, 1994; Porges \& Price, 2005). ${ }^{120}$ Considering the former, the fragmented membership of the Tokyo Round codes was perceived to create "free riders". A term used for those GATT members that benefited from the concessions made by members of the Tokyo Codes, but who were not members of the codes themselves. By eliminating the possibility the regime's members to decide selectively which substantive agreements they would like to join, this opportunity of free riding would obviously disappear and it could be ensured that the new areas - services and intellectual property regulations - would be applicable to all. With respect to the latter, the reinterpretation ended the institutional fragmentation of dispute settlement and thereby allowed for the opportunity of cross retaliation under a single dispute settlement system. Cross retaliation increases the means to enforce a particular agreement by allowing the plaintiff in a dispute to revoke concessions under a different agreement than the one that gave rise to the dispute. Especially the opportunity to enforce agreements on services and intellectual property rights via this system seemed attractive to the US at the time. Under the existing fragmented system this would not have been possible, since the different Tokyo Codes had different dispute settlement arrangements. ${ }^{121}$

\footnotetext{
${ }^{119}$ MIN.DEC

${ }^{120}$ This view was also expressed by a former US negotiator (Int02) who stated that "getting all countries to commit to the same rule-book; getting away from the non-MFN codes that were a feature of the GATT as a result of the Tokyo Round; and essentially getting countries to commit to including services and intellectual property, and having those items connected within the dispute system" belonged to the most important negotiation objectives of the United States.

${ }^{121}$ At one point in the negotiations the US tried to push for establishing an integrated dispute settlement system without establishing an organization. However, this was unanimously resisted by other parties, who accused the US of cherry picking (Croome, 1999). See section 3.2.4.1.
} 
Although the controversy about the scope of the negotiations had decreased and interest had become more homogenous by the early $1990 \mathrm{~s}^{122}$, the reinterpretation of the single undertaking could potentially have led to serious coordination problems regarding the closing of the round. Creating the WTO was helpful to avoid this despite the fact that linking the creation of the WTO and the single undertaking was not a necessity. Theoretically each of these two outcomes could have been achieved without the other. On the one side, revising the meaning of the single undertaking would have been possible without the creation of an organization. As mentioned above the United States supported such an approach during most of the round and others - while not in favor - agreed to its theoretical feasibility (Croome, 1999). After all, the US opposed the EC's arguments in the FOGS meeting where the organizational proposal was first formally discussed, pointing out that political will would be the key to end the fragmentation of the trade system and to integrate services in the regime. The US argued that the creation of an organization would not increase such political will and that it would not make countries accept agreements they would not want to accept. Correspondingly US suggestions to implement the Uruguay Round agreements by means of a protocol entailed that such a protocol would bind all parties to all substantive results (VanGrasstek, 2013). On the other side, it was also not the case that the creation of an organization would necessarily imply that all parties would be bound by all agreements. John Jacksons initial WTO proposal allowing for agreements with varying memberships under the umbrella of an organization is illustrative in this respect (Jackson, 1990). However, linking the creation of the organization and the single undertaking ensured that the coordination problems encountered during the negotiations could be overcome and that the fragmentation of the GATT system was brought to an end.

This happened on the terms of the most influential members of the regime and it shows that power can be an important factor influencing changes in centralization. Contrary to the United States initial assessment that the creation of an organization would not increase the political will of countries to end fragmentation by accepting substantive agreements they did not want to accept, the creation of the organization became an excellent tool to push weaker members of the regime to accept the re-interpretation of the single undertaking. It can be assumed that this realization made the creation of the organization significantly more attractive to the US. As former US negotiator Andrew Stoler (2008) put it:

"The agreement to create a new Multilateral Trade Organization was seen by the Quad countries as offering an opportunity not to be missed to rid the new system once and for all of free riders. In their decision to leave the old GATT and its MFN [most favorite nation] obligations behind, the Quad countries were able to force Uruguay Round participants into accepting obligations under all of the new system's agreements with the exception of Government Procurement and Civil Aircraft Codes. The Quad changed the meaning of the Uruguay Round's single undertaking at the end of the game and

\footnotetext{
122 In light of the rapid development of Southeast Asian emerging economies, the end of the Cold War and the emergence of the Washington Consensus, more developing countries shifted towards liberal economic policies and became more open to the GATT (Croome, 1999).
} 
they could get away with it only because of the creation of the new organization. I can assure you that few countries would have accepted this interpretation of the single undertaking in 1986." (p. 4)

Another US delegate's elaboration on this facet of the negotiations helps to understand why the creation of the organization was so useful to reinterpret the single undertaking, end free riding and renew the trade regime:

"... even the countries that were reluctant to get along with it were being told: well, we are going to withdraw from the GATT and enter into this new agreement. So you can stay in the GATT if you want, but it won't mean anything because we won't be in there. We are going to be in this new institution, which is called the WTO and which then incorporates the GATT and all these other agreements in this whole new system. And that ultimately forced everybody to go along with the idea." (Int02)

This rationale for the creation of an organization was also attractive to the Europeans. Like the Americans, they also had an interest to end free riding; and renouncing the original GATT to then accede to the WTO was seen an effective way to do so. In an interview a former EC negotiator (Int01) pointed out that linking the creation of the organization to the reinterpreted single undertaking was one of the reasons for the creation of the organization and "was probably the only way in which we could achieve what we did". ${ }^{123}$ This negotiation tactic was not uncontroversial and as early as July 1990 some negotiation parties expressed their concern in the Trade Negotiations Committee that the creation of an organization should not be used to establish a link between the different substantive agreements negotiated in the round. ${ }^{124}$

The fact that this tactic worked nonetheless clearly reflects the importance of power in overcoming coordination problems (Steinberg, 2002). ${ }^{125}$ It was only due to the fact that those parties in favor of the single undertaking were significantly more powerful than those parties opposed that the negotiation tactic to exit the GATT and enter the WTO was successful in implementing the results of the round as a single undertaking. By the announcement of the most influential countries to renounce the GATT upon accession to the WTO those opposed to the single undertaking where caught between a rock and a hard place: A GATT without the economically most influential members would have been irrelevant, since it would not have allowed for access to the biggest and most important markets. Thus staying in the GATT would have been of limited usefulness. While the alternative of joining the WTO with its single undertaking might not have been ideal, it was still preferable to membership in an irrelevant GATT. Consequently even those countries that would have preferred to continue the practice of

\footnotetext{
${ }^{123}$ The strategic use of creating a new organization to ensure that all negotiating parties would sign on to all substantive results of the Uruguay Round was confirmed in several other interviews too (Int06, Int07, Int08).

${ }^{124}$ MTN.TNC/16

${ }^{125}$ According to Barton, Goldstein, Josling and Steinberg (2006) power is an important factor in explaining the evolution of the trade regime across a variety of domains and not only with respect to institutional structures. This is also nicely exemplified by Kim (2010).
} 
selective membership in substantive agreements under the GATT had no real alternative but to go along and join the WTO. Had the market size of those in favor of the single undertaking not been sufficiently large, this tactic would not have worked out. Given these power asymmetries, for developing countries a strong multilateral organization with a binding rulebook as manifested in the WTO was preferable to a weak GATT structure, since it allows keeping powerful players in check. Accepting disadvantageous substantive agreements was the price to pay for a rules-based system under the aegis of an organization. According to a negotiator from a developing country the main priority "was that we should have a rules based multilateral system, even if the rules would not fall in line with what we would have liked" (Int16). ${ }^{126}$ Finally, according to Steinberg the early 1990s were an opportune moment to overtly use power in the described way, due to the geopolitical context at the end of the Cold War. In this context the western, developed countries did not have to be concerned anymore to alienate developing countries and drive them into the arms of the USSR and its competing economic ideology. This was a permissive factor for the developed countries to play out their economic strength (Steinberg, 2002). ${ }^{127}$

\subsubsection{Conclusion}

In conclusion, the account of the organizational negotiations and the employed tactics exemplifies how a purely functional explanation of the WTO's emergence would be incomplete. Certainly such an account would be accurate in ascribing the WTO's existence to the functional necessity of implementing substantive agreements. However, it would fail to recognize how interwoven the organizational and substantive negotiations were. The account just provided clearly shows that the creation of the organization needs to be examined in the wider context of the negotiations, which was in turn strongly influenced by the power asymmetries at the time. In this wider context it becomes clear that power played out differently in overcoming the coordination problem of creating the organization than one would expect when analyzing the creation of the organization in isolation. In isolation one would usually expect that a coordination problem characterized by heterogeneous preferences could only be resolved if one group of actors that prefers a particular negotiation outcome is sufficiently powerful to ensure that opposition can be overcome. Clearly this explanation does not apply to the emergence of the WTO, since the US as the opposed party was also the most powerful one in the negotiations.

However when recognizing the link between organizational and substantive negotiations two strands of reasoning show why agreement on the organization could nonetheless be achieved and how power as an explanatory factor played out. The first strand exemplifies the

\footnotetext{
126 The attraction of a stronger rules-based system was substantially increased by the US' use of unilateral measures to open foreign markets and relates strongly to the reform of the dispute settlement system (Ganesan, 2015). US unilateralism is another exemplification of the importance of power in the Uruguay Round negotiations and is addressed in further detail in the next chapter.

${ }^{127}$ According to Steinberg this also explains why the Kennedy and the Tokyo rounds were not closed with a more overt use of power to achieve a single undertaking (2002).

The historical context at the end of the Cold War was described out by a US negotiator as "a sweet spot in the history of international economic integration." (Int02)
} 
link between organizational and substantive negotiations rather straightforwardly. As it has been shown, opposition in organizational negotiations was used to achieve an advantage in substantive negotiations - the WTO was used as a bargaining chip. The second strand of reasoning exemplifies the importance of power. Without the existing power asymmetries at the beginning of the 1990s it would probably not have been possible to assert the reinterpretation of the single undertaking. However, this assertion was crucial since the US would not have agreed to have its autonomy circumscribed by the creation of an international organization in charge of implementing trade rules, if those rules had not been clearly in its favor. As a former US negotiator pointed out:

"On the idea of creating a proper international trade organization the US was probably the last to come to the party, not because we didn't think it would be a great idea, but because we weren't willing to have it adopted in a way in which it limited US flexibility, but which really didn't commit many of the developing countries, emerging countries and others...." (Int02)

In light of the prominence of services and intellectual property protection amongst US negotiation objectives such universal commitment across all the important substantive agreements was essential to ensure US support of the WTO. The creation of the organization was a necessary element to reach such commitment since it allowed developed countries to announce that they would abandon the GATT upon acceding to the WTO, leaving developing countries with hardly any choice but to accept the single undertaking. The interaction of organizational and substantive negotiations in the Uruguay Round clearly exemplifies the argument that international cooperation needs to be analytically approached as consisting of two kind of collective action problems - the negotiation of substance and the enforcement of substance - with the former being politically more controversial (Fearon, 1998). A purely functional account would mainly focus on the analytical dimension of enforcement and thereby neglect the interaction with substance and the fact that due to power asymmetries centralization occurred mainly on the terms of the most powerful countries.

The analysis provided in this section also sheds light on the question why the WTO succeeded while the ITO failed. In both cases US Congress was the decisive actor determining success or failure. According to several interviews the fact that the United States achieved virtually all of its negotiation objectives was also crucial in ensuring congressional approval of the WTO (Int02, Int05, Int09, Int13, Int14). Particularly the single undertaking was "the big selling point" to Congress according to one negotiator (Int09). Furthermore, in its report to Congress the US General Accounting Office estimated that the US would economically gain from the results of the Uruguay Round and that it would be beneficial to enter the WTO $(G A O, 1994)$. The negotiation outcomes also satisfied many industry groups and companies and led them to lobby for the adoption of the Uruguay Round's results in Congress (Porges \& Price, 2005). Such support had been absent when the Havana Charter was up for ratification in the late 1940s (Diebold, 1993-1994, 2002). 
However, despite all these positive aspects there were voices that raised concerns over the sovereignty implications that the creation of the WTO would entail (Jackson, 1997; VanGrasstek, 2013). According to two negotiators (Int02, Int09) reassuring that the organization would stay member driven and reference to consensus as the main decision-making principle were helpful to appease such concerns. This indicates that control was another important factor that cannot be neglected when examining the emergence of the WTO as an instance of centralization. The next section turns to the interaction of centralization and control. 


\subsection{Design Sets: Centralization and Control - Decision- Making in the WTO}

The theoretical conceptualization of centralization and control conducted in chapter 2 has highlighted that a meaningful empirical analysis of centralization needs to take institutional design features of control into account. Although centralization and control are analytically different variables, whose theoretical separation can be useful, their interplay in empirical manifestations needs to be examined to tell not only what is centralized but also how centralization is manifested in organizational structures. After all, mechanisms of control indicate how autonomous organizational structures can operate and thereby indicate the degree of centralization. Such control mechanisms can take a variety of forms including the precision of an organization's mandate, financial arrangements, oversight mechanisms and the permanence of an organization. However, with respect to the trade regime's legislative and administrative functions the most important control mechanisms indicating the degree of centralization are specified by decision-making arrangements and the role of the Secretariat in decision-making. This is largely determined by the authority vested in decision-making bodies, their composition with respect to their exclusivity, their decision-making procedures, and the rules that guide principal-agent relationship in instances of delegation. The combination of centralization as indicated by the institutional bodies that constitute the WTO and control as indicated by decision-making practices determines how the organization is governed - in other words, it indicates who takes which decisions (centralization) and how they are taken (control). This combination of centralization and control was an important element of the Uruguay Round negotiations and the resulting agreements constitute a puzzle that warrants further investigation.

This puzzle has empirical as well as theoretical facets. Empirically, section 3.2.1 in this chapter that analyzed the emergence of the WTO as an organization already came to the conclusion that - at least with respect to its legislative and administrative functions - the WTO is severely limited in its ability to act as an autonomous entity with a will and identity independent of its membership. This was illustrated by examining the institutional structures related to pooling and delegation as specifications of centralization. Each of these forms of centralization is characterized by a large degree of formal control that the membership can exert over the organization. This often results in the WTO being described as a member driven organization.

\subsubsection{The Puzzle of Rational Design}

This was not a forgone result of the Uruguay Round. After all, the round's negotiation mandate, as captured in the Punta del Este declaration asks the negotiating parties to aim for 
improving "the overall effectiveness and decision-making of the GATT as an institution...". ${ }^{128}$ Proposals to this effect where made inside, as well as outside of the GATT. Regarding the latter an independent expert report written on request of the Director General, which significantly influenced the Uruguay Round's negotiation agenda already suggested to establish a permanent ministerial body of limited membership to provide policy direction to the GATT and to establish the GATT as a permanent negotiation forum that would not only produce legislative policy output during rounds (Dunkel, 1987). Also, John Jackson's initial proposal for the creation of an organization includes the suggestion to create "a smaller body to act as more efficient guiding group for the organization, since the size of the GATT membership has now become such as to make such guidance difficult except through informal means which are sometimes resented" (Jackson, 1990, p. 95). Jackson also suggested to review decision-making processes of the GATT to find a more adequate balance between consensus on all issues and the one-nation-one-vote principle (Jackson, 1990). Also within the GATT proposals where made during the negotiations to establish a body with limited membership, as well as proposals to increase and formalize the role of the Secretariat (Croome, 1999; Xu \& Weller, 2004).

However, with respect to increasing the efficiency of decision-making the results of the Uruguay Round can be considered limited. "Despite growing disquiet with the traditional arrangements, many of the GATT decision-making practices were institutionalized in the WTO" (World Trade Organization, 2007, p. XXXV). The only agreement reached that relates to this point of the negotiation mandate was the decision taken by the GATT Council in April 1989 to conduct biannual meetings of contracting parties on ministerial level. ${ }^{129}$ This decision was firmly institutionalized in the WTO by the creation of the Ministerial Conference as the WTO's main policy-making body. Except for this, none of the attempts to increase centralization by reducing the formal control that members have over the organization succeeded. No institutional body of limited membership was established and all formal decision-making bodies remained inclusive. Meetings of the Consultative Group of 18 as the GATT's only body with restricted membership were even discontinued during the Uruguay Round and no similar body was created in the WTO. Also proposals to increase and formalize the role of the Secretariat did not travel very far during the negotiations and as such delegation has also not significantly increased with respect to the legislative and administrative functions carried out in the trade regime (Xu \& Weller, 2004).

Instead of changing the balance between centralization and control in favor of centralization the contrary happened. In comparison to the GATT the amount of formal control that members have over the WTO with respect to legislative decisions has even increased as an outcome of the Uruguay Round. In Article IX of the WTO agreement consensus as a decision-making procedure that developed informally in the GATT was formalized and codified as the preferred means to take decisions. Additionally decision-making was made more difficult by increasing the required

\footnotetext{
${ }^{128}$ MIN.DEC, p.8

${ }^{129} \mathrm{C} / \mathrm{M} / 231$ and L/6490
} 
special majorities on important decisions such as waivers and amendments. ${ }^{130}$ Both these aspects of decision-making where not specified in the initial drafts of the organizational charter. The explicit provision to take decisions by consensus and to increase threholds for special majorities was only added in later versions (VanGrasstek, 2013). In light of this, the empirical question arises why the Uruguay Round did not lead to further centralization, despite existing proposals.

This question gains in significance when considering that the results of the Uruguay Round also stand in an uneasy relationship with the theoretical assumptions of rational design. According to rational design an increase in centralization would have been justifiable on a functional account. After all, the conjecture of rational design that links number to centralization suggests that centralization should increase when membership increases in order to decrease transaction costs and increase efficiency (Koremenos et al., 2001a). This logic is strikingly similar to John Jackson's argument in favour of establishing an instituitonal body with limited membership as quoted above. Also those rational design conjectures that are related to control do not seem suitable to explain the the outcome of the Uruguay Round. Rational design would for example assume a decrease of individual control when number increases (Koremenos et al., 2001a). Examining the decision-making procedures of the WTO shows that this is clearly not the case for the trade regime. While under majoritarian voting in combination with a one-memberone vote principle as prescribed in the GATT individual control would decrease with every added member, the formalization of consensus and the resulting lack of voting allows members to formally retain a maximum of individual control. Also with respect to the symmetry of control rational design cannot provide an explanation of the formal decision-making procedures in the WTO. Rational design posits that control is asymmetrical, when the actors designing the institution are asymmetrical with respect to their power (Koremenos et al., 2001a). This is formally not reflected in the WTO - every member has one vote, independent of its standing in the international arena and the consensus principle assures that formally even the smallest members have the opportunity to veto a decision. In light of this, two questions emerge: First, why did centralization not go further, despite existing negotiation proposals that would have had this effect and despite functional advantages from a theoretical perspective? Second, why were asymmetries amongst actors not formally recognized in the WTO's institutional structures as suggested by rational design?

These questions can be partially answered when reflecting upon the complexity entailed in the design of decision-making structures of international organizations. Due to this complexity it is difficult to predict the interaction of centralization and control from a purely theoretical perspective. This is the case for several reasons. First of all it should be kept in mind that legislative decision-making is mainly concerned with fundamentally and primarily distributive issues, so an overall low baseline for the degree of centralization and a tendency to maintain high individual control should not be surprising.

${ }^{130}$ For decision-making on waivers see Article IX of the WTO Agreement; for decision-making on amendments see Article X. 
James Fearon's (1998) argument that international cooperation consists of two collective action problems, a negotiation and an enforcement problem, can be used to exemplify this point. When keeping in mind that the substantive terms of cooperation need to be agreed upon before such an agreement can be enforced and that the negotiation of such terms tends to be distributional, then it is plausible that actors are hesitant to give up control over the future (reInegotiation of such terms. Especially in an environment characterized by strong enforcement capacities, as it is the case with the WTO's binding dispute settlement procedures, actors have a strong desire to individually stay in control of the negotiation of rules that they expect to be binding (Pauwelyn, 2005; World Trade Organization, 2007). ${ }^{131}$ Furthermore it should not be forgotten that the creation of institutional arrangements can entail unintended side effects, resulting in uncertainty about the exact operation of an institutional agreement, especially when such arrangements are related to decision-making practices (Martin \& Simmons, 1998). Even the rational design framework itself assumes that risk averse actors desire to maintain control in light of uncertainty (Koremenos et al., 2001a). For these reasons it would be natural to assume that the balance of centralization and control in legislative decision-making is tilted towards control.

However, even when taking this into account it is still difficult to predict which balance is struck, as it seems simply impossible to apply the benchmark of functionality to design sets that balance centralization and control. Various ways to combine centralization and control in legislative decision-making can be seen as rational or not rational, depending on the perspective one chooses to take. This is due to the fact that two pairs of competing demands need to be balanced in designing decision-making structures in international organizations. These pairs are reflected in the taxonomy developed in chapter 2: the first relates to the autonomy of an organization, the second relates to the relative influence different members have in an organization. Regarding the former it is necessary to find a balance between the ability to come to decisions in an efficient manner on the one side, and the demand of members to minimize sovereignty costs and maintain a maximum of individual control on the other side. Regarding the latter, on the one hand decision-making structures should accurately reflect the relative standing of members in the international arena; as such they should give more weight to the powerful. On the other hand they also need to be perceived as at least minimally legitimate by the less powerful members. Therefore there are boundaries to formally manifesting high asymmetries of influence in institutional design (Stone, 2011).

If these competing demands are not accurately balanced difficulties in decision-making can arise: If an organization is too autonomous or too dominated by a few key members, then those who disagree to decisions made by the organization might not implement them or the organization is perceived as illegitimate. On the contrary, if decision-making is not autonomous enough or excessively inclusive, then deadlocks are likely and the organization can become paralyzed. Thus it is difficult to create a benchmark that enables the measurement of decision-

131 In several interviews it was pointed out that consensus decision-making is "the price to pay" for binding dispute settlement (Int02, Int05, Int07). 
making procedures as more or less rational. Highly centralized, exclusive decisions making structures are very efficient in creating new agreements at the risk that such agreements will not be implemented by those parties who are excluded, i.e. who lack control. Such implementation can be assured with highly inclusive decision-making structures, that are not as centralized, at the risk of paralyzing the decision-making process.

Although the rational design conjectures presume designs that favor efficiency over inclusiveness and that reasonably represent power asymmetries, a theoretical prediction, which balance of the competing demands on decision-making is struck is not possible. Designing decision-making structures is simply too complex. To explain why the balance of centralization and control was struck in the way it was an empirical investigation that takes institutional history and the negotiation process into account is necessary. In other words, to answer the questions why centralization did not go further and why asymmetries amongst actors are not formally recognized in the WTO's institutional structure it is necessary to trace the process how the decision-making structures of WTO emerged.

\subsubsection{Process Tracing of Decision-Making Arrangements in the Trade Regime}

Several conclusions can be drawn from such a process tracing exercise. First of all, the difficulty of striking the right balance between the competing demands of decision-making structures is mainly accommodated for by a combination of formal and informal practices. As such centralization and asymmetry of control seem formally limited, but are nonetheless represented in informally developed practices. Whether such informal practices are consciously designed can be questioned though. The kind of centralization and control that are reflected by these practices are ad hoc and their manifestation in the process of taking decisions depends on actor constellations at a particular point in time, and is related to the a particular issue under discussion. As such centralization and control are highly context dependent and the ability of the trade regime to produce decisions efficiently is equally dependent on such context. Secondly, the history of the trade regime and the negotiations during the Uruguay Round show that concerns over the reduction of transaction costs and improving efficiency are clearly of secondary importance in relation to concerns over individual control. For less powerful members of the trade regime such concerns over individual control are characterized by an insistence on the formal design features that resemble a low degree of centralization and no formal institutionalization of asymmetrical control. More powerful members permit this and rely on informal processes to exert control and informal centralized decision-making. Thirdly, from the underlying prevalence of individual control in combination with the formal and informal decision-making practices strongly path-depended trajectories emerged that led to lock-in effects. Such lock-in effects make it close to impossible to formally centralize decision-making in favor of efficiency and to institutionalize asymmetrical control, even when the institutional context does not allow existing informal practices to work efficiently. In light of these arguments 
the following process tracing clarifies why being member driven is one of the most robust features of the WTO's institutional identity.

\subsubsection{Design Sets in Historical Perspective: The Development of Decision-Making}

\section{Design Sets in the ITO}

Once again the ITO is the logical starting point to trace the historical roots of the trade regime's decision-making structures. Starting the process tracing of decision-making with an examination of the ITO provides valuable insights and helps to put existing structures into perspectives. The institutional arrangements that would have governed the ITO clearly exemplify the difficulty of striking the right balance between the competing demands of decision-making. Despite the stark power asymmetries existent at the time of the ITO's negotiation, it stands out that such asymmetries would have been underrepresented in the organization's institutional structure and that powerful members probably already expected to rely on informal means to exert influence. Yet, despite this underrepresentation, the existence of an executive board, the formal provision of a secretariat and the existence of independent commissions would have ensured that asymmetry of control and a higher degree of centralization would have been institutionalized more firmly in the ITO than in its successor, the GATT. Thus, the failure of the ITO is an interesting starting point highlighting the path dependent development of decision-making structures in the trade regime's history. It shows that institutional design opportunities that were present at one point in time might be difficult to realize once a different institutional path it pursued.

Before these arguments are fleshed out in further detail it is necessary to recap the formal institutional setup of the ITO. As it was described in section 3.2.3.1, two bodies that count as instances of pooling would have taken most of the decisions in the ITO. At the top of the organization's hierarchical structure would have stood the Conference, which had the ultimate authority to determine the organization's policies and which would have consisted of all of the its members. Below the Conference would have been the Executive Board, whose task it would have been to implement and execute the organization's policies and which would have had powers as delegated to it by the Conference In contrast to the Conference, membership in the Executive Board would have been restricted to eighteen members. Of these eighteen seats, eight would have been reserved to the ITO's members of chief economic importance as determined by the conference every three years by a two-thirds majority vote. The other ten members of the Executive Board would have been elected every three years by the Conference, also by a two-thirds majority. Although broad geographical representation of membership would have been required for the composition of the Executive Board, the reservation of eight seats for the economically most important members would have ensured the representation of economic might in this body.

In addition to this, two types of institutional structures that count as instances of delegation where formally provided for in the ITO charter: Commissions and the Secretariat. Commissions would usually have had the purpose to deal with specific problems related to international 
trade. Such commissions would have been established by the Conference. The Executive Board would have determined the specific tasks of the commissions, and appointed their members on the basis of expertise. While the commissions would have studied trade related issues, gathered information, prepared reports and provided advice to the Executive Board, taking decisions based on this would have been left to organs of the ITO that would have consisted of the ITO's members (Wilcox, 1972). Considering the Secretariat, the Havana Charter provides for the position of a Director-General as chief administrative officer in charge of day-to-day administration of the organization's policies and for staff working under the Director-General's supervision. The Conference would have determined the "powers, duties, conditions of service and terms of office of the Director-General" and would have appointed the Director-General upon recommendation by the Executive Board (Art. 84.1). The Director-General would in turn have appointed the Deputy Director-General and staff under the supervision of the Executive Board and based on regulations approved by the Conference. Director-General and staff would have worked in the capacity of international public servants and would therefore not have been allowed to receive instructions from governments (Art. 88.1). Yet again, while the Secretariat could have gathered information and prepared advice and reports, decisions based on this would have been left to the members in the Executive Board or the Conference (Wilcox, 1972). Furthermore, although the Director-General or one of his representatives could participate in meetings of any organ of the organization, in contrast to the administrative heads of the IMF and the World Bank, they would not have had the right to vote.

According to the formal rules of decision-making, most decisions would have been taken by simple majority voting. However special majorities would have been required to take the most important decisions. Taking such decisions would have been reserved for the Conference (Art. 77.2). These arrangements would have protected states from too much organizational autonomy an ensured symmetrical control regarding issues of outmost importance. Amongst those decisions were decisions on amendments and the election of the members for the Executive Board. Each of these decisions would have required two-thirds majorities (Art. 78.3 \& 100). For some forms of amendments further protection for states was built in. These kind of amendments that would have changed the rights and obligations of members would also have required the ratification of two-thirds of the ITO's members before they would become effective for the entire membership (Art.100.2). Members not accepting such amendments could either be suspended by the organization or withdraw from the organization within six weeks (Art. 100.2 \& 100.3). ${ }^{132}$

Considering the development of decision-making structures in the trade regime, two important insights can be drawn from the ITO's institutional arrangements. First of all, the ITO's formal institutional structure would have provided for a higher degree of centralization than the

${ }^{132}$ It is interesting to note that it would have been up to the Conference itself to decide by a two-thirds majority whether an amendment changes the rights and obligations of members (Art. 100.4). Thus the requirement for ratification of amendments by the domestic legislative bodies of members could theoretically have been circumvented in this way. 
GATT's. Although the decision-making rules that required special majorities were designed to avoid that the ITO would become too independent, their impact on reducing the degree of centralization should not be overestimated. Special decision-making requirements for the most important decisions are a usual characteristic of all sorts of legislative procedures and especially not uncommon in international organizations (Zamora, 1980). The decision-making thresholds required in the GATT for the most important types of were even higher than the ones in the ITO, making the GATT almost impossible to amend (Jackson, 1969). ${ }^{133}$ Most significantly the fact that that the Executive Board would have consisted of only eighteen members implies that a subset of the membership would have taken decisions on behalf of the entire membership. Clearly this would have increased the degree of centralization in comparison to the GATT. Also with respect to the Secretariat the ITO formally exhibited a higher degree of centralization. After all, the ITO's Secretariat, being embedded in a proper international organization, would probably have faced fewer obstacles to operate effectively than the GATT's Secretariat in its early days. As shown in section 3.2.3.2 the improvised nature of secretarial provisions in the GATT implied that it started out with a low profile, limited staff and restricted financial resources due to the fact that the GATT was not supposed to be formally recognizable as an international organization. Finally, it should not be forgotten that the provision for independent commissions in the Havana Charter was an institutional feature that did not formally reoccur in GATT. While panels consisting of people not acting as representatives of contracting parities were regularly established to assist dispute resolution in the GATT, most work on specific trade related topics was done by committees and working parties, consisting of contracting parties' delegates (Jackson, 1969). Committees of independent experts examining an issue where only initiated infrequently and ad hoc in the GATT, and tended to conduct their work outside of the GATT's official institutional setting.

The second insight that can be derived from the overview of the ITO's institutional structures is that despite the provision for an Executive Board with limited membership control would have been relatively symmetrical in relation to the existing power asymmetries at the time of the ITO's negotiation. This exemplifies one of the difficulties of designing-decision-making structures: they need to reflect existing geo-political power asymmetries to ensure the cooperation of the powerful, while not doing so too much to avoid alienating the less powerful. Nonetheless, it is surprising that existing asymmetries would not have been institutionalized more strongly (Hudec, 1990a). After all the IMF and the World Bank as the other two major international economic organizations created at the time operated on a basis of weighted voting. This was not provided for in the ITO. In the ITO each country would have had one vote

133 While the ITO required two-thirds majorities for amendments and amendments changing rules and obligations would have been applied to the entire membership upon ratification of two-thirds of the membership, some GATT amendments required unanimity and those that did not require unanimity became effective only for those GATT members that accepted them and only after two-thirds of the membership had accepted them. Throughout its history the CONTRACTING PARTIES minimized the problem that the GATT was extremely difficult to amend by behaving as if certain amendments would be in place, despite the fact that they formally never entered into force (Jackson, 1969). 
(Art. 75.1). Weighted voting was considered during negotiations of the Havana Charter, but many countries - especially smaller and economically less powerful ones - were not in favor of this.

Several possible explanations exist why the most powerful members, particularly the US, did not push hard to eventually establish weighted voting in the organization. Some authors argue that US negotiators were willing forego the possibility to establish weighted voting, because they regarded the demand for it as a bargaining chip that could be used in return for concessions by others on the substantive provisions of the charter (Brown, 1950; Odell \& Eichengreen, 1998). This is plausible, as the issue of weighted voting did not seem to be of major importance to US negotiators. The negotiators believed that for decisions of the ITO that would have depended on voluntary implementation weighted voting would be of limited value (McIntyre, 1954). Although weighted voting might have increased the chances of taking decisions in favor of a minority of most powerful members, the impact of such decisions would have been limited if a majority of opposed members would have refused to implement them (Mclntyre, 1954). Regarding the most important decisions, US negotiators assumed that the risk of being outvoted on issues of major US concern would have been limited by the requirement of special majorities and the US' guaranteed position on the Executive Board (Hudec, 1990a; Mclntyre, 1954). Furthermore, the negotiators thought US interests would be protected, because one of the most important exceptions to the charter - the balance of payments exceptions, allowing quantitative restrictions on imports - depended on a prior decision that had to be taken by the IMF. ${ }^{134}$ Since the US had the majority of votes in the IMF's weighted voting system, this provision also influenced the US negotiators' strategy to not insist on weighted voting (Hudec, 1990a). Finally, it should not be forgotten that the most powerful members would probably also have been able to exert their influence informally and that the negotiators were aware of this. As McIntyre (1954) points out: "The potent factor of "invisible weighting" which operates under any voting arrangement will always give to states with the major interest influence beyond the limits of their voting power" (p.491). Hudec (1990) adds to this, stating that the most influential countries during the negotiations of the Havana Charter had enough confidence in their power to trust that they could sufficiently shape the organization's behavior informally. Experience with other international organizations suggests that this is especially likely to be the case when decisions are important or require the agreement of all parties involved to be able to implement the decision (Gould, 2007; McIntyre, 1954; Reinalda \& Verbeek, 2004; Stone, 2011). Also, the historical development of the GATT's decision-making practices suggests that this was probably not an unrealistic assessment.

\footnotetext{
134 Only if the IMF would have had determined that an ITO member's balance of payments problems would have been serious, the ITO would have been permitted to allow this member to make use of the balance of payments exception under which quantitative restrictions on imports would have been possible (Art. 24.2).
} 


\section{Design Sets in the GATT}

With the failure of the ITO the stage was set for the emergence of two trajectories resulting from this failure and influencing the trade regimes institutional development until today. The first trajectory is characterized by the difficulty to formally increase centralization and the institutionalization of power asymmetries. This difficulty is ultimately reflected in the WTO's attribute of being member driven. Those features that would have provided for more centralization and institutionalization of power asymmetries in the ITO - the Executive Board and the explicit provision for a secretariat, in particular - got lost with its demise. The GATT's resulting unorthodox institutional development - shaped by the external obstacle to keep a low profile to not be recognized as an international organization - prohibited these institutional features to be developed in its early days. By the time external obstacles to develop such features had decreased in importance, internal lock in effects had set in that prohibited such development. The historical details of this argument have been outlined in section 3.2.3.3 on the institutional development of the GATT and are only to be recapped here briefly.

As the section on the incremental development of the GATT's institutional structure has shown the ITO's provision for a strong Executive Board would turn out to be a unique opportunity to institutionalize a high degree of centralization and asymmetry of control by creating a powerful body with exclusive membership. ${ }^{135}$ Any future attempt to create such a body was hampered by lock-in effects emerging from path dependent institutional structures that characterized the GATT as an organization that is collectively governed without formally excluding members in decision-making organs. The longer this path was followed, the more difficult it became to increase centralization at the expense of individual control. Naturally, those members that would have been formally excluded in more exclusive governance bodies refrained from giving up their rights in participating in the trade regime's decision-making and resisted the establishment of powerful institutional bodies with limited membership. Discussions in the GATT about institutional bodies with limited membership had always been controversial and faced a tradeoff between the authorities provided to such a body and the degree of exclusivity. This is illustrated by reviewing the developments that were described in the section on the GATT's institutional development: the Intersessional Committee was limited in membership, but was not very powerful with respect to its mandate; the Executive Committee of the OTC would have led to a more firmly institutionalized body of limited membership, but its mandate would not have significantly exceeded that of the Intersessional Committee; once the GATT Council replaced the Intersessional Committee it was equipped with much more power, but after intense debate it was decided that its membership would be inclusive; finally, the Consultative Group of 18 was moderately exclusive in its membership but

135 This is not to suggest that the establishment of the Executive Board and decision-making was politically uncontroversial during the ITO negotiations. Questions about the composition of the Executive Board and voting rights remained pending during the preparatory sessions and could only be resolved towards the very end of the Havana Conference, exemplifying the political sensitivity of striking the right balance between centralization and control (Brown, 1950; Feis, 1948; Wilcox, 1947, 1972). 
had no decision-making powers and only had a limited lifespan, due to controversies about membership. As it is shown below, this trajectory left a significant impact on the negotiation of the WTO's institutional structures in the Uruguay Round, but since this trajectory has been already analyzed previously in this chapter, the following part will focus on the second trajectory that characterized the development of decision-making of the GATT after the failure of the ITO.

This second trajectory exemplifies that the difficult balance of designing competing demands of decision-making structures was struck by developing a combination of formal and informal decision-making practices in the trade regime. Both, developments in formal and in informal practices indicate that it was the overriding interest of contracting parties to ensure individual control. The relation of formal and informal practices exemplifies the difficulty to cater to this interest for a diverse membership, characterized by stark power asymmetries. The combination of formal and informal practices was useful to maintain the illusion of sovereign equality as indicated by formal decision-making practices that reflected symmetrical control, while informal practices allowed the powerful to exert influence according to geopolitical realities.

On the formal side, the decision-making in the GATT was relatively straightforward and indicates a high degree of symmetry of control. As it was the case for the ITO, in the GATT votes were not weighted. Each contracting party had one vote and decisions would have to be taken by a majority of votes cast, unless specified differently in the agreement (Art. XXV.4). Notable special majorities are the two-thirds majorities for waivers freeing members from certain obligations imposed by the GATT (Art. XXV.5), and the provisions for amendments, which required - depending on the sort of obligations the amendment would relate to - either a twothirds majority or unanimity (Art. XXX.1). As a protection of sovereignty amendments taken by a two-thirds majority would only have been binding upon those members that accepted the amendment, leaving it to the individual control of each contracting party to accept new obligations under the GATT (Jackson, 1969). Another requirement for a decision to be taken by special majority was added to the GATT in 1948. To specify the accession process to the GATT the contracting parties decided that a two-thirds majority would be required for taking the decision whether a country or customs territory should be allowed to join the GATT. With this requirement another provision was added in favor of individual control. To protect those contracting parties that would not agree to the membership of a newly acceding country/customs territory, such contracting parties were allowed refrain from sharing their tariff commitments with the newly acceding country/customs territory (Jackson, 1969). All decisionmaking bodies in the GATT were fully inclusive.

However, the formal procedures of decision-making were rarely made use of. Throughout the lifetime of the GATT decisions were mostly taken by consensus. A decision by consensus is taken when none of the present parties involved in the decision-making process actively opposes the decision (Jackson, 1969). In theory this implies that every decision-making party has the opportunity to veto a decision, retaining a maximum of individual control. The potentially large amount of veto points makes consensus prone to path dependency, as it "inherently favors the status quo and can make it extremely difficult to achieve change" (Ehlermann \& Ehrig, 2005, 
p. 51). Theoretically the system can also be considered as even more egalitarian than the GATT's voting provisions, since every contracting party has the same ability to block a decision (Van den Bossche, 2005). However, in practice this assumption "is flawed in that it wrongly assumes that any Member is equally able to sustain a veto" (Ehlermann \& Ehrig, 2005, p. 66). This will be demonstrated in further detail below, but before this is done the question needs to be addressed how decision-making by consensus developed historically.

The exact development of decision-making practices in the GATT is not very welldocumented, but it seems that decisions were taken by consensus right from the beginning of the GATT (VanGrasstek, 2013). ${ }^{136}$ The earliest record of GATT decision-making procedures, which implies that decisions were taken by consensus dates back to 1953 (Footer, 1997; Steinberg, 2002; World Trade Organization, 1995). The report of a working party on Japanese participation in the GATT mentions that "the CONTRACTING PARTIES do not usually proceed to a formal vote in reaching decisions; generally, the Chairman takes the sense of the meeting..."137 Only decisions about accessions and waivers were regularly voted upon. The last officially recorded decision that was taken by a vote and that was not related to waivers or accessions dates back to 1959 (Ehlermann \& Ehrig, 2005; Steinberg, 2002; World Trade Organization, 1995). ${ }^{138}$ Consensus was the dominant form of decision-making throughout all of the GATT's bodies and can be considered as an extremely important practice regarding the functioning of the GATT (Patterson \& Patterson, 1994).

Why where the formal procedures to take decisions by voting neglected from the early years of the GATT onwards? Two answers can be given to this question. The first explains why the practice of consensus decision-making was introduced in the first place; the second points out why this practice became such a strong norm in the trade regime. Considering the first, Mary $\mathrm{E}$. Footer $(1997,2006)$ assumes that decisions were taken by consensus to stick to common practice in international relations and negotiate an issue until consensus is reached, before formally deciding upon it in an official meeting. This practice has several advantages. One of them is that the negotiations leading up to consensus tacitly take power asymmetries into account, without the necessity to formally acknowledge such asymmetries in institutional design. As such decision-making by consensus can be regarded as a substitute for weighted voting (Jackson, 1969). At the same time the absence of institutionalized asymmetry and the high degree of individual control that consensus theoretically provides for can provide decisions with legitimacy and ensure that they are implemented (Steinberg, 2002). Especially in the GATT's early days this approach to decision-making was relatively easy to manage, due to the limited amount of contracting parties and their relative homogeneity in terms of general interest (Footer, 2006, 2011).

${ }^{136}$ Decisions on judicial questions, relating to the interpretation of the GAT, were in the early days of the GATT taken by the Chairman of the CONTRACTING PARTIES which was tacitly or explicitly accepted, at times by a roll-call vote.

${ }^{137} \mathrm{G} / 55 /$ Rev.1, p.2

${ }^{138}$ SR.14/9 
The second answer points out why the practice of taking decisions by consensus was consolidated and highlights the importance of control in relation to centralization. Starting in the late 1950s an increasing amount of developing countries entered the GATT as a result of decolonization. This increase in membership implied that the most important trading nations i.e. the developed countries - could have been outvoted by a large group of less important, developing countries if decisions would be taken by majority voting. To avoid that developing countries could determine the decisions of the GATT, decision-making by consensus became increasingly important (Ehlermann \& Ehrig, 2005; Footer, 1997; Steinberg, 2002; World Trade Organization, 2007). This helped maintaining the relevance of the GATT since it ensured that the powerful and most relevant trading states would not be alienated from the organization (Footer, 1997). This development also highlights the difficulty that functional accounts face when aiming to explain the interaction between centralization and control from a purely theoretical perspective. The consolidation of the consensus principle runs contrary to the rational argument that an increase in number should lead to further centralization to reduce transaction costs of decision-making. Nonetheless, the consolidation of consensus was not irrational since it ensured that the GATT would remain relevant. Furthermore, as it has been shown previously, more formal attempts to institutionalize the asymmetrical relationships between members and to increase centralization by creating institutional bodies with limited membership where not successful in the history of the trade regime. ${ }^{139}$

While the lack of formal centralization of legislative procedures often made decision-making in the trade regime cumbersome, this could be partially compensated by informal procedures that supplement decision-making by consensus - leading to ad hoc centralization. To thoroughly understand this development it is first of all important to point out that consensus can not only describe the principle of adopting a decision, but also the process how the decision is derived (Blackhurst \& Hartridge, 2004; Footer, 1997, 2011). The former describes the definition of consensus as absence of explicit objection to a decision and is regularly labeled as passive consensus (Footer, 2006, 2011; Kissack, 2011). The latter describes the techniques used in the process to negotiate a consensus and is regularly labeled as active consensus (Footer, 2006, 2011; Kissack, 2011). It is this double meaning of consensus that allows it to be a highly egalitarian principle of decision-making that assures a maximum amount of individual control in theory, while at the same time acknowledging power asymmetries and permitting ad hoc centralization (Footer, 2006; Steinberg, 2002). Passive consensus allows for maintaining the illusion of sovereign equality in the international system, while active consensus permits decision-making according to geo-political realities with superior influence of the most dominating parties.

The practices associated with active consensus took various forms throughout the history of the trade regime and ensured from the very beginning that the most important members could

\footnotetext{
139 In addition to that, Steinberg posits that the powerful countries - and the US in particular - refrained from institutionalizing power asymmetries more explicitly to avoid alienating developing countries in the broader political context of the Cold War (2002).
} 
influence decision-making the most. As Curzon and Curzon already observed in 1973: "The outcome of all major collective decisions in GATT is strongly influenced by a few important countries. Their power to shape the course of decision-making in GATT is directly related to the extent of their participation in world trade" (p. 322). Initially it was only the US that had the capacity to single handedly initiate or veto decisions. This changed with the creation of the European Economic Community (EEC) in 1958, which was able to counterbalance US influence by the 1960s (Curzon \& Curzon, 1973; Jones, 2009). Since then and until the end of the Uruguay Round it was mainly the US and the Europeans that determined the direction of the GATT by exerting their influence in the negotiation process of active consensus (Ostry, 2001). In such negotiations informality is the defining feature of the techniques accompanying active consensus (Footer, 2011; Steinberg, 2002).

In an abstract way it is helpful to think of decision-making in the GATT as a set of nested concentric circles (Footer, 2011). Decisions are usually discussed amongst the most important contracting parties first - often the US and the EC. Afterwards they are presented step-by-step to increasingly larger groups of contracting parties. The more influential a party is and the higher its interest in a particular decision, the more likely it is that this party will be involved earlier rather than later in the decision-making process (Steinberg, 2002). Informal negotiations can take place inside as well as outside of the GATT and it lies in the nature of their informality that not all techniques related to active consensus are well documented. However when decisions started to increase in complexity and importance some more regular techniques were developed in the GATT, which are well known by now. Their emergence correlates with the inclusion of non-tariff measures (NTM) - exercises in international rule making that go beyond the negotiations of simple tariff reduction - on the agenda of the trade negotiation rounds. ${ }^{140}$

140 In the trade regime the most important legislative decisions are taken during negotiation rounds (Steinberg, 2002). The table below stems from the WTO's website and provides an overview of the different rounds that took place under the aegis of the GATT.

$\begin{array}{llll}\text { Year } & \text { Place/Name } & \text { Subjects covered } & \text { Countries } \\ 1947 & \text { Geneva } & \text { Tariffs } & 23 \\ 1949 & \text { Annecy } & \text { Tariffs } & 13 \\ 1951 & \text { Torquay } & \text { Tariffs } & 38 \\ 1956 & \text { Geneva } & \text { Tariffs } & 26 \\ 1960-1961 & \text { Geneva/Dillon Round } & \text { Tariffs } & 26 \\ 1964-1967 & \text { Geneva/Kennedy Round } & \text { Tariffs and anti-dumping measures } & 62 \\ 1973-1979 & \text { Geneva/Tokyo Round } & \text { Tariffs, non-tariff measures, "framework" } & 102 \\ & & \text { agreements } & 123 \\ 1986-1994 & \text { Geneva/Uruguay Round } & \begin{array}{l}\text { Tariffs, non-tariff measures, rules, services, } \\ \text { intellectual property, dispute settlement, }\end{array} & \\ & & \text { textiles, agriculture, creation of the WTO, etc. } & \end{array}$

It should also be acknowledged that with increasing complexity the conduct of negotiations also got increasingly institutionalized in negotiation rounds, with each round providing not only for more popular informal means of decision-making, but also for an increasing amount of formally established bodies to negotiate on particular issues (Winham, 2006). These formally established bodies were only temporary, subject to change and in principle open to the entire membership. 
During the Kennedy Round, for example, the most difficult decisions were discussed in the "Bridge Club". The "Bridge Club" is the name used to describe private meetings of the GATT's Director General - Sir Eric Wyndham White - with the representatives of the US, the United Kingdom (UK) and the EEC (Curzon \& Curzon, 1973). More prominent than the "Bridge Club" is the "Green Room", describing informal meetings of a limited group of members that came together upon the invitation of the Director General to discuss the most contentious issues during the Tokyo Round ${ }^{141}$ and the Uruguay Round (Blackhurst \& Hartridge, 2004; Jones, 2009; Pedersen, 2006). During the time of the GATT, Green Room meetings consisted of 20-25 representatives of key countries that had a particular stake in a certain decision. Although there was no objective set of criteria for participating in Green Room meetings, the US, the EC, Japan and Canada as the most important players always had a seat in the Green Room. They were usually joined by a few middle ranging countries like Australia, New Zealand, Switzerland or Norway, and by representatives of important developing countries such as Argentina, Brazil or India (Footer, 2006, 2011). ${ }^{142}$ In Green Room meetings contentious decisions were discussed that could ultimately be presented to the entire membership of the regime. Decisions prepared in Green Rooms were usually approved by consensus and seldom subject to major changes (Steinberg, 2002).

The Green Room is certainly the best-known method of informal negotiations amongst a restricted subset of the GATT's membership, but it should not be forgotten that other forms of informal small group meetings existed as well. During the Uruguay Round for example members of the Quad regularly met to discuss important decisions informally. Another example of informal meetings are the private dinners that DG Arthur Dunkel held with a selected group of the heads of delegations (Croome, 1999). ${ }^{143}$

Next to informal small group meetings other techniques are also used to facilitate active consensus. Some informal meetings for example are - while still being orchestrated by the most powerful players - not necessarily restricted in membership (Footer, 2006, 2011). Another technique consists of forming coalitions and alliances. Such coalitions are useful for countries to defend a common interest and speak with one voice on a particular issue. In the early days of the GATT this was not regularly done, but the popularity of coalitional politics increased with the expansion of the trade regime and the decrease of relative influence exerted by the US and the

141 While Green Room meetings seemed to exist during the Tokyo Round, apparently some also refer to the small group informal meetings used during the Tokyo Round as "7+7 meetings".

142 For an interesting recollection of memories from Green Room meetings consultation of the "WTO creation Project" is recommended. The project provides a number of video interviews with negotiators that participated in Green Room meetings. The videos are accessible online under www.wtocreation.org

${ }^{143}$ Also several former negotiators and Secretariat members indicate that the Green Room Meetings are just the most formal of the informal meetings and that a lot of background work was done ahead of Green Room meetings in even less formal and smaller groups. Statements in this respect can be found in several interviews conducted in the course of the WTO Creation Project (www.wtocreation.org), for example in interviews with: Arif Hussain, Richard Nottage, Rubens Ricupero and B.K. Zutshi.

Also Croome provides an overview of the various informal techniques during the Uruguay Round (1999, pp. 138-139). 
EC (Curzon \& Curzon, 1973; Footer, 2011). Furthermore, the chairman of a committee can structure discussions in such a way that it facilitates consensus building (Footer, 2006, 2011; Odell, 2005). The same task can also be conducted even more informally by facilitators that steer the consensus process, but that do not act as formal chairs (Footer, 2006, 2011). Finally, the Secretariat also played an important role in facilitating active consensus during trade negotiations. This role increased over time. ${ }^{144}$ However as it was pointed out in section 3.2.1.2 this form of centralization can be considered ad hoc, since the influence of the Secretariat was largely dependent on the personalities involved. Furthermore, its role should not be overestimated as it hardly went beyond that of a negotiation facilitating and moderating agency. Ultimately it was the contracting parties that determined the outcomes of trade negotiations.

All of the techniques associated with the active consensus process can be interpreted as means to facilitate decision-making in a complex negotiation process. Especially the restricted small group meetings can be considered as a form of ad hoc centralization. Blackhurst and Hartridge (2004) describe Green Rooms for example as the trade regime's

"de facto way of dealing with the fact that while membership in virtually every GATT and now WTO body is open to all GATT/WTO members, once the active participation in a group/committee exceeds a certain number (say 25 or 30), discussion, debate, and negotiation become increasingly cumbersome, inefficient and ultimately impossible." (p. 707)

Consequently it seems that at least partially, the decision-making process in the trade regime adheres to the rational design conjecture positing that centralization increases with number, after all. The informal means to reach decisions also correspond more to the rational design conjecture that asymmetry of control increases with asymmetry of the actor involved more than the formal decision-making procedures would suggest, since the powerful have an inherent advantage in informal negotiation processes. The de facto presence of centralization and acknowledgement of asymmetrical control are also visible in a special variation of the trade regime's decision-making, the negotiations of tariff reductions.

\section{Tariff Negotiations}

The rules and procedures that were applied in the process of tariff negotiations varied over time but in essence provided for centralization and the recognition of asymmetrical influence. In the first five rounds negotiations followed an item-by-item approach, in which tariff concessions were negotiated bilaterally and the results of these bilateral negotiations were applied to all members of the regime. Two important principles guiding the approach to negotiations ensured that centralization would occur and that control would be asymmetrical. Firstly, the outcomes of bilateral negotiations were applied multilaterally via the Most Favored Nation (MFN) principle, which requires that the trade concessions granted to one member of the regime should be

\footnotetext{
${ }^{144}$ See p. 116, footnote 100 .
} 
granted to all members of the regime. Secondly, negotiations were guided by the norm that countries with a major interest in a certain product could negotiate tariff concessions on that product (Dam, 1970; Finlayson \& Zacher, 1983; Jackson, 1969; Kim, 2010). This norm was embodied in the principal supplier rule, which had the effect that bargaining on tariffs was reduced to the most important members of the regime; i.e. those that had a principal interest in supplying the goods under consideration. ${ }^{145}$ It should be possible to see how these rules lead to centralization as pooling and to asymmetrical control: the principal supplier rule reduced the amount of actors determining the outcome of decisions taken in tariff negotiations to the most important economic actors, excluding those actors that are not principal suppliers of the goods under consideration (Dam, 1970; Kim, 2010). Nonetheless decisions taken amongst the limited set of actors were relevant to all members of the regime, as they were "multilateralized" via the MFN principle (Kim, 2010).

The principal supplier rule in an item-by-item bargaining approach combined with the MFN principle has several functional advantages. First of all it can be expected that bilateral negotiations with a principal supplier will maximize the amount of concessions in comparison to negotiations with a member that is not a principal supplier. It is obvious that a principal supplier has a higher interest in getting improved market access than a party that is not a principal supplier and consequently more can be asked in return from the principal supplier for granting that accesses (Dam, 1970). Secondly, the principal supplier rule minimizes the free rider problem that is associated with the MFN principle. Via the MFN principle even those members of the regime benefit from trade concessions that have not provided tariff concessions in return. If concessions are asked from the main beneficiary of improved market access, i.e. the principal supplier, at the outset the positive externalities of trade concessions are reduced to a minimum (Jackson, 1969; Kim, 2010). The principal supplier rule allowed to combine two seemingly contradictory norms underlying the trade regime, the demand for mutually advantageous negotiations, represented by the requirement for reciprocity in negotiations, and the demand for non-discrimination, represented by the MFN principle (Hoda, 2001; Kim, 2010). Furthermore, the principal supplier rule ensures that "unnecessary multiplicity of negotiations on the same product" (GATT document quoted in Kim, 2010, p. 61) is prevented.

Although the principal supplier rule had many advantages as elaborated above, it had the negative side effect that it effectively excluded those members of the regime that were not principal suppliers of any product (Dam, 1970; Kim, 2010; World Trade Organization, 2007). The rules and procedures during tariff negotiations were in the interests of the economically most powerful countries as they were principal suppliers of most products and could use their

\footnotetext{
145 The CONTRACTING PARTIES had the right to determine which regime member was considered as principal supplier or had substantive interest in negotiating tariff concessions of a good (Winham, 2006). However no set definition of principal supplier or substantive interest exists. In practice those members who had a significant market share of trade in a good (usually at least 10\%) and those who had a larger market share of trade in a good than the share of the member with whom the tariff concession was initially negotiated were considered principal suppliers (Jackson, 1969; Kim, 2010). Furthermore, "if the concession to be modified affects a major part of the total exports of a country, it may be deemed to have a 'principal supplying interest'" (Jackson, 1969, p. 233)
} 
economic power the most in bilateral, reciprocal bargaining (Dam, 1970; Finlayson \& Zacher, 1983; Kim, 2010). Thus the rules and procedures that governed tariff negotiations in the first five rounds essentially correspond to the rational design conjecture that asymmetry amongst members is institutionally reflected by asymmetrical control.

After the first five rounds the approach to tariff negotiations was changed. Despite its advantages the bilateral item-by-item approach towards tariff negotiations was increasingly questioned already from the early 1950s onwards. After intense discussions, eventually in the Kennedy Round new procedures for negotiations where followed. During a ministerial meeting of GATT contracting parties it was decided that the Kennedy Round would follow a linear approach to tariff negotiations, making use of a general formula to calculate tariff reductions (Dam, 1970). During the Tokyo round a linear approach, guided by a formula was adopted as well.

It could be argued that the step from bilateral, item-by-item negotiations towards multilateral, across the board reduction can be interpreted as a step towards further centralization, since linear tariff cuts determined by a formula are automatic. This simplifies decision-making and reduces the amount of specific negotiations for certain products, in light of an increased amount of actors participating in the negotiations and an increasing variety of products being negotiated (Kim, 2010). Jackson (1969) notes that by the time of the Kennedy round the "sheer bulk of detail that confronted negotiators" (p.223) required the adoption of a new approach.

However, it is questionable whether this interpretation is the most accurate one. While linear-tariff cuts simplify decision-making with respect to tariff cuts - once a formula is agreed upon that governs the linear cuts and exceptions are specified that do not fall under the formula - the original motivation to introduce the linear approach seems to stem from concerns about equity of tariff concessions and seems as such rather related to considerations of control. Already in the beginning of the 1950s, after the Torquay Round the bilateral approach to tariff negotiations was criticized. Those countries that had already relatively low binding tariff rates complained that they were disadvantaged in bilateral, reciprocal negotiations, because they had less negotiating leverage, i.e. concessions to offer in return for improved market access for their goods (Curzon \& Curzon, 1973; Dam, 1970; Jackson, 1969). Although a rule was introduced stating that "the binding against increase of low duties or duty-free treatment shall, in principle, be recognized as a concession equivalent in value to the reduction of high duties" (Article XXVIII bis, 2(a)), it was perceived that this rule was of limited influence in actual tariff negotiations (Dam, 1970). A discussion emerged in the GATT about alternatives to the approach that was taken in the first three rounds. The suggestion to reduce tariffs in the next round by introducing across-the-board tariff cuts, known as the 'French Plan' resulted from this discussion. Despite the fact that the majority of contracting parties was in favor of the plan, it was blocked by the opposition of the US and the UK (Dam, 1970; Jackson, 1969). Thus the fourth negotiation round still followed the item-by-item, bilateral bargaining procedure. Also the fifth round, the Dillon Round followed this procedure, despite the fact that a linear, across-the-board approach tariffs 
was suggested again. It was once more US opposition that prevented this move towards linear tariff cuts, since across-the-board tariff cuts were thought to go beyond the authority given to the US executive by the RTAA (Dam, 1970). Only after the US executive received permission to follow a linear approach under the trade Expansion Act of 1962 and after intense ministerial discussion the linear approach was introduced for the Kennedy Round - 13 years after it was initially suggested (Dam, 1970).

Even then controversy did not stop and while the negotiation procedures during the Kennedy round were certainly significantly different from the ones of previous rounds, it is questionable whether the step towards linear tariff cuts can really be considered a simplification of decision-making. This is the case because the linear approach allowed for excepting certain products from across the board tariff negotiations, making them subject to bilateral negotiations (Dam, 1970). In this respect Kim (2010) notes that:

\footnotetext{
"Item-by-item negotiations still took place bilaterally among principal suppliers. So rather than simplifying and lending greater efficiency to multilateral negotiations, the linear approach adopted for the Kennedy and Tokyo Rounds still relied on heavy bilateral bargaining and merely provided yet another tool for countries to bring to the negotiation table" (p.64).
}

During the Uruguay Round negotiating the formula to govern tariff cuts was extremely difficult and no agreement could be reached. Instead it was decided to agree on targets of concessions to be reached and it was left to delegations to decide on the negotiation technique used to achieve these targets (Croome, 1999). Consequently delegations used a diversity of tools to negotiated tariff concessions, with bilateral bargaining on specific items being the main approach taken to the negotiations (Hoda, 2001; Kim, 2010). The difficulty of negotiating a formula that governs automatic tariff cuts and hard fought battles over lists of exceptions that would not fall under this formula suggests that control remains a crucial factor governingdecision-making in the trade regime, even when negotiations only concern tariffs and not international rule making.

\section{Conclusion}

Having reviewed the trade regime's decision-making structures in their historical context several conclusions can be drawn. One of the most important amongst them is that formal rules of decision-making only paint a very incomplete picture of how decisions are actually taken. The informal practices that developed after the demise of the ITO are crucial to take into account when desiring to understand how decisions are taken in the trade regime. Examining these informal practices also shows that centralization and asymmetrical control are more prominent institutional design features of the trade regime than the formal structures would suggest. Especially the techniques that accompany active consensus are a strong indicator in this respect. However, considering their ad hoc nature it is questionable whether these institutional features can really be thought of as outcomes of conscious rational design. 
This is not to deny potential benefits of such an ad hoc approach. Taking informal small group meetings as one of the most important features of active consensus, the advantages of informality and ad hoc centralization become apparent. The composition of small groups is flexible and can consequently be adapted to the demands of an issue under negotiation. It lies in the nature of trade negotiations that the same set of parties can have congruent interest when negotiation on one particular product or rule, but highly diverging interest when another product or rule is concerned. A formal body with limited and relatively static membership that is supposed to be representative of all the regime's members would not have the advantage of flexibly adapting actor constellations according to the issue under consideration. The ad hoc nature of informal decision-making also ensures that the regime is able to flexibly adapt to changes in geopolitical realities. When countries gain in geopolitical importance this can be translated into decision-making without major institutional reform - if one thinks of discussions about the reform of the UN Security Council or the IMF's Executive Board it becomes clear how this could be advantageous. Furthermore, decisions reached by consensus can accurately balance the competing sets of decision-making. Passive consensus satisfies weak states since it is theoretically very egalitarian, while active consensus satisfies powerful states since it takes geopolitical realities into account. This can increase the chance that decisions are regarded as legitimate and that they will actually be implemented. ${ }^{146}$

However, despite these advantages the risks of relying on consensus and informality in the way that it is done in the trade regime should also be acknowledged. The methods that accompany active consensus are context dependent and while they can work efficiently, this only works when the involved actors have the ability to negotiate constructively and eventually agree on a decision. When this is not the case the large amount individual control ensured by passive consensus implies that decision-making can easily get paralyzed. This could happen when the group of actors dominating the active consensus system increases in terms of number or if their interests are so heterogeneous that they cannot reach an agreement (Curzon \& Curzon, 1973; Steinberg, 2002). Also, the informality of many procedures potentially reduces transparency and actors excluded from small group meetings might get alienated. When the delicate balance that the combination of passive and active consensus strikes breaks down, an organization with a large membership but no institutionalized form of centralized decisionmaking can have a difficult time to function.

Another important conclusion is that in the development of decision-making structures maintaining control was always the more important factor than the potential efficiency gains from further centralization. This is clearly exemplified in the development of institutional bodies as already described in section 3.2.3.3, but to a certain extent also by the underlying motivation and debate to change the approach to tariff negotiations from item-by-item to automatic reductions. As VanGrasstek (2013) puts it:

${ }^{146}$ These advantages where pointed out in several interviews (e.g. Int05, Int09, Int17). 
"In the trade-off between the community interest in facilitating the adoption of new trade agreements and the interest of sovereign states in maintaining their authority to reject undesirable pacts, the WTO membership has always shown a decided preference for the latter." (p.219.

Finally, from the combination of the informal approach with the primacy of individual control path dependencies emerge that prohibit formal institutional changes in centralization and control which are significantly different from existing practices. Lock-in effects emerge that make it close to impossible to formally centralize decision-making in favor of efficiency and to institutionalize asymmetrical control. An examination of the negotiations during the Uruguay Round reinforces this conclusion.

\subsubsection{Negotiating Design Sets during the Uruguay Round}

It has been pointed out above that the outcome of the Uruguay Round in terms of decisionmaking structures of the WTO is slightly puzzling. Although theoretical arguments would suggest an increase in centralization as a response to an increase in number and control mechanisms representing asymmetrical influence of actors, none of this occurred despite the fact that design proposals were discussed during the Uruguay Round negotiations that would have had this effect. Quite to the contrary decision-making structures resulted from the Uruguay Round that where formally even less centralized and more egalitarian than those of the GATT. Consensus as a decision-making principle was formalized, required voting thresholds to take decisions were increased, and no replacement for the Consultative Group of 18 - which was discontinued during the round - was established. This outcome is to be explained by the prevalence of control as the dominant factor influencing strategic calculations of actors during the design process of legislative institutional features, and by the influence of path dependence and historical experience. The prevalence of control and impact of history are reflected in three discussions that characterized the Uruguay Round's negotiation of legislative design features. Two of them the discussion about the establishment of an institutional body with limited membership and the negotiation of voting procedures - relate to pooling, and one - the discussion about the role of the Secretariat in the trade regime - relates to delegation. Each of them will be reviewed in the following sections.

\section{No Institutional Body with Limited Membership}

The discussion about the establishment of an institutional group that would be limited in its membership took place twice during the Uruguay Round. The first time it took place was well before the idea to create a new international organization was introduced. In this respect it needs to be pointed out that it belonged to the FOGS group's mandate to explore the improvement of the effectiveness of decision-making in the GATT by considering further involvement of ministers in the GATT. In this context it was Australia that launched a proposal in April 1987 to establish a permanent ministerial steering group that would be similar to the 
Consultative Group of $18 .{ }^{147}$ Developed countries tended to be in favor of the proposal, but varied in their ideas about the authority of such a group. While the US imagined it to be a GATT "steering body"148 others thought it would merely provide intellectual and political input in a way that would not be formally related to work of the GATT ${ }^{149}$ (Croome, 1999; Xu \& Weller, 2004). However, developing countries were strongly opposed, and being afraid that they would be excluded from such a group they argued that the establishment of such a group would undermine the legal equality of GATT members (Croome, 1999; Paemen \& Bensch, 1995; Xu \& Weller, 2004). ${ }^{150}$ These positions remained until the Montreal midterm review in 1988 and although the De la Paix Group ${ }^{151}$ submitted a text in preparation of the midterm review that called again for exploring the possibility to establish a smaller ministerial group, the issue was essentially ignored during the midterm review (Croome, 1999). After the midterm review Julio Lacarte replaced Juliuz Katz as the Chairman of the FOGS group. Lacarte was highly critical towards the idea of an exclusive group in his position as Uruguayan representative (VanGrasstek, 2013). ${ }^{152}$ As the Chairman of the FOGS group he suggested in 1989 to set discussions about a small ministerial meeting group aside, since there was hardly any possibility to make progress on this issue (Croome, 1999)..$^{153}$

The second discussion was triggered by the United States in 1990. As a response to the EC's organizational proposal submitted in summer 1990 in the FOGS group, the US argued to implement the results of the Uruguay Round by use of a protocol and suggested to create an effective, small management group consisting of 18 members (Steger, 2000). ${ }^{154}$ The group would have potentially replaced the Consultative Group of 18 and contrary to the Consultative Group of 18 was even supposed to have decision-making powers as delegated by the CONTRACTING PARTIES. In light of these vast authorities the proposal triggered even more controversy than the first time when idea to establish a limited membership group was brought up. The reaction of developing countries was quite hostile considering that they thought the issue was settled after the Montreal midterm review. One delegate described the suggestion as

${ }^{147}$ MTN.GNG/NG14/W/2 and MTN.GNG/NG14/W/16/Rev.1

In these documents Australia suggested to maintain the practice of occasional Ministerial Meetings involving the entire membership and more regular meetings of a small representative group of Ministers to guide the policies of the GATT.

Similar views, suggesting to strengthen the Consultative Group of 18 were already expressed during the preparatory phase of the Uruguay Round. See PREP.COM(86)W/27

${ }_{148}$ MTN.GNG/NG14/W/9

149 Proposals representing this view were made by Canada (MTN.GNG/NG14/W/10), Switzerland (MTN.GNG/NG14/W/7 and MTN.GNG/NG14/W/15) and a number of other contracting parties (MTN.GNG/NG14/W/30).

150 This view was explicitly expressed in communications by Jamaica (MTN.GNG/NG14/W/11 and MTN.GNG/NG14/W/22)

${ }^{151}$ The De La Paix Group was an informal coalition of several GATT members that influenced some of the outcomes of the Uruguay Round.

152 This was confirmed by Lacarte himself in an interview conducted for the WTO Creation Project. The interview can be retrieved from: http://www.wtocreation.org/videos?video=31948117

${ }^{153}$ MTN.GNG/NG14/11

154 MTN.GNG/NG14/W/45 
"hegemonic" (Croome, 1999). Although some developed countries' delegations suggested the issue to be picked up later in the context of the organizational negotiations (Croome, 1999), clearly the establishment of a limited group was politically not feasible. As a former negotiator put it in an interview: "The US attempted to argue for it a little bit in the negotiations... but they were completely blown out of court - immediately" (Int01). According to a former Secretariat member, "it was simply more than the market could bear" (Int06). ${ }^{155}$

Clearly the negotiation dynamics show that considerations of control are of primary importance. Those parties likely to be excluded from a body with limited membership are naturally opposed to it. Losing control over substantive decisions was a major concern as expressed by Julio Lacarte, who explained that Uruguay was opposed to the establishment of an exclusive body "not only because we would be part of such a body only infrequently, but mainly due to the inescapable fact that in the GATT (and now, in the WTO) there exists a very thin line between substance and procedure" (quoted in VanGrasstek, 2013, p. 207). ${ }^{156}$ Generally, the importance to stay in control of decisions is also expressed by a statement of a former negotiator from India, who mentioned that:

"India was not too concerned about having an organization that administered the different sort of agreements, but India was more worried about how the decisions would be taken by this kind of organization [...] We were most keen that every member should have an equal voice. It should not become like the IMF or the World Bank." (Int16)

Taking the GATT's history into account it also becomes clear what the impact of path dependency and lock in effects is. Finding a compromise on the establishment of a group with limited membership is extremely difficult. Either one is part of an exclusive group or one is not part and renders individual control - at least temporarily in case of rotating membership. Thus, the group of beneficiaries from such an institutional body needs to be sufficiently powerful to impose such a body on those who would lose out from it. In this sense a paradox emerged throughout the history of the GATT. With an increasing membership the functional gains in terms of more centralized decision-making would increase, while at the same time a larger membership makes it increasingly difficult to establish an exclusive institutional body. During one interview it was pointed out that it might have been possible to establish a steering group while membership was small and members where alike, but that an increase in number and diversity of interest prohibited this under the WTO (Int11). Another former negotiator pointed out that the existing GATT structures made changes towards further centralization of decisionmaking and establishing asymmetry of control extremely difficult: "You cannot go from one man

\footnotetext{
${ }^{155}$ For the discussions that took place in the FOGS group at the time, see MTN.GNG/NG14/20.

Also another negotiator confirmed that developing countries were opposed to the idea of group with limited membership (Int18).

${ }^{156}$ This statement can also be found in the recorded interview with Ambassador Lacarte on the website of the WTO Creation Project.
} 
one vote, to here are the guys who have all the power and the rest is just running along or having to play a different game" (Int01). Timing and power are of crucial importance to setup formal institutional structures of asymmetrical control like an executive body. As a former US negotiator indicated:

"Developing countries would never have agreed to that. They did so at a time when the IMF and the World Bank were created at the end of World War II, because they were pretty powerless and we had all the money. But they would never have agreed to that with the setup of the WTO. So it wouldn't have been possible to do that." (Int09)

As it has been argued previously, informal procedures where already developed throughout the history of the GATT to accommodate for the absence of centralized decision-making. In light of this the question arises whether there was even a strongly perceived need to establish an exclusive body and to push more firmly for its establishment at the time. Although the informal procedures where already criticized during the Uruguay Round for their exclusivity and a lack of transparency, they were preferred to formalized exclusivity (Croome, 1999; Paemen, 2005). Croome summarizes this debate in the following way:

"Some countries [...] suggested that a limited ministerial group firmly tied to GATT would be preferable to the twice-yearly informal meetings of trade ministers which were currently taking place with no generally accepted mandate and with obvious gaps in representation. Others replied that, even if excluded from the present informal meetings, they could at least ignore them: they did not wish to find themselves still on the outside of a restricted ministerial group which had been granted legitimacy within GATT." (1999, p. 131)

The rationale exemplified in this quote highlights the politically convenient, but hypocritical nature that the combination of passive and active consensus allows for: the illusion of sovereign equality can be maintained, while political realities are taken into account. ${ }^{157}$ This advantage would have disappeared with the establishment of formally exclusive institutional features. Also it might have been the case that the powerful countries were sufficiently confident that they could exert influence without further formalization of asymmetrical control (Steinberg, 2002). A former negotiator and current Secretariat member from a developing country thinks that the big players expected "that they would continue to being the influential players and that they don't need certain structures" (Int04). ${ }^{158}$ After all, the power play that developed countries used to close the Uruguay Round with the reinterpretation of the single undertaking proved that this was possible (Steinberg, 2002).

Another advantage of the informal system reducing the necessity to formalize centralized, asymmetrical decision-making lies in its flexibility. Being asked whether the existing informal

\footnotetext{
${ }^{157} \mathrm{~A}$ former negotiator and secretariat member pointed in a similar direction, in relation to exclusive meetings he stated that: "As long as you don't try to institutionalize it you can do it, I think" (Int17).

${ }^{158}$ Another former negotiator from the EC hinted at the same point (Int18).
} 
decision-making practices can be regarded as a substitute for more formal ones a former US negotiator answered:

"Yes, and the virtue of having an informal thing is that you can be flexible. If you are the DG and you organize a Green Room that a lot of African countries care about, you can have more of them involved. If it's an issue the Latin Americans care about, you can have them involved." (Int09)

The statement of another former negotiator supplements this view:

"The idea that you would have some sort of Security Council does not make sense, because the dynamics are different, depending on the agreement. The type of people you have on one issue and the position they have on this one issue is completely different if you go to another issue. If you have something like CG.18, it only works on a broad basis. It does not work anymore if you get to the nitty gritties.

Having said that: you always had the Green Room. It was just that. So why formalize it?"159 (Int05)

Overall, the strong opposition in an established institutional context characterized by formally egalitarian decision-making provisions and the existing informal substitutes, seem a to be a plausible set of explanatory factors for the absence of institutional bodies with limited membership in the WTO.

\section{Decision-Making Provisions}

Historical legacy and concerns over individual control also affected the negotiation dynamics about decision-making provisions of the WTO. The GATT's legacy clearly influenced these provisions as they are mainly an institutionalization of the practices that had already existed in the GATT (World Trade Organization, 2007). It has been pointed out in section 3.2.3 that the negotiation of the WTO's institutional setup consisted to a large part of an exercise in codifying existing customs and traditions. Designing decision-making practices was no exception to this, as a negotiator involved in this process clearly stated (Int01). However, as Ehlermann and Ehrig (2005) rightly point out, the GATT is only a "partial answer to the question where the rules on voting in the WTO Agreement come from"(p. 61). After all the precise provisions in the WTO Agreement make the process of decision-making considerably more difficult than those of the GATT. This is due to the codification of decision-making by consensus, which was an informal practice in the GATT, and due to the increase in voting thresholds in the WTO. The explanation for this development is to be found in the concerns over individual control.

Contrary to the negotiations about an institutional body with limited membership such concerns did not primarily stem from the trade regime's weakest members, but from some of its

\footnotetext{
${ }^{159}$ Similar views were also expressed in other interviews with former negotiators and secretariat members.
} 
most powerful ones - the United States in particular. ${ }^{160}$ Throughout the negotiations of the organizational provisions the US was worried that if decision-making rules would be too lax it could be outvoted by a majority of members - presumably a coalition of developing countries, who by that time formed the large majority of contracting parties. The US wanted to avoid that decisions could be taken by others which it was not prepared to accept (Croome, 1999; Ehlermann \& Ehrig, 2005; Patterson \& Patterson, 1994; Stewart, 1993; VanGrasstek, 2013). According to a former US negotiator staying in control of legislative decisions was especially important in light of the creation of a stronger dispute settlement system, which makes substantive agreements more enforceable (Int02). Another former US negotiator pointed out in an interview that "developed countries could never win a vote against a solid block of developing countries. That is a very important reason to keep consensus: to protect the developed countries against developing countries" and that voting thresholds were designed to make decision-making more difficult because "from an American standpoint we were writing a constitution that we did not want anybody messing around with later on" (Int09). The fact that decisions on voting provisions are always highly distributional made the negotiations about such provisions extremely difficult (Croome, 1999). How the two factors - history and control unfolded in the negotiation process can be estimated by examining the evolution of voting provisions from the GATT, over the different drafts of the organizational agreement during the Uruguay Round, to the WTO agreement. ${ }^{161}$

In one of the first comprehensive drafts for the establishment of an organization - the draft that was produced in late 1991 and annexed to the text of the Dunkel draft - the general provisions for decision-making were almost identical to those of the GATT. The draft states that "each member of the MTO shall be entitled to one vote, and, except as otherwise provided in this Agreement, decisions [...] shall be taken by a majority of votes cast" (Art. IX.1). The only main difference to the GATT was the reference to members instead of contracting parties. Probably the drafters of the text assumed that adding the provision that the "MTO shall respect the rules, decisions and customary practice of the" GATT (Art.XVI.1) would suffice to ensure that the informal practice of taking decisions by consensus would continue in the new organization. This general provision was not significantly changed in a revised draft produced in March 1992. ${ }^{162}$ However, concerns over control were sufficiently large to make the provision for

160 It should be pointed out that the US was not the only party concerned about voting provisions and individual control. Japan and others had similar concerns (Croome, 1999). However, according to Steger (2002c) the

"United States was the strongest proponent of decision making by consensus in the Uruguay Round because it realized that almost all other countries in the world are allied in some sort of regional or other grouping, and as a result, it feared that it could be overruled by a coalition of, for example, developing countries or by the EU and countries informally aligned with the EU"(p.568).

${ }^{161}$ Similar comparisons of the GATT text, drafts and the final WTO agreement can be found in Croome (1999) and VanGrasstek (2013).

${ }^{162}$ The revised 1992 text can be found in Stewart (1993). 
consensus explicit and defining its meaning in the agreement that eventually resulted from the negotiations. The WTO Agreement states in Article IX.1 that

"The WTO shall continue the practice of decision-making by consensus followed under GATT 1947. Except as otherwise provided, where a decision cannot be arrived at by consensus, the matter at issue shall be decided by voting [...] each Member of the WTO shall have one vote [...] Decisions of the Ministerial Conference and the General Council shall be taken by a majority of the votes cast, unless otherwise provided in this Agreement or in the relevant Multilateral Trade Agreement."

In a footnote added to the first sentence consensus is explicitly defined by the absence of a formal objection to a proposed decision.

Also other provisions, like those for interpretations of agreements and waivers, exhibit an evolution towards more difficult decision-making. On interpretations the 1991 draft provides the Ministerial Conference or the General Council with the right to interpret substantive agreements without specifying a majority (Art. IX.2). In the 1992 draft it is suggested that interpretations would either require consensus or a two-thirds majority (Art. IX.2). Those two options were placed between square brackets, indicating disagreement about the preferred provision and the need for further negotiation. Eventually the threshold for interpretations was even increased as a result of the negotiations. The WTO agreement requires in Article IX.2 a three-fourths majority and explicitly prohibits the use of interpretations to undermine the amendment provisions. For waivers the two drafts issued in 1991 and 1992 required a twothirds majority comprising more than half of the organization's members (Art. IX.3). Also in this case decision-making was made substantially more difficult in the eventual text that resulted from the negotiations. According to the WTO Agreement consensus is required to grant a waiver and if consensus cannot be reached, a vote requiring a three-fourths majority is necessary. Certain kinds of waivers are even exempted from the possibility of a vote and can only be granted by consensus (Art. IX.3).

Conducting the same comparative exercise for amendment provisions yields the same insights. In the 1991 draft amendments were required to be agreed upon by consensus, but would become effective for all members once two-thirds of the membership accepted it (Art. X). In comparisons to the GATT's amendment provisions this was a significantly lighter procedure. The GATT required unanimous acceptance to amendments of its most crucial provisions and acceptance by two-thirds of contracting parties for less important provisions. Yet, those amendments requiring a two-thirds majority would only have been binding upon those contracting parties that accepted them (Art. XXX). The amendment provision specified in the 1991 draft was a conscious attempt by the Canadians and Europeans to ease the amendment process, which had led to great difficulties in the past and made the GATT almost impossible to amend (Jackson, 1969, 1978, 1990; VanGrasstek, 2013). However, once again this functional motivation was compromised by considerations of control. Many square brackets in the 1992 draft indicate the difficulty of negotiating the amendment provisions. The draft in essence 
indicates a split amongst delegations on the question whether an amendment should take effect upon all members once it has been agreed by consensus to submit it for acceptance and twothirds of the membership have accepted, or whether it should only take effect upon those members that actually accepted it. Even for the first option the 1992 drafts caters to concerns over control in comparison to the 1991 draft by permitting the Ministerial Conference to suspend the entry into effect of the amendment for a particular member upon request by that member. On top of the debate as reflected in the 1992 draft some delegations considered to introduce a unanimity requirement for the amendment of the most crucial provisions of the new organization (Stewart, 1993). Although the $1992 \mathrm{draft}$ did not mention this, it was eventually included in the WTO Agreement. Article X of the WTO Agreement provides for rather complex amendment procedures. Consensus on deciding on the submission of an amendment for acceptance is the default rule and only if no consensus can be reached a two-thirds majority is required to take this decision. Some types of amendments require unanimous ratification, others require two-thirds of the membership ratifying but are only applicable to those members that did ratify them, and only those amendments that do not alter rights and obligation are applicable to the entire membership upon ratification of two-thirds of the members.

Clearly tracing the evolution of decision-making provisions during the negotiations shows the impact of historical legacies and control. Drafters took the GATT provisions as a guideline and tried to translate the spirit of the GATT into the WTO. According to a former EC negotiator, delegates aimed to codify decision-making in such a way that it attempted to be "an honest interpretation of what happened in GATT" (Int01). The impact of concerns over individual control ensured that this codification exercise eventually resulted in more difficult decisionmaking procedures in the WTO, which were nonetheless based on the spirit of the GATT. The increase of individual control was positive at the time since the agreed voting provisions "were crucial to the acceptability of the new trade organization" (Croome, 1999, p. 315). Already during the negotiations in informal meetings in early 1993 a lot of ideas were developed on voting to accommodate for the US' skepticism regarding individual control (Croome, 1999; Jackson, 1997). A former US negotiator pointed out in an interview that the reassurance of individual control was an important factor in getting congressional agreement on the WTO, stating that "one of the things we took back to Congress was: If you don't like some new agreement that is negotiated, we can block it" (Int02). Clearly designing appropriate control mechanisms was crucial to permit for the establishment of the WTO, even if they compromised on centralization.

It should be mentioned thought that this compromise is not unproblematic with respect to the WTO's ability to fulfill its legislative functions. The codification of consensus paved the way for a new dynamic of decision-making. Consensus is the only practice used in the WTO and voting has become more of a taboo than it was in the GATT (Ehlermann \& Ehrig, 2005; VanGrasstek, 2013). Taking a vote in the WTO is practically unthinkable. ${ }^{163}$ Even decisions on

${ }^{163}$ The excessive reliance on consensus was apparently already perceived to be problematic in the GATT. This is exemplified by proposals made by the Nordic Countries during the Uruguay Round, suggesting to not rely on 
waivers and accessions, which were voted upon in the GATT, are taken by consensus in the WTO (VanGrasstek, 2013; World Trade Organization, 2007). It is questionable whether negotiators intended this development at the time of the Uruguay Round, considering that they spend a lot of time on the difficult negotiations about the exact voting provisions. Apparently the voting procedures where thought of as a genuine institutional feature to fall back on in case consensus would not be functional. ${ }^{164}$ One negotiator expressed the opinion that

\begin{abstract}
"the codification we actually came up with has never been tested in the spirit in which we codified it [...] what we codified was not the exclusive consensus decision-making, which we see in practice at the moment. What we tried to codify is that the preferred choice is consensus, but if it is established that consensus cannot be reached, then we go to voting." (Int01)
\end{abstract}

The exclusive reliance on consensus in the WTO complicates decision-making and makes the legislative system prone to deadlock. Certainly the problems of WTO decision-making stem from a variety of sources, with some of them being potentially more important explanatory factors of current difficulties. Also it would probably be unwise to turn away from consensus as it is likely to be the most elegant option to balance to competing demands on decision-making. ${ }^{165}$ However the emphasis on control that resulted from Uruguay Round is problematic since it removed the shadow of a vote in the process of seeking consensus (Ehlermann \& Ehrig, 2005). As pointed out by a former Secretariat member, "consensus decision-making against the background of a vote - as done in the GATT - is completely different from consensus as a legal requirement" (Int14). The shadow of a vote is very important for the process of active consensus as it deters actors that are clearly in a minority position to obstruct decision-making for minor or irrelevant reasons (Ehlermann \& Ehrig, 2005; Kissack, 2011). ${ }^{166}$ Thus, while enabling the establishment of the WTO, the control mechanisms introduced complicates its legislative functioning.

\title{
The Secretariat
}

Such complications could theoretically be reduced by delegating further authorities to the Secretariat, to strengthen its role in the facilitation of negotiations and decision-making.

consensus for "minor" decisions (MTN.GNG.NG14/W/17 and MTN.GNG.NG14/5). These suggestions where not taken up during the negotiations.

${ }^{164}$ This was indicated in interviews with former negotiators (Int01, Int04, Int09, Int19).

165 Some argue that the decision-making procedures of the WTO themselves are not problematic and probably the best ones possible. According to this view the problem lies with member's commitment to use them in a proper manner (Yerxa, 2001).

166 One example of reaching consensus in the shadow of a vote occurred in the process of launching the Uruguay Round. Facing a paralyzed GATT Council the US tested whether there would be sufficient support for a new trade round by requesting a special Session of the CONTRACTING PARTIES. Such a request would have required a two-thirds majority vote by at least half of the membership. This was the same majority that would have been required to launch a new round. The fact that the US got sufficient support to call for a Session of CONTRACTING PARTIES implied that there would also be sufficient support for launching a trade round and paved the way for consensus on that matter (Croome, 1999). 
Proposals to this effect were made in the course of the FOGS negotiations. However, despite the fact that the establishment of the WTO implies that for the first time the Secretariat's role in the facilitation of decision-making is formally recognized in the trade regime, its role did not increase as a result of the Uruguay Round (Xu \& Weller, 2004). ${ }^{167}$ During the first official meeting of the FOGS group in April 1987 some delegations already expressed the view that the responsibilities and the role of the Secretariat should be strengthened. ${ }^{168}$ This view was reinforced in July by a communication from Canada. ${ }^{169}$ During a meeting in July 1988 such calls got more specific. On behalf of the Nordic countries the representative of Sweden argued that the institutional powers of the GATT should be increased and its identity strengthened. Equipping the Director-General with the right to propose negotiations on specific topics was amongst the more specific suggestions mentioned in this context. ${ }^{170}$ The reaction by other delegations was mixed. Some liked the idea, others questioned whether formalization of such functions is necessary, some expressed concern over the financial implications of equipping the Secretariat with more functions, while others where outright opposed to the idea. ${ }^{171} \mathrm{~A}$ similar suggestion to the one of the Nordic Countries was made by Switzerland in May 1990, calling for a more independent role of the Secretariat also with respect to the preparation of ministerial meetings. ${ }^{172}$ Again the suggestion lacked sufficient support. The concern was expressed that strengthening the Secretariat would enlarge the jurisdictional competence of the GATT and go beyond the mandate of the FOGS group. ${ }^{173}$ The proposal was regarded to be unacceptable since it would change the Secretariat into and institution with independent status. ${ }^{174}$ Also the EC's suggestion to create a new organization triggered concerns that it would imply a strengthening of the Secretariat's role (VanGrasstek, 2013). ${ }^{175}$

The discussions in the FOGS group indicates that a decisive group of members was not prepared to formally increase the role of the Secretariat and provide it with more independence. ${ }^{176}$ It seems the members wanted to retain control and not change the Secretariat's role that had incrementally evolved throughout history. The Secretariat was supposed to stay small, lean, and without the formal right to initiative. Especially the last point

167 It is argued that its informal role in decision-making even decreased since the establishment of the WTO (Elsig, 2010).

${ }_{168}$ MTN.GNG/NG14/1

169 MTN.GNG/NG14/W/10

${ }^{170}$ MTN.GNG/NG14/W/17

${ }_{171}$ MTN.GNG/NG14/8

172 MTN.GNG/NG14/W/41

${ }^{173}$ MTN.GNG/NG14/17

174 MTN.GNG/NG14/18

175 MTN.GNG/NG14/18

176 Regarding formalization of its role, it seems that even the Secretariat itself was skeptical regarding the merits of related proposals. Apparently the Secretariat was concerned that formalizing its role in a negotiated text would leave it with less powers instead of more (Croome, 1999). 
was crucial as indicated in interviews with former US and EC negotiators (Int01, Int09). ${ }^{177}$ Clearly the trade regime was supposed to stay member driven.

\subsubsection{Conclusion}

Recapitulating the preceding section it becomes clear why the desire to keep the regime member driven is one of its most resistant institutional characteristics. The connotation of a 'member driven organization' itself points to the interaction of centralization and control, where the former institutional feature is referred to by the term organization while the latter by the term member driven. This interaction has been reviewed and it has been clarified that theoretical predictions of how it is supposed to unfold in real-world institutional design exercises are extremely difficult, due to the complexity of designing decision-making mechanisms for international organizations. The recourse to historical process tracing has shown that the idea of a member driven organization was engrained in the GATT's roots from the beginning. The GATT's unorthodox institutional development that resulted from the failure of the ITO and that needed to stay underneath the radar of domestic scrutiny fostered the emergence of institutional structures that permitted large amounts of high individual control and inhibited the occurrence of a strong, independent Secretariat. Whenever centralization increased at the cost of individual control this was ad hoc and context dependent. This allows for flexibility and allows to balance the competing demands of decision-making structures, but entails the risk of deadlock when contextual factors such as actor constellations and interests prohibit efficient decision-making by ad hoc centralization.

Given the GATT's institutional history the dynamics that unfolded during the Uruguay Round are hardly surprising. The preponderance of formally high individual control led to lock in effects: weak countries rejected to give up this privilege in the discussions about an institutional body with limited membership; strong countries desired to guarantee individual control in the future by explicitly codifying the past practice of consensus decision-making - and thereby changed the dynamic of decision-making; and the membership as a whole was not ready to increase delegation by expanding the role of the Secretariat. Clearly functionalism was compromised, if not dominated, by concerns over control playing out in a setting of historically developed institutional trajectories. Yet given the complexities of designing control features, the trade regime's decision-making structures might be flawed, but possibly the best ones available.

177 Another former negotiator pointed out that in addition it was tempting to keep the secretariat small to keep expenditures for the newly established organization limited (Int18). 


\subsection{Conclusion}

After two failed attempts to create a formal organizational structure for the trade regime the establishment of the WTO finally provided for such a structure. As such the creation of the WTO can be regarded as a significant institutional change. This chapter aimed to explore why this change came about, how it came about, and why the WTO took the institutional form that it did. All in all it can be concluded that the rational design framework is a useful starting point to find answers to these three questions. On a high level of abstraction it can reasonably account for the creation of the WTO as an instance of centralization. However, it misses out on details and causal depth, which is necessary to answer the three questions comprehensively. On its own rational design cannot explain why centralization went as far as it did; nor can it explain why centralization was not taken further. Such nuances should not be neglected. As it has been shown in section 3.2.1 of the chapter, the creation of the WTO as such clearly counts as an instance of centralization, but only to a limited extent with respect to the organization's legislative and administrative functions. To explain this, the chapter relied on process tracing with an emphasis on the historical development of the GATT's institutional structures, the negotiation dynamics of the Uruguay Round, and the interaction of centralization and control. This clearly shows that rational design can explain the occurrence and form of the WTO only to a limited extent. While the underlying motivations for changes in centralization might be functional in nature, they are moderated or even distorted by historical context, negotiation dynamics and concerns over control.

Taking the historical perspective it is evident that the creation of the WTO cannot be interpreted as a single moment of institutional design, but rather as a significant last step on an institutional pathway that developed incrementally. This incremental development casts doubts of the conceptualization of actors as perfectly rational agents. The designers of the trade regime's institutional structure heavily relied on past practices as a source for ideas on future institutional design. Furthermore they were heavily influenced and inhibited by path dependent trajectories that limited possibilities of institutional design and required functionally sub-optimal arrangements of centralization. As such the historical investigation explains why the WTO took the shape that it did and also helps to explain why centralization could not be carried further.

Examining the negotiation dynamics of the Uruguay Round in turn helps to explain why centralization went as far as it did and why it was actually possible despite initial opposition by the US as powerful veto player. The negotiation process of the Uruguay Round highlights that institutional matters cannot be understood in isolation of substantive negotiations. It was possible to create the WTO because it was a means to ensure negotiation outcomes on substance that were advantageous for the most powerful parties. This does not put the functional assumption in question that the creation of an international organization is a useful means to facilitate the implementation of substantive agreements, but highlights that it does so on the terms of the most powerful. The power-play that led to the reinterpretation of the single 
undertaking also highlights that power asymmetries are necessary to overcome the coordination problem of reaching an agreement when interests are heterogeneous. It is unlikely that the US would have accepted the creation of the WTO if developing countries had been powerful enough to prevent the reinterpretation of the single undertaking. This explains why centralization was possible.

The interaction of centralization and control in turn is complementary to the historical account on the form that centralization took. The path dependencies that evolved throughout the trade regime's institutional history were reinforced in the WTO's institutional architecture, leading to a high level of formal control and limited institutional autonomy. Clearly throughout the regime's history and during the Uruguay Round considerations of individual control where highly important to all parties involved. The gains of reducing transactions costs of more centralized decision-making where certainly of secondary importance compared to considerations of control. This led to context dependent ad hoc centralization, which is characterized by a reliance on informal procedures.

Taking these different facets of the design process explicitly into account and tracing the process that leads to institutional design contributes to understand why it was possible to create the WTO and why its institutional structure looks the way it does. In such an exercise functional approaches like the one of rational design can only be regarded as a starting point. They provide reasonably adequate suggestions on the underlying motives for change, but cannot account how those motives are translated into actual design. Some ideas get lost in translation, since the historical context, negotiation dynamics, and design interactions moderate and at times distort institutional design. In case of the WTO this moderation implied that institutional change was more conservative with respect to its administrative and legislative functions than the news of the creation of a new international organization would suggest. For the WTO's judicial function this was significantly different, as it will be shown in the next chapter. 



\section{Adjudication in the Trade Regime: Reforming Dispute Settlement}

$4.1 \quad$ Introduction 173

4.2 The Case as a Matter of Centralization and Control 176

$\begin{array}{lll}4.2 .1 & \text { General } & 177\end{array}$

$\begin{array}{lll}4.2 .2 & \text { Specific } & 178\end{array}$

$\begin{array}{lll}\text { 4.2.2.1 Pooling } & 178\end{array}$

4.2.2.2 Delegation 179

4.3 Explanations of Rational Design 183

4.3.1 Positive Contributions of Rational Design 183

4.3.1.1 The Underlying Rationale (Theoretical Plausibility) 183

4.3.1.2 The Emergence of the Idea and its Rationale (Empirical Plausibility) 185

4.3.2 Problems of Rational Design 190

4.3.3 Conclusion 192

4.4 Design in Context: Historical Legacy 193

4.4.1 Dispute Settlement in the ITO 194

4.4.2 Dispute Settlement in the GATT (Initial Setup) 198

4.4.3 Development of Dispute Settlement in the GATT 201

4.4.4 The Impact of History on the Uruguay Round Negotiations 213

4.4.5 Conclusion 219

4.5 Negotiating Design: Process and Dynamics 221

4.5.1 Strengthening Procedures: Homogenous Preferences and Early Decisions 222

4.5.2 Blocking Decisions: Heterogeneous Preferences, Power and the Grand Bargain 226

4.5.2.1 The United States as Champion of Legalism 227

4.5.2.2 The EC and Pragmatism: Guarding the Status Quo 230

4.5.2.3 The Grand Bargain: Reverse Consensus for Exclusive Jurisdiction 231

4.5.3 Spin-off Design Changes 244

4.5.3.1 Compulsory Jurisdiction, Exclusive Jurisdiction and the Appellate Body in Relation to the Problem of Blocking 245

4.5.3.2 The Unified System and the DSB in Relation to the Expanding Scope of the Trade Regime and the Establishment of the WTO 251

4.5.4 Conclusion 256

4.6 Design Interaction: Centralization and Control 258 
4.6.1 Control of the DSB as an Instance of Pooling 259

4.6.2 Control of Delegation in Dispute Settlement: Panels and the Appellate Body 261

4.6.3 The Impacts of Dispute Settlement: Control over Domestic Implementation 266

4.6.4 Conclusion 268

$\begin{array}{lll}4.7 & \text { Conclusion } & 269\end{array}$ 


\subsection{Introduction}

While the previous chapter pointed out that the establishment of the WTO with respect to its administrative and legislative features cannot be regarded as a revolutionary outcome of the Uruguay Round, the same can certainly not be said for the changes in dispute settlement that resulted from the round. It is generally acknowledged that these changes constitute a fundamental constitutional reform that had a lasting effect on the functioning of the trade regime. Van den Bossche and Zdouc (2017) point out that the dispute settlement system as it emerged from the Uruguay Round is referred to as the 'jewel in the crown' of the WTO and they argue that it has "been the most prolific of all intergovernmental dispute settlement systems" (p. 22). Bohne (2010) even claims that it constitutes probably the most important international tribunal. Clearly the procedural institutional framework of dispute settlement that had developed pragmatically throughout the history of the GATT was elevated to an unprecedented level and constitutes one of the most centralized dispute resolution mechanisms in the international arena. Dispute settlement was transformed from a system where every party including the one losing a dispute - had to agree to the outcome of the process for such an outcome to become binding, to a quasi-automatic, court-like procedure. The main characteristic of the changed system is the strengthening of the judicial approach to dispute resolution at the expense of a more political approach that had relied on negotiation and less rigid procedures to allow for the resolution of disputes in a politically acceptable way. This led some commentators to assert that 'law won over politics' (Mora, 1993-1994; Young, 1995). Regardless of questions about victory and defeat, the changes were significant and can be described as 'legalization leap' (Elsig, 2014; Elsig \& Eckhardt, 2015).

This legalization leap consists of several institutional changes that resulted from the Uruguay Round. These changes included the unification of the dispute settlement system, covering all of the WTO's substantive agreements under a single Dispute Settlement Understanding (DSU). The Dispute Settlement Body (DSB) has been established to administer this unified system and to systematically monitor the implementation of the outcomes of dispute settlement procedures. Furthermore, and in contrast to the GAT's system, the DSU provides for compulsory and exclusive jurisdiction. The latter greatly contributes to centralization by prohibiting unilateral and other non-multilateral measures to resolve disputes on matters covered by the multilateral trade regime. Finally, and potentially most importantly, a standing Appellate Body was created and reverse consensus for the decisions to establish a panel, to adopt panel and Appellate Body reports, and to authorize retaliation was introduced as a result of the Uruguay Round.

Rendering authority to the international level to the extent that is exemplified by the institutional changes in dispute settlement is not only of high empirical relevance, but also constitutes a theoretical puzzle. Of course functional benefits could be used as an explanation, but the large degree of centralization in dispute settlement is nonetheless unusual. After all, the step to reverse consensus in lieu with the other institutional changes ensured that the control 
that the WTO's members can exercise over the dispute settlement process is minimal. In an international environment where sovereignty costs are a significant concern to most states, this outcome should not be taken for granted despite possible functional benefits. Furthermore, purely functional explanations would neglect the fact that influential GATT members, such as the EC, were strong advocates of a more diplomatic and less centralized approach to dispute settlement well into the Uruguay Round negotiations. Post hoc functionalist explanations cannot account for a change in their negotiation position. Consequently, the obvious question that arises and that this chapter seeks to answer is why the increase in centralization of dispute settlement came about.

In answering this question the chapter argues that functional explanations, like those provided by the rational design framework, account for the core motivation to increase centralization in dispute settlement, but that the degree of centralization and the exact institutional design can only be explained by power asymmetries and historical context respectively.

Before this argument is elaborated upon, section 4.2 of this chapter provides the necessary background information and reviews the changes that resulted from the Uruguay Round in the field of dispute resolution in further detail. It is shown that the changes indeed constitute a significant increase in centralization in all of its three dimensions - generally, as delegation, and as pooling. Regarding the last of these three, it is the changed control mechanisms of collective decision-making (reverse consensus) that boosts the degree of centralization to an unprecedented level. Section 4.3 reviews the strengths and weaknesses of rational design as an account for the increase in centralization. This section shows that the core motivation to change the system is indeed accurately captured by the functional explanations of rational design, but that such functional explanations fall short in explaining the exact design of dispute settlement and in explaining how opposing interest could be overcome throughout the negotiations to allow for reform. A first attempt to explain the exact design of dispute settlement is undertaken in section 4.4 of the chapter. By reviewing the institutional development of dispute settlement throughout the trade regime's history this section highlights that despite the revolutionary changes that resulted from the negotiations, large parts of the institutional design of dispute settlement in the WTO are a result of the incremental institutional development that occurred throughout the GATT's history. Furthermore, this section also provides a first explanation why the degree of change was so surprisingly large by positing that designers did not expect such a significant change. This is due to the fact that they estimated the likely effects of the changes in biased manner, influenced by a mindset that strongly relied on experience with past practices. Section 4.5 provides another explanation of the large degree of centralization by highlighting the US' dominant position and its ability to force those negotiating parties that were initially opposed to an increase in centralization to change their negotiating position in favor of more centralization. Section 4.6 pays attention to the interaction of centralization and control and points out that although designers rendered a large degree of control by introducing reverse consensus, they tried built in control mechanisms to compensate for the risks and potential 
costs of increased centralization. However, ultimately this was compromised by their reliance on past experience and the underestimation of the effects of change. Finally, the core tenets of the argument are summarized in a concluding section. 


\subsection{The Case as a Matter of Centralization and Control}

The WTO's dispute settlement system as it emerged from the Uruguay Round constitutes a highly institutionalized approach to resolve international trade disputes. A complex set of nested institutional structures embedded in the WTO ensures that dispute settlement is administered smoothly and follows a clear procedure. The most commonly used procedure consists of up to four steps and involves various institutional bodies: When two of the WTO's members face each other in a dispute, they are first required to resolve the dispute by consultations. Secondly, if such efforts to come to a negotiated resolution of the dispute fail, it is possible to turn to adjudication and ask the DSB to establish a dispute settlement panel. The panel adjudicates and reports on its findings and conclusions in form of a written report, which is adopted by the DSB by reverse consensus. In an optional third step the parties to a dispute have the right to appeal to the findings of a panel upon which a dispute is referred to the Appellate Body to review a panel's findings with respect to questions of law. Once again it is the DSB that is supposed to adopt the Appellate Body's findings by reverse consensus. Finally the outcome of the adjudication process is implemented and enforced. ${ }^{1}$

The emergences of this system can be regarded as an instance of centralization on several dimensions. On a general level a couple of significant changes of the main principles that govern dispute settlement and that are enshrined in procedural legal obligations ensure that the WTO is a stronger focal entity than the GATT used to be. On the more specific levels a change in centralization as pooling with the establishment of the DSB is observable, as well as a change in delegation with the strengthening of the panel process and the creation of the Appellate Body. However, while these changes might already indicate an increase in centralization on their own, their significance was boosted due to the introduction of reverse consensus as a decisionmaking principle of the DSB for the adoption of panel and Appellate Body reports. It is this change in control that is mainly responsible for the increased degree of centralization. This highlights the importance of design interaction. As it was pointed out in previous chapters, it is not only important that a focal entity conducts a certain task, but also how it conducts this task. This in turn is strongly influenced by institutional control mechanisms.

\footnotetext{
${ }^{1}$ This is a highly simplified description of the most commonly used procedure to resolve disputes. Next to this procedure, other means to resolve disputes can be used, namely: arbitration; good offices; and conciliation and mediation. However these procedures are used less regularly.

Regarding implementation and enforcement, this can take different forms. Ideally the losing party of a dispute withdraws those measures that are found to be inconsistent with WTO law as an outcome of the dispute resolution procedure. If this does not happen the two disputing parties can agree on compensation, or the winning party can be authorized by the DSB to retaliate by withdrawing concessions to the losing party.
} 


\subsubsection{General}

Taking the general perspective the WTO emerged as a highly strengthened international organization in comparison to the GATT regarding its dispute resolution function. It can be considered as the main focal entity in the international arena when it comes to the resolution of international trade disputes. The WTO owes this strengthened status in dispute resolution to a set of significant changes of core principles that govern its dispute settlement system.

First of all, and very importantly, the Uruguay Round introduced a unified dispute settlement system. According to Article 1.1 of the DSU, the DSU applies to almost all of the multilateral trade agreements negotiated during the round. This includes the WTO Agreement, the GATT 1994, the General Agreement on Trade in Services (GATS), the TRIPS agreement and the DSU itself. ${ }^{2}$ This stands in stark contrast to the GATT's dispute settlement system as it had emerged from the Kennedy and the Tokyo Round. As it was pointed out previously, the introduction of plurilateral trade agreements that occurred in these rounds let to a fragmentation of the trading system. One of the most significant characteristics of this fragmentation was that each of the plurilateral agreements had its own dispute settlement mechanism. Since the relation between the different mechanisms was insufficiently clarified, forum shopping was an option that GATT parties could use to increase their chances to be successful in settling a dispute (Jackson, 1990; Petersmann, 1994). The WTO's unified dispute settlement system put an end to this, clearly increasing centralization by establishing the DSU as a focal point that members have to refer to in order to settle disputes (Cossy, 2015).

Secondly, the dispute settlement system's jurisdiction is compulsory and exclusive. Both of these characteristics induce members to make use of the WTO's mechanisms for the resolution of international trade disputes, which is amongst the core objectives of the DSU (Van den Bossche \& Zdouc, 2017). With respect to the compulsory nature of the dispute settlement system, according to Article 23.1 of the DSU a complaining member needs to bring a dispute that is covered by the WTO agreements to the WTO. The responding member to the dispute has no opportunity but to accept the jurisdiction of the dispute settlement system, since Article 6.1 of the DSU guarantees the beginning of the panel procedure if the complaining party requests this. The fact that the parties to a dispute do not have the opportunity to individually accept or reject the jurisdiction of the DSU makes the system compulsory. Furthermore, the DSU's jurisdiction is also exclusive. Article 23.1 and 23.2 of the DSU ensure that members have to use the WTO's dispute settlement mechanisms. When a dispute under a WTO agreement arises other international forums are excluded from solving the dispute and unilateral means are prohibited.

Clearly, those core principles increase the WTO's standing as focal entity for the resolution of trade disputes. All of them induce members towards using the WTO's system instead of possible alternatives. However, centralization was also increased on a more specific level.

\footnotetext{
${ }^{2}$ The only multilateral agreement to which the DSU does not apply is the Trade Policy Review Mechanism
} (TPRM). 


\subsubsection{Specific}

When looking at the more specific variants of centralization a closer look at the types of institutional organs that carry out dispute settlement functions is warranted. Both specific variants of centralization are discernible: delegation and pooling. The Dispute Settlement Body (DSB) stands out with respect to pooling. Formally the DSB is the supreme institutional organ in the WTO concerning matters of dispute resolution. However, since its decision-making relies on reverse consensus regarding crucial steps of the dispute resolution process, panels and the Appellate Body - which count as instances of delegation and which are in theory controlled by the DSB - are practically of higher relevance to the process. The relationship of the different institutional bodies as defined by their control mechanisms points to the importance of design sets when analyzing centralization.

\subsubsection{Pooling}

The DSB is the WTO's supreme institutional body with respect to dispute resolution. It was established as a result of the Uruguay Round and is anchored in the WTO's institutional structure under Article IV:3 of the WTO Agreement. As it was mentioned in the previous chapter, the DSB is the sibling of the General Council. It is a political body, consisting of all WTO members, represented on ambassador level. ${ }^{3}$ As its sibling the DSB is placed on the same level within the WTO's hierarchy as the General Council. As Article IV.3 states: "The General Council shall convene as appropriate to discharge the responsibilities of the Dispute Settlement Body provided for in the Dispute Settlement Understanding." The two bodies are only different with respect to their chairman and their rules of procedure. Although the DSB is nothing but an "alter ego" $^{4}$ of the General Council, the provision for the DSB in the WTO agreement is a noteworthy development with respect to centralization insofar as it constitutes the first instance in the trade regime's history that a standing, institutionalized body is exclusively dedicated to dispute resolution. During the times of the GATT it used to be the CONTRACTING PARTIES and the GATT Council that discussed questions related to dispute resolution. However, these bodies also dealt with a variety of other issues.

The DSB fulfills several functions as listed in Article 2.1 of the DSU. Most generally its task is to administer the dispute settlement system. More specifically, it does so by establishing panels, adopting panel and Appellate Body reports, maintaining surveillance of the implementation of rulings and recommendations, and it has the authority to authorize the suspension of concessions (retaliation). Furthermore, the DSB appoints the members of the Appellate Body and adopts the rules of conduct of dispute settlement. Especially the DSB's explicitly mentioned and clearly regulated surveillance function has been interpreted by some commentators as a significant step towards a greater centralized enforcement capacity of the trade regime (Shell,

\footnotetext{
${ }^{3}$ Only when the DSB is concerned with judicial questions on the remaining plurilateral agreements its membership is restricted to those WTO members that are also parties to the respective agreement.

${ }^{4}$ This terminology is taken from Van den Bossche \& Zdouc (2017).
} 
1995; Young, 1995). To carry out these functions the DSB meets as often as necessary, but at least once a month.

Even more important than the establishment of the DSB and the specification of its functions are the changes in the DSB's decision-making procedures. These changes make the reform of dispute settlement truly revolutionary with respect to centralization. Although Article 2.4 of the DSU establishes that the DSB's default decision-making procedure is decision-making by consensus, several key decisions are taken by reverse consensus. Reverse consensus implies that a decision is accepted, unless there is a consensus not to take the decision. The decisions in the dispute settlement process that are taken by reverse consensus include the decision to establish a panel (Art. 6.1) ${ }^{5}$, decisions to adopt panel and Appellate Body reports (Arts. 16.4 and 17.14, respectively), and the decision to authorize retaliation (Art. 22.6). The introduction of reverse consensus makes dispute settlement quasi-automatic, since even the winning party of a dispute would have to join a consensus to stop the process - a highly unlikely scenario.

The introduction of reverse consensus constitutes a significant break with the past. During the times of the GATT every step in the dispute settlement process had to be agreed to by consensus, which enabled the losing party to block the process. Since the process is quasiautomatic, the WTO's autonomy vis-à-vis its membership in the field of dispute resolution has increased in comparison to the GATT (Van den Bossche \& Zdouc, 2017). While formally the DSB takes decisions on dispute settlement, it is unable to control panels and the Appellate Body with respect to key decisions of a dispute. This elevates the importance of panels and the Appellate Body as instances of delegation to unprecedented levels and in practice turns the WTO into a trade court, despite the fact that formally the DSB as a political body is the one that takes decisions on disputes. A closer look at these instances of centralization as delegation is warranted.

\subsubsection{Delegation}

Several entities that can be interpreted as instances of delegation are involved in dispute resolution; amongst them panels and the Appellate Body stand out as the most significant ones. ${ }^{6}$ These entities are involved in the actual adjudication of disputes, and since their findings are quasi-automatically adopted by reverse consensus they are the ones that de facto decide on the ruling in a dispute. This provides them with a highly significant role and is the reason why

\footnotetext{
${ }^{5}$ During the first meeting when the establishment of a panel is requested a decision by consensus is required to establish the panel. However, in the meeting thereafter the decision needs to be taken by reverse consensus (Art. 6.1, DSU).

${ }^{6}$ Van den Bossche and Zdouc (2017) provide a list of other bodies and persons that would count as instances of delegation, but that are less relevant. This list includes arbitrators; the Permanent Group of Experts and the Facilitator that are established under the SCM Agreement, experts who can be consulted in disputes arising under the SPS Agreement and the TBT Agreement, Expert Review Groups, the Chairman of the DSB, and the WTO Director-General.

Of course, the WTO's secretariat plays an important function in dispute settlement as well. The Secretariat supports panels throughout the dispute resolution process. Its supporting role has increased throughout the history of the trade regime. However, the Uruguay Round has not brought about any significant changes concerning the Secretariat's role. The Appellate Body has its own, independent Secretariat.
} 
they constitute important instances of centralization as delegation. In the following each of them is examined in further detail.

Panels are established ad hoc in order to adjudicate a particular dispute. Their composition is governed by Article 8 of the DSU. Accordingly a panel consists of three individuals who are supposed to be well qualified and who have to be independent of the parties involved in the dispute. ${ }^{7}$ Panels are established by the DSU upon request of the complaining party in a dispute, latest during the DSU meeting after the request to establish a panel has been filed (Art. 6, DSU). Finding suitable panel members is facilitated by the Secretariat, which possesses an indicative list of suitable individuals (Van den Bossche \& Zdouc, 2017). ${ }^{8}$ Once a panel is established it is supposed to review whether the measures that a complainant is concerned about are consistent with WTO law (Art. 11, DSU). Panels do so by following clear timeframes and procedures as elaborated in Article 12 of the DSU. Panels present their findings in a written report to the DSB. The DSB in turn decides on the adoption of the report by reverse consensus. Consequently the adoption of reports is de facto automatic. Once a report is adopted by the DSB, it becomes legally binding (Van den Bossche \& Zdouc, 2017).

Adjudicating disputes by using panels is in essence not a new development in the trade regime. As it will be shown in section 4.4 the panel procedure had been developed incrementally under the GATT already. However, the Uruguay Round led to a few changes that contributed to an increase in the degree of centralization. Already in 1989 a relatively uncontroversial step was taken regarding procedural issues (Croome, 1999). In an interim agreement on dispute settlement the CONTRACTING PARTIES agreed to streamline the dispute settlement process. This streamlining included the introduction of: time limits for consultations amongst parties; the possibility of conciliation and arbitration as alternative procedures to panel proceedings; the requirement that dispute settlements reached bilaterally or via arbitration should be consistent with the GATT; the requirement to establish a panel latest by the second Council meeting after establishment of the panel was requested; the specification of standard terms of reference for panels; the specification of explicit time limits for various stages of a panel's work; the possibility for developing countries to get legal advice when they would be involved in a dispute; and the establishment of an overall 15 month limit for the whole process of dispute resolution (Croome, 1999).

While the streamlining of procedures contributed to the institutionalization of dispute settlement, the changed means to control panels by deciding to take key decisions in the panel procedure by reverse consensus was far more significant regarding the degree of centralization. While the introduction of reversed consensus theoretically relates to pooling as it is describing a change decision-making amongst the trade regime's members, it is clear that the main

\footnotetext{
${ }^{7}$ The size of a panel increases if the disputing parties agree within 10 working days after the establishment of the Panel that the panel should consist of five persons (Art. 8.5, DSU).

${ }^{8}$ Based on a proposal for panel members made by the Secretariat, the parties to a dispute try to agree on the composition of a panel within 20 days after the establishment of the panel. If the parties cannot agree either party is allowed to request the Director General to compose the panel. The DG does so within 10 days and in consultation with the parties and the chair of the DSB (Art. 8.7, DSU).
} 
beneficiary of this was centralization of delegation since the decision-making rules in this instance of pooling constitute the control mechanisms of delegation. Reverse consensus ensured that delegation was strengthened. In a significant break with the past it was no longer possible that a single party could interfere and block the panel process. This would only be possible if the membership as a whole would agree to do so.

In contrast to panels the establishment of the Appellate Body constitutes a major innovation in the trade regime in and of itself. The Appellate Body was negotiated during the Uruguay Round and is provided for in Article 17.1 of the DSU. However, it was only after the round that the Appellate Body was formally established by a decision of the DSB in February $1995 .{ }^{9}$ The Appellate body is supposed to hear appeals to panel reports if this is requested by one of the disputing parties. In doing so the Appellate Body is restricted to only review questions of law and is prohibited from reviewing factual elements of a panel's report (Art. 17.6, DSU). According to Article 17.3 of the DSU the Appellate Body is allowed to uphold, modify or reverse the legal findings of a panel. Contrary to panels, the Appellate Body is a standing body, consisting of seven members (Art. 17.1, DSU). The members of the Appellate body need to be impartial and independent, and recognized authorities with expertise in law, international trade and the subject matters of the covered agreements (Art.17.3, DSU; Rule 2(3) of the Working Procedures for Appellate Review ${ }^{10}$ ). The DSB appoints the members of the Appellate Body mainly on the basis of their qualification, but tries to ensure that the membership of the Appellate Body is roughly representative of the WTO's membership. ${ }^{11}$ The decision to appoint Appellate Body members is taken by consensus (Art. 2.4, DSU). Members of the Appellate Body serve for a fouryear term, which can be renewed once (Art. 17.2, DSU). Out of the seven members three are in charge of hearing a particular appeal. The three members hearing an appeal are randomly selected, but exchange their views on a case with the other Appellate Body members who are not formally in charge of the appeal in question. According to Article 17.5 of the DSU the Appellate Body is supposed to complete the review of a case within 60 days. This timeframe can be extended to 90 days if the Appellate Body provides a proper justification for doing so. Once the Appellate Body has completed the review of a case it presents its findings in a written report, which is adopted by the DSB within 30 days after the report has been circulated. The DSB takes the decision on the adoption of reports by reverse consensus (Art. 17.14, DSU). Upon adoption by the DSB the report becomes legally binding.

The establishment of the Appellate Body certainly constitutes a change in centralization in the trade regime regarding dispute settlement. An independent standing body of experts to adjudicate on appeals to disputes by following clear procedures and timeframes was a new institutional feature of the trade regime. The relatively weak means to control the Appellate Body strengthen this instance of delegation further. Certainly the WTO membership can try to exert influence in the selection of Appellate Body members (Elsig \& Pollack, 2014), but once the

\footnotetext{
${ }^{9} \mathrm{WT} / \mathrm{DSB} / 1$

${ }^{10} \mathrm{WT} / \mathrm{AB} / \mathrm{WP} / 6$

${ }^{11} \mathrm{WT} / \mathrm{DSB} / 1$
} 
Appellate Body reviews a particular case the WTO's membership has no means to interfere since the Appellate Body's findings are quasi-automatically accepted by reversed consensus. As it is the case with panel reports, the rejection of a report is highly unlikely, since the beneficiary of a report would have to join the decision to reject the Appellate Body's findings. Furthermore, the Appellate Body has considerable freedom to determine the exact procedures it follows (Cortell \& Peterson, 2006). Contrary to panel procedures, the specification of appellate review procedures is relatively limited sparse in the DSU. This limited amount of precision provided the Appellate Body with a significant degree of discretion, which it was able to use to become highly influential (Ganesan, 2015; Shaffer, Elsig, \& Puig, 2016; Unterhalter, 2015; Van den Bossche, 2006). After all, Article 17.9 of the DSU explicitly permits the Appellate Body to draw up its own working procedures. Taken together, these features of the Appellate Body ensured that it would in essence become a trade court, despite the fact that it is formally subordinate to the DSB. This development was not the intention that the negotiators during the Uruguay Round had in mind when creating the new dispute settlement system (Steger, 2002a, 2002b, 2015). ${ }^{12}$ Thus, the development of the Appellate Body actually led to a higher degree of centralization than originally planned by institutional designers.

To sum up, the reforms undertaken in the Uruguay Round led to highly centralized dispute settlement in the WTO. Building on the GATT's development of panel procedures and their increasing formalization, delegation of dispute settlement has significantly increased in the WTO with the creation of the Appellate body and the introduction of reversed consensus as decisionmaking rule. The last aspect indicates an interaction of centralization as pooling and delegation, as the introduction of reversed consensus needs to be understood as a change in the decisionmaking procedures in pooling, which in turn had an impact on the autonomy of agents conducting a delegated task. On top of that, the WTO as a permanent international organization with a strong legal footing, in which different dispute settlement procedures are unified and which entails a body exclusively dedicated to dispute resolution adds to the picture of increased centralization. This picture is completed by the addition of important governing principles of dispute resolution, namely its compulsory and exclusive jurisdiction. Clearly the WTO is a much stronger focal entity in charge of multilateral trade dispute resolution than the GATT used to be. How did this come about?

\footnotetext{
${ }^{12}$ This point was confirmed in several interviews and will be further elaborated on in section 4.4.4.
} 


\subsection{Explanations of Rational Design}

Even more than it was the case for the establishment of the WTO as an international organization, the original ideas to reform the dispute settlement system were strongly functionally motivated, and from a theoretical perspective the outcomes of the negotiations suit the conjectures of rational design and supplementary rationalist accounts extremely well. However, a purely functional account does not fully explain these outcomes. Although contracting parties strongly agreed that the dispute settlement system of the trade regime had to be reformed, they initially disagreed on the general character and on the specific design features of such a reform. Furthermore, a rationalist account would also overlook the historical roots that explain such specific design features. Consequently this section only provides a partial explanation of the increase in centralization. Functional motivation can be regarded as a necessary, but not as a sufficient explanation of the dispute settlement system as it emerged from the Uruguay Round.

\subsubsection{Positive Contributions of Rational Design}

Testing the applicability of rational approaches to explain the increase in centralization of dispute settlement needs to include two steps. First, it is necessary to examine whether theoretical assumptions would be a plausible fit for the observed phenomenon. Secondly it is necessary to trace whether the motivations that brought the phenomenon really about match those that are assumed by rational approaches.

\subsubsection{The Underlying Rationale (Theoretical Plausibility)}

On first sight the reform of the trade regime's dispute settlement system corresponds strongly to functional theoretical accounts as provided by the rational design and other, supplementary frameworks. The most fitting theoretical explanation is to be found in the rational design conjecture that suggest that an increase in centralization corresponds to an increase in an enforcement problem (Koremenos, Lipson, \& Snidal, 2001a). The underlying rationale that centralized dispute resolution is a suitable means to facilitate cooperation when individual incentives to defect on an agreement threaten self-reinforcing cooperation is supported by legalization literature (K. W. Abbott \& Snidal, 2000). That this rationale is suitable to the domain of international trade has already been mentioned in the previous chapter. As mentioned there, mercantilist beggar your neighbor policies already contributed to the great depression in the 1930s. Centralized dispute resolution can counter such developments and contribute to the enforcement of international trade agreements (World Trade Organization, 2007). According to principal-agent theories delegation is a particularly suitable design feature for dispute resolution, since the benefits of delegation increase when impartiality, credibility, specialization and expertise are required from a design feature (Hawkins, Lake, Nielson, \& Tierney, 2006). 
The design logic that links enforcement problems to an increase in centralization can be reasonably well applied for all the specific design features of centralization that occurred in the Uruguay Round. On the general level the creation of the unified dispute settlement system contributes to enforcement since it eliminated the possibility for forum shopping and abuse of the existing, fragmented system. Furthermore, enforcement is facilitated as the unified system allows for cross-retaliation, i.e. the ability to withdraw concessions under one of the WTO's agreements for an infringement of an obligation under another agreement. This can facilitate enforcement and deter actors from defecting, since an increase in the number of available retaliatory measures leads to a higher the potential to target retaliation at a particularly vulnerable sector. Also, the WTO's compulsory and exclusive jurisdiction can be easily fitted to this design logic. The compulsory nature of the system ensures that a defendant cannot block the initiation of a dispute settlement procedure. The exclusive jurisdiction in turn hinders countries to take enforcement of trade agreements into their own hands. This could potentially trigger a retaliatory spiral due to perceived illegitimacy of unilateral enforcement, which in turn can have the same net effect of beggar-your neighbor policies.

With respect to centralization as pooling, the establishment of the DSB as a designated body that is solely in charge of dispute settlement and that has the explicit mandate to monitor the implementation of rulings and recommendations that emerge from the dispute settlement procedures also contributes to enforcement (Shell, 1995; Young, 1995). After all, centralized surveillance is a recognized factor that contributes to rule abidance (Koremenos et al., 2001a). However, as mentioned above, it is especially the changed decision-making procedures of the DSB that contribute to an increase in centralization and fit the conjecture. Turning to reverse consensus for the adoption of panel and Appellate Body reports strengthens delegation and ensures that no single WTO member can interfere with the dispute settlement process once it has reached the adjudicating stage. This contributes to the credibility of substantive agreements as well as to the legitimacy of the dispute settlement system. Both of these factors in turn can be assumed to contribute to the observance of substantive obligations.

With respect to delegation, it is not only the decision-making procedures in pooling but also the specific changes made in terms of delegation itself that suit the conjecture linking enforcement to centralization. The streamlining of the panel process ensures that dispute settlement proceeds more swiftly in comparison to the times of the GATT, implying that substantive rules gain in strength since possible violations of these rules are followed up upon in a predictable and expeditious manner. Finally, the creation of the Appellate Body suits the conjecture as well. A standing body of respected and impartial experts contributes further to the credibility of rules and can issue its judgments with a high degree of legitimacy.

Next to addressing enforcement problems, another possible - while slightly less comprehensive explanation - for the changes in dispute settlement could also be provided by the rational design conjecture that links centralization to the presence of uncertainty of behavior. According to this conjecture centralization is supposed to be present when actors are uncertain about the behavior of other actors that they are cooperating with. This conjecture 
suits dispute settlement in so far as centralized adjudication can provide information how the behavior of others should be interpreted (Koremenos et al., 2001a). Is an actor that seemingly violates the rules intentionally non-cooperating or should this behavior rather be interpreted as a justified exception to the rules? It seems plausible to assume that the higher the independence of a dispute settlement system - as promoted by the step to reverse consensus, the streamlining of the panel procedure and the creation of the Appellate Body - the higher the credibility of an answer provided to such a question. Additionally, the DSB's mandate to monitor implementation of outcomes of the dispute settlement procedure also ensures that it provides information about the behavior of actors and thereby reduces uncertainty. Finally, on a different but related note, it is one of the core functions of appeals mechanisms to ensure harmonization of legal systems (Shapiro, 1980). As such the creation of the Appellate Body potentially leads to more predictable outcomes of dispute settlement and reduces uncertainty about the functioning of dispute settlement itself. ${ }^{13}$

However, as plausible as these elaborations seem to be, it cannot be concluded that they are the real explanations for the increase in centralization. For this it is necessary to trace the actual motives that led designers to change the system. Do the functional explanations provided match these motives?

\subsubsection{The Emergence of the Idea and its Rationale (Empirical Plausibility)}

On first sight it seems that this question has to be answered in the affirmative. In the following the underlying motives of the idea to reform dispute settlement and its emergence will be traced back to its origins. It becomes clear that these underlying motives seem indeed to be functionally motivated, but that this functional motivation does not suffice to be a complete explanation due to different positions of the negotiating parties at the outset of the negotiations. The eventual result of the reform of dispute settlement needs to be interpreted as a function of the underlying motives, the negotiating dynamics that resulted from the different positions on dispute settlement reform, as well as the institutional context of dispute settlement as it incrementally emerged throughout GATT history.

A logical starting point to trace the motivations for reforming the dispute settlement system is to examine the negotiation mandate as expressed by the Punta del Este ministerial declaration of 1986. Contrary to the establishment of an organization, the reform of the trade regime's dispute settlement function was on the agenda of the Uruguay Round right from the start. The declaration mentions with respect to dispute resolution:

"In order to ensure prompt and effective resolution of disputes to the benefit of all contracting parties, negotiations shall aim to improve and strengthen the rules and the procedures of the dispute settlement process, while recognizing the contribution that would be made by more effective and enforceable GATT rules and disciplines.

\footnotetext{
${ }^{13}$ While this logic is also related to uncertainty it would rather suit the conjecture that centralization increases with uncertainty about the state of the world, if uncertainty about the state of the world is interpreted as uncertainty about the functioning adjudicatory process as implemented by panels.
} 
Negotiations shall include the development of adequate arrangements for overseeing and monitoring of the procedures that would facilitate compliance with adopted recommendations." ${ }^{14}$

According to Hilf (1991) this formulation expressed a "common understanding of all contracting parties that the enforceable character of agreed rules depends on an effective [dispute settlement] system" (p. 288). Also Steinberg (2004) posits that the primary purpose of dispute settlement reform was to enforce substantive agreements. The same point is made by Robert E. Hudec (1993), who describes the underlying rationale of reforming the system slightly more elaborately:

\begin{abstract}
"In retrospect, it can be seen that the decision to conduct a new round of trade negotiations made it inevitable that governments would have to make an even greater commitment to strong dispute settlement. The whole point of the new round, politically, was to stem a rising tide of protectionism by promising new and greater gains from trade liberalization. As in the Tokyo Round, the new gains (from the developed country point of view) would be largely in the form of new rules for new subject areas such as agriculture, services, and intellectual property. Again as in the Tokyo Round, none of these new rules would be worth anything without a strong dispute settlement system to enforce them." (p.169)
\end{abstract}

Thus, in essence the reform of dispute settlement can be explained by the necessity to protect the substantive outcomes of the negotiations - and especially those in the new negotiating areas - by proper dispute settlement, as a credible means for enforcement. According to one interviewee, the increased scope of the trade regime played a decisive role in this context, since the increased complexity that this entailed demanded a stronger institutional setting to ensure enforcement (Int16). This motivation fits the logic that informs the rational design conjecture which links centralization to enforcement perfectly. Especially developed countries had a strong interest in enforcing the agreements reached in the new negotiating areas. ${ }^{15}$ As a former US negotiator put it: "What good are the rules if they can't be enforced?" 16 (Int02). However, also developing countries shared an interest in multilaterally institutionalized enforcement. This interest can be almost regarded as a natural one amongst less powerful states, given that commonly agreed upon institutionalized multilateral enforcement procedures reduce the impact of power asymmetries in international cooperation (Shell, 1995). This point was confirmed in interviews with several Uruguay Round negotiators from developing countries.

${ }^{14}$ MIN.DEC, p.7

${ }^{15}$ This is also one of the explanations why intellectual property protection was negotiated under the GATT during the Uruguay Round and not under the already existing institutional framework for intellectual property protection that was provided by the World Intellectual Property Organization (WIPO). In contrast to the GAT WIPO did not possess credible enforcement mechanisms in the form of established dispute settlement mechanisms.

${ }^{16}$ The same view was expressed by several other delegations during the first meeting of the negotiating group on dispute settlement; see MTN.GNG/NG13/1. 
A former Brazilian negotiator mentioned that more institutionalized enforcement procedures "reduce the jungle effect" - i.e. the impact of power asymmetries - and favors the weaker states (Int05). This was also confirmed by former negotiators from Mexico and India (Int11, Int16). The Indian negotiator added that having a rules based system was a main priority for his country, despite the fact that some of the substantive rules were regarded as disadvantageous for India. ${ }^{17}$

It was not only the general desire to enforce the newly negotiated substantive agreements that would result from the Uruguay Round. Also the existing dispute settlement system exhibited serious weaknesses. In the strained economic environment that characterized the 1980s and with the looming threat of increased protectionism that arose at the time these weaknesses threatened to undermine the GATT's enforcement capacity and credibility (Croome, 1999; Hudec, 1993; Winham, 2005). The biggest problem at the time consisted of the possibility to block the dispute settlement procedure at nearly every stage of the process (Cossy, 2015; Croome, 1999; Jackson, 1990). Due to consensus as decision-making norm defendants were able to refuse to agree to join consultations, to establish a panel, to the panel's composition and the establishment of its terms of reference, and ultimately also to the adoption of a panel's report and the authorization of retaliation. This resulted in delaying tactics employed by defendants and in slow dispute settlement procedures that sometimes dragged on for years (Hilf, 1991; Jackson, 1990). The completion of a panel procedure did not necessarily imply the end of potential problems. Often the implementation of the results of the procedure was done sluggishly and was not systematically monitored by the GATT (Cossy, 2015; Jackson, 1990). Furthermore, the introduction of the Tokyo Round codes, with their own dispute settlement procedures implied a fragmentation of the dispute settlement system and even led to disagreements which dispute settlement procedure should be used for a particular dispute (Cossy, 2015; Jackson, 1990). Finally, it got increasingly difficult to muster a sufficient amount of panelists who were able to ensure a satisfactory quality of panel reports and instances of poorly reasoned reports increased (Hilf, 1991; Jackson, 1990). These weaknesses became particularly evident due to the fact that the contracting parties increased their use of the dispute settlement system from the beginning of the 1980s onwards (Hudec, 1993). ${ }^{18}$

That the many problems of the GATT's dispute settlement system provided a functional motivation to contracting parties to reform the system is supported by developments in the lead

${ }^{17}$ Similar statements were also made by Uruguayan negotiator Julio Lacarte and Brazil's Celso Lafer. They made these statements in interviews conducted for the WTO Creation Project, which can be accessed on http://www.wtocreation.org. Also Canada's ambassador to the GATT at the time of the Uruguay Round, John Weekes, mentions in an interview for the same project that even for Canada strong dispute resolution is important to mitigate power differences in conflicts with stronger actors.

${ }^{18}$ The reasons for the increased use of dispute settlement point to an interesting dynamic between substantive agreements and institutional procedures. The US increasingly filed disputes in order to clarify ambiguous substantive agreements that resulted from the Tokyo Round. This in turn led the defendants - and the $\mathrm{EC}$ in particular - to apply above mentioned delay tactics and to file more disputes themselves. Thus a weakness in substantive agreements facilitated the exposition of the dispute settlement's shortcomings (Marceau, Porges, \& Baker, 2015). 
up to the Uruguay Round. Already in the mid-70s the United States sought to strengthen the GATT's enforcement capacities in the context of the Tokyo Round and procedural problems had been discussed in the negotiations. At that time the consensus decision-making procedure already belonged to the main concerns (Hudec, 1993). However, despite some potentially groundbreaking proposals and the codification of previously uncodified practice, the main procedures for dispute settlement had not been significantly strengthened as a result of the Tokyo Round (Hudec, 1993). ${ }^{19}$ So, the issue stayed on the GATT's agenda and another attempt to strengthen dispute settlement was made in 1982. In the declaration that resulted from the 1982 Ministerial Meeting the CONTRACTING PARTIES expressed that dispute settlement is not living up to its full potential and agreed that more efficient use of existing procedures should be facilitated. ${ }^{20}$ Back then the practice to take decisions on disputes by consensus was once again questioned, but upon insistence of the EC the declaration explicitly reaffirms decision-making by consensus (Hudec, 1993). In the follow up of the Ministerial Meeting the Director General issued regular reports to the GATT Council on the panel process (Stewart, 1993). These reports expressed that the 1982 declaration had a limited effect on the GATT's dispute settlement capacity; blocking of the panel procedure was still problematic and concern arose that the GATT's dispute settlement could become paralyzed (Stewart, 1993). Although another attempt was undertaken to improve the system by introducing a roster of non-governmental panelists in $1984^{21}$, a report produced by independent experts on request of the DG reaffirmed concerns regarding dispute settlement. This so called Leutwiler Report - which would become an influential source of inspiration for the Uruguay Round's negotiation agenda - identified the speed and the quality of the panel procedure, as well as the lack of attention to the implementation of panel reports as main problems (Dunkel, 1987).

Clearly, the widely recognized problems of dispute settlement were on negotiator's minds when entering the Uruguay Round and deciding to include dispute settlement on the negotiation agenda. ${ }^{22}$ Some of these problems became more severe during the round, putting

${ }^{19}$ Some of the dispute settlement procedures for the plurilateral codes that emerged from the round had slightly stronger provisions, such as the right to a panel for example. For a more detailed account of the developments during the Tokyo Round see section 4.4.3.

${ }^{20} \mathrm{~L} / 5424$

${ }^{21} \mathrm{~L} / 5752$

22 This was clearly expressed in several interviews with former negotiators and secretariat members who mentioned the possibility to delay or block the process at almost every stage as the most crucial motivation to reform the system. Also several primary sources documenting the preparation of the Uruguay Round indicate this, e.g. SR.SOG/4, PREP.COM(86)SR/2, PREP.COM(86)SR/6 and PREP.COM(86)W/9. In this respect Paemen and Bensch (1995) state that the actual amount of blocked cases was less relevant for negotiators' reform motivations than the mere possibility that cases could be blocked, since this possibility on its own already undermined the credibility of the multilateral trading system. During the negotiations itself this functional motivation was evident as expressed in an analytical summary of the first meetings of the negotiation group on dispute settlement, produced by the Secretariat. The summary mentions that "[m]any delegations emphasized that prompt and effective resolution of GATT disputes was of vital importance for the effectiveness and implementation of both existing and new GATT rules. Some participants emphasized that the dispute settlement mechanism existed to protect the rights of contracting parties and to promote security and predictability in the multilateral trading system." See MTN.GNG/NG14/W/14/ Rev.2, (p.3). 
more pressure on negotiators to reform the system. Petersmann (1994) states that in the final years of the round procedural delays, forum shopping, non- or sluggish adoption of panel reports, and non-compliance with the outcomes of the procedure significantly increased. In light of an increasing amount of disputes being filed Croome (1999) assessed the situation in the beginning of the 1990s as being close to paralysis. Clearly, the developments ahead and during the negotiations strengthen the plausibility of functionalism as the underlying motivation that explains the reforms conducted in dispute settlement.

For some of the specific design measures this functional motivation can be more precisely traced back. The establishment of the DSB for example has its roots in concerns over the implementation of recommendations resulting from the panel procedure. Already in the prenegotiations of the round Hong Kong suggested to establish a standing body solely in charge of dispute settlement and responsible for monitoring the implementations of recommendations. ${ }^{23}$ This and alternative suggestions were discussed further during the negotiations. ${ }^{24}$ Although the issue was only seriously picked up again once the suggestion to establish an international organization arose, when this happened a functional motivation was still evident. When the EC tabled its initial suggestion for the creation of a new organization it argued that no competent body existed to administer a unified dispute settlement system. ${ }^{25}$ The resulting DSB closely resembles the initial considerations discussed at the beginning of the round. ${ }^{26}$

A functional account is also very plausible regarding the decision to streamline the panel procedure. Already at the Montreal midterm review in late 1988 ministers agreed to this. ${ }^{27}$ The negotiated procedural improvements were clearly an attempt to fix the problems that troubled the system since the late 1970s. Many of the elements of this early decision were aimed at making the process more efficient and expeditious, such as the introduction of clear time limits for various stages of the dispute settlement process, the introduction of an overall 15-month time limit for the whole process, and the introduction of standard terms of reference for panels. Such clear processes in turn facilitate enforcement (World Trade Organization, 2007). Furthermore, the requirement that dispute settlements reached bilaterally or via arbitration should be consistent with GATT rules and obligations was a signal to strengthen the enforcement of GATT rules, as it officially condemned the politically occasionally tempting path to resolve disputes outside of the GATT framework at the cost of other contracting parties. The Council's role in surveillance of the implementation of panel recommendations and rulings was specified in the midterm decision as well and intended to further strengthen enforcement. Finally, the decision also marked the first step towards compulsory jurisdiction since it provided for the establishment of a panel latest by the second Council meeting after establishment of the panel was requested.

\footnotetext{
${ }^{23}$ PREP.COM(86)SR/2

${ }^{24}$ MTN.GNG/NG13/W/14/Rev.2

${ }^{25}$ MTN.GNG/NG14/W/42

${ }^{26}$ MTN.GNG/NG13/W/14/Rev.2

${ }^{27}$ MTN.TNC/7(MIN)

The decision was formally adopted by the Council in April 1989; see L/6489.
} 
Most of these procedural changes had been relatively uncontroversial and supported by a majority of the negotiation group on dispute settlement from the early stages of the negotiations onwards (Croome, 1999). However, this cannot be said for all of the major changes in centralization of dispute settlement that resulted from the Uruguay Round. It is exactly in these cases where negotiation interests were heterogeneous that the weaknesses of the rational design account become apparent.

\subsubsection{Problems of Rational Design}

Four main problems can be identified as weaknesses that characterize a purely rational account as the sole explanation for the reform of the dispute settlement system. First of all, the rational account does not fare well when being confronted with heterogeneous interests of actors. While it was generally the case that there was strong agreement that the dispute settlement had to be reformed and while it needs to be admitted that this facilitated the negotiations, there were significant differences on the exact design this reform should take (Croome, 1999). The core of these differences is to be found in different attitudes towards the nature of the GATT's dispute settlement. Latest by the time of the Tokyo Round these different attitudes became apparent as represented by the US' position in favor of a more legal and automatic approach to dispute settlement on one end of the spectrum, and the EC's position in favor of a political, conciliatory approach on the other end.

These differences are clearly apparent in the documentation of various GATT meetings throughout the preparation for Uruguay Round and during the negotiations themselves. At the time of the negotiations the first written submissions of the US and the EC to the negotiation group on dispute settlement exemplify their differences nicely. The US argued that the "primary objective of dispute settlement should be to resolve disputes, and to do so expeditiously, fairly and in a manner that is consistent with the trade expansion objectives of GAT" and stressed that an effective process is crucial in this respect. ${ }^{28}$ It specified its ideas about an effective process in a discussion paper, which amongst other things also questioned the principle of consensus decision-making. ${ }^{29}$ In contrast to this, the EC stressed in its first submission to the negotiating group that the "primary objective of the machinery is to work out mutually satisfactory solutions to disputes in a multilateral framework" and that this means that parties "seek first and foremost a negotiated settlement that also takes account of the legal aspects, without the latter necessarily becoming the key element." ${ }^{\prime 30}$ It is also remarkable that the US considered dispute settlement as a means congruent with the trade expansion objectives of the GATT, while the EC understood that dispute settlement should simply restore "the balance of economic and trade advantages that have been nullified or impaired." ${ }^{31}$

\footnotetext{
${ }^{28}$ MTN.GNG/NG13/W/3

${ }^{29}$ MTN.GNG/NG13/W/6

${ }^{30}$ MTN.GNG/NG13/W/12

${ }^{31}$ MTN.GNG/NG13/W/12
} 
Obviously these different attitudes led to different stances regarding particular design features. The most controversial one was the introduction of reverse consensus. This was not only fiercely opposed by the EC, but at least at the beginning of the negotiations a majority of parties was convinced that panel reports should continue to be adopted by consensus (Petersmann \& Hilf, 1991). The same holds for the exclusive jurisdiction of the WTO's dispute settlement system, to which the US was opposed for a long time during the negotiations (Croome, 1999). This highlights that not all parties regarded the eventual result of the reform as a functional response to the problems of dispute settlement - at least not at the beginning of the round. This in turn casts doubt on the rational design account and suggests that an additional factor must be responsible for the change of actors' negotiating positions throughout the Uruguay Round. As it will be shown in section 4.5, US power was crucial in this respect.

Secondly, the rational design account is insufficient because the different interests and subsequent changes in negotiating positions led to a negotiation dynamic that eventually resulted in a reform that few would have initially anticipated at the outset of the negotiations. The establishment of the Appellate Body for example was not primarily motivated by the desire to reduce uncertainty or to strengthen enforcement, as the rational design conjecture would suggest. While it has this effect, the creation of the Appellate Body should rather be interpreted as a domino effect of the decision to abandon consensus decision-making for the adoption of panel reports. Also the introduction of exclusive jurisdiction has to be interpreted as part of a trade-off, which the EC got in return for the introduction of reverse consensus. ${ }^{32}$ Similarly the introduction of a unified dispute settlement was only seriously considered fairly late in the negotiations when the idea to establish an international organization entered the picture. Consequently it is crucial to trace the negotiation dynamics to supplement the rational design account.

The success of the Uruguay Round reforms in comparison to previous attempts to reform the system constitutes a third factor that casts doubt on the sufficiency of rational design explanations. As it was mentioned earlier, the deficiencies of the dispute settlement system were known well in advance of the Uruguay Round already and were tried to be rectified. Even already at the time of the Tokyo Round significant procedural changes were considered, up the idea to exclude the parties to a dispute from the decision-making on the dispute (Hudec, 1993). The same was considered in 1982 and the idea almost succeeded, but failed due to the last minute opposition of the EC which insisted on a reaffirmation of consensus decision-making (Hudec, 1993). What distinguished the Uruguay Round from previous attempts to reform the system? Certainly, functional problems got more severe throughout the 1980s, but once again as section 4.5 shows - it was the strengthened US ability to mobilize its power, which can be considered to be the decisive factor.

Fourth and finally, rational design cannot provide a full account of the exact design of all different institutional features that characterize the dispute settlement system. Some far

${ }^{32}$ These arguments will also be further elaborated on in section 4.5.2. 
ranging suggestions that were made during the negotiations, such as the idea to allow third parties to file disputes, did not end up as part of the reform. Conversely, some other longstanding features were not touched upon and stayed integral parts of the reformed system. This is a reminder that the reform took place in a historical context, which shaped designers' ideas and expectation about the reform, as it will be shown in next section.

\subsubsection{Conclusion}

The rational design framework provides a good starting point to understand the reform of the dispute settlement system as it resulted from the Uruguay Round. If one would only explore the plausibility of rational explanations in a post hoc fashion it is fairly easy to match the outcomes of the reform with the conjectures of the rational design framework that link enforcement problems and uncertainty to an increase in centralization. Parts of the outcome of such an exercise are confirmed by tracing the underlying motives of dispute settlement reform. It becomes clear that rational design, and especially the conjecture that establishes the relationship between enforcement problems and centralization suits the underlying rational of designers at least from an abstract perspective: the dispute settlement system was regarded as deficient, endangering the implementation of substantive agreements and the credibility of the GATT, leading to the desire to fix the system.

However, it becomes clear that it is only at this relatively high level of abstraction that rational design provides a sufficient explanatory account. On a more specific level the weaknesses of rational design becomes apparent: It cannot take into account why heterogeneous interests of actors turn into a homogenously supported reform; it suggests at times misleading motives for reform; it faces difficulties in accounting for the relative success of the reform in comparison to previous attempts; and it ignores the historical legacy that informed the reform process. As such rational design cannot provide a full and specific account of the exact design features of reform. Thereby it constitutes only a starting point - a useful one, but one which needs to be supplemented by different approaches. The first of these different approaches is to trace the historical legacy that informed dispute settlement reform. 


\subsection{Design in Context: Historical Legacy}

Delineating the historical development of dispute resolution is essential to understand the dynamics of institutional change in the trade regime and to appreciate the magnitude of change that occurred as a result of the Uruguay Round. Up until the round the dynamics of change where characterized by two main features: incrementalism and an ambivalent attitude towards the role of law in the trade regime. Concerning the latter Marceau, Porges and Baker (2015) posit that this attitude led to "a Janus- faced approach to law that would come to characterize the GATT as an institution: a suspicion for formal legalism on the one hand, but a deep commitment to rules and rules-based conduct on the other" (p.7). Indeed the designers of the trade regime often needed to strike delicate balance between legal procedures that were strong enough to safeguard the substantive agreements of the regime, while also flexible enough to take political realities that often required negotiated solutions to disputes into account (Hudec, 1990a). The result of this was famously labeled by Robert E. Hudec (1970) as 'diplomat's jurisprudence'.

Being aware of the incremental development that was influenced by the ambiguous attitude towards law provides several important insights to understand the institutional design as it emerged from the Uruguay Round. First of all, it exemplifies the significance of the Uruguay Round reforms. While the dispute settlement system became increasingly formalized and legalistic throughout the incremental development of the dispute settlement system, political considerations and a tendency to find negotiated solutions to disputes remained a strong element of the system. Only the Uruguay Round lead to a fundamental change of this. Previous attempts to fundamentally reform the system only delivered modest outcomes. The historical overview allows comparing the success of the Uruguay Round to those previous reform attempts. This puts the achievement of the Uruguay Round into perspective and helps to identify the factors that contributed to the success of the reform.

Secondly, the historical overview of the development of dispute resolution also highlights the influence of path dependency. Despite the groundbreaking character of the reform, many elements of the WTO dispute settlement system are a legacy of the past (Hudec, 1999b; Kantchevski, 2006; Steger \& Hainsworth, 1998; Van den Bossche \& Zdouc, 2017). This is explicitly acknowledged in Article 3.1 of the DSU, which states that: "Members affirm their adherence to the principles for the management of disputes heretofore applied under Articles XXII and XXIII of GATT 1947, and the rules and procedures as further elaborated and modified herein." Knowing how these rules and procedures developed provides a better understanding of the exact design features that characterize the WTO dispute settlement system and how they came about. It becomes clear that institutional design is only a bounded rational process, since the designers relied heavily on existing structures when thinking about new ones.

The influence of bounded rationality and path dependency is also reflected in the third and final insight that historical process tracing of the dynamics of institutional change provides. 
Evidence suggests that designers where strongly influenced by their experience with the diplomatic jurisprudence that characterized dispute resolution in the trade regime at the time of the GATT. It is posited that this influenced designers' cognitive scripts, which in turn led them to underestimate the eventual outcomes of reform. This seems to be especially the case for the creation of the Appellate Body. Despite awareness of the automaticity of the reformed system, many designers expected that dispute resolution would maintain political conciliatory features and would be used in a less judicial and frequent way than it eventually turned out to be. A post hoc functionalist account that would explain the emergence of the system by its current functioning would thus overestimate the designers' motivation for centralization as a rational response to collective action problems. The system - and the Appellate Body in particular - was not intended to be as judicial and as autonomous as it currently is. It is likely that reform would have been more difficult to achieve if the strength of the system had been more accurately estimated. Consequently, historical experience influencing cognitive scripts seems to be a relevant factor that contributed to the reform of the system. A logical starting point for an account of how this experience came about is the negotiation of the ITO.

\subsubsection{Dispute Settlement in the ITO}

Taking a broad perspective on centralization it is clear that focal entities for the resolution of disputes were present throughout the history of the trade regime right from the beginning. The ITO's drafters clearly envisaged that the organization would be in charge of the resolution of trade disputes and dedicated an entire chapter of the Havana Charter to this role (Bronz, 1949; Wilcox, 1972). The resolution of trade disputes in the ITO is regulated in Chapter VIII of the Havana Charter. It is noteworthy that it would have been possible under the Charter to start a dispute resolution procedure even in the absence of a violation of the Charter's substantive obligations. For a member of the ITO it would have been sufficient to claim that the benefits accruing to it under the Charter would have been "nullified or impaired" (Art. 93) to bring a dispute to the organization. This characteristic is a legacy of bilateral trade agreements concluded prior to the negotiation of the Havana Charter and indicates that reciprocity of benefits accruing from agreements - on top of compliance to formal rules - was one of the major norms guiding the trade regime (Finlayson \& Zacher, 1983; Hudec, 1990a, 1999a). ${ }^{33}$

In the case of a dispute between two members of the ITO the Havana Charter specified various steps. The first step required that the members in a dispute would conduct consultations (Art.93.1). Alternatively the Charter would have allowed for the possibility of arbitration on terms agreed upon by the disputing parties (Art.93.2). If no agreement on the resolution of the dispute would have been reached after following one of these procedures, a second step could have been taken. In this step any member of the organization would have been allowed to refer the dispute to the Executive Board of the ITO (Art.94.1). The Executive board would have had

${ }^{33}$ Nullification and impairment of benefits remained a sufficient condition to initiate dispute resolution throughout the history of the trade regime. 
the obligation to investigate the dispute and ultimately had the authority to rule on the case under consideration (Art.94.2). Based on this ruling the Executive Board would have had the authority to request a member to take appropriate measures to conform with the provisions of the Charter, in case that member would have been found to violate the substantive provisions of the Charter (Art.94.2(d)). If a member would have been found to nullify and impair the benefits of another member without violation of substantive provisions, the Executive Board could have recommended measures to rectify the situation (Art.94.2(e)). Ultimately the Executive Board would have had the power to allow the complaining party to take appropriate retaliatory measures against the other party, if the latter party would have failed to rectify the nullification and impairment (Art.94.3). Such authorization would have been permitted in any instance of nullification and impairment, notwithstanding the presence or absence of a violation of the Charter. However, it should be pointed out that it was clearly understood during the negotiations and also indicated in the Charter that retaliatory measures should be compensatory in nature. As such they should not be sanctioning, but rather restore the balance of benefits accruing to the disputing parties under the Charter (Hudec, 1990a, 1999a). As a third step in the procedure either of the members involved in the dispute would have had the right to appeal to the decision by the Executive Board and refer the case to the Conference, which could have confirmed, modified or reversed any action, decision or recommendation by the Executive Board (Art. 95.1). Finally, the Charter would have allowed for the possibility to ask the International Court of Justice (ICJ) for an advisory opinion on legal questions considering decisions by the Conference. Any member that would have regarded its interests to be prejudiced by a decision of the Conference would have had the right to do so. Although the ICJ would have been prohibited to provide advice regarding the economic issues of a dispute, its ruling on the legal issues under consideration would have been binding (Art. 96) (Wilcox, 1972).

In light of these provisions several aspects about centralization can be noted. With respect to legal effect it is noteworthy that the Havana Charter already exhibits the effort to find a balance between a judicial and a political approach to settle disputes, which would characterize most of the trade regime's developments in dispute resolution. Hudec (1990a) argues that some important provisions and the language used in the dispute settlement procedures were kept intentionally ambiguous to enable the ITO to impart as much legal strength as necessary to a decision, depending on the political circumstances within a given situation. On the one hand, the clear description of procedures for dispute settlement and specification of the ITO's authorities in this field - its ability to issue rulings, requests, recommendations, and to allow retaliation can be seen as features adding legal leverage to dispute settlement provisions (Hudec, 1990a, 1999a). On the other hand, the Charter's language does not imply that the organization was authorized to issue direct judicial decrees. It was left unspecified how much legal leverage could be ascribed to a request or a recommendation (Hudec, 1990a, 1999a). Furthermore the specification that retaliation would not be punitive but only compensatory in nature decreased the strength of enforcement mechanisms (Hudec, 1990a, 1999a). These ambiguities allowed modifying the strength of the signal that would be sent by a decision resulting from dispute 
settlement procedures according to political necessities. Overall the ITO's provisions were flexible enough to ascribe a high or a low degree of authority to decisions, depending on the consensus within the organization's membership, which kind of signal would be appropriate in a given situation (Hudec, 1990a, 1999a). According to Hudec, this balance between a legal code that was strong enough to safeguard the substantive commitments made by the members of the ITO, while at the same time flexible enough to take political realities - which often required negotiated solutions to disputes - into account was the starting point of the trade regime's diplomat's jurisprudence (Hudec, 1990a, 1999a).

Thus the strength of the ITO as a focal entity for dispute resolution was flexible. According to Hudec (1990a), the ambiguity in the Charter
"...had both a restricting and an expanding effect. It restricted the absolute force which the law might bring to bear, but it also encouraged a more creative process of application which might extend the reach of legal obligations a bit beyond the four corners of the legal text. ...Legal arrangements of this kind are not common, for governments do not easily entrust the eventual shape of an institution's regulatory powers to subsequent events." (pp. 46-47)

Thus, Hudec ascribed the potential of the ITO to expand its legal authority to the limited precision in the dispute settlement procedures. Whether this would have happened remains speculative, but it indicates the potential for an increase in the degree of centralization.

Another feature of the ITO's dispute settlement procedures that should be pointed out is that centralization mainly took the form of pooling. Hudec (1990a) points out that:

\begin{abstract}
"Surprisingly little attention was paid to the exact manner in which the ITO would make substantive rulings. ...It appears that no consideration was given to the possibility of establishing any sort of expert tribunal to rule on legal questions. Whether deliberate or not, this inaction by the delegates meant that the rulings would be made by the regular voting procedures of the Executive Board and the Conference." (pp. 3031)
\end{abstract}

This characteristic in itself could be understood as a limitation of centralization. No institutional, neutral body would have been exclusively dedicated to the ITO's dispute settlement function. It was planned that political bodies would have taken supposedly neutral legal decisions, leading smaller countries to be concerned about the dominance of the US and the UK in these bodies (Hudec, 1990a; Rubin, 1949). However, considering the apparent necessity to strike a balance between clear legal procedures and political necessities this design feature is not very surprising (Hudec, 1971, 1990a).

Looking at the rules and procedures guiding this pooled form of centralization a mixed picture emerges with respect to the degree of centralization. Contributing towards a higher degree of centralization is the fact that the formal decision-making procedures would have required that decisions on disputes would have been taken by majority voting. This indicates 
that the ITO would have had a relatively large degree of autonomy and that the members affected by its decisions would have had limited means to influence them. Furthermore, the Executive Board would have been the first instance to take decisions, implying that a sub-set of the membership would have taken decisions on behalf of the entire organization. However, the members affected by the Executive Board's decision would have been protected to a certain extent by their right to appeal to the Conference. This feature reduces the degree of centralization. Additionally, it is questionable whether the organization would in practice have resorted to majority decision-making for the resolution of disputes. In light of the necessity to take decisions that are sensible to political circumstances and considering subsequent practices in the GATT it seems plausible to assume that in practice decisions would have been taken by consensus.

Considering centralization as delegation, the possibility to refer disputes to the ICJ to get an advisory opinion on legal issues counts as an important exception to centralization as pooling. ${ }^{34}$ Looking at the negotiation history of the Havana Charter it becomes clear that the role of the ICJ was a contested issue during the negotiations, indicating that decisions about rules and procedures that govern delegation can be politically sensitive. ${ }^{35}$ In essence the debate about the ICJ's role in dispute resolution revolved around two issues, both related to centralization. The first issue concerned how easily the ICJ could have been accessed. It was debated whether the ICJ could have been approached by individual members, the Executive Board or only by the Conference (Rubin, 1949). In this respect it was considered that approval by the Conference would have been needed to refer disputes to the ICJ (Hudec, 1990a, 1999a; Rubin, 1949). Obviously this would have compromised the degree of centralization significantly, since the Conference could thereby control the submission of appeals to the ICJ. Contrary suggestions were also made that would have allowed the Executive Board or individual members to refer disputes to the ICJ, which would have indicated a higher degree of centralization. Eventually the compromise was found that no Conference approval would have been necessary to submit disputes to the ICJ, but that members who want to appeal to the ICJ would have to do so via the Conference (Rubin, 1949). So access to the ICJ would have been a matter of right for individual ITO members, while the Conference was involved in the process and could present its version of the case (Hudec, 1990a, 1999a; Rubin, 1949). The Executive Board would not have been permitted to refer cases to the ICJ and only members whose interest was prejudiced by a decision of the Conference could initiate an appeal (Rubin, 1949). Since appeals to the ICJ took the form of a collective request by the membership, individual parties would not have become subject to a ruling by the ICJ (Jackson, 1969). The second issue concerned the authority of the ICJ

\footnotetext{
${ }^{34}$ One could argue that the possibility of arbitration provided for in dispute resolution procedures also counts as an instance of centralization as delegation, but it is assumed that the degree of centralization that this institutional feature would have implied is negligible. Arbitration would have been an ad hoc procedure, guided by the terms agreed upon by the disputing members themselves, and the Havana Charter explicitly points out that decisions of the arbitrator would not have been binding (Art.93.2).

${ }^{35}$ Rubin (1949) provides a detailed account of the debate during the negotiation that surrounded the role of the IJC in dispute settlement.
} 
when deciding on an appeal. Eventually the ICJ was prohibited to review factual issues of the dispute settlement process and could only provide an advisory opinion on the "legal questions" of a case. This opinion would have been binding on the ITO (Rubin, 1949). Overall, institutional provisions were designed to strike a delicate balance between delegation and mechanisms of control. Once again this balance also needed to leave sufficient room to allow for political realities. Initially, a stronger role of the ICJ was conceived that would have adhered to more rigorous legal principles (Marceau et al., 2015; Rubin, 1949). However, eventually there "was wide consensus that, if anything, the involvement of the ICJ was to help find a diplomatic solution" (World Trade Organization, 2007, p. 261).

In conclusion, the ITO's dispute settlement mechanisms provided the foundation for dispute settlement in the trade regime and many of its elements continued to influence the way disputes would be settled throughout the regime's history. In terms of institutional mechanisms nullification or impairment as sufficient condition to launch a dispute, the requirement for consultations, the possibility for arbitration, and compensatory instead of punitive withdrawal of concessions as a means of enforcement are elements that characterize the dispute settlement in the regime until today. Furthermore, the design of the ITO's dispute settlement mechanisms constituted the beginning of the diplomat's jurisprudence. Centralization would have been present, but it was carefully tared to design procedures that would have allowed legitimate legal decisions and political flexibility at the same time (Hudec, 1990a, 1999a). The diplomat's jurisprudence in the ITO set the tone regarding the strength of focal entities for dispute resolution in the trade regime until the creation of the WTO. Clearly the need to strike a balance between judicial accuracy and political considerations is also reflected in the history of the GATT.

\subsubsection{Dispute Settlement in the GATT (Initial Setup)}

Comparing the dispute settlement provisions of the GATT to those of the ITO and examining their relationship provides interesting insights. On the one hand the provisions seem like a simplified mirror image of the ITO's. Considering that the GATT was negotiated within the wider context of the ITO negotiations and that the involved diplomats were, with a few exceptions, the same people in both negotiation settings, this is hardly surprising (Hudec, 1990a, 1999a). Certainly the GATT exemplifies the same need to strike a balance between a judicial and a diplomatic approach to dispute settlement as the ITO. On the other hand there are also remarkable differences between the two and the organizational framework of dispute settlement in the GATT was considerably different than that of the ITO. This is due to the GATT'S emergence as an interim agreement without organizational provisions. The legal text itself does not even mention dispute settlement as a function of the GATT, nor does it entail a coherent section exclusively devoted to dispute settlement. Consequently, the GAT's original provisions lack specificity in delineating the procedures to be followed in dispute settlement. The combination of similarities and differences of the GATT in comparison to the ITO are indicative of its strength as a focal entity for dispute resolution in the trade regime. Certainly the GATT was initially a significantly weaker focal entity than the ITO would have been. At the same time the 
lack of detail with respect to the powers of the CONTRACTING PARTIES and with respect to dispute settlement procedures permitted the GATT to incrementally develop its dispute settlement function and become a more prominent focal entity in this domain. Before this development is investigated in further detail it is necessary to take stock of the provisions the GATT had to start out with.

Although the GATT legal text does not mention dispute settlement as a function, several provisions in the text imply such a function without delineating procedures in great detail. Throughout the legal text of the GATT multiple articles hint at dispute resolution and call upon contracting parties to consult when being faced with a matter in dispute (Jackson, 1969). The most general of these are Article XXII and Article XXIII. Article XXII states that: "Each contracting party shall accord sympathetic consideration to, and shall afford adequate opportunity for consultation regarding, such representations as may be made by another contracting party with respect to any matter affecting the operation of this Agreement." Thus, in case a dispute arises, the accused party is required to enter consultations with the complaining party. Article XXIII deals with nullification and impairment. It allows for the possibility of a dispute to be referred to the CONTRACTING PARTIES in case consultations have not led to the resolution of the dispute. The CONTRACTING PARTIES in return are supposed to investigate the matter and either recommend which steps the disputing parties should take, or rule on the matter. If the findings of the investigation required it, article XXIII granted the CONTRACTING PARTIES the right to authorize the injured party to withdraw concessions from the party that caused the injury even if the party from which the injury stemmed is not in violation of the GATT's substantive provisions.

Contrary to the procedures specified in the ITO, the GATT made no distinction between nullification and impairment stemming from a violation of legal obligations or from other reasons (Hudec, 1990a, 1999a). In either case the CONTRACTING PARTIES were entitled to issue a recommendation or a ruling. Rulings by the CONTRACTING PARTIES can be considered as legally binding, authoritative interpretations of GATT's substantive provisions (Jackson, 1969; Petersmann, 1994). Recommendations are in contrast not legally binding (Jackson, 1969; Petersmann, 1994). However, similarly to the situation in the ITO the authoritative force of recommendations and rulings was flexible, depending on the community sentiment underlying the CONTRACTING PARTIES' decisions. They could be used as signals varying in strength depending on the message that was intended to be sent (Hudec, 1990a, 1999a). This implies that non-violation complaints would probably have been handled more leniently than those concerning a violation of legal obligations, and is an exemplification of the diplomat's jurisprudence.

The enforcement mechanisms of the GATT are similar to those of the ITO. On paper the power of the CONTRACTING PARTIES to permit retaliation seems even broader than that of the ITO, since retaliation was not limited to compensatory withdrawal of concessions (Hudec, 1990a, 1999a; Jackson, 1969). So in theory retaliation could have been used as a punitive, sanctioning mechanism. However, this power should not be overestimated. In practice the GATT's 
enforcement power was limited and in its early days peer pressure was the main means to induce compliance (World Trade Organization, 2007). In its history the GATT used its authority to permit withdrawal of concessions in a dispute only once, and even in this case permission to withdraw concessions was limited and eventually not made use of (Petersmann, 1994). ${ }^{36}$ Also it should be pointed out that in principle the authorization of retaliation as enforcement mechanism is limited in so far as it is contingent on the symmetry of the conflicting parties. If a country with a small economy would withdraw its concessions towards an economically powerful country with a big market, in all likelihood the small country would hurt its own economy more than the economy of the targeted country (Jackson, 1969). Proposals were made in 1966 and during the Uruguay Round negotiations to introduce more symmetrical means of enforcement. It was suggested to introduce the obligation to provide financial or other compensation to an injured party when the injuring party in a dispute fails to implement a panel's recommendation. ${ }^{37}$ However, such proposals were not accepted and providing compensation is merely a voluntary possibility that disputing parties can agree upon (Petersmann, 1994).

Furthermore the legal leverage of the GATT as a focal entity for dispute resolution was limited due to the fact that the GATT was only supposed to be an interim agreement, which was only provisionally applied. The GATT stood on a shaky legal basis due to the protocol of provisional application and it was relatively easy to withdraw from (Hudec, 1999a; Jackson, 1969). This implied that the GATT was even more in need to find politically acceptable solutions to the resolution of disputes than the ITO would have been. Hudec (1999a) goes so far to state that in the light of the ITO's failure the "need to act with some delicacy had [...] become more than a matter of good diplomacy. For the GATT, it was more nearly a matter of life and death" (pp. 40-41). So while the GATT theoretically had some power as a focal entity to rule on disputes in a centralized manner, this was compromised by necessity to find politically acceptable solutions.

Finally, the institutional and procedural provisions in the GATT did also not contribute to centralization. They were minimal - not only in relation to the ITO, but in general. This is not surprising considering that the GATT should not include any connotations towards being an international organization in order to bypass the necessity for US congressional approval. It was considered during the negotiations of the GATT to make reference to a 'Committee' that should be in charge for dispute administration. However this formulation was removed to appease the US Congress (Jackson, 1969). Similarly, a proposal to accept ICJ jurisdiction for the GATT was rejected during the negotiations (Hudec, 1990a, 1999a). Even a provision to observe the principles specified in the Havana Charter was revised to exclude specific reference to the Charter's chapter on dispute resolution (Hudec, 1990a). Thus, the only procedural and

\footnotetext{
${ }^{36}$ This occurred in the context of US Dairy Quotas Case. In 1952 the Netherlands was permitted to retaliate in response to US imposed illegal quantitative restrictions on dairy products (Hudec, 1990a; Petersmann, 1994).

${ }^{37}$ The GATT document MTN.GNG/NG13/W/32 is a note by the Secretariat, which provides an overview of the different proposals on compensation that were made during the Uruguay Round until July 1989.
} 
institutional hints in the GATT were to be found in Article XXIII mentioning the role of the CONTRACTING PARTIES in dispute settlement without clearly specifying procedures. As such, initially only centralization as pooling was provided for in the agreement.

Overall, with respect to the authority the GATT had towards its members, Hudec (1999a) provides a concise summary of the situation the GATT found itself in at its origin in comparison to the ITO:

"The principal effect of these structural differences was to make the components of the GATT legal system a good deal less distinct than those of the ITO. The GATT would have the same detailed code of substantive obligations. But instead of an unconditional treaty obligation under the jurisdiction of the International Court of Justice, it would have to rely on the ill-defined commitment of 'provisional application'. Likewise, instead of decisions issuing from formally constituted organs with regularly established procedures, the GATT would have to get along with whatever low-visibility procedures could be developed consistently with the pretense of not being an organization." (p. 40)

At the same time though the GATT was even less precise than the ITO with respect to dispute resolution, which opened possibilities for institutional development. As Hudec (1999a) also points out:

"Of course, on the other side, instead of a carefully delineated statement of its powers in various kinds of cases, the GATT would have a disputes provision giving practical no guidance at all.

Added together, this general blurring of things meant that the GATT would have less formal authority to work with, but even greater freedom to manipulate the symbols of authority that it had." (p.40)

Indeed, the lack of precision in the original agreement enabled the GATT to successively increase the degree of centralization in dispute settlement. The GATT used this ability and managed to incrementally develop remarkable institutional structures and procedures guiding the resolution of disputes throughout its history.

\subsubsection{Development of Dispute Settlement in the GATT}

From its initial setup the development of the GATT's dispute settlement procedures until the 1980s can be summarized as an evolution from rudimentary centralization as pooling towards an increase in centralization by pragmatically adding elements of delegation and specifying procedures. To understand how this development came about it is necessary to recall the vaguely defined authorities of the CONTRACTING PARTIES under article XXV of the GATT. According to this article the CONTRACTING PARTIES were authorized to take joint action "with a view to facilitating the operation and furthering the objectives of this Agreement." In theory this permitted the CONTRACTING PARTIES to give effect to the function of dispute settlement as it 
was implied in several provisions of the agreement (Jackson, 1969). The CONTRACTING PARTIES did so by pragmatically developing procedures for the settlement of disputes. Most remarkable in this context is the emergence of third party adjudication. Robert E. Hudec (1990a) provides a detailed account of this development. ${ }^{38}$

The first disputes arose at the second session of the CONTRACTING PARTIES in 1949. During this session three disputes were brought up. In two of these disputes the Chairman of the CONTRACTING PARTIES was asked to rule on them. Marceau et al. (2015) describe this as the first step to third party adjudication. This step was apparently only possible due to the great authority of the Chairman of the CONTRACTING PARTIES - Dana Wilgress, a high level Canadian diplomat who had already chaired the ITO Preparatory Committee (Williams, 2015). However, this approach to resolve disputes was only taken twice and at least one of the disputes referred to the Chairman was a very uncontroversial, clear-cut case. The third dispute was referred to a working party, which had the mandate to find practical solutions to the dispute. From then on, until 1952 referring disputes to working parties became the standard procedure that was used. ${ }^{39}$

A working party consists of a small group of delegates aiming to find a diplomatic solution to a dispute. The use of working parties was familiar to the contracting parties. Already during the ITO and the GATT negotiations working parties were established to negotiate issues that would have been too cumbersome to discuss will all parties involved. Members of working parties act in their capacity as contracting party representatives and were therefore not supposed to be neutral. As such working parties need to be considered as negotiating bodies (Marceau et al., 2015). The membership of a working party varied in size and - depending on the issue at stake consisted of anything between five and 18 contracting parties, including the disputing parties. ${ }^{40}$ The small and informal setting of a working party was assumed to be more efficient in finding a mutually acceptable approach to a dispute than a formal meeting of all contracting parties. However, it is important to note that the working parties did not decide on a dispute themselves. Such a decision was still formally taken by the CONTRACTINIG PARTIES by approving a working party's written report. These reports usually aimed to represent a mutually acceptable solution to the dispute. However if such a solution could not be negotiated, then the working party was unable to present a result. The working party procedure clearly highlights the strong diplomatic component of dispute settlement at the time and once more exemplifies the importance of political context in GATT dispute resolution. This highly diplomatic approach to dispute settlement was reasonably successful due to the cohesion of contracting parties, who at the time formed a rather small club of relatively like-minded diplomats (Hudec, 1990a; Luyten, 2015).

\footnotetext{
${ }^{38}$ The following paragraphs are mainly based on Hudec's account. Other accounts have been consulted as well. They largely overlap with Hudec's account, but are not as detailed. Whenever information of one of these other accounts is used, this is clearly referenced.

${ }^{39}$ In a few cases it was possible to resolve the dispute in a discussion amongst the contracting parties at large, without the establishment of a working party.

${ }^{40} \mathrm{~L} / 392$
} 
In 1952, at the seventh session of the CONTRACTING PARTIES working parties were replaced by panels as the main means to settle disputes. Since then, using panels became the dominant institutional procedure to settle disputes until today. ${ }^{41}$ The introduction of the panel procedure was a significant step towards a more rigorous, legal approach to settle disputes, since panels consists of three to five individuals who act in their personal capacity and not as representatives of contracting parties (Jackson, 1969; Petersmann, 1994). Also, contrary to working parties, the parties involved in a dispute were not members of a panel. Furthermore, the name change from working party to panel underlines the more legal and less political approach, since 'panel of experts' was already previously used in the trade regime whenever reference was made to a group of individuals who are able to judge on a technical matter due to their expertise. ${ }^{42}$ These points imply that the introduction of the panel procedure is to be interpreted as an instance of centralization as delegation. However, this delegation was limited in so far as panels are ad hoc bodies whose reports still had to be approved by the CONTRACTING PARTIES or the Council ${ }^{43}$, who took their decisions on disputes by consensus until the establishment of the WTO. Consequently, a panel's report had to be politically sensitive enough to allow the disputing parties to join the consensus for the adoption of the report.

The reasons for the introduction of the panel procedure are hardly officially documented. According to formal documents the establishment of the first panel emerged as a suggestion by the Chairman of the CONTRACTING PARTIES, which was adopted without any debate. ${ }^{44}$ While Jackson (1969) suggests that the working parties' professionalism facilitated the introduction of panels, by providing contracting parties with sufficient confidence to introduce a more impartial approach to dispute settlement, Hudec (1990a) posits that the working party approach did not

\footnotetext{
${ }^{41}$ At least in the early years working parties were still occasionally used when one of the disputing parties considered the issue of a dispute particularly sensitive with respect to domestic politics (World Trade Organization, 2007).

42 Initially the body introduced at the seventh session was called a working party (see SR.7/5). The nomenclature was change only a few days later when the Chairman of the CONTRACTING PARTIES referred back to the initial decision as the decision to establish a panel (see SR.7/7). Since then panel was the regular name that was used.

The supposedly neutral character of panels was emphasized at the ninth session of the contracting parties. While the initial panel that was established at the seventh session still listed contracting parties as members to the panel, from the ninth session onwards panelists were individually named (Hudec, 1990a).

${ }^{43}$ The role of institutional bodies consisting of contracting parties below the level of the CONTRACTING PARTIES is to be regarded as a development in pooling. Already the Intersessional Committee was permitted to make recommendations to the CONTRACTING PARTIES when a dispute was referred to it. When the Intersessional Committee was replaced by the Council, the Council had similar authorities. Between 1960 and 1968 it was allowed to recommend decisions on dispute resolution to the CONTRACTING PARTIES, which would have acted upon this. In 1968 it was decided to increase the authorities of the Council. To enable the CONTRACTING PARTIES to focus on the most important matters, the Council was allowed to handle all of the CONTRACTING PARTIES' business, including the adoption of panel reports. The Council was kept in check and centralization limited in so far as members who felt adversely affected by an action of the Council had the right to appeal to the CONTRACTING PARTIES. The development of the GATT's general institutional structure is described in greater detail in the previous chapter.

${ }^{44}$ SR.7/5 and SR.7/7

See note 42 for clarification on nomenclature.
} 
satisfy the legal instincts of GATT decision makers. The latter view is supported by a Secretariat paper produced in 1955, which reflects on the use of working parties and on the introduction of panels. ${ }^{45}$ According to this paper the working party approach had disadvantages that mainly relate to the presence of the disputing parties in the assessment of a dispute. The procedure put the defendant's delegate in a dilemma. As an active participant in the working parity, supporting a potentially critical working party report put the delegate in an uncomfortable position towards a domestic audience, while rejecting it would do the same towards colleagues in the GATT. Also the inability of a working party to express a frank judgment of a dispute due to the necessity to find a unanimously agreed upon solution was regarded as disadvantageous. According to the Secretariat's paper these were the main reasons for the introduction of the panel procedure, which was pointed out in the paper to have objectivity as its main advantage. Williams (2015) supplements this explanation by pointing out that the introduction of the panel procedure at the seventh session of the contracting parties was relatively unproblematic, since the disputes handled by the very first panel were relatively uncontroversial.

Notwithstanding the exact explanation for the decision to introduce panels, it should be noted that the GATT Secretariat in person of the Director General, Eric Wyndham White had a significant influence on the decision. Apparently the Secretariat had a preference for the introduction of the panel procedure and Wyndham White prepared this in informal conversations with the Chairman of the CONTRACTING PARTIES and the most relevant delegations (Hudec, 1990a; Williams, 2015). This also explains the lack of discussion in formal GATT meetings of the contracting parties. Hudec (1990a) assumes that this informal route was taken to ensure that the GATT would maintain low visibility and avoid the impression of being an international organization independently taking decisions. It thus seems that the introduction of panels was rather a pragmatic decision that could be taken in the context of politically uncontroversial disputes, than a conscious decision to venture down an institutional path that would imply an irreversible legacy. In hindsight it is clear though how important the decision was in creating a trajectory characterized by a strong path depended development.

With the introduction of the panel procedure also the influence of the Secretariat itself increased in the GATT's dispute settlement function. Already under the working parties the Secretariat had provided secretarial support and drafted reports on behalf of working parties, but the Secretariat could be more active in supporting panels due to the absence of the disputing parties in the production of the report (Hudec, 1990a). With increasing complexity of disputes the Secretariat could make use of its technical expertise and became more important in the assistance of panels (Marceau et al., 2015). By the early 1980s the need to provide assistance to an increasingly legalized and complex panel process had grown so much that the contracting parties even agreed to the establishment of a legal office, which further strengthened the profile of the Secretariat in the dispute settlement domain (Hudec, 1993; Marceau et al., 2015). In comparison to the ad hoc nature of panels the Secretariat as a standing

${ }^{45} L / 392$ 
body constitutes an important source of institutional memory, which contributes to its influence - especially in light of complexity (Weiler, 2001). Thus, the GATT became an increasingly stronger focal entity also with respect to delegation to the Secretariat and its assistance to panels. The role of the Secretariat in assisting panels became formally recognized in 1979 and 1982 when the contracting parties mentioned the Secretariat's function in their decisions on dispute settlement.

These decisions are part of a wider development of specification and codification of the panel procedures, which had incrementally developed in practice over the years. ${ }^{46}$ This specification and codification strengthened the panel trajectory further and made it decreasingly reversible by contributing to the institutionalization of procedures. The abovementioned Secretariat paper of 1955 was a first step in this respect since this written description of the purpose of panels and the basic procedure that panels follow can be regarded as verification that the use of panels was a formal GATT policy (Hudec, 1990a). In 1966 an attempt by developing countries to renegotiate Article XXIII resulted in a decision by the CONTRACTING PARTIES that specified the process of dispute resolution between developing and developed countries. This provided for automatic creation of panels, indicated time-frames for the different stages of a dispute and permitted the Director-General to act as a mediator if consultations amongst the disputing parties were unsuccessful (Hudec, 1990a; Jackson, 1969). ${ }^{47}$ A more comprehensive specification and codification of procedures resulted from the Tokyo Round negotiations. This resulted in a description of customary practice of dispute settlement. This counts as further evidence that third party adjudication had become a well-established feature of the GATT (Hudec, 1993). Furthermore, the Tokyo Round let to the adoption of 'Understanding on Notification, Consultation, Dispute Settlement and Surveillance of 28 November 1979.' This understanding aimed at increasing the efficacy of dispute settlement, by specifying procedures for the creation of panels and roughly indicating time limits for various separate phases, as well as for the panel procedure as a whole (Hudec, 1993). The same goal was pursued with the Decision on Dispute Settlement taken by the CONTRACTING PARTIES on ministerial level in November 1982 (Hudec, 1993). In order to improve the system further it introduced the possibility of asking the DG for the provision of good offices; permitted the DG to extend the deadline for the selection of panelists; confirmed the Secretariat's role in the assistance of

\footnotetext{
${ }^{46}$ Codification and specification also took place with respect to other procedures related to dispute resolution. Considering consultations, Article XXII was amended in 1955. The amendment specified that joint consultations with the CONTRACTING PARTIES could be initiated in case bilateral consultations would not lead to a satisfactory result. Thus, the CONTRACTING PARTIES were singled out as a focal entity to conduct consultations. Also, in 1958 a decision was adopted to regulate consultations under Article XXII. According to this decision, a party that intended to make use of the consultation procedures had to inform the Director-General of any consultation under Article XXII, so that other contracting parties were informed about this and had the possibility to join such consultations in case they would have been interested. Although this procedure was not always followed (Jackson, 1969), the formalization of consultation procedures can nonetheless be regarded as contributing to the institutionalization of dispute settlement under the GATT.

${ }^{47}$ It should be noted that these procedures were made use of only once and even then not very rigorously (Hudec, 1993).
} 
panels; requested panels to report its findings clearly and without undue delay, and requested the Council to consider panel reports promptly and to periodically monitor the implementation of panel reports (Bliss, 1987). In 1984 another decision was taken that called for the establishment of a roster of panelists in order to increase the pool and ease the process of finding sufficiently qualified, independent panelists in a timely manner. The DG was permitted to compose a panel from the roster if the disputing parties would be unable to agree on the composition of the panel and one of them would request the DG to do so (Bliss, 1987).

Certainly, the development and institutionalization of third party adjudication and the corresponding increasing role of the Secretariat is a remarkable one in light of the GATT's minimal institutional provisions at the outset. However, this narrative needs to be qualified as the diplomat's jurisprudence that characterized the setup of the ITO and the GATT continued to exert its influence in the GATT's development. ${ }^{48}$ Despite being an important step towards third party adjudication, the panel procedure still contained a strong diplomatic, political element. ${ }^{49}$ Leading to the characterization of the process as "murky, compromising, confrontation-avoiding style of rulings seeking to resolve disputes by diplomatic nuance" (Hudec, 1993, p. 168). Reflecting on this in light of panel practice in the first ten years of the GATT, Hudec (1990a) argues that
"the GATT disputes procedure never really succeeded in establishing and institutionalizing independent authority [...] the Panel procedure [...] relied heavily on the cooperation of the parties. Moreover, its decision-making capacity had never worked free from its immediate dependence on the current GATT consensus. Panels still needed to negotiate acceptance of more difficult decisions and could quickly be handcuffed by serious disagreement or lack of cooperation." (p. 205)

This was not problematic until the 1960s since the relatively small membership of the GATT shared an underlying, broad consensus with respect the GATT and its main policy direction (Hudec, 1990a). When this consensus began to crumble, also the panel procedure got under pressure and was neglected as a means for dispute settlement throughout the 1960s (Lipson, 1983)..$^{50}$ During this period disputes were increasingly settled diplomatically, outside of the GATT

${ }^{48}$ The following elaboration mainly points towards tangible institutional features that point towards the persistence of the diplomat's jurisprudence throughout the GATT's development. For an interesting overview of indicators that relate to institutional culture, see Weiler (2001).

${ }^{49}$ Hudec (1990a) points out that this was expressed by "the impressionistic technique of decision making". Hudec uses this expression to describe that the disputing parties were regularly consulted in decision-making of disputes to test whether it would be likely that they would agree to a particular interpretation of the GATT legal text. Based on the insights gained from such consultations, a panel was able to adapt the tone and argument provided in its report. Weiler (2001), also mentions this aspect in his list of dispute settlement features that indicate a diplomatic approach.

${ }^{50}$ The formation of the European Economic Community also contributed to the declining use of the GATT's institutional dispute settlement mechanisms. EEC members who previously filed disputes were required to speak with one voice, which led to a decline in their activities as complainants. Furthermore the formation of the EEC 
(Hudec, 1990a). This trend was reversed in the 1970s when dispute settlement was brought back into the GATT again and became increasingly legalistic. Nonetheless, even then a strong emphasis on negotiated settlements remained (Marceau et al., 2015). The 1979 dispute settlement understanding that resulted from the Tokyo Round could not significantly counter this. Although it aimed to improve the dispute settlement process, it also reaffirmed the diplomatic elements of the panel process by stating that "panels should consult regularly with the parties to the dispute and give them adequate opportunity to develop a mutually satisfaction solution." The 1982 ministerial decision signifies a change in tone calling for a decrease in the diplomatic features of the panel process and the resulting ambiguity of panel reports (Hudec, 1993). However, it also reaffirmed the practice of adopting panel reports by consensus and thereby implied that the results of the disputes would still have to be acceptable to the losing party of the dispute. All in all, despite becoming incrementally more legalistic, the GATT dispute settlement system was never fully independent of the disputing parties and it always contained an element of negotiation and diplomacy. In an interview a former negotiator and current Secretariat member described the approach to settle disputes in the GATT in the following way:

"The whole idea was: the law cannot operate in and of itself. It operates in a context. What you found in the GATT days was: there was an effort to find a resolution to the dispute that made everybody happy. The law played a role in guiding the adjudicators to find a solution. But the whole idea was to make the whole thing work. [...] The law is supposed to assist solving problems, not to create them." (Int04)

All attempts to reduce the political elements of the dispute settlement procedure further and to make the GATT an even stronger focal entity by reducing its dependency on the disputing parties were of limited success. Reform proposals were aimed at strengthening the panel procedure, turning the GATT into a prosecutor, and at strengthening enforcement mechanisms in form of introducing remedies additional to the withdrawal of concessions. Although some modest steps were taken throughout the lifespan of the GATT, any such major reform proposals were essentially blocked. These non-events are indicative of the dynamics of institutional design and change. They are another exemplification of the design challenge to develop legal procedures that were strong enough to safeguard the substantive agreements of the regime in a political environment, which often required negotiated solutions and political wiggle room.

The constraining factors that arose in the GATT's political environment and hindered reform were different in nature. During the early years of the GATT, dispute settlement procedures had to be cautiously designed due to the weak institutional standing of the GATT. After all, the GATT wanted to avoid raising the suspicion of domestic audiences - particularly the US Congress that it shared characteristics of an international organization. Later on, when the GATT had

itself was problematic for the GATT due to the EEC's agricultural politics and its preferential ties with former colonies. Less complaints were filed, since it was not desired to approach such sensitive issues judicially (World Trade Organization, 2007). 
acquired a more solid stance in the international arena impediments to reform were of a different nature and mainly arose from the heterogeneous interests of contracting parties. In the 1960s and 70s, efforts by developing countries to strengthen the GATT to make it a more powerful tool in challenging inequalities in the international arena were blocked by developed contracting parties. By the mid-1970s another dissent entered the scene characterized by different attitudes held by the US and the EC on the nature of dispute settlement in GATT. From the Tokyo Round onwards the US started to call for reducing the political elements of dispute settlement and for legalizing the GATT to make it a stronger tool to enforce liberal trade. ${ }^{51}$ However, the EC desire to continue settling disputes in a diplomatic way impeded the US' reform attempts vigorously. To fully understand the dynamics of institutional change it is useful to examine these non-events in further detail.

Early in the GATT history the contracting parties were already reluctant to strengthen the enforcement capacities of the GATT too much. In 1955 , at the $9^{\text {th }}$ session of the contracting parties Denmark suggested to expand the panel procedure to more areas of the GATT (Irwin, Mavroidis, \& Sykes, 2008). The proposal suggested to replace working parties consulting on balance-of-payments restrictions with panels, but also mentioned that it should be considered to approach any other commercial policy matter that could give rise to complaints by the appointment of panels. Furthermore, the Danish proposal already suggested creating a roster of individuals that would serve as the source for the selection of panelists. ${ }^{52}$ The contracting parties discussed these suggestions at their $10^{\text {th }}$ session..$^{53}$ Clearly they were not ready for such an extended use of panels. While many expressed their satisfaction with the panel procedure in its current form, it was stressed that panels should only be selectively used for the examination of factual issues and not for a "wholesale, automatic review of compliance" (Hudec, 1990a). There was a widely shared opinion that an extended use of panels could lead to too rigid interpretations of the GATT and that flexibility is desired to investigate sensitive economic or political questions. ${ }^{54}$ According to Hudec (1990a) the

"... rejection of the Danish proposal [...] proved [...] that the panel procedure itself could never really escape the basic political constraints which had dictated GAT's limited legal design in the first place. Now that the panel procedure had proved itself effective, its own range of operations would have to be controlled in turn." (p. 92)

Clearly, the contracting parties preferred flexibility and room for maneuver. This is also indicated by another decision that took place in the context of the 1954/55 discussion to establish the Organization on Trade Cooperation (OTC). In this context it was considered to

\footnotetext{
${ }^{51}$ Interestingly, the US Congress was one of the driving forces calling for stronger GATT enforcement mechanisms (Hudec, 1993; Porges \& Price, 2005).

52 W.9/171

53 These discussions took place based on a paper produced by the Director General, who was mandated to reflect on the Danish proposal, see L/392.

${ }^{54}$ SR.10/1
} 
include provisions on dispute settlement in the agreement to establish the OTC, but decided that the broad provisions mentioned in the GATT sufficiently accommodated for the settlement of disputes. ${ }^{55}$

Other attempts to strengthen the GATT as a focal entity in dispute resolution were undertaken in the 1960s and 1970s by developing countries. Uruguay and Brazil were particularly active. In 1961 Uruguay already suggested that the Secretariat should examine whether nontariff trade barriers imposed by developed countries would be in accordance with the substantive provisions of the GATT (Hudec, 1990a). This was followed two years later by a set of complaints by Uruguay against 15 leading developed countries. These complaints were filed based on a Uruguayan list of almost all nontariff barriers of the 15 accused developed countries. Uruguay suspected that the listed barriers negatively affected its exports, but did not further argue about the legality of the barriers. Instead Uruguay requested a panel to do so. In essence this amounted to an attempt to push the GATT into a prosecutor's role (Hudec, 1990a). The panel refused to take up this role, but Uruguay - this time together with Brazil - continued its attempts to strengthen the GATT to the benefit of developing countries. In a major effort to thoroughly reform Article XXIII in 1964-1966 Uruguay and Brazil suggested once again to equip the GATT with a prosecuting function, to establish a permanent arbitration body, and also demanded - even more controversially - that stronger remedies in form of financial compensation or collective retaliation would be introduced (Hudec, 1990a; Jackson, 1969). ${ }^{56}$ This attempt was blocked by developed countries, who preferred less confrontational and a more negotiated dispute settlement at the time (Hudec, 1990a). Eventually the result of the reform effort was limited to the comparatively modest changes embodied in the 1966 decision on Procedures under Article XXIII, which was mentioned above.

After this defeat the leading developing countries pursued their goal to strengthen the GATT less vigorously, but nonetheless still tried to establish procedures that would have allowed a panel to actively pursue potential GATT violations of a developed country as a kind of prosecutor. Once again these attempts did not succeed (Hudec, 1990a; World Trade Organization, 2007). Instead, the 'Group of Three' was established in 1971. This compromise solution exemplifies the ingredients on the diplomat's jurisprudence once again. The Group of Three consisted of the chairmen of the CONTRACTING PARTIES, the Council and the Committee on Trade and Development and was supposed to detect unjustified trade measures that disadvantaged developing countries. The group would rather have a monitoring and mediating than a prosecuting function (World Trade Organization, 2007). It was moderately successful, but was dissolved after three years at the beginning of the Tokyo Round (Hudec, 1990a). During the Tokyo Round Brazil launched another attempt at reform to the benefit of developing countries. In 1977 it revived the 1964-1966 discussion and suggested a prosecutorial role for the GATT, and once again financial compensation and collective retaliation as additional remedies (Hudec, 1993). Also the suggestion to establish a central, standing tribunal in place of the ad hoc panel

\footnotetext{
${ }^{55} \mathrm{~L} / 327$

${ }^{56} \mathrm{~L} / 2195, \mathrm{COM} . \mathrm{TD} / \mathrm{W} / 38$ and COM.TD/F/W.1
} 
procedure was brought up during the Tokyo Round negotiations (Hudec, 1993). However, once again these suggestions did not find sufficient support by the most powerful countries, who perceived them as too legalistic (Hudec, 1980, 1993)..$^{57}$

However the Tokyo Round also marked the start of a new dynamic in the discussion on changing dispute settlement procedures, which would continue way into the Uruguay Round. While the developing countries' failure to strengthen the GATT's role in dispute settlement can be ascribed to a lack of power in light of a strong opposition of developed countries, at the time of the Tokyo Round a considerably more powerful actor entered the stage in demand for change - the United States. During the 1960s the US had formed an alliance with the EC in sharing an anti-legalist attitude to keep developing countries' demands for stronger enforcement at bay (Hudec, 1993). In light of worsening terms of trade and domestic pressures for protectionism this changed and the US became a stronger proponent of a more legally rigorous approach to enforce the GATT (Hudec, 1993). This change in attitude put the US at odds with the EC, whotogether with some other contracting parties - continued to favor of the politically flexible, antilegalist approach of the 1960s. The dynamic that resulted from these opposing interests of two powerful players influenced the institutional development of dispute settlement until the end of the Uruguay Round.

The Tokyo Round marked the starting point for this. Due to congressional concern about the GATT's enforcement capacity, the US delegation entered the Tokyo Round with the permission to seek reform of dispute settlement procedures (Hudec, 1980, 1993; World Trade Organization, 2007). By that time the several possibilities of delaying the panel procedure had already become problematic (Hudec, 1980, 1993). The US wanted to counter this by making panel procedures more automatic. The 1966 decision that applied to disputes between developing and developed countries, granted developing countries the right to a panel and set clear time-frames for the different stages of the panel procedure, was the blueprint along which reform proposals were developed (Hudec, 1993). It was considered to apply this procedure to all disputes arising under the GATT and not only to those that arose between developing and developed countries (Hudec, 1993). More radically, the idea came up to even modify the consensus rule of adopting panel reports, but was not seriously negotiated (Hudec, 1993). Being afraid that it would most often end up as the losing party in a stricter judicial system and that it would have to change its agricultural policy due to this, the EC was opposed to any changes towards a more automatic panel procedure (Elsig \& Eckhardt, 2015).

The debates of judicial reform took place in two different settings during the Tokyo Round. The negotiations unfolded differently depending in which of the two settings they took place. One setting was constituted of the negotiation groups that negotiated on the different non-tariff codes. In this setting the negotiating parties realized that newly negotiated rules would require strong enforcement mechanisms to be credible (Hudec, 1980). Consequently it was possible to achieve more automaticity in dispute settlement provisions of the different codes. The exact

\footnotetext{
${ }^{57}$ Regarding the suggestion to establish a standing tribunal, also financial reasons and potential difficulties in finding a mutually agreeable composition of judges were arguments against such a body.
} 
dispute settlement mechanisms differed per code and some codes had stronger provisions than others, but at least all of them contained language that implied the right to a panel (Hudec, 1993). In the other setting the general dispute settlement structures under Article XXIII were addressed. It was in this setting where Brazil suggested the reforms mentioned above and that also saw the discussion on the application of the 1966 procedures to all GATT disputes. However, in this setting the results of the negotiation were considerably more limited as the negotiations were not tied to politically relevant new negotiations on substance, but would only addressed enforcement of rules that were already 20 to 30 years old and partially outdated (Hudec, 1993). This allowed the EC to keep the demands for reform at bay (Hudec, 1993). Eventually the negotiations resulted in the 1979 'Understanding on Notification, Consultation, Dispute Settlement and Surveillance', and in the codification of customary practices. As it has been pointed out above, the former was aimed at making dispute settlement more effective and the latter was significant in institutionalizing the panel procedure. However, in light of the changes demanded at the outset, the result was limited. It was rather a conservative reinforcement of existing practices - not granting the right to a panel and reaffirming the diplomatic elements of the panel process (Hudec, 1993). ${ }^{58}$ Clearly the Tokyo Round reforms remained unfinished business and apparently

“... radical reform was never a realistic possibility. The fundamental political constraints that limit GATT regulatory policy had not changed. The Tokyo Round debate over dispute settlement never seriously questioned the assumption that the GAT would continue to rely on the essentially normative force of declaratory rulings such as those produced by the existing panel procedure." (Hudec, 1980, p. 158)

Even more, taking a broad perspective on centralization, the results of the Tokyo Round even decreased centralization and led to institutional problems. Although the dispute settlement mechanism of the different codes were slightly stronger than the general mechanism under Article XXIII, the fact that each code had its own mechanism lead to the fragmentation of dispute settlement in the GATT and corresponding problems in terms of forum shopping.

It did not take the contracting parties long to recognize the shortcomings of the Tokyo Round reforms. Consequently, the next reform attempts started to emerge in 1982 already. Once more the US lobbied for more automatic dispute settlement and once more the EC was opposing this. However, being faced with the thread of jeopardizing the relevance of the GATT and starting to see dispute settlement as a potentially useful policy instrument, the EC did not take an entirely obstructive position (Hudec, 1993). It agreed to streamline the dispute settlement procedures on a declaratory level as expressed in the 82 Ministerial Decision on Dispute Settlement. However, it remained firm on the most problematic element of the system: the possibility to block several stages of the panel process due to consensus decision-making.

\footnotetext{
${ }^{58}$ As pointed out above, the diplomatic nature of the panel process was reaffirmed by the Tokyo Round's understanding, stating that "panels should consult regularly with the parties to the dispute and give them adequate opportunity to develop a mutually satisfactory solution" (L/4907, p.4).
} 
Apparently, right before the Ministerial Meeting the EC was close to agreeing to 'consensusminus-two' - i.e. a consensus that would exclude the disputing parties from the decision - as a new decision-making mechanism. However, eventually the EC reaffirmed its original, conservative position and insisted on written confirmation of consensus as the decision-making procedure to be used in dispute settlement (Hudec, 1993).

The Janus-faced dynamic of the development of dispute resolution is also exemplified in the development of the Secretariat. Although the Secretariat became increasingly influential in the panel procedures and staff increasingly occupied with legal questions, an anti-legalist attitude prevailed for a long time in the GATT's history (Marceau et al., 2015). This is indicated be the absence of staff formally being appointed as lawyers and the lack of a legal office until 1981. Only when disputes became legally more complex in an expanding organization, with increasingly divergent opinions on some legal questions a legal office was established (Lindén, 2015). Also in this episode of institutional development friction between the US and the EC was apparent. The US lobbied for the establishment of a legal office, which the EC resisted until the beginning of the 1980s and only agreed to upon the condition that it would not be staffed with an academically trained lawyer (Lindén, 2015). Eventually the office was created on a trial basis for two years and staffed with the former head of the Secretariat's Agricultural division. In 1983 the office was expanded and strengthened. Ake Lindén was appointed as head of the Office of Legal Affairs. This is to be interpreted as a compromise between the US and the EC, since Lindén was a lawyer by degree, but never practiced as one and had considerable experience with the GATT's pragmatic approach to disputes, since he had already joined the Secretariat in 1959 (Marceau et al., 2015).

The preceding section has clearly shown the ambivalent development of dispute resolution: On the one side, some forces pushed for the development of more centralized, streamlined and efficient means to objectively settle disputes in an independent, legally rigorous manner. On the other side, this was constrained by other forces that demanded political and economic flexibility, as well as control of the process. From this dynamic several insights can be drawn. First, dispute settlement developed cautiously and incrementally. In this respect it cannot be regarded as a single grant moment of rational institutional design. Each of the steps taken can with some good will be interpreted as a more or less rational decision given the circumstances at the time, but this does not imply that in the aggregate the result can be interpreted as a rational outcome of a conscious design process. As such, path dependence and bounded rational design seem to be appropriate attributes to describe the development of dispute settlement. Secondly, development only took place when favored by the most powerful actors, who usually did so when having an interest in seeing obligations they perceived as beneficial enforced and did not so when expecting enforcement of disadvantageous obligations. This suggests that the judgment which design is rational lies in the eye of the beholder and that institutional arrangements are linked to those on substance. Given the unsuccessful attempts by developing countries to strengthen the GATT by equipping it with a prosecuting function and introducing 
stricter remedies, the assumption of a homogenous, unified interest in one particular, rational design cannot be maintained. Power remains an important factor. Finally, the historical overview provided leads to a seemingly paradoxical interpretation of the institutional change that took place during the Uruguay Round. On the one hand it highlights the elements of path dependence that continued to influence the dispute settlement system of the WTO. On the other hand, it shows how revolutionary the reforms of the Uruguay Round have been. After all, the pragmatic diplomat's jurisprudence was a longstanding feature of dispute settlement. In a significant break with the past this was turned into one of the most legally rigorous and autonomous systems in international dispute resolution. Indeed, the reforms constituted a legalization leap! The next section further elaborates on this paradoxical observation.

\subsubsection{The Impact of History on the Uruguay Round Negotiations}

The GATT's history impacted the seemingly paradoxical result of the Uruguay Round on both dimensions of the paradox - the continuous as well as the revolutionary character of the reform. Under the assumption of bounded rationality it is possible to see how this can be the case. It is to be recalled that bounded rationality implies that actors are looking for design solutions to a given problem that are as close as possible to the status quo and that designers are prone to cognitive biases (Jupille, Mattli, \& Snidal, 2013). In this regard, the history of the dispute settlement system influenced designer's behavior by providing the status quo that designers relied on and by providing the cause of cognitive bias, which led to an underestimation of the likely effects of design changes. The former explains the elements of path dependence; the latter is a partial explanation of those elements that relate to revolutionary change. Under the assumption of bounded rationality the outcome of the Uruguay Round does not seem paradoxical anymore and designer's behavior is accurately captured as interviews with former negotiators and Secretariat members suggest. Conceptualizing actors as fully rational, as the rational design literature does it, would fall short in this respect and fails to account for the impact of history.

Regarding the elements of the reformed system that exemplify continuity, it has already been pointed out above that the WTO is strongly influenced by the practice that developed in the GATT (Hudec, 1999b; Kantchevski, 2006; Steger \& Hainsworth, 1998; Van den Bossche \& Zdouc, 2017). Article 3.1 of the DSU explicitly acknowledges this. The historical overview provided above shows that those design elements of the WTO's dispute settlement system that are a legacy of the GATT cannot be regarded as the outcome of a single, coherent process of rational design. Instead, they need to be regarded as series of incremental steps taken by designers that sought solutions to functional problems by relying on modifications of existing procedures.

Particularly the continuation to use non-standing panels as one of the core features of the system suits this interpretation. The Uruguay Round improved the exact procedures followed by panels as exemplified by the 1989 'Decisions on Improvements to the GATT Dispute Settlement Rules and Procedures'. However, the system was not thoroughly rethought. Designers built 
upon the procedures that had gradually developed, kept what they regarded as functional and only changed those elements that were regarded to be problematic. ${ }^{59}$ Amongst the things that have stayed the same or only slightly changed is the Secretariat's role in the selection of panelists, the profile of panelists and panels, the rosters, and most importantly the ad hoc nature of panels without an institutionalized mechanism to coordinate among different panels (Weiler, 2001). Interviews suggested that more substantial change of the panel procedure was not possible. The idea to create a standing body instead of creating panels ad hoc, for example, never received sufficient support due to budgetary constraints and due to the fact the panel procedure as such was not necessarily regarded to be problematic (Int02, Int05, Int06).

Reliance on the status quo and historical experience is also exemplified by the fact that the negotiators requested the Secretariat to provide background papers on the existing GATT dispute settlement system and its development. ${ }^{60}$ These papers were important to negotiators and influenced their search for solutions to functional problems. In this respect it is not surprising that the text of DSU is strongly inspired by the several texts and agreements on dispute settlement that emerged since the Tokyo Round, up to the point that it "borrows large chunks of text from all of these earlier reform documents" (Hudec, 1993, p. 235). In a pragmatic fashion designers build on existing structures. As a former negotiator pointed out, "tradition played a strong role and trying to preserve as much of this as possible. We created a lot of new features, but we kept many of the features of the old GATT" (Int01). ${ }^{61}$

However, this does not explain the groundbreaking changes the Uruguay Round brought about, such as the creation of the Appellate Body and the introduction of reverse consensus. Given the many non-events in dispute settlement and the persistence of the diplomat's jurisprudence at each previous reform attempt, the question arises which factors were permissive to overcome this and to turn to a fully legalized system.

Part of the answer could simply lie in cognitive bias. Designers underestimated the effects of the reforms and especially the impact that the Appellate Body would have on the system. ${ }^{62}$ Once again, the GATT's history - although this seems initially counterintuitive - can contribute to such an explanation. When anticipating the effects of the newly designed system it seems that designers once more relied heavily on existing structures and their experience with the past. Evidence suggests that the diplomatic jurisprudence played a strong role in influencing negotiator's expectations. It determined the cognitive scripts that they relied on when estimating the potential effects of reform. This in turn induced many of them to underestimate

\footnotetext{
${ }^{59}$ This was confirmed in several interviews with former negotiators and Secretariat members (Int01, Int02, Int06).

${ }^{60}$ MTN.GNG/NG13/W/4; MTN.GNG/NG13/W/4/Rev.1; MTN.GNG/NG13/W/20; MTN.GNG/NG13/W/27; MTN.GNG/NG13/W/27/Rev.1; MTN.GNG/NG13/W/28; MTN.GNG/NG13/W/29; MTN.GNG/NG13/W/31; MTN.GNG/NG13/W/32; MTN.GNG/NG13/W/35

${ }^{61}$ Even regarding the revolutionary change in decision-making the impact of tradition is at least linguistically discernible, as the reference to consensus is maintained but with a reversed meaning.

${ }^{62}$ Not only the designers themselves did so, also some commentators at the time were skeptical whether the institutional changes would have wide ranging implications (e.g. Stiles, 1996).
} 
the eventual outcomes of reform. Many designers expected that dispute resolution would maintain political conciliatory features, and would be used in a less judicial manner and less frequently than it eventually turned out to be. It seems that designers did not intend to create a system as powerfully centralized as we currently see it in the WTO and that reform would have been less likely if they would have predicted the strength of the system more accurately.

Several unintended effects have been pointed out by former negotiators in academic publications, as well as in interviews conducted for this research. As Debra Steger - one of the most influential negotiators of the DSU - points out in her publications, the designers never intended to create a trade court (Steger, 2002a, 2002b, 2015). In hindsight many designers were surprised how some of the features of the new system would be used and develop. ${ }^{63}$ Firstly, it was not expected that the dispute settlement system would be used as extensively and the amount of appeals was expected to be far lower than it eventually turned out to be (Elsig \& Eckhardt, 2015; Shaffer et al., 2016). ${ }^{64}$ Secondly, the Appellate Body from the start followed the rules of interpretation as set out by the Vienna Convention of the Law of Treaties (Lacarte Muró, 2015; Van den Bossche, 2006). It thereby follows customary rules of interpretation of public international law. This enabled it to apply rigorous standards to the interpretation of the WTO's substantive agreements, even when such agreements are formulated in a fairly vague manner. It does so up to the point that some observers even accuse the Appellate Body of judicial lawmaking (Barton, Goldstein, Josling, \& Steinberg, 2006; Greenwald, 2003; Matsushita, 2012; Steinberg, 2004). According to some negotiators this came as a surprise (Int01, Int04, Int05, Int10, Int18). They expected that the Appellate Body would follow the GAT tradition and consider the political context and negotiators' intentions more strongly in its interpretations. One former negotiator used rather strong terminology, mentioning that for many of his colleagues the Appellate Body's approach to interpretation amounted to 'heresy' (Int01). Another one mentioned that it was expected that the Appellate Body's members would act as a group of 'eminent grey', who would guard the system as a whole and leave the detailed analytical work to the panels (Int04). Thirdly and partially as a result of the previous points, the Appellate Body became a lot more influential than expected (Int01, Int04, Int06, Int14, Int15, Int17, Int19). It was expected that the Appellate Body would simply be a means to control panels and only be called upon rarely, when panels were suspected to have made a legal mistake. However, with the high frequency of appeals, a relatively large degree of discretion to fulfill its

\footnotetext{
${ }^{63}$ This was confirmed in several interviews conducted for this research (Int01, Int04, Int05, Int06, Int07, Int08, Int10, Int14, Int15, Int16, Int17). Also Julio Lacarte, the chair of the negotiation group on dispute settlement during the Uruguay Round, confirmed this in an interview conducted for the WTO Creation Project, see http://www.wtocreation.org.

64 This was also pointed out in several interviews conducted by the author (Int04, Int05, Int14). Julio Lacarte also pointed this out during the interview that was conducted for the WTO Creation Project, see http://www.wtocreation.org.

Also the initial proposal for the establishment of the Appellate Body, tabled by the Canadian delegation in the negotiation group on dispute settlement is quite telling concerning the negotiator's expectations. It mentions that the suggested appeals mechanism would only be used rarely and that the "intent would not be to have appellate review become a quasi-automatic step in the dispute settlement process." See, MTN.GNG/NG13/W/41, p.4
} 
function, and a very professional staff the Appellate Body was able to carve out a central place in the WTO and in essence became almost an international court (Ganesan, 2015; Shaffer et al., 2016; Unterhalter, 2015; Van den Bossche, 2006). Finally, it was pointed out in interviews that the dispute settlement culture changed after the introduction of the dispute settlement reform. WTO members themselves approach disputes with a less diplomatic mindset, but in a very legalistic manner (Int06, Int16, Int17). Already at the panel stage lawyers and law firms are strongly involved. A former negotiator complained that this led to 'hyper legalization' with very little room for political compromise and that "disputes are settled as if they were private disputes and not disputes among sovereign states" (Int16). Overall, the dispute settlement culture in the WTO is clearly different from that in the GATT. Dispute settlement in the WTO constitutes a clear renunciation of the diplomat's jurisprudence. Whether this is a positive or negative development depends on one's perspective and the criteria used for judgment. ${ }^{65}$ It is uncontroversial though that this was not fully expected.

The fact that the system developed contrary to expectations was probably due to the fact that the formal institutional design does not prescribe this new approach to dispute settlement. The designers of the DSU aimed to emphasize non-judicial means of dispute resolution when drafting the agreement (Bernauer, Elsig, \& Pauwelyn, 2012). This is implied by the language of the DSU, which states that the aim of dispute settlement is to find a "satisfactory settlement" (Art. 3.4, DSU) and "positive solution" (Art. 4.7, DSU) of a dispute. Furthermore, litigation via the use of panels and the Appellate Body is only one possible path to settle disputes. Several more diplomatic means to settle disputes are possible (Int06, Int09). Disputants can for example decide to resort to arbitration (Art. 25, DSU), or use good offices, conciliation or mediation to settle a dispute and ask the DG to assist them in doing so (Art. 5, DSU). Finally, it should not be forgotten that Article 4 of the DSU strongly encourages disputants to enter consultations before launching the panel procedure.

However, these mechanisms - except for consultations - are rarely used (Bernauer et al., 2012). Incentive structures changed due to the new system. While in principle still open to political solutions the reformed system permitted and induced the mentioned change in legal culture, which was then brought about by the actual use of the newly negotiated design in practice. The increased use of the dispute settlement system and the high amounts of appeals indicate this. The new incentives and the resulting unexpected dynamics were nicely expressed by a former negotiator during an interview:

"I think the very first idea was to stabilize the system to maintain a multilateral system in place and everyone was more or less counting on seeing recourse to litigation within

\footnotetext{
${ }^{65}$ Clearly the dispute settlement is an outstanding institutional development that strongly promotes the rule of law in international trade. However, from a pragmatic perspective it is claimed to lead to institutional imbalance. Some argue that the strong judicial function weakens the legislative function of the WTO. It hampers negotiations of new substantive agreements, since it limits the room for constructive ambiguity. WTO members are very careful in their negotiations since they are aware that whatever they agree too will eventually be subject to rigorous legal interpretation.
} 
the limits of what we had seen in the GATT. And the big 'mistake' - the thing that only very few anticipated - is that if you give your kids a toy for Christmas they are going to play with it extensively before losing interest in it. Here we were creating a completely new system of litigation and we jumped from annually six to seven disputes to annually 60 to 70 . And that was the big surprise to some. I think many had not anticipated that a system of a fully automatized litigating process would be tested until the bitter end." (Int01)

The last sentence of this quote refers to the large amount of appeals. This dynamic also was induced by the design of the system. If there is the possibility to appeal the finding of a panel, it would be domestically difficult for a losing party to justify why this possibility is not being used (Int05) (VanGrasstek, 2013). It seems plausible to assume that domestic interest groups would have an interest to ensure that all possible means to achieve a positive outcome of a dispute are being exhausted. According to this logic it is fairly obvious that most disputes would be appealed. Also consultations unfold a different dynamic in the shadow of a binding, quasiautomatic system in comparison to one where the disputing parties know that the litigating process can be easily blocked. The latter is more conducive to political compromise than the former, because a complainant is more likely to turn to adjudication if it is dissatisfied with the result of consultations.

In hindsight the negotiators also acknowledge this. One pointing out that the expectations negotiators had were naïve, but nonetheless plausible at the time given the cognitive scripts that influenced these expectations (Int05). Apparently, negotiators tried to introduce a stronger role for the rule of law - as implied by the tangible institutional changes - but without changing the legal culture - as implied by their expectation of the continuation of the diplomats jurisprudence. However, as Weiler (2001) points out: “... with one you get the other. The WTO moved to the rule of law without realizing that the accompanying legal culture is as integral as the compliance and enforcement dimensions of the DSU shift" (p. 339). ${ }^{66}$

Certainly, many were clear about the legal consequences of the changes as they appeared on paper and aware that the system would become fully automatic (Stoler, 2004). However, they still neglected or underestimated the unfolding dynamic. John Weekes, Canadian ambassador to the GATT and the WTO, suggests that designers were mainly concerned with solving practical problems of the time, without envisioning what the system would look like

\footnotetext{
66 Yet, the new dynamic did not come as a surprise to everyone. In an interview for the WTO Creation Project Arif Hussain, the Chief of Staff under DG Arthur Dunkel at the time of the Uruguay Round, points out in an interview for the WTO Creation Project that Dunkel was initially not in favor of the idea of the Appellate Body. Dunkel already expected that the majority of cases would be appealed and was concerned that there would be less discretion in dispute settlement to find diplomatic solutions. This was also confirmed in an interview with a former Secretariat member who stated that he had written a memo to the DG, outlining the potential dynamic that could result from the institutional changes (Int14). However, in the same interview he also suggested that other actors neglected such considerations. And indeed, the majority of interviewees pointed out that they were taken by surprise about the exact consequences of the reform.
} 
afterwards. ${ }^{67}$ This was also pointed out in some interviews conducted for this research (Int04 Int17). During other interviews it was suggested that it was simply not possible to fully anticipate how the dynamics of a new legal system would unfold, that many lacked the imagination to do so and that the reform was to a certain extent a leap of faith (Int02, Int05, Int07, Int17, Int18, Int19). As Robert Hudec (1993) put it:

"The process of building a legal system is not one that is accomplished by an architect's plans drawn in advance. No one can foresee the problems that come up, and even if they could, no one can control the way that individual governments will behave toward them." (p.177)

In light of this uncertainty actors were influenced by their existing experience with the GATT to estimate how the reforms would unfold (Int01, Int04, Int05, Int14, Int17,). One negotiator pointed out that

"The negotiators negotiated with a mindset and a way of approaching things that was coming from 47 to 86 - that's 40 years of experience. And that is the only experience they had. So they were very much informed by past practices." (Int04)

This is confirmed by others, stating that: "People were very much in a GATT frame of mind. In those days we knew nothing else. So it was kind of a feeling that the GATT would continue" (Int17). And that "we had done business in one way for such a long time that nobody thought that this tradition of the GATT would be lost with the new mechanisms being created" (Int05). Apparently this did not only hold for GATT insiders, but also for the governments of its membership (Int19). Overall it does not seem to be too controversial to claim that the reform of the dispute settlement system was at least partially an experiment based on the experience of the GATT and "created by the people at the time who were immersed in the GATT culture" (Int17). Clearly, the history of the GATT did not only influence the elements of the system that constitute a continuation of past practices, but even left their impact on the revolutionary changes.

It can even be posited that the underestimation of the effects of reform increased the likelihood of reform, since the full costs of reform were overlooked. From a rational perspective it is assumed that institutional design features are chosen in such a way that they provide functional benefits at the lowest possible costs (K. W. Abbott \& Snidal, 2000; Jupille et al., 2013). During the Uruguay Round designers were well aware of the benefits of the reforms. After all, the main problem of blocking panel reports was overcome by the introduction of reverse consensus and the potential costs of automaticity in terms of too much autonomy for panels was supposed to be controlled for by the introduction of the Appellate Body. However, many overlooked the costs that came in form decreased political room for maneuver in dispute

67 This was pointed out in an interview conducted for the WTO Creation Project, see http://www.wtocreation.org. 
settlement, brought about by the unexpected prominence of the Appellate Body and the strong turn towards a highly legalistic institutional culture. Perhaps the degree of centralization was only permitted to be as high as it is, because it was never fully anticipated to be. This hypothesis was suggested in three interviews (Int04, Int05, Int19). Especially regarding the Appellate Body one former negotiator said that the regime's members were never willing to give it as much authority as it eventually acquired, but that they simply did not realize the importance of the institutional entity that they were about to setup at the time (Int19). ${ }^{68}$ Another former negotiator and current Secretariat member mentioned that "one thing that I can also tell is that if they [the negotiators of the Uruguay Round] knew then what they know now, the agreements would not look the way that they look now. It's as basic as that" (Int04).

\subsubsection{Conclusion}

Investigating the history of the institutional structures of dispute resolution in the trade regime provides several insights that are useful to understand the institutional design as it emerged from the Uruguay Round. First of all it becomes clear that the development of institutions related to dispute resolution occurred incrementally and path dependently. As it has been shown the WTO's dispute settlement system is to a certain extent a continuation of this development. Consequently, the institutional design of the WTO's system can hardly be regarded as the outcome of a single moment of rational design. Of course, significant new elements were introduced and parts of the reform were revolutionary. However, even these elements build upon the basis of the system as it had evolved in a long-term process. In this respect the Uruguay Round rather constitutes a tipping point - a brief, but quick acceleration of a long moving process of institutional development (Pauwelyn, 2005). Secondly, the history of the GATT shows how significant the acceleration of this development was. Despite path dependence, some reforms and especially the dynamics that resulted from these reforms constitute a significant break with the past. The introduction of reverse consensus and of the Appellate Body are not only significant changes in their own right, they also triggered a dynamic in dispute settlement that led to the abandonment of the longstanding diplomat's jurisprudence. Thirdly, this abandonment was hardly expected by negotiators. The reforms led to a higher degree of centralization than the negotiators would have predicted, with a highly influential Appellate Body at the center. Consequently, a post hoc functionalist explanation of change deriving its insights by explaining the emergence of the system based on its current functioning would overestimate the motivation for centralization. It rather seems that the creation of the most innovative institutional features that resulted from the Uruguay round was the result of bounded rational actors that used previous GATT experiences as a cognitive script to estimate the potential results of their decisions. According to this script the decisions seemed

${ }^{68}$ Related to this, one interviewee suggested that not anticipating that the Appellate Body would turn to general principles of international law to interpret the agreements relevant to a dispute might have been particularly conducive to permitting the reform of the system (Int18). 
to be more conservative than they actually turned out to be. This shows that bounded rationality might not only caution approaches to institutional design, as suggested by some (Jupille et al., 2013), but that it can also result in more adventurous design when playing out as seen in the Uruguay Round. Indeed, it might be that the system would not look as it does right now, had the designers predicted the consequences of the reforms more accurately.

However, history cannot fully explain the design of the WTO dispute settlement system as it emerged from the Uruguay Round. After all, some parties - especially the EC - were opposed to the reform of dispute settlement already since the 1970s and their position had not changed significantly until the beginning of the Uruguay Round. Even more so, some of their arguments against reform were pointing to the risks of automaticity and losing the political room for maneuver well in advance of the Uruguay Round already (Hudec, 1993). So cognitive bias can at most partially account for the revolutionary design changes. A more convincing explanation needs to exist to explain why those parties that were skeptical at the outset of the negotiations changed their perspective throughout the round. Such an explanation can only be found when examining the negotiation process. 


\subsection{Negotiating Design: Process and Dynamics}

As it was pointed out in section 4.3.1, from an abstract perspective approaching the reform of dispute settlement in the Uruguay Round can be regarded as functionally motivated. The expansion in scope and complexity of the substantive agreements negotiated during the round simply demanded a strong dispute settlement system to ensure enforcement. However, as elaborated in section 4.3.2 this account would leave several gaps. While some of these gaps could be filled by the historical account provided in the previous section, the crucial question how it was possible to overcome interest heterogeneity still needs to be addressed.

Tracing the process of the negotiations does so and allows exposing the negotiations' dynamics. This in turn leads to several revealing insights that supplement the rational and the historical accounts provided so far. The following section shows that almost all of the changes in centralization that resulted from the Uruguay Round - as listed in section 4.2-depended on the particular dynamics that unfolded during the negotiations. Although all negotiating parties shared the common goal to improve the dispute settlement system, the results of the reform were not a forgone conclusion. Significant differences existed on the kind of design features that should be employed to reach the desired improvement of the system and on the question how far reaching the aspired reform should be. In light of this background the negotiated design features can be roughly grouped into three clusters according to the underlying dynamics of the negotiations.

The first cluster consists of the relatively low-key procedural improvements of the panel process that were already agreed to during the Montreal midterm review in 1988. This cluster is characterized by a relatively quiet dynamic that resulted from the absence of significant interest heterogeneity. As it will be seen, process tracing of the Uruguay Round's negotiation history adds relatively little to the previously provided rational and historical accounts on the emergence of the design features in this cluster.

This is in contrast to the second cluster, which is characterized by significant preference heterogeneity of the most influential negotiating parties and corresponding controversy during the negotiations. As it was elaborated on in section 4.4.3, since the Tokyo Round the US and the EC clashed with respect to their attitude on the nature of dispute settlement in the trade regime. While the US championed a legalist approach, the EC desired to preserve the political, conciliatory features of the system and blocked significant reform attempts to change the decision-making practices on the resolution of disputes. These opposing positions had not changed by the time of the Uruguay Round and strongly influenced the negotiations. In contrast to the rational and historical explanations provided so far, process tracing is particularly useful to understand how interest heterogeneity surrounding the question of decision-making in the dispute settlement process could be resolved and why the introduction of reverse consensus was possible. It becomes clear that the increasingly credible threat of the US to rely on aggressive unilateralism towards the end of the 1980s was the decisive factor that led the EC- 
and other parties that opposed the idea to change the decision-making mechanisms of dispute settlement - to change their position. This highlights the importance of power in overcoming preference heterogeneity and enabling new institutional design. Without the ability of the US to force other players to change their negotiation position on automatic resolution of disputes it is unlikely that the step to reverse consensus would have been taken.

The remaining design changes that resulted from the Uruguay Round, including the introduction of the Appellate Body and the introduction of exclusive jurisdiction can be grouped in a third cluster. The common characteristic in terms of negotiation dynamics of this cluster is that all the design features in the cluster can be regarded as spin-off effects of larger considerations in the negotiations and were consequently hardly foreseen at the outset of the round. The decision to establish the Appellate Body and the introduction of exclusive jurisdiction can be regarded as domino effects of the introduction of reverse consensus. Similarly, the decision to unify the dispute settlement system and with it, the establishment of the DSB, are most usefully interpreted in the context of the reinterpretation of the single undertaking and the establishment of an international organization as it was elaborated upon in the previous chapter.

In the following each of these clusters is examined in further depth and embedded in the chronology of the negotiation process. It becomes clear that rational design would at most be a plausible explanatory account for the design features in the first cluster. The design features in the second and third cluster are at least as much a function of power relationships amongst the actors involved and the resulting negotiation dynamics as they are influenced by rational considerations. For these design features rational accounts only hold in so far as the results of the negotiations are most rational from the perspective of those actors who were powerful enough to overcome a less powerful opposition.

\subsubsection{Strengthening Procedures: Homogenous Preferences and Early Decisions}

Long before the beginning of the Uruguay Round functional problems of the dispute settlement system had been evident. Throughout the 1980s awareness of the weaknesses of the dispute settlement system increased amongst contracting parties and attempts to rectify these weaknesses were undertaken. ${ }^{69}$ As it was pointed out in section 4.3.1.2 contracting parties were generally concerned whether the existing dispute settlement system would be able to ensure proper enforcement of newly negotiated substantive agreements. This concern

${ }^{69}$ Several of these attempts have been mentioned above, such as the introduction of the legal affairs office and the 1982 ministerial declaration on dispute settlement. Additionally the DG was mandated to regularly report on the implementation of the 1982 declaration. In these reports the DG mainly pointed out delays in the panel procedure as main problems, which increased the problem awareness of contracting parties with respect to dispute settlement. As a result the contracting parties reviewed the dispute settlement procedure once again in 1984 and decided to establish a roster of panelist. The DG was allowed to appoint a panelist from the roster, if this was requested by one of the disputing parties. For a detailed overview of these developments, see Steward (1993). 
stemmed from the possibility to block procedures and resulting delays in the process, sluggish implementation of results resulting from a lack of systematic monitoring, fragmentation of the system and corresponding forum shopping, as well as the difficulty to find sufficiently qualified panelists. Unfortunately the attempts made prior to the round to improve the system where of limited success. This induced contracting parties to address dispute settlement in the Uruguay Round. Although there were disagreements whether the weaknesses of the system originated from the procedures of the system themselves or rather from a lack of political will to properly use the given procedures, already in preparation of the Uruguay Round contracting parties generally agreed that the system is in principle highly valuable and that it should be improved. ${ }^{70}$ Parties entered the round with this common goal in mind and since many views were already exchanged in preparation of the round, delegations were ready to start constructive negotiations based on specific proposals right from the beginning (Croome, 1999).

Interest homogeneity and the work done ahead of the negotiations allowed for quick progress in the negotiation group on dispute settlement regarding those matters that would contain limited political costs. Many proposals by various parties were introduced in the early phases of the negotiations throughout 1987. These proposals had much in common and contained relatively uncontroversial procedural suggestions to improve the dispute settlement process by expediting the establishment and the work of panels (Croome, 1999). Even the EC, as the main proponent of a diplomatic approach to dispute settlement, already agreed in its first written communication to the negotiation group on dispute settlement that strengthening procedures would be desirable and made several specific suggestions in this respect. ${ }^{71}$ By mid1987 there was already general agreement on several specific measures. These included the provision that requests for panels should include a summary of the complaint and a suggestion of terms of reference; the introduction of a standard format for terms of reference; the provision that panels should be established latest at the second Council meeting after the establishment of the panel had been requested; the idea to strengthen the role of the DG in the appointment of panel members in case the contracting parties would have difficulties to decide on the composition of a panel; the introduction of standard time-limits for the different stages of the panel process; the requirement to raise objections to a panel report within a month after the report had been circulated; the suggestion to accept a report within two months after its circulation; the introduction of time-limits to implement a panel's recommendations; and a more systematic monitoring of the implementation of recommendations (Croome, 1999). Other suggestions that received less, but still wide-ranging support included the idea to preferably rely on panelist that had no affiliation with any government, to strengthen the position of third

70 See for example SR.SOG/4, PREP.COM(86)SR/2, PREP.COM(86)SR/6, and PREP.COM(86)W/9. Also, during the first meeting of the negotiating group on dispute settlement is was pointed out that new agreements on substance where of limited value without dispute settlement as a means for enforcement, see MTN.GNG/NG13/1.

${ }^{71}$ MTN.GNG/NG13/W/12 
parties and to introduce the possibility to voluntarily resort to independent arbitration (Croome, 1999).

With the Secretariat's support and the guidance by Julio Lacarte-Múro, as highly experienced Chairman of the negotiation group it was possible to prepare a proposal for procedural reforms that would be adopted already at the midterm Ministerial Meeting in Montreal in December 1988. Several negotiating parties, as well as the Secretariat created comprehensive proposals and documents that served as focal points for the negotiating groups' discussions in order to derive this proposal. The Secretariat for example produced and updated a non-paper that served as a basis for discussion ${ }^{72}$, provided the group with a summary and comparative analysis of the proposals that had been made ${ }^{73}$, and produced a document that compared existing GATT texts with the suggestions that were made to improve the system. ${ }^{74}$ Equally useful, Mexico merged the different suggestions made in the negotiation group into a comprehensive proposal in June $1988 .{ }^{75}$ It updated this proposal according to informal consultations and brought it back to the formal meetings of the group in October. ${ }^{76}$ Also other parties provided the negotiation group with a comprehensive document in October. ${ }^{77}$ By fall 1988 the discussions had progressed so far that Julio Lacarte-Múro was mandated to create a chairman's text that could be provided to ministers during their meeting in Montreal. In a series of informal discussions the chairman's text was finalized for the Ministerial Meeting, where it was approved without much further discussion. This text would later on become the interim agreement on dispute settlement, which was formally brought into effect by a decision of the GATT Council in April 1989. ${ }^{78}$

The interim agreement was provisional in nature ${ }^{79}$ and applied to the regular GATT dispute settlement procedures (i.e. not to the Tokyo Round Codes) (Mora, 1993-1994). In essences it was an agreement on procedural reforms that included several of the changes that where already evident by mid-1987. This included the introduction of a 15-month time limit for the entire dispute settlement process, with specific deadlines for each step of the procedure. ${ }^{80}$ The

\footnotetext{
72 The Secretariat was asked to produce the non-paper in early March 1988 (MTN.GNG/NG13/6) and updated according to a request made in July (MTN.GNG/NG13/8).

${ }^{73}$ MTN.GNG/NG13/W14/; MTN.GNG/NG13/W14/Rev.1; MTN.GNG/NG13/W14/Rev.2

${ }^{74}$ MTN/GNG.NG13/W/29; MTN/GNG.NG13/W/29.Corr.1

75 MTN.GNG/NG13/W/26

${ }^{76}$ MTN.GNG/NG13/E/26/Rev.1

77 MTN.GNG/NG13/W/30

${ }^{78}$ For the actual agreement, including all details see $\mathrm{L} / 6489$.

It took until April for the agreement to become effective, because the Uruguay Round was essentially on hold between January 1989 and April 1989 due to disagreements in several substantive key-negotiating sectors (Croome, 1999).

${ }^{79}$ The agreement was to be applied until the end of the Uruguay Round.

80 Consultations had to be completed within 60 days. Terms of reference needed to be agreed to within 20 days. The composition of a panel also needed to be agreed to within 20 days. Once a panel had been composed and its terms of reference established, it was required to submit its final report to the Council within six months or - in cases of urgency - within three months. A panel was allowed to exceed these deadlines to a maximum time frame of nine months if it would inform the Council of the reasons for the delay in writing.
} 
decision also introduced standard terms of reference for panels and specified the procedure for composing a panel. To assist the composition of panels it was decided to expand and improve the roster of panelists. In case the composition of the panel would be deadlocked nonetheless, the DG could have been requested to compose the panel in consultation with the Chairman of the Council and the disputing parties. Furthermore the interim decision specified regulations for the provision of good offices, conciliation and mediation; this included the permission of the DG to provide good offices, conciliation or mediation in an ex officio capacity. Arbitration was also explicitly mentioned, as an alternative to following the panel process, provided the disputing parties would agree to this. Additionally the procedures for third party intervention in disputes were specified and provisions for legal advice to developing countries included. To strengthen enforcement the agreement provided to review the implementation of a panel's recommendations within six months after the adoption of the report. Finally, the decision aimed to strengthen the right of complainants to get a panel established, by stating that the decision to establish a panel should be taken latest at the second Council meeting after the establishment of the panel had been requested, unless the Council would decide otherwise. ${ }^{81}$

Most of the provisions included in the interim agreement were widely supported and negotiations focused mainly on refining details instead of bridging fundamentally different interests. After all, the interim agreement can largely be interpreted as a set of incremental changes to the already existing procedures. This implied that negotiators were tinkering with a system they were already well familiar with and could therefore reliably estimate the risks of the institutional changes made. The fact that most of the changes where merely procedural in nature and that the agreement was only implemented on a provisional basis further reduced the risk of unanticipated consequences, kept the system under tight control and implied that the costs of change would remain limited. This, in combination with the information that all parties shared the common goal to improve the dispute settlement procedures and in light of lacking evidence to the contrary, implies that the combination of functional explanations elaborated upon in section 4.3.1.2 and the dynamics of path dependent institutional change in the GATT as elaborated on in sections 4.4 .3 and 4.4.4, together provide a highly plausible, comprehensive account for this cluster of design changes. It seems that the combination of homogenous interests, low costs and limited risk provides fertile soil for functionalism to occur within the parameters set by path dependency emerging from a given institutional context.

However, this is not the case if interests are heterogeneous and costs of change are potentially high. The question whether parties should be able to block the dispute settlement process contains these attributes and was one of the most controversial topics addressed in the negotiations. Although negotiators hoped that the procedural changes introduced in the interim agreement would sufficiently address functional problems of the dispute settlement process, they were well aware that the possibility of blocking was compromising the disputes settlement system significantly. In comparison to the question of blocking the interim agreements where of

\footnotetext{
${ }^{81}$ For the actual agreement, including all details see L/6489.
} 
minor significance (Hudec, 1993). Functionalism and historical context do not suffice to understand how this question was resolved. As the next section shows, power is a crucial factor that needs to be taken into account to derive a full explanation of the outcomes of the negotiations.

\subsubsection{Blocking Decisions: Heterogeneous Preferences, Power and the Grand Bargain}

The core issue that had not been addressed in the midterm decision on dispute settlement was how to deal with the problem of parties blocking the dispute settlement process. This was the most important of several more controversial negotiating items that the negotiating group on dispute settlement discussed right from the beginning of the round, but was not able to resolve until the midterm review in Montreal. To the contrary, despite the fact that suggestions to change the decision-making procedures in dispute settlement where made early in the negotiations, and despite the fact that functional problems of dispute settlement where increasing rather than decreasing throughout the $1980 \mathrm{~s}$ and early $1990 \mathrm{~s}^{82}$, the interim agreement even reaffirmed decision-making by consensus. ${ }^{83}$

The main reason for this was the presence of the two opposing attitudes toward dispute settlement that had been present in the GATT from the 1970s onwards, as explained in section 4.4.3. To recall, on one side of the spectrum where those who regarded dispute settlement as a legal exercise that should rule on disputes via clearly defined procedures, which were supposed to be largely independent of political considerations. The US was the main proponent of this school of thought and advocated to reduce the possibilities to block procedures. On the other side, several parties - with the EC as the figurehead amongst them - regarded dispute settlement procedures as a tool for diplomacy that would assist in helping to find politically acceptable solutions to disputes in a largely conciliatory manner. This side was clearly in favor of maintaining control and continuing the practice of taking decisions by consensus. These different views had not disappeared by the time of the Uruguay Round and reconciling them should turn out to be one of the main challenges during the negotiations.

\footnotetext{
82 The beginning of this increase in problems coincides with the end of Tokyo Round and was characterized by several features, which might not all have had the possibility of blocking as a root cause, but at least strengthened the sensitivity to perceive blocking as problematic. First of all, there was an increase in disputes. The 1980s saw 115 complaints being filed in contrast to 32 in the 1970s (Srinivasan, 2007). Secondly, this increase was characterized by a relatively larger number of difficult and sensitive cases. Often these cases involved the US and the EC as disputing parties and reflected a lack of political agreement on sensitive questions that had not been resolved in the Tokyo Round (Hudec, 1993; Stoler, 2004; VanGrasstek, 2013). Disputing parties tried to resolve these essentially political questions by following the judicial procedure offered via dispute settlement, which in turn resulted in an increased amount of blocked cases and lack of compliance (Bliss, 1987). Clearly the system continued to work for technical questions, but failed on resolving politically contentious ones (Mora, 1993-1994). In this context the theoretical possibility of blocking alone contributed to undermine the legitimacy of the system (Paemen \& Bensch, 1995).

${ }^{83}$ See L/6489, section G, paragraph 3.
} 
In the following it is shown that overcoming interest heterogeneity on the question of decision-making in dispute settlement was only possible because the US was powerful enough to induce other parties to change their negotiating position by resorting - or threatening to resort - to unilateral means of dispute resolution. In the following this argument will be made with a focus on the US and the EC as the most prominent negotiating parties (Shell, 1995). This is not to suggest that other parties did not make important contributions to the negotiations Canada and Mexico are two examples that underline this point. ${ }^{84}$ Yet a focus on the US and the EC as representatives of the two attitudes on dispute settlement largely reflects the negotiation dynamics and political considerations in a representative manner. As a logical starting point the different positions of the US and the EC at the time of the Uruguay Round will be elaborated on in further detail. Thereafter US unilateralism as the crucial factor that permitted the to strike a bargain will be introduced and embedded in the chronological progression of the Uruguay Round.

\subsubsection{The United States as Champion of Legalism}

Examining the outcome of the Uruguay Round without tracing the process that brought it about would leave many observers puzzled: Why would the United States as one of the most powerful trading states voluntarily accept to be bound by one of the most sophisticated dispute settlement systems in the international arena? After all, the US Congress has a well-known history of being skeptical towards ceding sovereignty to international organizations. ${ }^{85}$ Furthermore, United States would not have been dependent on multilateral enforcement mechanisms to defend its trade interests in particular cases. However, examining US interests throughout the GATT's history and the Uruguay Round in particular provides a convincing account why the US was a proponent of strong dispute settlement throughout the negotiations and eventually willing to be bound by the results of the round.

Ahead of the Uruguay Round the US had already a long-standing desire to strengthen the GATT's dispute settlement system. From the early 1970s it started to see the GATT as a potentially useful tool to tackle its emerging trade deficit and started to lobby for stronger dispute settlement procedures (Mora, 1993-1994). There was a widely held perception starting to emerge in the US that other parties exploited GATT rules and that the US was investing more in the multilateral trading system than it got in return. The trade deficit was regarded as a result of this and with an increase of the deficit the perception of an imbalanced system increased as well (Preeg, 1995; Srinivasan, 2007; Stiles, 1996). To tackle this perceived imbalance in the international trading system and to appease Congressional demands for protectionism the US administration regularly launched GATT complaints. However, already by the time of the Tokyo Round a Congressional review suggested that the GATT was ineffective and the US started to

\footnotetext{
${ }^{84}$ One might wonder why Japan, as one of the most important players in the multilateral trade regime at the time, is not explicitly taken into account. However, Japan took mainly a pragmatic and informal approach to trade policies and most of its interests where directed at very specific questions during the round. It was not in an active leadership role on general institutional questions (Preeg, 1995).

${ }^{85}$ Refusal to enter the League of Nations, the ITO and the OTC act as prominent examples in this respect.
} 
engage in efforts to strengthen the GATT (Hudec, 1990a, 1993). However, as it was shown in section 4.4 .3 the attempts to significantly reform the system throughout the 1970 s and in the early 1980s fell short of the desired results.

In line with this it is not surprising that strengthening the dispute settlement system was one of the principal US negotiating objectives for the Uruguay Round (GAO, 1994; Porges \& Price, 2005; Stoler, 2004). According to Porges and Price (2005) Congress even labeled the requirement that dispute settlement should become more expeditions and effective as "its number one specific priority for the round" ${ }^{86}$ The more specific means to achieve this objective included the ambition to eliminate blocking and to ensure that the dispute settlement system would follow the same time frame as that of US domestic legislation used for the unilateral resolution of disputes (Stoler, 2004). ${ }^{87}$ Ahead of and throughout the round the political pressures to achieve these goals increased. A high budget deficit and the strengthening of the dollar led the US trade deficit to rise drastically throughout the 1980s and also unemployment rates increased (Porges \& Price, 2005; Preeg, 1995). As it was the case since the 1970s foreign trade barriers were blamed for this and frustration with the GATT system for its inability to tackle these barriers rose.

The desire to strengthen dispute settlement was facilitated by the expectation that a stronger dispute settlement system would not come with unintended negative consequences in terms of losing disputes. The perception that the US trade deficit was due to foreign restrictions and that international trade is conducted unfairly by others had turned into a firm conviction by the end of the 1980s (Hudec, 1990b). Despite some experts arguing that foreign practices should not be regarded as the main cause of the trade deficit, such practices served as an welcoming scapegoat and the increasing deficit was regarded by parts of Congress and the public as sufficient proof that foreign practices were indeed unfair and needed to be addressed (Bhagwati, 1990; Hudec, 1990b). This in turn led to the assumption that the US was following more liberal trade policies than other countries and that it would be more often in compliance with the GATT than its trading partners (Barton et al., 2006; Goldstein \& Gowa, 2002; Goldstein \& Steinberg, 2008; Hudec, 1990b). Although this assessment was not necessarily in line with realty, it implied that the US assumed that it could only gain from a more rigorous dispute settlement system, as it would hardly end up on the losing side of disputes (Elsig, 2013; Elsig \& Eckhardt, 2015; Hudec, 1990b; Stoler, 2004). This assumption was supported by past experience, as a statistical analysis of the disputes the US had been engaged in throughout the 1980s indeed indicates that the US had largely positive experiences with the system (Elsig \& Eckhardt, 2015).

\footnotetext{
${ }^{86}$ In an interview with a former US negotiator it was even pointed out that there was "great enthusiasm" for the strengthening of dispute settlement at the time (Int02).

${ }^{87}$ Further specific outcomes the US sought to ensure that the general objective would be met included the introduction of cross-retaliation into the system and the introduction of a standard of review for disputes involving anti-dumping (Stoler, 2004).
} 
Next to this, the widened substantive scope of the Uruguay Round also increased the US willingness to be bound by a quasi-automatic dispute settlement system. Throughout the negotiations the US qualified its support for the strengthening of the system by attaching it to the condition that the results on substance needed to be in its interest too (Barton et al., 2006; Goldstein \& Steinberg, 2008). ${ }^{88}$ Once it became evident that this was likely to be the case and that the results of the round would be implemented under the re-interpreted notion of the single undertaking ${ }^{89}$, the US supported the establishment a quasi-automatic system unconditionally (Barton et al., 2006; Elsig, 2013; Goldstein \& Steinberg, 2008). From the American perspective a strong multilateral dispute settlement system would be advantageous as means to legitimately enforce US economic interests. This was especially the case regarding the newly negotiated agreements in services and intellectual property (Barton et al., 2006; GAO, 1994; Goldstein \& Steinberg, 2008; Steinberg, 2004). Additionally, strong multilateral means for enforcement did not only assure legitimacy, but also guaranteed that beneficial substance would continue being defended even if the US would become less influential in international trade at some point in the future (Sarooshi, 2005).

The substantively beneficial results of the Uruguay Round also helped to ensure congressional agreement to the reformed dispute settlement system. As it was mentioned in the previous chapter already, the results of the round were indeed largely in the US' interest, as they coincided with almost all of the its negotiating objectives (GAO, 1994; Porges \& Price, 2005). This ensured that the balance in Congress was tilted in favor of a binding, quasi-automatic dispute settlement system, despite concerns about sovereignty costs of dispute settlement being raised when the Uruguay Round agreements were up for ratification (Jackson, 1997; VanGrasstek, 2013). The substantive advantages outweighed these concerns and the inclusion of services and intellectual property in the regime introduced influential constituencies that were in favor of the agreements to the considerations of Congress (GAO, 1994; Goldstein \& Steinberg, 2008; Porges \& Price, 2005; Steinberg, 2004; VanGrasstek, 2013). The remaining concerns over sovereignty costs were appeased by reassuring Congress that the Uruguay Round agreements would not prohibit the US to employ unilateral means of enforcement, as long as they would be in line with WTO obligations and principles (GAO, 1994). Furthermore it was pointed out that the US could in principle even disregard these obligations if it was willing to bear the costs in terms of retaliation by other parties. These costs in turn where downplayed by the executive, which referred to US relative economic strength and argued that possible retaliation might hardly affect the US economy (GAO, 1994).

Given this review it should not be surprising why the US did not only have the objective to establish a stronger dispute settlement system throughout the round, but also explains why it

\footnotetext{
${ }^{88}$ This was confirmed in an interview with a former US negotiator and is also expressed in formal negotiating statements made by the US delegation during the round, see MTN.GNG/NG13/19; MTN.GNG/NG13/W/40; MTN.GNG/IN/1.

Similarly, the EC also made its agreement on a strengthened dispute settlement system contingent on the overall negotiation outcomes of the round; see MTN.GNG/NG13/19; MTN.GNG/NG13/W/44.

${ }^{89}$ See section 3.2.4.
} 
was willing to join the system once it had achieved this objective. The perception of dispute settlement as a tool to legitimately challenge others' practices, who were assumed to be more often in violation of the legal obligations under the trade regime than the US; the resulting expectation to remain on the winning side of most disputes; the strong interest to enforce substantive agreements that were largely regarded as highly beneficial; and the reassurance that sovereignty costs would remain limited, provide a convincing explanation for the US interest in a stronger dispute settlement system. Whether all these expectations and assumptions turned out to be accurate in the long run is of secondary importance, since it were not the real effects but the assumed effects of the agreement that influenced the stance toward it at the time.

\subsubsection{The EC and Pragmatism: Guarding the Status Quo}

In contrast to the US the EC had a much more pessimistic outlook on the potential effect of a quasi-automatic dispute settlement system throughout most of the round. Traditionally the EC had been defending a pragmatic approach to dispute settlement and regarded the system as an instrument to assist finding a negotiated, mutually satisfactory solution to disputes. Consequently it was strongly opposed to a more legalist, quasi-automatic approach. This position was partially embedded in the nature of the EC, as it had legal concerns regarding the compatibility of the Treaty of Rome with the GATT (Mora, 1993-1994). Furthermore, the EC was very concerned over its subsidy program in the context of the Common Agricultural Policy and found itself often as defendant in dispute settlement due to this policy (Elsig \& Eckhardt, 2015; Mora, 1993-1994; Paemen \& Bensch, 1995; Shell, 1995). In contrast to the US the EC had made less positive experience with the dispute settlement system throughout the 1980s and was not very confident in its ability to use the system in its favor (Elsig \& Eckhardt, 2015). ${ }^{90}$ It was also skeptical regarding the implication a quasi-automatic system would have with respect to the influence of the Secretariat's legal department on the outcome of disputes.

The EC's position did not change fundamentally until the late 1980s, despite the fact that its vigor in defending a conciliatory, diplomatic approach to disputes had slightly decreased throughout the 1980s in comparison to the 1960s and 70s (Preeg, 1995). According to Hudec (1993) the EC's support of the 1982 agreement on dispute settlement was a first step towards more legalism, which it was willing to accept in order to safeguard the legitimacy of the multilateral trading system. Also the EC's early support of the procedural changes agreed to in Montreal can be regarded as indicating a realization that some more legalism would be unavoidable. This attitude was strengthened further when EC officials came to the insight that it had to strengthen its legal expertise in panel proceedings, which in turn strengthened the voices in favor of more legalism within the EC (Elsig \& Eckhardt, 2015).

${ }^{90}$ Additionally, the EC was concerned that a quasi-automatic system would increase the impact that the Secretariat's legal department would have on the outcome of disputes. The legal department assisted the panels in drafting their reports, but was regarded by some in the EC as a politicized body. Automatic adoption of reports would not have allowed to keep perceived political undertones in panel reports, stemming from holding the legal department at bay (Paemen \& Bensch, 1995). 
Nonetheless, for a long time in the negotiations the EC vigorously defended the position that the system should not become quasi-automatic and that contracting parties should ultimately be able to control the eventual output of the dispute settlement machinery. From the prenegotiations until well into the round the EC argued that making the dispute settlement machinery more automatic would permit to use the system in order to impose interpretations of the legal texts that where not agreed upon in negotiations. ${ }^{91}$ According to the EC the GATT rules reflected the outcome of a complex process of negotiations, which often led to ambiguity in an effort to paper over a lack of compromise. The EC argued that such kind of rules where not suitable for legal interpretation (Young, 1995). It defended its position on the grounds that the interpretation of rules should involve all contracting parties. ${ }^{92}$ The EC had good reasons to defend this position, as it was indeed the case that from the beginning of the 80 s the US tried to clarify the vague substantive outcomes that reflected a lack of political compromise during the Tokyo Round by launching dispute settlement procedures. The EC was particularly often targeted and defended itself by employing the blocking and delaying tactics that casted doubt on the credibility of the dispute settlement system in the first place (Xu \& Weller, 2004). Against this background it is not difficult to comprehend why the EC firmly defended the consensus decision-making procedure for a large part of the round.

However, while doing so the EC also wanted to contain the unilateral practices that the US increasingly used and threatened to use in response to the weak GATT procedures. This combination paved the way for agreement on reverse consensus as it is shown in the following.

\subsubsection{The Grand Bargain: Reverse Consensus for Exclusive Jurisdiction}

If it would not have been for the US' ability to exert pressure on its negotiating partners by means of unilateral threats and actions, it would not have been possible to overcome the opposition of those who resisted a more automatic dispute settlement procedure and who desired to maintain decision-making by consensus. After all, it was only possible to find a compromise solution on this question after the US had strengthened its unilateral policy with the passage of the 1988 Omnibus Trade and Competitiveness Act. Stiles (1996) describes this as the most significant force that moved negotiations on dispute settlement forward. It induced those negotiating parties opposing more automaticity to change their negotiating position and offer agreement to a strengthened system in return for the US curtailing its unilateral policy. How this came about in detail is described in the following chronological account of the negotiations.

The question of blocking the adoption of panel reports and consensus decision-making was discussed in the negotiating group on dispute settlement from the very beginning. There was a generally held belief that the possibility of blocking procedures is problematic and should be avoided. Even the EC joined this view. However, opinions differed on how to address this and the different attitudes on dispute settlement clashed right from the beginning. In the first years

\footnotetext{
${ }^{91}$ See for example PREP.COM(86)SR/2; PREP.COM(86)SR/6; MTN.GNG/NG13/W/12; MTN.GNG/NG13/W/22

${ }_{92}$ MTN.GNG/NG13/W/22
} 
of the negotiations there was no significant convergence towards compromise. On the one side several parties argued for the reform of consensus as the decision-making practice in dispute settlement. One of the most prominent suggestions made in the early phases of the negotiations was that the disputing parties and potentially other parties with an explicit interest in a dispute should be excluded from the decision on the adoption of a panel's report. ${ }^{93}$ This became known as the 'consensus minus two' approach. It was pointed out that this option would make the dispute settlement process more expeditious and stop the erosion of the system. ${ }^{94}$ The consensus minus approach was also suggested by the United States as one possibility to overcome the problem of blocking. ${ }^{95}$ However, the US also pointed out that this option would have the disadvantage that 'surrogate' parties could block the adoption of a panel report on a disputant's behalf. ${ }^{96}$ During the discussions the US nonetheless indicated an interest to explore this option further. ${ }^{97}$ The US also mentioned that further reaching options would possibly exist. In its proposal of June 1987 it listed as the most extreme alternative the option that panel reports could be automatically binding without any further decision-making procedures being required by contracting parties. ${ }^{98} \mathrm{As}$ a more feasible and potentially desirable alternative the proposal also mentioned for the first time the introduction of reverse consensus. ${ }^{99}$ Furthermore, the proposal mentioned that injured parties should have the right to retaliation in case the defendant in a dispute would fail to implement panel recommendations. ${ }^{100}$

Unsurprisingly, the suggestions for reform met the opposition of those that sought to defend the status quo. As mentioned previously, this group - including the EC as most influential member - argued that dispute settlement procedures should not be used to create new obligations by a panel's constructive interpretation of vague substantive agreements and that panels should not be used as supranational jurisdiction. ${ }^{101}$ Furthermore it was argued that the problem of blocking might not primarily stem from existing procedures, but rather from the way these procedures were implemented by contracting parties. ${ }^{102}$ This group stressed the conciliatory features of dispute settlement, the importance of consultations, and regarded the system as a means for negotiation. ${ }^{103}$ The group posited that all concerned parties should have the right to participate in the decision-making on dispute settlement. ${ }^{104}$ Furthermore it was

\footnotetext{
${ }_{93}$ MTN.GNG/NG13/2; MTN/NG13/3; MTN/NG13/4; MTN.GNG/NG13/W/11; MTN.GNG/NG13/W/17

${ }^{94}$ MTN.GNG/NG13/6

${ }^{95}$ MTN.GNG/NG13/W/6

${ }^{96}$ MTN.GNG./NG13/NG13/3

${ }^{97}$ MTN.GNG/NG13/4

${ }^{98}$ MTN.GNG/NG13/W/6

${ }^{99}$ MTN.GNG/NG13/W/6

${ }_{100}$ MTN.GNG/NG13/W/6

${ }_{101}$ MTN.GNG/NG13/2; MTN.GNG/NG13/4; MTN.GNG/NG13/W/7; MTN.GNG/NG13/W/12

102 MTN.GNG/NG13/2

${ }^{103}$ MTN.GNG/NG13/6; MTN.GNG/NG13/9; MTN.GNG/NG13/W/12

${ }^{104}$ MTN.GNG/NG13/W/12
} 
argued that consensus decision-making would promote the implementation of a panel's recommendations, since the losing party expresses agreement to these recommendations by joining a consensus. If decision-making would exclude the losing party, implementation would become less likely. ${ }^{105}$ The group explicitly pointed to the 1982 Ministerial Declaration and its reaffirmation of consensus as the reference point to stick to. In several meetings it did not change its position and continuously demanded to retain consensus. ${ }^{106}$

To overcome the problem of blocking the proponents of consensus suggested several compromise measures that fell short of a reform of decision-making. This included the suggestions to raise the political costs of blocking the adoption of reports by explicitly requesting parties to refrain from 'unduly obstructing' the dispute settlement process and to demand that reasons for rejecting the adoption of a report should be submitted in writing. ${ }^{107}$ Next to this, it was also suggested to introduce procedures for raising objections to panel reports, and to improve the quality of panels by selecting more qualified panelists and expand the staff in the legal section of the Secretariat to allow for more secretarial support of panels. ${ }^{108}$ The latter was supposed to avoid those instances of blocking that were motivated by objections to the quality of a panel's report. Unsurprisingly, in the eyes of those desiring to reform decision-making these suggestions did not go far enough. ${ }^{109}$ Another compromise suggestion brought forward was to distinguish when taking a decision on the adoption of a panel's reports between a decision on the legal interpretation of the GATT text as brought forward by a panel and a decision on the panel's recommendations. ${ }^{110}$ The former decision would require consensus and allow all parties to participate in the interpretation of the legal texts, while the latter decision could be taken more flexibly - avoiding the defendant to be a judge in its own case. ${ }^{111}$ However, opponents pointed out that this reasoning was flawed, since interpretation and remedy are inextricably linked, and since panel reports are in any case only binding on the disputing parties and should not be regarded as authentic interpretations of the GATT. ${ }^{112}$

The different positions on dispute settlement where repeated during several of the negotiation group's meetings, without any sign of convergence. The majority of parties seemed to be in favor of maintaining consensus. Considering this deadlock one party called upon the group in spring 1988 to start concentrating on the issues of convergence to produce a tangible

Also Japan explicitly expressed the view that disputes should be mainly resolved by consultations and that current problems stemmed mainly from a lack of agreement on the interpretation of the GAT legal text (MTN.GNG./NG13/7).

${ }^{105}$ MTN.GNG/NG13/W/21

106 MTN.GNG/NG13/4; MTN.GNG/NG13/6; MTN.GNG/NG13/8; MTN.GNG/NG13/W7; MTN.GNG/NG13/W9; MTN.GNG/NG13/W/12; MTN.GNG/NG13/W22

${ }^{107}$ MTN:GNG/NG13/4; MTN.GNG/NG13/W/9; MTN.GNG/NG13/W/12, MTN.GNG/NG13/W/22

${ }_{108}$ MTN.GNG/NG13/W/21; MTN.GNG/NG13/6

${ }^{109}$ MTN.GNG/NG13/4

${ }_{110}$ MTN.GNG/NG13/W/18; MTN.GNG/NG13/22

${ }^{111}$ MTN.GNG/NG13/22

112 MTN.GNG/NG13/6 
proposal for the Montreal Ministerial Meeting. ${ }^{113}$ In light of that, the comprehensive proposals that where produced by Mexico and other negotiating parties in summer and fall of 1988 - and which served as focal points for the group to arrive at a proposal for the Ministerial Meeting refrained from making controversial suggestions on the nature of decision-making in dispute settlement. ${ }^{114}$ The minimum compromise that was eventually reached and which also appeared in the interim agreement on dispute settlement contained an affirmation of consensus as decision-making principle, but called upon parties to submit objections to a panel's report in writing and to avoid delaying the process. ${ }^{115}$ Clearly, these provisions can only be interpreted as a reflection of deadlock on the question blocking. A way out of this deadlock only started to appear with the strengthening of US unilateral policy on enforcement of trade agreements in the summer of 1988.

Unilateral policy to enforce trade agreements had a long history in US domestic legislation and evolved to become a powerful tool to pursue US trade interests. As early as 1962 the Trade Expansion Act provided the President with the discretionary authority to take retaliatory action against foreign governments that harmed US companies (Sarooshi, 2005). However, by the mid70s Congress expressed its dissatisfaction on how the President used this authority and also got increasingly frustrated with the weak GATT dispute settlement machinery. Consequently it introduced stronger and more formal provisions for unilateral action under Section 301 of the 1974 Trade Act (O'Neal Taylor, 1997; Sarooshi, 2005). The section introduced a distinction between 'unjustifiable' and 'unreasonable' trade policies of US trading partners. The former targeted policies that are considered to breach international agreements, while under the latter provisions policies do not necessarily have to be illegal but could still be target for unilateral action if considered harmful to US interests (O'Neal Taylor, 1997). Thus, the section permitted for action by the President no matter whether other countries' policies where considered illegal or not. US citizens could trigger such action by filing complaints on other countries' policies (Hudec, 1990b). Despite the 74 Act's specification and formalization of unilateralism, the President still maintained broad discretion to decide whether complaints should be pursued and retaliation was warranted (Hudec, 1990b).

Section 301 of the Trade Act got amended three times, leading to a tightening of unilateral policy. The first two times - in 1979 and 1984 the amendments specified the procedures for initiations of 301 complaints and the time-limits for different stages of the procedure (O'Neal Taylor, 1997). This contributed to restricting the discretion of the President and section 301 became an increasingly powerful tool, which was used to pursue unilateralism more actively from 1985 onwards (O'Neal Taylor, 1997). However, it was the third amendment to the section that brought this development to a climax (Hudec, 1990b; Preeg, 1995; Sarooshi, 2005).

In the summer of 1988 Congress enacted the Omnibus Trade and Competitiveness Act of 1988. The act did not only specify the US negotiation objectives for the Uruguay Round but also

\footnotetext{
${ }^{113}$ MTN.GNG/NG13/6

${ }^{114}$ MTN.GNG/NG13/W/26; MTN.GNG/NG13/W/30

${ }^{115} \mathrm{~L} / 6489$
} 
tightened unilateral policy significantly by amending Section 301. This was done because the previously mentioned US perception that its trading partners were engaging in unfair trading practices and that the GATT system was not well suited to tackle these practices had grown particularly strong by the mid-1980s (Barton et al., 2006; Feketekuty, 1990; Milner, 1990; O'Neal Taylor, 1997). In this context Congress perceived strengthened unilateral measures as a suitable tool to pursue GATT violations and to tackle the problem of the accumulating trade deficit. Furthermore, the US administration regarded resort to unilateralism under a strengthened section 301 as a useful means to channel domestic protectionists pressures ${ }^{116}$ and to set the agenda for the Uruguay Round (Bhagwati, 1990; Feketekuty, 1990; Milner, 1990; O'Neal Taylor, 1997; Preeg, 1995).

The amendment contained several elements to strengthen Section 301. First of all, in an effort to make the administration more responsive, it shifted the authority to implement Section 301 from the President to the United States Trade Representative (USTR). Secondly, it tightened the time-limits applying to Section 301 procedures (Preeg, 1995). Thirdly, it expanded the definition of unreasonable trade practices, i.e. those practices that where not illegal, but still regarded as being unfair (Preeg, 1995). Fourthly, unjustified trade practices - i.e. those in violation of international agreements - became mandatory to pursue, unless the GATT dispute settlement system would rule against the US in such a case (O'Neal Taylor, 1997). Thus, the USTR enjoyed far less discretion in the decision to pursue Section 301 complaints than the President previously did. Fifth, the amendment introduced Special 301 procedures. Under these procedures the USTR was required to identify and initiate investigations of inadequate protection of US intellectual property rights abroad. This increased the pressure to bring the protection of intellectual property rights under the realm of GATT dispute settlement (O'Neal Taylor, 1997; Preeg, 1995). Finally, the amendment also introduced the requirement to proactively pursue foreign practices. Under the so-called Super 301 provisions the USTR was mandated to compile a list of countries considered to have the most significant trade barriers and to initiate investigations against them (O'Neal Taylor, 1997). In total these measures where a powerful tool, which the US was not hesitant to use or at least threaten to use (Hudec, 1993). Although the US legislation provided for unilateralism before, US behavior in the late $80 \mathrm{~s}$ and the passage of the 88 Trade Act in particular marked a significant shift towards 'aggressive unilateralism'.

This impacted the dynamics during the Uruguay Round negotiations tremendously. While US unilateralism had been regarded problematic before ${ }^{117}$, the passage of the 1988 Omnibus Trade

116 The increasing use of unilateralist measures and the amendment of section 301 had its origins in a domestic argument between the US administration and Congress at the time. By the mid-1985 many members of Congress thought that the President was not using Section 301 rigorously enough and wanted to limit his discretion to decide whether Section 301 should be used in a particular case. For more details on the legislative history of Section 301 see: Bhagwati (1990); Hippler Bello \& Holmer (1990).

117 Latest when the US started to increasingly use Section 301 in 1985 other contracting parties started expressing their concern (O'Neal Taylor, 1997). The topic had also been discussed in the negotiation group on 
Act put the multilateral trading system in uproar and catapulted the item on top of many negotiating parties' priority lists (Ganesan, 2015; O'Neal Taylor, 1997; Preeg, 1995; Shell, 1995; Stiles, 1996; Stoler, 2004; VanGrasstek, 2013). As VanGrasstek (2013) states: "It would be difficult to exaggerate the priority that other participants in the Uruguay Round placed on ending the practice by which Washington defined and enforced its rights under its own "reciprocity" (i.e. retaliatory) laws rather than through the GAT" (p.52). Already at the time that the Trade Act was decided on by Congress in July and August 1988 the negotiation group on dispute settlement, in its meeting on the $21^{\text {st }}$ of July started to pay considerably more attention to the problem of unilateralism than it did before. ${ }^{118}$ Clearly targeting Section 301, many parties supported the suggestion to strengthen the commitment to multilateral procedures by requiring contracting parties to bring their domestic regulation in conformity with GATT obligations. ${ }^{119}$ These calls were repeated in several of the negotiating group's following meetings ${ }^{120}$ and in February 1989 the Council even held a special meeting dedicated to discuss unilateralism. ${ }^{121}$

The arguments exchanged during the discussions on unilateralism stayed roughly the same throughout formal meetings. ${ }^{122}$ On the one side the wide majority, with the EC in the lead, portrayed unilateralism as an existential threat to the multilateral trading system. ${ }^{123}$ It was argued that unilateralism undermines the GATT's credibility and could lead to a dangerous retaliatory spiral if other parties would decide to respond to US unilateralism in kind and also start acting outside of the multilateral system. On the other side the US argued that it had no intention to undermine the GATT, but that it was forced to act unilaterally as long as the dispute settlement system would still allow for blocking and stay as weak as it is. It argued that refraining from unilateralism would only be possible if the multilateral system would become more attractive. It was this line of thought that was eventually followed and that permitted progress in the negotiations on dispute resolution.

The constellation of opposing interest on unilateralism and reform of decision-making paved the way for the grand bargain on dispute settlement. The concerns over unilateralism grew so strong after the US had strengthened its legislation that those who were initially opposed to reforms on decision-making dropped this opposition in return for a strengthened US commitment to multilateral procedures. ${ }^{124}$ Like this, two essential developments in

dispute settlement in its very first meeting already (see MTN.GNG/NG13/1) and mentioned several times thereafter.

118 MTN.GNG/NG13/9

119 MTN.GNG/NG13/9

${ }^{120}$ MTN.GNG/NG13/10; MTN.GNG/NG13/16; MTN.GNG/NG13/17; MTN.GNG/NG13/19

${ }^{121} \mathrm{C} / 163$

$122 \quad$ MTN.GNG/NG13/10; MTN.GNG/NG13/16; MTN.GNG/NG13/17; MTN.GNG/NG13/19; MTN.GNG/NG13/W/43; C/163

${ }^{123}$ The representative of the EC stated that stopping unilateralism would be the only way to ensure survival of the GATT (C/163).

${ }^{124}$ That this was the fundamental tradeoff that enabled compromise on dispute settlement is not only confirmed by secondary literature, but was also pointed out in several interviews with former negotiators and secretariat members (Int01, Int02, Int07, Int08, Int09, Int11, Int14, Int16). 
centralization - automaticity and exclusive jurisdiction - were reached by connecting agreement on the one element to agreement on the other. However, it needs to be stressed that this did not happen overnight. It took years and the introduction of supplementary design features until this agreement was eventually reached.

According to the records of formal meetings the strengthening of Section 301 seemed to have limited impact on the negotiations except for increasing controversy and discussion until spring 1990. During the mid-term review in Montreal the focus lay on the low hanging fruits in form of confirming the suggested agreement on procedural improvements. The controversial questions on blocking and unilateralism where largely ignored in Montreal (Croome, 1999). The first formal meetings during which these items where explicitly discussed again were the meetings of the negotiation group on dispute settlement in September and December 1989. On decision-making and unilateralism these meetings hardly went beyond a repetition of the already well-known opposing positions on both issues. However, during the December meeting of the negotiation group the important observation was made that the reform of decisionmaking and provisions to curtail unilateralism were interrelated design features. ${ }^{125}$

How this interrelation would lead to compromise in the negotiations on dispute settlement became apparent for the first time during the negotiation group meeting in April 1990. ${ }^{126}$ After the Chairman of the group had reminded negotiation parties that negotiations needed to become more substantial at the end of the group's February meeting ${ }^{127}$, the EC and the US presented comprehensive suggestions for the reform of dispute settlement during the following April meeting. ${ }^{128}$ The US proposal covered various subjects - including the introduction of an interim panel report, appellate review and questions on decision-making -, analyzed problems with current practice, and provided an overview of different possibilities to explore solving these problems. The EC proposal largely covered the same ground and very importantly explicitly indicated that compromise was possible. For the first time in a formal meeting the EC representative pointed out that a strengthening of the dispute settlement system would be possible if several conditions would be met. In particular the representative referred to the need that clear-cut rules that would apply to every member of the multilateral trade regime would be essential, including the end of the grandfather clause and new rules on waivers. He also demanded that it would be essential that all contracting parties would bring their domestic legislation in line with GATT obligations and that parties would have to commit to refrain from unilateral action. Another condition was the establishment of an appeals body, composed of distinguished individuals of high expertise in the field of international trade. The EC

125 MTN.GNG/NG13/17

${ }^{126}$ MTN.GNG/NG13/19

${ }^{127}$ MTN.GNG/NG13/18

${ }^{128}$ MTN.GNG/NG13/19

The views presented by the representatives of the EC and the US were based on two written proposals. For the EC proposal see MTN.GNG/NG13/W/39. For the US proposal see MTN.GNG/NG13/W/40. The views described in the paragraph are based on the minutes of the negotiation group's meeting and the respective written proposals of the EC and the US. 
representative concluded by pointing out that it would be possible to consider adapting the consensus decision-making principle for the adoption of panel reports if these conditions were met. Clearly, in this meeting the grand bargain that would eventually be struck was already discernible: automaticity was introduced in return for exclusive jurisdiction, with the appeals body to be introduced as a control mechanism to shield parties from low quality panel reports and thereby limit the costs of automaticity.

However, declaring that consensus was reached at this stage of the negotiations already would be premature. This is for several reasons. First of all, many other negotiation parties reacted reserved regarding the EC willingness to compromise on consensus in return for a greater commitment to the multilateral system. Most remained in favor of maintaining consensus for the adoption of panel reports and the authorization of retaliation. ${ }^{129}$ Also in case that an appeals body would be introduced its findings should still be decided upon by involving the CONTRACTING PARTIES. ${ }^{130}$ Secondly, the EC compromise suggestion was still hypothetical in nature and both, the EC and US, explicitly pointed out that its proposals would be contingent upon a satisfactory overall outcome of the Uruguay Round. ${ }^{131}$ This qualification was repeated at later stages of the round and the compromise on dispute settlement remained formally pending until the very end of the round. ${ }^{132}$ Finally - and obviously - the details of the compromise still needed to be worked out, including the question on the exact kind of modification of consensus and how strong the wording regarding a greater commitment to the multilateral system would be. Progress towards resolving these issues was mainly made in informal negotiations during the upcoming years and is indicated by changes in formal documents and drafts of agreements.

Canada and Mexico provided the starting points for this progress by following up on the negotiation group's discussion in April with their own comprehensive proposals. ${ }^{133}$ Both proposals in essence capture the compromise that the April meeting hinted at. Each of them makes specific provisions for the establishment and design of an appeals body. Both also elaborate on changing decision-making procedures, albeit with slight differences. The Canadian proposal mentions that the language on the decision to establish a panel should be clarified to strengthen the right of the panel. On the adoption of panel reports the proposal mentions that adoption should be automatic unless one of the disputing parties would appeal. Decisions of the appeals body would in turn be final. Also the authorization of withdrawal of concessions in case losing party would fail to implement a panel's recommendations would be automatic. In comparison, the Mexican proposal also suggested significant changes in decision-making, but used less strong language. The procedure for deciding on the establishment of a panel was not picked up again. Regarding the adoption of panel and Appellate Body reports the proposal still provides room for action by the Council by mentioning that they would be automatically

\footnotetext{
${ }^{129}$ MTN.GNG/NG13/19

130 MTN.GNG/NG13/19

${ }^{131}$ MTN.GNG/NG13/19; MTN.GNG/NG13/W/39; MTN.GNG/NG13/W/40

132 MTN.GNG/NG13/W/40; MTN.GNG/IN/1

${ }^{133}$ MTN.GNG/NG13/W/41; MTN.GNG/NG13/W/42

The suggestions described in this paragraph are based the respective written proposals of Canada and Mexico.
} 
accepted unless the Council would decide otherwise. Although not fully specified, this can be regarded as a step towards the introduction of reverse consensus. Regarding the problem of unilateralism the Mexican proposal was also more cautious than the Canadian one by refraining from elaborating on the issue. The Canadian proposal in turn called upon a strengthening of commitment to multilateral procedures and to refrain from unilateralism. The proposals were discussed in several informal meetings of the negotiation group in summer 1990. However, the time was seemingly not ripe for major strides towards convergence.

In the chairman's report of July 1990 Julio Lacarte could only list few subjects where general agreement was reached and had to mention several areas that would still require serious negotiations. ${ }^{134}$ On the question of taking the decision on the authorization of retaliation the report mentions that most negotiating parties indicated support for the idea that the nonimplementing party should not be able to block the decision. Regarding the establishment of an appeals body, the majority of parties expressed good will to explore the concept but concerns were expressed on how to limit the filing of appeals to truly exceptional cases. Furthermore it was debated how the reports of such a body would be adopted. The chairman's report also still indicated a lack of agreement on the decision-making procedures for the adoption of panel reports and simply listed all possible alternatives that had been discussed so far, including the possibility to retain consensus. Also no agreement could be reached on condemning unilateralism. On this aspect the report notes that one delegation stated that it would only be possible to addressed unilateralism when there would be "clear rules, enforceable through dispute settlement procedures that eliminate opportunities for delay and blockage." ${ }^{135}$ In accordance with the Chairman's report, the status of the negotiations is also reflected in a draft text on dispute settlement that the Secretariat composed to facilitate further informal negotiations in preparation of the Brussels Ministerial Meeting in December $1990 .{ }^{136}$

These informal consultations took place in a series of meetings in fall. During these meetings the parties got closer to agreement as indicated by the proposed Draft Final Act that was submitted to the Ministerial Meeting in Brussels. ${ }^{137}$ The Draft Final Act indicated consensus on the establishment of an appeals body. Although this was not the case for the controversial questions on decision-making and unilateralism, the way the Draft Final Act was phrased implies convergence in capturing the possible bargain to be struck formally on paper. On decisionmaking the draft lists the possible alternatives by using square brackets. In relevant sections decisions on the establishment of panels, on the adoption of panel and Appellate Body reports, and on the authorization of retaliation - the draft paves the way to reverse consensus by indicating that a decision shall be taken unless the Council decides [otherwise] [by consensus] [not to take the decision]. ${ }^{138}$ As it is well known the first alternative mentioned was not used and

${ }^{134}$ MTN.GNG/NG13/W/43

135 MTN.GNG/NG13/W/43, p.5

${ }^{136}$ MTN.GNG/NG13/W/45

${ }^{137}$ MTN.TNC/W/35/Rev.1

${ }^{138}$ The formulation captured in the last square brackets differs according to the section it was used in. In the section on the establishment of panels it mentions 'not to establish a panel'; on adopting panel and Appellate 
the ultimate solution lay in deleting the square brackets of the last two. On unilateralism, the text includes a section that requires parties to act in accordance with the GATT, to abide to the outcomes of a dispute settlement procedure, refrain from unilateralism or threats thereof, and to adapt domestic legislation in such a way that it would ensure conformity of all measures with the GATT dispute settlement procedures. Interestingly this part was not put in square brackets. However, it contained a footnote that captured the eventual bargain by explicitly linking this section as being contingent on the final provisions of those sections that would imply automaticity of decision-making. Despite these developments the Brussels Ministerial Meeting itself did not lead to major progress on the unresolved questions on dispute settlement. As it was mentioned in the previous chapter, the Ministerial Meeting stumbled over a deadlock in agriculture, throwing the Uruguay Round into crisis and leading to a hiatus of the negotiations until spring 1991.

When the negotiations picked up again the discussions on dispute settlement where linked to the discussions on the creation of a new, formal organization, by creating a single negotiation group in charge of both subjects. At that time the pressure to make progress on the reform of dispute settlement had increased, since more and more disputes where being filed, while also the amount of blocking had gone up (Croome, 1999; VanGrasstek, 2013). When the negotiation group on institutions met for the first time in September 1991 all the ingredients for compromise where present, but the main players hesitated to commit to them until the most political decisions could be taken in the final phase of the round (Croome, 1999). ${ }^{139}$ Nonetheless, the group resolved the main outstanding issues in a series of informal meetings that were held in November and December to provide a suggested text for the Draft Final Act that Director General Dunkel composed in December 1991. ${ }^{140}$ This text eventually contains the major elements that would also appear in the DSU. It provided for reverse consensus as a decisionmaking principle for the establishment of panels, the adoption of panel and Appellate Body reports, and for the authorization of retaliation. It also entails a section on strengthening multilateralism, which in essence implies exclusive jurisdiction and bans unilateralism.

In light of the time gap between the US introduction of 'aggressive unilateralism' in summer of 1988 and the compromise that was found by the end of 1991, how can it be claimed that the indeed the United States' power to act unilaterally was the decisive factor to bring about an increase in centralization in form of reverse consensus? Why can it not be argued that the US was bound by other parties and forced into multilateralism instead of the US forcing others to accept automaticity? Or alternatively, why can the emergence of automaticity not simply be interpreted as another functional response towards the threat of an escalation spiral of unilateral retaliation as a collective action problem undermining the multilateral trade order? In

Body reports it mentions 'not to adopt the report'; and in the section on authorization of requests for retaliation it mentions 'to reject the request'.

${ }^{139}$ MTN.GNG/IN/1

${ }^{140}$ MTN.TNC/W/FA 
response to these questions, first of all it needs to be acknowledged that the two alternative interpretations are plausible and contribute to a full understanding of the emergence of reverse consensus and exclusive jurisdiction as important changes in institutional design. After all, unilateralism was perceived as one of the biggest threats to the multilateral trading system since World War II (O'Neal Taylor, 1997). The opponents of unilateralism portrayed this thread in a way that fits the theoretical description of a collective action problem demanding a functional response perfectly. The EC for example pointed out that US unilateralism was undermining the credibility of the GATT and if it would not be tackled multilaterally then other parties would be forced to act unilaterally as well, which was expected to cause an existential crisis of the multilateral trading system. ${ }^{141}$ Thus a functional explanation such as the one provided by rational design that links an increase in centralization to an increasing enforcement problem seems very suitable. From this perspective the increase in centralization was enabled by the capacity of the vast majority of parties in the GATT to force the US into the straightjacket of exclusive jurisdiction. However, while the factors mentioned in this explanation - the collective action problem and the ability to ensure that the US would accept exclusive jurisdiction - are important to understand the change in centralization, they are not the decisive ones.

Several reasons support the argument that the US power represented by its unilateral action or threat thereof is the decisive factor that permitted the increase in centralization that resulted from the Uruguay Round. First of all, the US had the advantage of being the most powerful actor in pursuing its negotiating objectives and was able to credibility threaten with the use of its power by resorting to unilateralism. This is not to say that the US was the only party that was in theory able to resort to unilateralism. The EC as a similarly powerful party had its own unilateral legislation. The EC's Regulation 2641/84 could be considered as the European counterpart to Section 301. However, the Section 301 was a more viable tool to mobilize power in comparison to Regulation 2641/84, since the EC regulation required the exhaustion of international procedures before permitting unilateral measures (Stiles, 1996). Also, the US threat to rely on its power and neglect the multilateral system was particularly credible. Domestic protectionist pressures originating from its high trade deficit and the fact that the US had not hesitated to shy away from unilateralism and the threat thereof, was useful backing for announcements that the US would not hesitate to retreat from the multilateral system if the system was not improved (Hudec, 1993; Preeg, 1995). ${ }^{142}$ That the US did not hesitate to put pressure on its negotiating partners is exemplified by a statement made by Robert Mosbacher, the US Secretary of

${ }^{141} \mathrm{C} / 163$

142 In this context Hudec (1990b) raised the question whether the violation of GATT obligations by using Section 301 could be interpreted as an act of justified disobedience on behalf of necessary legal reform - a constructive contribution to break the deadlock in the dispute settlement situations and help the GATT to progress to another level. It is not clear whether this was the main strategy of the US all along, however this is exactly what happened.

However, Hudec points out though that the degree of unilateralism the US resorted to was disproportionate and could therefore not be labelled legitimate. 
Commerce at the time, who reminded the Europeans that "we are okay either way. The US always could make regional or other agreements" (quoted in Paemen \& Bensch, 1995, p. 197).

Secondly, the US ability and willingness to act unilaterally is the main factor explaining the increase in centralization, because it was the change in US practice that induced the change in other's negotiating positions and not the other way around (Stiles, 1996). After all, in contrast to others the US entered the negotiations with the explicit aim to strengthen the dispute settlement system. Those opposed to a significant reform of the system only changed their position after the US had resorted to use unilateralism more aggressively. They assumed that giving up consensus would be the only means to contain unilateralism (Feketekuty, 1990; Ganesan, 2015; Hudec, 1993; Mora, 1993-1994; O'Neal Taylor, 1997). This was a realistic assessment, since the US Congress was adamant that it would not tolerate significant changes to Section 301 (Jackson, 1997). Apparently the EC changed its negotiating position on dispute settlement by virtually 180 degrees in response to US unilateralism (GAO, 1994). This is confirmed by those involved in the negotiations. Pointing to the lack of viable alternatives to address unilateralism, the EC chief negotiator during the Uruguay Round, Hugo Paemen, reports that multilateralism via the GATT was the "only effective weapon against the unilateral impulses of its major partners" (Paemen \& Bensch, 1995, p. 212). ${ }^{143}$ Another EC negotiator involved in the negotiation of the DSU nicely summarized the negotiation dynamics in a personal interview. In this interview he mentioned that the EC in theory had two options to counter US unilateralism. The first was to also start acting unilaterally, while the second was to strengthen the multilateral system. His elaboration why the EC chose the latter option exemplifies the impact of US power nicely:

"[The multilateral option] was the option we took. This was not simply because we were more multilateralist - I think we are - but we were more multilateralist because we were the $2^{\text {nd }}$ boy in the street. The biggest boy was the other side. So even if we had solid retaliation capabilities to the US, we felt that we would be better off with an impartial system rather than having to take on the biggest guy in the street fight." (Int01)

When being asked about potential concerns to lose control in a fully automatized system he responded that this was accepted as the necessary price to be paid (Int01). Also others testify to the importance of US unilateralist power in influencing their negotiating position. A negotiator from India mentioned that:

"One of the key points agitating India at that moment was the unilateral type of action that the United States was taking under Section 301. [...] Our whole focus at the time was to have a shield against this unilateral action. [...] That was felt even more so by Japan and Korea. [...] People wanted a kind of protection against unilateralism, even if the WTO agreement conceded certain things in the way the US wanted it to be conceded." (Int16)

${ }^{143}$ This was confirmed in a personal interview with a EC negotiator (Int18). 
Thus, the US negotiation partners were willing to bear significant costs to curtail unilateralism. Although unilateralism was a concern before, it was the US ability to strengthen this practice, which changed the negotiation dynamics and induced others to change their position.

The third reason why the change in centralization needs to be understood as a function of power is that the multilateral dispute settlement system adapted to US procedures and not vice versa. The United States managed to ensure that the time-frames of multilateral procedures would coincide with those required by domestic legislation (Goldstein \& Steinberg, 2008). Negotiators that negotiated the procedural details for the dispute settlement process confirmed in personal interviews that this was a highly important element to be considered (Int01, Int11). As stated by a EC negotiator

"[T]he Europeans started to reflect a lot on how to bring the US back to the table. We felt it would be impossible to ask the US to go back to Congress and modify the legislation, so the focus was on: is there a way to create a multilateral system that supersedes the US system, without asking changes in the US system. That was quite a challenge, but it was possible from our assessment because in the US legislation there was reference to failure of the multilateral system to deliver, in which case the unilateral thing would come in. So we came up with the logic: if we can make the multilateral system provide an answer in every case within the deadlines that the US legislation had put, then even without changing the US legislation there was no more justification for the US to take a unilateral decision and that was the whole game." (Int01)

Unsurprisingly the DSU is almost perfectly synchronized to the procedural time-frame that Section 301 sets out for the unilateral pursuit of trade disputes (Barton et al., 2006). ${ }^{144}$ Given this circumstance Goldstein and Steinberg (2008) posit that: “From the U.S. government's perspective, the radical judicial reforms of the Uruguay Round represented not a multilateralization of U.S. unilateralism, but an Americanization of the GATT/WTO disputesettlement process" (p. 267).

There is a fourth, slightly more indirect way how US power determined the outcome of the Uruguay Round negotiations on dispute settlement. The United States pursued unilateralism strategically to influence the substantive negotiations in its favor (Feketekuty, 1990; Milner, 1990; O'Neal Taylor, 1997). By using the provisions in Section 301 that permitted to target countries with not necessarily illegal but nonetheless 'unreasonable' trade policies, by pursuing assumed intellectual property violations under the Special 301 provision, and by proactively listing countries with high trade barriers according to the Super 301 provisions, the US managed to broaden the scope of the trade regime and force services and intellectual property rights on the Uruguay Round's negotiation agenda (Bhagwati, 1990; O'Neal Taylor, 1997). In lieu with the reinterpretation of the single undertaking - as mentioned in the previous chapter - this was an

144 US negotiators were actively involved during the drafting of the DSU to ensure that its articles would comport with Section 301 (Int19). 
effective means to ensure that those parties which were initially opposed to the inclusion of the new issues eventually agreed to the trade regime's increase in scope (Bhagwati, 1990; Feketekuty, 1990; Milner, 1990). The less powerful countries rather accepted the inclusion of disadvantageous substance under multilateral supervision, than facing disputes with the US on this substance outside of multilateralism (Ganesan, 2015). As it has been pointed out above, the inclusion of the new issues was a crucial factor to ensure Congressional approval of the DSU. This is a reminder that questions on substance and institutional issues are strongly connected: Institutional changes are possible if they bring substantial benefits to the powerful. Power in turn can be used to assure these benefits.

Having examined the negotiation dynamics regarding the reform of decision-making it is thus undeniable that the power asymmetry between the US and its negotiating partners is a crucial explanatory factor to understand how the increase in centralization came about: The United States was able to change the negotiation environment by resorting to a more aggressive use of its unilateral policy, which in turn forced others to change their negotiating position. This allowed overcoming the interest heterogeneity that prohibited significant reforms in the first years of the Uruguay Round. ${ }^{145}$ Of course the dynamics that unfolded throughout the negotiations can be seen as a narrative that still fits a general interpretation of the rational design logic which links enforcement to centralization. After all, it was the main goal of the EC and other negotiating parties to fit the US in the "straightjacket" of multilateral procedures, thereby promoting a multilateral enforcement of the rules of the regime instead of a unilateral enforcement of such rules. However, the decisive point is that without the US's capacity to put pressure on its negotiating parties by the ability to mobilize its enforcement power more effectively than other states, this would not have come about. Thus power asymmetries are to be regarded as a decisive factor brining about a particular interpretation of rationality, when possibly competing views on what is regarded as rational exist. This dynamic sets the Uruguay Round apart from previous attempts that fell short of a significant reform of dispute settlement during the Tokyo Round and in 1982.

\subsubsection{Spin-off Design Changes}

Some of the changes in centralization of the dispute settlement system can be regarded as spin-off effects that were driven by or even resulted from two core debates that were central to the negotiations. One core debate surrounded the question of blocking and the resulting grand bargain as just described in the previous section. The introduction of the Appellate Body, as well as compulsory and exclusive jurisdiction can be regarded as instances of centralization that

\footnotetext{
145 The importance of power is also highlighted in comparison to non-events in the form of negotiating proposals by less powerful countries that were blocked by a powerful opposition. Attempts by developing countries to further institutionalize special procedures for disputes involving developing countries, or to establish mandatory, multilateral, or retroactive compensation as a means of restitution remained unsuccessful (Croome, 1999). While the DSU's language indicates awareness of the special needs of developing countries, its tone allows for taking such needs into account flexibly and shies away from strict prescriptions.
} 
emerged in the slipstream of this debate. The other core debate surrounded the expansion in scope of the trade regime in lieu with the reinterpretation of the single undertaking and the establishment of the WTO. The unification of the system and with it the creation of the DSB benefited from the dynamics of this discussion. The emergence of each of these remaining design features and its relation to the core debates is briefly elaborated upon in the following.

\subsubsection{Compulsory Jurisdiction, Exclusive Jurisdiction and the Appellate Body in Relation to the Problem of Blocking}

The introduction of compulsory jurisdiction was an integral part of the reform of decisionmaking. After all, the quasi-automatic establishment of panels by reverse consensus leaves disputants no choice but to accept the jurisdiction of the WTO in a particular dispute. Although negotiating the decision-making for the establishment of panels was less controversial than negotiating decision-making for the adoption of reports, the US resort to aggressive unilateralism was nonetheless a necessary factor to achieve the quasi-automatic establishment of panels and make jurisdiction compulsory. This becomes clear when examining the midterm agreement's provision on the establishment of panels and ensuing developments.

The relevant section of the midterm agreement states that:

"... a decision to establish a panel or working party shall be taken at the latest at the Council meeting following that at which the request first appeared as an item on the Council's regular agenda, unless at that meeting the Council decides otherwise." 146

This formulation seems to already establish the right to a panel and with it compulsory jurisdiction. As such the development would belong to the uncontroversial procedural changes elaborated upon in section 4.5.1. However, this would overlook the fact that the language of the midterm agreement is ambiguous. Although the formulations requires the Council to take a decision to prevent instead of permit the establishment of a panel, it does not specify how such a decision would be taken. Thus, it was not clear whether the decision not to establish a panel would have to be taken by consensus - implying that the establishment of a panel would have been quasi-automatic - or whether a panel could have been blocked by a lighter decisionmaking requirement. This ambiguity was a useful strategy to paper over lack of agreement on the decision-making procedure to establish a panel.

That there was a lack of agreement became clear in 1991 in the context of a Brazilian request for the appointment of a panel to investigate a complaint that Brazil brought forward against the US. The US saw this request as a chance to clarify the Brazilian position on the midterm agreement. The US itself interpreted the agreement to mean that a consensus would be necessary to block the establishment of a panel and asked Brazil whether it shared this interpretation. Brazil remained ambiguous in its response and eventually pointed out that this question was still under negotiation (Hudec, 1993).

${ }^{146}$ L/6489, pp.3-4 
It needs to be acknowledged, that the opponents of more automaticity in dispute settlement where more willing to compromise on decision-making procedures for the establishment of panels than on those for the adoption of panel reports. Nonetheless the wording of the midterm agreement and the discussion between the US and Brazil about its interpretation indicates that the ambiguity in the midterm agreement was not coincidental, but that it was a clear reflection of diverging positions on decision-making in dispute settlement. ${ }^{147}$ It was only in the context of the grand bargain explained in section 4.5.2.3 that this ambiguity could be removed and reverse consensus for the establishment of panels be introduced.

Also the exclusive jurisdiction of the WTO emerged in this context. As it has been pointed out, the opponents of decision-making reform dropped their opposition in return for a US pledge to abstain from unilateralism. This pledge is manifested in form of Article 23 of the DSU, which establishes the exclusive jurisdiction of the WTO. Section 2(a) of the article demands of all WTO members to

"not make a determination to the effect that a violation has occurred, that benefits have been nullified or impaired or that the attainment of any objective of the covered agreements has been impeded, except through recourse to dispute settlement in accordance with the rules and procedures of this understanding...."

Thus the aim to get a stronger US commitment to multilateral procedures eventually was achieved by establishing exclusive jurisdiction as one of the core principles of the WTO's dispute settlement system.

It is interesting to note thought that this principle was established in a weaker form than initially demanded by those who wanted to contain unilateralism. Once the discussion on unilateralism was in full swing, most negotiating parties demanded a strong legal commitment to prohibit unilateralism by requiring that domestic legislation would have to conform to the dispute settlement procedures of the multilateral system. ${ }^{148}$ In line with this the Draft Final Act that was prepared for the 1990 Ministerial Meeting in Brussels contains strong language that requires parties to act in accordance with the GATT, to abide to the outcomes of a dispute settlement procedure, refrain from unilateralism or threats thereof, and to adapt domestic legislation in such a way that it would conform with GATT dispute settlement procedures. ${ }^{149}$

The US was opposed to this. It was one of the core demands of Congress that no significant changes should be made to Section 301 (Jackson, 1997). With such credible backing the US delegation was eventually able to soften the language on exclusive jurisdiction. In contrast to the earlier draft, the Dunkel Draft Final Act of 1991 does not request domestic laws to be in

\footnotetext{
${ }^{147}$ That the midterm agreement does not reflect a uniform position of all parties on the establishment of panels is also indicated by the fact that Canada called for a clarification regarding the language on the establishment of panels in its comprehensive negotiation proposal of June 1990 (MTN.GNG/NG13/W/41).

148 MTN.GNG/NG/9; MTN.GNG/NG13/10; MTN.GNG/NG13/17; MTN.GNG/NG13/19; MTN.GNG/NG13/W/39; MTN.GNG/NG13/W/43; MTN.GNG/NG13/W/45

${ }^{149}$ MTN.TNC/W/35/Rev.1
} 
accordance with the dispute settlement provisions anymore and is less explicit in condemning unilateralism. ${ }^{150}$ This was also carried over into the final version of the DSU. The legal text as it was eventually agreed upon is ambiguous whether domestic laws need to be in accordance with the dispute settlement procedures, as it seems to permit domestic laws that are incongruent with the DSU to exists, as long as they would not be made use of (Naiki, 2004). ${ }^{151}$ This compromise was the last missing piece to reach the grand bargain, which entailed the establishment of exclusive jurisdiction in exchange for the introduction of reverse consensus.

The dynamics of the grand bargain also facilitated the emergence of another, even more popular design feature - the Appellate Body. As it is shown in the following, the establishment of the Appellate Body and the reform of decision-making were interdependent. On the one hand, the more likely it got that decision-making would become quasi-automatic, the more attractive the idea to establish an appellate review mechanism became. On the other hand the introduction of the Appellate Body permitted the reform of decision-making, because appellate review was regarded as a necessary control mechanism to avoid that legally flawed panel reports would be adopted without being checked in the process of quasi-automatic decisionmaking (Elsig \& Eckhardt, 2015; Steger, 2002a, 2002b, 2015; Stiles, 1996; Stoler, 2004). ${ }^{152}$

The first hint towards an appeals body arose before the US had strengthened its unilateral policy and while opposition to reform decision-making was still strong. In spring 1988 Japan suggested establishing an independent group of experts to review panel reports. Aiming to increase the chances that panel reports would be adopted while consensus would be retained, Japan suggested to formalize procedures for the Council to review a panel report when objected by one of the disputing parties. ${ }^{153}$ When elaborating on its ideas Japan mentioned that the Council could delegate carrying out the actual review to "an independent professional body separate from the Council." 154 Only under exceptional circumstances parties should be permitted to oppose the results of such a review. Japan argued that this review would reduce the likelihood of blocking by improving the results of the dispute settlement procedure and that

150 MTN.TNC/W/FA

151 Interestingly, Article XVI:4 of the WTO Agreement requires conformity of domestic legislation with agreements covered under the WTO. The US only gave up opposition to this article at the very end of the negotiations in late 1993 when the most important political decision where taken (Paemen \& Bensch, 1995). Due to its vague phrasing different interpretations as to the legal effect of the article are possible (Naiki, 2004).

Such different interpretations permitted a dispute between the US and the EC to arise, which the EC brought to the WTO. In the US-Sections 301-310 of the Trade Act of 1974 the EC accused the US to violate its obligations under the WTO Agreement since the US kept its domestic regulations that would permit it to act unilaterally. The US in turn argued that it is not violating WTO law since it pledged to base its action under Section 301-310 on decisions taken by panels, the Appellate Body and the DSB. The panel that ruled on the case in essence agreed with both arguments. It ruled that Sections 301-310 of the Trade Act of 1974 constitutes a prima facie violation of WTO obligations, but concluded that the US pledge to refrain from deciding unilaterally ensures that there was no violation of WTO law in the case it had to judge upon (Naiki, 2004). See also WT/DS152/R.

152 This dynamic was also confirmed in several interviews with Uruguay Round negotiators and Secretariat members (Int01, Int02, Int04, Int05, Int06, Int07, Int08, Int09, Int10, Int17).

153 MTN.GNG/NG13/W/21

154 MTN.GNG/NG13/6 
the establishment of an independent body would be useful to ensure that the review would not become a mere repetition of the arguments that had already been exchanged during the panel procedure. However, the time was not ripe for such a suggestion. Some delegations reacted reserved and the idea was not further discussed for one and a half years. ${ }^{155}$

Only in fall 1989, after the US had turned towards aggressive unilateralism, the idea entered the formal negotiations again. Apparently pre-discussed in informal Quad meetings, the suggestion to establish an appeals body was raised in the September meeting of the negotiating group on dispute settlement (Donaldson, 2005; Paemen \& Bensch, 1995). ${ }^{156}$ Similar to the Japanese proposal the issue was initially framed as a way to approach the problem of blocking from a different angle. Again, the possibility of appeal was regarded as a means to ensure the quality of panel reports and thereby increase the likelihood of their adoption. Similar to the Japanese proposal, the idea could be interpreted as an alternative to the reform of decisionmaking procedures.

However, soon it became clear that the introduction of an appeals body was rather meant as a supplement instead of an alternative to the reform of decision-making. This is exemplified by the fact that several delegations stressed in the 1989 December meeting of the negotiation group that the reform of decision-making, the introduction of an appellate body and provisions to curtail unilateralism where all interrelated design features. ${ }^{157}$ Furthermore, when the EC indicated for the first time in April 1990 that it would be willing to consider a reform of decisionmaking, it listed the establishment of an appeals body as one of the conditions that would have to be met to consider such a reform. ${ }^{158}$ The link between the reform of decision-making and the establishment of the Appellate Body was explicitly pointed out in the dispute settlement proposal by Mexico of July 1990, which states that the "purpose of establishing an appellate body is to compensate for the virtually automatic adoption of panel reports" (p. 3). ${ }^{159}$ Thus latest by that time the motivation to establish the Appellate Body was to create a control feature for the quasi-automatic decision on panel reports.

Given this rationale, most countries reacted positively when the idea to establish an appeals body entered the negotiations. Also the US was in principle supportive to establish an additional control mechanism for badly reasoned panel reports (Paemen \& Bensch, 1995; Stoler, 2004). However, once the idea of establishing an appeals body had entered the negotiations it was quickly pointed out that important questions would have to be addressed. One of the concerns raised was that virtually every case would be appealed and that procedures would have to be introduced to discourage losing parties to file appeals on a routine basis. ${ }^{160}$ Another prominent concern was that the introduction of appellate review would lead to further delays of the

\footnotetext{
${ }^{155}$ MTN.GNG/NG13/6

${ }^{156}$ MTN.GNG/NG13/16

157 MTN.GNG/NG13/17

${ }_{158}$ MTN.GNG/NG13/19; MTN.GNG/NG13/W/39

${ }^{159}$ MTN.GNG/NG13/W/42

${ }^{160}$ MTN.GNG/NG13/16; MTN.GNG/NG13/17; MTN.GNG/NG13/W/43
} 
dispute settlement procedure. ${ }^{161}$ Other questions that needed to be addressed included the composition of the Appellate Body and the decision-making procedures for adopting the Appellate Body's findings. ${ }^{162}$

Three out of these four questions were carefully answered in mainly informal negotiations in fall 1990. The arrangements discussed at that time where hardly changed and made it into the final version of the DSU. The concern about time limits was addressed by requesting the Appellate Body to complete its procedures within a maximum of 90 days after an appeal has been filed (DSU, Art. 17.5), and by requesting the DSB to adopt Appellate Body reports within 30 days after their completion (DSU, Art. 17.14). Also, clear agreements had been negotiated to address the question on the composition of the Appellate Body. Article 17.1-3 of the DSU provide for its establishment as a standing body of seven independent experts that are appointed by the DSB for a term of four years, which is renewable once. ${ }^{163}$ Finally, the question of taking decision on the outcomes of appellate review was taken care of in the context of the larger reform of decision-making and the introduction of reverse consensus. ${ }^{164}$

The concern that virtually all panel reports would be appealed was the only issue that the negotiators failed to properly address. Although it was mentioned several times in the negotiations that appellate review should be limited to exceptional circumstances and that procedures should be established to discourage losing parties from routinely filing appeals ${ }^{165}$, such procedures are largely absent from the provisions of the DSU and the draft agreements that led towards it. Only Article 3.7 of the DSU that states that "[b]efore bringing a case, a Member shall exercise its judgment as to whether action under these provisions would be fruitful" could be interpreted as discouraging appeals. According to a former EC negotiator involved in the negotiations on the Appellate Body this soothed the concerns over appeals being filed on a routine basis (Int18). The same negotiator also pointed out that the desire of the trade regime's members to be in full control over the decision to file an appeal ensured that no further obstacles to this decision were introduced. Another possible explanation for the lack of further provisions to discourage appeals concerns the timing of the Appellate Body negotiations. Since the idea for the Appellate Body was only seriously discussed at a rather late stage of the negotiations, it left negotiators with limited time to work out very detailed arrangements. Due to this the DSU only sketches the broad parameters for the Appellate Body's establishment

161 MTN.GNG/NG13/17; MTN.GNG/NG13/18; MTN.GNG/NG13/19; MTN.GNG/NG13/W/40

162 MTN.GNG/NG13/19; MTN.GNG/NG13/W/40; MTN.GNG/NG13/W/43

163 Early on in the negotiations it was also suggested to establish a roster of panelist from which the Director General would select an appeal panel on a case by case basis (MTN.GNG/NG13/17) or to refer the case back to the panel that was initially in charge of the dispute (MTN.GNG/NG13/W/40).

164 Alternatives discussed were the same ones as described in the main debate on decision-making in section 4.5.2.3: maintaining consensus, consensus minus-two, and automatic adoption without including the Council (MTN.GNG/NG13/W/43; MTN.GNG/NG13/W/45).

$165 \quad$ MTN.GNG/NG13/17; MTN.GNG/NG13/19; MTN.GNG/NG13/W/40; MTN.GNG/NG13/W/41; MTN.GNG/NG13/W/42; MTN.GNG/NG13/W/43 
(Donaldson, 2005). ${ }^{166}$ Additionally, the negotiators probably neglected this question because they underestimated its importance. As described in section 4.4.4 few expected in the early 1990s how prominent the Appellate Body would become and how frequently it would be resorted to. After all, negotiators never had the intention to create an international tribunal (Donaldson, 2005; Steger, 2002a, 2002b, 2015). Debra Steger - one of the key negotiators of the DSU - provides an interesting insight on negotiators' attitudes in this context: "When issues such as the mandate of this new Appellate Body or the applicable standard of review were discussed, the response of delegations was always - let us see what the experience is and leave it to the Appellate Body to develop its own procedures" (Steger, 2004, p. 42). As it has been pointed out in section 4.4.4 the negotiators' expectations would turn out to be inadequate. Nevertheless, given the assessment of the situation at the time the negotiators were satisfied with the outcome achieved.

By the end of 1990 there was general agreement on the establishment of the Appellate Body and the negotiation group was able to provide a comprehensive draft on its establishment for the Brussels Ministerial Meeting (Croome, 1999). Except for the decision-making provisions the Brussels draft outlines all the essential features of the Appellate Body that would also appear Dunkel Draft Final Act. By the time of the Dunkel Draft, in December 1991, also the issue on decision-making had been addressed in the context of the grad bargain. The sections on the Appellate Body in the Dunkel Draft are largely identical with those of the DSU. Thus, by late 1991 the negotiations on the Appellate Body were essentially completed. The Appellate Body was eventually established in February 1995 by a decision of the DSB taken during its first meeting. ${ }^{167}$

Clearly the establishment of the Appellate Body was facilitated by the negotiation dynamics of the grand bargain. The more likely the introduction of quasi-automatic decision-making became, the bigger the support for the Appellate Body got (and vice versa). The timing is telling in this respect: While the Japanese idea for an independent review was largely ignored before the midterm ministerial, once the concern of unilateralism had increased, the idea of the Appellate Body entered the negotiations, and principal agreement on its establishment had been reached only nine months after the EC had indicated its willingness to compromise on decision-making in return for a stronger US commitment to multilateralism. ${ }^{168}$

${ }^{166}$ This was confirmed by two former negotiators who were involved in the negotiations of the Appellate Body (Int18, Int19)

167 WT/DSB/1

The DSU does not establish the Appellate Body itself, but only provides for its establishment via the DSB (Art. 17.1). The decision of the DSB on the establishment of the Appellate Body was prepared by the Preparatory Committee for the World Trade Organization. Throughout 1994 the committee discussed detailed questions related to staffing of the Appellate Body, such as conditions of employment, profile of members and the selection procedure for members. It also worked out detailed recommendations regarding the administrative support for the Appellate Body and discussed the body's working procedures (PC/IPL/M/7; PC/IPL/M/9; PC/IPL/W/15).

168 One might question the plausibility of this account, given the fact that negotiation parties reached consensus on the establishment of the Appellate Body well in advance of confirming consensus on the reform of decision-making. However it should not be forgotten that consensus on decision-making reform remained 
Overall, the emergence of compulsory and exclusive jurisdiction, and the Appellate Body can only be fully understood by taking a holistic perspective on the negotiations. After all, they only emerged in the slipstream of the wider discussion of blocking and the reform of decisionmaking.

\subsubsection{The Unified System and the DSB in Relation to the Expanding Scope of the Trade Regime and the Establishment of the WTO}

Not only compulsory and exclusive jurisdiction, and the Appellate Body came about in the context of negotiations on a broader issue, but also the unification of the dispute settlement system and the establishment of the DSB. Both of these design features emerged in the slipstream of the trade regime's expansion in scope, which was in turn closely related to the reinterpretation of the single undertaking and the establishment of the WTO as analyzed in the previous chapter. ${ }^{169}$ Similar to the previous sections, the following brief overview highlights once again that functional motives are often not sufficient to fully explain changes in centralization. While such motives had been present in the case of creating a unified system and the DSB, they do not suffice to explain the emergence of these two design features. It is necessary to take the debate on the trade regime's expansion in scope and the corresponding power play that led to the reinterpretation of the single undertaking into account to fully understand how the unified system and the DSB emerged. This is exemplified by the fact that the nature of the negotiations on the two design features changed substantively when the reinterpretation of the single undertaking entered the discussion. From low-key, mainly functionally motivated discussion without much momentum in the first years of the round, the unification of the system and establishment of the DSB turned in the early 1990s to an integral part of one of the key issues of the round, in which power asymmetries played a significant role.

The roots of the negotiations on creating a unified system are to be found at the very beginning of the negotiations. In September 1987 the Nordic Countries ${ }^{170}$ and the EC suggested in their proposals to the negotiation group on dispute settlement to create a single consolidated text of all the procedures of dispute settlement. ${ }^{171}$ This was further discussed in the spring of 1988 and notes of an informal meeting in April suggest that the negotiation group was close to an agreement on the issue. ${ }^{172}$ After the midterm review, in spring 1989, the Chairman of the group started to encourage the group to put the intention of creating a consolidated text into

pending, because the main actors in the negotiations made their agreement to reform contingent on the overall outcome of the Uruguay Round. It can be assumed that the Appellate Body was negotiated under the assumption that decision-making would be reformed, even if that was not formally agreed to at the time. This reasoning was confirmed by a former negotiator, who was directly involved in the negotiations on the institutional changes of the dispute settlement system (Int18).

169 See section 3.2.4.2

170 The term Nordic Countries was used during the Uruguay Round to refer to a group of countries consisting of Finland, Iceland, Norway and Sweden.

${ }_{171}$ MTN.GNG/NG13/3; MTN.GNG/NG13/W/10; MTN.GNG/NG13/W/12

172 MTN.GNG/NG13/W/29/Rev.1 
practice. ${ }^{173}$ Although one delegation expressed the view that no consensus had been reached on the creation of a single, consolidated text, the Secretariat was asked to prepare a draft of such a text in preparation for further discussions in spring 1990. ${ }^{174} \mathrm{Up}$ to that point the idea to create a consolidated text was motivated by the desire to improve transparency, and contrary to the unified system as it would eventually emerge it was only meant to cover the different dispute settlement procedures for trade in goods. ${ }^{175}$ Thus, there was no implication at the time to also cover the plurilateral codes or the agreements on trade in services and intellectual property in such a text.

This started to change in late 1989. During the December meeting of the negotiation group on dispute settlement the US requested the Secretariat to provide an overview of dispute settlement issues being negotiated in other negotiation groups and in the code committees. ${ }^{176}$ During the discussion of this overview in spring 1990 at least one delegation expressed its support for the harmonization of procedures across the GATT, the codes and any agreements in new areas. ${ }^{177}$ Other delegations reacted skeptically and pointed out that uniform procedures would be welcome, but that unified procedures are undesirable due to the fact that different parties have different levels of obligations in different substantive agreements. ${ }^{178}$ Furthermore they responded that there was no agreement to incorporate the newly negotiated areas into the GATT. ${ }^{179}$ This response indicates that by 1990 the consideration to create a unified text was no longer a technical exercise in improving transparency, but had become embedded in the wider political question on the implementation of the Uruguay Round agreements.

This was facilitated by the idea to create a new international organization, which was introduced to the FOGS group in parallel to the discussions in the dispute settlement group. After all, the EC's July 1990 proposal for the establishment of an organization made a clear reference to the advantages of an integrated dispute settlement system administered by a formal international organization. ${ }^{180}$ It pointed out that such a system would end the fragmentation of the trade regime that had resulted from the different plurilateral agreements and that a centralized body would beneficial to administer this system. ${ }^{181}$ Although these arguments were mainly functional in nature and fitted well to concerns about fragmentation and forum shopping that were expressed in the dispute settlement group, by summer 1990 the negotiations about the unification of the dispute settlement system belonged to a broader and highly political question.

\footnotetext{
${ }^{173}$ MTN.GNG/NG13/15

174 MTN.GNG/NG13/15; MTN.GNG/NG13/17

${ }^{175}$ MTN.GNG/NG13/14

176 MTN.GNG/NG13/17

177 MTN.GNG/NG13/18

${ }^{178}$ MTN.GNG/NG13/19

${ }^{179}$ MTN.GNG/NG13/19

This view was also expressed in the Trade Negotiation Committee (e.g. MTN.TNC/16).

${ }^{180}$ MTN.GNG/NG14/W/42

${ }^{181}$ MTN.GNG/NG14/W/42

See also section 3.2.2.1.
} 
This question concerned the implementation of the Uruguay Round agreements: Should a GATT à la carte approach as reflected by the plurilateral codes be feasible or should all members of the trade regime subscribe to all the agreements covered by the regime? Clearly the developed countries had a strong interest in ensuring the latter. Particularly the US had the explicit aim to create a less fragmented system where all actors would commit to all of the most important substantial agreements, including trade in services and the agreement on intellectual property (GAO, 1994; Porges \& Price, 2005). In this context a unified dispute settlement system would be crucial to enforce such an expansion in scope. The capacity to enforce agreements would be further strengthened, by offering the possibility to retaliate by withholding concessions in a different sector than the one a dispute arose in. Thus, withholding concessions of trade in goods, for example, could be used to retaliate against a violation of the agreement in intellectual property rights. Such cross-retaliation was highly attractive to developed countries as a means to enforce the newly negotiated agreements. Contrary to this several developing countries initially regarded the expansion in scope of the trade regime as disadvantageous and were consequently less open to a unified dispute settlement system (Croome, 1999; Preeg, 1995). Throughout the remainder of 1990 it was not possible to reconcile the opposing positions. ${ }^{182}$

Once the negotiations started again after the hiatus caused be the failure of the Brussels Ministerial Meeting, the parallel discussions on unified dispute settlement and the establishment of an organization were addressed together in the newly created negotiating group on institutions. The different views on a unified system were still present as expressed during the first meeting of the group in October $1991 .{ }^{183}$ Although there seemed to be general agreement in the negotiating group that avoiding proliferation of different approaches to dispute settlement and the resulting risk of forum shopping would be desirable, it was unclear how this would be achieved. Again, some delegations expressed their interest in a unified system that would not only cover trade in goods, but also all other agreements. Others responded that the group on institutions was only related to negotiations on goods and had therefore no mandate to discuss the establishment of a unified system that would also cover trade in services. Such a question would have to be discussed on a higher political level. ${ }^{184}$

The issue was taken up again in a series of informal negotiations in late 1991. These informal negotiations resulted in an agreement on "Elements of an Integrated Dispute Settlement System", which was annexed to the Dunkel Draft Final Act. ${ }^{185}$ This agreement provides for a unified system applicable to all of the substantive agreements negotiated during the Uruguay Round. It also provides for the possibility of cross retaliation and establishes the DSB. Once this agreement was reached the focus throughout the remainder of the negotiations on dispute

\footnotetext{
182 MTN.GNG/NG13/W/43

183 MTN.GNG/IN/1

184 In this context it is not surprising that the development of a single consolidated text was presented as a technical exercise only to be undertaken once substantive negotiations had further developed.

185 MTN.TNC/W/FA
} 
settlement laid mainly on technical questions. Throughout 1992 and 1993 most that was left to be done was to refine the rules on cross-retaliation and to integrate the agreement on the unified system with other agreements related to dispute settlement (Croome, 1999).

What explains the agreement on a unified system despite initial interest heterogeneity? Certainly, functional approaches contribute to understand this increase in centralization. As it was mentioned in section 4.3.1.2 parties had the ambition to stop the fragmentation of the system and to avoid forum shopping. With the crisis of the system worsening, in the early 1990s this ambition was bigger than ever before (Croome, 1999). However, this problem could also have been solved by developing uniform procedures for different agreements that would not necessarily have been applicable to all contracting parties (Jackson, 1990). A unification of the system where all agreements are equally applicable to all parties was thus no functional necessity. As it was pointed out earlier several negotiating parties preferred a uniform to a unified system. It needs to be acknowledged that the opposition to a unified system had softened by the early 90 s in comparison to the mid-80s, since several developing countries were more open towards a more liberal trade regime by that time (Croome, 1999). Nonetheless, to get a full understanding of the unification of dispute settlement power asymmetries have to be taken into account.

The impact of such asymmetries was manifested in two different ways. The first has been explained in detail in the previous chapter already: the unified dispute settlement was an integral part of a new international organization, whose establishment was linked to the reinterpretation of the single undertaking. Those who preferred a GATT à la carte approach and who resisted the unification of the system were given the choice between staying in a largely irrelevant GATT, abandoned by the most influential parties, and joining the newly created WTO where all agreements would be applicable to all its members. In this context the unified dispute settlement system as administered by the organization would be the logical institutional feature to ensure enforcement. The second way power influenced the emergence of the unified system is once again related to unilateralism. The US used Section 301 to target a set of developing countries to set the agenda for the Uruguay Round, ultimately aiming to integrate services and intellectual property protection in the multilateral trading system (Bhagwati, 1990; O'Neal Taylor, 1997). This strategy was eventually successful, since those countries preferred a multilateral system that covered sectors, which were not regarded as beneficial, over facing the US in trade disputes bilaterally (Ganesan, 2015). In essence the unification of the dispute settlement system can be described as a tradeoff between developed and developing countries: Developed countries received binding and enforceable commitments to all of the negotiated substance, while developing countries got a stronger multilateral system to keep the powerful in check in return (VanGrasstek, 2013). Power asymmetries set the preconditions for this tradeoff and the unification of the system can hardly be understood without taking the reinterpretation of the single undertaking and the emergence of the WTO into account.

This also holds for the establishment of the DSB. Devoting a specialized body to dispute settlement had been discussed several times from the very beginning of the negotiations 
onward, but did not gain momentum until the idea to establish an organization and to unify the system arose. Already during the preparatory work for the negotiations Hong Kong suggested to establish a new standing body in charge of dispute settlement in order to enhance the effectiveness of the system. ${ }^{186}$ This idea was repeated during the first meetings of the negotiation group on dispute settlement in $1987 .{ }^{187}$ However, support for the idea was apparently limited. This led to the suggestion of an alternative proposal. ${ }^{188}$

In November 1987 Argentina, Canada, Hong Kong, Hungary, Mexico and Uruguay submitted a joint proposal to the group, suggesting that the Council would regularly meet in 'dispute settlement mode'. ${ }^{189}$ The content of this early proposal bears remarkable similarity to the current setup of the DSB. In dispute settlement mode the Council would meet preferably once per month to carry out all functions related to dispute settlement. Level of representation and membership would be the same as during regular meetings; only the chairman - who would be elected by the contracting parties - would differ. Similar to the original idea of creating a new institutional body, this suggestion was functionally motivated. It was argued that Council meetings solely dedicated to dispute settlement would be able to give more systematic attention to the dispute settlement processes and the implementation of results by focusing more on surveillance. This in turn was assumed to facilitate compliance and enhance the entire dispute settlement system. ${ }^{190}$

Many delegations reacted positively to the idea, but there was also serious opposition. Some parties were skeptical whether the roles and competences of the different chairmen could clash and whether their relation could be properly arranged. ${ }^{191}$ It was also pointed out that dispute settlement is often more relevant for developed than for developing countries and that Council meetings solely dedicated to dispute settlement could therefore discourage developing countries from participating. ${ }^{192}$ Furthermore some parties were afraid that Council meetings in dispute settlement mode could undermine the standing of the regular Council. ${ }^{193}$ It was argued that dispute settlement as one of the most valuable and important features of the GATT should be reserved to the Council proper. ${ }^{194}$ Finally, the concern was expressed that frequent meetings in dispute settlement mode could lead to politicization of dispute settlement and put an unnecessary burden on the system. ${ }^{195}$

Follow up attempts to reinvigorate the idea in 1988 encountered the same opposition. In April that year the EC suggested to reserve time on the Council's agenda to dispute settlement and to let these agenda items be chaired by a 'designated' chairman - the EC suggested a

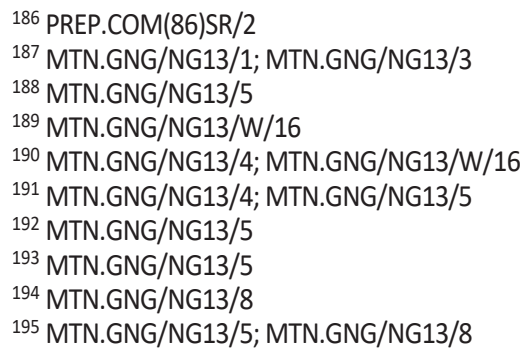


deputy Director General - who would act as a mediator. ${ }^{196}$ This was as unsuccessful as the Mexican attempt to reintroduce the idea of the Council meeting in dispute settlement mode in its comprehensive negotiation proposal submitted in in June. ${ }^{197}$ Each time opponents reminded the negotiating group of their serious reservations, leading Mexico to delete the relevant section from its proposal. ${ }^{198}$ Since then the idea laid dormant.

This only changed when the idea to unify the system under the aegis of an international organization entered the negotiations again in 1990. There is hardly any documentation on the establishment of the DSB, but the original EC proposal for the creation of an organization mentions that one of the advantages of such an organization would be the creation of a competent body to examine a matter in the light of all multilateral agreements. ${ }^{199}$ Thus the idea became linked to the creation of an organization, which was used to ensure unification of the system. This is manifested by the Dunkel Draft's section on the establishment of an integrated dispute settlement system, which provides for the establishment of the DSB. Interestingly, the language used in the draft suggests the establishment of an entirely new institutional body. This had changed by the end of the Uruguay Round and the setup of the DSB in its current form seems to be heavily influenced by the original idea of the Council meeting in dispute settlement mode.

As it is the case with the other design features of centralization that emerged from the Uruguay Round, the negotiation history of the DSB suggests that the early, functionally motivated calls on centralizing the administration of dispute settlement were not sufficient to bring about institutional change. This was only possible once the negotiations of a new body where linked to the wider question of expansion in scope and the unification of the system via the establishment of a new international organization.

\subsubsection{Conclusion}

Having traced the negotiation process of the different design features that constitute the increase in centralization of dispute settlement, it is evident that functional explanations contribute, but do not suffice to thoroughly understand institutional change that resulted from the Uruguay Round.

For the procedural improvements of the panel process agreed to at the midterm Ministerial Meeting, functionalism provides a plausible account. It needs to be recalled though that these changes were also influenced by path dependence, as they largely built up on existing procedures. This ensured that the risk of unintended consequences of institutional change was

${ }_{196}$ MTN.GNG/NG13/6; MTN.GNG/NG13/W/26

${ }_{197}$ MTN.GNG/NG13/W/26

Interestingly the Mexican suggestion introduced two alternative options for the profile of the chair of the Council in dispute settlement mode. One option restated the original idea of having the meetings chaired by a delegate elected by the contracting parties. The other option was seemingly inspired by the EC proposal and provided for a representative of the Secretariat to chair the meetings.

${ }^{198}$ MTN.GNG/NG13/8; MTN.GNG/NG13/9; MTN.GNG/NG13/10; MTN.GNG/NG13/W/26/Rev.1

${ }^{199}$ MTN.GNG/NG14/W/42 
low. The low risk in combination with the relatively low sovereignty costs and high interests homogeneity on these institutional changes probably provided fertile ground for a negotiation dynamic largely characterized by functional ambitions.

The reform of decision-making did not feature such characteristics. The negotiations were characterized at least as much by power asymmetries as by functionalism. Risk and costs were potentially high, and interests largely heterogeneous. Under these circumstances the explanatory power of functionalism decreases. While the desire to avoid blocking constitutes a motivation for functional change that would fit perfectly to the rational design conjecture which links an increasing enforcement problem to an increase in centralization, tracing the negotiation process highlights that institutional change would not have been possible if the US would not have been powerful enough to induce others to change their negotiating position. Thus power asymmetries are important to take into account in light of heterogeneous preferences. Only when those in favor of change are powerful enough to overcome opposition, such change is possible. Additionally, the reform of decision-making procedures once again highlights the important link between substance and institutions. Without being confident that substantive results of the negotiations would have been largely in its favor, it is likely that the domestic political support permitting the US to subscribe to a quasi-automatic dispute settlement system would have been absent.

Also the negotiations of the five remaining changes in centralization were characterized by supplementary factors to functionalism to be brought about. Clearly the negotiations of all these design features exhibit functional motivations, but these features failed to receive sufficient support until the negotiations were affected by broader, more political developments. Compulsory jurisdiction was functionally argued for in the first years of the round, but left vague in the midterm agreement. It only became a strong feature of the trade regime as an integral part of the power based reform of decision-making. The same holds for exclusive jurisdiction as an integral part of the grand bargain - although it was mentioned before, no results could be reached until it was linked to the reform of decision-making and until it was certain that the substantive results of the round would be beneficial to the US. Also the emergence of an independent appeals mechanism was neglected when it was presented as an alternative to reform of decision-making. The Appellate Body only became attractive and its emergence facilitated once it was framed as a supplementary control feature to such a reform. Finally, the unification of the system and the creation of the DSB only gained momentum once developed countries had used their power to ensure that the results of the round would be implemented under the reinterpreted meaning of the single undertaking. All of this shows that functional accounts provide a good starting point to trace some core motivations of institutional change, but that they need to be supplemented by contextual features that influence a dynamic negotiation process. One such feature that still warrants explicit elaboration is the existence of adequate control mechanisms. 


\subsection{Design Interaction: Centralization and Control}

Centralization and control are highly interdependent. After all, changes in control largely determine the degree of centralization by specifying how an institutional body can conduct its tasks. In this respect it is evident that the account of institutional change provided so far has been at least as much an account of centralization as it has been of control. This can hardly be avoided when analyzing complex, interdependent institutional structures. The introduction of reverse consensus as a decision-making principle of the DSB is strictly speaking a change in control of an institutional body that can be classified as an increase in the degree of centralization as pooling. This in turn affected the degree of centralization as delegation by assuring that panel and Appellate Body decisions are quasi-automatically accepted - panels and the Appellate Body as manifestations of delegation enjoy a much higher autonomy by being able to take decisions that can hardly be reversed.

Furthermore, the controversy that surrounded the introduction of reverse consensus shows the relevance of control when actors consider changing institutional design. Even functional approaches such as rational design assume that actors are risk averse and desire to maintain control when facing uncertainty (Koremenos et al., 2001a). In institutional design, respectively change, uncertainty can be particularly high as such design can entail unintended side effects (Martin \& Simmons, 1998). It is thus not surprising that control mechanisms constituted an integral part of negotiators' considerations to increase centralization during the Uruguay Round. As it has been pointed out in chapter 2 , although the two variables are analytically separate, empirically they are often manifested in design sets were centralization and control are inextricably linked.

In the following these links as they emerged from the Uruguay Round are explained. Since considerable attention has been paid already to the introduction of reverse consensus as a decrease in control that lead to an increase in the degree of centralization, the main focus in this section lies on control features that were introduced to counterbalance this effect with the aim to limit the risks and potential costs of increased centralization. An overview of such features is provided in three parts. The first examines control features related to the DSB as an instance of pooling. The second focuses on the control of panels and the Appellate Body as instances of delegation. The third elaborates on control as members' ability to determine whether and how they implement the results of the dispute settlement process.

This overview shows that considerations of control were indeed important in the design process of the DSU. During the negotiations designers often considered which institutional design would allow for an adequate degree of control. It should not be too surprising though that such considerations seem less important in the design of dispute settlement in comparison to control considerations that characterized the design process of the institutional features that relate to the WTO's legislative function. Countries naturally hesitate more to render control over bargaining substance than they do over the enforcement of that substance after it has been 
agreed upon. In the design of control it is furthermore evident that control mechanisms influencing the autonomy of the organization are more prominently represented than design features that determine the symmetry of control in the organization. Since dispute settlement requires impartiality and expertise as core characteristics to be regarded as legitimate, this is not surprising. Nonetheless, even in such a domain a small degree of asymmetry is present and will be mentioned when relevant.

\subsubsection{Control of the DSB as an Instance of Pooling}

The DSB as the supreme administrative organ of dispute settlement is controlled within the wider institutional structure by four design features. First, the DSB faces limitations in its mandate to interpret the substance covered under the WTO agreement. Second, stringent decision-making rules to legislate on this substance according to the WTO's legislative procedures serve as institutional checks and balances that protect members from strong enforcement of substance they disagree to. Third, in the worst case members always have the possibility to withdraw from the organization when being dissatisfied with the WTO's strong enforcement mechanisms. Finally it should not be forgotten that access to the WTO's dispute settlement system is limited to the trade regime's members and not open to third parties.

Regarding the first control element, the WTO agreement clearly stipulates in Article IX:2 that the "Ministerial Conference and the General Council shall have the exclusive authority to adopt interpretations of this Agreement and of the Multilateral Trade Agreements." Thus, despite the fact that disputes often concern the interpretation of a particular agreement, the DSB is seriously limited in this respect. ${ }^{200}$ Furthermore, members are protected from the DSB by the explicit provision in Article 3.2 of the DSU that rulings of the DSB cannot diminish members' rights and obligations. The negotiation history of the DSB suggests that these provisions did not appear coincidentally in the legal agreements, but that they were conscious responses to concerns over control. Already in the first proposal for a separate body in dispute settlement it was mentioned that such a body would not alter the rights and obligations of the contracting parties. ${ }^{201}$ Nonetheless parties expressed concern that such a body might undermine the standing of the Council. ${ }^{202}$ Consequently it is not surprising that delegations stressed in the first meeting of the negotiation group on dispute settlement that only contracting parties have the right to alter the rights and obligations of the members of the trade regime. ${ }^{203}$ The provisions limiting the mandate of the DSB are likely to be a direct response to this.

Secondly, the decision-making rules for interpretation or other legislative acts by the Ministerial Conference and the General Council are in turn extremely stringent. This is often interpreted as a flaw of the WTO's institutional setup, since judicial decisions that easily come

\footnotetext{
${ }^{200}$ In this context it is interesting to note that Article 3.2 of the DSU frames one of the purposes of dispute settlement to be 'clarification' of existing provisions and not interpretation.

${ }^{201}$ MTN.GNG/NG13/W/16

${ }^{202}$ MTN.GNG/NG13/5; MTN.GNG/NG13/8

${ }^{203}$ MTN.GNG/IN/1
} 
about by the quasi-automatic adoption of panel and Appellate Body reports can hardly be counterbalanced or corrected by flexible legislative responses (Cortell \& Peterson, 2006; Jackson, 1997). The WTO's legislative branch is simply too inertial, if not even paralyzed by its high decision-making thresholds. Clearly, this leads to problems. However, it can also be regarded as a conscious control feature in light of a very strong judiciary. According to Pauwelyn (2005) the strong judicial and the weak legislative arm not paradoxical, but rather constitute a logical design set of centralization and control. He argues that "[b]ecause WTO norm can now be enforced through an automatic dispute process with limited exit options, control of the norm itself, that is, at the time it is created, is the only possible solution for WTO members" (p. 30). Clearly the tightening of decision-making structures as analyzed in the previous chapter was a precondition for the strengthening of dispute settlement (Pauwelyn, 2005; World Trade Organization, 2007). ${ }^{204}$

Thirdly, permanence of an international agreement such as the DSU as well as possibilities for withdrawal from an agreement can be used as means of control. In this respect the caution of designers deserves to be noted. The procedural reforms of dispute settlement that were agreed to at the midterm review were initially only applied on a trial basis until the end of the round. ${ }^{205}$ The final outcome of the round is subject to a similar element of caution. As an element of control ministers demanded in April 1994 that the rules and procedures of the WTO's dispute settlement rules should be fully reviewed and if necessary adjusted within four years after the WTO's establishment (Petersmann, 1994). ${ }^{206}$ Furthermore, as a matter of last resort, according to Article XV of the WTO agreement members of the organization always have the possibility to withdraw from the organization after a six-month notification. Although this would be costly, at least in theory it would be a way to escape the dispute settlement system. ${ }^{207}$

Finally, it should not be forgotten that the system is a government to government dispute settlement system that restricts access to the members of the WTO. No third parties or private actors have the right to initiate a dispute. Although it seems that this could be taken for granted

\footnotetext{
204 That this was an important consideration during the negotiations was confirmed in several interviews with former negotiators and Secretariat members (Int02, Int05, Int07).

${ }^{205} \mathrm{~L} / 6489$

206 This was already considered during the negotiations as exemplified by the comprehensive dispute settlement proposal from Canada submitted in 1990 (MTN.NG13/W/41). The proposal mentions that in light of the significant change that the suggested reforms would imply, review and adaptation could be necessary after having gathered some experience with the reformed system. The provision for reviewing the system was already entailed in an early draft text on dispute settlement, created in preparation of the Brussels Ministerial Meeting (MTN.GNG/NG13/W/45).

207 In the United States concerns over the control of the dispute settlement system led to a particularly interesting development regarding the possibility to withdraw. To ensure congressional approval President Clinton agreed to the establishment of a dispute settlement review commission. This commission would review panel and Appellate Body reports. If the commission would find three instances within five years in which panels or the Appellate Body demonstrably exceed their authority, alter treaty rights or obligations, act arbitrarily or capriciously, or engaged in misconduct or depart from standard procedures, then Congress would withdraw the US from the WTO (Goldstein \& Gowa, 2002; Jackson, 1997; Preeg, 1995; Sarooshi, 2005). Although this commission was never established, it ensured concessional support and indicates the importance of control.
} 
it is noteworthy that delegations explicitly pointed this out during the negotiations. ${ }^{208}$ Also the fact that a suggestion by Switzerland to strengthen the rights of private actors in dispute settlement did not receive much support is telling in this respect. ${ }^{209}$ Keeping the participation in the system confined to governments was important to designers, since it gives the members of the trade regime control over the decision to initiate a dispute - including the possibility not to do so when this is considered politically opportune. According to a former EC negotiator this was an important consideration during the negotiations:

"It's a member driven organization. The basic simple principle is: We have established rules, but if no member complains, there is no problem. If you pass the red light, someone can blame you, but if no police agent has seen it, you get away with it. The same is in the WTO; and the Secretariat is not the policeman. It was very clear consensus, very broad consensus, we didn't want the Secretariat to become a policeman. We wanted parties to have to take this role, because we did not want to focus on minor deviations - if you have not played by the book, but no one bothers, why would you raise an international issue out of it. So fundamentally the philosophy was: for there to be an infringement there needs to be someone injured and the one injured would have to be a party, not the Secretariat." (Int01)

\subsubsection{Control of Delegation in Dispute Settlement: Panels and the Appellate Body}

Next to the control of the DSB as an instance of pooling, its subsidiary bodies - panels and the Appellate Body -, which can be classified as instances of delegation, are also controlled. This control takes various forms: It is manifested by the fact that these two judicial bodies are formally subordinate to the DSB as a political body, leading to an incomplete separation of powers in the WTO. It is also reflected by limitations on the mandate of panels and the Appellate Body. Furthermore, review stages in dispute settlement procedures allow for some control. And finally, members can try to exert control by influencing the selection of panelists and Appellate Body members

Formally speaking panels and the Appellate Body are subordinate to the DSB. Although the actual amount of control that can be exerted by this institutional arrangement is limited, this is a design element that should not be neglected and puts the introduction of reverse consensus into perspective. After all the DSB is a political body supervising a judicial process. It is the DSB that formally takes decisions and needs to adopt panel and Appellate Body reports, and thereby stays at least formally in diplomatic control. ${ }^{210}$ This stands in contrast to other international

\footnotetext{
${ }^{208}$ MTN.GNG/NG13/3
}

Furthermore, developing country attempts to equip the GATT with a prosecuting role as pointed out in section 4.4.3 indicate that changing the character of the dispute settlement system to allow the Secretariat to initiate disputes is not a completely unrealistic scenario.

${ }^{209}$ MTN.GNG/NG13/W/36

210 Of course, the fact that decisions are taken by reverse consensus implies that de facto control is minimal. However the supervisory function of the DSB in combination with the framing of decision-making rules in the DSU 
tribunals that lack such form of political supervision and implies that the dispute settlement system of the WTO should strictly speaking not be described as judicial, but more accurately as quasi-judicial. The DSB's supervision of the dispute settlement process implies an incomplete separation of powers in the WTO (Steger, 2015). According to Matsushita (2015) this arrangement reflects the desire of designers to find a compromise between functionality via centralization, while still maintaining control. Designers wanted to allow for an effective resolution of trade disputes, while keeping the organization member driven and judicial activism in check. ${ }^{211}$ This compromise is also reflected in the terminology that is used in the DSU. The Appellate Body is referred to as 'body' and not as 'court', its members are 'members' not 'judges', and as output the dispute settlement process produces 'reports' and makes 'recommendations' and not 'judgments'. This can be regarded as a form of discursive control, which can in theory limit the normative authority of the dispute settlement process and the Appellate Body in particular (Elsig \& Pollack, 2014; Shaffer et al., 2016). Furthermore, the adoption process of reports in the DSB allows WTO members to signal disapproval of panel and Appellate Body decisions by commenting on them in DSB meetings. If such disapproval is expressed collectively, this can send a disciplining signal to the Appellate Body, even if the report is eventually still adopted (Shaffer et al., 2016; Steinberg, 2004). ${ }^{212}$

Despite this option, the quasi-automatic adoption of reports of course implies that there are severe limits to control when understood in terms of limiting institutional autonomy. However, the introduction of reverse consensus as a control feature of delegation had a very real effect in terms of symmetry of control. More automaticity in dispute settlement procedures is almost always to the benefit of weaker actors in the regime. Already during the negotiations of the ITO smaller parties preferred that the ICJ as a review body could be more automatically accessed (Hudec, 1999a; Rubin, 1949). With the advent of the GATT and its lack of institutional structures hopes for automaticity were gone and dispute settlement was initially hard to distinguish from political negotiation (Jackson, 1969). Although this changed throughout the years, with the increasing institutionalization of dispute settlement, by the 1970 s the anti-legalist culture and the possibility of blocking in the GATT required strong and determined parties to push through formal dispute settlement procedures and to bear the costs of possible delay (Hudec, 1980). With the introduction of reverse consensus and resulting automaticity this changed. Reverse consensus reduced the impact of political leverage by ensuring that disputes are no longer

(the DSB decides unless there is a consensus not to) at least leads to the impression of members staying in control (Paemen \& Bensch, 1995). According to Cossy (2015) this was an astute strategy, since it allowed for preserving the impression that consensus still applies, while introducing a de facto judicial process. The introduction of a judicial process proper, without keeping the language on consensus would probably have been politically more difficult.

${ }^{211}$ This was also confirmed by former negotiators and Secretariat members in personal interviews (Int04, Int05)

212 That this was important to designers is exemplified by the fact that the option to make acceptance of Appellate Body reports automatic and unconditional, without any involvement by the Council (as expressed in several negotiation documents, e.g.: MTN.GNG/NG13/17; MTN.GNG/NG13/19; MTN.NG13/W/41; MTN.NG13/W/42; MTN.GNG/NG13/W/43; MTN.GNG/NG13/W/45) was eventually rejected. 
resolved in the shadow of blocking. Of course richer countries still have more resources than poorer ones available to effectively make use of the system ${ }^{213}$, but overall the participation of developing countries in the system has significantly increased and the range of countries making use of the system is wider than ever (Stone, 2011). Thus it seems fair to state that the introduction of reverse consensus has leveled the playing field with respect to symmetry of control.

It needs to be acknowledged though that the negotiation history of the Uruguay Round indicates that in light of this development, developed countries were not willing accommodate developing countries much further. Demands to further institutionalize special and differential treatment of developing countries in dispute settlement were largely neglected and rebutted by pointing out that any strengthening of a rule-oriented system would already constitute special and differential treatment since this would be proportionally more beneficial to developing countries. ${ }^{214}$ Thus, despite the fact that reforms leveled the playing field, considerations of relative influence remained relevant.

Going back to design elements that signal control over an institution instead of the relative influence of its members, designers tried to increase control by limiting the mandate of panels and the Appellate Body. In line with the limits set on the DSB regarding the interpretation of substantive provisions, the DSU reaffirms these limits for the instances of delegation. According to Article 19.2 of the DSU neither panel nor Appellate Body reports can add to or diminish the rights and obligations of the WTO's members under the covered agreements. Again, this provision stems from members' concern of unexpected interpretations of substantive agreements and aimed at foreclosing judicial activism (Elsig \& Pollack, 2014; Jackson, 1997). That this concern was a relevant factor during the negotiations is exemplified by discussions in the negotiation group on the matter and elaboration on the question whether panel and Appellate Body reports are to be regarded as formal precedents. ${ }^{215}$ The abovementioned article is clearly reflecting the collectively held view that the results of a particular dispute settlement procedure should only be binding on the disputing parties and should not count as precedents.

Furthermore, according to Article 17.6 of the DSU the scope of the Appellate Body's review is restricted to questions of law and legal interpretation mentioned in the panel report. Thus the Appellate Body is not allowed to review facts or take into account issues of law that have not

${ }^{213}$ To compensate for this imbalance the International Trade Centre (ITC) was established already in 1964. The ITC is a joint institution under the aegis of GATT (now WTO) and the United Nations Conference on Trade and Development (UNCTAD) and provides trade related technical assistance to developing countries (Jackson, 1969). Also the WTO Secretariat can provide legal assistance to developing countries if this is requested, but needs to do so in an impartial manner (Van den Bossche \& Zdouc, 2017). Additionally developing countries can seek support from external sources, such as the Geneva based Advisory Centre on WTO Law (AWCL).

${ }^{214}$ For an overview of suggestions and arguments exchanged, see MTN.GNG/NG13/W/27/Rev.1.

The DSU contains provisions that take the development status of disputing parties into account. However, these provisions fall short of the suggestions made during the Uruguay Round. Most of these provisions are relatively soft and some commentators argue that they are not sufficiently institutionalized (Van den Bossche \& Zdouc, 2017).

215 See for example: MTN.GNG/NG13/6; MTN.GNG/NG13/17; MTN.GNG/NG13/18; MTN.GNG/NG13/W/43 
been addressed at the panel stage. This was a design feature that was apparently commonly agreed upon in the negotiation group on dispute settlement and consciously inserted as a control mechanism. ${ }^{216} \mathrm{~A}$ statement by a US negotiator who participated in the DSU negotiations confirms this:

\begin{abstract}
"The Appellate Body does not have the jurisdiction to go back and look at the facts of the case again. All it can do is to look at issues of law and interpretation; because that is what we wanted. We did not want it to get back and look at the whole case again. We wanted to ensure that it is good law that came out of the case. Setting limits to the Appellate Body was important for negotiators." (Int09)
\end{abstract}

In hindsight it is clear that setting such limits was only partially successful. As it has been pointed out in sections 4.4.4 and 4.5.3.1 designers underestimated the impact of reforms and especially the prominence of the Appellate Body in the new system. This leads some commentators to claim that designers have not been successful in forestalling judicial activism. However, this does not imply that control mechanisms did not figure prominently on negotiators' minds at the time. Their design was simply tared to a different set of expectations.

Another facet of control features for the instances of centralization consists of review procedures. As it has already been explained in section 4.5.3.1 the core motivation for the establishment of the Appellate Body itself was to serve as a quality control mechanism for panels. This became the more appealing to designers the more likely it got that the introduction of reverse consensus would reduce the direct individual control disputing parties would have over panels. In the same vein an additional control feature was institutionalized. In the context of the reinvigorated discussion about the introduction of a review mechanism that occurred in fall 1989 and that eventually triggered the emergence of the Appellate Body, it was also suggested to institutionalize and formalize the production of interim panel reports. ${ }^{217}$ According to this proposal a panel would provide the disputing parties with a full draft of its report. The disputing parties would have the possibility to comment on the draft. The panel in turn would decide whether and how to take such comments into account and then submit the final report to the Council. This suggestion was initially presented as an alternative to the introduction of an appeals review, but was quickly endorsed as an additional control feature to protect regime members from poor panel reports. ${ }^{218}$

A final way for WTO members to control the instances of delegation is by influencing the selection of panelists and Appellate Body members. Control in this regard is possible ex ante and ex post. Ex ante control can be exerted during the appointment procedures of panelists and

${ }^{216}$ MTN.GNG/NG13/W/40; MTN.GNG/NG13/W/41; MTN.GNG/NG13/W/43; MTN.GNG/NG13/W/44

${ }^{217}$ MTN.GNG/NG13/17

The practice of circulating interim reports had been established before, but was regarded as problematic, because these reports where limited to factual, descriptive sections and therefore did not give parties the possibility to review the legal arguments of a panel before the final report was discussed in the Council.

218 MTN.GNG/NG13/19; MTN.GNG/NG13/W/40; MTN.GNG/NG13/W/41; MTN.GNG/NG13/W/42; MTN.GNG/NG13/W/43 
Appellate Body members. This allows parties to select agents that are assumed to have similar attitudes and preferences to their own (Hawkins et al., 2006). Regarding the composition of panels, the Uruguay Round has led to a streamlining of this procedure and the Secretariat is allowed to suggest which persons should serve on a panel. Nonetheless, disputants can still exert influence on the composition of a panel by rejecting the nominees that are suggested by the Secretariat. Although Article 8.6 of the DSU specifies that this should only happen when parties have compelling reasons to do so, disputants regularly reject panel members without providing much justification (Van den Bossche \& Zdouc, 2017). The Director General is only allowed to intervene and decide on the composition of a panel when being requested to do so by one of the disputing parties.

Also the selection of Appellate Body members constitutes an opportunity for the WTO's members to exert control. This opportunity has become more important over the years (Elsig \& Pollack, 2014; Shaffer et al., 2016). While WTO members initially selected candidates based on judicial expertise, with a rising concern of judicial activism by the Appellate Body, WTO members increasingly try to select candidates that are assumed to closely resemble their own preferences and attitudes regarding sovereignty and limitations on the WTO's judicial branch (Elsig \& Pollack, 2014). To screen candidates for their preferences the most influential WTO members interview candidates, read their previous publications and examine their past judicial decisions if applicable (Elsig \& Pollack, 2014; Steinberg, 2004). Thus ex ante control is an important design feature for delegation of dispute settlement.

Additionally ex post control is also an option. This is provided for by the 'Rules of Conduct for the Understanding on Rules and Procedures Governing the Settlement of Disputes'. According to the rules of conduct disputing parties can request the disqualification of panelists or Appellate Body members if they assume a violation of these rules by these persons (Van den Bossche \& Zdouc, 2017). The rules of conduct demand panelists and Appellate Body members to be independent, impartial, to avoid conflicts of interests and to respect confidentiality proceedings.

Furthermore WTO members can refuse to reappoint an Appellate Body member. According to Article 17.2 of the DSU the term of Appellate Body members is limited to four years and can only be renewed once. Clearly this design feature was introduced to hold the members of the Appellate Body accountable (Elsig \& Pollack, 2014). It is criticized that this relatively short term limits the independence of the Appellate Body's members and makes them vulnerable to the favor of the membership (Steger, 2004, 2015; Unterhalter, 2015). While this is true and problematic from a judicial perspective, from a political perspective it might be exactly the control feature designers wanted to insert in the system.

The selection of Appellate Body members does not only constitute a design feature to control the institution, but also one that reflects asymmetry of control. This is indicated by the fact that the most influential members in the trade regime have a larger informal influence on the selection of Appellate Body members than less influential ones (Elsig \& Pollack, 2014; Steinberg, 2004). Furthermore the US, the European Union (EU) and Japan as the most influential parties at the time of the Uruguay Round informally assured that each of them would 
get one seat on the Appellate Body (Elsig \& Pollack, 2014). The importance of relative influence for powerful parties is also underlined by the fact that the EU and the US even asked for more seats on the Appellate Body. When the first seven members of the Appellate Body were chosen in 1995 the EU and the US demanded that each of them could reserve two seats for their candidates (Elsig \& Pollack, 2014; Steger, 2015; Stoler, 2008). Apparently the EU even threatened to block the selection of the first Appellate Body when this demand met strong opposition (Steger, 2015). However, when the US eventually retreated from this demand the EU followed suit (Elsig \& Pollack, 2014). To nonetheless ensure that the views of their candidates would not be ignored in any given dispute, the US and the EU insisted that disputes would be considered the Appellate body 'en banc' (Stoler, 2004). This was incompatible with the DSU, which provides for only three Appellate Body members to serve on a particular case (Art. 17.1). However, in response to the sensitivity of the two most influential members of the regime the Appellate Body developed a collegial approach that ensures that for each dispute all of its members exchange their views on the dispute (Stoler, 2004). This episode shows that even in dispute settlement as a functional domain that champions independence and impartiality, considerations of symmetry are relevant when designing control features. The same holds for the last set of design elements related to control.

\subsubsection{The Impacts of Dispute Settlement: Control over Domestic Implementation}

Control cannot only be expressed with respect to institutional bodies, but also with respect to the legal effect of the results of the dispute settlement procedure. In this respect the notion that countries are ultimately in control of the implementation of the outcomes of procedures was a decisive design element that permitted the reform of the dispute settlement system and that reflects the impact of asymmetry in the system most strongly.

Ultimately the WTO's members can control how they want to handle the outcomes of a dispute settlement. Although the results of the dispute settlement process are binding as a matter of international law, in most countries such results do not have a direct effect (Goldstein \& Steinberg, 2008). Thus a losing party in a dispute does not necessarily have an obligation to change its laws to conform to a panel's or the Appellate Body's recommendation. Clearly, conforming to the result of a dispute by changing domestic legislation is the preferred outcome of dispute settlement (DSU, Art. 21.1), but the DSU also allows for the provision of compensation or the withdrawal of concessions as temporary remedies (Art. 22.1). Consequently members are free to decide whether and how to change laws to comply whit the results of dispute settlement procedures (Jackson, 1997; Sarooshi, 2005; Steinberg, 2004). ${ }^{219}$

\footnotetext{
${ }^{219}$ In case of non-violation complaints there is even more control over the implementation of results, since panel and Appellate Body recommendations are not automatically binding for these kind of disputes (DSU, Art. 26). Apparently for the $\mathrm{EC}$ this was an important negotiation outcome, since it was afraid of agricultural nonviolation complaints at the time of the Uruguay Round (Elsig \& Eckhardt, 2015).
} 
Maintaining this sort of control was crucial to ensure the reform of the dispute settlement system and the emergence of the WTO. If it would not have been present, it is unlikely that the US Congress would have agreed to the outcome of the Uruguay Round. During the debate on the WTO Agreement Congress was reassured that the WTO could not force the US to change its laws and that non-compliance would always remain an option (GAO, 1994; Jackson, 1997). The implementing bill of the WTO agreement even included an explicit provision that confirms that the WTO agreement does not override federal or state law (Porges \& Price, 2005).

Of course if a country chooses not to comply with the outcome of a dispute settlement procedure it needs to be ready to bear the costs, either by providing compensation to the injured party or by facing retaliation. Due to the introduction of reverse consensus decisions on these remedies cannot be blocked any longer. However, even these remedies contain elements of control. The losing party of a dispute can still influence the amount of compensation to be paid as this is to be negotiated amongst the disputing parties (DSU, Art. 22.2). Regarding the withdrawal of concession, the losing party can resort to arbitration if it is dissatisfied with the level of concessions withdrawn (DSU, Art 22.6-7). Furthermore, especially for large members the withdrawal of concessions can constitute a relatively low price to pay when being in a dispute with a small member, since the impact of retaliation is contingent on market power.

This allows WTO members to play on time as another means to control implementation of dispute settlement results. When the domestic situation would not allow to comply with recommendations or such compliance would be politically prohibitively expensive, WTO members can buy time by dealing procedures, providing compensation or accepting retaliation until a more opportune moment for compliance occurs (Shaffer et al., 2016; Stone, 2011). In the meantime economic circumstances might even change in such a way that compliance is essentially free of any costs and political goals are achieved, because the delay has led the market to adapt already (Shaffer et al., 2016; Stone, 2011). Furthermore, the flexibility in determining how compliance is conducted allows a WTO member to comply without a real effect, because the act of compliance can be offset with another policy (Shaffer et al., 2016).

The fact that the ultimate means to induce compliance is withdrawal of concessions is also the clearest exemplification of asymmetry of control in the dispute settlement system. The severity of retaliation is ultimately a function of market power. Countries with a larger market share are hit less hard when being retaliated against by a country with a small market and vice versa. Retaliation can also be self-defeating, as it might even be the case that a country with a small market might hurt its own market more than the one of the country it retaliates against. Smaller countries are also in a worse position when negotiating compensation and are less well suited to make use of the abovementioned delay tactics. Ability to retaliate can apparently already influence a county's decision whether to launch a complaint (Stone, 2011). In this context it might be surprising that despite the difference in retaliatory capacity, compliance with the outcomes of dispute settlement is reasonably high (Stone, 2011). Nevertheless, the Uruguay Rounds negotiation history suggests that this element of asymmetry was an institutional feature that the most influential parties wanted to keep. Suggestions by developing countries to level 
the playing field, such as the introduction of collective retaliation, or the idea to let panels determine the amount of compensation and to make compensation a legal requirement, were opposed and did not make it into the text of the DSU. ${ }^{220}$

\subsubsection{Conclusion}

The dispute settlement system represents the judicial function of the trade regime. The purpose of such a function is usually to facilitate the implementation and enforcement of substantive provisions that result from legislative processes. As such impartiality and independence are beneficial features of dispute settlement systems. In this context it is not surprising that the WTO's dispute settlement procedure entails less stringent design features of control than its legislative procedures. Yet, looking at the dispute settlement system as a complex formation of interdependent design sets highlights how important the interaction of centralization and control is in empirical manifestations. Especially the introduction of reverse consensus constituted a remarkable reduction of control and a corresponding increase of centralization. Nonetheless, designers were still concerned about control and sought to counterbalance the loss of it that was brought about by the introduction of reverse consensus with other institutional design features. In the current setup of the system such features take a variety of forms: quasi-automatic decision-making in the DSB is counterbalanced by tight control over legislative processes; mandates of the DSB, panels and the Appellate Body are limited; the system is supposed to stay member driven by limiting access to governments; initially design changes were temporary, subject to review, and withdrawal from the WTO always remains an option of last resort; panel reports are reviewed by disputants and the Appellate Body; WTO members can influence the selection of panel and Appellate Body members; and finally implementation of results is flexible, leaving the WTO's members ultimately in control whether and how to implement the outcomes of a dispute settlement procedure.

In the design of these features considerations of controlling the autonomy of the institution were more important than representing asymmetry. Nonetheless, the composition of the Appellate Body, the circumstance that demands to strengthen special and differential treatment for developing countries were only included in the DSU to a limited extent, and the fact that the system ultimately leaves enforcement capability contingent on market power indicate that considerations of relative influence were still relevant in the design of the system.

Overall, the design interaction of centralization and control represented by the dispute settlement system as an institutional arrangement of interdependent design sets indicates the strength of the system and its relative autonomy. The large degree of centralization was not necessarily intended as already explained in section 4.4.4, but this section has shown that considerations of maintaining control were nonetheless important during the design process.

\footnotetext{
${ }^{220}$ For an overview of suggestions and arguments exchanged, see MTN.GNG/NG13/W/27/Rev.1.
} 


\subsection{Conclusion}

The reform of dispute resolution that resulted from the Uruguay Round constitutes a significant change of institutional design. In a 'legalization leap' centralization increased and control decreased significantly. As a consequence, dispute settlement in the multilateral trade regime got significantly strengthened. It changed from a relatively soft system, susceptible to political influence where parties had the right to be the judge in their own case, to a highly sophisticated judicial one with quasi-automatic, court like procedures.

In deconstructing this system, it becomes clear that a combination of several design features are responsible for this change. When interpreting centralization generally, it is apparent that several core features of dispute settlement ensure that the WTO is regarded as a stronger focal entity that induces members more to settle disputes multilaterally than the GATT did. These core features include compulsory and exclusive jurisdiction, as well as the unification of the system. On a more specific institutional level the establishment of the DSB resembles an increase in centralization as pooling. On centralization as delegation, the degree of centralization increased because the introduction of reverse consensus decreased control over panels and the Appellate Body. At the same time the streamlining of the panel procedures and the establishment of the Appellate Body constitute instances of centralization as delegation on their own. All these design features are interdependent and together they constitute a complex arrangement of nested institutional design sets that ensure the strength of the system.

In light of the regime's institutional history, with its emphasis on approaching disputes diplomatically, naturally high sovereignty concerns of states acting in the international arena, and significant preference heterogeneity during the Uruguay Round the strengthening of the system constitutes a theoretical and empirical puzzle. To explore this puzzle, the chapter has sought to analyze how this remarkable change came about.

This was done by analyzing the merits of functional explanations, by embedding the change in the regime's institutional history, by tracing the negotiation process of the Uruguay Round, and by examining how centralization and control interacted to bring about the design sets that constitute the dispute settlement system as we currently know it. Each of these approaches provided valuable insights to find out how the reform of the dispute settlement system was brought about.

Functional explanations such as the ones provided by the rational design framework offer a powerful analytical starting point by accurately identifying the core motivation for reform: the desire to improve the system and to overcome its shortcomings. However, such an approach shows weaknesses when being faced with the preference heterogeneity that characterized the negotiations with respect to the kind and degree of reform that was envisaged. The approach also is not well able to capture the negotiation dynamics that unfolded from such heterogeneity and any additional design features resulting from this. As such, it helps to explain general trends, but not how institutional design would be constructed in detail. Finally, purely functional 
approaches would face challenges when having to explain why institutional change was possible as a result of the Uruguay Round and not during early reform attempts, despite similar functional problems in both settings. In short, functionalism is a powerful analytical tool when employed on a high level of abstraction, but falls short when a more nuanced and detailed account on the dispute settlement reform is required.

Embedding the Uruguay Round in the historical development of the dispute resolution in the multilateral trade regime helps to get such a more detailed account and highlights additional explanatory factors to understand the dynamics of institutional change. Such an exercise shows that designers often try to find functional responses to problems they perceive, but that they regularly do so in a bounded rational manner. This ensures that institutional change is more often incremental and follows a previously established path than it is a revolutionary act of a single grant moment of institutional design. In this respect the Uruguay Round can be regarded as a tipping point that added significant new features to a well-established system, which had incrementally developed. In adding these significant new features path dependency continued to be influential by leaving an impact on the cognitive scripts of designers. Influenced by more than 40 years of experience with the diplomatic judicial culture in the GAT, designers underestimated the degree of change and the rigorous legalistic culture it would bring with it. This insight needs to be taken into account to get a full understanding of the change in dispute settlement. If this is not done post hoc functionalist explanations would overestimate impact of the functional motivations of change. To a certain extent designers simply did not have the intention to create the degree of centralization that they did. Yet, adding the historical approach to functional explanations is still insufficient to get a full explanation of the reform in dispute settlement. For this, it is necessary to trace the actual negotiation process.

This kind of process tracing clarifies how it was possible to overcome interest heterogeneity and highlights that many specific design features emerged from the wider negotiation dynamics that characterized the Uruguay Round. Only the procedural improvements of the panel process which were characterized by low risk - due to historical familiarity with them -, limited costs and preference homogeneity can be fully explained by a functionalist account embedded in institutional history. The introduction of reverse consensus in turn entailed a high risk, considerable sovereignty costs and designers had heterogeneous preferences regarding the desirability of this reform. The fact that dominant actors in the negotiations expected to strongly benefit from the new substantial agreements resulting from the Uruguay Round was a precondition for this institutional change. Furthermore the US' dominant position and its ability to force those negotiating parties that were initially opposed to an reform of decision-making to change their negotiating position in favor of more centralization was the decisive factor to permit the introduction of reverse consensus. The dynamics unfolding from this constellation in turn facilitated the emergence of compulsory and exclusive jurisdiction, lead to the unification of the system, and ensured the creation of the DSB and the Appellate Body.

Despite the dynamics of a reform towards a significant strengthening of the system, considerations of control nonetheless remained important. Designers used a variety of 
institutional design features that were aimed to ensure control of the system and that slightly resemble the asymmetry of membership in the trade regime. Attention to considerations of control completes the picture and allows to understand the detailed setup of the dispute settlement system as a complex arrangement of nested institutional design sets.

Given all the different insights derived from the various perspectives, some general conclusions can be derived from the increase in centralization that resulted from the Uruguay Round. First of all, in comparison with the WTO's legislative features, its judicial features are more suitable to be analyzed by functionalism. Considerations of controlling the organization and representing symmetry of membership in control features are less prominently represented than the desire to design a functional means to enforce substance. This confirms the argument that institutional design consists of two steps - first negotiating an agreement on substance; then, bargaining how this substance is to be enforced - where the former step is usually more controversial than the latter. Tracing the motives of designers' highlights that functionalism is a powerful explanatory framework for design features related to enforcement as it correctly identifies the core motivation to pursue the reform of dispute settlement in the Uruguay Round. Yet, while this is necessary, it is not sufficient. Because, secondly, the dynamics of change are more often incremental than they are revolutionary. The history of the GATT exemplifies this. Thirdly, significant revolutionary change can only be brought about when the negotiated substance is expected to be highly beneficial to the most powerful actors in the regime. This explains why the US was strongly in favor of a quasi-automatic unified dispute settlement system. Fourthly, even then, change is only possible when those in favor of change are powerful enough to overcome opposition to change in case interests are heterogeneous. This is exemplified by the US' successful resort to aggressive unilateralism during the Uruguay Round a strategy not available at the time of the Tokyo Round when reforms fell short of expectations. Fifth even if change is brought about actors try to limit risks by designing control features. Sixth, bounded rationality is a more plausible assumption than full rationality and has real implications for institutional change. This is exemplified by path dependency and by the fact that change can lead to unexpected consequences. In the case of the Uruguay Round the fact that the consequences were unexpected is likely to have led to a higher degree of centralization than initially anticipated.

To sum up: functional explanations, like those provided by the rational design framework, account for the core motivation to increase centralization in dispute settlement, but the degree of centralization and the exact institutional design can only be explained by power asymmetries and historical context respectively. 



\section{Transparency in the Trade Regime: The Emergence of the Trade Policy Review Mechanism}

$\begin{array}{lll}5.1 & \text { Introduction } & 274\end{array}$

5.2 The Case as a Matter of Centralization and Control 277

$\begin{array}{lll}\text { 5.2.1 General } & 277\end{array}$

$\begin{array}{lll}5.2 .2 & \text { Pooling } & 278\end{array}$

$\begin{array}{ll}5.2 .3 & 279\end{array}$

5.3 Explanations of Rational Design 282

5.3.1 The Underlying Rationale (Theoretical Plausibility) 282

5.3.2 The Emergence of the Idea and its Rationale (Empirical Plausibility) 284

5.4 Design in Context: Historical Legacy 291

5.4.1 Providing Information and Facilitating Transparency in the ITO 291

5.4.2 Providing Information and Facilitating Transparency in the GATT 293

5.4.3 The Impact of History on the Uruguay Round Negotiations 299

5.5 Negotiating Design: Process and Dynamics 301

5.5.1 Reviewing General Developments, Notifications and Domestic Transparency 301

5.5.2 Individual Member Review 303

5.5.2.1 The Nature of Reviews: Scope and Strength of Conclusions 304

5.5.2.2 The Institutions and Procedures of Review 308

5.5.3 Conclusion: Balancing Design and Reaching Agreement 312

$\begin{array}{lll}5.6 & \text { Conclusion } & 314\end{array}$ 


\subsection{Introduction}

The emergence of the Trade Policy Review Mechanism (TPRM) is another instance of significant institutional change that emerged from the Uruguay Round. This is often overlooked, which might be related to the circumstance that the TPRM was established already after two and a half years of the negotiations. As such it had been in place for almost four years already by the time that the Uruguay Round closed and did not get the publicity that the establishment of the WTO with its reformed dispute settlement system enjoyed. Indeed, in comparison to the reforms in dispute settlement and the emergence of a new international organization it is tempting to neglect the importance of the TPRM. However, this would be mistaken.

The TPRM gathers and disseminates information about trade policies and practices and is thereby the trade regime's principal transparency instrument. Transparency in turn is a fundamental basis for a well-functioning trading system. It allows markets to function more effectively by providing actors in the trade regime with the information about trading partners' policies and practices that is necessary for a smooth functioning of international transactions. It reduces uncertainty and information asymmetries, provides reassurance of what others are doing and thereby enhances predictability. Furthermore, transparency can also facilitate adherence to international trade regulations by exposing policies to public scrutiny - both, by domestic as well as international audiences (Collins-Williams \& Wolfe, 2010). In short, transparency is a crucial pillar of international trade (Laird \& Valdés, 2012).

Given this general importance of transparency, it is evident that the trade regime's function to facilitate transparency and related institutional mechanisms are highly important, despite the fact that they are probably the least discussed (Ghosh, 2010). In allusion to the common attribute of the far more popular dispute settlement system Wolfe and Mavroidis (2015) even posit, that transparency mechanisms might be the 'real jewel' in the WTO's crown. In this respect it should not be underestimated how significant the emergence of the TPRM was in comparison to previous GATT mechanisms aimed at enhancing transparency. According to Price (1992) the TPRM provided the trade regime for the first time with a standing general monitoring device. For Abbott (1992) the establishment of the TPRM even constituted the clearest example of the trade regime's institutions starting to be equipped with more agencies to promote a common goal, making "inroads on the autonomy of the contracting parties, the institutional weakness of GATT, and, to a limited extend the horizontal nature of dispute settlement and enforcement" (p. 68). With the establishment of the TPRM the multilateral trade regime was for the first time equipped with the explicit authority to regularly and systematically review the trade policies and practices of its individual members.

The members of the trade regime generally value the activities conducted under the TPRM. By providing information that facilitates a smooth functioning of the trade regime the TPRM constitutes a public good that is especially useful for smaller regime members who might not have the resources to gather such information themselves (Keesing, 1998; Laird \& Valdés, 2012). 
Furthermore, by providing information on how a particular regime member behaves it is also useful as a means to facilitate adherence to international rules and keep protectionism at bay, because it allows other members to exert peer pressure. Further than that, even for the member under review itself the review can be a beneficial experience. It allows for a moment of self-reflection, including a coherent reexamination and reevaluation of trade policies (Boonekamp, 2009; Keesing, 1998; Laird, 1999). ${ }^{1}$ Additionally, the review allows a member to justify its trade policies and to highlight positive developments (Keesing, 1998). Finally, for developing countries a review can be a good way to gather experience with and confidence in the WTO, to learn, and to identify in which policy areas further technical assistance is necessary (Boonekamp, 2009; Laird, 1999). Given these benefits it is hardly surprising that the WTO's membership evaluated the TPRM positively in its regular appraisals of the mechanism (Boonekamp, 2009). ${ }^{2}$

How did this often neglected, but nonetheless crucial institutional feature of the trade regime came about? This is the question this chapter seeks to answer. In doing so it is found that the functional explanations of rational design provide a highly adequate account of the TPRM's emergence. The institutional context provided by the trade regime's previous historical development supplements this account, but in comparison to the establishment of the WTO and the reforms in dispute settlement it had only a moderate impact. Also tracing the negotiation process of the TPRM reveals that major additional factors, such as the power plays that characterized the organizational and dispute settlement negotiations, were largely absent. In a largely rational design process negotiators tried to balance the functional benefits of a multilateral transparency mechanism while keeping its costs limited, and sought compromises were interests diverged. Possible explanations for the adequacy of rational design as an analytical account can be found in the relatively low sovereignty costs of the mechanism as well as in its largely non-distributive character. As it was put in the section that elaborated on the procedural changes to the panel process in dispute settlement reform, it seems that the combination of homogenous interests, low costs and limited risk provides fertile soil for functionalism within the parameters set in a given institutional context.

The chapter derives these insights in the following manner. At first, the institutional structure of the trade policy review mechanism is further elaborated on and it is explained in what ways the mechanism constitutes a design set of centralization and control. In this section it is shown that the establishment of the TRPM should indeed be regarded as an increase in centralization in comparison to previous GATT practices, albeit at a relatively low degree due to its limited mandate. Secondly, the plausibility of rational design as an explanatory account for the TPRM's emergence is tested. This is done by analyzing how the setup of the mechanism fits

\footnotetext{
${ }^{1}$ Given that policies are often developed ad hoc by different agencies and ministries at different points in time, the value of such coherent reflection should not be underestimated (Keesing, 1998).

${ }^{2}$ It should also be pointed out that next to these benefits for the trade regime's membership, the TRPM also provides a valuable source of information to outsiders, such as businesspeople and academics (Keesing, 1998; Laird, 1999).
} 
the theoretical assumptions of functional accounts and by examining the core motivations of institutional designers. Clearly, these motivations correspond to functional theoretical assumptions. The third and the fourth section seek to rule out the presence of alternative explanatory factors. In the third section this is done by embedding the TPRM in the historical development of transparency mechanisms in the trade regime. This shows that traces of path dependency are present but limited. In the fourth section the negotiation process of the TPRM is traced to examine whether other factors beyond the core functional motivation significantly impacted the emergence of the TPRM. In contrast to the emergence of the WTO and the reform of dispute settlement such factors are largely absent and only left a minor impact on the negotiations. The process tracing shows though that devising a design set that balances the benefits of centralization with sensible control features was important to designers. At the end a concluding section reflects on the main insights derived throughout the chapter. 


\subsection{The Case as a Matter of Centralization and Control}

Clearly the establishment of the TPRM constitutes a remarkable increase in centralization regarding the trade regime's transparency function. Although this function had always been part of the regime, the TPRM is its most institutionalized manifestation (Ghosh, 2010). The TPRM's provisions contribute to this increase on all of its three dimensions: general, as pooling and as delegation. Each of them is briefly discussed in the following.

\subsubsection{General}

The provisions of the TPRM are contained in Annex 3 of the WTO agreement and entail several design features that strengthen the WTO as a focal entity for the collection, analysis and dissemination of information about policies and practices in the multilateral trading system. The heart of the TPRM and the most significant innovation the Uruguay Round brought about are the provisions for regular, systematic reviews of members' trade policies and practices. According to these provisions each member of the WTO is subject to a policy review according to a fixed interval. The intervals vary depending to a member's share of world trade. The original agreement of the TPRM stipulates that the four members with the largest share in world trade were to be reviewed every two years, the next 16 were to be reviewed every four years, and the rest in an interval of six years. ${ }^{3}$

The reviews themselves are conducted by the Trade Policy Review Body (TPRB) and take the form of a discussion about the trade policies of the member under review. The input for the discussion is provided by two reports. One is produced by the member under review; the other one is produced by the Secretariat. These reports as well as the minutes of the actual review meeting in the TPRB are made public after the review meeting.

Next to this individual country review, the TPRM entails three more, but slightly less prominent features that contribute to an increase the WTO's role as a focal entity for providing information about trade policies. First of all, the TPRB is mandated to annually review general developments that have an impact on the multilateral trading system. These reviews are supposed to be conducted based on a report by the Director General. The practices of reviewing general developments in the trade regime had already been established in the GATT throughout the 1980s, but its inclusion in the TPRM implies that it was firmly institutionalized. Secondly, the TPRM entails a reporting requirement. This requirement does not only call upon members to provide full reports when they are under review, but also to provide brief reports whenever they

\footnotetext{
${ }^{3}$ In light of limited resources of the WTO's Secretariat the TRPM was amended in 2017 and the intervals were changed to three, five and seven years respectively (WT/L/1014).

To accommodate for possible difficulties that least developed countries' might face due to capacity limitations the TPRM allows that such countries may be reviewed in longer intervals.

Furthermore the TPRM allows for bringing a review forward in case a member's policies or practices are changed in such a way that it might have a significant impact on the member's trading partners.
} 
significantly change their trade policies. Thirdly, the TRPM entails a political, non-binding commitment by members to recognize the value of domestic transparency of trade policies and calls upon members to promote transparency within their own domestic systems. Although this commitment might be weak due to its voluntary nature, it is a genuinely new provision that the GATT lacked.

The TPRM clearly constitutes an increase in centralization since it is the first time in the trade regime's history that the institutions of the regime are granted the authority to take an active, regular role in monitoring individual country's trade policies. As remarkable as this is, it needs to be acknowledged though that designers deliberately kept the degree of centralization moderate by limiting the mandate of the TPRM. While the mechanism aims to facilitate adherence to the substantive provisions of the multilateral trade regime it is not supposed to be a means to directly enforce legal obligations. According to section A(i) of the TPRM the mechanism is not "intended to serve as a basis for the enforcement of specific obligations under Agreements or for dispute settlement procedures, or to impose new policy commitments on members." Furthermore, designers kept the mechanism under control by only establishing it on a preliminary basis at first, and when the mechanism was made permanent they introduced that it would have to undergo an appraisal in regular intervals (Section G, TPRM). ${ }^{4}$ Overall, it can nonetheless be concluded that the TPRM makes the WTO a more prominent focal entity to provide information and facilitate transparency than the GATT used to be. This does not only hold from a general perspective, but also with respect to the more specific institutional structures in charge of the provisions of the TPRM.

\subsubsection{Pooling}

The TPRB is the principal body in charge of the TPRM. Although other bodies in the trade regime gather information about members' specific trade policy and practices as well, the TPRB represents an instance of centralization as pooling in so far as it is the only body that conducts comprehensive reviews of all aspects of trade policy by the entire membership of the WTO (Keesing, 1998). The importance members ascribe to the TRPB is represented by its standing as a senior body at the top of the WTO's general institutional structure. Just as the DSB, the TPRB is the alter ego of the General Council and has the same membership, represented at a senior level. However - just as the DSB - it annually elects its own chairperson. Generally, the TPRB serves as a forum in which information and concerns are exchanged, and trade policies discussed and explained. It is regarded as one of its strengths that it does this in an nonconfrontational, non-legalist manner (Laird, 1999; VanGrasstek, 2013). The TPRB meets regularly according to an annual plan that it adopts itself.

These meetings are key to the actual review process (Price, 1992). They aim to be a fair and non-confrontational way to discuss and clarify trade policies of a particular WTO member, but

\footnotetext{
${ }^{4}$ The first appraisal had to be held within the first five years after the TPRM's establishment. Thereafter appraisal intervals are to be determined by the Ministerial Conference.
} 
can also be used to exert peer pressure. ${ }^{5}$ Each meeting usually takes place in two sessions. The first session is opened by an introductory statement of the chairperson, followed by a statement of the representative of the member under review. To ensure a substantial review another member's delegate acts in personal capacity as a discussant, whose task it is to trigger a discussion by making the first comments and asking the first questions after the member under review has finished its statements. After this, other members can raise questions and make comments. Some members submit their questions to the member under review in advance and are given priority in this part of the meeting. After all interested members have made their statements the first session ends. The second session usually takes place two days after the first. This allows the representative of the country under review to prepare replies to the questions raised in the first meeting. The second meeting starts with the member under review delivering the prepared replies. Afterwards other members are given the chance to ask for clarification and to raise further questions. At the end of the second meeting the chair presents concluding remarks that are supposed to represent the views expressed during the meeting. The member under review has up to one month after the review to address all questions that were left unanswered during the meeting in writing.

In terms of control it is important to point out that the review does not conclude with a formal decision of the TPRB or with recommendations on actions that the member under review should take. Despite this lack of decision-making power, the TPRB nonetheless indicates an instance of centralization as pooling since it constitutes a high-level institutional body that is solely dedicated to ensure that information is gathered and transparency is facilitated in a coherent manner. To allow the TPRB to fulfill this function successfully it is assisted by the Secretariat.

\subsubsection{Delegation}

Without the support of the Secretariat it is unlikely that the TPRM would function successfully and the increase in centralization as delegation that the Uruguay Round brought about is significant. As VanGrasstek (2013) puts it: "The TPRM is the premier example of a function in which the members have vested greater responsibility in the WTO Secretariat than they had been willing to cede to its GATT predecessor" (p. 280). Additionally it should be pointed out that the Secretariat's role in the TPRM is larger than in most other functional areas covered by the WTO (Elsig, 2010b).

The Secretariat's Trade Policy Review Division (TPRD) plays an important role in gathering the information for the reviews. Based on this it produces a report that is used during the actual review meeting in the TPRB, alongside the report that is produced by the reviewed member. Initially the member's and the Secretariat's report where approximately equal in length and detail. Over the years the members' reports have become shorter and have taken the form of general policy statements (Benzing, 2006; Laird, 1999). The Secretariat report has thus become

\footnotetext{
${ }^{5}$ The following description of the process is based on the work of Laird and Valdés (2012).
} 
the backbone of the review process, providing detailed information on a wide range of a member's relevant policies and practices.

The text of the TPRM does not specify in great detail how the Secretariat report is to be produced or what it should entail. As such the Secretariat enjoys wide discretion in gathering information (Bohne, 2010). It uses information on policies reported by members in response to the various WTO notification requirements, reports from other international organizations and academic articles. The Secretariat also requests information from members in form of a questionnaire, and visits the member under review to meet with government officials, representatives of industry and academics to collect further information (Benzing, 2006; Laird \& Valdés, 2012). It needs to be acknowledged though that the Secretariat has no powers to subpoena information from a member, leaving a member ultimately in control over the information it provides. If a member does not want to share information on trade policies and practices it does not have to. This is important to the membership and it makes use of this possibility. ${ }^{6}$ Of course this constitutes a limit to the Secretariat in its ability to gather information, but when the Secretariat encounters such difficulties it notes this in its report. Overall the cooperation between the members and the Secretariat is working well though (Laird \& Valdés, 2012).

The Secretariat also has some discretion to analyze a member's policies and practices with respect of their impact on international trade in its report (Benzing, 2006). However, in doing so the Secretariat is cautious in assessing policies and making a value judgment. ${ }^{7}$ The analytical part of a report is usually rather short and the focus of the report lies on the facts (Bohne, 2010). When members feel that a report is getting too critical they complain about this (Bohne, 2010). Especially in the early years of the TPRM the relatively neutral character of the report has been criticized by several commentators who claim that a more rigorous and specific analysis by the Secretariat would be beneficial for the smooth conduct of international trade (Keesing, 1998; Laird, 1999; Laird \& Valdés, 2012; Mavroidis, 1991-1992; Qureshi, 1990, 1992). Yet, it should be kept in mind that equipping the Secretariat with the authority to independently gather information about members' policies and practices in preparation of reviews was a significant break with the past at the time that the TPRM was created and in comparison with the very early reports the tone of the reports has already become slightly more daring (Laird, 1999).

Furthermore, it is at the Secretariat's discretion to determine the structure and the exact scope of its report (Benzing, 2006; Bohne, 2010). It is not clarified which exact areas of trade policy the Secretariat report must cover. This provides the Secretariat with the possibility to emphasize certain policies, up to the point that it even includes at times policy areas that are not covered under WTO agreements, such as competition and investment policies (Bohne, 2010). Qureshi (1995) points out that this gives the Secretariat some latitude in setting the agenda of reviews and can imply a form of judgment.

\footnotetext{
${ }^{6}$ This was confirmed in an interview with a former senior official of the TPRD (Int10).

${ }^{7}$ This was confirmed in interviews with former senior officials of the TPRD (Int10, Int12).
} 
Once the Secretariat has drafted its report it sends it to the member under review to comment upon and to check facts. This constitutes another control element in the TPRM. However, ultimately the TPRM establishes that the Secretariat bears the full responsibility for its report and it is therefore at its discretion to what extent it takes the member's comments into account. Overall, it cannot be denied that centralization as delegation has significantly increased in comparison to the past by assigning the Secretariat the responsibility to independently prepare reports; despite the fact that it is kept in check by the membership regarding the approach it takes towards writing reports. 


\subsection{Explanations of Rational Design}

Having shown that the emergence of the TPRM constitutes an increase in centralization, the question can be addressed how this increase came about. Functional accounts serve as a logical explanatory starting point in this respect. The adequacy of these accounts is tested first by evaluating how well their theoretical assumptions fit in principle to the centralization of information gathering and transparency facilitating function of the TPRM. Secondly it is evaluated how well these theoretical assumptions correspond to the real motivations of the designers of the TPRM. It is found that on both tests functional accounts fare extremely well in explaining the emergence of the TPRM.

\subsubsection{The Underlying Rationale (Theoretical Plausibility)}

Collecting, analyzing and distributing information is one of the key functions of international institutions (K. W. Abbott \& Snidal, 1998; Collins-Williams \& Wolfe, 2010; Keohane, 1984). Imperfect information can constitute problems for international cooperation in general and for the trade policy domain in particular. Centralizing the production and dissemination of information in an international organization can be a cost efficient solution to tackle such problems and is particularly advantageous due to the assumed neutrality of such organizations (K. W. Abbott \& Snidal, 1998; Thompson, 2006). In light of this, it is not surprising that information gathering and dissemination fares prominently in all centralization conjectures stipulated by the rational design literature (Koremenos, Lipson, \& Snidal, 2001a). In academic analyses of the TPRM it is possible to find arguments that link the TPRM to the underlying rationale of each of these conjectures.

The first two conjectures on centralization assume an increase in centralization when uncertainty increases (Koremenos et al., 2001a). The types of uncertainty can differ and either refer to uncertainty about others' behavior or to uncertainty about the state of the world. Especially regarding the former, strong arguments exist that suggest why the TRPM suits the dynamic expressed in this conjecture. The starting point of these arguments is that a lack of information in itself constitutes a trade barrier (Jackson, 1969): An exporter lacking information about the relevant regulations in the country to which it wants to export has to operate under significantly more difficult conditions than one who does not lack this information. Centralized information gathering as done in the TPRM is a relatively-cost efficient and reliable way to overcome this problem as it increases transparency, which in turn is an essential prerequisite for the smooth functioning of international markets (Blackhurst, 1991; Laird \& Valdés, 2012; Mavroidis, 1991-1992). The transparency provided by the TPRM increases knowledge at the domestic level about the policies and practices of one's trading partners (Collins-Williams \& Wolfe, 2010; Hainsworth, 1995). It thereby reduces the transaction costs that arise from information deficits (Benzing, 2006). This is especially important in times when economic 
transactions are not solely affected any longer by measures at the border such as tariffs, but more and more by domestic policies (Collins-Williams \& Wolfe, 2010). In this context centralizing the provision of information in contrast to providing it in a non-centralized manner is useful for two reasons. First, the WTO's Secretariat can be regarded as a neutral actor gathering the information, which increases the information's reliability. Secondly, centralized information gathering reduces costs. This is especially advantageous for those members of the regime that face resource constraints, since the costs of acquiring the relevant information individually could be prohibitive (Collins-Williams \& Wolfe, 2010; Ghosh, 2010; Keesing, 1998). According to this line of reasoning the transparency provided by the TPRM is to be regarded as a public good, useful to all economic actors to get a better understanding of the environment they operate in. This in turn is supposed to facilitate good decision-making on trade policies (World Trade Organization, 2007).

Another argument why uncertainty about behavior leads to an increase in centralization that fits the emergence of the TPRM, relates to the interpretation of behavior. The policy dialogue triggered by the TPRM allows policies to be explained and clarified. This reduces the risk of disputes arising due to misinterpreting a trading partner's behavior as a conscious act of rule violation, while it might actually only be an excusable side effect of another policy (CollinsWilliams \& Wolfe, 2010; Ghosh, 2010; World Trade Organization, 2007).

The TPRM can also be related to the conjecture that suggests centralization to correlate with uncertainty about the state of the world. According to this conjecture centralization in information gathering can be a joint response to cost-efficiently tackle this uncertainty (Koremenos et al., 2001a). In line with this the annual reviews of general trends in the trade regime can be understood as such a joint approach to reduce uncertainty about the state of the world.

The third conjecture on centralization links an increase in centralization to an increase in number. This follows a similar logic as the conjectures on uncertainty since it assumes that centralization can be a means to reduce transactions costs that are caused by an increase in regime membership (Koremenos et al., 2001a). The larger the size of the trade regime the more costly and less efficient individual monitoring of behavior becomes, which provides a strong incentive for centralization of information gathering (Ghosh, 2010). The emergence of the TPRM coincides with an increase in the trade regime's membership and the continually updated comprehensive inventory of policy measures that the TPRM provides for reduces the costs of monitoring compliance with the regime's rules (Price, 1992). As such, relating the establishment of the TPRM to an increase in regime membership seems plausible.

The final conjecture on centralization posits that centralization increases with the severity of an enforcement problem. The emergence of the TPRM can be interpreted as a response to an enforcement problem, because there are several ways in which the TRPM is assumed to contribute to rule adherence. First of all, it is generally assumed that an increase in transparency reduces incentives to cheat (Hainsworth, 1995; Price, 1992; Qureshi, 1995). As Gosh (2010) puts it: 
"If there were any chance that deviant behavior would not be spotted, then a state would have an incentive to renege on its commitments if short-term payoffs from defection are greater than the discounted long-term benefits of cooperation. The decision to cooperate or defect is solely determined by the fear of being caught." ( $p$. 423)

The TPRM allows for such deviant behavior to be spotted, and although the TPRM is not linked to dispute settlement and does not serve as a direct means to enforce substantive obligations, it allows the membership of the trade regime to induce compliance by exerting peer pressure (Ghosh, 2010; Hainsworth, 1995; Laird \& Valdés, 2012; Paemen \& Bensch, 1995; Qureshi, 1990, 1992, 1995; VanGrasstek, 2013). This can manifest itself directly during review meetings, but also indirectly, since even the prospect of being reviewed can already exert normative pressure (Benzing, 2006; Qureshi, 1990, 1992). In this context the TPRM's soft way of inducing compliance can be a valuable institutional supplement to dispute resolution, because it might pick up dubious trade practices that members of the regime would not regard as serious enough to bring to formal dispute settlement, but which nonetheless deserve being addressed (Ghosh, 2010; Hainsworth, 1995; Price, 1992).

Furthermore, the increased transparency provided by the TPRM can also lead to greater conformity with the liberal economic norms of the trade regime by influencing domestic policy discussions. Based on a classic public choice argument it is assumed that the domestic beneficiaries of protectionism are better organized and can exert more political pressure than those who bear the costs of protectionism. This is assumed to be the case because benefits of protectionism tend to be fairly concentrated, while costs tend to be dispersed. It is assumed that more transparency leads to more awareness of the costs of protectionist policies leading to a mobilization of public opinion against such policies. This in turn is assumed to stimulate policy reform and to lead to a greater adherence to the norms of the trade regime (Blackhurst \& Hartridge, 2004; Ghosh, 2010; Laird, 1999; Laird \& Valdés, 2012).

In sum it seems that the conjectures of rational design provide a suitable framework to account for the emergence of the TPRM. The question that remains is whether the motivations of the TPRM's designers were really functional in nature as it is suggested by the rational design conjectures. The following section addresses this question.

\subsubsection{The Emergence of the Idea and its Rationale (Empirical Plausibility)}

Tracing the emergence of the idea for the TPRM confirms that that its establishment was indeed largely functionally motivated. The reasoning that was expressed in the run up and throughout the negotiations to justify the strengthening of the GATT's surveillance and transparency function corresponds well to the assumptions of the rational design framework. Particularly the design logics underlying the conjectures that link an increase in centralization to 
increasing uncertainty and to an increase in the severity of an enforcement problem are prominently represented in the discourse that led to the TPRM.

To understand the origins of this discourse it is once again useful to recall the wider economic context in which the Uruguay Round was launched. Latest since the early 1980s the multilateral trade regime was perceived to be in crisis. Protectionism was on the rise and the regime's members increasingly acted outside of the GATT's normative framework. This included the use of so called 'grey area' measures - trading practices that were not necessarily in violation of GATT obligations, but nonetheless ran contrary to the underlying liberal values of the regime (Croome, 1999; VanGrasstek, 2013). At the same time the GATT's existing transparency and information gathering mechanism did not function satisfactorily. The surveillance exercise that was conducted by the Council since the early 80s constituted an improvement in comparison with past practices, but was not regarded to be sufficient. ${ }^{8}$ Also various notification requirements in different parts of the GATT's legal text did not provide an adequate amount of information and the desired transparency, because they were hardly abided by. ${ }^{9}$ Even when regime members provided notification the informational value was limited because the notification system was fragmented and the Secretariat had difficulties to keep track of the incoming notifications (Keesing, 1998; VanGrasstek, 2013). ${ }^{10}$ Already in preparation of the Uruguay Round contracting parties expressed their dissatisfaction with the shortcomings of the existing system and generally agreed that improving the GATT's surveillance function was necessary. ${ }^{11}$

These views where fueled by an influential policy report that analyzed the state of the trade regime in the mid-1980s - the so-called Leutwiler Report (Dunkel, 1987). This report had been produced by an independent group of experts upon request of GATT Director General Arthur Dunkel and was published in 1985. The report strongly influenced the Uruguay Round negotiations in general and those on the TPRM in particular. This is exemplified by the fact that it was regularly referred to by negotiators in official meetings. ${ }^{12}$ In this respect it can be regarded as intellectual blueprint for the negotiations and is consequently a useful starting point to trace

\footnotetext{
${ }^{8}$ On the introduction of this exercise see section 5.4 .

${ }^{9}$ Wolfe and Mavroidis (2015) mention four reasons why countries might not comply with notification requirements. First, they might simply not have the bureaucratic capacity to do so. Secondly, they might be concerned that providing other regime members with information on their policies could trigger disputes or lead to a disadvantage in negotiations. Third, trust between trade delegates in Geneva and other government agencies at home might be missing, hampering communication channels on change in polices that can affect trade. Fourth, it might sometimes no be clear what kind of policies are to be notified and which ones not.

${ }_{10}$ In an interview a former Secretariat member used an interesting metaphor to point towards this problem, by comparing the existing surveillance mechanisms in the GATT to a doctor who only examines single body parts to make a diagnosis, but who never looks at the body in its entirety to understand a problem (Int12).

${ }^{11}$ SR.SOG/6; SR.SOG/10; SR.SOG/11; PREP.COM(86)SR/4; PREP.COM(86)SR/7; PREP.COM(86)W/31

12 SR.SOG/10; PREP.COM(86)SR/7; PREP.COM(86)W/37; MTN.GNG/NG14/3; MTN.GNG/NG14/W/37; MTN.GNG/NG14/14
} 
the underlying rationale of the TPRM. ${ }^{13}$ The report starts out with analyzing the dire situation the trade regime found itself in by the mid-1980s, referring to increasing protectionism and the negligence of GATT rules. ${ }^{14}$ Based on this the report develops several recommendations to the members of the multilateral trade regime. One of the core arguments underlying the report is that more transparency in the trade regime was required to highlight the costs of protectionism. This argument is further elaborated upon in the recommendations that are related to information gathering and transparency.

Two main recommendations address this function of the trade regime. The very first recommendation states that:

"In each country, the making of trade policy should be brought into the open. The costs and benefits of trade policy actions, existing and prospective, should be analyzed through a 'protection balance sheet'. Private and public companies should be required to reveal in their financial statements any subsidies received. Public support for open trade policies should be fostered." (Dunkel, 1987, p. 41)

The underlying rationale for this recommendation resembles the public choice argument that was mentioned above in the context of the rational design conjecture that links centralization to enforcement problems: it was assumed that protectionism was on the rise because trade policies are not carefully scrutinized domestically. More transparency was assumed to lead to a higher awareness of the hidden costs of protectionism, mobilizing political support for more liberal trade policies. Although the recommendation is mainly aimed at the domestic level, the theme of domestic transparency was picked up in the negotiations, carrying the rationale expressed in the report into the setting of the Uruguay Round. ${ }^{15}$

The second recommendation on information gathering and transparency made in the report resembles an even closer similarity to the TPRM as it eventually emerged. It suggests that:
"At the international level, trade policy and the functioning of the trading system should be made more open. Countries should be subject to regular oversight or surveillance of their policies and actions, about which the GATT Secretariat should collect and publish information." (Dunkel, 1987, p. 49)

The rationale of this recommendation also corresponds to the conjecture that links centralization to enforcement. The Leutwiler report argues that such a regular review

\footnotetext{
${ }^{13}$ According to VanGrasstek (2013) two other external reports also provided an impetus for the negotiations of the TRPM. One was produced by the OECD, the other one by the Trade Policy Research Center, a high-level study group chaired by former GATT Director General Olivier Long. Like the Leutwiler Report these reports also suggested to strengthen the information gathering and transparency mechanisms of the trade regime. While these reports probably reflect the thinking of the time and might have had an impact on designers' mindsets, no direct reference could be found to them in negotiation documents or interviews with witnesses of the TRPM design process.

${ }^{14}$ For the full report see Dunkel (1987).

${ }^{15}$ MTN.GNG/NG14/4; MTN.GNG/NG14/14; MTN.GNG/NG14/W/13; MTN.GNG/NG14/W37
} 
mechanism was needed to hold governments accountable for their trade policies. The Secretariat was supposed to act as a watchdog, gathering information that would be assessed by a review panel of three to five government representatives. The panel would question the regime member under review and make recommendations. As an alternative the report suggested setting up a Trade Policy Committee that would be in charge of reviews and be serviced by the Secretariat. In addition to this it argued for a strengthened role of the Secretariat in initiating studies of national trade policies, administer information and trigger policy discussion based on this information. According to the Leutwiler report these measures were supposed to strengthen adherence to the GATT rules.

The report increased the awareness of the need for better surveillance procedures in the trade regime, as expressed in the preparatory meetings for the round. ${ }^{16}$ Australia picked up on it and provided a specific negotiation proposal that merged both ideas expressed in the report even ahead of the round already. ${ }^{17}$ The proposal called for annual standardized reports by contracting parties on their trade policies of which the Secretariat would provide a summary report to the Council. Furthermore, just as the Leutwiler report did, it suggested a trade policy review of selected contracting parties, conducted by a small group of other contracting parties based on a Secretariat report. While the preparatory committee for the Uruguay Round was not ready to discuss the matter at such a detailed level and despite the fact that there was some disagreement on the specific measures suggested in the Australian proposal, the discussions in the preparatory committee imply an early consensus on the general idea to strengthen surveillance and the underlying functional motivation. ${ }^{18}$ Accordingly, the preparatory committee picked up Australia's suggestion to include a negotiation mandate for the improvement of surveillance in the Punta del Este ministerial declaration that launched the Uruguay Round. The functional reasoning of the Leutwiler report was thus directly carried over into the round and further discussed in the negotiation group on the Functioning of the GATT system.

When the FOGS group started its work in 1987 it did so based on the mandate to negotiate understandings and arrangements that aim at enhancing "the surveillance in the GATT to enable regular monitoring of trade policies and practices of contracting parties and their impact on the functioning of the multilateral trading system....". ${ }^{19}$ The common view regarding the value of improved surveillance that had already emerged in the preparatory phase was reaffirmed throughout the negotiations (Croome, 1999). Functional thinking in line with the reasoning of the Leutwiler Report was a general feature informing the negotiations. This was already expressed in the first meeting of the group. ${ }^{20}$ During this meeting three functional benefits of improved surveillance were pointed out. Two of them correspond to the reasoning in the Leutwiler report, pointing out that enhanced surveillance should provide a continuous and

\footnotetext{
${ }^{16}$ SR.SOG/6; SR.SOG/10; SR.SOG/11; PREP.COM(86)SR/4; PREP.COM(86)SR/7; PREP.COM(86)W/31

17 PREP.COM $(86) \mathrm{W} / 37$

${ }^{18}$ PREP.COM(86)SR/4; PREP.COM(86)SR/7; PREP.COM(86)SR/8

${ }^{19}$ MIN.DEC, p.8

${ }^{20}$ MTN.GNG/NG14/1
} 
systematic system to facilitate compliance with the GATT rules and that it should function as a counterweight to domestic protectionist pressures by enhancing transparency. The third one introduced a new element, pointing out that a surveillance system should be preventive, serving as an 'early warning' system to enable tackling problems in the multilateral trading system in a timely manner. ${ }^{21}$ While the first two expected benefits resonate with the rational design conjectures that links centralization to enforcement, the last one corresponds to the conjectures that link centralization to uncertainty.

Variations of this reasoning were repeated in several negotiation proposals submitted by contracting parties. Proposals by Australia ${ }^{22}$, the US ${ }^{23}$, New Zealand ${ }^{24}$, the Nordic Countries ${ }^{25}$, the $\mathrm{EC}^{26}$, India on behalf of developing countries ${ }^{27}$, and Switzerland on behalf of a number of contracting parties ${ }^{28}$ all express that the ambition of strengthened surveillance mechanisms in the GATT should be to reduce uncertainty by increasing transparency and predictability, and to contribute to enforcement by facilitating compliance.

In some instances functional reasoning can even be traced to the specific design elements that would eventually constitute the TPRM. Most importantly in this respect might have been the independent role of the Secretariat in preparing review reports, which counts as an instance of centralization as delegation. As it will be shown below, the role of the Secretariat in the TPRM was contested and initially not all contracting parties wanted the Secretariat's role to be as prominent as it eventually turned out to be. However, in the debate about the Secretariat's role functional arguments as expressed during the FOGS meetings in June and October $1988^{29}$ carried the day. In these meetings it was pointed out that leaving the provision of information to the country under review would undermine the credibility and objectivity of the review process and thereby compromise on its main goals. ${ }^{30}$ This reasoning is clearly functional. As it has been pointed out in the previous section, one of the core arguments for centralizing information provision is that an international organization's neutrality ensures the information's credibility.

Also other design features can be related back to functional reasoning. The idea to designate discussants to trigger the debate in the actual review meeting followed a similar logic as the one to strengthen the role of the Secretariat. When proposing this design feature the Nordic Countries argued that this would secure independence and professionalism, which should

\footnotetext{
${ }^{21}$ In several interviews it was also expressed that the main motivation for the introduction of the TPRM was to increase transparency and receive information about regime member's policies from a neutral source (Int04, Int06, Int09, Int12, Int13).

${ }^{22}$ MTN.GNG/NG14/W/1

${ }^{23}$ MTN.GNG/NG14/W/9

${ }^{24}$ MTN.GNG/NG14/W/13

${ }^{25}$ MTN.GNG/NG14/W/17

${ }^{26}$ MTN.GNG/NG14/W/20

${ }^{27}$ MTN.GNG/NG14/W/23

${ }^{28}$ MTN.GNG/NG14/W/30

${ }^{29}$ MTN.GNG/NG14/8; MTN.GNG/NG14/10

${ }^{30}$ This has also been confirmed in several interviews (Int01, Int10, Int12, Int13).
} 
ultimately lead to more efficient and penetrating reviews. ${ }^{31}$ This can be regarded as aiming to strengthen the indirect enforcement character of the TPRM. Furthermore, the idea to conduct reviews of general trends in the trading system can rather be interpreted as a response to uncertainty about the state of the world. As expressed by the negotiation proposal that India submitted on behalf of developing countries, this design feature of the TRPM was supposed to work as an 'early warning' mechanism to notice problems in multilateral trade soon enough to develop an adequate response. Also the suggestion to introduce a general reporting requirement aimed to reduce uncertainty, since it was argued that regular reporting is a crucial element to increase transparency. ${ }^{32}$ Finally, the proposal to introduce a political, non-binding commitment by contracting parties to support domestic transparency mechanisms was suggested by Australia, Canada, Hong Kong and New Zealand with direct reference to the public choice argument mentioned in the Leutwiler Report. ${ }^{33}$ As such this design feature arose out of a motivation to reduce uncertainty and enhance adherence to the liberal norms of the trade regime.

The functional arguments in favor of the TPRM were resonated throughout the discussions in the FOGS negotiation group and soon widely supported..$^{34}$ It is therefore only a logical consequence that they were incorporated as objectives in the final text of the TPRM. In section A(i) the TRPM states that:

"The purpose of the Trade Policy Review Mechanism ("TPRM") is to contribute to improved adherence by all Members to rules, disciplines and commitments made under the Multilateral Trade Agreements and, where applicable, the Plurilateral Trade Agreements, and hence to the smoother functioning of the multilateral trading system, by achieving greater transparency in, and understanding of the trade policies and practices of Members. Accordingly, the review mechanism enables the regular collective appreciation and evaluation of the full range of individual Members' trade policies and practices and their impact on the functioning of the multilateral trading system."

Thus the purpose of the TPRM is threefold: To improve adherence to GATT rules, to facilitated transparency and understanding of trade policies and practices, and to collectively appreciate and evaluate the impact of members' policies on the multilateral trading system (Qureshi, 1990). The first and the last goal of the TPRM express the ambition to facilitate rule adherence, and can consequently be related to the rational design conjecture that links centralization to an enforcement problem. The second and the last goal are related to transparency. In light of the negotiation history it is plausible to interpret the inclusion of these

\footnotetext{
${ }^{31}$ MTN.GNG/NG14/W/25; MTN.GNG/NG14/9

${ }^{32}$ MTN.GNG/NG14/W/30

${ }^{33}$ MTN.GNG/NG14/14; MTN.GNG/NG14/W/37

34 MTN.GNG/NG14/1; MTN.GNG/NG14/2; MTN.GNG/NG14/3; MTN.GNG/NG14/4; MTN.GNG/NG14/5; MTN.GNG/NG14/6; MTN.GNG/NG14/10
} 
goals in the text of the TPRM as an expression of the desire of designers to use the TPRM as a mechanism to tackle uncertainty.

The preceding overview of the motives that underlined the negotiation process has shown that the purpose expressed in the text of TPRM is not just diplomatic window dressing, but that it represents the actual motivation of designers from the very beginning of the negotiation process all the way to the end. This confirms the suitability of the rationale design framework to explain the emergence of the TPRM. Yet, to verify this it is necessary to rule out alternative factors that could explain this increase in centralization. This is done in the following sections by analyzing the historical development of information and transparency mechanisms in the trade regime and by tracing the TPRM negotiation process in further detail. 


\subsection{Design in Context: Historical Legacy}

To what extent was the design of the TPRM influenced by the development of past information gathering and transparency mechanisms? Is the emergence of the TPRM to be regarded as a single grant moment of rational design or does it merely constitute another incremental step down an evolutionary, path dependent trajectory? Exploring these questions in the following section contributes to a fuller understanding of the dynamics that influenced the design of the TRPM. In doing so it becomes clear that information gathering and facilitating transparency had always been regarded to be important functions of the trade regime's institutions. This was explicitly acknowledged in the ITO, which was equipped with the mandate and institutional mechanisms to fulfill this function. In light of the peculiar origins that required the GATT to reduce or hide its institutional features to a bare minimum, the GATT lacked such an explicit mandate and institutional mechanisms. Nonetheless the need for gathering information and facilitating transparency was implied in several of its substantive provisions. When tracing the GATT's historical development it becomes clear that along with the GATT's general, pragmatic institutional evolution, also its information gathering and transparency function developed and got increasingly institutionalized. This provided designers of the TPRM with a repertoire of institutional features they could use as inspiration to design the new review mechanism. The given institutional structures also constituted a basis to build on. In this sense the emergence of the TPRM appears to be a logical continuation of the GATT's institutional development, in which the introduction of regime wide member specific review constitutes a remarkable tipping point. This tipping point was mainly functionally motivated but also shows signs of the institutional context in which it emerged.

In the following the historical development of information gathering and transparency functions will be examined in further detail, starting with an exploration of the relevant institutional provisions in the ITO.

\subsubsection{Providing Information and Facilitating Transparency in the ITO}

The ITO's institutional provisions indicate that centralizing information provision and transparency promotion where important to the designers of the trade regime's institutional features right from the start. When interpreting centralization broadly, this function was explicitly ascribed to the ITO and the ITO was supposed to be the focal entity to gather trade relevant data. Article 72.1(a) of the Havana Charter lists as first function of the ITO the task to "collect, analyze and publish information relating to international trade, including information relating to commercial policy, business practices, commodity problems and industrial and general economic development." Clair Wilcox, deputy chairman of the US delegation at the Havana Conference, envisioned that the ITO would effectively take up the role as an international trade information center. He posited that the ITO "will undertake to improve trade 
statistics. It will collect, analyze, and publish data on exports, imports, balances of payments, prices, subsidies, customs regulations, and national commercial policies; on treaties and other agreements affecting trade; on conventions, laws and procedures relating to restrictive business practices; on commodity problems and the operation of commodity agreements" (Wilcox, 1972, p. 61).

To fulfill this function the ITO would have largely relied on self-reporting requirements. The Havana Charter entails several provisions that call on ITO members to publish or report on their actions and policies. The core provision in this respect was Article 38 of the Charter. It stipulates a general requirement that trade regulations need to be promptly published and that these publications need to be easily accessible. The article also requires that copies "of such laws, regulations, decisions, rulings and agreements shall be communicated promptly to the Organization." ${ }^{35}$ Furthermore Article 39 asks members to share trade statistics with the ITO and mandates the organization to be the "centre for the collection, exchange and publication of statistical information" (Art. 39.6). Other articles throughout the charter also require selfreporting related to specific trade topics. The ITO could have asked members to report which actions they undertake with respect to restrictive business practices, and ask for reports on standards of customs valuation for example (Wilcox, 1972).

Specifying which exact institutional mechanisms would have carried out and administered the ITO's information gathering and transparency facilitating function is difficult and remains to a certain extent speculative. The Havana Charter does not specify exact institutional provisions and procedures and mostly only refers to 'the organization' to carry out a task. It is for example not specified which institutional bodies would carry out the general mandate to conduct studies and collect, publish and analyze information as it is expressed in Article 39 of the Charter. Also more specific tasks, such as the requirement of Article 23 that the ITO should report annually on quantitative restrictions and the one in Article 65 asking the ITO to conduct regular reviews on commodity agreements only refer to 'the organization' and not to a specific organizational body. Article 98 is exceptional in this respect, stating that the Executive Board would regularly review the trade relations between members and non-members of the ITO. Nonetheless, it is not possible to determine with certainty which exact institutional form centralization of the ITO's surveillance function would have taken.

Yet this should not necessarily be regarded as weakening the organization, since it would have provided it with wide discretion to setup suitable design features itself. As Bronz (1949) points out, it was considered during the negotiation of the ITO to include more specific institutional provisions in the Havana Charter, but it was decided to leave it to the ITO to establish such more detailed provisions as it would have seen fit. Thus it is highly likely that the organization would have developed specific design features to centralize information gathering.

\footnotetext{
${ }^{35}$ The requirement of Article 38 was limited in so far as it did not request "any Member to divulge confidential information the disclosure of which would impede law enforcement or otherwise be contrary to the public interest or would prejudice the legitimate commercial interests of particular enterprises, public or private" (Art. 38.1).
} 
After all, article 82 of the Havana Charter explicitly permitted the setup of commissions to allow the ITO to fulfill its functions. Also, it is not unlikely that the Secretariat would have taken up at least some tasks related to information gathering (Wilcox, 1972).

To sum up, it can be concluded that the ITO would certainly have been a focal entity for the collection and dissemination of trade related information, but that the exact form of centralization cannot be determined by relying on the Havana Charter. Yet the lack of precision in the Charter would have provided the ITO with the possibility to expand centralization by using the organization's discretion to setup the institutional features, as it would have been required to fulfill its functions. However, the ITO's failure leaves all statements on how it would have used this discretion speculative.

\subsubsection{Providing Information and Facilitating Transparency in the GATT}

After the failure of the ITO the GATT became the main focal entity for the administration of the multilateral trade regime, including the provision of information and facilitation of transparency. However given that this role was not anticipated at time of the GATT's design and that the GATT was originally not supposed to bear any signs of being an international institution, it was a much weaker focal entity than the ITO would have been. Contrary to the ITO the GATT had no mandate for surveillance and collecting information, as it did not have explicitly mentioned functions. In line with this it hardly had any institutional arrangements that could have facilitated surveillance and information gathering, except for the CONTRACTING PARTIES' right to take decisions that facilitate the functioning of the GATT. Over the years it made use of this right to incrementally institutionalize and centralize information gathering and transparency facilitation. According to Ghosh (2010) this institutionalization and centralization took place in three phases. The first is characterized largely by the absence of institutional features to support information gathering. The GATT was nonetheless functioning adequately due to its small membership and ad hoc monitoring exercises. Institutionalization increased in the second phase, which is characterized by the emergence of institutional bodies in charge of administering specific monitoring, and notification requirements stipulated in the GATT's substantive agreements. In this phase centralization as pooling can be witnessed. In the third phase centralization as delegation started to emerge, indicated by the Secretariat starting to play a larger role in gathering and administering comprehensive information on developments in the trade regime.

The basis for the information provision and transparency facilitation function to be institutionalized can be found in the GATT's substantive provisions. Some of these provisions require contracting parties to self-report on their trade policies - e.g. Articles $\mathrm{VI}, \mathrm{X}, \mathrm{XII}, \mathrm{XIII}, \mathrm{XV}$, XVI, XVII, XVIII, XIX, XXIV, XXVII and XXVIII (Jackson, 1969). The most general of these is Article X, which asks contracting parties to promptly publish trade regulations and laws (Laird \& Valdés, 2012). Article $X$ of the GATT was the mirror image of Article 39 of the Havana Charter, with the important distinction that it does not make any reference to providing copies of trade regulations or laws to the GATT. This is not surprising considering the need of the GATT to avoid 
any connotation to being an organization, but implies that procuring information was costly since the GATT would not serve as a central repository of this information (Mavroidis \& Wolfe, 2015). Although the GATT had to cope without any institutional provisions for the collection of information, the various reporting requirements contributed to the GATT becoming a hub for the collection of information nonetheless (Jackson, 1969). ${ }^{36}$

This development can be witnessed from the very beginning of the GATT. In an early analysis of the GATT's performance Gorter pointed out in 1954 that GATT consultations and reports on quantitative restrictions are valuable in exposing trade limiting behavior and concluded that this contributed to the GATT being an excellent forum for the exchange of information relevant to trade policy. The small membership of the GATT at the time permitted that this first phase of information exchange did not have to be accompanied by significant institutionalization (Ghosh, 2010). Information exchange was usually confined to specific issues discussed at the CONTRACTING PARTIES' regular sessions and wider monitoring exercises of developments in the trade regime were only done ad hoc.

As two important examples of ad hoc surveillance during the GATT's early years Ghosh (2010) singles out the $9^{\text {th }}$ Session of the CONTRACTION PARTIES and the establishment of a Panel of Experts to investigate trends in international trade. The $9^{\text {th }}$ Session of the CONTRACTING PARTIES, which is also known as Review Session, took place between 1954 and 1955 and was dedicated to review the state of the multilateral trading system and the GATT's role therein. ${ }^{37}$ Four working groups on quantitative restrictions, tariff schedules and costumes administration, other barriers to trade, and on organizational and functional questions were established for this purpose. These working groups produced reports that were later on adopted by the CONTRACTING PARTIES. ${ }^{38}$ The second instance of ad hoc review highlighted by Ghosh began in 1957, when a Panel of Experts was established to investigate trends in international trade with particular attention to the role of developing countries in the regime. The report this group of experts produced - named Harberler Report, after the chairman of the group - noted that developing countries are disadvantaged in the trade regime and that their participation in the regime was hindered by the policies of developed countries (Ghosh, 2010). The conclusions of the Harberler Report led to the establishment of the Committee II which was charged with the task of reviewing agricultural policies of almost all contracting parties between 1959 and 1962 (Blackhurst, 1991; Ghosh, 2010).

The establishment of Committee II can already be seen as an example of the main feature that characterized the second phase of the institutionalization of the GATT information

\footnotetext{
${ }^{36}$ For a detailed overview how the GATT fulfilled this function see Courage van Lier (1984).

${ }^{37}$ MTN.GNG/NG14/W/12

${ }^{38}$ During the review session an attempt was made to create the OTC, to provide the trade regime with a more solid institutional structure than the GATT provided. This would also have implied a strengthening of centralization of information gathering and transparency facilitation, since the OTC would have had the specific function to collect and analyze information and statistical data on trade policies (L/327). However, since the plan to establish the OTC failed, the GATT had to continue to cope with the limited institutional provisions at its disposal. See also section 3.2.3.3.
} 
gathering and transparency facilitating function. This phase was an integral part of the sharpening of the GATT's institutional profile that started to emerge as of the late $1950 \mathrm{~s} .{ }^{39} \mathrm{It}$ is related to the development of intersessional procedures and the practice to establish committees and working groups. Many of the committees and working parties were only temporarily established to study particular issues during the sessions of the CONTRACINT PARTIES - just as it was the case during the review session - or ceased to exist after some time just as Committee II. ${ }^{40}$ However some committees became permanently institutionalized and performed important surveillance functions in the GATT (Jackson, 1969). The functioning of some these committees provided designers with useful inspiration for the exact design features of the TRPM. ${ }^{41}$

The oldest and most prominent of these committees was the Balance of Payments committee. Provisionally set up in 1956 and turned into a standing body in 1958, it held regular ${ }^{42}$ consultations with those countries that made use of balance of payments restrictions. The committee's work resembles the enforcement function surveillance features can fulfill. Its importance is pointed out by Jackson who stated in 1969 already that the "its continuous scrutiny and its reports tend to inhibit the use of improper quantitative restrictions" (p. 159). Institutionally, like all GATT committees, it constituted an instance of pooling. Consultations were initially based on a basic report supplied by the country that was subject to the consultations and information on recent economic developments in the country provided by the IMF. After the Tokyo Round a Secretariat background paper was added as another source to the documents used for consultations. Additionally the committee could ask the Secretariat for analyses of legal and economic aspects of balance of payments measures taken by contracting parties (Blackhurst, 1991).

Another important committee carrying out a surveillance function was the Committee on Trade and Development and sub-committees thereof. Established in 1964 one of its tasks was to review whether special rights to developing countries granted under Part IV of the GATT and under the enabling clause were properly implemented. Such review exercises were based on

${ }^{39}$ See section 3.2.3.3.

${ }^{40}$ Another relevant surveillance mechanism that was temporary but deserves to be mentioned was the 'Group of Three'. It was established in 1971 as a response to complaints by developing countries over trade restrictions of developed countries. The group consisted of the chairmen of the Contracting Parties, the Council and the Committee on Trade and Development. Its task was to identify apparently unjustified trade restrictions affecting developing countries and propose their removal. The group of three was suspended in 1974. See also section 4.4.3.

${ }^{41}$ The following elaboration on institutional bodies that carried out a surveillance function is based on an overview produced by the GATT Secretariat in 1987 to support the FOGS negotiations on the TPRM, see: Existing Surveillance Functions in the GATT - Note by the Secretariat (MTN.GNG/NG14/W/3). Ghosh (2010) and Blackhurst (1991) list the same institutional arrangements as most important in carrying out information gathering and transparency facilitating tasks. The bodies mentioned in the following paragraphs do not constitute an exhaustive list. Many GATT bodies could be assumed to facilitate information gathering in one way or another even if it is only in their function as forums for discussion. Also, specific contracting parties were regularly subject to individual review under their accession or waiver agreements for example.

42 For developed countries consultations took place annually, for developing countries every two years. 
notifications by contracting parties. In 1983 an interesting new dimension was added to the Committees review work when a program was introduced that reviewed how individual contracting parties lived up to the requirements of Part IV. The procedure this program followed bears similarity to the procedure of the TPRM. Reviews were based on documentation by the reviewed party in combination with a factual, descriptive background paper by the Secretariat. The discussions held in the committee were captured in a final report, which did not derive any formal conclusions. This program was carried out until 1985. Further surveillance work under the Committee on Trade and Development was done by the Sub-Committee on Protective measures established in 1979. This was done based on notifications and reverse notifications ${ }^{43}$ by contracting parties and supported by information from the Secretariat that had to be based on official sources. Also the Sub-Committee on Trade of Least-Developed Countries was conducting reviews on general developments in trade policies that were of particular interest to least-developed countries.

Three other institutional arrangements warrant to be mentioned that contributed to the GATT's information gathering and transparency function. One of them, the Textiles Surveillance Body (TSB), emerged in 1974 under the Multi Fiber Agreement (MFA). This standing body was limited, but geographically representative in membership and regularly reviewed policies and practices covered by the MFA. In this context it had the authority to not only rely on reporting by signatories of the MFA, but could also actively seek information. Furthermore, the codes established as result of the Tokyo Round also provided for committees in charge of reviewing adherence to the codes' substantive provisions. Procedures for this varied per code, but the main aim of all of these provisions was to increase transparency on relevant policies and practices by signatories of the code, and to induce compliance. Reviewing adherence to the codes was based on data provided by signatories themselves, inventories established by the Secretariat, and on discussions taking place in the codes' Committees or Councils. Reviews were held regularly and, depending on the code, could vary regarding the strength of their conclusions. In some cases a review would simply determine the facts of a market situation, while in other cases the consistency of policies with legal obligations was assessed, even leading to rulings or recommendations. Finally, it needs to be pointed out that the Uruguay Round itself entailed surveillance arrangements. For the purpose of the round the Surveillance Body was set up. This body monitored the adherence to the standstill and rollback provisions ${ }^{44}$ that were agreed to at the outset of the round. It met at least three times a year and conducted reviews on the basis of notifications that were provided to the Secretariat by contracting parties. Based on the reports produced by the Surveillance Body the Trade Negotiations Committee assessed the implementation of the standstill and rollback commitments at least every six months.

\footnotetext{
${ }^{43}$ Reverse notifications are notifications on a measure of a contracting party provided by another contracting party.

${ }^{44}$ The standstill and rollback provisions form part of the Punta del Este Ministerial Declaration. According to these provision negotiating parties to the Uruguay Round commit to refrain from introducing protectionist measures for the time of the Uruguay Round (standstill) and to repeal existing GATT inconsistent measures until the end of the round (rollback). See MIN.DEC
} 
Establishing all of the mentioned committees contributed to strengthen the GATT's role as a focal entity on information provision and exchange in the multilateral trade regime. However, despite this increased institutionalization the GATT continued to suffer from weaknesses in its information gathering function due to lacking a coherent overview of trade policies - both, of the trading system as a whole and of particular parties therein. Each of the abovementioned bodies only centralized information gathering in a specific policy domain. The only provision in the GATT that aimed to approach transparency facilitation holistically was the relatively weak general policy publication requirement mentioned in Article X. In 1964 the CONTRACTING PARTIES aimed to add an element of centralization as delegation to this article and strengthen the GATT's role as a central repository, by recommending that members of the regime should provide the Secretariat with copies of the measures that Article $X$ required to be published (Jackson, 1969). However, given that this was only a recommendation and that no institutional mechanism accompanied the recommendation to facilitate its implementation, its effect remained limited. Furthermore, it has to be pointed out that until the end of the Tokyo Round none of the existing surveillance activities in the different institutional bodies included a significant role for an independent third party, such as the Secretariat. This situation started to change in third phase of the development of the GATT's information gathering and transparency facilitating function.

This third phase began in 1979 and was characterized by an increase in centralization as delegation and by the introduction of holistic review exercises that covered trade policies comprehensively. Instances of the former element have already been mentioned above, such as the decision to add Secretariat reports as a source for the reviews conducted by the Balance of Payments Committee and the Secretariat's changing role as information provider for individual country reviews conducted between 1983 and 1985 by the Committee on Trade and Development. In addition to this the Secretariat's role did increase further with the introduction of a holistic review exercise that emerged from the Tokyo Round's 'Understanding Regarding Notification, Consultation, Dispute Settlement and Surveillance' adopted in November 1979. ${ }^{45}$

The understanding entailed two parts that were relevant to the GATT's information gathering function. The first was concerned with notifications and reaffirmed the political commitment to abide with the GATT's notification provisions, including the intention to not just publish, but also to notify measures that would be covered under Article $X$ to the GATT. Even more important was the second part, which addressed surveillance. In this part the CONTRACTING PARITES agreed to "conduct a regular and systematic review of developments in the trading system." ${ }^{46}$ Based on this the Director General recommended in 1980 that the Council should hold bi-annual special meetings for this purpose. ${ }^{47}$ Such reviews where to be based on a factual report by the Secretariat. In producing the report it was suggested that the Secretariat would rely on contracting parties' notifications, but also on other relevant

\footnotetext{
${ }^{45} \mathrm{~L} / 4907$

${ }^{46}$ L/4907, p.5

${ }^{47} \mathrm{C} / 111$
} 
information. The Council adopted this proposal and the GATT started to conduct biannual systematic reviews of developments in the trade regime. ${ }^{48}$

In June 1983, at the sixth review two significant changes were made to the review exercise, which strengthened the GATT as a focal entity. The first relates to centralization as delegation and the role of the Secretariat. For the first five reviews that took place between November 1980 and June 1982, the Secretariat based its reports only on official notifications. According to the DG this constituted a significant shortcoming of the review process, because notifications were often not complete and thereby failed to uncover hidden information on non-tariff trade barriers and grey-area measures (Croome, 1999). To address this the Secretariat started to make full use of the mandate it received by the Council in 1980 and actively searched for information from non-official sources in preparation of the report for the sixth review. The second development strengthened the GATT as a focal entity in general by increasing the scope of the review exercise. Based on a recommendation by the CG.18, the DG suggested to the Council that the Special Council meetings should also be used to review the implementation of paragraph 7(i) of the 1982 Ministerial Declaration. This paragraph called upon parties to refrain from taking measures that are inconsistent with GATT principles and rules, avoid protectionism and not to maintain GATT inconsistent measures already in place. ${ }^{49}$ It thereby provided a benchmark by which member performances could be judged (Croome, 1999). Being reassured by the DG that neither the inclusion of information from unofficial sources, nor expanding the scope of reviews to paragraph 7(i) of the 1982 Ministerial Declaration would be used to conduct a legal assessment of contracting parties' behavior towards their GATT obligations, the reaction to these changes was positive and the Council agreed to both. ${ }^{50}$ According to Hudec (1993) these developments are to be regarded as milestone's in the GATT's institutional growth. For the first time in its history the Secretariat was explicitly authorized to independently collect data on trade restrictive measures in the context of a holistic review exercise. To enable the Secretariat to do so the DG established the Trade Policies Division in 1983.

The introduction and expansion of the Council's comprehensive review exercise and the corresponding increase of the Secretariat's responsibilities constitute the last significant step in the development of the GATT's information gathering and transparency function. This development testifies that the GATT's role as a focal entity regarding this function got strengthened throughout the years and that procedures to fulfill this function got increasingly institutionalized. As with all of the GATT's institutional features this development occurred incrementally and pragmatically. In this respect the question arises whether the establishment of the TPRM can be interpreted as just another incremental step down the already established trajectory or whether should it be regarded as a genuinely new development? In other words, how and to what extent has the design of the TPRM been influenced by the GATT's history?

\footnotetext{
${ }^{48} \mathrm{C} / \mathrm{M} / 139$

${ }^{49} \mathrm{~L} / 5424$

${ }^{50} \mathrm{C} / \mathrm{M} / 169$
} 


\subsubsection{The Impact of History on the Uruguay Round Negotiations}

Assessing the impact of the GATT's historical development on the design of the TPRM is a matter of interpretation. While the existing institutional context certainly influenced the negotiations of the TPRM, a definite assessment on the impact of history depends on the perspective one choses to take. As it has been pointed out in section 5.2 the TPRM as it emerged from the Uruguay Round consists of four features: The provision for regular member specific reviews and related institutional procedures; the provision for annual reviews of general developments in the trade regime; a general requirement to report changes in trade policies; and the political commitment to enhance domestic transparency. Two of these features can clearly be regarded as an affirmation of already existing practices that had developed throughout the GATT's history. The negotiation history of the TRPM strongly indicates that the annual reviews of general developments in the trade regime conducted by the TPRB were largely influenced by the established practice of Special Council meetings that emerged throughout the 1980s. Also the TPRM's general reporting obligation can be regarded as a logical continuation of the attempts that were made in 1964 and 1979 to turn the requirement to publish changes in domestic trade policy as originally expressed in Article X of the GATT into a notification requirement that asks the regime's members to file changes in their policy with the institutions of the regime. In contrast, the commitment to enhance domestic transparency on trade policies is a genuinely new feature. Yet, its voluntary nature limits the importance of this provision. The most interesting question concerns the most important feature of the TPRM: the provision for regular, systematic individual trade policy reviews and the accompanying institutional procedures.

Different standpoints can be taken on the degree of innovation entailed in the provisions for individual reviews, especially regarding the related institutional procedures. On the one hand the provision for individual reviews seems in itself genuinely new in the context of the GATT. The idea was brought into the negotiations by the Leutwiler Report, which constitutes a policy recommendation by independent experts who seemed to be at most marginally immersed in the GATT's institutional context at the time. Furthermore, it seems that the design of the individual review procedure was influenced by the example of already existing review mechanisms in the IMF and the OECD (Mavroidis, 1991-1992; Preeg, 1995). This was expressed in interviews conducted for the purpose of this research (Int01, Int07, Int09, Int10) and is supported by the fact that the Secretariat provided the negotiators of the TPRM with an overview of surveillance activities in these organizations. ${ }^{51}$ Especially the review procedure in the OECD's Committee on Liberalization of Capital Movements - consisting of individual country reviews in regular three to four year intervals, which are based on a report by the country under review and another report by the OECD Secretariat - is very similar to the TPRM as it would eventually emerge (Blackhurst, 1991). Thus it seems that the idea and design of the individual

${ }^{51}$ MTN.GNG/NG14/W/19 
country reviews was within the GATT context an innovation, largely inspired by external sources and not by internal historical precedent.

Yet, on the other hand it needs to be acknowledged that institutional structures had been developed throughout the GATT's history that designers could refer to and build upon. In this respect it is to be recalled that the Committee on Trade and Development launched a review program of individual contracting parties' policies in 1983 that already followed similar procedures as the ones that TPRM would later on adopt. During the TPRM negotiations explicit reference to this practice was made at least once. ${ }^{52}$ Also, the TPRM negotiators were informed about existing GATT practices relating to surveillance by a Secretariat document that was used as a reference point. ${ }^{53}$ Generally, it would be plausible to assume that the experience the contracting parties gathered with centralization as delegation, as it had developed in form of larger information gathering responsibilities of the Secretariat since the end of the Tokyo Round, fostered the inclusion of an element of delegation in the TPRM as well. Also regarding centralization as pooling, past practices seemed to have inspired institutional design. Negotiators preferred making use of the practice of Special Council meetings to conduct reviews over alternative suggestions to create a separate review body within the GATT's institutional structure. The Special Council meeting setup was available in negotiator's design repertoire since it had been introduced in 1980 for the bi-annual reviews of general developments in the trade regime. When individual country reviews where preliminarily launched in 1989 for the first time, they were conducted in the setting of such Special Council meetings. The TPRB was only added later in the context of the establishment of the WTO, but constitutes the same institutional arrangement as the Special Council on all matters except its name. Regarding this background the design of individual country reviews was probably at least moderately influenced by the institutional context at the time.

Overall it might be fair to describe the emergence of the TPRM as a logical continuation of the GATT's institutional development, with the introduction of regime wide and comprehensive individual member reviews as a significant change that constitutes a tipping point in this development. This tipping point was strongly functionally motivated but nonetheless bears traces of the GATT's institutional context at the time. To verify this conclusion, and to fully understand the emergence of the TPRM and its specific design features it is necessary to trace the negotiation process and check whether other factors that explain its emergence were also present.

\footnotetext{
${ }^{52}$ MTN.GNG/NG14/6

${ }^{53}$ MTN.GNG/NG14/W/3
} 


\subsection{Negotiating Design: Process and Dynamics}

When examining the negotiation process of the TPRM it is evident that designing the mechanism was relatively uncontroversial. Interests where rather homogenous, since there was a general agreement that it was necessary to improve the GAT's information gathering and transparency facilitation function. In contrast to the negotiation process that led to the emergence of the WTO and the reforms in dispute settlement no significant factors that are not accommodated by the rational design framework can be identified. Most of the negotiation process was characterized by reaching compromise solutions on specific design features of the provision for individual country reviews. In this process, considerations about costs, risks and symmetry played a role and shaped the interaction of centralization and control in the TPRM, as it would eventually emerge. The other three features covered under the TPRM were even less controversial. The explanation for this uncontroversial design process is probably to be found in the relatively low costs and risk of the TPRM, and in the fact that it did not raise sensitive distributional questions. In the following this design process is traced. The negotiations of the individual member review process are in the focus of this process tracing exercise but first a very brief overview about the emergence of the TPRM's other features is provided.

\subsubsection{Reviewing General Developments, Notifications and Domestic Transparency}

The annual reviews of general developments in the trade regime, the introduction of a general notification requirement and the plea to enhance domestic transparency are the three provisions that stand next to the individual country reviews as the key feature of the TPRM. Not only are they less significant than the conduct of individual review, they were also relatively easily negotiated. None of these features led to a significant discussion during the Uruguay Round negotiations. To provide a complete overview how the different features of the TPRM emerged it is nonetheless warranted to briefly examine each of these features in turn.

Considering the annual review of general developments in the trade regime as provided for in part $\mathrm{G}$ of the TPRM's text, designers could build on the historical precedents of bi-annual Special Council reviews as mentioned in the previous section. Already in the preparatory phase of the Uruguay Round it was suggested to make use of this practice. ${ }^{54}$ Also the FOGS group discussed the idea to continue reviews of general trends in the trade regime from early on. ${ }^{55}$ Several contracting parties submitted proposals to this effect and suggested to continue using the Special Council meetings as the forum for such reviews and to base these reviews on a

\footnotetext{
54 PREP.COM(86)SR.4

${ }^{55}$ MTN.GNG/NG14/2
} 
report provided by the Director General. ${ }^{56}$ As pointed out in section 5.3.2 the motivation for this was largely functional. Contracting parties aimed to reduce uncertainty and considered annual reviews of general trends in the trade regime as a useful source of information to enhance policy making. The experience that was gathered with such reviews since 1980 implies that this feature of the TPRM is not genuinely new and can explain why there was not much discussion about the introduction of it. Already in the first half of 1988 there was consensus in the FOGS group to complement enhanced surveillance in the GATT by an overall assessment of trends in the regime in Special Council meetings (Croome, 1999).

Similarly, the discussions to introduce a general reporting requirement was very uncontroversial too. Most of the discussions on notifications were technical in nature and revolved around the question to streamline the different notification procedures already existent in the GATT. ${ }^{57}$ In March 1988 the EC added to this discussion by suggesting the introduction of a general obligation to notify, which it justified by the assumption that notification is a basic transparency requirement that is necessary for effective surveillance. Without much controversy, by June 1990 the FOGS negotiation group had agreed upon a text for the improvement of notification procedures, including a general obligation to notify, the establishment of a central registry for notifications and an indicative list of measures to be notified. ${ }^{58}$

Also the suggestion to include a commitment to enhance domestic surveillance did not trigger major controversy once it was clarified that specific measures to this effect would be at the discretion of individual contracting parties (Croome, 1999). The strong idea expressed in the Leutwiler Report to request that contracting parties should produce a 'protectionist balance' sheet that quantifies the costs and benefits of every trade policy measure, which was supported in the first year of negotiations by Australia and New Zealand ${ }^{59}$, did not receive sufficient support in the FOGS group. However, once this idea was weakened and turned into a general political commitment to recognize the value of domestic transparency as suggested by Australia, Canada, Hong Kong and New Zealand in late 1989, objections were easily overcome. ${ }^{60}$ Although some contracting parties questioned the usefulness to include such a weak voluntary provision in the legal framework of the trade regime, it was argued that on a political dimension a nonbinding commitment is better than none. ${ }^{61}$ Clearly, considerations of control and the degree of centralization needed to be taken into account, as it was the voluntary nature and the flexibility of the provision that made agreement on it possible in the first place. This is highlighted by the

56 MTN.GNG/NG14/W/13; MTN.GNG/NG14/W/17; MTN.GNG/NG14/W/20; MTN.GNG/NG14/W/23; MTN.GNG/NG14/W/20

${ }^{57}$ MTN.GNG/NG14/2; MTN.GNG/NG14/W/9; MTN.GNG/NG14/W/13

${ }^{58}$ MTN.GNG/NG14/18

The chairman's report of July 1990 confirms that this agreement had been reached ad referendum (MTN.GNG/NG14/W/44).

${ }^{59}$ MTN.GNG/NG14/W/1; MTN.GNG/NG14/W/13

${ }^{60}$ MTN.GNG/NG14/14; MTN.GNG/NG14/W/37

${ }^{61}$ MTN.GNG/NG14/15 
fact that several contracting parties demanded in the FOGS group to make the voluntary nature of the provision as explicit as possible. ${ }^{62}$ Once this was assured the FOGS group agreed and the provision was eventually included in the text of the TPRM.

\subsubsection{Individual Member Review}

The negotiations for regular reviews of individual contracting parties where more complex than the ones of the TPRM's other features. This complexity did not emerge from a disagreement in principle about the introduction of individual reviews, but rather from the necessity to find compromises between different views on how such reviews should best be conducted and from the need to address designers' concerns over control.

As it was mentioned in section 5.3.2. the origins of the negotiations can be found in the ideas that were expressed in the Leutwiler Report of 1985. With reference to this it was already generally agreed upon in the preparation for the Uruguay Round that the GATT's surveillance function had to be improved. ${ }^{63}$ In this context Australia even submitted a specific negotiation proposals on provisions for member specific reviews already ahead of the round.$^{64}$ It is thus not surprising that the Punta del Este declaration entailed the specific mandate to negotiate improvements to the GATT's surveillance function. These negotiations were conducted in the FOGS group, which picked up on this task in between early 1987 and late 1988. In this context Australia resubmitted the proposal it had made in the preparation for the round. ${ }^{65}$ Many negotiating parties regarded this proposal as a useful starting point, but disagreed on the details expressed in the proposal. ${ }^{66}$ Several other contracting parties followed Australia's example and also submitted proposals on individual country review. Based on this Julius Katz, the Chairman of the FOGS group at the time produced a discussion paper with support of the Secretariat in the fall of 1987. This paper served as a focal point for discussion throughout the rest of 1987 and 1988 (Croome, 1999; VanGrasstek, 2013). By mid-1988 it was evident that it would be possible to reach an agreement on individual country reviews during the Montreal Ministerial Meeting in December 1988 (Croome, 1999). During the Montreal meeting all remaining questions on individual country reviews were resolved and it was decided to introduce the TPRM in its original from in 1989 on a provisional basis. Only the detailed format of country reports was left to be negotiated in the spring of 1989. When this was done the stage was set for the Council to adopt the agreement on individual country reviews in July $1989 .{ }^{67}$ This decision was confirmed in

\footnotetext{
${ }^{62}$ MTN.GNG/NG14/16

63 PREP.COM(86)/7; PREP.COM(86)SR.4; PREP.COM(86)/W/31

${ }^{64}$ PREP.COM(86)W/37

${ }^{65}$ MTN.GNG/NG14/W/1

${ }^{66}$ MTN.GNG/NG14/1

${ }^{67} \mathrm{~L} / 6554$
} 
$1992^{68}$ and eventually the conduct of individual country reviews became a permanent function of the World Trade Organization under the TPRM. ${ }^{69}$

The most important questions that had to be addressed in the negotiation process between 1987 and 1988 related to the general nature of the TPRM in terms of its coverage and the kind of conclusions that would be derived from individual reviews; and to institutional questions, with a particular emphasis on clarifying the role of the Secretariat in the process of conducting reviews. Very roughly speaking a distinction can be made between developed and developing countries on these questions. The former generally expressed a tendency to prefer a review mechanism that covers a wide spectrum of policies, subjecting all members to review, and allowing the Secretariat to independently draw up reports that would not only describe but also analyze policies. The latter were skeptical of a strong review process and especially the role of the Secretariat therein, due to negative experiences made with IMF country surveillance in the context of the 1980s debt crisis (Croome, 1999). How these questions were resolved is elaborated upon in the following. This also shows a strong desire of contracting parties to limit the degree of centralization by introducing control features, such as the limitation of the review mechanism's mandate by clearly delimiting it from dispute settlement procedures.

\subsubsection{The Nature of Reviews: Scope and Strength of Conclusions}

One set of questions that needed to be addressed in the negotiations on individual country reviews were related to the general nature of the review mechanism. Initially this included a short debate whether a strengthening of the GATT's surveillance function should even entail individual member review or whether it should be done on a general level, without targeting specific members. This question was settled by clearly delineating the limits of the review process. In an important debate concerning the kind and the strength of conclusions that would be reached from reviews the members of the trade regime showed a strong preference to limit the degree of centralization by explicitly setting the review process apart from dispute settlement. Nonetheless, the idea of individual country reviews remained subject to debate, as it was also important to reach an agreement on the scope of reviews, in terms of the policies that they would cover. Finally it had to be addressed which countries should be reviewed and to what extent developing countries should be subject to individual review. All of these discussions reflect an underlying motivation to setup the TRPM as a design set that would carefully balance advantages of centralization with considerations of control.

In the pre-negotiations and at the very beginning of the Uruguay Round it needed to be clarified first whether reviews should focus on individual members of the trade regime or whether they should rather take the form of a general, collective assessment of trade policies. In response to Australia's initial proposal on individual reviews some countries reacted skeptically during the preparatory phase of the Uruguay Round. The EC expressed a preference for global

\footnotetext{
${ }^{68} \mathrm{~L} / 6887$

${ }^{69}$ In light of the single undertaking, the scope of reviews increased from reviewing policies related to trade in goods, to also include policies on services, intellectual property and all other agreements covered by the WTO.
} 
instead of individual reviews, arguing that individual annual reviews are of limited success in other international organizations. ${ }^{70}$ It nonetheless indicated a willingness to explore the matter further, as long as it could be reconciled with the overall balance of contracting parties' rights and obligations. ${ }^{71}$ Brazil was even more skeptical, initially rejecting that individual member surveillance should be a subject for negotiations in the Uruguay Round. ${ }^{72}$ Given the generally positive attitude of most of the other contracting parties towards a strengthening of the GATT's surveillance function this position was indefensible. Nonetheless, the discussion about individual member reviews was picked up in the second meeting of the FOGS negotiation group. ${ }^{73}$ Those who were skeptical of individual reviews pointed to the risk that the review process could become similar to dispute settlement and that members might feel like being put on trial for their policies. Reviewing policies collectively would eliminate this risk. Those in favor of individual reviews responded that a collective approach would be diffuse and too general, and would not contribute as much to ensure adherence to the GATT obligations as the individual approach would do. Eventually it was possible to convince all parties to agree to the idea of individual review, but the discussion held at the second FOGS meeting pointed out that the strength of the review mechanism should be controlled for.

While not too controversial, this aspect was fundamental in the negotiations and highlights the importance of control. Several parties argued that an effective surveillance instrument would have to entail some kind of analysis or evaluation of the impacts of policies, and some clarification whether they are in line with the general norms of the multilateral trade regime. ${ }^{74}$ It was assumed that this would facilitate compliance with the rules of the GATT and serve as a counterweight to domestic protectionist pressures. Yet, basically everyone also agreed that reviews should not be regarded as a tool for enforcement of individual GATT obligations, that they should be different from dispute settlement and that they should cast no judgment on the legality of trade measures. ${ }^{75}$ Some parties specified this further by demanding that the TPRM should not lead to any additional obligations imposed on contracting parties. ${ }^{76}$ These qualifications were so important to the negotiating parties that they explicitly included them in the text of the TPRM, which mentions that the mechanism is not "intended to serve as basis for the enforcement of specific obligations under the Agreements or for dispute settlement procedures, or to impose new policy commitments on members" (TPRM, A(i)). Clearly, the degree of centralization was supposed to be limited and reviews should at most be an instrument to exert peer pressure (Croome, 1999). This limitation in the degree of centralization was crucial to enable an agreement on individual country reviews (Int01, Int04, Int09, Int12). As

\footnotetext{
70 PREP.COM(86)SR.4

${ }^{71} \operatorname{PREP} . \operatorname{COM}(86) / 7$

72 PREP.COM(86)/8

${ }^{73}$ MTN.GNG/NG14/2

${ }^{74}$ MTN.GNG/NG14/1; MTN.GNG/NG14/W/1; MTN.GNG/NG14/W/13; MTN.GNG/NG14/W/30

${ }^{75}$ MTN.GNG/NG14/4; MTN.GNG/NG14/5; MTN.GNG/NG14/9; MTN.GNG/NG14/W/8; MTN.GNG/NG14/W/9; MTN.GNG/NG14/W/13; MTN.GNG/NG14/W/20; MTN.GNG/NG14/W/23; MTN.GNG/NG14/W/30

${ }^{76}$ MTN.GNG/NG14/1; MTN.GNG/NG14/W/22; MTN.GNG/NG14/W/23
} 
R. Abbott (1993) put it, "if countries had thought that they would in any sense be facing a kind of tribunal leading to legal judgment. It is probable that there would have been no agreement to launch the exercise in the first place" (pp.117-118).

Related to this was the question on the kind of conclusions that the body in charge of the reviews would reach and how it would reach them. Canada raised this question in July 1987 when asking whether the CONRACTING PARTIES would make recommendations to the member under review. ${ }^{77}$ This was discussed at the FOGS meeting in November $1987 .{ }^{78}$ Some parties suggested that the body in charge of the reviews should directly draw conclusions itself. Others stated that conclusions should be proposed for adoption by the CONTRACTING PARTIES. Some questioned whether conclusions should be drawn at all, and if so what the relation of such conclusions would be to existing rights and obligations of contracting parties. One party pointed out that if conclusions would be drawn they should be descriptive, but not prescriptive. The question was eventually resolved by a proposal of the Nordic Countries, who suggested that the Council should simply take note of a report, but not derive any decisions from this. ${ }^{79}$ This is the practice that is followed in the TPRM and also highlights a cautious approach of contracting parties, aiming to limit the degree of centralization. Reviews are simply meant to provide information and thereby indirectly facilitate compliance, but not to derive any policy prescriptions or recommendations.

Another debate that took place on the nature of the TPRM was related to the scope of reviews. From early on it was suggested that members should write their review report based on a common format, to ensure that the review exercises would be comparable. ${ }^{80}$ However, it remained a matter of debate what the reports should actually entail. One aspect of this debate would be the rigor of the analysis conducted in review reports. Some, and Australia in particular, favored a quantitative economic analysis of the impact of trade policies like it was suggested in the Leutwiler report. ${ }^{81}$ The majority however preferred a softer approach that would be largely descriptive, accompanied by a cautious, mainly qualitative analysis (VanGrasstek, 2013). That the softer approach ultimately came out on top of the negotiations indicates again that a careful balance had to be found between functional benefits of centralization and keeping its degree limited. Another aspect of the debate was related to the scope of reviews. Several developed countries argued that a meaningful review had to be embedded in the wider context of a member's overall macroeconomic policies, including policies that were not covered by the GATT, such as grey area measures. ${ }^{82}$ Still affected by negative experiences from IMF and World Bank surveillance many developing countries argued that review should be confined to trade

\footnotetext{
77 MTN.GNG/NG14/W/10

${ }^{78}$ MTN.GNG/NG14/4

${ }^{79}$ MTN.GNG/NG14/W/17

This was later on confirmed in a proposal by the EC (MTN.GNG/NG14/W/20).

${ }^{80}$ MTN.GNG/NG14/4; MTN.GNG/NG14/W/1; MTN.GNG/NG14/W13

${ }^{81}$ MTN.GNG/NG14/W/1; MTN.GNG/NG14/5

82 MTN.GNG/NG14/4; MTN.GNG/BG14/6; MTN.GNG/NG14/9; MTN.GNG/NG14/17
} 
policies only and not encompass the general economic framework of a member. ${ }^{83}$ Yet, they did also suggest that reviews should pay attention to problems faced by developing countries in their external economic environment, and that they should take financial and monetary developments in this environment, and the impact such developments have on developing countries' trade policies into account. ${ }^{84}$ Eventually a compromise between these positions was found by explicitly establishing in the text of the TPRM that the wider economic context and developmental needs have to be taken into account in reviews of trade policies, but that only trade policies themselves would be subject to review. ${ }^{85}$

Another debate between developed and developing countries was held about the question whether all contracting parties would be subject to review, how often they would be reviewed, and how the burden of undergoing a review could be limited for developing countries. Many developing countries argued that the review exercise should mainly target developed countries. They perceived a surveillance asymmetry in the GATT, because more developing countries had to make use of balance of payments exceptions than developed ones and were thereby more often subject to surveillance by the Balance of Payments Committee. They welcomed the idea to introduce systematic individual member reviews as an opportunity to address this asymmetry, as long as such a mechanism would mainly focus on developed countries. ${ }^{86}$ Furthermore, developing countries argued that the reporting requirements demanded by the review process could be too burdensome for them and that those countries that are already subject to balance of payments consultations should be exempted from review for 24 months. ${ }^{87}$ Others responded that stressing the asymmetry of existing arrangements would be counterproductive and differences in review obligations under GATT committees simply reflect differences in trade policies. ${ }^{88}$ Nonetheless, the first proposals by Australia and by Japan suggested conducting a regular individual review exercise only for a selected group of approximately 30 members of the trade regime. ${ }^{89}$ Several parties regarded this to be problematic and argued that no exceptions should be made and every member should undergo regular individual review. ${ }^{90}$ They were willing to accommodate for developing countries' demands by suggesting that the frequency of reviews could be determined by a contracting party's share of world trade, with the countries having a larger share in world trade being reviewed more often than those with a smaller share. ${ }^{91}$ This suggestion paved the way for agreement and was generally endorsed. ${ }^{92}$ Eventually

${ }^{3}$ MTN.GNG/NG14/W/23

${ }^{84}$ MTN.GNG/NG14/8; MTN.GNG/NG14/9; MTN.GNG/NG14/10; MTN.GNG/NG14/W/23

${ }^{85}$ This is established in section A(ii) of the TPRM, but became already apparent throughout the FOGS negotiations (MTN.GNG/NG14/10; MTN.GNG/NG14/W/30)

$86 \quad$ SR.SOG/10; PREP.COM(86)/8; MTN.GNG/NG14/1; MTN.GNG/NG14/2; MTN.GNG/NG14/4; MTN.GNG/NG14/6; MTN.GNG/NG14/W/23

${ }^{87}$ MTN.GNG/NG14/6; MTN.GNG/NG14/8; MTN.GNG/NG14/W/23

${ }^{88}$ MTN.GNG/NG14/1

${ }^{89}$ MTN.GNG/NG14/W/1; MTN.GNG/NG14/W/8

${ }^{90}$ MTN.GNG/NG14/2; MTN.GNG/NG14/4; MTN.GNG/NG14/10

${ }^{91}$ MTN.GNG/NG14/4; MTN.GNG/NG14/W/13; MTN.GNG/NG14/W/17 
it was agreed to follow a proposal by the Chairman of the FOGS group, suggesting that the four countries with the largest share in world trade would be reviewed every two years, the next 16 every four years, and the rest every six years. Additionally, to address concerns of a double burden, a compromise was found on adapting the review cycle for those members already under balance of payments surveillance. Instead of exempting such members for 24 months, it was agreed that the Chairman of the TPRB would together with the concerned member and the Chairman of the Balance of Payments committee agree on a review schedule that harmonizes regular and balance of payments reviews in a way that would not lead to a postponement of regular reviews for more than 12 months (TPRM, E). Furthermore, to ensure that the burden of review would not be too high it was agreed that members would only have to submit full reports in the years of a review, while short reports on most important policy changes and updated statistical information would suffice in the years between reviews (TPRM, D). Finally, to accommodate least developing countries, it was agreed that longer review periods might be fixed for them, that they could diverge from the standard format of country reports, that their reviews pay particular attention to economic and developmental needs, and that the Secretariat would provide technical assistance in the preparation of a report. ${ }^{93}$

In sum, it can be concluded that limiting the degree of centralization by explicitly separating the TPRM from dispute settlement, by not taking any decisions on conclusions or recommendations of a review and by reducing the analytical rigor of reports, as well as devising appropriate arrangements to take asymmetries of the regime's membership into account was important to reach an agreement on the TPRM. However, these were not the only issues that had to be addressed. A good part of the discussion also surrounded the institutional structures and procedures that would have to be established to conduct individual country reviews.

\subsubsection{The Institutions and Procedures of Review}

A large part of the TPRM negotiations focused on specifying which institutional bodies would conduct the reviews and how these bodies would do so. This involved considerations of centralization as pooling, such as the questions whether existing structures should be used or new ones established to conduct reviews, and whether reviews would be conducted by an open ended body or a small group of selected contracting parties. Also centralization as delegation had to be addressed by specifying the role of the Secretariat in the review process.

Considering centralization as pooling, at the beginning of the negotiations it needed to be clarified whether reviews would be conducted by a plenary body open to all GATT members such as the Council or whether they would be conducted by a limited group of selected contracting parties. Already in the Leutwiler Report and during the preparation of the Uruguay Round it was suggested that groups of two to three contracting parties could form examining panels to conduct reviews under supervision of the Council. ${ }^{94}$ Japan picked up on these

92 MTN.GNG/NG14/5; MTN.GNG/NG14/6; MTN.GNG/NG14/9; MTN.GNG/NG14/10; MTN.GNG/W/23; MTN.GNG/NG14/W/30

${ }^{93}$ MTN.GNG/NG14/16

${ }^{94}$ PREP.COM(86)/7 
suggestions in its first contribution to the FOGS negotiation group and proposed that two to three impartial reviewers selected by the party under review should conduct reviews. These reviews would be finalized in discussions taking place during the bi-annual Special Council meetings. ${ }^{95}$ Also the original Australian proposal suggested that next to annual Special Council reviews based on member reports, a more extensive review of selected individual contracting parties should be conducted by a small group of other contracting parties with the assistance of the Secretariat. ${ }^{96}$ Inspired by this the first version of the FOGS Chairman's discussion paper also suggested that reviews should be carried out by a small number of governmental representatives in the capital of the reviewed member. Based on these reviews a report would have been produced that would have been submitted to the Council (or an alternative body in charge) to comment upon and to adopt it (VanGrasstek, 2013). However, in the FOGS group the view was expressed that in recognition of a shared responsibility for the trade regime, reviews should not be conducted by small panels but collectively. ${ }^{97}$ It was also argued that reviews being conducted by a plenary body would enhance transparency and understanding of each other's trade policies. ${ }^{98}$ By spring 1988 there was general consensus that the reviews themselves should be conducted in a plenary body, but that they should be prepared either by review teams of selected contracting parties, the Secretariat, or a combination thereof. ${ }^{99}$

Parallel to this discussion the question arose what kind of plenary body should be in charge of the reviews. During the preparatory meetings of the Uruguay Round Switzerland had already suggested to establish a Trade Policy Committee to administer GATT's review and surveillance activities. $^{100}$ It repeated this suggestion during the FOGS negotiations. ${ }^{101}$ While some contracting parties where positive about this proposal, suggesting that such a new body could replace the bi-annual Special Council meetings, many others pointed out that the possibility to make use of existing institutional structures should be explored before the establishment of new institutional bodies would be considered. ${ }^{102}$ The Special Council meeting setup constituted the most suitable of these existing structures and many parties focused on this during the negotiations. ${ }^{103}$ The EC argued that conducting reviews in the Council would ensure the unity of the GATT system and avoid the proliferation of specialized bodies. It expressed the concern that the establishment of a new body could send the wrong signal and evoke the impression that a judgment is passed on parties' trade policies in the course of the review process. ${ }^{104}$ Additionally the Nordic Countries pointed out that conducting reviews in the Council would be beneficial,

\footnotetext{
${ }_{95}$ MTN.GNG/NG14/W/8

${ }^{96}$ PREP.COM(86)W/37; MTN.GNG/NG14/W/1

${ }^{97}$ MTN.GNG/NG14/1

${ }^{98}$ MTN.GNG/NG14/4

${ }^{99}$ MTN.GNG/NG14/6

100 PREP.COM $(86) / 7$

${ }^{101}$ MTN.GNG/NG14/W/7

102 MTN.GNG/NG14/2; MTN.GNG/NG14/4

${ }^{103}$ MTN.GNG/NG14/4; MTN.GNG/NG14/6; MTN.GNG/NG14/9; MTN.GNG/NG14/W/30

${ }^{104}$ MTN.GNG/NG14/W/20
} 
because it would underline the importance of reviews. ${ }^{105}$ Many developing countries also supported the idea to conduct reviews in Special Council meetings ${ }^{106}$ and by fall 1988 agreement was reached to make use of the Special Council sessions to conduct reviews. ${ }^{107}$ Later on, in the context of the establishment of the WTO the tasks of the Special Council where taken over by the TPRB.

The negotiations on centralization as pooling where rounded off by a proposal by the Nordic Countries, who suggested in summer 1988 to designate discussants for the Special Council meetings. ${ }^{108}$ These discussants would be governmental representatives acting in personal capacity and would have the task prepare detailed questions and comments for the review meeting. By doing so, the Nordic Countries argued, it would be ensured that review meetings in the Council would actually consist of a real, meaningful discussions, and not end up as a mere procedural exercise to take note of reports. Reactions in the negotiation group where mixed at first ${ }^{109}$, but eventually it was agreed to provide the Chairman of the Council (and later on TPRB) with the authority to select discussants (TPRM, C(iv)).

Next to the discussions on centralization as pooling, centralization as delegation and the role of the Secretariat in the review process had to be clarified. The earliest proposals by Australia, Japan, the US and New Zealand that suggested to conduct reviews by small panels consisting of contracting parities' representatives, already stressed that the Secretariat would play a crucial role in preparation of such reviews by providing reports on the trade policy of the member under review. ${ }^{110}$ When it became apparent in early 1988 that the idea of review panels would not receive sufficient support the Nordic Countries suggested that a mixed team, consisting of external experts and the Secretariat would jointly prepare policy reports for reviews conducted by the Council. ${ }^{111}$ However also the suggestion for mixed teams was not sufficiently supported and it was eventually decided to only let the Secretariat prepare a report. This report would together with the report by the member under review provide the necessary input for the actual reviews conducted by the Council (VanGrasstek, 2013). However, the decision to let the Secretariat prepare a report did not end discussions.

Positions differed strongly regarding the independence of the Secretariat in preparing its report. While developed countries tended to prefer a relatively strong role of the Secretariat in the review process, developing countries tried to limit this role as much as possible. Developed countries argued that it is necessary to equip the Secretariat with the authority to independently prepare an analytical report that would include some form of assessment of the impact of a member's policies. ${ }^{112}$ Adding an analytical report by a neutral party next to a governmental

\footnotetext{
${ }^{105}$ MTN.GNG/NG14/W/17

${ }^{106}$ MTN.GNG/NG14/6

${ }^{107}$ MTN.GNG/NG14/10

108 MTN.GNG/NG14/25

${ }^{109}$ MTN.GNG/NG14/10

${ }^{110}$ MTN.GNG/NG14/W/1; MTN.GNG/NG14/W/8; MTN.GNG/NG14/W/9; MTN.GNG/NG14/W/13

${ }^{111}$ MTN.GNG/NG14/W/17

112 MTN.GNG/NG14/4; MTN.GNG/NG14/6; MTN.GNG/NG14/10
} 
report was regarded to be crucial to assure that the review exercise would not end up as a whitewash (Croome, 1999; VanGrasstek, 2013). ${ }^{113}$ It was furthermore argued that the Secretariat should be allowed to use information from non-official sources and have the right to visit capitals to gather information and discuss with public officials in preparation of its report. ${ }^{114}$ In contrast to this, many developing countries - especially India, Brazil, Malaysia and Yugoslavia - where highly skeptical of equipping the Secretariat with greater authorities due their negative experiences with IMF surveillance (Croome, 1999; VanGrasstek, 2013). They argued that Secretariat reports should be merely factual and leave an assessment of the facts to the member under review. Furthermore they were adamantly opposed the idea that the Secretariat would visit capitals. ${ }^{115}$ For some developing countries this was a highly sensitive issue as they were concerned that such visits could raise the impression that a government would be under the tutelage of an international organization (Croome, 1999).

These opposing views led to big conflicts in the negotiation process, up to the point that some developed countries considered to let go of the undertaking to establish the TPRM if no agreement on the role of Secretariat could be reached (VanGrasstek, 2013). Eventually the issue was relatively elegantly resolved by not specifying the role of the Secretariat much further in the agreement of the TPRM. Regarding the report written by the Secretariat the agreement neither refers to it as being analytical or evaluative, nor does it delimit it to be factual. The agreement simply mentions that a report is "drawn up by the Secretariat on its own responsibility". Also the question of Secretariat visits to capitals was resolved by not specifying it. During the Montreal Ministerial Meeting the delegations of the US and Brazil got into a considerable argument on this question, debating whether the text of the agreement should specify that the Secretariat would visit the capital of the member under review. In the middle of the night the delegations decided to bring the issue to a Green Room meeting. There DG Dunkel pointed out that it would not be necessary to specify in the legal text that the Secretariat could visit capitals for such a practice to be established. This resolved the issue and Dunkel turned out to be right. Although it is not mentioned in the agreement, the practice of Secretariat visits to capitals was quickly established as part of the TPRM (Croome, 1999). ${ }^{116}$ This last comprise permitted the provisional introduction of the TPRM as part of the early harvest that was agreed to at the Montreal Ministerial Meeting.

In light of the controversy about the role of the Secretariat it is not surprising that an attempt by Switzerland to strengthen the role of the Secretariat further after the TPRM had been provisionally established was bound to fail. In May 1990 Switzerland submitted a proposal

\footnotetext{
113 This was confirmed in several interviews with former negotiators and Secretariat members (Int01, Int09, Int12, Int13).

114 MTN.GNG/NG14/4; MTN.GNG/NG14/6; MTN.GNG/NG14/10; MTN.GNG/NG14/W/20

115 MTN.GNG/NG14/4; MTN.GNG/NG14/6; MTN.GNG/NG14/9; MTN.GNG/NG14/10; MTN.GNG/NG14/W/23

During the FOGS meeting in October 1988 two parties even expressed the view that no Secretariat document would be necessary at all to conduct reviews (MTN.GNG/NG14/10).

116 This was confirmed in an interview with one of the negotiators involved in this episode (Int09).
} 
to the FOGS group that suggested strengthening the GATT as an institution. ${ }^{117}$ In this proposal Switzerland picked up on an idea expressed in the Leutwiler Report and argued that the Secretariat should be equipped with a mandate that would explicitly permit it to independently collect information on trade policies, analyze such policies, and to trigger policy dialogues to ensure the success of the TPRM. To conduct such tasks it was furthermore suggested to establish better structures in the Secretariat and to equip it with more resources. However, this suggestion was rejected in the FOGS group, based on the argument that such a step would change the character of the Secretariat from an institution providing support to the contracting parties to one with an independent status that would actively participate in policy dialogues. ${ }^{118}$ This exemplifies that as much as the introduction of the TPRM entailed an increase in the degree of centralization, there were clear limits to this as the contracting parties wanted the GATT to stay a member driven institution.

\subsubsection{Conclusion: Balancing Design and Reaching Agreement}

This last insight summarizes the dynamics that characterized the entire negotiation process of the TPRM quite well. As a former negotiator put it in an interview: "We did not want to fundamentally change the member driven character of the institution, but it was considered to be useful to have a review, a political moment were we could frame some concerns that might come up" (Int01). Clearly most of the discussions during the negotiations were motivated by this basic statement, which expresses nothing else than the necessity to balance functional advantages of centralization with its potential risks and costs. ${ }^{119}$ On some matters the membership was more unified on how this balance was to be struck, such as the decision to limit the mandated of the TPRM, to let reviews be conducted by a plenary body, not to permit the TPRB to reach conclusions based on reviews or to make policy recommendations, and to keep the commitment to domestic transparency voluntary. On other matters, such as the questions about the scope of reviews and the role of the Secretariat, the membership was relatively divided. However, the establishment of the TPRM was never seriously put into question and even the most controversial debates on the TPRM were more about details than about fundamental questions. On the Secretariat's role for example, the overall preference of the membership was to keep centralization in check and sovereignty costs limited (Keesing, 1998). As it was put by a former EC negotiator:

"I think there would have been no way in which one would have accepted a Secretariat view as the final view. The final view within a member driven organization would have to be with the members. So it was very clear throughout the process that the individual member would have the right to present its policy, then we do have a phase were a non-biased Secretariat is doing an objective assessment, but then it goes back to a

\footnotetext{
${ }_{117}$ MTN.GNG/NG14/W/41

118 MTN.GNG/NG14/18

${ }^{119}$ This observation was confirmed in several other interviews as well (Int04, Int10, Int12).
} 
discussion amongst members to check whether questions that might have been raised by the Secretariat are echoed by the members or felt to be nit-picky, too legalizing, or not important. We did not want to create a system were a tiny derogation or violation of a marginal thing would create a problem on an international level." (Int01)

Thus, even the most controversial aspects of the negotiation process were uncontroversial in comparison to negotiation dynamics on other matters during the Uruguay Round. The low sovereignty costs and limited risks of the TPRM that came with the qualification of its mandate and limits the mechanism to be solely an information exercise, as well as the fact that that the TPRM was regarded as a public good without major distributive implications probably explain the relative ease with which the negotiations could be concluded. ${ }^{120}$ To borrow the language of former negotiators, in essence the TPRM is only a 'red face test' that a party, which is reviewed critically, could simply sit out (Int09), and even if a party would be dissatisfied with a review it could get comfort in the thought that 'this time it's me, but next time it's the other and then we are going to have a ball' (Int05). The TPRB simply did not "have any sharp edges from anyone's point of view", it was an exercise in "institution building that wasn't pointed at anybody in particular" (Int10).

${ }^{120}$ This was confirmed in several interviews (Int05, Int09, Int10, Int12, Int17). 


\subsection{Conclusion}

Next to the other institutional changes that the Uruguay Round brought about the TRPM can easily be forgotten. In comparison to the establishment of the WTO and the reforms in dispute settlement the significance of the TPRM seems to shrink. However, underestimating the TPRM would be mistaken. The TPRM is an important institutional feature of the multilateral trade regime. By providing information and promoting transparency it significantly facilitates the smooth conduct of international trade. The relevance of the introduction of the TPRM increases further if it is not compared to the current institutional structures of the regime, but to those existent at the time of its creation. While the GATT fulfilled an information gathering and transparency facilitation function, its surveillance efforts did not systematically target policies of individual contracting parties in a comprehensive manner. In this regard the introduction of the TPRM constitutes a significant increase in centralization. For the first time in the trade regime's history institutional structures were established that aimed to comprehensively review the policies of individual members of the regime. Especially regarding centralization as delegation the introduction of the TPRM constituted a significant development, since the contracting parties had not entrusted the Secretariat with a function as significant as the production of comprehensive individual review reports ever before. This chapter sought to explore how this remarkable development came about.

Overall it can be concluded that functional explanations like the ones suggested by the conjectures of the rational design framework are largely adequate to understand the emergence and design of the TPRM. Not only do theoretical assumptions fit well to the centralization of information gathering and transparency facilitation in the trade regime, they also accurately reflect the underlying motivations of designers to establish the TRPM.

Of course the design process was embedded in the institutional context of the GATT as it had developed throughout history. As such it is plausible that it was shaped by this context and it seems that the existing institutional structures served as a basis that facilitated the design of the TRPM. In this respect the introduction of the TPRM can be regarded as a functionally motivated tipping point in a process of long-term institutional development.

Taking a more general perspective on historical legacy the examination of the negotiation process of the TRPM suggests that the self-conception of the GATT as a member driven organization, which had been firmly established by the time of the Uruguay Round, left an impact on the TPRM. As much as the introduction of the mechanism constituted a remarkable change in centralization in the trade regime, it also exemplifies the caution of contracting parties not to vest too much authority in the hands of the regime's institutions. While interests where rather homogenous, coordination problems limited and explanatory factors that are not accounted for in the rational design framework largely absent, tracing the negotiation process highlights that designers aimed to keep the degree of centralization moderate by carefully balancing centralization and control. In this process the limited interest heterogeneity that was 
present could be bridged by compromise solutions that all parties had an interest in reaching, due to the perception of the mechanism as a public good. Given this perception of the TPRM in combination with its limited degree of centralization, its emergence constitutes a significant, but relatively unspectacular episode of institution building that entailed limited sovereignty costs and did not touch upon distributive questions. Under these conditions functional motivations fell on a fertile soil and could flourish without meeting many significant obstacles. 

6 Conclusion 
This study has started out with the statement by John $\mathrm{H}$. Jackson that in the long run institutional structures might be more important to the multilateral trading system than specific substantive rules. The preceding chapters have shown how such institutional structures have developed and changed throughout the history of the trade regime. Particular attention has been paid to the significant institutional changes that resulted from the Uruguay Round. These changes provide the basis for the institutional architecture of the WTO as it stands today. As it has been pointed out at the beginning, this architecture is beset by shortcomings that become increasingly visible and relevant in the strained situation that the multilateral trading system presently finds itself in. The WTO is currently subject to severe criticism by some of the its most influential members and finds itself in a time of crisis. Unsurprisingly calls for institutional change are getting louder. In light of its problems the trade regime might indeed be currently in need of such change - especially with respect to its legislative functioning and the uneasy relationship between a weak legislative organizational branch and a strong judicial one. In this context Jackson's statement should be taken to heart and attention be paid to institutional structures once again.

In the following this is done by recapitulating the emergence of the trade regime's current institutional structures as it was analyzed in the preceding case studies, including a reflection on how the findings of the case studies correspond to and inform the theoretical elaborations provided in chapter 2 . This allows to derive some general conclusions on the factors that are most likely to influence the dynamics of institutional change. In a separate section these conclusions are summed up in an effort to provide an impetus for further theoretical development on institutional change in the governance structures of international cooperation and organization. Overall it is confirmed that institutional change should be thought of as a bounded rational process, in which the relationship between a particular collective action problem and a supposedly functional institutional response can be compromised by actors' desire to limit the costs and risks of institutional design, by coordination problems of institutional change, and by the given institutional context as it developed throughout history. In a final section the insights of this research are used to reflect on the root causes of the WTO's current institutional problems and the prospects to rectify these problems by institutional change.

\section{Institutional Change in the Trade Regime and Rational Design}

The theoretical framework that was developed in chapter 2 took the rational design literature as a basis. This was done because with centralization and control it provides suitable analytical concepts to capture the empirical phenomena this research is interested in. Furthermore the conjectures developed by the rational design framework provide powerful theoretical assumptions that can guide empirical investigation by pointing out which factors should be paid attention to when examining institutional change. Given its central role in guiding the research it is essential to assess how suitable the rational design framework is to account for instances of institutional change in the trade regime. 
From an abstract perspective this assessment bears a positive result. All three cases analyzed in this study - the emergence of the WTO, the reform of dispute settlement and the introduction of the TRPM - have their origins in the Uruguay Round. The Uruguay Round in turn can be regarded as a deliberate response of the trade regime's membership to address the shortcomings that beset the regime at the time. These shortcomings correspond well to the kind of collective action problems that influence institutional variation according to the rational design framework. In the 1980s the trade regime found itself in crisis, protectionism was on the rise and regime members increasingly acted outside of the GATT's normative framework. There was a need to reduce the incentives to defect on agreements, to get a better overview how regime members behave, and to increase the regime's responsiveness to topical issues that its membership regarded important to address. Given the assumption that the Uruguay Round was motivated by a desire to find a functional response to these problems, and that the institutional changes resulting from it are an integral part of this response, then the rational design framework can be broadly conceived to provide a suitable account.

To some extent this also holds when examining the changes that the case studies analyzed in more detail. The creation of the WTO was partially motivated by the assumption that a stronger focal entity than the GATT would be required to ensure stable cooperation in the context of a changing economic environment, and to deal with the increased scope and complexity of the substantive agreements that were expected to result from the Uruguay Round. In this regard the WTO was thought of as a common house to host all the different outcomes of the Uruguay Round. Such a house was assumed to be advantageous due to its functional benefits in form of a stronger capacity to effectively implement and administer the agreements under its roof. This motivation follows roughly the same logic as the rational design framework does, since it implies that the creation of an organization would facilitate adherence to a variety of substantive provisions, and would reduce the transaction costs of international cooperation in an increasingly complex system.

The reform of the dispute settlement system can be linked to the rational design framework even more explicitly. Especially the rationale of the conjecture that assumes that centralization increases with an increase in the severity of an enforcement problem is clearly reflected in designer's motivations to reform the system. At the time of the Uruguay Round negotiations the dispute settlement mechanisms in the trade regime where regarded to be deficient, endangering the implementation of substantive agreements and the credibility of the GATT. The membership entered the negotiations with the joint motivation that these shortcomings would have to be addressed and that the system had to be fixed to ensure greater adherence to the rules of the regime.

The emergence of the TPRM corresponds to the rational design framework even better. Three of rational design's conjectures on centralization are represented in the motivations that induced the trade regime's membership to negotiate the TPRM. In this respect the TPRM can be regarded as an instance of centralization that was meant to reduce uncertainty about the behavior of individual regime members, to reduce uncertainty about the state of the trading 
system and function as a device to provide early warnings of problems emerging in the system, and to contribute to greater rule adherence. These goals are not only mentioned in the actual agreement that established the TPRM, but were also the driving force behind the TPRM throughout the negotiation process.

Thus, from an abstract perspective the rational design framework can explain all the instances of institutional change that are examined in this study. It can be considered as a powerful tool to investigate institutional change, since the logic that informs its conjectures directs the attention of empirical investigations to the relevant parameters of a collective action problem that influence change. In all three case studies these parameters constitute relevant factors that accurately capture at least parts of the underlying motivations for institutional change.

However, this conclusion needs to be treated cautiously for two reasons. First of all, the framework struggles to account for the specific institutional architecture that emerges from an episode of institutional change. Even when it identifies the underlying motives for change correctly, it faces difficulties in explaining how these motives are translated into the actual design of specific institutional structures. The process of devising such structures is complex, can manifest itself over a long period of time, and functionally motivated ideas can get lost in translation. Carefully tracing processes of change is necessary to understand how the specific setup of institutional structures comes about and shows that several factors can interfere with the design process. As such rational design does not provide information under which conditions functional motivations suffice to bring about change and when such change is absent or different than expected, because other factors interfered. This leads to the second reason why the functional approach of rational design is not sufficient to fully understand institutional change. It runs the risk of overlooking important explanatory factors. In all three cases analyzed for this research the process of change was more complex than the link between collective action problems and functional institutional response that is offered by rational design would suggest. In two out of the three cases important explanatory factors would have been overlooked if the investigation had stopped after the application of the rational design framework. The framework was not shown incorrect in its assumptions, but it proved to be incomplete - it only accounted for some of the factors that influenced change.

Only on the emergence of the TPRM rational design would not have missed out on major explanatory factors. Possibly the low sovereignty costs of the TPRM and its non-distributive character have been important in this respect. These conditions seem to be conducive for functional motivations to be translated into institutional design without much disturbance by intervening factors. However even in the case of the TPRM - just as in the other cases - the functional advantages of an increase in centralization had to be balanced with considerations of control. This highlights the importance of design interaction.

\section{Institutional Change and the Interaction of Centralization and Control}

Chapter 2 made two claims concerning the interaction of centralization and control. Firstly, it provided a theoretical argument that none of the two concepts can be understood without 
taking the other into account. Centralization indicates which institutional entity is in charge of a particular task, while control indicates how this entity is governed to conduct this task. Depending on the form of centralization, control mechanisms differ, because pooling and delegation pose different strategic problems to institutional design that are addressed by different means of control. Concerning the former, control mechanisms manage the horizontal relationship between the different members of an institutional body that takes collective decisions. Concerning the latter, control mechanisms manage the vertical relationship between the membership of an international organization and a third party, to ensure that the third party is acting in a manner that is desired by the membership. The amount of control in turn determines the degree of centralization of an institutional entity. The more control the members of an international organization have over the implementation of an organization's policy output and over the process to derive such output, the lower the degree of centralization. Thus centralization and control supplement each other and are necessary to be examined in tandem to fully understand how they constitute design sets in the institutional architectures that govern international organizations. Secondly, chapter 2 argued that the interaction of centralization and control constitutes one set of factors that needs to be taken into account when examining the process of institutional change. Because actors are assumed to be risk averse and seek to limit the costs of institutional design it was posited that functional benefits of centralization could be compromised by considerations of control when designing institutional structures. Furthermore, when devising control mechanisms close attention needs to be paid to the adequate representation of power relationships in the international arena. This can be difficult since control mechanisms need to reasonably reflect power asymmetries in the international arena, but cannot be too asymmetrical, as they would otherwise risk that institutional design is regarded as illegitimate. Consequently an examination of the process of institutional change needs to be attentive to the dynamics that can unfold from the need to devise design sets that strike an adequate balance between centralization and control. Both theoretical arguments made in chapter 2 have been supported by the case studies.

Considering design interactions in the WTO it has been established that the advent of the WTO constituted a significant change in centralization. For the first time in its history the multilateral trade regime could rest on the support of a proper international organization, with a solid legal basis, clearly defined functions, and stronger means to facilitate the enforcement of a wider scope of substantive agreements that are applicable to its entire membership. However, this significant change in centralization is compromised by strong control mechanisms regarding the organization's legislative and administrative work. All institutional bodies in the organization that have legislative decision-making authority take the form of centralization as pooling and are open to the entire membership; all decisions are taken by consensus; and the Secretariat plays only a marginal role in facilitating decision-making. Due to this, the autonomy of the organization to actively shape policy output independent of its membership is severely limited and the attribute of being member-driven constitutes one of the strongest elements of the WTO's institutional culture. Also, control is formally highly symmetrical in the WTO. Tracing the 
design process of the WTO reveals that formally maintaining symmetrical, individual control was more important to the regime's membership than further centralization, even if this would have been functionally beneficial. The preponderance of formal individual control is exemplified in the negotiation process of the WTO. The less powerful parties rejected the establishment of a small institutional body with limited membership. The more powerful ones in turn pursued to solidify consensus decision-making and to increase the majorities for important decisions such as waivers and amendments, to ensure that they could not be outvoted. Additionally, the membership as a whole was not ready to strengthen the role of the Secretariat in administration and decision-making. The functional deficiencies that can arise from the formally stringent individual control in the trade regime have been addressed by resorting to informal ways of decision-making, which also take power asymmetries into account. However, if anything these forms of centralization are ad hoc and context dependent. If they fail to deliver results, then relying on formal institutional structures is unlikely to resolve the problem. The member-driven character of the organization is not always functionally beneficial and is not easy to reconcile with the rational design framework, but it was a deliberate choice by the membership. This shows that understanding institutional change of centralization is only fully possible when also taking control into account.

The same holds when examining the reform of dispute settlement. Clearly the reformed system ensures that the WTO is a much stronger focal entity in the dispute settlement domain than the GATT used to be, which is characterized by a much more legalist culture. As such the degree of centralization has certainly increased. This is largely due to a change in control mechanisms and considerations of such mechanisms took a prominent role in the reform process. The introduction of reverse consensus constitutes a change in control that boosted the degree of centralization as delegation. Even the introduction of the Appellate Body, which in in itself constitutes an instance of centralization as delegation, was originally meant to be a control mechanism to counterbalance the risk that poor panel reports would be automatically adopted due to the introduction of reverse consensus decision-making. Overall, the reforms of the dispute settlement system led to the emergence of a complex system where different forms of centralization interact with different mechanisms of control. Contrary to the establishment of the WTO the reforms of dispute settlement are characterized by relative institutional autonomy. This is probably mainly due the fact that impartiality and independence are key ingredients of a legitimate dispute settlement system, and because the enforcement of existing rules tends to be less politically sensitive than the negotiation of new rules. Nonetheless, this does not imply that concerns over maintaining control were not important to regime members when negotiating the new system, and they need to be taken into account to understand why the institutional setup of the DSU looks the way it does. While the introduction of reverse consensus constitutes a significant decrease in individual control, several design features were devised during the negotiations to counterbalance this and to limit the risks and potential costs of increased centralization. As it was mentioned, even the Appellate Body in itself was thought to be such a control feature. Furthermore, it should be kept in mind that the significance and the strength of 
the reformed system - and the Appellate Body in particular - as it unfolded after the Uruguay Round came as a surprise to many; i.e. the high degree of centralization that we witness today was not fully intended. It can be assumed that control would have been more stringent if the expectations of designers had been more accurate and less influenced by the conciliatory judicial culture in the GATT. Finally, it needs to be pointed out that considerations about symmetry of control where less important in the design of the dispute settlement system, but nonetheless present. Especially the fact that control over the implementation of the outcomes of a dispute settlement process is ultimately contingent on market power is an important feature of the system. This all shows again that a full understanding of the institutional design of centralization is only possible when also paying attention to control.

This is no different for the last case study. Just as the other instances of change in centralization the TPRM constitutes an increase in the degree of centralization. Nonetheless, its setup and its negotiation history imply that considerations over control constituted an important factor in the design process. Most important in this respect is the limitation of the TPRM's mandate, which sets it apart from dispute settlement and explicitly points out that it is not meant as a means to enforce agreements. Also, the TPRB has no decision-making power and does not even provide the members under review with recommendations. That control is important and that balancing centralization and control can be a delicate task is also exemplified by the TPRM's negotiations on the role of the Secretariat. While providing the Secretariat with the authority to independently carry out research to write trade policy reports constitutes an increase in the degree of centralization in itself, the negotiations of the TPRM where largely characterized by a disagreement how much that should be controlled for. The text of the TPRM solves this disagreement by staying ambiguous and neither explicitly restricting, nor enhancing the role of the Secretariat. This provides the Secretariat with some discretion in the drafting of its reports, but it needs to use this discretion carefully to avoid alienating the membership.

Comparing the different case studies it becomes clear that the balancing act of centralization and control that determines the degree of centralization is dependent on the political sensitivity of the issue under consideration. This in turn can depend on the relationship between different forms of control. When control over implementation of policy outputs is high, then it is less likely that control over the process to derive this output is also high - as it is the case in the TPRM. Furthermore, it is important to take into account whether an institutional body is concerned with policy outputs that are likely to be distributional in nature - such as the negotiation of new substantive agreements - or whether such distributional considerations are largely absent - as it is the case when an institutional body's main task is to gather information. Thus, when an institutional entity is concerned with highly distributional policy outputs that can include large sovereignty or compliance costs, then controlling the process to derive this output is highly important to each individual actor, the degree of centralization can be expected to be limited and the struggle over symmetry of control is likely to be high. However, when an institutional entity is producing policy outputs that do not have large distributional implications and that entail low sovereignty or compliance costs, then the degree of centralization can be high as 
concerns over control decrease. Despite these general tendencies it needs to be stressed though that it can only be understood how the exact balance between centralization and control is struck when examining the design process of institutional arrangements. The same holds when one wants to understand how coordination problems of institutional change are resolved.

\section{Institutional Change and Coordination Problems}

Chapter 2 has pointed out that rational approaches tend to assume more homogeneity of interests amongst actors than there might be present in empirical manifestations of institutional design. In many cases the design of institutional structures constitutes a coordination problem, because actors may have heterogeneous interests regarding the kind of institutional structures they prefer. Such heterogeneity is likely to dependent on the distributive implications of institutional design. Such implications can manifest themselves directly or indirectly. Regarding the direct distributional effects, institutional structures concerning the symmetry of control are per definition distributional in nature. When symmetry of control is defined as determining the relative influence of an organization's members in relation to each other, then designing such institutional features is necessarily a zero sum game. As one member gains in relative influence, another one has to lose. Consequently design processes of these kinds of institutional structures are likely to encounter formidable coordination problems. Regarding indirect distributional effects, chapter 2 argued that interest heterogeneity can also depend on the distributive implications of the substantive agreements that institutional structures are supposed to govern. If a country does not regard substantive agreements to be in its favor and is therefore concerned about compliance costs, it is unlikely to support institutional mechanisms that are meant to facilitate the enforcement of such substantive agreements. The opposite is likely to be the case when a country expects to benefit from substantive agreements and assumes that compliance costs are low. Thus even institutional structures that are not distributive themselves can be difficult to design due to coordination problems. Whether such coordination problems can be overcome is often a function of the distribution of power amongst the parties that negotiate the institutional design. If no compromises can be found then coordination problems can only be resolved if those in favor of changing institutional design are sufficiently powerful to overcome the opposition of those who are against such an endeavor. Thus, investigating institutional change requires investigating how coordination problems are overcome. In this respect attention should be paid to the distributive implications of institutional arrangements and those of the governed substance, as well as to the influence of power as a relevant factor.

Two of the three analyzed cases exemplify this line of reasoning. To understand the emergence of the WTO and the reforms in dispute settlement it is crucial to take the Uruguay Round's negotiations on substance into account, and to pay attention to the impact of power as a significant factor that helped to overcome coordination problems and strongly influenced the negotiation outcome. Considering the establishment of the WTO, the idea to create a proper international organization initially faced a formidable hurdle in form of US opposition. The link to substance helps to understand how this hurdle could be overcome and shows that power had an indirect impact on the negotiation result. The creation of the WTO was a useful means to 
ensure the reinterpretation of the single undertaking and to induce all of the trade regime's members to accept almost all of the substantive agreements of the Uruguay Round - including those on intellectual property rights and trade in services - as a single package that would be enforceable under a unified dispute settlement system. For a long time throughout the Uruguay Round this way of implementing the negotiated substance was contested. It became possible because a sufficient amount of powerful developed countries decided to leave the GATT and enter the WTO, leaving those opposed to the reinterpretation of the single undertaking with the choice between staying in an irrelevant GATT or joining a highly relevant new international organization at the price of singing up to substantive agreements that they otherwise would probably not have joined. Without the given power asymmetries at the time this strategic maneuver would not have been possible. So, a power play to which the creation of the WTO was an integral part was used to overcome a coordination problem regarding the question about the implementation of the substantive agreements negotiated during the Uruguay Round. This in turn helped to overcome the coordination problem regarding the creation of a new organization, because ending the fragmentation of the GATT and making the Uruguay Round's result binding on all regime members, and enforceable via a unified dispute settlement system was highly attractive to the US. The realization that creating the WTO would be useful to achieve this goal provided sufficiently large incentives for the US to give up its opposition to the idea of creating an organization. Thus, without taking the substantive results of the round into account and the influence of power that was necessary to achieve these substantive results, understanding the emergence of the WTO would be incomplete. At the same time the advent of the WTO also shows though that not all coordination problems can be overcome. Regarding the highly distributive issue of symmetry of control, all parties insisted on maintaining formally equally distributed high individual control in the organization. Developing countries where fundamentally opposed to the introduction of a small institutional body with limited membership, while some developed countries had an interest in formalizing consensus to ensure they could not be outvoted. This led to the reinforcement of the trade regime's member driven institutional culture, at the costs of efficiency in administrative and legislative decisionmaking.

Considering the reforms in dispute settlement it is also important to pay attention to coordination problems, the link to substance and especially the use of power to understand how the reform could succeed. At the heart of the negotiations on dispute settlement reform was a coordination problem that arose from opposing interest on the scope of reform, with the US and the EC exemplarily representing the different positions on the matter. The US was in favor of a more rigorous system that would not offer the opportunity of blocking anymore and therefore wanted to reform consensus decision-making. The EC in contrast wanted to ensure individual control over the process and retain decision-making by consensus. The link to substance explains how these different positions emerged. While the US expected to benefit from a rigorous adjudicatory system and thought that compliance costs would be low, the EC was concerned that it would have to face many complains about its agricultural policy that it could not block any 
longer when consensus decision-making would be reformed. It thus expected compliance costs of substantive agreements to increase from a strengthening of the dispute settlement system. Power in turn helps to understand how this coordination problem could be overcome, since it was the US' resort to aggressive unilateralism that induced those who were opposed to a substantive reform of dispute settlement to change their negotiation position.

Only regarding the establishment of the TPRM interests were relatively homogenous and the negotiation process focused mainly on finding compromises on the preferred balance between centralization and control. While not always easy, the negotiations of the TPRM encountered relatively limited coordination problems and proceeded without a significant impact of additional factors. A plausible explanation for this is the absence of distributive implications of the TPRM and its low sovereignty costs that arise from the limitation of its mandate.

Overall the case studies show that the design of institutional features that have distributive and potentially costly effects are likely to encounter significant coordination problems. To understand how these coordination problems affect the process of institutional change, it is necessary to pay attention to the substantive agreements that the institutional features in question are supposed to govern and to take power as a potentially significant factor into account. The impact of the link to substance and power does not necessarily contradict the rational design framework's basic idea that institutional structures are a functional response to collective action problems, but points out that the tone of this response is shaped by the interests of the most powerful. How such a response is developed and how a coordination problem is resolved can only be fully understood when carefully tracing the process of institutional change.

\section{Institutional Change and Institutional History}

In addition to process tracing of a particular episode of institutional change chapter 2 also argued that expanding the timeframe of an investigation by embedding an episode of change in its wider historical context can provide valuable insights. Two main advantages of a longitudinal approach to institutional change have been pointed out in chapter 2. First of all, in contrast to the static-equilibrium approach by rational design, it can detect long-term dynamics of change. For example, institutions might develop in many incremental steps whose accumulated effect constitutes significant change. While each small step on its own might be dismissed by a snapshot approach to institutional change because it seems insignificant, a longitudinal approach is likely to recognize the importance of the single steps and thereby does not miss out on an important dynamic of change. Incremental institutional changes can also prepare a solid basis for a more momentous episode of large-scale institutional change that might not have been possible without such preparation. In this sense an episode of institutional change can be regarded as a tipping point, i.e. a brief, but quick acceleration of a long-term process of small scale, incremental developments. Only examining such a tipping point without paying attention to the basis that it rests upon, would very likely lead to an overestimation of its relevance. Secondly, chapter 2 pointed out that previously established design features can affect future 
choices. Early design decisions can establish path dependent trajectories that determine the available options and direction of change at a later point in time. Thereby the possibilities of institutional change as a response to changes in the characteristics of a collective action problem might be limited to an institutionally pre-defined subset, which could compromise the functionality of change. Two variants of path dependency were mentioned in chapter 2 . The first refers to tangible institutional structures that need to be taken into account in the process of change. This can include decision-making structures that need to be followed to bring change about. Depending on the design of such structures lock-in effects can occur when those who are opposed to change are able to block it because they are in control of decision-making. The second variant of path dependency is cognitive and assumes that institutional change follows previously established trajectories because actors' mind-sets are influenced by the given institutional structure that they are embedded in. Consequently actors interpret the need for change, the options that exist to bring it about, and its likely effects through a cognitive script that is influenced by exactly the institutional setting that they are seeking to change.

For all three case analyses the longitudinal approach has provided a deeper understanding of the institutional design features that emerged from the Uruguay Round and their specific setup. Generally speaking all observed changes can - to varying degrees - be interpreted as tipping points, which were based on the existing institutional structures that had incrementally developed throughout the trade regime's history. This incremental development was conducted cautiously and pragmatically. Each step that was taken relied on previously established design features and sought to address problems of functionality without being unnecessarily adventurous. The case studies have found that the ambiguity regarding the CONTRACTING PARTIES' powers as expressed in Article XXV of the GATT was key in permitting this development. It provided the GATT with the necessary discretion to develop the institutional structures to facilitate the functioning of the trade regime. By the time of the Uruguay Round these structures served as a stepping-stone for larger scale institutional change. As such it would be mistaken to solely regard the institutional structures that emerged from the round to be the result of a single moment of institutional design.

However, this incremental development has not only provided the stepping-stone that facilitated the institutional changes that Uruguay Round brought about, but also restricted the direction of these changes by providing firmly established trajectories that were followed in a path depended process. At least for the establishment of the WTO and the reforms in dispute settlement the impact of path dependence was significant.

Considering the institutional structures of the WTO, its administrative and decision-making structure can largely be interpreted as a formalized continuation of the practices that had incrementally developed in the GATT. Designers relied on an existing set of structures and either took them directly over into the WTO or used them as a source of inspiration to model new ones based on their example. Clearly, designers were in a GATT frame of mind when they devised the institutional architecture of the WTO. The fact that the WTO carries on the GATT's legacy is even explicitly provided for in Article XVI.1 of the WTO agreement. An important part of this legacy is 
the preponderance of symmetrical individual control and the WTO's self-perception as a member driven organization. This institutional feature has its origin in the very early days of the GATT, when being member driven was an externally induced necessity due to the need of the GATT not to bear resemblance to a proper international organization. Throughout the years this feature was consolidated and by the time that external restraints to create more centralized institutional mechanisms for decision-making and regime administration had disappeared, internal lock in effects had emerged that prohibited a reduction of the GATT's member driven character, because none of the GATT's members wanted to give up the privilege of high individual control. Over the years being member driven has become a self-reinforcing norm in the trade regime, but one that did not arise out of functional considerations but simply from the GATT's idiosyncratic historical development. That alternative trajectories would have been possible if they would have been taken at an early enough stage in the regime's development is exemplified by the case of the ITO, which at least would have provided for an executive board as an institutional body with limited membership in charge of efficiently administrating the day to day activities of the organization.

Also in the dispute settlement system important traces of path dependence are discernible. First, as it is the case for the WTO at large, the DSU also relies heavily on previously developed GATT practices. This is explicitly provided for in the legal text of the DSU (Article 3.1). Particularly the panel procedure is a continuation of the GATT's approach to disputes that started to emerge in the early 1950s and that was incrementally institutionalized from then on. Secondly, path dependence manifested itself cognitively, but did this in such a manner that it paradoxically lead to a significant break with the past instead of reinforcing existing institutional structures. The designers of the dispute settlement reform relied on their experience with the GATT's conciliatory approach to dispute settlement to estimate the effects of the reform. This led them to underestimate the impact of the changes they made to the system. The reforms led to a higher degree of centralization, than the negotiators had predicted, with a highly influential Appellate Body at the center. Consequently a post hoc functionalist explanation of change that derives its insights by explaining the emergence of the system, based on its current functioning would overestimate the motivation for centralization.

Overall the historical approach to the case studies adds causal depth to the explanation of the institutional change that emerged from the Uruguay Round. It provides a rich insight of the context in which an episode of institutional change took place and highlights how early design choices affect later endeavors for change.

\section{Summing Up: Implications for Theory Development}

This research has started out with the ambition to contribute to a better theoretical understanding of the underlying dynamics of institutional change in the organizational structures that govern international cooperation. Having conducted three cases studies on changing institutional structures in different functional domains of the multilateral trade regime several conclusions can be drawn that may indeed be conducive to develop such an understanding. 
The first main contribution this dissertation provides to theory development concerns the conceptualization of variables that was provided in chapter 2. Based on a review of existing conceptualizations and applications of the variables, chapter 2 provided an explicit and systematic overview of different forms of centralization and control, and theorized in which relation the two stand to each other in institutional design sets. Thereby two main criticisms of the rational design framework - the high level of abstraction of its variables and the lacking specification of interaction effects - have been addressed. The contribution in this respect lays not so much in deriving new analytical concepts, but more in the clarification of existing ones and their relationship towards each other. The taxonomy of design sets that was derived provides an overview of the different meanings that can be attached to centralization and control. By making these differences explicit and systematically listing them analytical clarity is enhanced and the taxonomy can facilitate a precise discourse on the governance structures of international cooperation. Throughout the case studies the conceptualizations of variables and design sets turned out to be a useful analytical tool to guide empirical investigation. They provided a guideline to systematically examine an organization's institutional anatomy and how its constituent parts form interdependent design sets on different layers within a wider, complex organizational structure. The case studies have shown that centralization and control are indeed mutually dependent on each other. As it will be further elaborated below, this is not only helpful to analyze institutional structures as they stand, but also contributes to a better understanding of institutional change and highlights friction inherent in the rational design framework.

The second main contribution of this dissertation concerns the different factors that influence institutional change. As pointed out in the preceding sections, all in all the case studies confirm the assumption made in chapter 2 that institutional change is best conceived as a bounded rational process. In this sense change can still be understood as an intended functional response to changes in the characteristics of a collective action problem, but the quality of this response can be compromised by desire to reduce risks and costs of change, coordination problems, and path dependent trajectories as they emerged throughout history. How the balance between an intended functional response and compromising factors is struck is case and context specific. Consequently, process tracing remains a methodological necessity to understand the dynamics of change in detail. Yet, to move from theory guided inductive empirical investigations as conducted in this dissertation, towards the development of a theory of institutional change in the governance structures of international cooperation some conclusions can be derived from the case studies that posit which factors are particularly relevant to take into account when examining change. This addresses the remaining two criticisms of the rational design framework - neglecting the notion of change and inducing post hoc explanations that risk overlooking important explanatory factors. In this respect it is noteworthy that the preceding sections have pointed out that many of the theoretical assumptions made in chapter 2 were confirmed by the case studies. In the following an overview of the dynamics that are assumed to influence institutional change the most according to the case studies is provided: 
First: Institutional change tends to be motivated by the desire to address functional problems deriving from a change in the parameters of a collective action problem. This is to say that functional concerns tend to form the initial motivation for change. ${ }^{1}$ As such, the assumptions of the rational design project seem to hold, implying that it is useful to pay attention to changing levels of uncertainty, changing numbers of actors and asymmetry amongst them, and a change in enforcement problems when trying to gain an understanding of changes in centralization and control. However changes in the parameters of a collective action problem are not a sufficient condition to bring about institutional change and often the rational design framework's conjectures only hold at a high level of abstraction. The research suggests that the rational design framework's accuracy is dependent on the costs and risks of change, its distributive effects, and the institutional context in which change is taking place. As it was posited in chapter 2 , more often than not such intervening factors compromise the link between the characteristics of a collective action problem and a functional institutional response that is assumed by the framework.

Second: Designers carefully balance centralization and control to limit the risks and potential costs of institutional change. For this, different design features are used and combined in design sets. This interplay does not only highlight the abovementioned necessity to always analyze centralization and control in tandem, but also points towards inherent friction in the rational design framework. On the one hand the conjectures on centralization mainly rest on the logic that an increase in centralization is motivated by efficiency gains when acting collectively. On the other hand the framework also assumes that control increases with an increase in uncertainty about (the future state of) the world. Assuming that institutional changes in governance structures are themselves subject to substantial uncertainties regarding their exact future effects and likely to bring about unintended side effects, designers are torn between the efficiency gains of centralization and the desire to limit uncertainty by devising adequate control mechanisms. This is entirely rational but shows that the conjectures on centralization are thwarted by the one on control - or vice versa. Depending on one's perspective either more centralization or more control could be regarded rational. ${ }^{2}$ This leaves process tracing as the only methodological possibility to understand institutional change, since it is difficult to predict how designers will strike the balance between centralization and control in design sets. However the case studies suggest some general tendencies that can be taken into account when analyzing how such a balance is struck: When control over the implementation of policy outputs of an international organization is low, this implies potentially high sovereignty costs and controlling the process of deriving such outputs becomes more important. Thus, when control over implementation is low, then the degree of centralization as pooling or centralization as delegation also tends to be low (i.e. control over processes is high). Additionally, when in a

\footnotetext{
${ }^{1}$ The case studies suggest that this applies to both, large scale as well as incremental institutional change.

${ }^{2}$ This implies that the rational design framework is ill suited as a coherent theory in itself, because contrary designs can both be declared to fit the framework by either focusing more on the logic underlying the conjectures on centralization or the one that informs the conjecture on control.
} 
situation where control over implementation is low the policy outputs in question are also likely to have distributional implications, then considerations about symmetry of control will become more important in institutional change, as each relevant actor has a higher desire to maintain individual control - this can lead to formidable coordination problems.

Third: Coordination problems can compromise initial ambitions for institutional change and are necessary to overcome for institutional change to occur. Institutional change of centralization and control is inherently political. As pointed out in the previous paragraph, what is regarded functional can be a matter of perspective. Such perspectives can differ amongst the actors participating in institutional change. Some actors might expect to benefit from strong institutions and as such prefer a larger degree of centralization to maintaining control, while those that expect to lose out from strong institutions regard design sets that strike the balance in favor of control to be more functional. ${ }^{3}$ Depending on the actor constellations and the distribution of power amongst them such difference in preferences can lead to coordination problems that need to be overcome for change to be successful. When analyzing coordination problems in the process of change the results of this research suggest that distributional considerations are key to understand the severity of the coordination problem. When symmetry of control is a major factor inherent in the design set in question, distributional questions are also inherent in this set. In this case change is a zero-sum game and coordination problems are particularly severe. In such situations changing formal structures might not be possible and informal control mechanisms might be relied on to compensate for the lack of formal change. Legislative decision-making structures in instances of pooling tend to be affected by this. Additionally, even institutional structures that are not intrinsically distributive (i.e. symmetry of control only plays a minor role) can be indirectly affected by distributional considerations. When such structures facilitate the implementation of substantive agreements, then those who face low compliance costs of these agreements will favor stronger institutions (i.e. a larger degree of centralization) than those who expect compliance costs to be high. Thus the distributive implications of the substance that is governed by institutional design sets of centralization and control need to be taken into account to understand the severity of coordination problems and the related dynamics of change. When compliance costs to substantive agreements that design sets facilitate to implement differ across actors, then coordination problems tend to be large. Also, centralization in such design sets is only likely to increase if the implementation of substantive agreements is likely to offer direct and significant benefits to those in favor of change. Finally, whether change in the presence of coordination problems is successful depends on the distribution of power amongst the relevant actors. When preferences over change are

\footnotetext{
${ }^{3}$ This can also help to understand the initiation of institutional change, as those actors who perceive to be disadvantaged by the distributive implications of a given institutional setup, might regard such a setup to function sub-optimally and demand change. This is in line with the first claim that posits change to be motivated by the intention to address functional problems, but highlights that the perception of problems and consequently the motivation for change can differ across actors.
} 
heterogeneous, then change will only be successful if the supporters of change are sufficiently powerful to overcome the opposition of those who intend to block it.

Fourth: The direction, kind and degree of change are strongly influenced by a given institutional context as it developed throughout history. In this respect paying attention to history can help to explain the exact design of institutional structures that emerge from an episode of change and also informs the coordination problem that needs to be taken into account when analyzing change. The risk aversion and caution of designers that already informs the interplay of centralization and control, as well as bounded rationality implies that change often occurs incrementally and that in such cases its magnitude can only be grasped when taking a long-term perspective. Existing structures are kept in place as much as possible and only really problematic ones are subject to change. The initial setup of control features is important to understand incremental change. Ambiguous mandates tend to be conducive to incremental change, since they provide the possibility to change institutional mechanisms while avoiding cumbersome procedures. A series of incremental changes in turn can provide a springboard for tipping-points. This is because sufficient experience with gradually strengthened institutional structures allows initially cautious actors to eventually take more adventurous steps. However, even in the case of tipping points it should be kept in mind that existing structures can hinder change to be fully functional, as the direction and kind of change is confined to follow the path laid out by these structures. This tendency is reinforced by cognitive path dependence, which implies that designers rely on their experience with given institutional structures when designing new ones and that their ideas about institutional change are subject to cognitive bias that emerged from such experience. Often this implies that change is conservative and even when change occurs, cognitive path dependence can remain influential, because formally changed structures are still used according to longstanding behavioral patterns and norms. This limits the degree of change, even if it seems significant on paper. However, as the example of the dispute settlement reforms in the trade regime show, cognitive bias can also lead to change becoming unexpectedly revolutionary. Finally, institutional path dependencies are also important to take into account when analyzing change. They tend to be influenced by existing design sets of centralization and control, as they determine which actors are involved in change and influence the power relationship in which these actors stand towards each other. When such design sets introduce self-reinforcing veto points that require actors that benefit from existing institutional structures to agree to changes that make them worse off, then the coordination problem of institutional change can be severely reinforced. This can strengthen conservatism and stall change altogether.

The above elaboration suggests that institutional change is best conceived to work according to a logic of 'history dependent rationality' instead of 'functional rationality'. From the interplay of facilitating and compromising factors that influence supposedly functional institutional change unique dynamics can arise, and in the process of change idiosyncrasies emerge that lead to design sets that where not intended or foreseen at the beginning of the process. This makes it difficult to theoretically predict the precise design of the institutional structures that emerge from an episode of change. However, the provided overview of the dynamics that seem to occur 
regularly may guide further empirical investigations of institutional change in other contexts of international cooperation. In their current state they should mainly be regarded as educated guesses of patterns that inform change in governing structures of international cooperation and not as a coherent theory of change. It would be presumptuous and overgeneralizing to speculate on a theory of institutional change in centralization and control based on the limited empirical investigations conducted in this research. Much work remains to be done and other instances of changes in international cooperation and international organization should be investigated to test whether the conclusions of this dissertation hold on a more general level. In this respect it would be interesting to see whether change follows similar dynamics in international organizations that emerged as more mature and organizationally more complete than the GATT. More than that, further thought needs to be given to the interplay of the different factors that are supposed to affect change and additional factors could be added. In this respect it seems particularly interesting to investigate how the concept of 'flexibility' as it is introduced in the rational design framework affects design sets of centralization and control, because it is another design feature that can be used to reduce the costs and risks of centralization, and seems related to control over implementation. The conclusions provided so far can be used as a starting point to work on this agenda and can already assist in reflecting on the current state of the trade regime's institutional setup.

\section{Reflecting on the Institutional Debate in the WTO}

In the introduction of this dissertation it was observed that the WTO finds itself in an institutional crisis and three major problems that currently beset the WTO's institutional setup were identified. The organization's inability to derive significant new substantive agreements and inefficient decision-making stands out as the first problem. Related to this, the dissertation identified that the WTO lacks the ability to shape and facilitate decision-making independently of its membership. Secondly, the strong judicial branch of the WTO is increasingly getting under pressure and risks alienating important members that accuse the dispute settlement system and the Appellate Body in particular - to have appropriated powers to itself that the membership never granted to it. Finally, the first two problems lead to an institutional imbalance that is characterized by the membership's inability to counterbalance unsatisfactory judicial decisions with legislative responses.

Having reviewed the history of the trade regime concerning its institutional development the sources of these problems can be clearly identified. The institutional origins of the first problem have been pointed out in the case study that analyzed the emergence of the WTO. Regarding administrative structures and decision-making the failure of the ITO and exceptional origins of the GATT necessitated that the trade regime had to be largely administered by its members. This initiated institutional and cognitive path dependencies, which ensured that the regime's membership has always shown a clear preference to formally maintain high individual control to the potential efficiency gains of further centralization. By the time of the WTO's creation this preference and existing path dependencies had become strong enough to prevent the streamlining of administrative and legislative decision-making in the organization, and being 
member-driven would continue to be one of the key institutional attributes of the multilateral trade regime. To a certain extent the first problem is self-induced by the membership and was a conscious design choice.

Partially, the same holds for the second problem. During the Uruguay Round the trade regime's membership clearly aimed to strengthen the regime's judicial function to address enforcement problems. However, the case study on the reform of the dispute settlement system made clear that the magnitude of reform and the large degree of centralization was not fully intended. Particularly the prominence of the Appellate Body and its court like functioning was not expected. It seems that at the time of the Uruguay Round the regime's membership wanted the best of both worlds: a reliable, automatic legal system that would nonetheless maintain conciliatory features and leave room for political maneuver. However, the institutional design sets that were created for this purpose eventually ensured that the legalistic features of the system would trump the political ones in unexpected ways. In the absence of updated and new significant substantive agreements some of the trade regime's members regard this as increasingly problematic.

This points towards the third problem in the WTO's institutional structure - the imbalance between its weak legislative and its strong judicial branch. Although the origins of the first two problems already provide an explanation for this, this explanation is to be supplemented by highlighting the interdependence of the two institutional branches. For this the interaction between centralization as delegation or pooling and the amount of control over implementation should be recalled. The emergence of the TPRM serves as a good example for this, showing that maintaining large control over implementation by constraining the TPRM's mandate increased the membership's willingness to delegate further authorities to the Secretariat in the production of its reports. In case of legislative decision-making and dispute settlement the opposite dynamic was at play. The strengthening of the dispute settlement system reduced control over the implementation of substantive agreements, leading the membership to regard individual control over the process to derive such agreements as even more important than it already had before. Consequently the degree of centralization in institutional decision-making was kept low. In this respect cumbersome decision-making structures and the WTO's limited ability to shape and facilitate decision-making independently of its membership can be regarded as the ultimate control mechanisms for a stronger judicial system. As such, also the third problem should be regarded less as an unintended constitutional flaw, but as a conscious and rationally motivated design feature.

Having reflected on the roots of the WTO's current institutional problems, the insights gained from this research can also be used to inform reflection on the prospects of reform to rectify these problems. In this respect it seems that a fundamental overhaul of the system to deepen multilateral cooperation in the trade regime by further centralization is highly unlikely. Existing path dependencies have not disappeared, the member-driven mantra is even stronger in the WTO than it used to be in the GATT, and it seems that the membership is unwilling to 
strengthen the organization. ${ }^{4}$ Clearly, concerns over individual control are even larger today than they used to be. This is indicated by the fact that in the WTO's legislative and administrative domain the possibility of voting has virtually been outlawed, notwithstanding that the legal text actually provides for it. As it was pointed out in the previous paragraph such concerns over individual control are increased by the strength of the dispute settlement system, leading to a situation where the institutional problems reinforce each other, which dims the prospects for reform. In light of this situation, the coordination problem that would have to be overcome to strengthen the organization and reform its decision-making structures would be formidable. The case studies have shown that overcoming coordination problems requires a sufficiently powerful number of members in favor of change to overcome opposition. However, in the case of centralization of decision-making this is unlikely to happen. Already at the time of the WTO's creation it was not possible to streamline the organization's decision-making, and in light of an even larger and more diverse membership in which power is more widely distributed than it used to be at the beginning of the 1990s, a major overhaul of the system that would put current decision-making practices in question seems outright impossible. This is not even to mention that currently hardly any influential members are in favor of such a major overhaul. It is even questionable whether this would be desirable. As it was pointed out in chapter 3 , consensus is an elegant approach to maintain the illusion of sovereign equality, while taking geo-political realities into account. Thereby it is probably the most appropriate way to balance the competing-demands that decision-making systems have to take into account. Any system that would formally be more exclusive or more autonomous risks alienating the members of the WTO even further from the organization. Furthermore, decision-making by consensus is advantageous as it allows for flexibility in building coalitions along issue specific preferences.

Does the gloomy outlook for institutional reform of the WTO's legislative branch necessarily imply that its judicial branch has to be cut back to restore institutional balance? Given the current political climate the risk for this to happen certainly exists and the fate of the Consultative Group of 18 shows that centralization is not a one-way street in the trade regime. After all, revoking authorities is a possible and not unusual control mechanism to sanction an agent that is perceived to run out of control. The US seems to currently follow this strategy by blocking the appointment of new Appellate Body members. However it is to be hoped that this approach to restore the WTO's institutional balance will not be further pursued. Although not fully intended in its magnitude, the reform of the dispute settlement system as it emerged from the Uruguay Round and the way it has evolved is one of the most significant institutional advancements in the history of international trade cooperation and perhaps even international cooperation in general. Certainly the WTO's members are not always pleased with the output

\footnotetext{
${ }^{4}$ This even holds for the generally appreciated TPRM. A recent decision on reforming the TPRM is exemplary of this. Instead of increasing the capacity and resources of the Secretariat to address the problems of the TPRM in keeping up with the review cycle of two, four and six years it was decided in 2017 to extend the cycle to three, five and seven years, despite the fact that functional improvements could have been brought about at relatively limited costs and a low risks to impinge sovereignty.
} 
and performance of the dispute settlement system in particular cases (especially when they lose), but on a general level the system provides an invaluable contribution to the stabilization of trade relations and predictability under the rule of law.

Given these assessments, what should be the way forward to approach the institutional problems of the trade regime? Considering that thorough reform is either unrealistic or undesirable, the most straightforward way to answer this question is to advise using the existing institutional structures in a different way. Although this would require overcoming solidified patterns of behavior, resisting institutional incentive structures and retreating from longstanding mantras, the existing institutional framework provides for sufficient flexibility to do things differently. In the dispute settlement domain it is not to be forgotten that the membership still has the possibility to approach disputes in a more conciliatory way. For example by turning to the possibility for arbitration that the DSU provides for. Also in the case of decision-making changing the use of formal mechanisms instead of the mechanisms themselves is a viable option. The notion of active consensus is inherently flexible and does not set formal limits on the means that are used to derive a decision taken by passive consensus. In this respect it would be important to discard the taboo of voting, at least for less important or procedural decisions. Even if actual voting would not take place, reintroducing the credible possibility of a vote again would already be helpful, since the dynamics of reaching consensus are fundamentally different and more conducive to reach a decision in the shadow of a vote than in the absence of this shadow. Furthermore, the focus on large negotiation rounds to derive new substantive agreements should be reduced. Instead negotiations could take place on a more continuous basis and perhaps more incrementally. After all, the WTO agreement does not require negotiations to take place in rounds. Continuous negotiations would increase the possibility to reach new agreements in particular sectors when opportunities arise and avoid creating unrealistic expectations of a large round to deliver a ground breaking, comprehensive set of new agreements. This could also reduce the expectations on the meetings of the Ministerial Council to deliver negotiated breakthroughs and allow the supreme organ of the WTO to focus more on providing general policy directions. Finally - and probably most importantly - it is not necessary to approach the negotiations of new agreements as a single undertaking that all members have to sign up to. Coordination problems of decision-making decrease by limiting the number of relevant actors. To avoid standstill, like-minded regime members should be allowed to go ahead and the tendency towards the negotiation of new plurilateral agreements - that are properly integrated into the WTO - should be strengthened in a multi-speed WTO. These steps could provide advancements on substance, which eventually might also increase support for a dispute settlement system again that ensures the enforcement of a rule set that would not regarded to be outdated any longer. 


\section{References}

Abbott, K. W., \& Snidal, D. (2002). Filling in the Folk Theorem: The Role of Gradualism and Legalization in International Cooperation to Combat Corruption. Paper presented at the American Political Science Association Meetings, Boston.

Abbott, K. W., Keohane, R. O., Moravcsik, A., Slaughter, A., \& Snidal, D. (2000). The Concept of Legalization. International Organization, 54(3), 401-419.

Abbott, R. (1993). GATT and the Trade Policy Review Mechanism: Further Reflections on Earlier Reflections. Journal of World Trade, 27(3), 117-119.

Axelrod, R. (2003). The Evolution of Cooperation. In M. Hechter \& C. Horne (Eds.), Theories of Social Order: A Reader (pp. 261-272). Stanford: Stanford University Press.

Baldwin, R. E., \& Kay, D. A. (1975). International trade and international relations. International Organization, 29(01), 99-131.

Barnett, M. N., \& Finnemore, M. (1999). The Politics, Power, and Pathologies of International Organizations. International Organization, 53(4), 699-732.

Barton, J. H., Goldstein, J. L., Josling, T. E., \& Steinberg, R. H. (2006). The Evolution of the Trade Regime: Politics, Law, and Economics of the GATT and the WTO. Princeton: Princeton University Press.

Benzing, M. (2006). Trade Policy Review Mechanism (TPRM). In R. Wolfrum, P.-T. Stoll, \& K. Kaiser (Eds.), WTO: Institutions and Dispute Sett/ment (pp. 619-634). Leiden/Boston: Martinus Nijhoff Publishers.

Bernauer, T., Elsig, M., \& Pauwelyn, J. (2012). Dispute Settlement Mechanism - Analysis and Problems. In A. Narlikar, M. Daunton, \& R. M. Stern (Eds.), The Oxford Handbook on the World Trade Organization (pp. 485-506). Oxford: Oxford University Press.

Bhagwati, J. (1990). Aggressive Unilateralism: An Overview. In J. Bhagwati \& H. T. Patrick (Eds.), Aggressive Unilateralism: America's 301 Trade Policy and the World Trading System (pp. 1-45). Ann Arbor: The University of Michigan Press.

Blackhurst, R. (1991). Strengthening GATT Surveillance of Trade-Related Policies. In E.-U. Petersmann \& M. Hilf (Eds.), The New GATT Round of Multilateral Trade Negotiations: Legal and Economic Problems (pp. 123-155). Deventer: Kluwer Law and Taxation Publishers.

Blackhurst, R., \& Hartridge, D. (2004). Improving the Capacity of the WTO Institutions to Fulfil their Mandate. Journal of International Economic Law, 7(3), 705-716. 
Bliss, J. C. (1987). GATT Dispute Settlement Reform in the Uruguay Round: Problems and Prospects. Stanford Journal of International Law, 23, 31-55.

Bohne, E. (2010). The World Trade Organization: Institutional Development and Reform. Basingstoke: Palgrave Macmillan.

Boonekamp, C. F. J. (2009). Trade Policy Review Mechanism. In K. A. Reinert \& R. S. Rajan (Eds.), Encyclopedia of the World Economy (pp. 1123-1126). Princeton: Princeton University Press.

Boughton, J. M. (2004). The IMF at 60: Reflections on Reform at the IMF and the Demands of a Changing World Economy. Finance and Development, 41(3), 9-13.

Bradley, C. A., \& Kelley, J. G. (2008). The Concept of International Delegation. Law and Contemporary Problems, 71(1), 1-36.

Bronz, G. (1949). The International Trade Organization Charter. Harvard Law Review, 62(7), 1089-1949.

Bronz, G. (1956). An International Trade Organization: The Second Attempt. Harvard Law Review, 69(3), 440-482.

Brown, R. L. (2010). Measuring Delegation. The Review of International Organizations, 5(2), 141175.

Brown, W. A. J. (1950). The United States and the Restoration of World Trade: An Analysis and Appraisal of the ITO Charter and the General Agreement on Tariffs and Trade. Washington, D.C.: The Brookings Institution.

Campbell, J. L. (2004). Institutional Change and Globalization. Princeton: Princeton University Press.

Copelovitch, M. S., \& Putnam, T. L. (2014). Design in Context: Existing International Agreements and New Cooperation. International Organization, 1-23.

Colgan, J. D., Keohane, R. O., \& Van de Graaf, T. (2012). Punctuated Equilibrium in the Energy Regime Complex. The Review of International Organizations, 7, 117-143.

Collins-Williams, T., \& Wolfe, R. (2010). Transparency as a Trade Policy Tool: The WTO's Cloudy Windows. World Trade Review, 9(4), 551-581.

Cortell, A. P., \& Peterson, S. (2006). Dutiful Agents, Rogue Actors, or Both? Staffing, Voting Rules, and Slack in the WHO and WTO. In D. G. Hawkins, D. A. Lake, D. L. Nielson, \& M. J. Tierney (Eds.), Delegation and Agency in International Organizations (pp. 255-280). Cambridge: Cambridge University Press.

Cossy, M. (2015). From Theory to Practice: Drafting and Applying the Dispute Settlement Understanding. In G. Marceau (Ed.), A History of Law and Lawyers in the GATT/WTO: The Development of the Rule of Law in the Multilateral Trading System. Cambridge: Cambridge University Press.

Cottier, T. (2007). Preparing for Structural Reform in the WTO. Journal of International Economic Law, 10(3), 497-508. 
Croome, J. (1999). Reshaping the World Trading System: A History of the Uruguay Round (2. ed.). The Hague: Kluwer Law International.

Courage-van Lier, I.H. (1984) Supervision within the General Agreement on Tariffs and Trade. In P. van Dijk (Ed.), Supervisory Mechanisms in International Economic Organizations (pp. 47-223). Deventer: Kluwer Law and Taxation Publishers.

Curzon, G., \& Curzon, V. (1973). GATT: Trader's Club. In R. Cox \& H. K. Jacobson (Eds.), The Anatomy of Influence: Decision Making in International Organization. New Haven; London: Yale University Press.

Dam, K. W. (1970). The GATT: Law and International Economic Organization. Chicago: The University of Chicago Press.

Davey, W. J. (2005). Institutional Framework. In P. F. J. Macrory, A. E. Appleton, \& M. G. Plummer (Eds.), The World Trade Organization: Legal, Economic and Political Analysis (Vol. 1, pp. 52-87). New York: Springer.

De Souza Farias, R. (2013). Mr GATT: Eric Wyndham White and the Quest for Trade Liberalization. World Trade Review, 12(3), 463-485.

Diebold, W. (1993-1994). Reflections on the International Trade Organization. Northern Illinois University Law Review, 14, 335-346.

Diebold, W. (2002). The End of the ITO. In K. Anderson \& B. Hoekman (Eds.), The Global Trading System (Vol. 1: The Genesis of the GATT, pp. 81-111). London/New York: I.B. Tauris \& Co. Ltd.

Donaldson, V. (2005). The Appellate Body: Institutional and Procedural Aspects. In P. F. J. Macrory, A. E. Appleton, \& M. G. Plummer (Eds.), The World Trade Organization: Legal, Economic and Political Analysis (Vol. 1, pp. 1277-1340). New York: Springer.

Drache, D. (2000). The Short but Significant Life of the International Trade Organization: Lessons for Our Time. Retrieved from http://wrap.warwick.ac.uk/2063/

Duffield, J. S. (2003). The Limits of "Rational Design". International Organization, 57(2), 411-430.

Dunkel, A. (1987). Trade Policies for a Better Future: The 'Leutwiler Report' the GATT and the Uruguay Round. Dordrecht: Martinus Nijhoff Publishers.

Ehlermann, C.-D., \& Ehrig, L. (2005). Decision-Making in the World Trade Organization: Is the Consensus Practice of the World Trade Organization Adequate for Making, Revising and Implementing Rules on International Trade? Journal of International Economic Law, 8(1), 51-75.

Elsig, M. (2010a). Principal-agent Theory and the World Trade Organization: Complex Agency and "Missing Delegation". European Journal of International Relations, 20(10), 1-23.

Elsig, M. (2010b). The World Trade Organization at Work: Performance in a Member Driven Milieu. The Review of International Organizations, 5(3), 345-363.

Elsig, M. (2013). Legalization Leap and International Institutions - The Design of the WTO's Dispute Settlement System. NCCR Trade Working Papers. NCCR. 
Elsig, M. (2014). Legalization Leap and International Institutions - The Design of the WTO's Dispute Settlement System.

Elsig, M., \& Eckhardt, J. (2015). The Creation of the Multilateral Trade Court: Design and Experiential Learning. World Trade Review, 14(1), 13-32.

Elsig, M., \& Pollack, M. A. (2014). Agents, Trustees, and International Courts: The Politics of Judicial Appointment at the World Trade Organization. European Journal of International Relations, 20(2), 391-415.

Endo, M. (2005). Japan. In P. F. J. Macrory, A. E. Appleton, \& M. G. Plummer (Eds.), The World Trade Organization: Legal, Economic and Political Analysis (Vol. 3, pp. 171-181). New York: Springer.

Fearon, J. D. (1998). Bargaining, Enforcement, and International Cooperation. International Organization, 52(2), 269-305.

Feis, H. (1948). The Geneva Proposals for an International Trade Charter. International Organization, 2(1), 39-52.

Feketekuty, G. (1990). U.S. Policy on 301 and Super 301. In J. Bhagwati \& H. T. Patrick (Eds.), Aggressive Unilateralism: America's 301 Trade Policy and the World Trading System (pp. 91-103). Ann Arbor: The University of Michigan Press.

Finlayson, J. A., \& Zacher, M. W. (1983). The GATT and the Regulation of Trade Barriers: Regime Dynamics and Functions. In S. D. Krasner (Ed.), International Regimes (Vol. 273-314). Ithaca: Cornell University Press.

Footer, M. E. (1997). The Role of Consensus in GATT/WTO Decision-making. Northwestern Journal of International Law \& Business, 17(653-680).

Footer, M. E. (2006). An Institutional and Normative Analysis of the World Trade Organization. Leiden: Martinus Nijhoff Publishers.

Footer, M. E. (2011). The WTO as a 'Living Instrument': The Contribution of Consensus DecisionMaking and Informality to Institutional Norms and Practices. In M. Elsig \& T. Cottier (Eds.), Governing the World Trade Organization: Past, Present and Beyond Doha (pp. 217-240). Cambridge: Cambridge University Press.

Frieden, J. A. (1999). Actors and Preferences in International Relations. In D. A. Lake \& R. Powell (Eds.), Strategic Choice and International Relations (pp. 39-76). Princeton: Princeton University Press.

G7. (1990). Huston Economic Declaration. Retrieved from http://www.g8.utoronto.ca/summit/1990houston/declaration.html - trade

Ganesan, A. V. (2015). The Appellate Body in its Formative Years: A Personal Perspective. In G. Marceau (Ed.), A History of Law and Lawyers in the GATT/WTO: The Development of the Rule of Law in the Multilateral Trading System (pp. 517-546). Cambridge: Cambridge University Press. 
GAO. (1994). Report to Congress - The General Agreement on Tariffs and Trade: Uruguay Round Final Act Should Produce Overall U.S. Economic Gains. (GAO/GGD-94-83a). Washington, D.C.: United States General Accounting Office.

General Agreement on Tariffs and Trade, (1986).

Ghosh, A. (2008). Monitoring the Monitors: Strengthening the WTO's Information System. Paper presented at the South Asia Research-Policy Dialogue on Global Economic Governance on Trade, New Delhi.

Ghosh, A. (2010). Developing Countries in the WTO Trade Policy Review Mechanism. World Trade Review, 9(3), 419-455.

Goldstein, J. L. (2002). Creating the GATT Rules: Politics, Institutions, and American Policy. In K. Anderson \& B. Hoekman (Eds.), The Global Trading System (Vol. 1: Genesis of the GATT, pp. 156-180). London: I.B. Tauris.

Goldstein, J. L., \& Gowa, J. (2002). US National Power and the Post-War Trading Regime. World Trade Review, 1(3), 153-170.

Goldstein, J. L., \& Steinberg, R. H. (2008). Negotiate or Litigate? Effects of WTO Judicial Delegation U.S. Trade Politics. Law and Contemporary Problems, 71(1), 257-282.

Goldstein, J. L., Kahler, M., Keohane, R. O., \& Slaughter, A. (2000). Introduction: Legalization and World Politics. International Organization, 54(3), 385-399.

Gorter, W. (1954). GATT after Six Years: An Apprisal. International Organization, 8(1), 1-18.

Gould, E. R. (2007). When Do IO Voting Rules Matter?: A Comparative Analysis of International Organizations' Formal Decision-Making Rules.

Greenwald, J. (2003). WTO Dispute SettIment: An Exercise in Trade Law Legislation. Journal of International Economic Law, 6(1), 113-124.

Haggard, S. (1988). The Institutional Foundations of Hegemony: Explaining the Reciprocal Trade Agreements Act of 1934. International Organization, 42(1), 91-119.

Hainsworth, S. M. (1995). Sovereignty, Economic Integration, and the World Trade Organization. Osgoode Hall Law Journal, 33(3), 583-622.

Hall, P. A. (2009). Historical Institutionalism in Rationalist and Sociological Perspective. In J. Mahoney \& K. Thelen (Eds.), Explaining Institutionalism in Rationalist and Sociological Perspective (pp. 204-224). Cambridge: Cambridge University Press.

Hathaway, O. A. (2008). International Delegation and State Sovereignty. Law and Contemporary Problems, 71(1), 115-149.

Havana Charter for an International Trade Organization, (1948).

Hawkins, D. G., \& Jacoby, W. (2006). How Agents Matter. In D. G. Hawkins, D. A. Lake, D. L. Nielson, \& M. J. Tierney (Eds.), Delegation and Agency in International Organizations (pp. 199-228). Cambridge: Cambridge University Press.

Hawkins, D. G., Lake, D. A., Nielson, D. L., \& Tierney, M. J. (2006). Delegation Under Anarchy: States, International Organizations, and Principal-Agent Theory. In D. G. Hawkins, D. A. 
Lake, D. L. Nielson, \& M. J. Tierney (Eds.), Delegation and Agency in International Organizations (pp. 3-38). Cambridge: Cambridge University Press.

Hay, C., \& Wincott, D. (1998). Structure, Agency and Historical Institutionalism. Political Studies, 46(5), 951-957.

Hilf, M. (1991). Settlment of Disputes in International Economic Organizations: Comparative Analysis and Proposals for Strengthening the GATT Dispute Settlement Procedures. In E.-U. Petersmann \& M. Hilf (Eds.), The New GATT Round of Multilateral Trade Negotiations: Legal and Economic Problems (2nd ed.). Deventer: Kluwer Law and Taxation Publishers.

Hippler Bello, J., \& Holmer, A. F. (1990). The Hear of the 1988 Trade Act: A Legislative History of the Amendments to Section 301. In J. Bhagwati \& H. T. Patrick (Eds.), Aggressive Unilateralism: America's 301 Trade Policy and the World Trading System (pp. 49-89). Ann Arbor: The University of Michigan Press.

Hoda, A. (2001). Tariff Negotiations and Renegotiations under the GATT and the WTO: Procedures and Practices. Cambridge: Cambridge University Press.

Hoekman, B. (2009). Uruguay Round. In K. A. Reinert, R. S. Rajan, A. J. Glass, \& L. S. Davis (Eds.), The Princeton Encyclopedia of the World Economy. Princeton: Princeton Universty Press.

Hoekman, B. M., \& Kostecki, M. M. (2009). The Political Economy of the World Trading System: The WTO and Beyond ( 3 ed.). Oxford: Oxford University Press.

Hooghe, L., \& Marks, G. (2015). Delegation and Pooling in International Organizations.Review of International Organizations, 10(3), 305-328.

Hudec, R. E. (1970). The GATT Legal System: A Diplomat's Jurisprudence. Journal of World Trade, 4, 615-665.

Hudec, R. E. (1971). GATT of GABB? The Future Design of the General Agreement on Tariffs and Trade. The Yale Law Journal, 80(7), 1299-1386.

Hudec, R. E. (1980). GATT Dispute Settlement after the Tokyo Round: An Unfinished Business. Cornell International Law Journal, 13(2), 145-203.

Hudec, R. E. (1990a). The GATT Legal System and World Trade Diplomacy (2nd ed.). Salem: Butterworth Legal Publishers.

Hudec, R. E. (1990b). Thinking about the New Section 301: Beyond Good and Evil. In J. Bhagwati \& H. T. Patrick (Eds.), Aggressive Unilateralism: America's 301 Trade Policy and the World Trading System (pp. 113-159). Ann Arbor: The University of Michigan Press.

Hudec, R. E. (1993). Enforcing International Trade Law: The Evolution of the Modern GATT Legal System. Salem: Butterworth Legal Publishers.

Hudec, R. E. (1999a). Essays on the Nature of International Trade Law. London: Cameron May.

Hudec, R. E. (1999b). The New WTO Dispute Settlement Procedure: An Overview of the First Three Years. Minnesota Journal of Global Trade, 8(1), 1-53. 
Irwin, D. A. (1998). From Smoot-Hawley to Reciprocal Trade Agreements: Changing the Course of U.S. Trade Policy in the 1930s. In M. D. Bordo, C. Goldin, \& E. N. White (Eds.), The Defining Moment: The Great Depression and the American Economy in the Twentieth Century (pp. 325-352). Chicago: University of Chicago Press.

Irwin, D. A., Mavroidis, P. C., \& Sykes, A. O. (2008). The Genesis of the GATT. Cambridge: Cambridge University Press.

Jackson, J. H. (1967). The General Agreement on Tariffs and Trade in United States Domestic Law. Michigan Law Review, 66(2), 249-332.

Jackson, J. H. (1969). World Trade and the Law of GATT. Indianapolis: Bobbs-Merrill Company, Inc.

Jackson, J. H. (1978). The Crumbling Institutions of the Liberal Trade System. Journal of World Trade, 12(2), 93-106.

Jackson, J. H. (1990). Restructuring the GATT System. London: Pinter Publishers.

Jackson, J. H. (1991). Strengthening the International Legal Framework of the GATT-MTN System: Reform Proposals for the New GATT Round. In E.-U. Petersmann \& M. Hilf (Eds.), The New GATT Round of Multilateral Trade Negotiations: Legal and Economic Problems (2nd ed.). Deventer: Kluwer Law and Taxation Publishers.

Jackson, J. H. (1997). The Great 1994 Sovereignty Debate: United States Acceptance and Implementation of the Uruguay Round Results. Columbia Journal of Transnational Law, 26, 157-188.

Jackson, J. H. (2006). Sovereignty, the WTO and Changing Fundamentals of International Law. Cambridge: Cambridge University Press.

Jones, K. (2009). Green Room Politics and the WTO's Crisis of Representation. Progress in Development Studies, 9(4), 349-357.

Jupille, J., Mattli, W., \& Snidal, D. (2013). Institutional Choice and Global Commerce. Cambridge: Cambridge University Press.

Kaiser, K. (2006). Article IV WTO Agreement. In R. Wolfrum, P.-T. Stoll, \& K. Kaiser (Eds.), WTO: Institutions and Dispute Sett/ment. Leiden/Boston: Martinus Nijhoff Publishers.

Kantchevski, P. D. (2006). The Difference between the Panel Procedures of the GATT and the WTO: The Role of GATT and WTO Panels in Trade Dispute Settlement. Brigham Young University International Law \& Management Review, 3(1), 79-140.

Katznelson, I., \& Weingast, B. R. (2005). Intersections Between Historical and Rational Choice Institutionalism. In I. Katznelson \& B. R. Weingast (Eds.), Preferences and Situations: Points of Intersection Between Historical and Rational Choice Institutionalism (pp. 124). New York: Russell Sage Foundation.

Kazeki, J. (2009). Permanent Group of Experts under the SCM Agreement. Journal of World Trade, 43(5), 1031-1045. 
Keesing, D. B. (1998). Improving Trade Policy Reviews in the World Trade Organization. Washington, DC: Institute for International Economics.

Keohane, R. O. (1984). After Hegemony: Cooperation and Discord in the World Political Economy. Princeton: Princeton University Press.

Keohane, R. O., \& Nye, J. S. (1977). Power and Interdependence: World Politics in Transition. Boston: Little, Brown and Company.

Kim, S. Y. (2010). Power and the Governance of Global Trade: From the GATT to the WTO. Ithaca: Cornell University Press.

Kissack, R. (2011). Crisis Situations and Consensus Seeking: Adaptive decision-making in the FAO and Applying its Lessons to the Reform of the WTO. In M. Elsig \& T. Cottier (Eds.), Governing the World Trade Organization: Past, Present and Beyond Doha (pp. 241262). Cambridge: Cambridge University Press.

Koremenos, B. (2007). If Only Half of International Agreements Have Dispute Resolution Provisions, Which Half Needs Explaining? The Journal of Legal Studies, 36(1), 189-212.

Koremenos, B. (2008). When, What, and Why do States Choose to Delegate? Law and Contemporary Problems, 71(1), 151-192.

Koremenos, B., \& Snidal, D. (2003). Moving Forward, One Step at a Time. International Organization, 57(2), 431-444.

Koremenos, B., Lipson, C., \& Snidal, D. (2001a). The Rational Design of International Institutions. International Organization, 55(4), 761-799.

Koremenos, B., Lipson, C., \& Snidal, D. (2001b). Rational Design: Looking Back to Move Forward. International Organization, 55(5), 1051-1082.

Krasner, S. D. (1983). Structural Causes and Regime Consequences: Regimes as Intervening Variables. In S. D. Krasner (Ed.), International Regimes (pp. 1-21). Ithaca: Cornell University Press.

Lacarte Muró, J. (2011). The Origins and Back to the Future: A Conversation with Ambassador Julio Lacarte Muró. In T. Cottier \& M. Elsig (Eds.), Governing the World Trade Organization: Past, Present and Beyond Doha. Cambridge: Cambridge University Press.

Lacarte Muró, J. (2015). Launching the Appellate Body. In G. Marceau (Ed.), A History of Law and Lawyers in the GATT/WTO: The Development of the Rule of Law in the Multilateral Trading System (pp. 476-481). Cambridge: Cambridge University Press.

Laird, S. (1999). The WTO's Trade Policy Review Mechanism - From through the Looking Glass. The World Economy, 22, 741-764.

Laird, S., \& Valdés, R. (2012). The Trade Policy Review Mechanism. In A. Narlikar, M. Daunton, \& R. M. Stern (Eds.), The Oxford Handbook on the World Trade Organization (pp. 463484). Oxford: Oxford University Press.

Lake, D. A. (2007). Delegating Divisible Sovereignty: Sweeping a Conceptual Minefield. The Review of International Organizations, 2(3), 219-237. 
Lake, D. A., \& McCubbins, M. D. (2006). The Logic of Delegation to International Organizations. In D. G. Hawkins, D. A. Lake, D. L. Nielson, \& M. J. Tierney (Eds.), Delegation and Agency in International Organizations (pp. 341-368). Cambridge: Cambridge University Press.

Lindén, A. (2015). The First Years of the GATT Legal Service. In G. Marceau (Ed.), A History of Law and Lawyers in the GATT/WTO: The Development of the Rule of Law in the Multilateral Trading System (pp. 135-140). Cambridge: Cambridge University Press.

Lipson, C. (1983). The Transformation of Trade: The Sources and Effects of Regime Change. In S. D. Krasner (Ed.), International Regimes (pp. 233-271). Ithaca: Cornell University Press.

Luyten, P. (2015). We were Young Together: At the GATT, 1956-58. In G. Marceau (Ed.), A History of Law and Lawyers in the GATT/WTO: The Development of the Rule of Law in the Multilateral Trading System (pp. 79-84). Cambridge: Cambridge University Press.

Marceau, G., Porges, A., \& Baker, D. A. (2015). Introduction and Overview. In G. Marceau (Ed.), A History of Law and Lawyers in the GATT/WTO: The Development of the Rule of Law in the Multilateral Trading System (pp. 1-59). Cambridge: Cambridge University Press.

March, J. G., \& Olsen, J. P. (1996). Institutional Perspectives on Political Institutions. Governance: An International Journal of Policy and Administration, 9(3), 247-264.

March, J. G., \& Olsen, J. P. (1998). The Institutional Dynamics of International Political Orders. International Organization, 54(4), 943-969.

Martin, L. L. (1992). Interests, Power, and Multilateralism. International Organization, 46(4), 765792.

Martin, L. L., \& Simmons, B. A. (1998). Theories and Empirical Studies of International Institutions. International Organization, 52(4), 729-757.

Matsushita, M. (2012). The Dispute Settlement Mechanism at the WTO: The Appellate Body Assessment and Problems. In A. Narlikar, M. Daunton, \& R. M. Stern (Eds.), The Oxford Handbook on the World Trade Organization (pp. 507-534). Oxford: Oxford University Press.

Matsushita, M. (2015). Reflections on the Functioning of the Appellate Body. In G. Marceau (Ed.), A History of Law and Lawyers in the GATT/WTO: The Development of the Rule of Law in the Multilateral Trading System (pp. 547-558). Cambridge: Cambridge University Press.

Mattli, W. (2001). Private Justice in a Global Economy: From Litigation to Arbitration. International Organization, 55(4), 919-947.

Mavroidis, P. C. (1991-1992). Surveillance Schemes: The GATT's New Trade Policy Review Mechanism. Michigan Journal of International Law, 13, 374-414.

Mavroidis, P. C., \& Wolfe, R. (2015). From Sunshine to a Common Agent. The Evolving Understanding of Transparency in the WTO. Robert Schuman Centre for Advanced Studies Research Paper No. RSCAS PP 2015/01; Columbia Public Law Research Paper 
No. 14-461. Available at SSRN: https://ssrn.com/abstract=2569178 or http://dx.doi.org/10.2139/ssrn.2569178.

McIntyre, E. (1954). Weighted Voting in International Organizations. International Organization, $8(4), 484-497$.

McKenzie, F. (2008). GATT and the Cold War: Accession Debates, Institutional Development, and the Western Alliance, 1947-1959. Journal of Cold War Studies, 10(3), 78-109.

Milner, H. (1990). The Political Economy of U.S. Trade Policy: A Study of the Super 301 Provision. In J. Bhagwati \& H. T. Patrick (Eds.), Aggressive Unilateralism: America's 301 Trade Policy and the World Trading System (pp. 163-180). Ann Arbor: The University of Michigan Press.

Mitchell, R. B., \& Keilbach, P. M. (2001). Situation Structure and Institutional Design: Reciprocity, Coercion and Exchange. International Organization, 55(4), 891-917.

Moe, T. M. (2005). Power and Political Institutions. Perspectives on Politics, 3(2), 215-233.

Mora, M. M. (1993-1994). A GATT With Teeth: Law Wins Over Politics in the Resolution of International Trade Disputes. Columbia Journal of Transnational Law, 31, 103-180.

Morrow, J. D. (2001). The Institutional Features of the Prisoners of War Treaties. International Organization, 55(4), 971-991.

Naiki, Y. (2004). The Mandatory/Discretionary Doctrine in WTO Law: The US - Section 301 Case and its Aftermath. Journal of International Economic Law, 7(1), 23-72.

Oatley, T. H. (2001). Multilateralizing Trade and Payments in Postwar Europe. International Organization, 55(4), 949-969.

Odell, J. S. (2005). Chairing a WTO Negotiation. Journal of International Economic Law, 8(2), 425448.

Odell, J. S., \& Eichengreen, B. (1998). The United States, the ITO, and the WTO: Exit Options, Agent Slack, and Presidential Leadership. In K. A.O \& C. Aturupane (Eds.), The WTO as an International Organization. Chicago: The University of Chicago Press.

O'Neal Taylor, C. (1997). The Limits of Economic Power: Section 301 and the World Trade Organization Dispute Settlement System. Vanderbilt Journal of Transnational Law, 20, 209-348.

Ostry, S. (2001). World Trade Organization: Institutional Design for Better Governance. In R. B. Porter, P. Sauvé, A. Subramanian, \& A. Beviglia Zampetti (Eds.), Efficiency, Equity, and Legitimacy: The Multilateral Trading System at the Millennium (pp. 361-386). Washington, D.C.: Brookings Institution Press.

Paemen, H. (2005). The European Union. In P. F. J. Macrory, A. E. Appleton, \& M. G. Plummer (Eds.), The World Trade Organization: Legal, Economic and Political Analysis (Vol. 3, pp. 111-135). New York: Springer.

Paemen, H., \& Bensch, A. (1995). From the GATT to the WTO: The European Community in the Uruguay Round (Vol. 31). Leuven: Leuven University Press. 
Pahre, R. (2001). Most-Favored-Nation Clauses and Clustered Negotiations. International Organization, 55(4), 859-890.

Patterson, G., \& Patterson, E. (1994). The Road from GATT to MTO. Minnesota Journal of Global Trade, 35-59.

Pauwelyn, J. (2005). The Transformation of World Trade. Michigan Law Review, 104, 1-70.

Pedersen, P. N. (2006). The WTO Decision-Making Process and Internal Transparency. World Trade Review, 5(1), 103-131.

Petersmann, E.-U. (1994). The Dispute SettIment System of the World Trade Organization and the Evolution of the GATT Dispute Settlment System Since 1948. Common Market Law Review, 31, 1157-1244.

Petersmann, E.-U., \& Hilf, M. (1991). The New GATT Round of Multilateral Trade Negotiations: Legal and Economic Problems. Deventer: Kluwer Law and Taxation Publishers.

Pierson, P. (2000). The Limits of Design: Explaining Institutional Origins and Change. Governance: An International Journal of Policy and Administration, 13(4), 475-499.

Pierson, P. (2004). Politics in Time: History, Institutions, and Social Analysis. Princeton University Press: Princeton.

Porges, A. (2015). The Legal Affairs Division and Law in the GATT and the Uruguay Round. In G. Marceau (Ed.), A History of Law and Lawyers in the GATT/WTO: The Development of the Rule of Law in the Multilateral Trading System (pp. 223-235). Cambridge: Cambridge University Press.

Porges, A., \& Price, D. M. (2005). The United States. In P. F. J. Macrory, A. E. Appleton, \& M. G. Plummer (Eds.), The World Trade Organization: Legal, Economic and Political Analysis (Vol. 3, pp. 379-435). New York: Springer.

Preeg, E. H. (1995). Traders in a Brave New World: The Uruguay Round and the Future of the International Trading System. Chicago: The University of Chicago Press.

Price, V. C. (1992). New Institutional Developments in GATT. Minnesota Journal of Global Trade, 1, 87-110.

Putnam, R. D. (1988). Diplomacy and Domestic Politics: The Logic of Two-Level Games. International Organization, 42(3), 427-460.

Qureshi, A. H. (1990). The New GATT Trade Policy Review Mechanism: An Exercise in Transparency or "Enforcement"? Journal of World Trade, 24(3), 147-160.

Qureshi, A. H. (1992). Some Reflections on the GATT TPRM, in the Llght of the Trade Policy Review of the European Communities. Journal of World Trade, 26(6), 103-120.

Qureshi, A. H. (1995). Some Lessons from 'Developing' Countries' Trade Policy Reviews in the GATT Framework: An Enforcement Perspective. The World Economy, 18(3), 489-503.

Reinalda, B., \& Verbeek, B. (2004). The Issue of Decision Making within International Organizations. In B. Reinalda \& B. Verbeek (Eds.), Decision Making Within International Organizations. London: Routledge. 
Richards, J. E. (2001). Institutions for Flying: How States Built a Market in International Aviation Services. International Organization, 55(4), 993-1017.

Rubin, S. J. (1949). The Judicial Review Problem in the International Trade Organization. Harvard Law Review, 63(1), 78-98.

Ruggie, J. G. (1983). International Regimes, Transactions, and Change: Embedded Liberalism in the Postwar Economic Order. In S. D. Krasner (Ed.), International Regimes (pp. 195231). Ithaca: Cornell University Press.

Sarooshi, D. (2005). Internaltional Organizations and their Exercise of Sovereign Powers. Oxford: Oxford University Press.

Scharpf, F. W. (1988). The Joint-Decision Trap: Lessons From German Federalism and European Integration. Public Administration, 66(2), 239-278.

Scharpf, F. W. (1997). Games Real Actors Play: Actor Centered Institutionalism in Policy Research. Boulder: Westview Press.

Schermers, H. G., \& Blokker, N. M. (2003). International Institutional Law: Unity within Diversity (4 ed.). Leiden: Nijhoff.

Shaffer, G., Elsig, M., \& Puig, S. (2016). The Extensive (but Fragile) Authority of the WTO Appellate Body. Law and Contemporary Problems, 79(1), 237-273.

Shapiro, M. (1980). Appeal. Law \& Society Review, 14(3), 629-661.

Shell, G. R. (1995). Trade Legalism and International Relations Theory: An Analysis of the World Trade Organization. Duke Law Journal, 44(5), 829-927.

Srinivasan, T. N. (2007). The Dispute Settlement Mechanism of the WTO: A Brief History and an Evaluation from Economic, Contractarian and Legal Perspectives. The World Economy, 30(7), 1033-1068.

Steger, D. (2000). The World Trade Oranization: A New Constitution for the Trading System. In M. Bronckers \& R. Quick (Eds.), New Directions in International Economic Law: Essays in Honour of John H. Jackson (pp. 135-153). London: Kluwer Law International.

Steger, D. (2002a). The Appellate Body and its Contribution to WTO Dispute Settlment. In D.L.M Kennedy \& J.D. Southwick (Eds.), The Political Economy of International Trade Law: Essays in Honor of Rovert E. Hudec (pp. 482-495). Cambridge: Cambridge Univeristy Press.

Steger, D. (2002b). The Rule of Law or the Rule of Lawyers. Journal of World Investment, 3(5), 769-792.

Steger, D. (2002c). Free Trade, Sovereignty, Democracy: The Future of the World Trade Organization, by C.E. Barfield [book review]. Journal of International Economic Law, 5(2), 165-170.

Steger, D. (2004). Improvements and Reforms of the WTO Appellate Body. In F. Ortino \& E.-U. Petersmann (Eds.), The WTO Dispute Sett/ment System 1995-2003 (pp. 41-49). The Hague: Kluwer Law International. 
Steger, D. (2015). The Founding of the Appellate Body. In G. Marceau (Ed.), A History of Law and Lawyers in the GATT/WTO: The Development of the Rule of Law in the Multilateral Trading System (pp. 447-465). Cambridge: Cambridge University Press.

Steger, D., \& Hainsworth, S. M. (1998). World Trade Organization Dispute Settlement: The First Three Years. Journal of International Economic Law, 1(2), 199-226.

Stein, A. A. (1983). Coordination and Collaboration: Regimes in an Anarchic World. In S. D. Krasner (Ed.), International Regimes (pp. 61-91). Ithaca: Cornell University Press.

Steinberg, R. H. (2002). In the Shadow of Law or Power? Consensus-Based Bargaining and Outcomes in the GATT/WTO. International Organization, 56(2), 339-374.

Steinberg, R. H. (2004). Judicial Lawmaking at the WTO: Discursive, Constitutional, and Political Constraints. The American Journal of International Law, 98(2), 247-275.

Stewart, T. P. (1993). The GATT Uruguay Round: A Negotiation History (1986-1992). Deventer: Kluwer Law and Taxation Publishers.

Stiles, K. (1996). Negotiating Institutional Reform: The Uruguay Round, the GATT and the WTO. Global Governance, 2(1), 119-148.

Stoler, A. L. (2004). The WTO Dispute Settlment Process: Did the Negotiators Get what They Wanted? . World Trade Review, 3(1), 99-118.

Stoler, A. L. (2008). Breaking the Impasse: A Critical Mass Approach to Multilateral Trade Negotiations.

Retrieved

from http://www.iit.adelaide.edu.au/docs/critical_mass_speech_final.pdf

Stone, R. W. (2011). Controlling Institutions: International Organizations and the Global Economy. Cambridge: Cambridge University Press.

Sutherland, P., Bhagwati, J., Botchwey, K., FitzGerald, N., Hamada, K., Jackson, J. H., . . . De Montbrial, T. (2004). The future of the WTO: Addressing institutional challenges in the new millennium. Report of the Consultative Board to the Director-General Supachai Panitchpakdi. Geneva: WTO.

Tallberg, J. (2002). Delegation to Supranational Institutions: Why, How and with What Consequences? West European Politics, 25(1), 23-46.

Thelen, K. (1999). Historical Institutionalism in Comparative Politics. Annual Review of Political Science, 2, 269-404.

Thompson, A. (2006). Screening Power: International Organizations as Informative Agents. In D. G. Hawkins, D. A. Lake, D. L. Nielson, \& M. J. Tierney (Eds.), Delegation and Agency in International Organizations (pp. 229-254). Cambridge: Cambridge University Press.

Thompson, A. (2010). Rational Design in Motion: Uncertainty and Flexibility in the Global Climate Change Regime. European Journal of International Relations, 16(2), 269-296.

Toye, R. (2003). Developing Multilateralism: The Havana Charter and the Fight for the International Trade Organization, 1947-1948. The International History Review, 25(2), 282-305. 
Unterhalter, D. (2015). The Authority of an Institution: The Appellate Body under Review. In G. Marceau (Ed.), A History of Law and Lawyers in the GATT/WTO: The Development of the Rule of Law in the Multilateral Trading System (pp. 466-475). Cambridge: Cambridge University Press.

USTR. (2018). 2018 Trade Policy Agenda and 2017 Annual Report of the President of the United States on the Trade Agreements Program. Washington, D.C.: Office of the United States Trade Representative. Retrieved from https://ustr.gov/sites/default/files/files/Press/Reports/2018/AR/2018\%20Annual\%20 Report\%20FINAL.PDF.

Van den Bossche, P. L. H. (2005). Radical Overhaul or Pragmatic Change? The Need and Scope for Reform of Decision-Making in the World Trade Organization. Paper presented at the International Institutional Reform: 2005 Hague Joint Conference on Contemporary Issues of International Law, The Hague.

Van den Bossche, P. L. H. (2006). From Afterthought to Centrepiece: The WTO Appellate Body and its Rise to Prominence in the World Trading System. In G. Sacerdoti, A. Yanovich, \& J. Bohanes (Eds.), The WTO at Ten (pp. 289-325). Cambridge: Cambridge University Press.

Van den Bossche, P. L. H., \& Zdouc, W. (2017). The Law and Policy of the World Trade Organization: Text, Cases and Materials (4th ed.). Cambridge: Cambridge University Press.

VanGrasstek, C. (2013). The History and Future of the World Trade Organization. Geneva: WTO Publications.

Weiler, J. H. H. (2001). The Rule of Lawyers and the Ethos of Diplomats: Reflections on WTO Dispute Settlement. In R. B. Porter, P. Sauvé, A. Subramanian, \& A. Beviglia Zampetti (Eds.), Efficiency, Equity, and Legitimacy: The Multilateral Trading System at the Millennium (pp. 334-350). Washington, D.C.: Brookings Institution Press.

Wendt, A. (2001). Driving with the Rearview Mirror: On the Rational Science of Institutional Design. International Organization, 55(4), 1019-1049.

Wilcox, C. (1947). The London Draft of a Charter for an International Trade Organization. The American Economic Review, 37(2), 529-541.

Wilcox, C. (1972). A Charter for World Trade. New York: Arno Press.

Wilkinson, R. (2011). Barriers to WTO Reform: Intellectual Narrowness and the Production of Path-Dependent Thinking. In T. Cottier \& M. Elsig (Eds.), Governing the World Trade Organization: Past, Present and beyond Doha (pp. 313-336). Cambridge: Cambridge University Press.

Williams, P. (2015). Law and Lawyers in the Multilateral Trading System: Back to the Future. In G. Marceau (Ed.), A History of Law and Lawyers in the GATT/WTO: The Development of 
the Rule of Law in the Multilateral Trading System (pp. 85-108). Cambridge: Cambridge University Press.

Winham, G. R. (2005). An Interpretative History of the Uruguay Round Negotiation. In P. F. J. Macrory, A. E. Appleton, \& M. G. Plummer (Eds.), The World Trade Organization: Legal, Economic and Political Analysis (Vol. 1, pp. 3-25). New York: Springer.

Winham, G. R. (2006). An Institutional Theory of WTO Decision-Making: Why Negotiation in the WTO Resembles Law-Making in the U.S. Congress. Controversies in Global Politics \& Societies. Munk Centre for International Studies.

Winham, G. R. (2008). The Evolution of the Global Trade Regime. In J. Ravenhill (Ed.), Global Political Economy (2nd ed., pp. 137-171). Oxford: Oxford University Press.

World Trade Organization. (1995). Guide to GATT Law and Practice: Analytical Index (6th ed.). Geneva WTO

World Trade Organization. (2007). World Trade Report 2007 - Six Decades of Multilateral Trade Cooperation: What Have We Learnt? Geneva: WTO Publications.

Xu, Y.-C., \& Weller, P. M. (2004). The Governance of World Trade: International Civil Servants and the GATT/WTO. Cheltenham; Northampton: Edward Elgar Publishing.

Yerxa, R. H. (2001). Comment. In R. B. Porter, P. Sauvé, A. Subramanian, \& A. Beviglia Zampetti (Eds.), Efficiency, Equity, and Legitimacy: The Multilateral Trading System at the Millennium (pp. 381-386). Washington, D.C.: Brookings Institution Press.

Young, M. K. (1995). Dispute Resolution in the Uruguay Round: Lawyers Triumph over Diplomats. The International Lawyer, 29(2), 389-409.

Zamora, S. (1980). Voting in International Economic Organizations. The American Journal of International Law, 74(3), 566-608.

Zutshi, B. K. (2001). Comment. In R. B. Porter, P. Sauvé, A. Subramanian, \& A. Beviglia Zampetti (Eds.), Efficiency, Equity, and Legitimacy: The Multilateral Trading System at the Millennium (pp. 387-391). Washington, D.C.: Brookings Institution Press. 



\section{Interviews}

The following list gives an overview of the interviews conducted with former Uruguay Round negotiators, as well as former and current Secretariat officials of the World Trade organization.

\begin{tabular}{|c|c|c|c|c|c|}
\hline Alias & & Date & Place & $\begin{array}{l}\text { Former } \\
\text { negotiator for }\end{array}$ & $\begin{array}{l}\text { Secretariat } \\
\text { official }\end{array}$ \\
\hline Int01 & & 01.02 .2015 & Brussels & EC & \\
\hline Int02 & & 03.11 .2015 & Telephone & US & formerly \\
\hline Int03 & & 09.11 .2015 & Geneva & EC & currently \\
\hline Int04 & & 09.11 .2015 & Geneva & South Africa & currently \\
\hline Int05 & & 09.11 .2015 & Geneva & Brazil & currently \\
\hline Int06 & & 10.11.2015 & Geneva & & formerly \\
\hline Int07 & & 16.11 .2015 & Telephone & Switzerland & \\
\hline Int08 & & 15.12 .2015 & Telephone & & formerly \\
\hline Int09 & & 15.12 .2015 & Telephone & US & formerly \\
\hline Int10 & & 15./17.12.2015 & Telephone & & formerly \\
\hline Int11 & $*$ & 09.02 .2016 & Geneva & Mexico & \\
\hline Int12 & & 10.02 .2016 & Geneva & & formerly \\
\hline Int13 & $*$ & 10.02 .2016 & Geneva & & formerly \\
\hline Int14 & $*$ & 11.02 .2016 & Geneva & & formerly \\
\hline Int15 & $*$ & 12.02 .2016 & Geneva & & formerly \\
\hline Int16 & & 25.02.2016 & Telephone & India & \\
\hline Int17 & & 22.11 .2016 & Telephone & Hong Kong & formerly \\
\hline Int18 & & 22.05 .2018 & Telephone & EC & formerly \\
\hline Int19 & & 08.06 .2018 & Telephone & Canada & formerly \\
\hline
\end{tabular}

Interview Transcripts on file with the author.

* Memory based interview transcript upon request of the interviewee. 



\section{Summary}

This dissertation aims to explore the dynamics of institutional change in the multilateral trade regime. It focuses on those institutional structures that relate to the governance of the regime; i.e. the structures of the trading system's international organizations that determine policy output. These kind of structures are politically very sensitive, as they capture how much authority is transferred from the national to the international level and how decisions are taken on this level. The most recent episode of significant institutional change of this nature came about in 1995 as a result of the Uruguay Round, which led to the creation and design of the World Trade Organization (WTO), including reforms in the trade regime's dispute settlement system and the introduction of the Trade Policy Review Mechanism (TPRM). This episode of institutional change stands at the center of the investigation conducted in this dissertation. Exploring this episode is highly relevant as it sheds light on the origins of the current institutional problems that the trade regime is facing, and because it provides a rich narrative that is useful to inform the development of theories on institutional change of the governance structures of international organizations.

In doing so, the research relies on theory guided process tracing. Making use of literature on rational and historical institutionalism a theoretical framework is developed to guide empirical investigation of institutional change in the trade regime. Three cases are examined in the course of this investigation. The first addresses the establishment and institutional setup of the WTO, including its legislative decision-making structures. The second examines the reforms in dispute settlement that resulted from the Uruguay Round, and the third sheds light on the creation of the TPRM.

The theoretical framework is developed in chapter 2 of this dissertation. It takes the rational design framework developed by Koremenos et al. $(2001)^{1}$ as underlying basis for this. This framework is suitable because with centralization and control it provides two variables that capture the institutional structures that are of interest to this dissertation. Centralization indicates whether a focal entity conducts a particular institutional task. It thereby indicates who, i.e. which institutional bodies or actors, are in charge of a certain kind of policy output. Control in turn indicates how such output is derived. Together they can indicate the institutional architecture that governs an international organization. Furthermore, the rational design

\footnotetext{
${ }^{1}$ Koremenos, B., Lipson, C., \& Snidal, D. (2001). The Rational Design of International Institutions. International Organization, 55(4), 761-799.
} 
framework provides conjectures that specify under which conditions centralization and control are assumed to vary. It thereby offers a starting point to conceptualize institutional change.

However, the chapter argues that the rational design framework only constitutes a starting point to guide empirical investigations, because it depicts four weaknesses that need to be addressed. First, the framework's variables are only very broadly defined and need to be specified further before they can be applied to the empirical analyses of international organizations. Second, the framework does not elaborate on the possible interaction of its different variables. Yet, such interaction can be important to fully understand real-world instances of institutional design. Third, rational design has not been developed to explicitly capture the notion of change. It approaches institutional design as a static-equilibrium and takes a 'snapshot' of an organization's institutional structure at a particular point in time. Thereby the framework is prone to neglect long-term dynamics of institutional change. Fourth, the rational design framework takes a functional approach to the emergence of institutional structures. This can induce post-hoc research designs that explain the existence of such structures by the functions they fulfill. Such approaches are at risk to overlook alternative explanatory factors of institutional design.

To address these shortcomings the chapter adapts the framework for the purpose of this dissertation in two steps. In the first step, centralization and control as relevant variables are specified, and their interaction is explored. This results in finer conceptual distinctions of the variables and shows that the variables can take different forms. It is argued that such differentiation is important, because the different forms that the variables can take follow different logics of institutional design. Furthermore, the different conceptualizations are necessary to analyze the institutional architecture of an international organization in detail. In this respect, it is shown that different kinds of centralization and control necessarily occur together and form building blocks that constitute the complex, multilayered architecture of an international organization.

In the second step, the chapter elaborates on the notion of institutional change. Four sets of factors are identified that need to be taken into account to understand the underling dynamics of institutional change. The first set is provided by the rational design framework itself. Resting on functional assumptions institutional change is regarded as a response to the variation in the characteristics of a collective action problem. Although this is a powerful theoretical starting point, change tends to be more complex than the suggested functional link between a collective action problem and institutional design. This is highlighted by the three other sets of factors. The second set points out that institutional change is affected by the desire to reduce the risks and costs of such change. The third set highlights that institutional change is often contested, which might lead to compromises in institutional design that are functionally suboptimal. The fourth set of factors points to the importance of the institutional and historical context in which an episode of change takes place. This shows that that change can be a long-term process, characterized by path dependencies that limit the options for change and that make it contingent on previous institutional developments. To understand how these different sets of 
factors play out the chapter argues that empirical process tracing is a methodological necessity. The presences of factors that tend to interfere with functional approaches to institutional change also shows that such change should not be conceived as a fully rational, but rather as a bounded rational process.

Equipped with these insights, the dissertation proceeds with the empirical investigation of the case studies. Chapter 3 explores the creation of the WTO and the design of its administrative institutional structures and legislative decision-making procedures. It first establishes why the creation of the WTO is to be regarded as a change of centralization and control in comparison to its predecessor, the GATT. This shows that the advent of the WTO clearly constitutes an increase in centralization in comparison to the GATT, due to its more formal status as a proper international organization, its stronger enforcement capacity, wider scope and larger membership. However, when examining the WTO's institutional architecture in detail differences to the GATT are less pronounced and it becomes clear that the degree of centralization is significantly limited by the tight control that the membership maintains over the organization's legislative and administrative functioning.

The chapter proceeds by exploring how the functional explanations offered by the rational design framework can account for the emergence and design of the organization. In doing so it is shown that on a high level of abstraction rational design can account reasonably well for the creation of the WTO. Generally speaking, the idea to create the WTO was motivated by the desire for having a proper organizational structure to support the implementation of the substantive agreements that resulted from the Uruguay Round, which was in turn initiated as a response to address the collective action problems that beset the multilateral trading system during the 1980s. However, rational design faces shortcomings in accounting for the WTO's specific institutional architecture and in answering the question why the organization emerged despite initially strong opposition by the US as the most powerful actor during negotiations.

To address these shortcomings the chapter examines the wider history of the trade regime's institutional development. This shows that the WTO's administrative and decision-making structure can largely be considered as a formalized continuation of (informal) practices that had developed incrementally in the GATT. In this respect the creation of the WTO is to be interpreted as a significant last step, a tipping point, of a long-term process of institutional development that shows strong traces of path dependency. This helps to understand the architecture of the WTO and the high degree of control that the membership has over the organization. However, it does not address how the opposition to the creation of the organization could be overcome.

Tracing the negotiation process that led to the creation of the WTO sheds light on this matter. Such process tracing points to power as an important factor influencing institutional change and shows that institutional questions can often not be separated from questions on substance. This section of the chapter argues that the US as an initially powerful veto player, eventually dropped its opposition to the establishment of the WTO after it had realized that the 
creation of an organization could be used as a means to ensure substantively beneficial negotiation outcomes. Given the asymmetric distribution of power at the time, the US and other developed countries were able to use the creation of the WTO to overcome the opposition of many developing countries to a uniform application of the Uruguay Round's substantive agreements. In essence, the creation of the organization was used to resolve contested distributive questions on substance to the advantage of the trade regime's most influential members, which in turn provided sufficient incentive for the US to drop its opposition. This argument does not necessarily contradict functional explanations of institutional change, but highlights that it is often the most powerful who are able to define what is to be regarded as functional.

Finally, chapter 3 examines how concerns over costs and risks of institutional change influenced the WTO negotiations and how they are reflected in the WTO's design. Adding to the historical section, it is shown that the long-standing emphasis on individual control and sovereign equality that characterized the trade regime's history also shaped the Uruguay Round negotiations. Concerns over control, playing out in a path dependent institutional context limited the opportunities for formal institutional change and reinforced existing trajectories. Functional gains from further centralization were of secondary importance to considerations of individual control during the negotiations and had to be forgone. Thus, the WTO remained very similar to the GATT in terms of decision-making and regime administration. To compensate for this lack of formal centralization, the WTO continues the trade regime's practice to rely on informal procedures that are less inclusive and that account for power asymmetries. This mix of formal and informal procedures is a convenient way of maintaining the illusion of sovereign equality amongst states while taking political realities into account. In the current setup, informal approaches can facilitate decision-making; but when they fail, the large amount of formal individual control implies that decision-making can easily get paralyzed.

Overall, the chapter shows that functional approaches like the one of rational design are a useful starting point to understand the emergence of the WTO, its institutional architecture and decision-making principles. They provide reasonably adequate accounts of the underlying motives for change. However, they face weaknesses in explaining how these motives are translated into actual design. Some ideas get lost in translation, since historical context, negotiation dynamics, and concerns over individual control moderate and at times distort functional design. In the case of the WTO this moderation implied that institutional change was more conservative with respect to its administration and legislative function than the news of the creation of a new international organization would on the surface suggest.

Chapter 4 shows that this was significantly different concerning the WTO's judicial function. The changes in centralization and control that the Uruguay Round brought about in the field of dispute resolution constitute a remarkable increase of centralization in the trade regime. On a general level, centralization increased because the Uruguay Round brought about the unification of a previously fragmented dispute settlement system, with a compulsory and exclusive 
jurisdiction under the auspices of the WTO as a proper international organization. More specifically, several institutional design features that characterize the setup of dispute settlement in the trade regime were changed, leading to more centralization and less control than it used to be the case before the Uruguay Round. The introduction of reverse-consensus as a decision making practice for key decisions in the dispute settlement process, the creation of the Appellate Body, and the streamlining of panel procedures are to be identified in this respect.

To understand this institutional change, the rational design framework is consulted first, showing that in theory the framework is highly suitable to account for the reform of the trade regime's dispute settlement mechanism. Also empirical investigations reveal that the underlying motives that motivated the reform correspond well to the assumptions of the framework. In essence, the trade regime's membership wanted to address functional deficiencies of the dispute settlement system that were thought to endanger the implementation of substantive agreements and the credibility of the GATT. However, such a purely functional account is unable to explain how the interest heterogeneity that characterized the negotiations on dispute settlement was overcome, and it would overlook the impact of historical legacies on institutional change.

To address this, the chapter proceeds by delineating the development of dispute settlement mechanisms throughout the trade regime's history. In doing so it becomes clear that path dependencies partially explain the dynamics of change and the resulting design of the WTO's dispute settlement system. They provide a seemingly paradoxical explanation of both, conservative but also revolutionary aspects of the institutional reforms that the Uruguay Round brought about. On the one side, institutional path dependencies show that large parts of the WTO's approach to dispute settlement, are a continuation of practices that had incrementally developed throughout the history of the GATT. In this regard the reform of dispute settlement can be interpreted as a significant tipping point in a long-term process of institutional development, rather than the result of a revolutionary moment of rational design. On the other side, some elements of the reform - like the introduction of reverse consensus and the Appellate Body - constitute a significant break with the past and changed the trade regime's culture of dispute settlement from a political, conciliatory one to a highly legalistic one. It is argued that cognitive path dependencies contribute to understand this revolutionary change: Designers underestimated the implications of the reform and did not expect a significant shift in legal culture, because their expectations of the results of change were biased by their experiences with the longstanding GATT system. Thus the break with the past was not fully intended and the degree of centralization that resulted from the reforms was higher than initially foreseen. It seems plausible that this facilitated the reforms, as it downplayed potential costs of the large increase in centralization. Overall, the historical review illuminates how past practices have informed the design of the WTO's dispute settlement system in a bounded (instead of fully) rational process. Yet it does not help to understand how coordination problems during the negotiations were overcome. 
Such problems certainly existed. Despite the fact the trade regime's members shared the general view that the dispute settlement system needed to be reformed, they differed in opinion on how this reform should look like. To show how such problems were overcome, the chapter continues by tracing the negotiation process that led to the reforms. At the heart of the problems were different negotiation interests of the US and the EC regarding decision-making procedures in dispute settlement. Initially the EC was firmly opposed to US demands for a more automatic approach to dispute settlement, which included calls to reform the existing approach of decision-making by consensus. Only when the US made use of its powerful position in the international trading system and resorted to aggressive unilateral policies to open foreign markets, the EC (and others) were induced to change their negotiating position and agreed to the introduction of reverse consensus as a new decision-making practice. Power thus played a crucial role in the reform of the system. Furthermore, tracing the negotiation process also shows that several of the institutional changes in dispute settlement should be regarded as spin-off effects of larger discussions that took place during the Uruguay Round. The decision to establish the Appellate Body for example can be considered as a domino effect of the introduction of reverse-consensus. The unification of the dispute-settlement system in turn emerged in the slipstream of the wider negotiations that led to the establishment of the WTO.

The last section of the chapter takes a closer look at the design interaction of centralization and control, and highlights how the trade regime's membership sought to find an adequate balance between the benefits, the costs and the risks of creating a more independent dispute settlement system by devising adequate control elements. Since impartiality and independence are important features of the dispute settlement system, and since the enforcement of existing obligations is politically less sensitive than the negotiation of new obligations, it is not surprising that control is less stringent for dispute settlement than for the WTO's legislative procedures. This is best exemplified by the introduction of reverse consensus for major decisions in the dispute settlement process. However, several other design features were supposed to counterbalance this revolutionary reduction of control, indicating that controlling the WTO's autonomy in dispute settlement was a relevant factor that influenced the design of the system. The chapter also shows that the same holds true for control mechanisms that determine the relative influence of different members on the system - albeit to a lesser extent.

In sum, the chapter finds that the explanations of rational design account well for the core motivation of the change in the dispute settlement system, but historical process tracing and attention considerations of control is necessary to get a better understanding of its particular design features. Furthermore power is highly significant to account for the large degree of centralization that the Uruguay Round brought about in the trade regime's dispute settlement domain.

Chapter 5 introduces the last case study and examines the emergence of the Trade Policy Review Mechanism (TPRM) - a design feature that can be easily overlooked in comparison to the establishment of the WTO and the reforms in dispute settlement, but which is nonetheless 
important. The TPRM clearly constitutes a change in the degree of centralization regarding the trade regime's information gathering and transparency facilitation function. For the first time in its history the regime's institutions were explicitly mandated to systematically and comprehensively review the policies of individual regime members. This included a significant increase in centralization as delegation, since the Secretariat was entrusted with an unprecedented role in the production of comprehensive review reports of individual members.

The chapter shows that the functional explanations of rational design are highly adequate to understand how this increase in the degree of centralization came about. Theoretical assumptions of rational design fit extremely well to the centralization of information gathering and transparency facilitation in the trade regime and are confirmed when tracing the actual motivations that led to the introduction of the TPRM. In contrast to the other case studies, it is shown that the impact of the regime's previous historical development and of coordination problems during the negotiation process was relatively limited.

This is not to say that the historical context in which the emergence of the TPRM was embedded is completely irrelevant. Of course, the TPRM was not created in isolation of this context. After all, the long-term incremental development of the GATT provided a suitable basis of institutional structures to build upon. However the impact of path dependence on the TPRM was moderate. While the TPRM might have been facilitated and inspired by existing GATT practices, external influences - such as a policy proposal by an independent expert group that informed the Uruguay Round negotiations and existing surveillance mechanisms in other international organizations - were at least as, if not more influential in its creation and design. In this light the TPRM can be described as a tipping point that builds upon existing structures, but that was at most moderately influenced by these structures.

Turning to the negotiation process of the TPRM it is evident that its design process was relatively uncontroversial. The TPRM did not touch upon major distributional questions and interests were mainly homogenous. Tracing the TPRM's negotiation process does therefore not disclose significant explanatory factors that cannot be accounted for by the rational design framework. However, it shows once more that he trade regime's membership aimed to devise institutional structures that balance centralization and control carefully. In the eventual agreement that resulted from the negotiations the concern over control is primarily expressed by the TPRM's limited mandate, which explicitly sets it apart from dispute settlement and which stresses that the TPRM is not a means to enforce substantive obligations. This limits the impact of the TPRM and makes it a relatively soft tool to facilitate compliance with the substantive rules of the multilateral trade regime, keeping sovereignty costs low.

Overall, these low costs in combination with the fact that the TPRM did not touch upon major distributional questions probably explains why the rational design approach is so suitable to explain its emergence. These conditions seem to provide fertile soil for functional design to flourish in a given institutional context without major disturbances. 
The conclusion of this dissertation summarizes the main findings of this research. It ultimately argues that institutional change should be thought of as a bounded rational process that is motivated by the desire to find functional solutions to collective action problems, but that devising such solutions is compromised by intervening factors such as risk aversion, coordination problems, and historically developed path dependencies. Reflecting on the current institutional problems of the trade regime in light of the findings of this dissertation, it is posited that the likelihood of thorough institutional reform towards further centralization is low and that the most feasible way of addressing these problems is to make use of existing institutional structures differently than it is currently done. 


\section{Valorization Addendum}

In the following, three arguments are provided that point towards the societal relevance of this dissertation.

The first and most significant of these arguments relates to the importance of stable institutions that are required for the governance of multilateral trade.

It is generally accepted that liberal trade, governed by a clear set of rules that ensure stability and predictability, provides economic benefits and enhances societal well-being. On an international level, free trade fosters growth and development, facilitates cooperation amongst countries and contributes to peaceful relations amongst them.

Despite these benefits, it is crucial to keep in mind that maintaining free trade multilaterally should not be taken for granted. Stable institutional structures are required that help countries to resist the temptation to resort to unilateral, mercantilist policies. Although free trade entails the high aggregate gains, restricting trade can provide benefits for individual countries at the costs of all others. If too many countries resort to such "beggar they neighbor" policies, multilateral trade cooperation can break down, leaving every country worse off. The clearest and most severe example of this scenario occurred in the 1930s, when the great depression induced countries to resort to such policies, which worsened the already dire economic situation even further and contributed to the outbreak of the Second World War. To avoid such disasters, it is generally accepted that multilateral trade cooperation is facilitated when taking place under the tutelage of an international organization, such as the WTO. Such an organization serves as a forum for negotiations, assembles and disseminates information, monitors the behavior of its members, facilitates the resolution of disputes by acting as an honest broker and conciliator amongst conflicting parties, and ensures compliance to rules by adjudication and authorization of sanctions. All of these functions decrease the likelihood of cooperation to break down, and ensure that multilateral trade takes place according to a previously established set of rules, which induce stability and predictability.

The absence of a properly performing organization to fulfill such functions would certainly be harmful, not only to states but also to their citizens. This was clearly pointed out by the WTO's Director General, Roberto Azevêdo at the Paris Peace Forum in November 2018:

"Think about the world without the WTO. It would be the law of the jungle. It would be a return to unilateralism, with no global cooperation on trade issues. Our economists have been looking at the effects of such a scenario and the question is not whether people are going to lose - the question is how much. In fact, everyone would lose out. 
Two-thirds of products traded are produced in at least two countries, so if you disrupt trade it affects everyone in some manner. Trade is like oxygen - you only notice it when it's gone." ${ }^{1}$

Given this counterfactual of a world without the WTO, it is concerning that the organization currently finds itself in a time of institutional crisis, triggered by the growing dissatisfaction of its membership with shortcomings in its institutional setup. This setup has been subject to severe criticism. Amongst several critics the US is presently the most vocal and influential one. In its 2018 Trade Policy Agenda the US government expresses its dissatisfaction with the WTO, stating that "[i]nstead of serving as a negotiation forum where countries can develop new and better rules, it has sometimes been dominated by a dispute settlement system where activist "judges" try to impose their own policy preference on Member States." ${ }^{2}$

This statement serves as a condense overview to exemplify the main problems that beset the institutional setup of the WTO. First, it highlights the shortcomings of the WTO's decisionmaking structures and its inability to legislate. The reoccurring failures of the Doha Round to live up to its ambitions and to produce significant new multilateral trade agreements are exemplary for this problem and already led to various proposals for WTO reform in the past. Related to this is the observation that the WTO as an actor in itself is not very well setup to help overcome problems regarding its legislative and administrative functions. Generally seen as a 'member driven organization', the WTO possesses limited actorness, and the role of its Secretariat in influencing and facilitating the production of the WTO's policy output is severely confined. Second, the statement shows that even the dispute settlement system, which used to be the organization's most complimented feature, is increasingly getting under pressure. The US is just the most relentless amongst several critics that are suspicious of an increasingly legalized system and who accuse the WTO's main adjudicative organ - the Appellate Body - of judicial activism, regularly overstepping the boundaries of its mandate. ${ }^{3}$ These first two problems give rise to a third one, which is also implied in the US statement: The organization's weak legislative branch in contrast to its strong judicial branch lead to an institutional imbalance. Judicial decisions that displease the WTO's membership cannot be offset by legislative action due to the cumbersome decision-making practices of the organization and its limited actorness. This puts the entire multilateral system at risk, since influential members feel increasingly alienated by judicial decisions, while the legislative system is stalled. The US is very vocal about this, claiming in the 2018 trade policy agenda that it is subject to "outdated and underperforming trade deals" and international bureaucracies that undermine its interests. ${ }^{4}$ While the US position is certainly an

${ }^{1}$ Comment during the public discussion at the Paris Peace Forum on 11 November, 2018. Retrieved from https://www.wto.org/english/news_e/news18_e/dgra_12nov18_e.htm.

2 USTR. (2018). 2018 Trade Policy Agenda and 2017 Annual Report of the President of the United States on the Trade Agreements Program. Washington, D.C.: Office of the United States Trade Representative, (p.2). Retrieved from https://ustr.gov/sites/default/files/files/Press/Reports/2018/AR/2018\%20Annual\%20Report\%20FINAL.PDF.

${ }^{3}$ For an overview of US accusations against the Appellate Body, see the government's 2018 trade policy agenda as referred to above, pp. 24-28.

${ }^{4}$ Ibid. (p.1). 
extreme one, the listed problems indicate that the trading system is beset with fundamental flaws regarding those institutional structures that are supposed to govern international cooperation.

These flaws are not new, and calls for reform have been frequent throughout the history of the WTO. However, in the current political climate such flaws become increasingly relevant and more dangerous to the multilateral trading system than ever before. As a result of the WTO's institutional shortcomings, more and more countries focus on regional and bilateral agreements to manage their trade relations, reducing the relevance of the multilateral system. More than that, as one of its most important members the US is responding to the institutional shortcomings and is currently acting in a way that is likely to significantly harm the system. Its current administration already showed in other contexts that it is less concerned about long standing patterns of international cooperation than its predecessors, and that it does not hesitate damaging multilateral structures to achieve short term national interests. It already made clear that the multilateral trading system poses no exception to this, stating that the US "will not allow the WTO - or any other multilateral organization - to prevent us from taking actions that are essential to the economic well-being of the American people" and that "our trade policy will aggressively defend U.S. national sovereignty. ${ }^{\prime 5}$ The administration already put these words into practice by focusing increasingly on protectionist policies, bilateral deal making, and by blocking the appointment of new members to fill vacant positions in the Appellate Body - risking to leave the Appellate body hamstrung by 2019.

These actions - particularly blocking the appointment of Appellate Body members - are undermining the multilateral system and put the WTO in a serious institutional crisis. As one of the WTO's Deputy Director Generals, Alan Wolff said at the UK Trade Forum on 19 November 2018:

"Members may disagree on the degree of danger to world trade inherent in the loss of the WTO's Appellate function. We do not know whether trade rules would lose their force gradually or quickly were there no effective WTO dispute settlement. Doing nothing would constitute taking an unnecessary increase in level of risk. Without the rule of law, in domestic society or international relations, the end result can easily be chaos." $^{6}$

Clearly, the need to address the longstanding governance problems of the WTO seems more pressing than ever before and the debate about institutional reform of the organization is currently on top of the political agenda. As Director General Azevêdo stated: "Whatever the precise arguments, there's no question that this focus on WTO 'reform' or 'modernization' is growing rapidly. A serious and substantive debate is beginning to emerge, driven by leaders

\footnotetext{
${ }^{5}$ Ibid. (pp.2-3).

${ }^{6}$ Retrieved from https://www.wto.org/english/news_e/news18_e/ddgra_20nov18_e.htm.
} 
around the world." ${ }^{\prime 7}$ The three institutional problems mentioned above are all part of this debate. Engaging in this debate can be an opportunity to update the World Trade Organization according to the needs of the 21st century.

Given the momentum for institutional change and the severity of the current situation, this dissertation is both, topical and relevant. This dissertation explores the dynamics of institutional change throughout the history of the multilateral trade regime. Assuming that a good understanding of the past can inform current debates, the dissertation helps to explain the current shortcomings of the organization and to assess the likelihood of successful future institutional change. It traces the historical roots of the institutional structures that characterize the present setup of the trade regime. This contributes to a better understanding why these structures look the way they do and thereby helps to identify the underlying causes of the institutional problems that are currently witnessed. Furthermore, the dissertation's investigation of the dynamics of institutional change is helpful in analyzing different proposals for institutional reform and their likelihood to succeed. The fact that this dissertation embeds its historical investigation of institutional change in the trade regime in a theoretical framework facilitates the identification of general patterns of change and helps to apply past insights to analyze the present situation. This sets the research apart from existing historical accounts of the trade regime's development, which constitute valuable and factually rich narratives but hardly ingrain their findings in a wider theoretical context.

Taking historical experience as a guideline, it becomes clear that a thorough institutional reform would be unlikely to succeed in the current situation. Instead, the focus should lie on using the WTO's existing institutional structures differently than it is currently done. This observation strengthens those voices that call for using the existing WTO rules more flexibly. Efforts to advance multilateral trade legislation by allowing the WTO's membership to move forward at different speeds and to allow a subset of the membership to enter into agreements that are embedded in the institutional structure of the WTO (such as the Information Technology Agreement or the Government Procurement Agreement) should be strengthened.

With its potential to inform the current debate on institutional change, this dissertation is particularly relevant to all those that actively participate in this debate: WTO members and policy makers, public officials and WTO Secretariat members, representatives of civil society, academics, and all other interested commentators. It is hoped that the contribution this dissertation can make will eventually facilitate a positive outcome of the debate, which would ensure that multilateral trade stays open and predictable under a guiding set of rules, administered by a well-functioning international organization. This would enhance welfare and be beneficial to society at large.

The second argument concerning the societal relevance of this dissertation is a broader one that is not confined to the current situation of the multilateral trade regime, but relates to

7 Speech by Director General at a conference in Paris on 16 November 2018, retrieved from https://www.wto.org/english/news_e/spra_e/spra246_e.htm. 
enhance the understanding of governance structures of international organizations in general. The question how these governance structures change has received limited attention by researchers so far. The dissertation aims to provide an impetus to strengthen research on changing governance structures of international cooperation and organization. This might eventually lead to a better theoretical understanding of such change. Reoccurring debates about the reform of the UN, the IMF, the World Bank and other international organizations indicate the relevance of such a theory. In a world where nationalistic sentiments are on the rise, it is of vital importance to gather a better understanding how international organizations can adapt to changing circumstances, in order to keep international cooperation fruitful.

The third argument is much more specific than the previous two. The work conducted for this dissertation will enhance my academic teaching activities. Based on the dissertation a tutorial/lecture session has already been developed to introduce students of University College Maastricht to the history of the trade regime and to enhance their understanding of the political dynamics that inform the governance structures of the regime. The experience gathered throughout the research process will also be useful to develop future undergraduate courses on global governance and international organizations, and in International Political Economy.

Next to the teaching activities, the insights gained in the course of this research will be disseminated via the publication of a series of academic articles and/or in form of a monograph that will be based on this dissertation. Furthermore, presentations at academic conferences and workshops will be given, just as it has been done in the past already during several seminars at the Institute for Globalization and International Regulation (IGIR) of Maastricht University, the lus Commune Conferences in 2013 and 2016, and a PhD Research Colloquium in Antwerp in 2016. 



\section{About the Author}

Wolfgang Giernalczyk was born on 22 March 1985 in Geilenkirchen, Germany. He obtained a Bachelor of Arts (summa cum laude) from University College Maastricht in July 2008. During his bachelor studies, he focused on a combination of International Relations, Economics and Sociology. After his bachelor education, he studied at the Maastricht Graduate School of Governance with a specialization in globalization, trade and development. He graduated with a Master of Science in Public Policy and Human Development (cum laude) in July 2009. For his performance during his master studies, he received the 'Best $3 \%$ ' scholarship of Maastricht University. Since September 2009, he is working at University College Maastricht; first as a teaching assistant, and since July 2010 as a lecturer and researcher. At the College, he is in charge of teaching courses in the field of argumentation and logic. From June until August 2015 he was a DAAD visiting fellow at University College Freiburg, teaching the course "Argumentation and Critical Reasoning". Next to his teaching and research activities, since October 2016, he is involved in the management and design of the curriculum at University College Maastricht. 
Which factors drive institutional change in the multilateral trade regime? This is the underlying question that inspires this dissertation. In light of the institutional crisis that the WTO currently finds itself in, posing this question is highly relevant. An answer to this question can help to understand the root causes of the current shortcomings in the WTO's governance structure and informs the emerging debate on its institutional reform.

In addressing the question, this dissertation makes use of literature on rational and historical institutionalism to develop a theoretical framework that is applied to guide the empirical investigation of institutional change throughout the history of the trade regime. Three case studies stand at the center of this investigation: The first addresses the establishment and institutional setup of the WTO, including its legislative decision-making structures. The second examines the origins of the WTO's dispute settlement system; and the third sheds light on the creation of the WTO's Trade Policy Review Mechanism. All three case studies are embedded in the wider historical development of the multilateral trade regime. The institutional changes examined by the case studies were ultimately brought about as a result of the Uruguay Round negotiations and form the institutional basis of the multilateral trading system, as we know it today.

Informed by the case studies, this dissertation ultimately argues that institutional change should be thought of as a bounded rational process that is motivated by the desire to find functional solutions to collective action problems, but that devising such solutions is compromised by intervening factors such as risk aversion, coordination problems, and historically developed path dependencies. This insight contributes to a better theoretical understanding of the underlying dynamics of institutional change in the organizational structures that govern international cooperation.

Reflecting on the current institutional problems of the trade regime in light of the findings of this dissertation, it is posited that the likelihood of thorough institutional reform is low and that the most feasible way to address the current problems is to make use of existing institutional structures differently than it is currently done.

ISBN: 978-94-6380-149-2 